RODRIGO DE ALMEIDA AMARANTE

\title{
COMPRESSÃO DINÂMICA EM RISERS
}



RODRIGO DE ALMEIDA AMARANTE

\section{COMPRESSÃO DINÂMICA EM RISERS}

Tese apresentada à Escola Politécnica da Universidade de São Paulo para a obtenção do título de Doutor em Engenharia

São Paulo

Maio, 2015 

RODRIGO DE ALMEIDA AMARANTE

\section{COMPRESSÃO DINÂMICA EM RISERS}

Tese apresentada à Escola Politécnica da Universidade de São Paulo para a obtenção do título de Doutor em Engenharia

Área de Concentração:

Hidrodinâmica, Dinâmica e Controle de Sistemas Oceânicos

Orientador:

Prof. Dr. André Luís Condino Fujarra

São Paulo

Maio, 2015 
Este exemplar foi revisado e alterado em relação à versão original, sob responsabilidade única do autor e com a anuência de seu orientador.

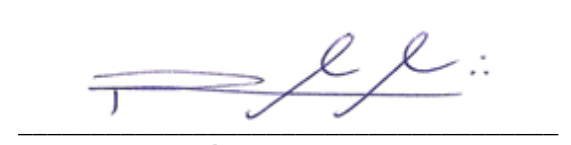

Assinatura do autor Dr. Rodrigo de Almeida Amarante
São Paulo, 26 de Maio de 2015

Assinatura do orientador

Prof. Dr. André Luís Condino Fujarra

\section{Catalogação-na-publicação}

Amarante, Rodrigo de Almeida

Compressão dinâmica em risers / R.A. Amarante. - São Paulo, 2015.

249 p.

Tese (Doutorado) - Escola Politécnica da Universidade de São Paulo. Departamento de Engenharia Naval e Oceânica.

1.Tubulações 2.Compressão dinâmica I.Universidade de São Paulo. Escola Politécnica. Departamento de Engenharia Naval e Oceânica Il.t. 


\section{Resumo}

O presente trabalho foi realizado por meio de uma abordagem tríplice do problema de compressão dinâmica em risers, fundamentado em ensaios em um Calibrador Hidrodinâmico, com posterior confrontação dos resultados com formulações analíticas e o uso de programas comerciais dedicados ao estudo da estática e dinâmica de linhas flexíveis.

O principal objetivo foi a determinação acurada, a partir de uma instrumentação pouco invasiva, dos comprimentos das ondas de flexão geradas no TDP, durante a compressão dinâmica. Esse objetivo, de per si, encerra o caráter de ineditismo da presente tese.

Os ensaios consistiram na realização de movimentos circulares no topo de um modelo flexível lançado em catenária, sob diversas configurações, totalizando um total de 72 experimentos: foram utilizados três frequências de movimento, três amplitudes, quatro ângulos de topo e dois sentidos de rotação.

Um sistema de monitoramento óptico foi utilizado como principal instrumentação. Além desse equipamento, foi utilizada uma célula de carga, posicionada entre o equipamento que prescrevia os movimentos ao modelo flexível e uma rótula, que permitia que a célula de carga se movimentasse solidariamente ao sistema.

Rotinas numérica próprias foram utilizadas para o pós-processamento dos dados obtidos.

Os resultados foram, então, comparados com formulações analíticas constantes da literatura, bem como a adaptação da equação para a carga crítica de flambagem de vigas curvas, para as condições de contorno dos ensaios realizados.

Como resultado principal, é possível citar a confirmação experimental da suposição corrente com relação ao número de onda associado às ondas de flexão geradas na compressão dinâmica, até então assumida como uma hipótese ad hoc.

Além disso, o procedimento adotado, embasado teoricamente, foi utilizado desde o estabelecimento do material com que o modelo foi construído, passando pela elaboração racional da matriz de ensaios e finalizando com as análises realizadas, quando os resultados experimentais foram confrontados com as previsões analíticas.

Palavras-chave: Riser flexível, catenária, dinâmica local, compressão dinâmica. 



\section{Abstract}

This work was carried out through a threefold approach to dynamic compression in risers, based on tests in a Hydrodynamic Calibrator, with subsequent comparison of results with analytical formulations and the use of commercial softwares dedicated to the study of static and dynamic flexible lines.

The main aim was an accurate determination, from a minimally invasive instrumentation, the lengths of flexural waves generated in the TDP, during dynamic compression. This goal, in itself, is the novelty of this thesis.

The tests consisted in performing circular motion on top of a flexible catenary model launched under several conditions, amounting to a total of 72 experiments: three motion frequencies, three imposed amplitudes , four top angles and clockwise and counter-clockwise rotation.

A tracking monitoring system was used as main instrumentation. In such equipment, a load cell was used, positioned between rotor used to prescribe top movements at the top of a flexible model, allowing the load cell jointly move around a bar conected to the shaft motor.

Numerical routines, made by author, were used for data post-processing.

The results were then confronted with analytical formulations from specialized literature, as well as the adaptation of the equation for the buckling critical load for curved beams under the boundary conditions of the tests.

As a main result, it is possible to mention the experimental confirmation of the current assumption with respect to the wave number associated with bending waves generated during the dynamic compression, hitherto assumed as an ad hoc hypothesis.

In addition, the procedure adopted, based in analytical theories, was used since the establishment of the material with which the model is built, through the rational development of the test matrix and ending with the analyzes carried out when the experimental results were compared with analytical predictions.

Keywords: Flexible riser, catenary, local dynamic, buckling, dynamic compression. 



\section{Dedicatória}

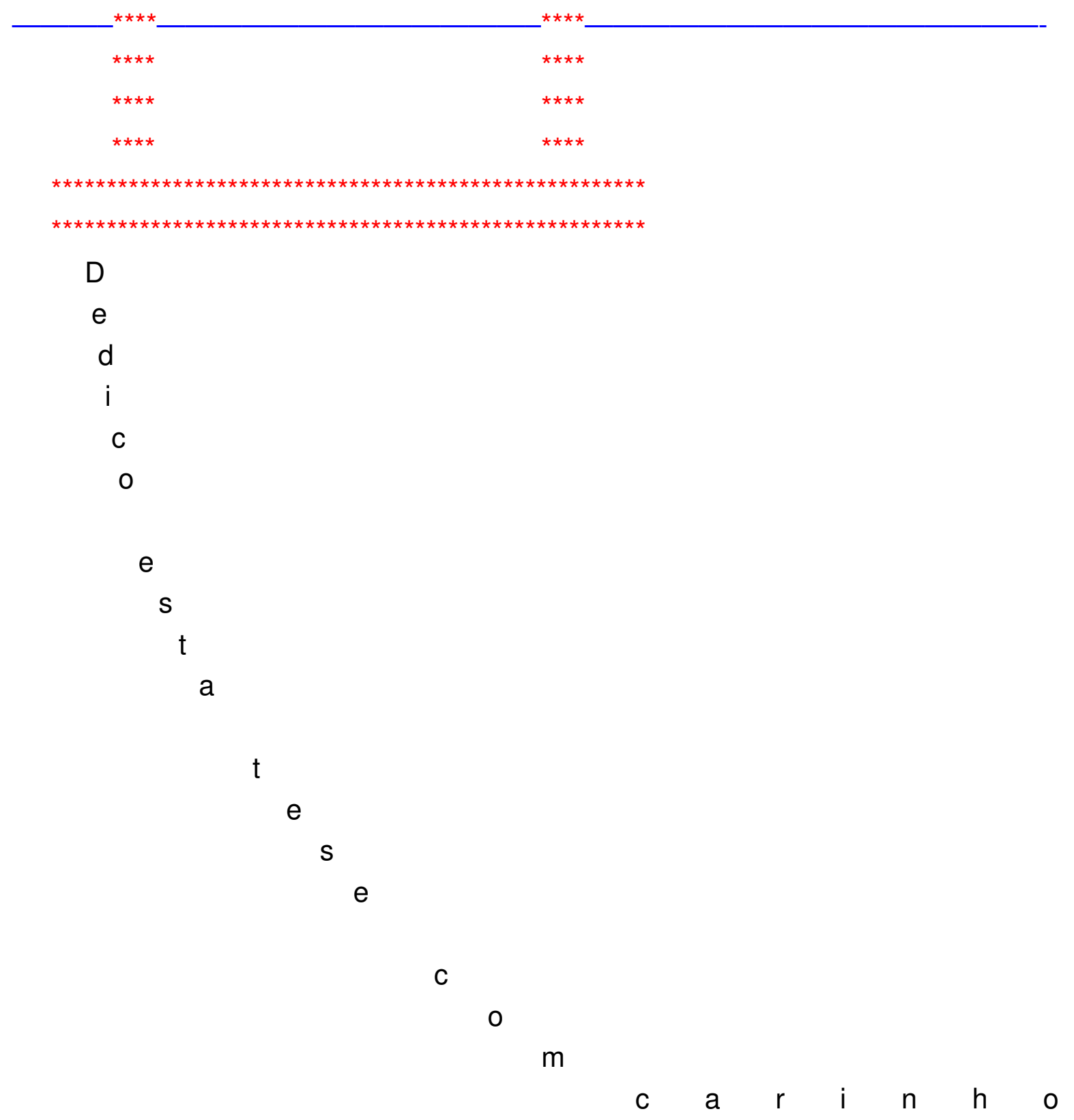

Aos meus pais, Às minhas filhas $\mathrm{e}$ À minha esposa. 



\section{Agradecimentos}

Talvez um dos trabalhos mais difíceis (e ingratos!) de todos esses quatro anos de dedicação e empenho a esta tese seja este capítulo.

Embora seja opcional, relevar sua presença é como assumir mediocremente uma posição de egolatria típica de alguns dos chamados PhDeuses.

Minha base familiar, meu crescimento como ser humano e minha necessidade de estar cercado de pessoas de bom caráter me impedem de tal escolha.

Faltam apenas quatro horas para o final do prazo para depósito desta tese e cá estou eu, escrevendo.

Primeiramente, gostaria de agradecer à inestimável ajuda do meu orientador, o Prof. Dr. André Luís Condino Fujarra. Sei quanto envolvimento você põe no seu trabalho, o quanto você abdica de diversas situações, tentando equilibrar suas funções como docente, pai, marido e amigo. Meus mais sinceros agradecimentos por esses pouco mais de dez anos de parceria.

Meus mais sinceros agradecimentos aos componentes da Banca Examinadora que, com suas críticas, sugestões e arguições, muito acrescentaram à versão final revisada desta tese. Gratidão aos Profs. Drs. Eduardo Setton Sampaio da Silveira (UFAL), Celso Pupo Pesce (PME-USP), Marcos Mendes de Oliveira Pinto (PNV-USP) e ao DSc. Eng. Rafael Loureiro Tanaka (Prysmian Cables and Systems).

Gostaria de aproveitar para agradecer aos Professores Kazuo Nishimoto, Alexandre Nicholaos Simos, Cláudio Müeller Prado Sampaio, Eduardo Aoun Tannuri e todos os demais professores do Departamento de Engenharia Naval e Oceânica os quais sei que, direta ou indiretamente, torceram pelo meu sucesso e me auxiliaram, de diversas maneiras, nessa árdua empreitada.

A todos os técnicos do IPT-SP e da Oficina do Departamento de Engenharia Mecânica. À minha família. Agora várias!! Aos Amarantes, aos Almeidas, aos Righettis, aos Motas, aos Silveiras, aos Médicis... Devo muito a vocês.

Agradecimentos especiais aos meus pais, Belmiro e Goret (Rudra) por todas as oportunidades que me propiciaram e, inclusive, aos momentos em que fui criticado por seguir carreira acadêmica. Afinal, quem quer um filho doutor de verdade? Não médico, advogado, ... Obrigado por tudo!!

À minha amada esposa, Marianny de Almeida Amarante, que de maneira avassaladora entrou na minha vida e me ajudou tanto e de tantas formas, que é impossível achar, em poucas palavras, agradecimentos suficientes. Amo você!! E... "Por você, eu dançaria tango no teto, eu limparia os trilhos do metrô"...

Às minhas princesinhas, Beatriz Chagas Amarante e Carolina Chagas Amarante. Vocês são os maiores presentes que a vida poderia me dar. E deu!! 
Aos meus irmãos, Caio e Bianca. Aos meus sogros, Sônia e llídio.

A todos os meus amigos reais, virtuais, colegas, companheiros e curiosos de jornada. Sei que vocês também torcem pelo meu sucesso.

Aos meus padrinhos de casamento - grandes companheiros de jornada, irmãos de coração: Miriam e Neguinho, Tati e Gustavo, Juliana e Marcello, Fabi e Luís, llídio Júnior e Rafa, Mari "Porrinha" Robortella e Bruno "Axé". Amo cada um de vocês!!

À Turma de Graduação de 2006 do Curso de Engenharia Naval e Oceânica. Navaaaaaaal, Crauuuuuuu!! Cada um dos nossos encontros mensais ou bimestrais me fazem aprender cada vez mais sobre amizade, política, cerveja, churrasco...

Nominalmente, não posso deixar de agradecer aos grandes amigos Rafael de Andrade Watai (e todos os companheiros de Argonáutica, Feitosa, PG e Lavieri), Rateiro, Ed, Mizuno (todos da Technomar), aos amigos do TPN - com agradecimentos especiais ao Pedro Cardozo de Mello, ao Daniel "Canaleta" Prata Vieira (parabéns pela família que está constituindo juntamente à Natasha), ao Fábio Amorim e ao Dênis Maluf Ganberine pelas inestimáveis ajudas nos ensaios, ao Presidas, ao Beto, ao Zé e ao Nélson -, aos antigos estagiários e hoje companheiros de jornada, Peter, Xotta, Digão... E perdoem-me os demais por não citar a todos. O tempo urge e tenho que enviar esse trabalho para a gráfica. Falando nisso: obrigado, Rodrigo Peternella pela força nesse momento! Aos amigos da Secretaria do PNV-USP!!

Aos amigos peruanos Miguel e Paola. À Dra. Anyara Menezes Lasheras pelo carinho, suporte e profissionalismo com que me acompanhou e ainda acompanha.

Aos eternos Ozzy Osbourne, Janis Joplin, Led Zeppelin, The Doors, Pink Floyd, Nirvana, Bob Dylan, Supertramp e tantas outras bandas que partilharam horas e horas de trabalho (quase infindável), de dia, de noite, de madrugada...

Sem falar na Banda HNT!! Obrigado, Montanha, Pimpas, T-Rex, Thiago e Diego.

Ao Conselho Nacional de Desenvolvimento Científico e Tecnológico - CNPq, pelo suporte dado com a concessão de uma bolsa de Doutorado, sem a qual esse trabalho não teria sido possível.

É isso. Até a proxima jornada...

\section{Keep your eyes on the road, Your hands upon the wheel}

(Roadhouse blues, The Doors)

E, parafraseando Baudelaire:
É necessário estar sempre bêbado.

Tudo se reduz a isso; eis o único problema.

Para não sentirdes o fardo horrível do Tempo, que vos abate e vos faz pender para a terra, é preciso que vos embriagueis sem tréguas.

Mas - de quê ? De CIÊNCIA, de poesia ou de virtude, como achardes melhor.

Contanto que vos embriagueis. 
Eu gosto de catar o mínimo e o escondido. Onde ninguém mete o nariz, aí entra o meu, com a curiosidade estreita e aguda que descobre o encoberto. (J. M. Machado de Assis) 



\section{Lista de Figuras}

1.1 Evolução das lâminas d' água na exploração brasileira de óleo e gás em

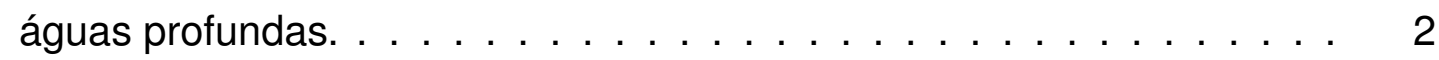

1.2 Principais tipos de risers: rígido (à esquerda) e flexível (à direita). . . . 2

1.3 Principais configurações de geometrias de risers flexíveis. . . . . . . . 3

1.4 Configuração interna de um riser flexível. . . . . . . . . . . . . 4

1.5 SCR da plataforma P18 da Petrobras durante a instalação. . . . . . . 5

1.6 Esquema de instalação dos SCRs na plataforma P18 da Petrobras. . . 6

1.7 Falha estrutural por compressão do tipo birdcaging em risers. . . . . . . 7

2.1 Primeiras frequências naturais de vibração de vigas para cada modelo. 13

2.2 Os quatro primeiros modos de vibrar de uma viga em balanço. . . . . 14

2.3 Esforços externos sobre um riser dinamicamente excitado. . . . . . . 25

2.4 Saturação das assinaturas temporais de tração durante a compressão dinâmica. . . . . . . . . . . . . . . . 26

2.5 Ondas de compressão se propagando do TDP ao topo de uma linha em catenária. . . . . . . . . . . . . . . . . . . 26

2.6 Padrão esperado para o PSD de trações na ocorrência de compressão dinâmica. . . . . . . . . . . . . . . . . . . 28

2.7 Diagrama de estabilidade de Mathieu, em função dos parâmetros $\delta$ e $q . \quad 30$

3.1 Esforços genéricos atuantes sobre um elemento de linha em catenária. 34

3.2 Equilíbrio estático de um elemento deformado de comprimento infinitesimal $d \bar{s} \ldots \ldots \ldots \ldots \ldots \ldots \ldots \ldots$

3.3 Tração efetiva estática ao longo da linha de (Ribeiro et al., 1998). . . . . 44

3.4 Tração efetiva estática ao longo da linha de (Simos \& Fujarra, 2006). . . 44

3.5 Sistemas de coordenadas envolvidos no problema dinâmico. . . . . . 48

3.6 Resolução gráfica da equação transcendental. . . . . . . . . . . . 63

3.7 Representação gráfica de $F(\alpha)=\tan (\alpha)-\alpha-\frac{\alpha^{3}}{3}+\frac{\alpha^{5}}{\gamma^{2}(\chi)} \ldots \ldots \ldots .63$

3.8 Representação gráfica de $F(\alpha)=\tan (\alpha)-\alpha-\frac{\alpha^{3}}{3}+\frac{\alpha^{5}}{\gamma^{2}(\chi)}$, para $0,01<$

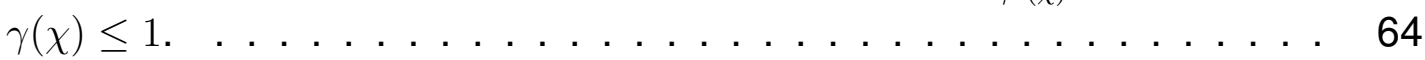

3.9 Representação gráfica de $F(\alpha)=\tan (\alpha)-\alpha-\frac{\alpha^{3}}{3}+\frac{\alpha^{5}}{\gamma^{2}(\chi)}$, para $0<\gamma(\chi) \leq$

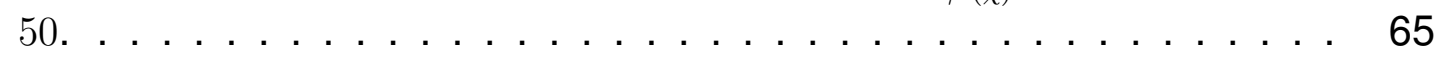


3.10 Valores de $\beta_{c r}$ em função das estimativas iniciais $x_{0}$ para a equação transcendental. . . . . . . . . . . . . . . . 66

3.11 Comportamento do denominador de $\gamma^{2}(\chi)$, para $\frac{\pi}{2}<\alpha<\frac{3 \pi}{2}$. . . . . . . 67

3.12 Valores de $\beta_{c r}$ em função das estimativas iniciais $x_{0}$, para $1<\beta_{c r} \leq$

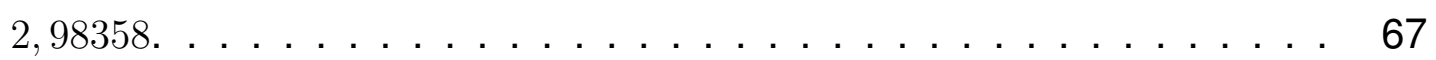

3.13 Relação gráfica entre $\beta_{c r}^{2}$ e $\Gamma(\chi), 1 \leq \beta_{c r} \leq 2,98358$. . . . . . . . . . 69

3.14 Aproximação por função de Richards para $\beta_{c r}^{2}=f[\Gamma(\chi)] . . . . .70$

3.15 Diferenças relativas entre os valores exato e aproximado de $\beta_{c r}^{2}$. . . . . 71

3.16 Relação aproximada entre os comprimentos das ondas de flexão em vigas curvas e retas. . . . . . . . . . . . . . . . . . . . . . 73

3.17 Comparação entre as relações de comprimentos de onda para as condições de ensaio. . . . . . . . . . . . . . . . . . . . . . . . . . . 77

3.18 Soluções diretas da Equação 3.83 graficamente. . . . . . . . . . . . . . 78

3.19 Soluções indiretas da Equação 3.83 graficamente. . . . . . . . . . . . . 78

3.20 Comportamento do denominador da função $F(\alpha)$, para o caso engastadopinado. . . . . . . . . . . . . . . . . . . 79

3.21 Curva que representa $\beta^{2}$ como função de $\Gamma$ para o caso engastado-pinado. 80

3.22 Aproximação algébrica de $\beta^{2}=f[\Gamma]$ pela função Logística. . . . . . . . . 80

3.23 Diferenças percentuais entre a função exata e a aproximação pela função Logística. . . . . . . . . . . . . . . . . . . . . . . . . . . . . . . . . . 81

3.24 Comportamento da relação entre os comprimentos de onda de flexão na viga curva engastada-pinada e na viga reta. . . . . . . . . . . . . . 82

3.25 Relação gráfica exata entre $\beta_{c r}(\chi)^{2}$ e $\Gamma(\chi)$ para ambas as condições de contorno. . . . . . . . . . . . . . . . . 82

3.26 Relação gráfica aproximada entre $\beta_{c r}(\chi)^{2}$ e $\Gamma(\chi)$ para ambas as condições de contorno. . . . . . . . . . . . . . . . . . . . . 83

3.27 Diferenças percentuais entre os valores aproximados de $\beta_{c r}(\chi)^{2}$ em fun-

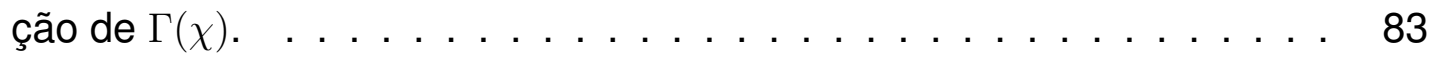

4.1 Fluxograma do procedimento para elaboração da matriz de ensaios. . . 90

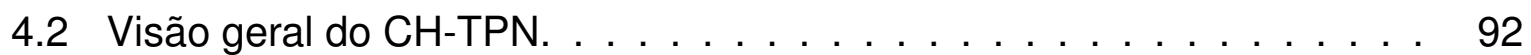

4.3 Câmeras do sistema óptico de monitoramento. . . . . . . . . . . . . . . 94

4.4 Alvos refletivos passivos utilizados pelo sistema de rastreamento óptico. 94

4.5 Calibração do volume de controle do sistema de rastreamento óptico. . 95

4.6 Identificação da estrutura de referência pelo software do sistema óptico. 95

4.7 Visão geral do dispositivo atuador, sobre a bancada de montagem. . . . 96

5.1 Utilização dos recursos e vertentes para avaliação dos ensaios e simulações. . . . . . . . . . . . . . . . . . . . . . . . . . . . . . . 102

5.2 Esquema ilustrativo do lançamento do modelo no $\mathrm{CH}-\mathrm{TPN}$. . . . . . . . 103 
5.3 Posições relativas entre o dispositivo atuador e as câmeras aéreas utilizadas nos ensaios. . . . . . . . . . . . . . . . . . . . . . . 104

5.4 Estrutura fixada na saída do eixo do atuador e equipamento de calibração das câmeras. . . . . . . . . . . . . . . . . . . . . . . . . 104

5.5 Visão frontal do dispositivo atuador montado com a rótula. . . . . . . . 105

5.6 Detalhes da fixação do rolamento e célula de carga na saída do eixo do redutor. . . . . . . . . . . . . . . . . . 106

5.7 Um ciclo de movimento prescrito pelo dispositivo atuador. . . . . . . . . 106

5.8 Esquema ilustrativo da estrutural utilizada nos ensaios físicos (vista frontal). . . . . . . . . . . . . . . . . . . . 108

5.9 Trecho do modelo utilizado com fitas refletivas para rastreamento óptico. 108

5.10 Exemplo de lançamento do modelo flexível na água. . . . . . . . . . . 109

5.11 Estrutura aquática utilizada para calibração das câmeras. . . . . . . . . 109

5.12 Estrutura de sustentação e posicionamento das câmeras aquáticas. . . 110

5.13 Monitoramento em tempo real das câmeras aquáticas, pré-calibração. . 110

5.14 Visualização do volume de calibração durante parte de um ensaio. . . . 111

5.15 Campo visual de cada câmera durante parte de um ensaio. . . . . . . . 111

5.16 Montagem do sistema de monitoramento para aferição do atuador. . . . 112

5.17 Mapeamento bidimensional com os resultados esperados para os ensaios. . . . . . . . . . . . . . . . . . . 113

5.18 Visualização do conteúdo de um dos arquivos de monitoramento da célula de carga. . . . . . . . . . . . . . . . . . . . 115

5.19 Exemplo de propagação de ondas de flexão durante um dos ensaios. . 117

5.20 Exemplo de movimentação lateral do modelo durante um dos ensaios. . 117

5.21 Determinação iterativa do ângulo de topo a partir das trações medidas pela célula de carga. . . . . . . . . . . . . . . . . . . . 121

5.22 Mensagem de erro do Poliflex quando da ocorrência de compressão dinâmica. . . . . . . . . . . . . . . . . . . 121

5.23 Recomendação da DNV para cálculo de $C_{a} \ldots \ldots \ldots \ldots \ldots \ldots$

5.24 Recomendação da DNV para valores do coeficiente de arrasto $C_{d} . \ldots 127$

5.25 Sugestão de coeficientes para a Equação de Morison. . . . . . . . . . 127

5.26 Regimes de escoamento em função de KC. . . . . . . . . . . . . . . 128

5.27 Coeficientes de inércia e arrasto em função de $\mathrm{KC}$, para vários valores

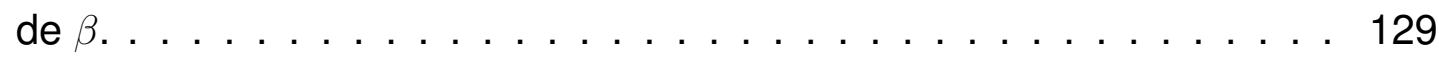

5.28 Parâmetros de simulação do Anflex. . . . . . . . . . . . . . . . 130

5.29 Parâmetros de simulação do Poliflex. . . . . . . . . . . . . . . . . . 130

6.1 Mapeamento bidimensional dos resultados dos ensaios finais. . . . . 132

6.2 Vistas frontal, lateral e superior dos alvos, a partir do sistema de coordenadas das câmeras. . . . . . . . . . . . . . . . . . . . . . 134

6.3 Exemplo de tranformações de coordenadas, vistas originais. . . . . . 135 
6.4 Vistas frontal, lateral e superior dos alvos, após rotação em torno de Z. 136

6.5 Vistas frontal, lateral e superior dos alvos, após rotação e translação (sistema xyz) . . . . . . . . . . . . . . . . . . . . 136

6.6 Visualização, em perspectiva, dos alvos identificados, após rotação e translação. . . . . . . . . . . . . . . . . . . . . . . . . 137

6.7 Exemplo de não necessidade de eliminação de alvos do TDZ. . . . . . . 139

6.8 Exemplo de necessidade de eliminação de alvos do TDZ. . . . . . . . . 140

6.9 Exemplo de aproximação polinomial para a elástica instantânea. . . . . 141

6.10 Exemplo de determinação do comprimento de onda de flexão. . . . . . . 142

6.11 Sequência de quadros sem ocorrência de compressão dinâmica. . . . . 143

6.12 Exemplo de procedimento para determinação do comprimento de onda. 143

6.13 Série de trações no TDP e respectivo PSD para o caso F080A100T80. 144

6.14 Seleção preliminar dos casos para detalhamento. . . . . . . . . . . . . 145

6.15 Série de trações no TDP e respectivo PSD para o caso F080A050T80. 146

6.16 Série de deslocamentos na direção tangente e respectivo PSD para o caso F080A050T80. . . . . . . . . . . . . . . . . . . . . . . . . . 147

6.17 Série de deslocamentos na direção normal e respectivo PSD para o caso F080A050T80. . . . . . . . . . . . . . . . . . . . . . . 147

6.18 Retratos de fases dos alvos submersos, caso F080A050T80, direção tangente. . . . . . . . . . . . . . . . . . . . . . . . . 148

6.19 Retratos de fases dos alvos submersos, caso F080A050T80, direção normal. . . . . . . . . . . . . . . . . . . . . . . . . . . . 148

6.20 Série de trações no TDP e respectivo PSD para o caso F080A100T85. 149

6.21 Série de deslocamentos na direção tangente e respectivo PSD para o caso F080A100T85. . . . . . . . . . . . . . . . . . . . 150

6.22 Série de deslocamentos na direção normal e respectivo PSD para o caso F080A100T85. . . . . . . . . . . . . . . . . . . . . . . 150

6.23 Evolução temporal dos deslocamentos tangencial e normal para o caso F080A100T85.

6.24 Retratos de fases dos alvos submersos, caso F080A100T85, direção tangente. . . . . . . . . . . . . . . . .

6.25 Retratos de fases dos alvos submersos, caso F080A100T85, direção normal. . . . . . . . . . . . . . . . . . . . . . . . . . 152

6.26 Sequência de quadros do caso F100A200T65, com ocorrência de compressão dinâmica. . . . . . . . . . . . . . . . . . . . . . . . . . . . . . 154

6.27 Determinação do comprimento de onda de flexão, caso F100A200T65. 155

6.28 Série de trações no TDP e respectivo PSD para o caso F100A200T65. 156

6.29 Visualização do caso F125A050T70 pelo programa dedicado. . . . . . . 156

6.30 Exemplo de determinação do comprimento de onda de flexão, caso F125A050T70. . . . . . . . . . . . . . . . . 157 
6.31 Série de deslocamentos na direção normal e respectivo PSD para o caso F125A050T80. . . . . . . . . . . . . . . . . . . . . . . 158

6.32 Determinação do comprimento de onda de flexão, caso F125A050T80. 159

6.33 Série de deslocamentos na direção normal e respectivo PSD para o caso F125A100T85. . . . . . . . . . . . . . . . . . . . . . . 160

6.34 Evolução temporal dos deslocamentos tangencial e normal para o caso F125A100T85.

6.35 Retratos de fases dos alvos submersos, caso F125A100T85, direção tangente.

6.36 Retratos de fases dos alvos submersos, caso F125A100T85, direção normal.

6.37 Detalhe das séries temporais de trações, caso F125A100T85, via Anflex. 163

A.1 Viga-coluna sob carregamento axial compressivo e carga lateral distribuída.

A.2 Comparação da geometria estática de um SCR, por 6 métodos distintos. 181

A.3 Comparação da geometria estática de um riser em catenária direta, por 6 métodos distintos.

B.1 Comparação da geometria estática de um SCR, utilizando o Anflex. . . 188

B.2 Comparação da geometria estática de um riser em catenária direta, utilizando o Anflex.

B.3 Modelo numérico em Anflex, baseado na linha flexível apresentada em (Ribeiro et al., 1998).

B.4 Excertos das séries temporais de tração no TDP.

B.5 Snapshot de vídeo gerado pelo Anflex evidenciando ondas de compressão.

B.6 Configuração de lançamento e estática da linha de Simos \& Fujarra (2006) no Anflex.

B.7 Esquema ilustrativo do aparato experimental utilizado por Simos \& Fujarra (2006). . . . . . . . . . . . . . . . . . . . . .

B.8 Série temporal de tração e respectivo PSD do caso A50F75TDP. . . . . 195

B.9 Série temporal de tração e respectivo PSD do caso A100F100TDP. . . 196

B.10 Série temporal de tração e respectivo PSD do caso A100F100TOP. . . 197

B.11 Excerto da série temporal de tração do caso A100F100TOP. . . . . . . 198

B.12 Série temporal de tração e respectivo PSD do caso A150F150TDP. . . . 199

B.13 Excerto da série temporal de tração do caso A150F150TDP. . . . . . . 199

B.14 Mapeamento da compressão dinâmica no TDP da linha de Simos \& Fujarra (2006). 
C.1 Comprimentos pré-caracterização do modelo em água, preenchimento com areia. . . . . . . . . . . . . . . . . . . . . . . . . . 205

C.2 Comprimentos pré-caracterização do modelo em água, preenchimento com água. . . . . . . . . . . . . . . . . . . . . 206

C.3 Envelope de trações no TDP, $A=50 \mathrm{~mm}, T=1,20 \mathrm{~s}$ (modelo com areia pré-caracterização). . . . . . . . . . . . . . . . . . . 208

C.4 Envelope de trações no TDP, $A=50 \mathrm{~mm}, T=1,20 \mathrm{~s}$ (modelo com água pré-caracterização). . . . . . . . . . . . . . . . . . . 208

C.5 Envelope de trações no TDP, $A=100 \mathrm{~mm}, T=1,00 \mathrm{~s}$ (modelo com areia pré-caracterização). . . . . . . . . . . . . . . . . . . . . 209

C.6 Envelope de trações no TDP, $A=100 \mathrm{~mm}, T=1,00 \mathrm{~s}$ (modelo com água pré-caracterização). . . . . . . . . . . . . . . . . . . . . . 209

C.7 Envelope de trações no TDP, $A=200 \mathrm{~mm}, \mathrm{~T}=0,80 \mathrm{~s}$ (modelo com areia pré-caracterização). . . . . . . . . . . . . . . . . . . 210

C.8 Envelope de trações carga crítica no TDP, $A=200 \mathrm{~mm}, T=0,80 \mathrm{~s}$ (modelo com água pré-caracterização). . . . . . . . . . . . . . . 210

C.9 Número de casos de compressão previstos para o TDP, modelo com

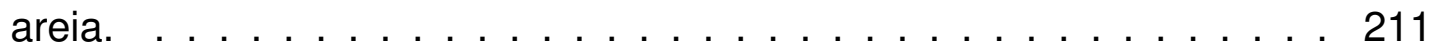

C.10 Número de casos de compressão previstos para o TDP, modelo com

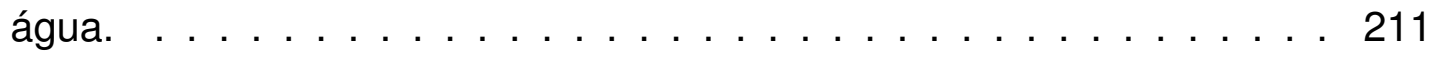

C.11 Mapeamento 3D preliminar da linha de silicone com preenchimento com areia, para o TDP. . . . . . . . . . . . . . . . . . . 214

C.12 Mapeamento 3D preliminar da linha de silicone com preenchimento com água, para o TDP. . . . . . . . . . . . . . . . . . . . .

C.13 Amplitudes de excitação por ângulo de topo da linha de silicone com areia, para o TDP. . . . . . . . . . . . . . . . . . . 215

C.14 Amplitudes de excitação por ângulo de topo da linha de silicone com água, para o TDP. . . . . . . . . . . . . . . . 216

C.15 Comprimentos de ondas de flexão no TDP esperados para o modelo com areia. . . . . . . . . . . . . . . . . . . . . . . . 218

C.16 Comprimentos de ondas de flexão no TDP esperados para o modelo com água. . . . . . . . . . . . . . . . . . . . 218

C.17 Análise de sensibilidade da densidade em função dos diâmetros e incertezas associadas. . . . . . . . . . . . . . . . . . 221

C.18 Aparato experimental utilizado para determinação da rigidez axial do modelo. . . . . . . . . . . . . . . . . . . . . . 223

C.19 Visualização em tempo real dos alvos sobre a linha durante o ensaio de tração. . . . . . . . . . . . . . . . . . . . . . . . . . . 224

C.20 Visualização dos alvos refletivos sobre o modelo no ensaio de tração (modelo com areia). . . . . . . . . . . . . . . . . . . . . . 225 
C.21 Visualização dos alvos refletivos sobre o modelo no ensaio de tração (modelo com água). . . . . . . . . . . . . . . . . . . . . 225

C.22 Forças efetivas medidas ao longo do modelo vazio durante o teste de tração. . . . . . . . . . . . . . . . .

C.23 Forças efetivas medidas ao longo do modelo com areia durante o teste de tração.

C.24 Forças efetivas medidas ao longo do modelo com água durante o teste de tração.

C.25 Diagrama tensão $x$ deformação para o modelo ensaiado sem preenchimento. . . . . . . . . . . . . . . . . . . . . . . . . . 228

C.26 Diagrama tensão $x$ deformação para o modelo ensaiado com areia. . . 228

C.27 Diagrama tensão x deformação para o modelo ensaiado com água. . . 229

C.28 Aparato experimental utilizado para determinação da rigidez flexional. . 232

C.29 Visualização dos alvos sobre a linha no ensaio de flexão (modelo com areia).

C.30 Visualização dos alvos sobre a linha no ensaio de flexão (modelo com água).

C.31 Aparato experimental utilizado nos ensaios de decaimento.

C.32 Exemplo das trajetórias assumidas pelos alvos nos ensaios de decaimento.

C.33 Determinação do amortecimento estrutural (tubo com areia, $\theta_{t}=66,2^{\circ}$ ).

C.34 Determinação do amortecimento estrutural (tubo com água, $\theta_{t}=63,5^{\circ}$ ).

C.35 PSD de deslocamentos de todos os alvos, tubo com areia, excitação longitudinal em 0xyz.

C.36 PSD de deslocamentos de todos os alvos, tubo com areia, excitação transversal em 0xyz.

C.37 PSD de deslocamentos de todos os alvos, tubo com água, excitação longitudinal em 0xyz.

C.38 PSD de deslocamentos de todos os alvos, tubo com água, excitação transversal em 0xyz.

C.39 Número de casos de compressão previstos para o TDP, areia, póscaracterização.

C.40 Número de casos de compressão previstos para o TDP, água, póscaracterização.

C.41 Comparação gráfica dos resultados, separados por preenchimento do tubo.

C.42 Previsão de ocorrência de compressão dinâmica no TDP para os ensaios.248 



\section{Lista de Tabelas}

3.1 Relações adimensionais das principais grandezas físicas . . . . . . 32

4.1 Características do modelo em silicone, dados de ensaios . . . . . . 98 98

4.2 Valores obtidos para rigidez flexional (EI) do modelo com areia . . . . 98

5.1 Comparação entre os ângulos de topo estáticos, sentido anti-horário. 119

5.2 Comparação entre os ângulos de topo estáticos, sentido horário. . . . . 120

5.3 Comparação entre as frequências naturais obtidas para o modelo ensaiado. . . . . . . . . . . . . . . . . . . . . . . 123

6.1 Comprimentos de onda de flexão medidos do caso F080A100T85 ‥ 153

6.2 Comprimentos de onda de flexão do caso F100A200T65 . . . . . . . 154

6.3 Comprimentos de onda de flexão do caso F125A050T70 . . . . . . 157

B.1 Características do modelo SCR de (Ribeiro et al., 1998) . . . . . . . 189

B.2 Características do modelo flexível de (Simos \& Fujarra, 2006) . . . . . 193

C.1 Características do modelo em silicone, dados de catálogos . . . . . 204

C.2 Características gerais utilizadas nas simulações . . . . . . . . . . 204

C.3 Compilação dos resultados das simulações pré-caracterização para o TDP. . . . . . . . . . . . . . . . . . . . . . . . 212

C.4 Compilação dos resultados das simulações pré-caracterização para o topo. . . . . . . . . . . . . . . . . . . . . . 212

C.5 Previsões analíticas dos comprimentos das ondas de flexão (modelo com areia, pré-caracterização) . . . . . . . . . . . . . . 217

C.6 Previsões analíticas dos comprimentos das ondas de flexão (modelo com água, pré-caracterização) ․ . . . . . . . . . . . 217

C.7 Valores obtidos para rigidez flexional (EI) do modelo com areia . . . . 234

C.8 Valores obtidos para rigidez flexional (EI) do modelo com água . . . . 235

C.9 Amortecimentos estruturais do modelo no ar - direção x . . . . . . . . 241

C.10 Amortecimentos estruturais no ar - direção y . . . . . . . . . . 241

C.11 Amortecimentos estruturais no ar - direção z . . . . . . . . . . . 241 
C.12 Frequências observadas, sistema de rastreamento $\mathrm{x}$ célula de carga (modelo com areia). . . . . . . . . . . . . . . . . . . . . . . 242

C.13 Frequências observadas, sistema de rastreamento $\mathrm{x}$ célula de carga (modelo com água). . . . . . . . . . . . . . . . . . . . . 243

C.14 Características do modelo em silicone, dados de ensaios . . . . . . . 243

C. 15 Compilação dos dados referentes às simulações pós-caracterização. . 244

C.16 Previsões analíticas dos comprimentos das ondas de flexão durante os ensaios (modelo com areia, pós-caracterização) . . . . . . . . . . . 249

C.17 Previsões analíticas dos comprimentos das ondas de flexão durante os ensaios (modelo com água, pós-caracterização) … . . . . . . . 249 


\section{Lista de Símbolos}

\section{Alfabeto latino}

\begin{tabular}{|c|c|}
\hline Símbolo & Descrição \\
\hline$T_{0}=T(0)$ & Tração horizontal ou tração no TDP, em uma catenária \\
\hline$L$ & $\begin{array}{l}\text { Comprimento, pode se referir a grandezas relacionadas, quando } \\
\text { acompanhada de índices subescritos }\end{array}$ \\
\hline EI & Rigidez flexional \\
\hline$K$ & Parâmetro adimensional relacionado à rigidez do solo \\
\hline$k$ & Constante elástica do solo, supostamente linear \\
\hline$m$ & Massa própria no ar, por unidade de comprimento \\
\hline$m_{a}$ & Massa adicionada, por unidade de comprimento \\
\hline$t$ & Tempo \\
\hline$x$ & $\begin{array}{l}\text { Posição ou coordenada ao longo do eixo homônimo, no sistema } \\
\text { 0xyz }\end{array}$ \\
\hline$T$ & $\begin{array}{l}\text { Símbolo utilizado período de um movimento ou parâmetro tem- } \\
\text { poral }\end{array}$ \\
\hline$B_{v}$ & Rigidez na direção $v$ \\
\hline$f_{n}(t)$ & Função temporal utilizada na separação de variáveis \\
\hline$X_{n}(x)$ & Função posicional utilizada na separação de variáveis \\
\hline$f$ & Parâmetro adimensional \\
\hline$q$ & Por definição, $\left(m-m_{a}\right) \cdot g$ \\
\hline$c$ & Coeficiente de amortecimento, suposto linear com a velocidade \\
\hline$S$ & Área (em geral, da seção transversal) \\
\hline$V$ & Volume \\
\hline$F$ & Força \\
\hline$v$ & Velocidade, também pode ser denominada por $u$ \\
\hline$E A$ & Rigidez axial \\
\hline$P$ & Carregamento pontual em unidades de força \\
\hline$d$ & \\
\hline$B$ & Constante \\
\hline$D$ & Constante (em alguns casos, diâmetro externo) \\
\hline$A$ & Constante \\
\hline$g$ & Intensidade do campo gravitacional local \\
\hline$V$ & $\begin{array}{l}\text { Em alguns casos, a deflexão total de um cabo ou viga; em outros, } \\
\text { volume }\end{array}$ \\
\hline C & Constante \\
\hline
\end{tabular}




\begin{tabular}{|l|l|}
\hline$E$ & Constante \\
$n$ & Número inteiro positivo \\
& Versor paralelo à direção tangente ou a nomenclatura do referido \\
$P_{c r}$ & eixo \\
$s$ & Carga crítica de flambagem \\
$H$ & Coordenada curvilínea \\
& Lâmina d'água, eventualmente pode ser denominada também \\
$z$ & por LDA \\
$M$ & Cota vertical no sistema Oxyz \\
$y$ & Momento-fletor; quando em negrito, matriz de inércia \\
$N$ & Distância ou coordenada relativa ao sistema 0xyz \\
$h$ & Esforço normal \\
$C_{m}$ & Esforços hidrodinâmicos \\
$C_{a}$ & Coeficiente de inércia \\
$C_{d}$ & Coeficiente de massa adicional \\
$a$ & Coeficiente de arrasto \\
$Q$ & Razão entre massa adicionada e massa própria \\
$b$ & Esforço cortante \\
& Adimensional cuja definição é apresentada no texto (idem para \\
$U$ & $c, d$ e $e$ ) \\
$c$ & Amplitude de movimento, também denominada por $A_{m}$ \\
& Momento de inércia de área \\
\hline & Celeridade de onda (vide definição de b, acima, para desambi- \\
\hline & Número de onda \\
\hline
\end{tabular}




\section{Alfabeto grego}

\begin{tabular}{|c|c|}
\hline Símbolo & Descrição \\
\hline$\widetilde{\lambda}$ & Coeficiente adimensional relativo ao comprimento de flexão \\
\hline$\lambda_{f}$ & Comprimento de flexão (ou flexural) \\
\hline$\partial$ ou $d$ & Operador diferencial \\
\hline$v_{x}$ ou $v_{s}$ & Deflexão lateral ou flecha \\
\hline$\tau$ & Tração dinâmica \\
\hline$\omega$ & $\begin{array}{l}\text { Velocidade angular, pode ter significados específicos quando } \\
\text { acompanhado de índice subescrito }\end{array}$ \\
\hline$\alpha$ & Argumento de função trigonométrica \\
\hline$\Pi$ & $\begin{array}{l}\text { Coeficientes adimensionais determinados a partir do Teorema } \\
\text { de Pi-Buckingham }\end{array}$ \\
\hline$\mu$ & Por definição, $m+m_{a}$ \\
\hline$\Psi$ & Função genérica \\
\hline$\eta$ & Coeficiente de atrito entre riser (ou modelo) e solo \\
\hline$\rho$ & Densidade \\
\hline$\epsilon$ & Deformação específica (normal) \\
\hline$\theta$ & Ângulo, com respeito à horizontal \\
\hline$\chi$ & Curvatura em um dado ponto de uma curva \\
\hline$\zeta$ & Coeficiente de amortecimento \\
\hline$\Omega$ & Parâmetro adimensional de frequência \\
\hline$\Lambda$ & $\begin{array}{l}\text { Parâmetro adimensional, razão entre as forças restauradoras } \\
\text { responsáveis pelo mecanismo de reação do cabo qualquer des- } \\
\text { locamento imposto }\end{array}$ \\
\hline$\beta$ & $\begin{array}{l}\text { Argumento de função trigonométrica, fator de amplificação da } \\
\text { carga crítica }\end{array}$ \\
\hline$\Gamma$ & Parâmetro adimensional definido no corpo do texto \\
\hline$\varpi$ & $\begin{array}{l}\text { Parâmetro relacionado com a perturbação dinâmica, definido no } \\
\text { texto }\end{array}$ \\
\hline$\sigma$ & $\begin{array}{l}\text { Parâmetro relacionado com a perturbação dinâmica, definido no } \\
\text { texto }\end{array}$ \\
\hline
\end{tabular}





\section{Conteúdo}

1 Introdução 1

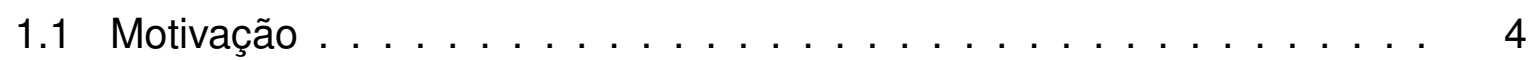

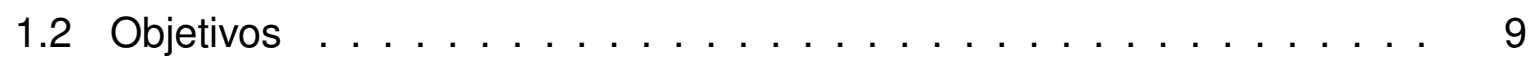

1.3 Organização desta tese $\ldots \ldots \ldots \ldots \ldots \ldots$

2 Revisão Bibliográfica $\quad 11$

2.1 Aspectos Teóricos Básicos de Elementos Estruturais . . . . . . . . . 12

2.2 Estática e Dinâmica de Risers . . . . . . . . . . . . . . . . . . 16

2.3 Compressão Dinâmica em Risers . . . . . . . . . . . . . . 25

3 Subsídios Teóricos 31

3.1 Estática de Risers em Catenária . . . . . . . . . . . . . . . . 33

3.1.1 Adimensionais que regem a estática de risers em catenária . . . 33

3.1.2 Formulação analítica do equilíbrio estático de risers em catenária 33

3.1.3 O papel físico dos adimensionais na estática de risers em catenária 41

3.2 Dinâmica de Risers em Catenária . . . . . . . . . . . . . . . . 45

3.2.1 Adimensionais que regem a dinâmica de risers em catenária . . 45

3.2.2 Formulação analítica da dinâmica risers em catenária . . . . . . 47

3.2.3 O papel físico dos adimensionais na dinâmica de risers em catenária . . . . . . . . . . . . . . . . . . 54

3.3 Compressão Dinâmica em Risers . . . . . . . . . . . . . . . . . 57

3.3.1 Adimensionais que regem a compressão dinâmica de risers em catenária . . . . . . . . . . . . . . . . . . 57

3.3.2 Carga crítica de flambagem para risers em catenária . . . . . 58

3.3.3 O papel físico dos adimensionais na carga crítica de flambagem 73

3.4 Considerações a respeito do uso de ancoragem nos ensaios . . . . . 75

3.4.1 Aproximação algébrica para o cálculo da carga crítica de vigas curvas engastadas-pinadas . . . . . . . . . . . . . 79

4 Metodologia $\quad 85$

4.1 Métodos . . . . . . . . . . . . . . . . . . 86

4.1.1 Programa de análise de linhas flexíveis . . . . . . . . 87 


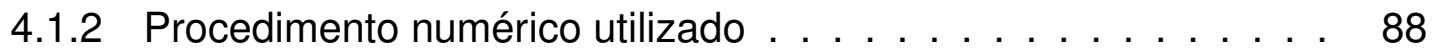

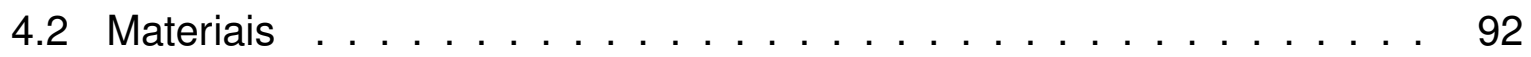

4.2.1 Calibrador Hidrodinâmico CH-TPN . . . . . . . . . . . . . 92

4.2.2 Instrumentação utilizada nos ensaios . . . . . . . . . . . 9 93

4.2 .3 Dispositivo atuador . . . . . . . . . . . . . . . . . 96

4.2.4 Modelo de linha flexível . . . . . . . . . . . . . . . . . . 97

5 Planejamento da Matriz de Ensaios e Simulações Numéricas 99

5.1 Matriz de Ensaios . . . . . . . . . . . . . . . . . . . . . . 100

5.2 Aparato Experimental Utilizado nos Ensaios . . . . . . . . . . . 103

5.3 Aferição do Dispositivo Atuador . . . . . . . . . . . . . . . . . . . . 112

5.4 Ensaios Físicos . . . . . . . . . . . . . . . . . . . . . 115

5.5 Simulações Numéricas . . . . . . . . . . . . . . . . 118

6 Resultados e Análises 131

6.1 Metodologia de Análise dos Resultados . . . . . . . . . . . . . 134

6.2 Principais Resultados . . . . . . . . . . . . . . . . . . . . . 145

6.2.1 Apresentação e discussão dos resultados do caso F080A050T80 146

6.2.2 Apresentação e discussão dos resultados do caso F080A100T85 149

6.2.3 Apresentação e discussão dos resultados do caso F100A200T65 154

6.2.4 Apresentação e discussão dos resultados do caso F125A050T70 156

6.2.5 Apresentação e discussão dos resultados do caso F125A050T80 158

6.2.6 Apresentação e discussão dos resultados do caso F125A100T85 160

7 Conclusões e Perspectivas

Bibliografia

169

Apêndices

$\begin{array}{ll}\text { A Sobre os vigas, cabos e colunas } & 177\end{array}$

A.1 Deflexões em vigas, cabos e colunas . . . . . . . . . . . . 177

A.1.1 Validade da aproximação de um riser pela teoria de cabos . . 179

A.1.2 Vibrações em vigas, cabos e colunas . . . . . . . . . . . 183

B Validação do Procedimento Numérico Sugerido 187

B.1 Comparação com os resultados estáticos de Ribeiro et al. (1998) e de Simos \& Fujarra (2006) . . . . . . . . . . . . . . . . . . 187

B.2 Comparação com resultados dinâmicos de Ribeiro et al. (1998) . . . . . 189

B.3 Comparação com resultados dinâmicos de Simos \& Fujara (2006) . . 192 
C Caracterização Física do Modelo Flexível 203

C.1 Validação numérica preliminar do modelo . . . . . . . . . . . . 203

C.1.1 Resultados preliminares dos modelos de silicone com areia e com água . . . . . . . . . . . . . . . . . 205

C.2 Caracterização físico-mecânica do modelo flexível . . . . . . . . . . . 219

C.2.1 Checagem dos diâmetros interno e externo do tubo . . . . . . 219

C.2.2 Massas lineares no ar e pesos submersos . . . . . . . . . 220

C.2.3 Determinação da rigidez axial do tubo de silicone . . . . . . . . 222

C.2.4 Determinação da rigidez flexional do tubo de silicone . . . . . . 231

C.2.5 Decaimentos no ar e frequências naturais de vibração . . . . . . 235

C.2.6 Compilação dos resultados de caracterização do modelo . . . . 243

C.2.7 Conclusões acerca dos resultados de caracterização . . . . . . 243 



\title{
Capítulo 1
}

\section{Introdução}

\author{
千里之行, 始於足下。 \\ Uma longa jornada inicia-se com um simples passo. \\ (Frase atribuída controversamente a Lao-Tzu)
}

Durante a década de 1970, o mundo atravessou duas grandes crises do petróleo em consequência de diversos fatores; dentre eles, a divulgação por parte dos cientistas de que o petróleo é uma fonte de energia esgotável e não renovável.

A primeira dessas crises aconteceu em 1973, quando o preço do barril de óleo chegou a triplicar em apenas 3 meses. A recuperação dos preços a patamares anteriores à crise só ocorreu em meados da década seguinte.

À época, a empresa estatal detentora do monopólio de exploração no país viu-se diante de um grande problema econômico, dado que a maior parte do óleo combustível utilizado no Brasil era proveniente de importações.

Como soluções, a Petrobras optou por duas estratégias distintas: a criação do Programa Nacional do Álcool (Pró-Álcool) em 1974 e o sucessivo aumento nas pesquisas por novas jazidas, lançando-se a lâminas d'água cada vez maiores.

Em 1973, a Petrobras descobriu a Bacia de Campos, na costa norte do estado do Rio de Janeiro, em uma área que se estende por cerca de $100 \mathrm{mil} \mathrm{km}^{2}$. Essa bacia começou a ser explorada em 1977 e hoje responde por cerca de $80 \%$ da produção nacional de petróleo.

A partir dessa descoberta, a exploração de óleo e gás passou a ocorrer em profundidades cada vez maiores. As descobertas dos campos de Albacora e de Marlim, respectivamente em 1984 e 1985, provou a existência de grandes reservas em águas profundas. Em 1997, quando ocorreu a quebra do monopólio estatal do petróleo, o país já havia experimentado um crescimento de quase $1300 \%$ nas lâminas d' água de exploração, desde a descoberta da Bacia de Campos (vide Figura 1.1). 


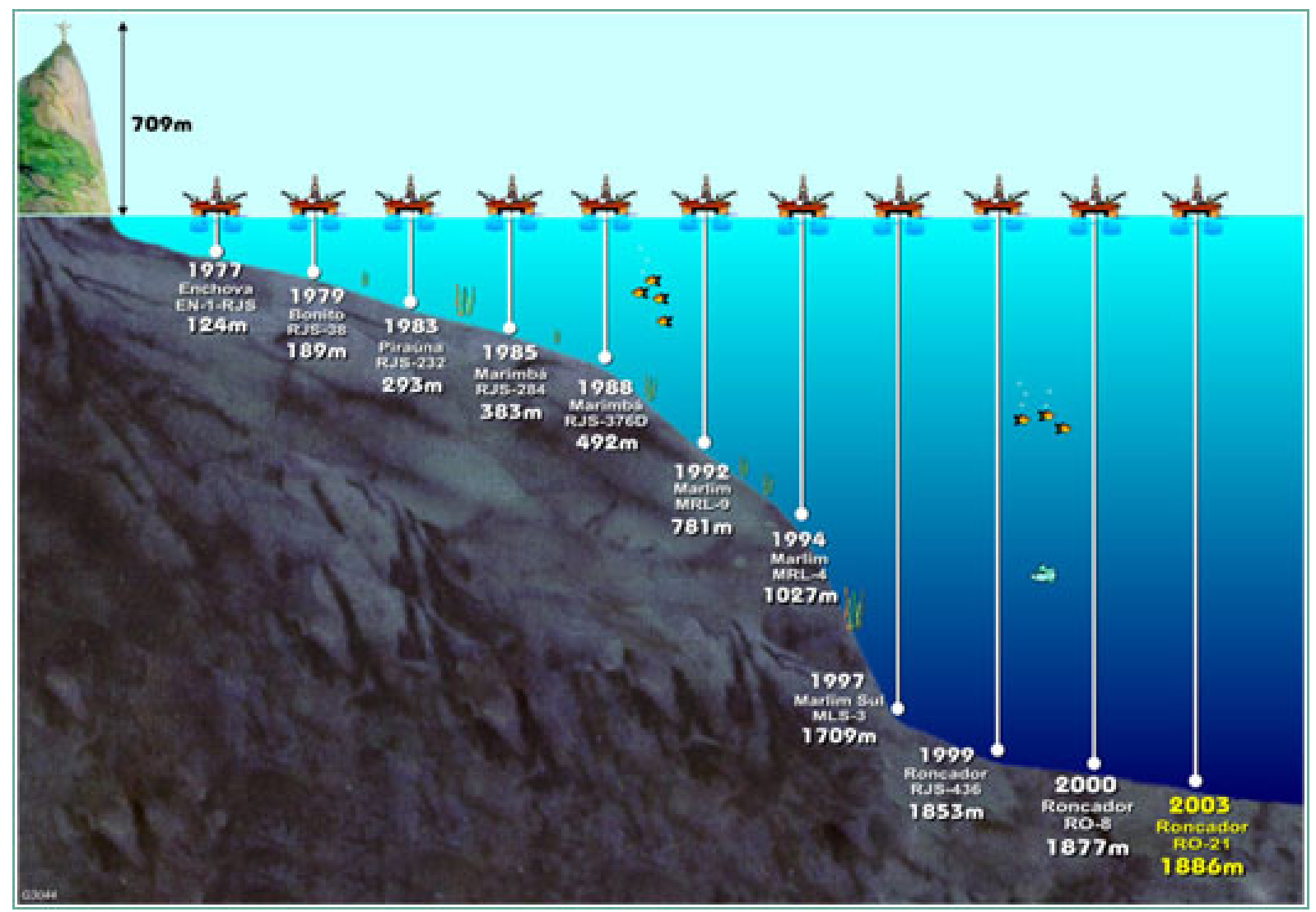

Figura 1.1: Evolução das lâminas d'água na exploração brasileira de óleo e gás em águas profundas. Fonte: Site da Petrobras, acessado em 17/12/2012.

A evolução da exploração em águas profundas e ultraprofundas só foi possível graças a vultosos investimentos no setor de pesquisa, desenvolvimento e inovação.

Os sistemas oceânicos tornaram-se maiores e mais complexos, demandando a concepção de novas tecnologias, a fim de enfrentar os novos desafios.

Nesse sentido, destaca-se o progresso conquistado nos sistemas de amarração e de produção de petróleo e gás, esses últimos formados por dutos e cabos conhecidos como risers e umbilicais.
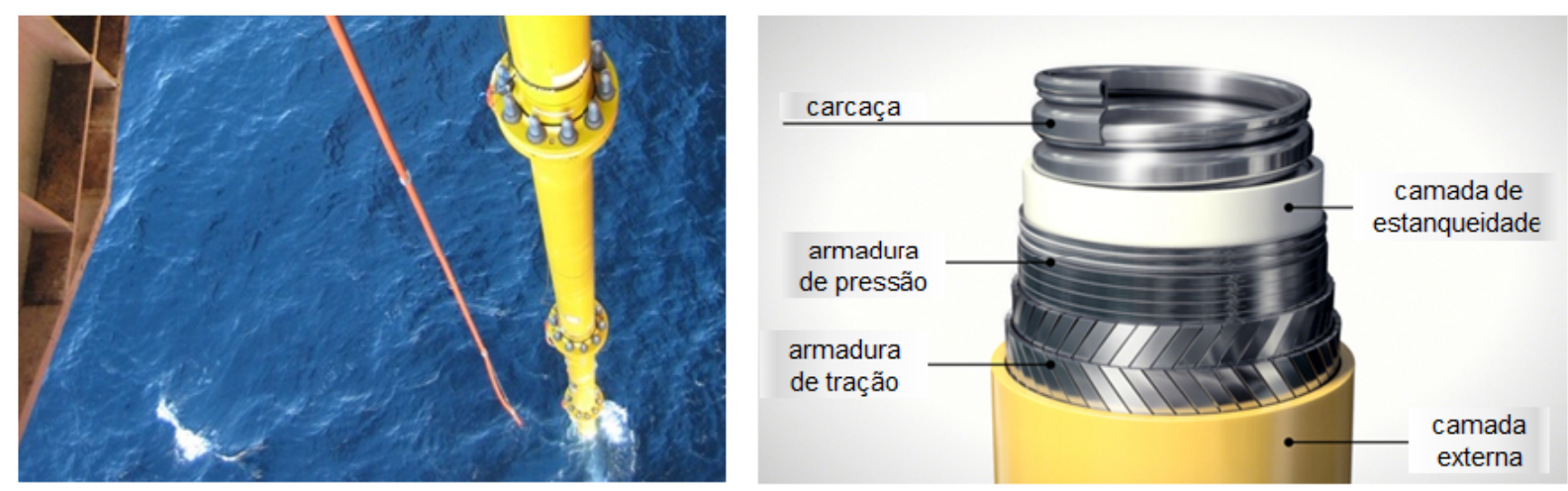

Figura 1.2: Principais tipos de risers: rígido (à esquerda) e flexível (à direita). Fonte: Adaptado de sítios da internet, autores desconhecidos. 
O riser é um duto especializado na perfuração de poços ou na produção de petróleo e gás, enquanto que um umbilical é responsável pelo transporte de fluidos de serviço e o provimento de energia elétrica para o funcionamento dos equipamentos submarinos. A Figura 1.2 ilustra os dois principais tipos de de risers (rígido e flexível).

Com relação a essas estruturas delgadas, diversos estudos têm sido realizados a fim de se conhecer com detalhes suas condições de operação; dependendo da configuração de lançamento (vide Figura 1.3), das propriedades físicas dessas linhas e dos esforços a que são submetidas.

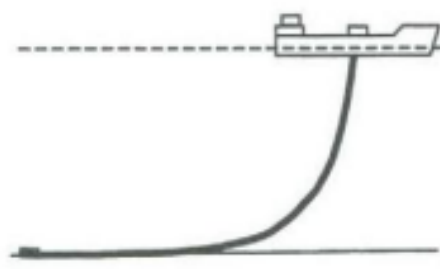

Free Hanging

Catenary

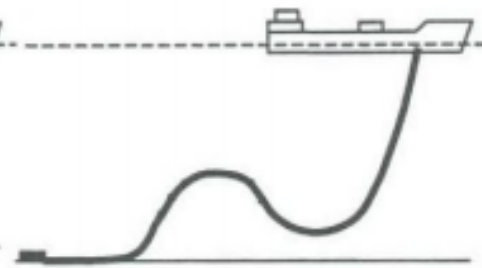

Lazy Wave

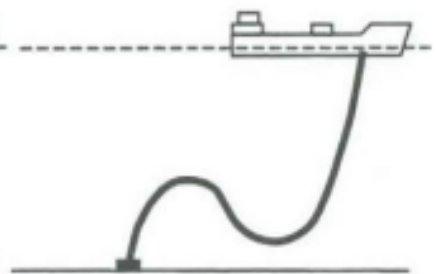

Steep Wave

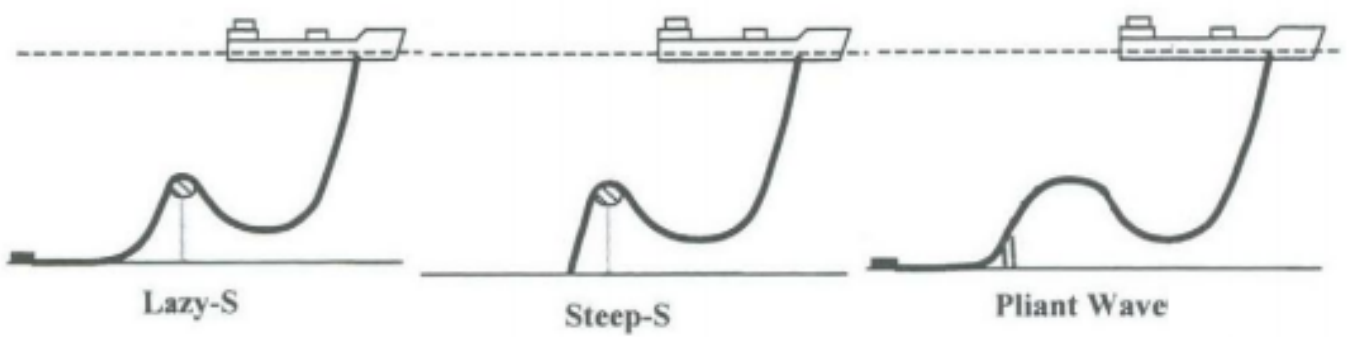

Figura 1.3: Principais configurações de geometrias de risers flexíveis. Fonte: http://www.diva-portal.org/smash/get/diva2:566013/FULLTEXT01.pdf. Acessado em 11/12/2014, disponível como documento de acesso público.

Dentre os diversos problemas abordados pela Mecânica de Cabos e Tubos Submersos, é possível citar, entre outros, as vibrações induzidas pela emissão de vórtices (VIV, da sigla em inglês para vortex-induced vibrations ${ }^{1}$ ), a interação com a unidade flutuante, os efeitos de impactos contra o solo, as interações hidrodinâmicas, a interferência entre os risers, fadiga, falhas e a compressão dinâmica.

Com respeito a esse último fenômeno, é mister entender que da compressão dinâmica decorrem grandes curvaturas locais no riser. Dessa maneira, diferentemente de outros fenômenos físicos que podem afetar esse tipo de estrutura, o problema não está associado à ciclicidade dinâmica capaz de culminar em um rompimento por fadiga, mas à forma abrupta com que a compressão dinâmica ocorre, visto que se configura como um fenômeno de instabilidade (flambagem).

\footnotetext{
${ }^{1} \mathrm{O}$ VIV é um fenômeno causado pelo desprendimento alternado de vórtices por estruturas com seção transversal circular. As vibrações desse fenômeno são autoexcitadas e autocontroladas, com amplitudes da ordem de um diâmetro da seção transversal.
} 


\subsection{Motivação}

Os risers, por sua função específica, são projetados para trabalhar sob determinados níveis de tração. Entretanto, em condições particulares, é possível que fiquem indesejavelmente sujeitos a cargas de compressão, podendo culminar em falhas estruturais. A escolha pelo tipo de riser (rígido ou flexível) e sua configuração de lançamento (vertical, catenária direta ou um ajuste híbrido) são vitais para as atividades de operação e são função de uma variedade enorme de aspectos; tais como, fatores geográficos e ambientais da locação, legislações pertinentes, sistema flutuante a que estará conectado, presença de estrutura submersa, entre outros.

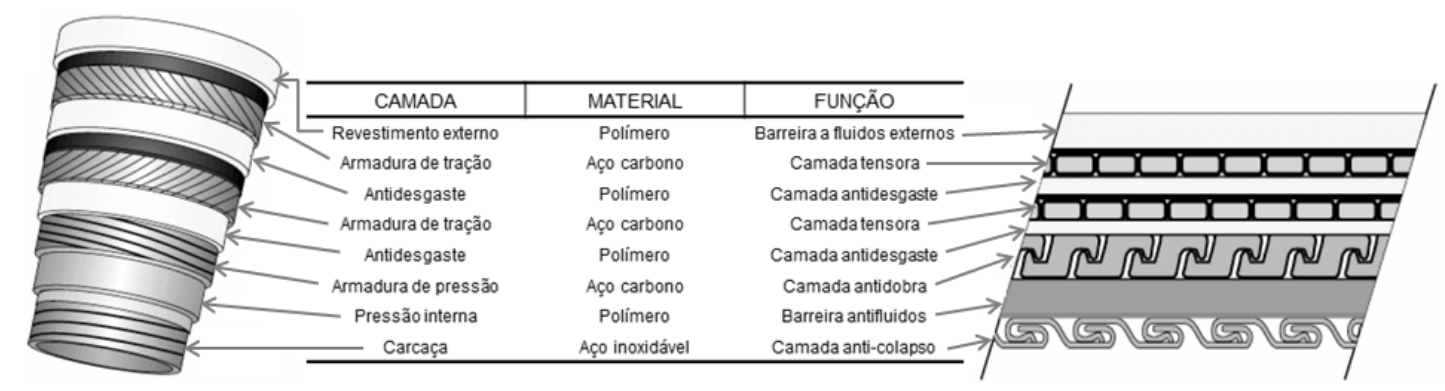

Figura 1.4: Configuração interna de um riser flexível.

Fonte: Site www.wellstream.com (adaptado).

No que tange à sua estrutura física, os risers flexíveis são constituídos por diversas camadas concêntricas de diferentes configurações e materiais (ver Figura 1.4), enquanto que os rígidos são compostos por tubos de aço ligados em série por meio de solda de topo, podendo ser envolvidos por flutuadores, a fim de diminuir seu peso aparente, quando instalados em lâminas d'água muito profundas.

Os risers flexíveis, a despeito do seu alto custo relativo de aquisição, são mais complacentes dinamicamente, atingindo maiores níveis de curvatura, comparativamente aos risers rígidos. Além disso, suas diversas camadas conferem à estrutura características interessantes no que dizem respeito à estanqueidade, isolamento térmico e fricção. Os risers rígidos são bastante utilizados na perfuração e produção, principalmente pelo seu baixo custo relativo de aquisição e manutenção, sendo comumente subdivididos em verticais e $\mathrm{SCR}^{2}$, sendo esse último uma solução comprovadamente viável para grandes profundidades, nas quais o uso do riser flexível ainda é tecnicamente menos usual.

Segundo Sertã et al. (2001), as maiores vantagens relativas do uso de SCRs, comparativamente aos flexíveis, são: permitem maiores diâmetros, possuem maior resistência termomecânica, necessitam de equipamentos de instalação/desinstalação mais usuais, apresentam menor custo de aquisição, representam baixo impacto no projeto do sistema flutuante e suportam intervenções de sondas.

\footnotetext{
${ }^{2}$ SCR é o acrônimo, em inglês, para Steel Catenary Riser, ou riser rígido em catenária.
} 
Quanto às desvantagens, os SCRs demandam desconexão submarina, despendem maior tempo nas operações de instalação e remoção (vide Figuras 1.5 e 1.6) e provocam tensionamentos indesejáveis nos equipamentos submarinos.

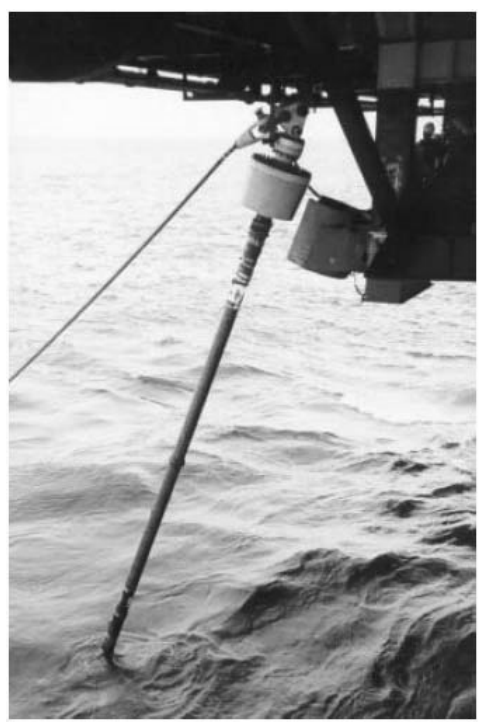

Figura 1.5: SCR da plataforma P18 da Petrobras durante a instalação.

Fonte: Torres et al. (2008).

Os lançamentos em catenária são mais utilizados em sistemas flutuantes mais "transparentes" às ondas de superfície, como são os casos das FPSO e das $\mathrm{FSO}^{3}$.

O uso cada vez mais frequente de embarcações convertidas leva, por conseguinte, à utilização de risers em catenária direta (ou suas variantes). Esses risers possuem maior custo de aquisição e manutenção, necessitam de maiores comprimentos suspenso e total e acarretam em maior dificuldade em eventuais manutenções.

Se por um lado, o lançamento de um riser flexível em catenária direta é simplificado e utiliza baixa quantidade de elementos redutores de esforços, possibilitando um menor custo em termos de material e instalação; por outro, o aumento das profundidades de produção pode inviabilizar esse tipo de lançamento, particularmente no que tange a três aspectos:

1. Alto nível de trações no topo, dado que todo o comprimento suspenso é sustentado pelo ponto de conexão com a plataforma;

2. Vida útil relativamente baixa, decorrente da fadiga nas extremidades do seu comprimento suspenso (topo e TDP ${ }^{4}$ ), que são extremamente solicitadas;

3. Possibilidade de compressão dinâmica, relacionada à flambagem do riser nas proximidades do TDP.

\footnotetext{
${ }^{3}$ FPSO e FSO são os acrônimos para Floating Production Storage and Offloading e Floating Storage and Offloading, respectivamente. Essas denominações referem-se a sistemas flutuantes responsáveis pela extração e armazenamento de petróleo, para posterior transferência a um navio aliviador. A diferença entre ambos os sistemas é que o primeiro é capaz de iniciar o processamento dos hidrocarbonetos armazenados.

${ }^{4}$ TDP é a sigla, em inglês, para touchdown point, definido como o primeiro ponto de contato de um riser com o solo. Tecnicamente, a terminologia mais rigorosa deve se referir à uma região no entorno desse ponto, visto que a posição do mesmo não é fixa. Nesse caso, a nomenclatura mais adequada seria touchdown zone, ou TDZ.
} 

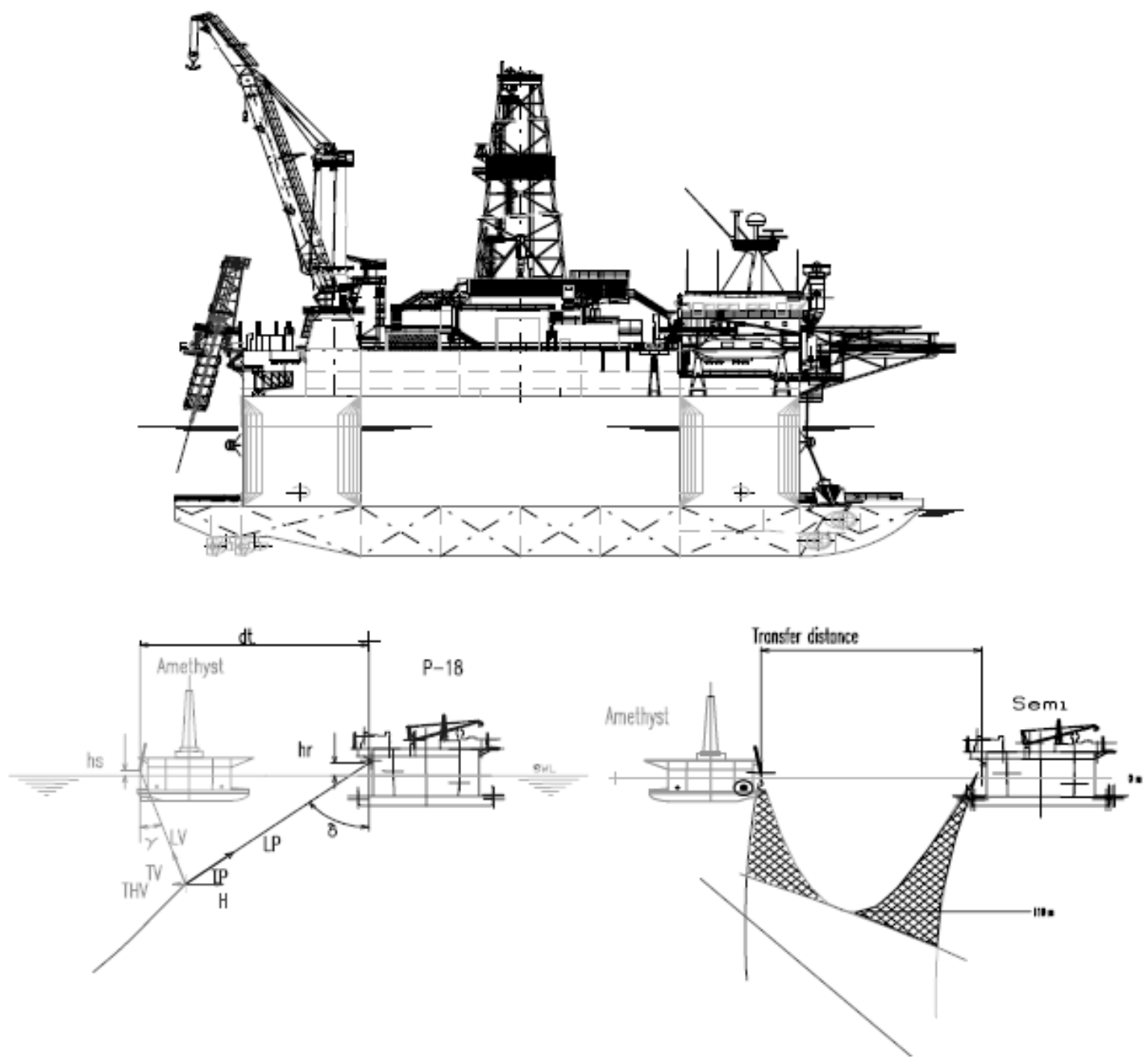

Figura 1.6: Esquema de instalação dos SCRs na plataforma P18 da Petrobras.

Fonte: Porciuncula et al. (1999).

Dentre as citadas, a configuração mais simples e barata é a catenária livre; entretanto, essa solução apresenta níveis elevados de tração solicitante na conexão com à unidade de produção. Com o intuito de reduzir estes esforços são colocados flutuadores ou bóias nas seções intermediárias do riser (vide Figura 1.3).

Independentemente do tipo de riser ou sua configuração de lançamento, é importante salientar que um eventual rompimento dessa estrutura especializada acarretaria problemas das mais diferentes origens, dentre os quais é possível citar: os danos ambientais e ecológicos; a inutilização do riser em si; a interrupção da produção, acarretando grandes perdas em termos econômicos; e a possibilidade de prejuízo à imagem das empresas envolvidas, o que pode culminar com desvalorização financeira das mesmas. Esses aspectos sustentam a importância do projeto e estudo de risers. Navios, plataformas, seus sistemas e subsistemas são regulados por normas e regulamentos específicos, ditados por Sociedades Classificadoras. Sem a classificação por uma dessas entidades, é praticamente impossível garantir a segurança das embarcações, sistemas, equipamentos e pessoal embarcado. 
Consequentemente, nenhuma empresa seguradora se responsabilizará por eventuais problemas decorrentes de operações, na ausências dessas certificações.

A American Bureau of Shipping (ABS) é uma das Sociedades Classificadoras mais importantes e prestigiadas, sendo uma das fundadoras da IACS ${ }^{5}$. Em um de seus inúmeros documentos - o (ABS, 2008) - é possível encontrar o seguinte excerto:

Buckling of the composite riser pipe body due to external overpressure combined with torsion, bending, or axial compression, if applicable, is to be considered. (...) Analytical solutions or numerical methods may be used to calculate the resistance of pipe body to buckling. (...) Since local buckling is not allowed to occur in composite riser joints, propagating buckling needs not to be considered.

Embora uma tradução, mesmo que livre e adaptada, não se faça necessária, esse pequeno trecho da (ABS, 2008) mostra a importância do assunto que é objeto de estudo do presente trabalho. Note-se que soluções analíticas e métodos numéricos são citados como ferramentas para a determinação da resistência à flambagem, sendo que nenhuma menção é feita com relação a testes empíricos.

Como sugere o trecho extraído de (ABS, 2008), nenhuma consideração a respeito da propagação de eventual flambagem é necessária, dado que, por hipótese, o riser é construído de maneira a não permitir esse tipo de falha estrutural. Nesse sentido, a presente tese não abordará, em momento algum, aspectos inerentes ao comportamento estrutural pós flambagem do riser.

Neste ponto, é mister diferenciar as flambagens local e global de um riser. A primeira, conhecida comumente como birdcaging, corresponde a uma falha estrutural local (Figura 1.7), em que as componentes internas do riser forçam o rompimento de sua carcaça; enquanto que o segundo caso, denominado compressão dinâmica, ocorre globalmente, fletindo a linha como um todo.
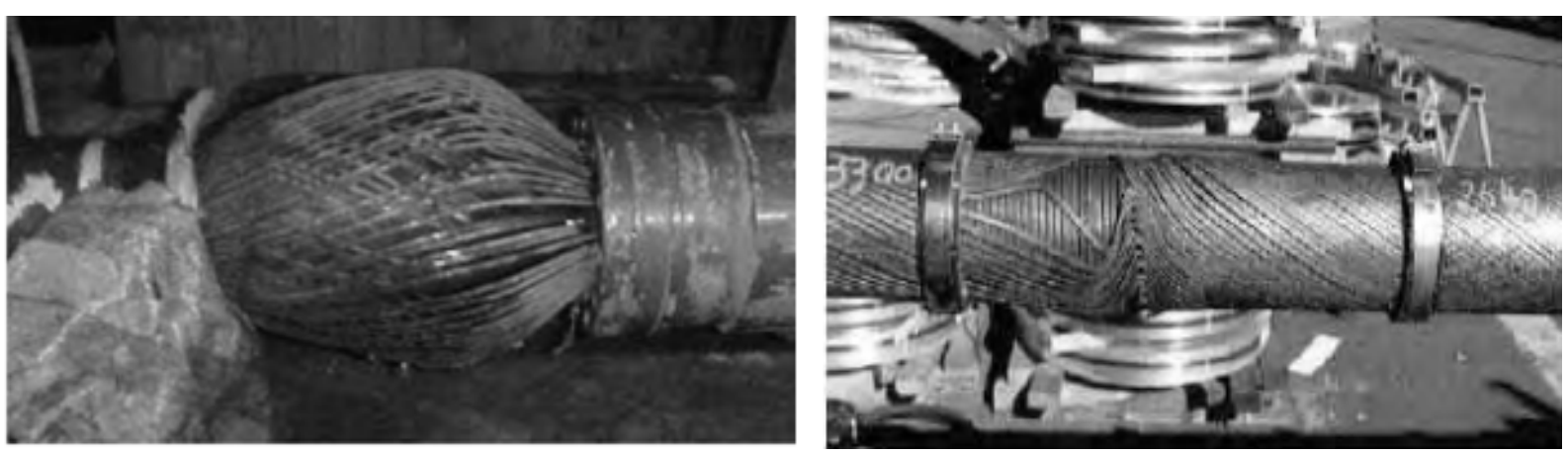

Figura 1.7: Falha estrutural por compressão do tipo birdcaging em risers.

Fonte: Site www.wellstream.com.

\footnotetext{
${ }^{5}$ Existem mais de 50 Sociedades Classificadoras em todo o mundo, mas apenas 13 (dentre elas a ABS) fazem parte de um seleto grupo denominado IACS - International Association of Classification Societies (Associação Internacional das Sociedades Classificadoras), responsáveis pela certificação de mais de $90 \%$ das embarcações de longo curso.
} 
O fato de a flambagem ser um fenômeno de instabilidade que ocorre repentinamente, podendo acarretar danos estruturais severos, com a consequente perda do riser, faz com que seu estudo seja prontamente justificado.

As grandes curvaturas relativas decorrentes da flambagem impactam fortemente no projeto estrutural, assumindo importância fundamental nessa fase. Ademais, caso 0 fenômeno de instabilidade se repita ciclicamente, em um estado de mar severo, por exemplo, pode culminar em fadiga mecânica de baixo ciclo.

A natureza desse fenômeno, aliada à necessidade de pesquisas que viabilizem o uso de risers flexíveis em determinadas situações, sustentam a motivação da presente pesquisa, focada em ensaios físicos para o estudo da compressão dinâmica em risers flexíveis.

A apresentação desses argumentos e considerações aponta para a importância de maiores estudos relativos à compressão dinâmica, a fim de avançar no entendimento do fenômeno, bem como para criar ferramentas de projeto adequadas para evitar a flambagem dos risers. 


\subsection{Objetivos}

A presente tese propõe uma abordagem tríplice para o problema de compressão dinâmica, ou seja, a confrontação de resultados decorrentes de formulações analíticas existentes e as que advêm deste trabalho, com o produto de simulações numéricas e de ensaios físicos realizados em ambiente controlado.

O objetivo principal é a determinação experimental das características da onda de compressão gerada com a ocorrência do fenômeno de compressão dinâmica, o que por si só é inédito, possibilitando sua comparação com os resultados das demais vertentes que encerram esta investigação, a partir do amplo levantamento bibliográfico realizado.

Como objetivo secundário, é possível citar a elaboração racional e sistemática de uma metodologia capaz de prever, de maneira simples e objetiva, a possibilidade de ocorrência do fenômeno em estudo, culminando, inclusive, na simplificação de formulações analíticas consagradas, promovendo sua confirmação experimental.

Saliente-se, por fim, que esse último objetivo pretende conferir um caso de referência para futuros trabalhos de cunho experimental, bem como discutir os aspectos relacionados à vertente analítica, explorando suas qualidades e limitações. O uso de simulações numéricas, nesta tese, realizado a partir de códigos numéricos próprios e comerciais, se configura mais como um meio, que como uma finalidade em si. 


\subsection{Organização desta tese}

A estrutura da presente tese, nos capítulos que se seguem, está distribuída de maneira que o Capítulo 2 apresenta uma extensa revisão bibliográfica, com base em três temas distintos e complementares: o estudo de vigas, cabos e colunas; as modelagens estática e dinâmica de risers; e a compressão dinâmica em risers.

Seguindo a estruturação desta tese, o Capítulo 3 apresenta as formulações analíticas existentes na literatura, a partir dos textos apresentados no Capítulo 2, explicitando suas virtudes, hipóteses e restrições de uso. Além disso, encerra o desenvolvimento de uma formulação própria, decorrente diretamente do que foi postulado por outros autores, mas que traz luz à compreensão do problema, bem como suscita um procedimento simples para evitar a ocorrência de compressão dinâmica em risers, tanto na fase de projeto, quanto na sua utilização durante as operações inerentes à sua função. O Capítulo 4 trata dos materiais e métodos envolvidos nas simulações e ensaios físicos do presente trabalho, de maneira a apresentar, inclusive, um procedimento para elaboração da matriz de ensaios, com validação a partir de diversos estudos de caso, baseados em trabalhos presentes na literatura especializada.

Os ensaios e simulações numéricas (provenientes das formulações analíticas e dos programas Anflex e Poliflex), em termos de seus respectivos resultados, serão apresentados no Capítulo 5. Destaque-se, uma de suas subdivisões apresenta a sistematização das tarefas realizadas para determinar o conjunto de experimentos realizados no $\mathrm{CH}$-TPN, corroboradas pelos resultados do Capítulo 4.

O Capítulo 6, por seu turno, é dedicado à análise e discussão dos resultados apresentados no Capítulo 5. O Capítulo 7 discorrerá sobre as conclusões que puderam ser depreendidas a partir do que foi estudado e dos resultados obtidos, além de apresentar algumas sugestões para trabalhos futuros. 


\title{
Capítulo 2
}

\section{Revisão Bibliográfica}

\author{
"If I have seen further it is by standing on the shoulders of giants". \\ Se pude enxergar mais longe é porque me apoiei sobre os ombros de gigantes. \\ (Isaac Newton)
}

A fim de facilitar a compreensão do tema em questão e nortear os estudos relativos à compressão dinâmica em risers, o levantamento bibliográfico apresentado mais adiante foi dividido em três partes independentes que, ao final, convergem para a formação do arcabouço teórico sobre o assunto, a saber:

- A primeira parte refere-se ao estudo clássico de elementos estruturais comumente abordados pela Resistência dos Materiais e conceitos rudimentares da Teoria de Estabilidade, aqui recuperados na busca por sedimentar os mecanismos que regem a estática e a dinâmica das vibrações desses elementos;

- A segunda parte trata da Mecânica de Linhas, assunto recorrente no âmbito da Engenharia Naval e Oceânica, principalmente no que concerne aos estudos de risers, umbilicais e linhas de amarração;

- A terceira parte aborda os aspectos relacionados à compressão dinâmica em risers, com o objetivo de situar o leitor quanto ao "estado da arte" sobre esse tema.

Embora algumas formulações sejam apresentadas ao longo do texto, o objetivo do presente capítulo não é o de recuperá-las ou explorá-las antecipadamente. Assim, mesmo quando alguma equação for apresentada, sua formalização será feita, adequada e oportunamente, no Capítulo 3 ou nos Apêndices, devidamente referenciada. Por fim, cabe notar que a divisão proposta para o presente capítulo é mais didática que corriqueira: ao final, espera-se que o leitor compreenda a motivação do autor por essa apresentação, de maneira a facilitar a compreensão do fenômeno em estudo, baseada em abordagens usuais, e de como isso ocorreu historicamente, tanto em termos dos tratamentos físico-matemáticos, como dos aspectos práticos de projeto e operação. 


\subsection{Aspectos Teóricos Básicos de Elementos Estruturais}

De acordo com as recomendações da API (1993) ${ }^{1}$, para os propósitos relativos à análise de risers, estes podem ser considerados como vigas tensionadas, modeladas sob as hipóteses de Euler-Bernouli, desde que se possam considerar curvaturas cujo ângulo entre a linha neutra e a vertical não ultrapassem $10^{\circ}$. Ainda que essas recomendações sejam relativas a risers de perfuração, tal aproximação pode ser utilizada para as extremidades do riser de produção, de maneira que se configure adequada como primeira aproximação.

Dentre as diversas formas de se conceituar uma viga, é possível defini-la como um elemento estrutural linear sujeito, preponderantemente, a cargas de flexão.

Como qualquer estrutura real, seu estudo demanda a utilização de modelos matemáticos que encerram em si determinadas simplificações, dadas as hipóteses consideradas. Love (1906), Han et al. (1999), Oliveira (2004) e Costa (2006), dentre outros trabalhos, citam, como modelos de vigas mais estudados, aqueles propostos por EulerBernoulli, por Rayleigh, por Vlasov (modelo da força cortante) e por Timoshenko, os quais são representados por equações diferenciais parciais, sujeitas a determinadas condições iniciais e de contorno.

Historicamente, Galileu foi o primeiro matemático a considerar a resistência dos materiais sólidos (até então tratados como inelásticos), além de fornecer a relação entre o comprimento de um pêndulo e seu período de oscilação, o que, de certa maneira, se configura como um dos primórdios da análise das vibrações.

Entre o estabelecimento da relação linear entre carregamento e deformação, em 1660, por Hooke, e a formulação da teoria geral da elasticidade, em 1821, por Navier, diversos problemas decorrentes dos estudos de Galileu foram examinados, dentre eles as vibrações em barras e placas e a estabilidade de colunas.

Dentre os modelos citados, o de Euler-Bernoulli é o mais utilizado, sendo a base da teoria clássica de vigas. Nele o cisalhamento e a inércia de rotação são desprezados, o material que constitui a viga é suposto isotropicamente homogêneo e linearmente elástico e sua seção transversal considerada plana e perpendicular ao eixo longitudinal, mesmo após a deformação.

Como consequência, a predição de suas frequências naturais de vibração é tanto mais precisa quanto mais esbelta for a estrutura em estudo. Adicionalmente, essa teoria tende, em geral, a superestimar as frequências naturais, o que acarreta maiores discrepâncias para os modos de vibrar mais elevados.

O modelo proposto por Rayleigh incorpora o efeito da rotação da seção transversal, o que, segundo Han et al. (1999), corrige parcialmente os efeitos de superestimação das frequências naturais, embora não incorpore os efeitos de cisalhamento.

\footnotetext{
${ }^{1} \mathrm{~A}$ API - American Petroleum Institute, sigla em inglês para Instituto Americano do Petróleo, é a maior associação comercial americana relacionada à indústria de petróleo e gás natural. Sua participação global engloba as áreas econômica, social, governamental, ambiental e legal, além do estabelecimento de práticas e o fomento à educação e pesquisa.
} 
Por outro lado, o modelo de Vlasov leva em conta o efeito de distorção devido ao cisalhamento, incorporando essa hipótese ao modelo de Euler-Bernoulli, porém sem tratar do efeito de rotação das seções transversais.

O modelo de Timoshenko, finalmente, incorpora ao modelo clássico as modificações propostas por Rayleigh e por Vlasov. Sendo assim, é o modelo mais adequado ao estudo de estruturas não delgadas sob vibrações em altas frequências.

As relações citadas entre frequências e modos de vibrar, dependendo do modelo de viga utilizado, podem ser visualizadas nas Figuras 2.1 e 2.2. Ambas extraídas de (Han et al., 1999).
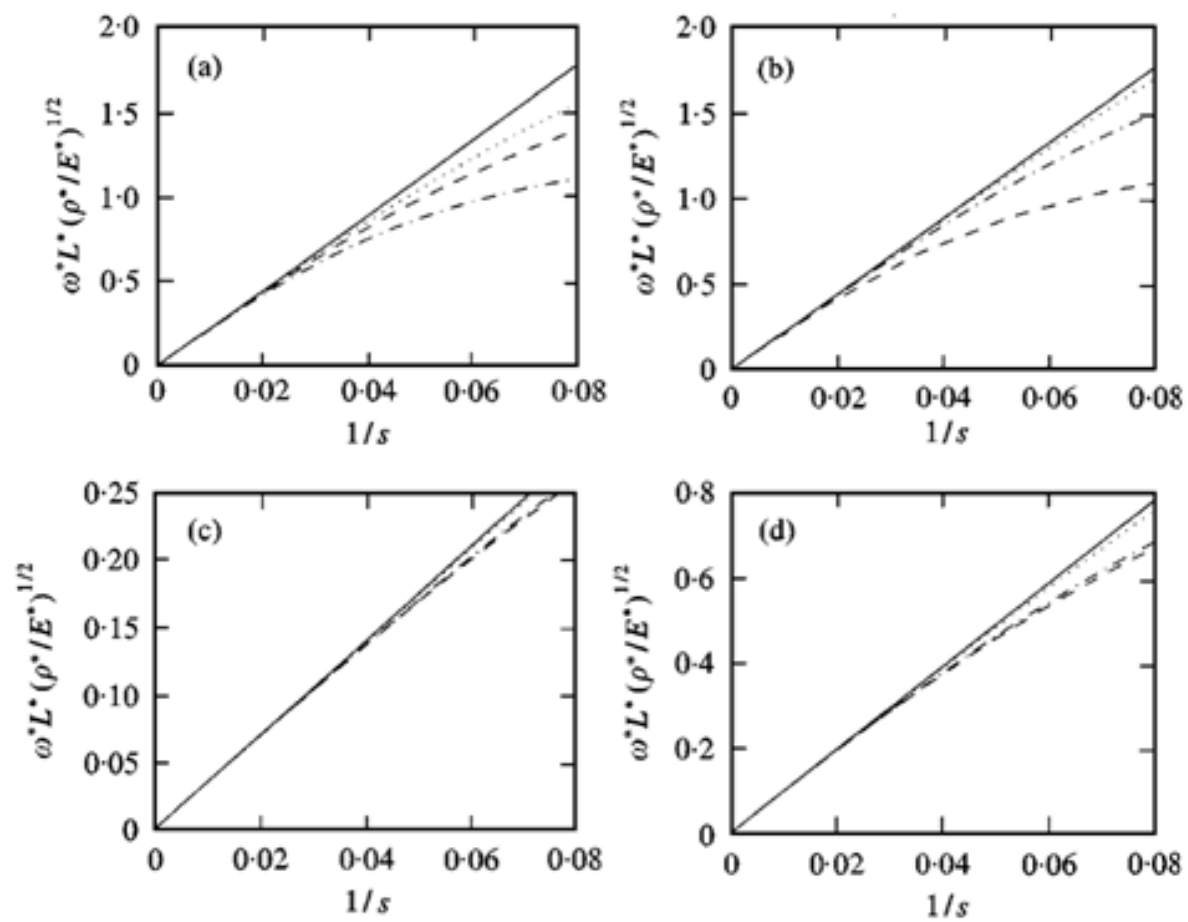

Figura 2.1: Primeiras frequências naturais de vibração de vigas para cada modelo.

- Euler-Bernoulli ... Rayleigh, - - - Vlasov, - - - Timoshenko.

(a) viga livre-livre, (b) viga biengastada, (c) viga em balanço, (d) viga biapoiada.

Umas das principais conclusões de Han et al. (1999) é que o número de onda é fortemente relacionado à esbeltez da viga.

Ainda com relação aos quatro modelos de vigas citados anteriormente, Costa (2006) reforça as hipóteses básicas comuns, sendo estes:

- As vigas são longas e esbeltas, de maneira que a dimensão na direção axial é consideravelmente maior que nas demais;

- O material é linear e elástico. O efeito de Poisson, relacionado à estriç̧ão do elemento, é desprezado;

- Existe coincidência dos eixos neutro e longitudinal central, de maneira que a seção transversal seja simétrica;

- Ângulos de rotação são considerados relativamente pequenos. 

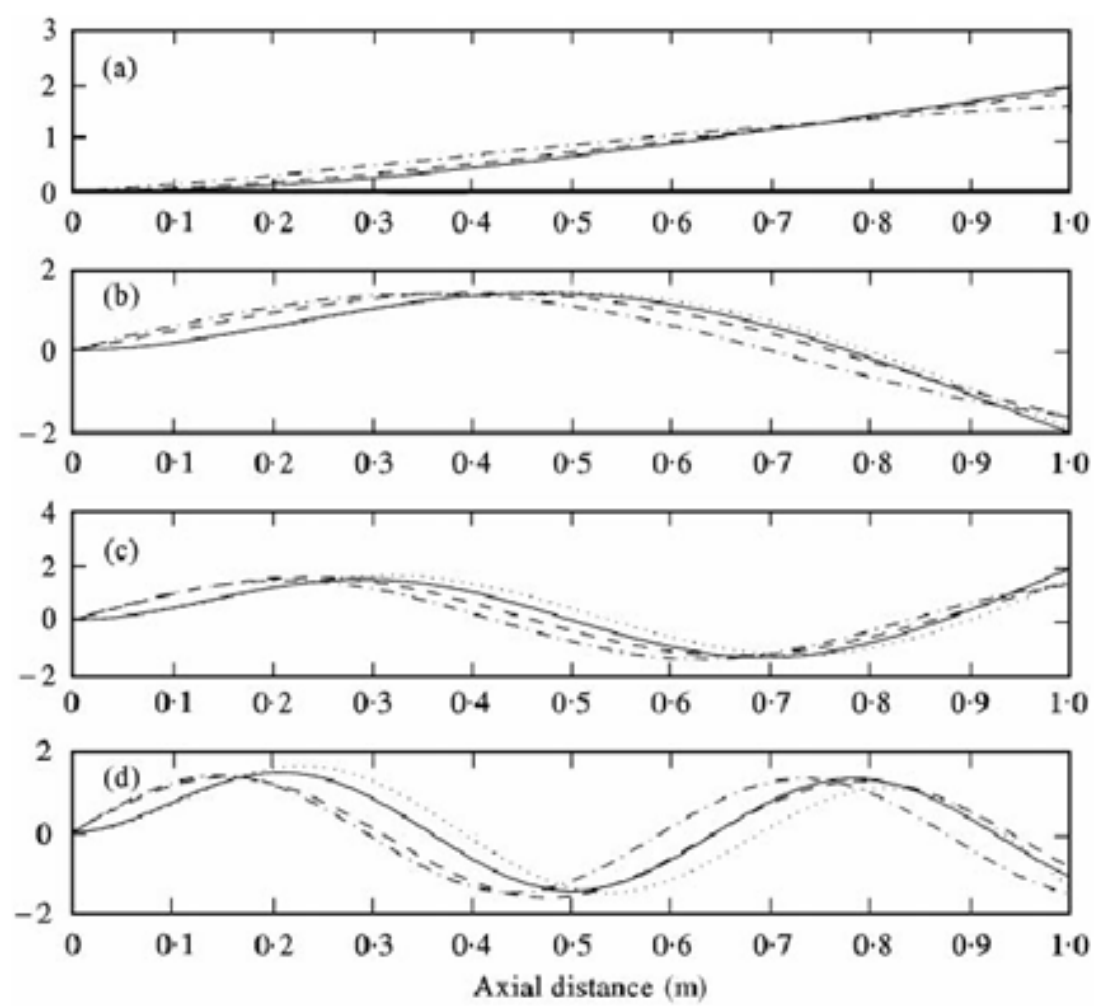

Figura 2.2: Os quatro primeiros modos de vibrar de uma viga em balanço. - Euler-Bernoulli, . . Rayleigh, - - - Vlasov, - - - Timoshenko.

(a) primeiro modo, (b) segundo modo, (c) terceiro modo, (d) quarto modo.

Dando sequência às ponderações iniciais necessárias para a continuidade do presente texto, é possível definir um cabo como sendo uma estrutura esbelta e extremamente flexível, de maneira que, fisicamente, considera-se desprezível a sua capacidade de resistir à flexão (rigidez flexional aproximadamente nula).

O interesse histórico a respeito de cordas e cabos remonta à Antiguidade Clássica, quando Pitágoras associou os sons produzidos por cordas tensionadas aos seus comprimentos e à tração a que estão sujeitas.

De acordo com Irvine \& Caughey (1974), durante a primeira metade do século XVIII, diversos matemáticos, como Taylor, D’Alembert, Euler e Bernoulli, dedicaram estudos e trabalhos à teoria de vibrações em cordas retesadas e fixas em suas extremidades, mesmo que, à época, a teoria de equações diferenciais parciais, considerada essencial para a resolução deste tipo de problema, ainda estivesse em desenvolvimento. Somente em 1820, a teoria de vibrações em cabos recebeu sua maior contribuição, após um trabalho publicado por Poisson. Até então, soluções corretas só haviam sido concebidas para vibrações livres lineares em cabos uniformes e sob ação de seu peso próprio (catenária).

A fim de dar continuidade ao estabelecimento dos fundamentos que cercam a compressão dinâmica em risers, sem que o fenômeno seja formalmente definido, convém discutir alguns aspectos relevantes da deflexão lateral de colunas que, por definição, são elementos esbeltos sujeitos a uma força axial de compressão. 
Dependendo do valor do carregamento axial a que está sujeita, uma coluna pode sofrer flambagem, que se configura como uma flexão repentina que ocorre quando a força axial ultrapassa um determinado valor, denominado carga crítica, de maneira que a mesma atinja repentinamente um estado de equilíbrio instável, sem que atinja seu limite de escoamento (bifurcação de equilíbrio).

Por extensão dos conceitos apresentados, elementos estruturais esbeltos, sujeitos a carregamentos laterais e carga de compressão, são denominados vigas-coluna. Todos esses elementos possuem uma capacidade instrínseca comum: a possibilidade de resistência à flexão. Os elementos incapazes de resistir a cargas compressivas são chamados de cabos.

Embora discussões detalhadas sobre instabilidade de estruturas não façam parte do escopo deste trabalho, o fenômeno de flambagem é assunto correlato ao tema central desta tese. Assim, faz-se necessária uma breve introdução de alguns conceitos básicos sobre estabilidade de sistemas dinâmicos, ainda que de maneira não rigorosa. Segundo Savi (2006), os primeiros estudos relativos a sistemas dinâmicos são atribuídos a Kepler (por seus trabalhos de Mecânica Celeste) e a Newton (pelo desenvolvimento da matemática da Mecânica Clássica).

A partir daquele momento, o nível de sofisticação na modelagem de sistemas ganhou um impulso considerável, possibilitando diversos outros trabalhos, como os de Lagrange e Hamilton, aos quais é atribuído o formalismo matemático da Mecânica Clássica. No final do século XIX, Poincaré, a partir do célebre problema dos três corpos, tomou contato com o caos determinístico, o que, posteriormente, culminou em novos conceitos matemáticos, considerados o início da Topologia Matemática. Suas ideias, estendidas por Birkhoff, Lyapunov e Kolgomorov, entre tantos outros, culminaram nos trabalho de Lorenz, na década de 1960.

Matematicamente, um sistema dinâmico pode ser descrito por equações diferenciais que envolvem o tempo. Além disso, um sistema é considerado estável se, após sofrer uma "pequena perturbação", retorna ao seu estado inicial quando cessada a ação sobre ele imposta.

Cabe salientar, no entanto, que a estabilidade de um sistema, assim definida, é denominada assintótica, pois as perturbações ocorrem sobre as condições iniciais do sistema. Se as perturbações ocorressem sobre as equações diferenciais que modelam esse sistema, o problema seria definido como de estabilidade estrutural. Para definições formais e mais precisas ver, por exemplo, (Savi, 2006).

Essas poucas definições são suficientes para os objetivos da presente tese.

No Capítulo 3, serão tratadas as deflexões e vibrações de vigas, colunas e cabos, de maneira que o levantamento bibliográfico diretamente relacionado ao tema central dessa tese é tratado na sequência, sem desviar o foco do leitor. Saliente-se, entretanto, a importância das definições até aqui apresentadas, consideradas como primeiras aproximações para a estática de risers. 


\subsection{Estática e Dinâmica de Risers}

Do ponto de vista da Engenharia Oceânica, é usual a utilização dos modelos mais simples para descrever estaticamente o riser, ou mesmo para análises dinâmicas em que o foco seja o sistema flutuante como um todo, com posterior estudo específico e aprofundado da estrutura esbelta.

Entretanto, deve-se ter o cuidado de incorporar os efeitos mais importantes como a rigidez flexional nas extremidades e modelos adequados para o solo e sua interação com o riser, embora esse último tópico ainda seja tema de muitos estudos, dada sua complexidade.

Ademais, cabe ressaltar que a dinâmica de risers e cabos umbilicais depende fundamentalmente da estática, de maneira que esta deve ser meticulosamente determinada.

Uma possibilidade usual consiste na sua aproximação pela Teoria de Cabos, em conjunto com a consideração, da Teoria de Vigas ou a incorporação local da rigidez flexional, nas extremidades práticas recomendadas pelas Sociedades Classificadoras, dentre as quais: ABS (2008), DNV (2010a) e DNV (2010b). Explicitamente:

- DNV (2010a):

"In most situations, it is convenient to include all mooring lines, tethers and risers in the $F E^{2}$ slender structure model. (...) More detailed riser responses requiring a refined FE model of the riser system are carried out separately in dedicated riser analyses to save computation time and increase the analysis flexibility. Examples are (...) curvature in critical areas, e.g. touch-down area for SCRs."

- DNV (2010b):

"Some computer programs tailor made for slender structure analysis offers an alternative strategy utilising the catenary solution as starting point for FE analysis. The basic idea behind this approach is that the overall influence from bending stiffness is moderate (...), which means that the FE and catenary solutions are close. (...) This combined use of catenary/FE analysis gives a significant reduction in computation time."

- ABS (2008):

"Both static and dynamic responses of the riser are to be performed. Detailed analysis is to be conducted in areas of high loading/stress, such as touch down point and at the interface with the floating installation. The relevant static configuration is to be applied as the initial condition for a time-domain analysis. (...)"

\footnotetext{
${ }^{2}$ FE é o acrônimo de Finite Element (Method) que, em português, corresponde ao chamado Método dos Elementos Finitos.
} 
Ainda que essas aproximações sejam válidas, a solução exata para o problema estático (catenária) é corriqueiramente utilizada, sem que isso seja um empecilho em termos numéricos ou analíticos.

Os comentários e as considerações da seção precedente apontaram claramente para a possibilidade de uso de elementos estruturais mais simples, corroborando as práticas que utilizam essa aproximação como ponto de partida para modelos numéricos. Essa discussão será retomada, a partir de formulações clássicas, na Seção A.1.

Cumpre mencionar que com relação ao comportamento dinâmico de risers, diversos tipos de análises podem ser considerados, sendo que, em geral, os estudos analíticos envolvem o uso de técnicas de perturbação a partir da configuração de equilíbrio, enquanto que computacionalmente tem-se optado pelo uso de soluções aproximadas via, por exemplo, os Métodos das Diferenças Finitas ou dos Elementos Finitos.

No que concerne ao escopo da presente tese, um riser será entendido como um elemento tubular esbelto, longo e flexível [ABS $(2008)^{3}$ ], cuja configuração estática inicial será dada por uma catenária, na ausência de correnteza e sob consideração de ausência de momentos aplicados sobre a linha extensível.

Pesce (1997) derivou as formulações estática e dinâmica para o problema de tubos submersos em catenária, a partir das equações gerais tridimensionais apresentadas por Love (1906), com as devidas adaptações e considerando as simplificações típicas comumente utilizadas.

Wei et al. (1999) parte do problema plano de um cabo suspenso entre dois pontos fixos, sujeito apenas ao seu peso próprio, com a incorporação dos efeitos da rigidez axial, culminando na proposição de "elementos de catenária" para aplicação do Método de Elementos Finitos (MEF).

A utilização do MEF envolve a escolha racional do tipo de elemento discreto a ser usado na representação da estrutura em estudo. Nas aplicações mais comuns da Mecânica de Linhas, esses elementos podem ser de viga, de pórtico e/ou de treliça. O programa Anflex, que é utilizado ao longo desta tese, permite a escolha desses elementos para estudo estático e dinâmico de risers.

Embora tenha sido intensamente estudado nas últimas décadas, o primeiro riser foi utilizado apenas em 1949 [Harris (1972) apud Bernitsas \& Papalambros (1980)], enquanto o primeiro relatório técnico relevante de que se tem notícia só foi publicado 15 anos depois, por Fischer (1966).

Naquele trabalho, o autor apresenta uma solução simplificada para problema de projeto de um riser vertical de perfuração, resolvendo a equação que rege sua deflexão, além de calcular a tensão de topo mínima requerida para efeitos de projeto. Logo em sua introdução, o autor tece considerações a respeito dos comprimentos críticos de flambagem e aponta para uma conclusão importante acerca das simplificações até hoje utilizadas:

\footnotetext{
${ }^{3}$ De acordo com ABS (2008), "a flexible riser pipe is a pipe with low bending stiffness and a high axial stiffness".
} 


\begin{abstract}
“(...), é melhor encarar o projeto de risers não como o problema de flambagem em colunas, mas como o problema da deflexão de uma viga, no qual a deflexão lateral pode aumentar consideravelmente pela compressão axial ou, ao contrário, descrescer substancialmente devido à tração axial." ${ }^{* 4}$
\end{abstract}

Outra contribuição que se pode encontrar em (Fischer, 1966) é a conceituação de tração efetiva, extremamente importante para o estudo de risers, e que é habilmente discutida em (Pesce, 1997). Mesmo sem considerar explicitamente um modelo para determinação dos efeitos dinâmicos devido às ondas, Fischer (1966) utiliza métodos de cálculo aproximados para sua avaliação.

No final da década de 1960, dois trabalhos acerca da estabilidade elástica de vigas curvas (com ocorrência de flambagem) foram de extrema importância, embora não associados diretamente ao estudo de risers, mas que apresentaram importantes características associadas.

Em (Lo \& Conway, 1967) é possível identificar: o efeito da curvatura inicial de uma viga engastada-apoiada; o estudo da extensibilidade da viga e a incorporação de nãolinearidades para os casos de viga extensível e inextensível, sob a hipótese de EulerBernoulli. A continuação desse trabalho, publicado em (Conway \& Lo, 1967), trata dos casos de vigas sob outras condições de contorno (biapoiada e biengastada).

Em um trabalho sobre a teoria de vibrações de cabos suspensos, Irvine \& Caughey (1974) estudaram tais estruturas sob o ponto de vista linear, em que o cabo apresenta um perfil quase parabólico, parametrizando as equações em função do vão e da flecha e deduzindo, a partir daí, uma relação para a componente horizontal da tração no cabo. Este procedimento permitiu a aproximação das equações até então utilizadas, reduzindo consideravelmente o gasto computacional para relações entre flecha e vão menores ou iguais a $1 / 8$. Naquela publicação, os resultados analíticos foram confrontados com experimentos realizados.

Bernitsas \& Papalambros (1980) deduziram as equações que regem a estática do riser de maneira simplificada, sob as hipóteses de pequenos ângulos e deflexões, tratanto o problema linearmente, inclusive com o uso da equação linearizada para o momentofletor. Nesse mesmo trabalho, os autores incorporaram os esforços de correnteza, chegando a uma equação diferencial adimensionalizada de quarta ordem para a deflexão, bastante similar à de vigas-coluna sob carregamento axial compressivo e carga lateral distribuída.

Assim como em (Fischer, 1966), Bernitsas \& Papalambros (1980) utilizaram um parâmetro adimensional $\widetilde{\lambda}$, apresentado na Equação 2.1, relacionado ao comprimento de flexão (a ser definido mais adiante, nesta mesma seção), sob condições equivalentes à consideração de vigas simplesmente apoiadas em suas extremidades.

O problema foi resolvido numericamente, tanto para obter a solução exata, quanto com a finalidade de compará-la com a aproximação feita a partir da Teoria de Cabos.

\footnotetext{
${ }^{4}$ Tradução livre do autor da presente tese.
} 


$$
\tilde{\lambda}=\frac{T_{0} \cdot L^{2}}{E I}
$$

onde $T_{0}=T(0)$ é a tração efetiva no TDP, $L$ é o comprimento suspenso do riser e $E I$ sua rigidez flexional, suposta constante ao longo de sua extensão longitudinal.

Assim como apresentado, o problema foi rediscutido em (Bernitsas, 1981), com a incorporação de uma breve discussão a respeito da validade da aproximação pela Teoria de Cabos. Cabe ressaltar que, na consideração dos efeitos de correnteza, foi utilizado um modelo linear, diferente do apresentado por Burke (1974), que se baseou em um modelo quadrático para a força de arrasto, estratégia bastante usual ${ }^{5}$.

Em uma época em que grande parte dos estudos era voltada para risers verticais, Chakrabarti \& Frampton (1982) apresentaram uma ampla revisão dos estudos realizados até então, incluindo análises estáticas e dinâmicas, incorporando termos inerciais e considerando a massa adicional; utilizando uma linguagem matemática muito próxima da atualmente usada em grande parte das publicações sobre o assunto. Neste trabalho, também foi discutida a influência da pressão de líquido interno ao riser.

Outro trabalho importante relacionado à instabilidade elástica de dutos pode ser encontrado em (Hobbs, 1981), no qual foram estudados os modos de flambagem lateral e vertical da porção de riser que fica assentada no solo marinho, causado por cargas axiais de diferentes origens. As soluções teóricas foram ilustradas por meio de exemplos numéricos, amplamente discutidos.

Na mesma linha, Taylor \& Gan (1984) trataram especificamente de cargas laterais devidas a aumentos de temperatura, com especial atenção com os coeficientes de atrito entre o duto e o solo, que apresentam importância prática indiscutível.

Ainda em meados da década de 1980, Bernitsas et al. (1985) estudaram o problema da estática de risers do ponto de vista de grandes deformações tridimensionais, incorporando não-linearidades devidas ao arrasto hidrodinâmico, à geometria e a efeitos estruturais, particularmente em estruturas longas, a grandes profundidades.

Em Burgess \& Triantafyllou (1988) é possível encontrar o estudo das frequências dos modos elásticos de cabos retesados inclinados, excitados em uma faixa bastante ampla de frequências onde é verificada, claramente, a ocorrência do fenômeno de crossover.

No início dos anos 1990, Perkins (1992) apresenta um extenso trabalho sobre as interações modais não-lineares tridimensionais em cabos elásticos, sob excitações externas e paramétricas. Inicialmente, estabelece um modelo aproximado (de primeira ordem), usando teoria de cabos e a aproximação da catenária por uma parábola, mesma estratégia utilizada em (Irvine \& Caughey, 1974), sob a hipótese de pequenas relações flecha-vão.

\footnotetext{
${ }^{5}$ Esse modelo utiliza a Equação de Morison, que é uma equação semiempírica, bastante utilizada em Hidrodinâmica e, portanto, associada a diversos fenômenos estudados na Engenharia Naval e Oceânica.
} 
Para estudar o efeito das interações modais, Perkins (1992) utiliza o Método das Escalas Múltiplas, um caso particular de técnica de perturbação, que visa obter sucessivas aproximações e separar os efeitos devidos às diferentes escalas inerentes ao problema. Para fins de comparação, realizou experimentos físicos com instrumentação utilizando sensores ópticos. Segundo o autor, o modelo foi ensaiado próximo à região de crossover. Nessa região, foi verificada a presença de uma excitação interna, do tipo $2: 1$, entre o modo fundamental fora do plano da catenária e o primeiro modo simétrico planar, com boa aderência entre experimentos e as predições teóricas.

Uma revisão sobre a teoria dinâmica de cabos foi publicada por Starossek (1994), na qual a aproximação parabólica é novamente utilizada. No mesmo trabalho, são citados diversos fenômenos de interação fluido-estrutura, tais como VIV e galloping ${ }^{6}$, sem grande profundidade. Um grande mérito foi a extensa bibliografia apresentada e discutida.

No ano seguinte, Patel \& Seyed (1995) publicaram uma revisão sobre a modelagem de risers flexíveis e técnicas de análise. De forma meticulosa, esse texto tratou das análises estática e dinâmica de risers sob diversas configurações: rígido vertical e flexível em catenária direta, Steep-S, Steep-wave, Lazy-S, W-wave, Lazy-wave e "lanterna chinesa". Além disso, apresentaram resultados e comparações referentes a técnicas iterativas, Métodos das Diferenças Finitas e Elementos Finitos, formulações lagrangeanas, aproximações assintóticas, análises nos domínios do tempo e da frequência, efeitos das pressões internas e externas, bem como do fluxo interno, finalizando com a validação de análises numéricas.

Na conclusão do trabalho, Patel \& Seyed (1995) citam efeitos que eram negligenciados até então e que demandariam esforços e estudos mais aprofundados, como aqueles devidos ao amortecimento estrutural, ao arrasto hidrodinâmico tangencial e às interações com o leito marinho.

Em (Pesce, 1997) foram abordados os problemas estático e dinâmico de risers em catenária. De acordo com esse trabalho:

“(...) a tração dinâmica solicitante pode ser aproximadamente considerada como função tão somente do tempo e invariante ao longo da linha".

Segundo Pesce (1997), essa afirmação se configura como a hipótese básica para a aplicação da técnica da camada limite, que leva em conta o fato de coexistirem escalas de tempo distintas associadas à dinâmica de risers, de maneira que a rigidez geométrica apresenta maior importância relativa para os modos de vibração associados a frequências mais baixas, enquanto que para os modos naturais mais elevadas, prevalecem os efeitos das rijezas axial e flexional.

\footnotetext{
${ }^{6}$ O fenêmeno de galloping é resultado da instabilidade da esteira à juzante de um corpo com seção transversal não circular. Diferentemente do VIV, o movimento resultante pode atingir amplitudes relativamente grandes.
} 
Tal fato é reforçado pelas características do amortecimento hidrodinâmico do fluido circundante, cujo efeito é quadrático na velocidade (Equação de Morrison). Com isso, nas baixas frequências, as perdas de energia associadas à viscosidade são consideradas relativamente pequenas, prevalecendo aquelas inerentes à estrutura. Nas altas frequências, ao contrário, a dissipação viscosa aumenta consideravelmente, de modo que a linha pode ser considerada como "congelada" em sua posição de equilíbrio, sobressaindo os efeitos da rigidez axial (Aranha et al., 1993).

Além das já citadas diferentes escalas de tempo envolvidas no problema dinâmico de risers, também existem discrepâncias nas escalas de comprimento: a importância da rigidez flexional nas extremidades do riser, junto ao ponto de contato com o solo e na junta flexível do topo, está associada a uma escala curta de comprimento. De acordo com (Aranha et al., 1997), trabalho cujo tema central foi a influência da rigidez flexional e, portanto, do momento-fletor no TDZ:

"A curvatura da catenária é descontínua no touchdown point: ela é igual a $q / T_{0}$ à direita desse ponto e igual a zero à esquerda. $\mathrm{O}$ efeito da rigidez flexional El é suavizar a transição entre esses dois valores de curvatura, enquanto desloca para a esquerda a posição real do TDP".

Cite-se que a escala de comprimento associada à região na qual a rigidez flexional tem importância destacada na análise dinâmica de risers está relacionada com o comprimento de flexão, parâmetro interpretado como a distância entre as posições real e ideal do TDP (Pesce et al., 1998b), definido como:

$$
\lambda_{f}=\sqrt{\frac{E I}{T_{0}}}
$$

Aranha et al. (1997) propuseram uma aproximação analítica para o momento-fletor dinâmico na região do TDP, a partir da aplicação da técnica da camada limite. Nesse mesmo trabalho, é citada a aproximação analítica para a tração dinâmica na linha, originalmente apresentada em (Andrade, 1993).

A formulação proposta para o momento-fletor mostra a forte dependência com relação à tração dinâmica e ao deslocamento do ponto de contato com o solo. Assim, são discutidos os casos possíveis para essas duas variáveis e os efeitos sobre a linha, inclusive com a constatação de que a rigidez flexional nas proximidades do solo permite a possibilidade de que alguma compressão seja suportada pelo riser nessa região, propiciando estudos adicionais referentes ao tema central desta tese.

Concatenando estudos experimentais e solução analítica por meio da técnica da camada limite, Pesce et al. (1998a) desenvolveram e validaram experimentalmente uma expressão matemática simples capaz de relacionar (no tempo e no espaço) a curvatura dinâmica e a excursão do TDP de um riser, quando ao seu topo é aplicada uma excitação harmônica. 
O modelo analítico utilizado, aquele deduzido em (Aranha et al., 1997), partiu das equações linearizadas de um cabo ideal, com a aplicação posterior das não-linearidades da solução via camada limite. Os resultados das duas abordagens mostraram grande concordância entre si, não apenas com relação aos valores médios dos parâmetros estudados, mas também com relação a suas respectivas séries temporais.

O efeito da rigidez do solo na dinâmica do riser, citado por Patel \& Seyed (1995) como um dos tópicos que até então carecia maiores estudos, foi abordado em (Pesce et al., 1998b) para o problema estático, também utilizando técnicas assintóticas e a solução pela técnica da camada limite, complementando os trabalhos anteriores que consideravam o solo como sendo infinitamente rígido. No estudo apresentado, definiu-se um parâmetro adimensional, $K$, relacionado à rigidez do solo, definido pela equação 2.2, onde $k$ é a rigidez por unidade de comprimento e penetração.

$$
K=\frac{k \cdot L^{4}}{E I}=\frac{k \cdot \lambda_{f}^{2}}{T_{0}}=\frac{k \cdot E I}{T_{0}^{2}}
$$

Além disso, foram analisados o ângulo com a horizontal, a elástica local, os esforços cortantes e a curvatura, todos como função do parâmetro adimensional $\xi=s / \lambda$, onde $s$ é a coordenada curvilínea.

Obtidos com variação crescente do parâmetro $K$, os resultados mostraram o comportamento oscilatório típico da elástica, bem como a remoção da descontinuidade dos esforços cortantes, que é observada quando o solo é considerado rígido. Para os casos em que $K \geq 10$, o ângulo com a horizontal, a elástica local, os esforços cortantes e a curvatura recuperaram os valores esperados para o solo não elástico.

Em (Pesce et al., 1999), o estudo de cabos lançados sob configuração de catenária foi abordado do ponto de vista do problema de autovalor, particularmente importante para a análise da sincronização do fenômeno de VIV (lock-in) e problemas de instabilidade do tipo Mathieu, entre outros. Nesse trabalho, foi utilizada uma técnica padrão de perturbação (método WKB a partir da configuração estática), utilizando como premissa a inextensibilidade do cabo, o que é fisicamente inadequado, em termos estritos. Ainda assim, a formulação bidimensional para o problema, apresentado como dinâmica de catenary riser-like, foi recuperada na forma apresentada em (Pesce, 1997).

Os resultados foram comparados com aqueles analogamente resultantes da solução para uma equação de Bessel aproximada e do programa Poliflex ${ }^{7}$, apresentando boa aderência.

Importante destacar que as equações foram adimensionalizadas e manipuladas matematicamente de maneira que o método WKB pudesse ser aplicado adequadamente.

\footnotetext{
${ }^{7}$ O Poliflex é um programa desenvolvido na Escola Politécnica da Universidade de São Paulo, sob coordenação do Prof. Dr. Clóvis de Arruda Martins, que resolve o problema da configuração de equilíbrio estático tridimensional de risers e cabos umbilicais, bem como o problema dinâmico linear no domínio da frequência, além de calcular as frequências e os modos naturais de vibração.
} 
Como resultado desse trabalho, foi apresentada uma formulação analítica simples para determinação das frequencias e modos naturais de vibração de cabos lançados em catenária direta, com a explicitação e discussão das diversas hipóteses físicas e matemáticas utilizadas.

A primeira década dos anos 2000 foi marcada pela divulgação de diversos trabalhos baseados em (ou complementados por) simulações numéricas, dado o avanço na capacidade de processamento dos computadores que, até então, se configurava como um fator limitante bastante importante.

São exemplos desse tipo de trabalho: (Bortolan Neto, 2009), (Campos \& Martins, 2001), (De Sousa et al., 2004), (Chang et al., 2008), (Chatjigeorgiou \& Mavrakos, 2009) e (Pesce \& Martins, 2005) ${ }^{8}$. Este último se apresenta como uma compilação dos diversos trabalhos desenvolvidos no âmbito da dinâmica de risers e se configura como um ótimo suporte para a modelagem numérica de estruturas esbeltas submersas lançadas em catenária direta.

Em um trabalho sobre a dinâmica tridimensional de risers, Takafuji (2011) apresenta uma boa compilação dos aspectos relacionados a esse tema, com formulações e aproximações analíticas, além da elaboração de um código numérico baseado no Método de Elementos Finitos, cujos resultados foram confrontados com os obtidos a partir de um programa comercial bastante conhecido, o Orcaflex 9 .

A despeito dessa aparente tendência quanto à publicação de estudos fundamentados em simulações numéricas, (Aranha \& Pinto, 2001) apresentaram uma formulação analítica, desenvolvida a partir dos trabalhos de Andrade (1993), que culminou em uma expressão analítica simples para a tração dinâmica em risers e que se configura como uma das bases fundamentais do presente trabalho, no que concerne à confecção da matriz de ensaios realizados, bem como da análise posteriormente realizada.

Ainda no âmbito do desenvolvimento de formulações analíticas, o chamado Método das Múltiplas Escalas (MME), como técnica de perturbação baseada na existência de diferentes escalas de tempo em um problema dinâmico particular, vem sendo bastante utilizado. Diversos trabalhos relacionados a aplicações dessa técnica podem ser encontrados em: (Nayfeh \& Mook, 2008), que é uma excelente fonte para o estudo de oscilações não-lineares; Kamel \& Hamed (2010), que aplica o MME na análise não-linear de cabos elásticos sob excitação harmônica, e Mansur (2011), que aplica a técnica para a análise não-linear de oscilações de risers em catenária sujeitos a flexão composta.

Além desses, outros trabalhos analíticos podem ser citados, ainda no escopo da dinâmica não-linear de risers. Mazzilli \& Sanches (2010) apresentam o problema do ponto de vista da sua formulação via Método dos Elementos Finitos, seguido de aproxima-

\footnotetext{
${ }^{8}$ Embora seja comum encontrar essa referência sob essa forma, na verdade o texto correponde ao Capítulo 7 Riser Dynamics) do livro Numerical Models in Fluid-Structure Interactions, de S. K. Chakrabarti.

${ }^{9} \mathrm{O}$ programa Orcaflex, desenvolvido pela Orcina, permite uma grande variedade de aplicações relativas à Engenharia Oceânica, principalmente no que tange sistemas de amarração, risers, sistemas de alívio, análise de instalações etc. Apesar dessas qualidades, ele não será utilizado no âmbito deste trabalho.
} 
ções por Variedades Invariantes e Modos Normais (lineares e não-lineares), apontando possibilidades de trabalhos futuros e pontos a serem investigados. (Nayfeh \& Mook, 2008) e (Lenci \& Rega, 2000) são boas referências para as técnicas utilizadas por Mazzilli \& Sanches (2010).

Cabe, por fim, citar um importante e recente trabalho, Gay Neto (2012), que apresentou o estudo da estabilidade estrutural estática de risers em catenária, levando em consideração a composição de sua estrutura interna (que contém armaduras metálicas helicoidais de tração).

Segundo o autor, essas estruturas metálicas "podem induzir a ocorrência de giro axial quando o tubo é solicitado à tração. Se esse movimento não for permitido, surgirá um momento de torção na estrutura".

A associação desse momento de torção com os baixos níveis de tração observados em algumas configurações de lançamento, em especial as mais verticais, pode culminar na formação de laços (físicos) na estrutura, efeito altamente indesejável, dada a possibilidade de ocorrência posterior de dobras (kinking) que tendem a danificar estruturalmente o riser.

Um resultado bastante importante quanto à predição do fenômeno de formação de laços, advindo de (Gay Neto, 2012), se refere à boa concordância entre os resultados numéricos obtidos e uma expressão analítica baseada na Fórmula de Greenhill ${ }^{10}$. A literatura especializada é profícua em resultados e trabalhos relacionados à interação fluido-estrutura e a dinâmica de risers. A importância desses subsistemas, já destacada anteriormente, associada principalmente à produção de petróleo e gás natural, se reflete na enorme quantidade de publicações relacionadas ao seu estudo, das quais apenas uma pequena parte foi destacada neste texto, com o intuito de embasar os capítulos que se seguirão, bem como apresentar ao leitor os trabalhos mais importantes, dentre os averigados, para os objetivos da presente tese.

\footnotetext{
${ }^{10} \mathrm{~A}$ Fórmula de Greenhill pode ser entendida como uma generalização do equacionamento para a carga crítica proposto por Euler, dado que associa o momento de torção à compressão axial, único esforço considerado na flambagem de colunas.
} 


\subsection{Compressão Dinâmica em Risers}

Essa última seção da Revisão Bibliográfica trata especificamente de tópicos e publicações relacionados à compressão dinâmica ou aos conceitos envolvidos.

Considere-se um riser conectado por uma de suas extremidades (topo) a uma unidade flutuante e cuja extremidade oposta repousa sobre o leito marinho. A unidade flutuante está sujeita a ações ambientais diversas, tais como vento, ondas e correnteza, bem como o riser à ação direta da correnteza.

Nesse cenário, dada a aleatoriedade dos movimentos conferidos à unidade flutuante, o riser estará sujeito a carregamentos que, em algum momento, podem comprimí-lo (os agentes desse carregamento genérico são ilustrados na Figura 2.3).

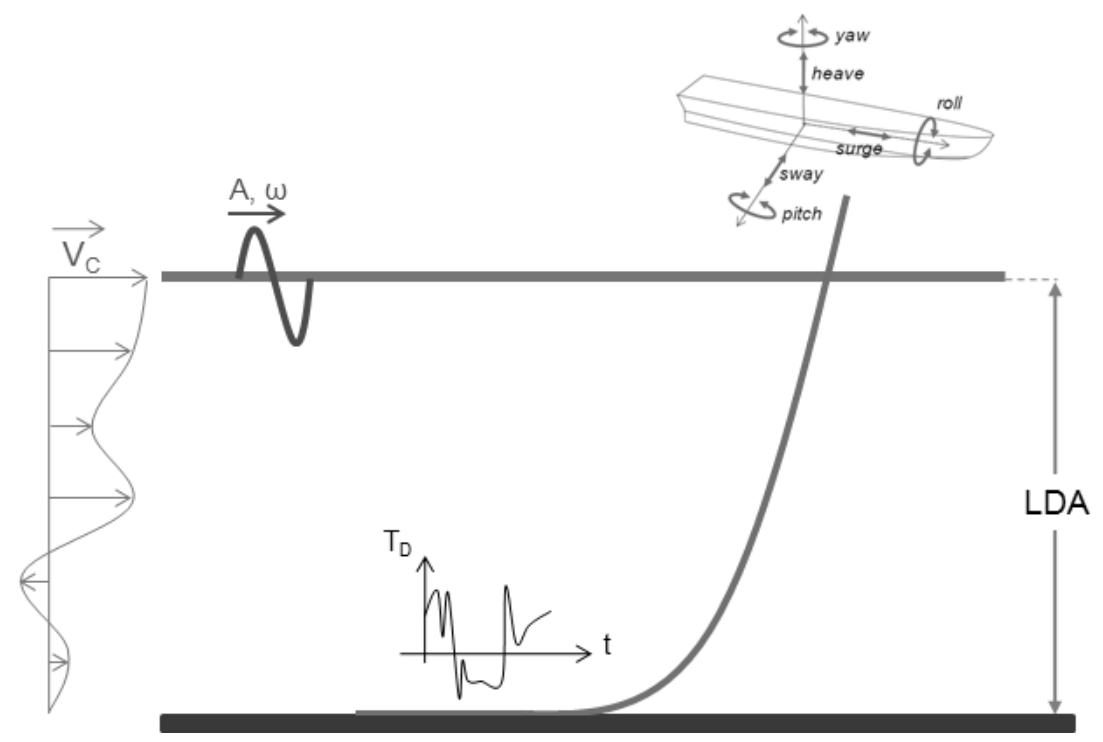

Figura 2.3: Esforços externos sobre um riser dinamicamente excitado.

Conforme mencionado anteriormente, um riser, contrariamente ao que ocorre com um cabo, suporta um certo nível de compressão sem que ocorra flambagem. Ao maior carregamento de compressão que um riser pode suportar, sem que ocorra flambagem global, dá-se o nome de carga crítica. O Capítulo 3 encerra formulações analíticas e discussões relacionadas à carga crítica.

Se, em algum momento, a tração efetiva atuante sobre o riser for tal que ultrapasse 0 valor dessa carga crítica, a estrutura flamba globalmente, em um fenômeno denominado de compressão dinâmica.

Durante a compressão dinâmica, o riser tenta suportar a carga compressiva que lhe é imposta, absorvendo a energia recebida. Nesse momento, a linha parece "congelar", de sorte que por alguns instantes a série temporal de trações apresenta um patamar, associado a um certo nível de "saturação", em valores ao redor da carga crítica, Figura 2.4, até que, não suportando tal carregamento, o riser "alivia", devolvendo a energia não absorvida em forma de ondas de compressão que se propagam da região do TDZ em direção ao topo da linha, como ilustrado na Figura 2.5. 


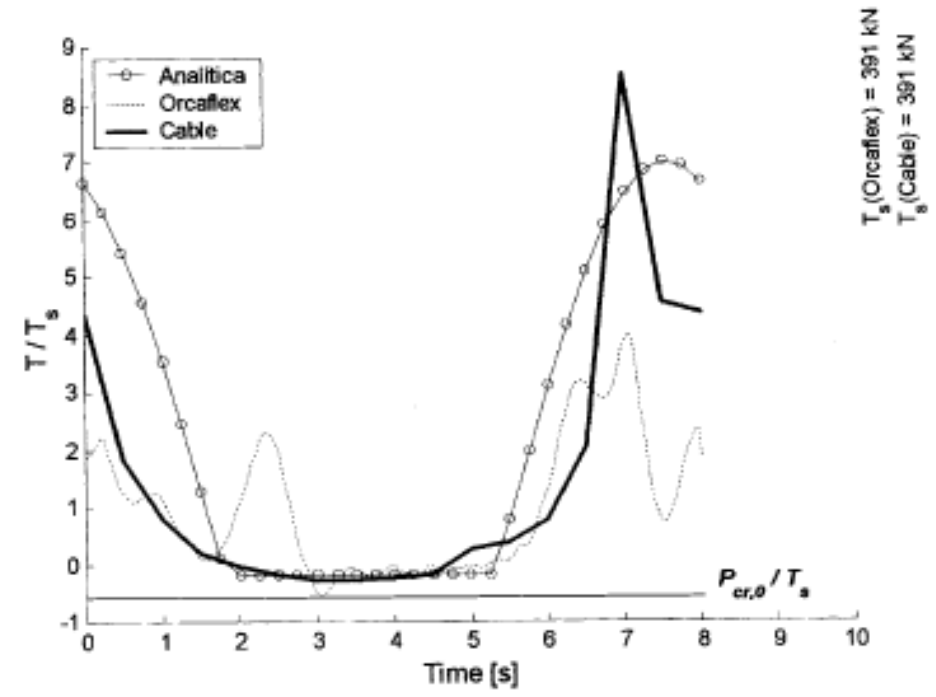

Figura 2.4: Saturação das assinaturas temporais de tração durante a compressão dinâmica.

Fonte: (Aranha \& Pinto, 2001)

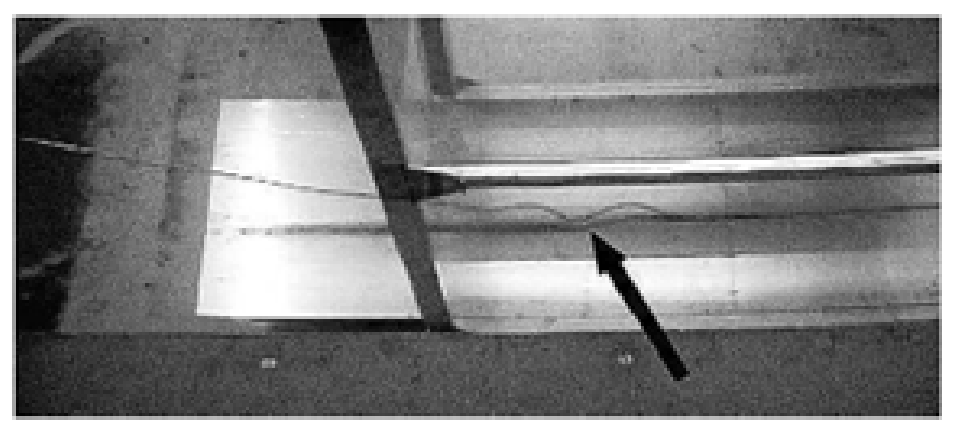

Figura 2.5: Ondas de compressão se propagando do TDP ao topo de uma linha em catenária. Fonte: (Simos \& Fujarra, 2006)

Ribeiro et al. (1998) realizaram um estudo, com o uso do Anflex, de um riser em catenária direta conectada a uma FPSO, descrevendo detalhadamente o modelo utilizado e discutindo os resultados em termos de análises de sensibilidade (coeficientes de arrasto, amortecimento, correnteza etc). Para a modelagem numérica, assumiram, por hipótese, que a carga compressiva em qualquer segmento não poderia exceder a crítica de Euler, deduzida para colunas retas.

Em (Aranha et al., 2001), é desenvolvida uma formulação analítica que culmina em uma expressão algébrica simples para a carga crítica em vigas curvas biapoiadas. Além disso, apresentam-se comparações com os resultados advindos de experimentos realizados por Andrade (1993) e simulações numéricas (Cable ${ }^{11}$ e Orcaflex).

A formulação apresentada em (Aranha et al., 2001) é recuperada e discutida no Capítulo 3, com posterior continuidade analítica e apresentação de alguns resultados aparentemente inéditos. Alguns pontos relativos à formulação de (Aranha et al., 2001), bem como as desenvolvidas no citado capítulo são apresentadas no Apêndice A, com a finalidade de complementar o presente estudo, sem prejuízo à fluidez do texto.

\footnotetext{
${ }^{11}$ Programa desenvolvido pelo M.I.T., para uso interno, não comercial.
} 
A tridimensionalidade do problema, principalmente pela presença de torção da linha e movimentos na direção perpendicular ao plano da catenária, é de relevância inegável. Dois trabalhos bastante interessantes a esse respeito são: (Ramos Jr, 2001) e (Ramos Jr \& Pesce, 2003). No primeiro, a tridimensionalidade da dinâmica de tubo submersos é explorada de maneira profunda e sistemática sob o ponto de vista analítico. O segundo é uma publicação baseada no primeiro (tese de Doutorado), com maior foco na compressão dinâmica.

Ainda com relação a esses trabalhos, o equacionamento tridimensional é apresentado, com clara referência a (Love, 1906) e (Pesce, 1997), suscitando uma formulação para a carga crítica de flambagem para risers em catenária na presença de torção, como generalização da equação obtida por (Aranha et al., 2001), bem como sua recuperação para o caso 2D, sob determinadas condições. Outras importantes conclusões do trabalho referem-se ao uso da Equação de Greenhill para predizer as condições de estabilidade de cabos e risers com curvatura inicial e na presença de compressão dinâmica; bem como à proposição de que, nas regiões de curvaturas moderadas, o carregamento crítico proposto em (Aranha et al., 2001) é superestimado por um fator de $\frac{9}{4}$, se a torção não for considerada.

Em (Simos \& Fujarra, 2006) ${ }^{12}$, os resultados analíticos decorrentes de (Aranha et al., 2001) e de (Ramos Jr \& Pesce, 2003) foram utilizados para comparação com resultados de simulações numéricas e ensaios físicos em tanque de provas sobre dois modelos (um flexível, outro mais rígido), na presença ou não de correnteza, e sob excitação harmônica no topo. O objetivo, claramente atingido, foi evidenciar a compressão dinâmica em risers experimentalmente, ilustrada na Figura 2.5.

Como principais conclusões advindas desse trabalho, citam-se: (i) as trações no modelo mais rígido apresentaram um comportamento mais uniforme no tempo e oscilações fora do plano não foram observadas, enquanto que, no modelo flexível, saídas laterais da linha foram visivelmente observadas e as séries temporais de tração se mostraram bastante irregulares; (ii) a amplitude da tração cresceu monotonicamente com a amplitude e a frequência da excitação de topo; (iii) no modelo flexível, harmônicos de ordem superior foram claramente excitados, vide Figura2.6, "como esperado em cabos comprimidos dinamicamente"13.

Além disso, concluíram que os resultados provenientes do modelo mais rígido foram mais aderentes aos modelos analíticos, que os do modelo flexível, o qual apresentou níveis de compressão dinâmica mais acentuados, fenômeno percebido, inclusive, no topo da catenária.

Segundo os autores, o modelo flexível apresentou visualmente saídas laterais do plano que o continha inicialmente, com presença de torção.

\footnotetext{
${ }^{12}$ (Simos \& Fujarra, 2006) é, em realidade, um trabalho decorrente da compilação dos resultados de outros dois trabalhos de Simos, A.N. e Fujarra, A.L.C.: (Simos et al., 2003) e (Fujarra et al., 2003).

${ }^{13}$ Conclusões extraídas de (Fujarra et al., 2003), embora seja extensíveis aos demais trabalhos citados.
} 

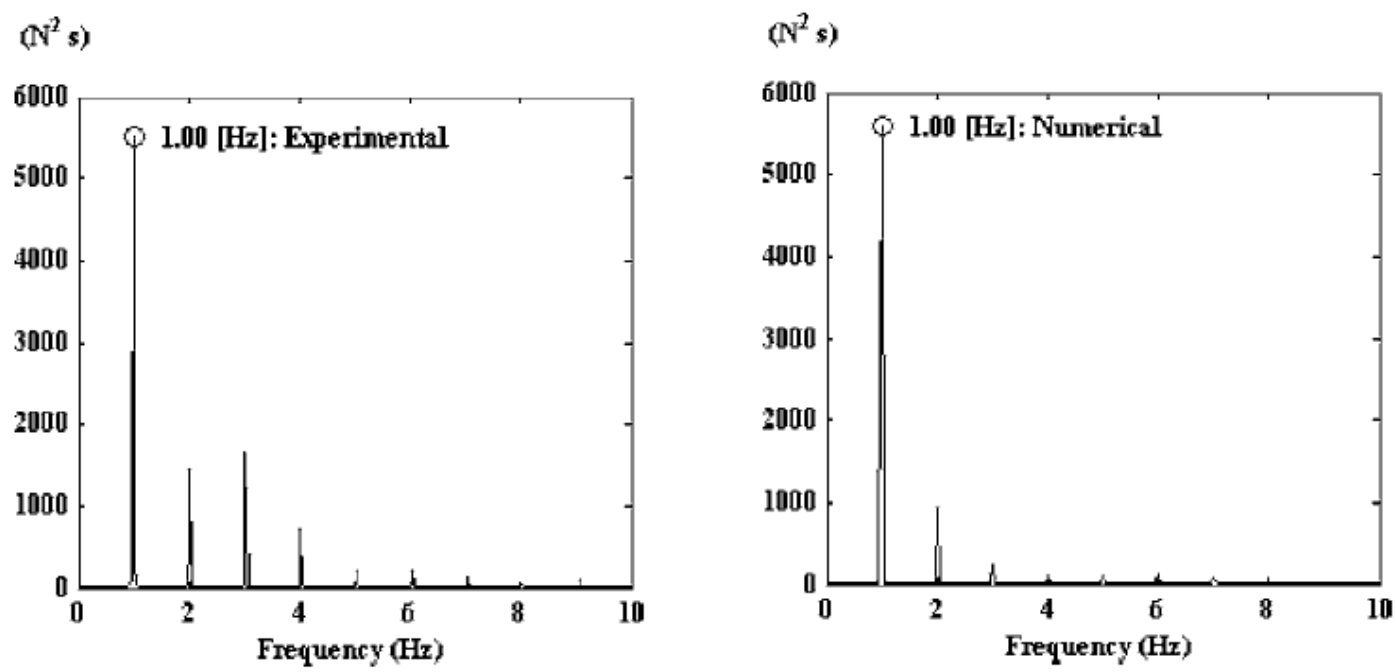

Figura 2.6: Padrão esperado para o PSD de trações na ocorrência de compressão dinâmica. Fonte: Adaptado de (Simos \& Fujarra, 2006)

As predições numéricas para as amplitudes de tração dinâmica, também realizadas naquele trabalho, foram condizentes com os resultados experimentais; os quais apresentaram aderência apreciável com as formulações utilizadas ${ }^{14}$.

Simos \& Fujarra (2006) citam como características típicas do fenômeno de compressão dinâmica: o aparecimento de ondas de compressão (Figura 2.5) e o aparecimento de picos proeminentes no espectro de energia relativo à série temporal de trações (Figura 2.6), exatamente nos múltiplos inteiros da frequência de excitação (harmônicos de ordem superior).

Dada a natureza não-linear do fenômeno de compressão dinâmica, é importante a citação de mais alguns trabalhos, não relacionados a risers, tais como: (Nayfeh \& Mook, 2008); Lestari \& Hanagud (2001), que apresentam o problema de vibração não-linear em vigas flambadas com algumas soluções analíticas exatas e avaliam o comportamento pós-flambagem; e (Emam \& Nayfeh, 2004), onde é discutido o problema da dinâmica de vigas flambadas sujeitas a excitação ressonante, com resolução do problema linear discretizado e comparação entre resultados numéricos e experimentais. Referências mais gerais, mas com certa relevância, são relacionados à instabilidades do tipo Mathieu. Esse tipo de instabilidade aparece na modelagem de diversos sistemas como: o pêndulo invertido e a excitação paramétrica do roll em embarcações.

Em determinadas condições é possível modelar a compressão dinâmica em risers pela Equação de Mathieu. Exemplos de trabalhos nessa linha são: (Carbo et al., 2010), (El-Bassiouny \& Abdel-Khalik, 2009), (Si-Yu \& Jin-Yuan, 2008) e (Simos \& Pesce, 1997). Este último trabalho é digno de algumas notas, pela particularidade da aplicação, na qual a variação da tração ao longo dos tendões de uma TLP $^{15}$ se mostra bastante relevante na dinâmica da plataforma.

\footnotetext{
${ }^{14}$ Conclusões extraídas de (Simos et al., 2003).

${ }^{15}$ TLP é o acrônimo, em inglês, para Tension Leg Platform, expressão traduzida, em geral, como "plataforma de pernas atirantadas". Essa plataforma é do tipo fixa, amarrada ao solo marinho por tendões tracionados.
} 
A dinâmica global do movimento lateral dos tendões é governado pela Equação de Mathieu, resultado da equação linearizada de um cabo, excitado harmonicamente, mas com movimentos limitados pelo amortecimento viscoso.

Matematicamente, a dinâmica desses tendões é dada pela adaptação da equação de vibrações em vigas retas, com carregamento lateral nulo e a incorporação de termos de inércia adicional e amortecimento. Segundo Simos \& Pesce (1997), a equação que rege a deflexão dinâmica dos tendões de uma plataforma do tipo TLP fica dada por:

$$
\left(m+m_{a}\right) \cdot \frac{\partial^{2}}{\partial t^{2}} v(x)-\frac{\partial}{\partial x} v(x)\left[T(x) \cdot \frac{\partial}{\partial x} v(x)\right]+B_{v} \cdot\left|\frac{\partial}{\partial x} v(x)\right| \cdot \frac{\partial}{\partial x} v(x)=0
$$

A Equação 2.4 é, então, manipulada algebricamente até que se apresente como uma equação de Bessel modificada e, posteriormente, resolvida da maneira convencional. A solução dinâmica em termos dos modos naturais de vibração, sob a suposição de sincronicidade de movimentos (Equação 2.5), foi obtida a partir do Método Variacional de Galerkin, com a expressão final tomando a forma aproximada da Equação de Mathieu, Equação 2.6.

$$
\begin{gathered}
v_{n}(x)=f_{n}(t) \cdot X_{n}(x) \\
\frac{\partial^{2}}{\partial \tau^{2}} f+[\delta-q \cdot \cos (2 \cdot \tau)] \cdot f+c \cdot\left|\frac{\partial}{\partial \tau} f\right| \cdot \frac{\partial}{\partial \tau} f=0
\end{gathered}
$$

A definição de cada um dos parâmetros da Equação 2.6 é apresentada em Simos \& Pesce (1997) e foge ao escopo da presente tese. Ainda assim, é interessante identificar os padrões de estabilidade como função dos parâmetros $\delta$ e $q$, o que é apresentado na Figura 2.7.

Em (Chatjigeorgiou \& Mavrakos, 2009), é feita a afirmação de que "o equilíbrio dinâmico 3D de uma catenária submersa é governado por dez equações diferenciais parciais". No trabalho essas equações são apresentadas, muitas delas provenientes de trabalhos já citados, a saber: Pesce et al. (2006), Abramowitz \& Stegun (1965), Burgess \& Triantafyllou (1988), Chang et al. (2008), entre outros.

Juntamente com as formulações apresentadas, são feitas discussões a respeito das soluções numéricas (via Método das Diferenças Finitas) e da contribuição das nãolinearidades, além da apresentação e discussão de resultados numéricos. 


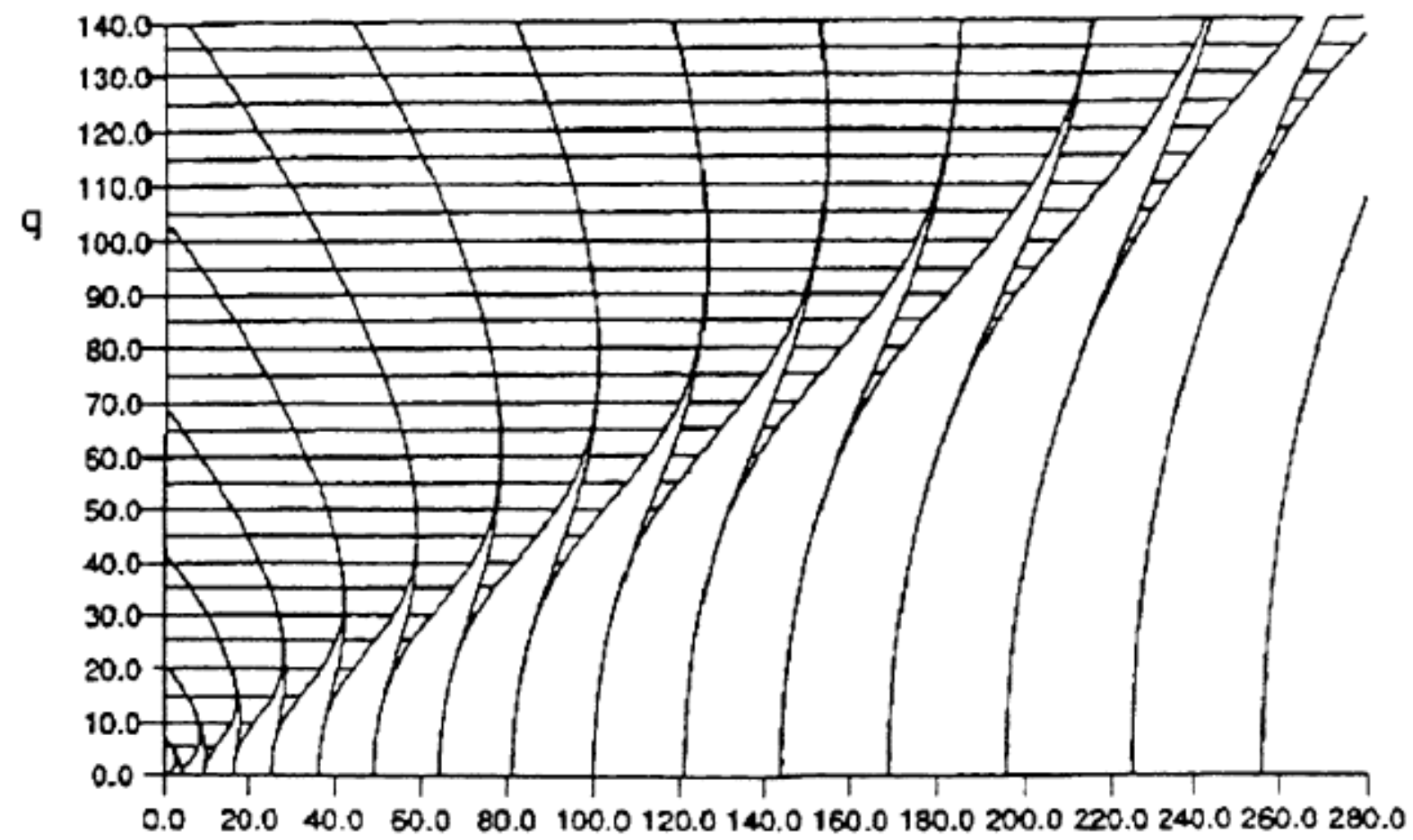

$\delta$

Figura 2.7: Diagrama de estabilidade de Mathieu, em função dos parâmetros $\delta$ e $q$. Fonte: (Simos \& Pesce, 1997)

A partir dos resultados auferidos, analogia com as chamadas Funções (pares e ímpares) de Mathieu é recuperada, a fim de embasar matematicamente o que os autores denominaram como "principal descoberta do trabalho", qual seja, a de que sob uma excitação de topo (em heave), os movimentos do riser no plano da catenária são regidos pelos harmônicos $\omega, 2 \omega, 3 \omega, \ldots$; enquanto que, fora do mesmo, são determinados pelos harmônicos $\frac{\omega}{2}, 3 \frac{\omega}{2}, 5 \frac{\omega}{2}, \ldots$

Chatjigeorgiou \& Mavrakos (2009) chegam a fazer um paralelo entre a ocorrência dessas frequências e as trajetórias assumidas pela linha, embora essa associação seja matematicamente bastante direta.

Resultados semelhantes aos de Simos \& Fujarra (2006) e Chatjigeorgiou \& Mavrakos (2009) são recuperados no presente trabalho, numérica e experimentalmente, sendo apresentados nos capítulos finais desta tese.

Ressalte-se que, com relação à compressão dinâmica em risers, poucos trabalhos foram encontrados, provavelmente por ser uma aplicação demasiado particular.

Sinteticamente, é possível afirmar que o riser pode, estática e globalmente, ser estudado como um cabo, sujeito ao seu peso próprio. Melhorias a esse modelo demandam correções nas extremidades, relacionadas à rigidez flexional. Nessas regiões, o riser passa a ser modelado como uma viga, embora abordagens numéricas possam sobrepujar as dificuldades da resolução analítica do problema dinâmico, para a qual essas aproximações são interessantes e, por vezes, necessárias. 


\section{Capítulo 3}

\section{Subsídios Teóricos}

" $\tau O \quad \Sigma v \mu \pi \alpha \iota \epsilon \iota \nu \alpha \iota \quad \eta \quad \alpha \rho \nu \iota \alpha \quad \tau \omega \nu \quad \alpha \nu \tau \iota \theta \epsilon \tau \omega \nu "$.

O Universo é a harmonia dos contrários.

(Pitágoras)

O presente capítulo tem por objetivo a apresentação e discussão dos subsídios teóricos relevantes para esta tese, que serão introduzidos de maneira compartimentada, em uma sequência análoga à utilizada no capítulo precedente: iniciar-se-á com as modelagens estática e dinâmica de risers e finalizando com os aspectos teóricos e formulações do fenômeno de compressão dinâmica. O Apêndice A encerra os equacionamentos típicos para deflexões e vibrações em vigas, colunas e cabos, meramente para a comparação entre os reaultados estáticos exatos e as aproximações usualmente utilizadas, inclusive como base de alguns programas e rotinas computacionais. É importante destacar, nesse ponto, que não serão feitas demonstrações detalhadas das formulações apresentadas, visto que o cerne desta tese é a vertente experimental. Todas as seções do presente capítulo serão iniciadas com uma breve análise dimensional, baseada no Teorema de Pi-Buckingham, de maneira a determinar os adimensionais característicos de cada problema. Na sequência, serão explicitadas as formulações básicas utilizadas no âmbito da presente pesquisa e, por fim, uma breve discussão buscando apontar a relevância de cada um dos adimensionais apresentados para a física do problema e como essa é modelada em função daqueles.

O Teorema de Pi-Buckingham é de importância fundamental para a análise dimensional $^{1}$. Este teorema afirma que, dado um problema com $n$ variáveis físicas dimensionais, de maneira que uma delas possa ser escrita em função das demais, se elas puderem ser representadas por $k$ dimensões fundamentais físicas independentes ${ }^{2}$,

\footnotetext{
${ }^{1}$ Segundo Macagno (1971), cabe uma correção histórica: esse teorema foi formulado pela primeira vez por Aimé Vaschyem, em 1892, no artigo "Sobre as leis da semelhança em física". Entretanto, o resultado foi publicado apenas em 1914, por Edgar Buckingham, em seu artigo "Sobre sistemas fisicamente semelhantes" ((Buckingham, 1914)).

${ }^{2}$ Dimensões físicas independentes são, por exemplo, massa $(M)$, comprimento $(L)$ e tempo $(T)$.
} 
então a equação do sistema pode ser reescrita em função de $i=n-k$ variáveis adimensionais, denominadas $\Pi^{3}$.

Neste ponto, cabe uma nota importante para o presente trabalho, em que a principal abordagem é experimental: na Engenharia Naval e Oceânica, é muito comum a utilização de modelos em escala para ensaios em tanques de prova, túneis de vento e calibradores hidrodinâmicos. Em geral, utiliza-se a nomenclatura "dimensão real" e "dimensão do modelo" para, respectivamente, o comprimento característico do maior e do menor corpo. Fazendo uso dessa nomenclatura e usando os índices subscritos "r" para as variáveis físicas relativas à dimensão real do corpo e "m" para aquelas relacionadas ao modelo, seja $\alpha$ a relação entre comprimentos característicos do corpo $\left(L_{r}\right)$ e do modelo $\left(L_{m}\right)$. Deste modo, defina-se $\alpha=\frac{L_{r}}{L_{m}}$.

A partir da relação entre os comprimentos característicos é possível determinar a relação entre outras grandezas de fundamental importância para o estudo de problemas físicos em geral. Tais relações, cujas demonstrações são meras manipulações algébricas de adimensionais, são expressas na Tabela 3.1.

Para as deduções dessas relações, uma boa referência é o Capítulo 1 de (Bertram, 2012). Um trabalho interessante sobre grupos adimenionais que regem as respostas dinâmicas de risers SCR é (Quéau et al., 2013). O uso de adimensionais para determinação das características de um modelo de riser para ensaios em tanques de provas é muito bem descrito e encaminhado em (Rateiro et al., 2012).

Tabela 3.1: Relações adimensionais das principais grandezas físicas

\begin{tabular}{|c|l|}
\hline Grandeza & Relação \\
\hline Comprimento, $L$ & $\frac{L_{r}}{L_{m}}=\alpha$ \\
\hline Área, $S$ & $\frac{S_{r}}{S_{m}}=\alpha^{2}$ \\
\hline Volume, $V$ & $\frac{V_{r}}{V_{m}}=\alpha^{3}$ \\
\hline Força, $F$ & $\frac{F_{r}}{F_{m}}=\alpha^{3}$ \\
\hline Tempo, $t$ & $\frac{(E A)_{r}}{(E A)_{m}}=\sqrt{\alpha}$ \\
\hline Velocidade, $v$ & $\frac{(E I)_{r}}{(E I)_{m}}=\frac{1}{\sqrt{\alpha}}$ \\
\hline Rigidez Axial, $E A$ & $\frac{(E A)_{r}}{(E A)_{m}}=\alpha^{3}$ \\
\hline Rigidez Flexional, $E I$ & $\frac{(E I)_{r}}{(E I)_{m}}=\alpha^{5}$ \\
\hline
\end{tabular}

${ }^{3}$ Para maiores detalhes sobre a formulação precisa deste teorema, vide (Buckingham, 1914), páginas 345 a 348. 


\subsection{Estática de Risers em Catenária}

A presente seção, e as duas seguintes, serão iniciadas com a apresentação dos adimensionais que regem o problema em questão, seguida da formulação dos seus princípios com base na revisão bibliográfica explicitada anteriormente e finalizando com uma breve discussão relativa aos adimensionais obtidos na primeira parte e as formulações analíticas advindas da segunda.

\subsubsection{Adimensionais que regem a estática de risers em catenária}

Iniciando o estudo da estática de risers em catenária com a aplicação do Teorema de Buckingham, suponha-se que a tração efetiva $T_{e f}=T_{e f}(s)^{4}$ é a variável desejável para análise e possa ser escrita em função das variáveis dimensionais: peso linear imerso, $q^{5}$, da tração no TDP $T_{0}$, rijezas axial $E A$ e flexional $E I$, comprimento suspenso $L_{s}$, comprimento repousado sobre o solo $L^{\prime}$, lâmina d'água $H$, o coeficiente de atrito entre o solo e o riser $\eta$, a aceleração da gravidade local $g$ e, obviamente, a coordenada curvilínea $s$ ao longo do comprimento do riser $\left(0 \leq s \leq L_{s}\right)$. Dessa forma:

$$
T_{e f}(s)=\Psi_{1}\left(q, T_{0}, E A, E I, L_{s}, L^{\prime}, H, \eta, g, s\right)
$$

A aplicação do Teorema de Pi-Buckingham leva a:

$$
\frac{T_{e f}(s)}{T_{0}}=\Psi_{1}\left(\frac{H}{L_{s}}, \frac{L^{\prime}}{L_{s}}, \frac{E I}{T_{0} \cdot L_{s}^{2}}, \frac{T_{0}}{E A}, \frac{q \cdot L_{s}}{T_{0}}, \eta, \frac{s}{L_{s}}\right)
$$

Note-se que o coeficiente de atrito entre o solo e o riser $\eta$ já é, de per si, adimensional, mas de extrema importância para o problema estático, daí sua presença nessa formulação, como será explicitado na seção 3.1.3. Além disso, ressalte-se a aparente independência da tração efetiva com respeito à aceleração da gravidade $g$, dado que a definição do peso submerso próprio $q$ envolve implicitamente esse parâmetro, definido formalmente na Seção 3.1.2 adiante.

A interpretação física de cada um desses parâmetros adimensionais será discutida a seguir, nesta mesma seção, após apresentação da formulação para a estática de um riser em catenária.

\subsubsection{Formulação analítica do equilíbrio estático de risers em catenária}

Ilustre-se, pela Figura 3.1, a estática de uma linha lançada inicialmente sob geometria de catenária, sujeita ao seu peso linear próprio $m$ (por unidade de comprimento).

\footnotetext{
${ }^{4} \mathrm{~A}$ tração efetiva é definida formalmente no Item 3.1.2.

${ }^{5}$ Nesse ponto, basta que se entenda que o conceito está relacionado à diferença entre peso próprio no ar e o empuxo resultante do campo de pressão hidrostática ao redor do corpo imerso em um fluido qualquer.
} 


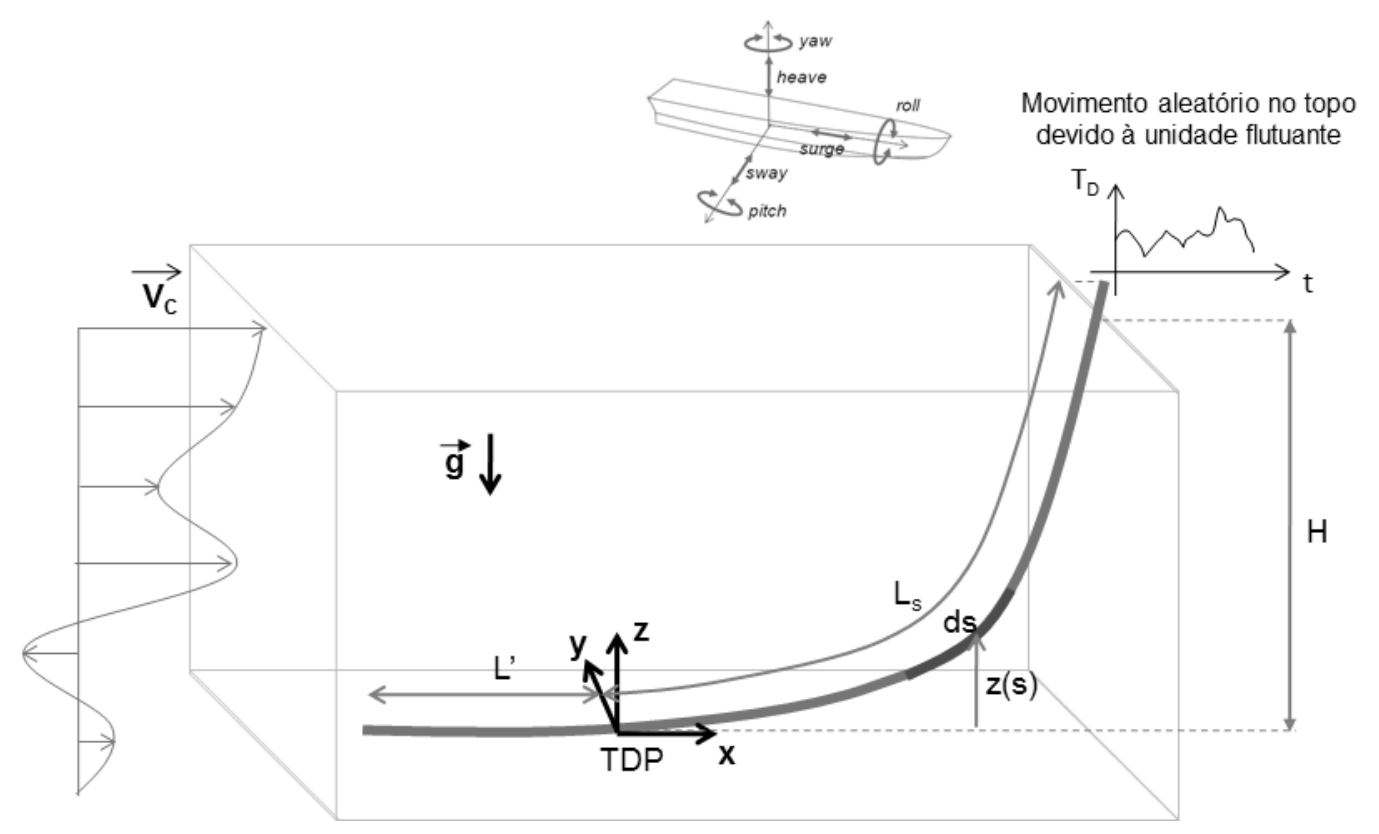

Figura 3.1: Esforços genéricos atuantes sobre um elemento de linha em catenária.

A lâmina d'água é denominada por $H$, enquanto seus comprimentos suspenso e repousado sobre o leito marinho por $L_{s}$ e $L^{\prime}$, respectivamente. O sistema global de coordenadas $(0, x, y, z)$ está representado na figura, com a origem no TDP estático ${ }^{6}$. Além disso, sob a linha poderão atuar esforços devidos à correnteza, arrasto de origem hidrodinâmica e excitação de topo, resultante da movimentação da unidade flutuante à qual o topo do riser está conectado.

No presente trabalho, os efeitos de correnteza serão desconsiderados, dado que o fenômeno de interesse não depende da presença desses esforços hidrodinâmicos.

Neste ponto, o arrasto hidrodinâmico e a excitação de topo não serão considerados, dado que o objeto de estudo é a estática do riser em catenária. A Figura 3.1 é, pois, genérica e atende à presente seção e a que se seguirá a ela.

No topo da Figura 3.1, ao centro, destaque-se a ilustração de uma embarcação e seus respectivos movimentos de translação e rotação, com respeito aos eixos coordenados apresentados, e denominados por surge (translação na direção do eixo $x$ ), sway (translação na direção do eixo y), heave (translação na direção do eixo $z$ ), roll (rotação ao redor do eixo $x$ ), pitch (rotação ao redor do eixo $y$ ) e yaw (rotação ao redor do eixo $z$ ).

Ainda na Figura 3.1 é possível visualizar, em destaque, um elemento de linha de comprimento infinitesimal $d s$. Seu centro está sob uma cota $z(s)$, onde $s$ é a coordenada curvilínea, definida ao longo do comprimento do riser, com origem fixada no TDP, coincidente com o sistema de coordenadas $(0, x, y, z)$.

\footnotetext{
${ }^{6}$ Cabe lembrar que o touchdown point, primeiro ponto de contato da linha com o solo, a partir do seu topo, não é estático e modifica-se em função do tempo e da excitação. Assim, uma alternativa seria utilizar um sistema de coordenadas móvel, fixado no TDP instantâneo, o que não será feito na presente análise.
} 
As projeções desse elemento de linha sobre os eixos $x, y$ e $z$ correspondem a comprimentos dados, respectivamente, por $d x, d y=0$ e $d z$.

Antes de proceder ao estudo propriamente dito da estática de um riser lançado em catenária, é importante estabelecer o conceito de tração efetiva. O desenvolvimento aqui descrito é baseado no Capítulo 3 de (Pesce, 1997).

Seja um elemento de comprimento infinitesimal $d s$, como o apresentado na Figura 3.1. Sobre esse elemento atuam os seguintes esforços:

- Seu peso próprio no ar, $m \cdot g \cdot d s$;

- O campo de pressões hidrostáticas, $P_{\text {ext }}$; e

- Trações nas extremidades do elemento, dadas por $F(s)$ e $F(s+d s)$.

De um resultado bastante conhecido decorre a definição de empuxo ${ }^{7}$, qual seja, a resultante (neste caso, vertical) devida ao campo de pressões hidrostáticas ao redor de um corpo imerso ou flutuante, cujo sentido, no problema em questão, é contrário à atuação do campo gravitacional local.

Não é possível, diretamente, reconhecer o empuxo apenas a partir dos esforços citados, dado que as extremidades do elemento de riser são abertas e sobre elas não atuam, portanto, efeitos de natureza hidrostática.

Uma maneira engenhosa de explicitar o empuxo, é baseado no seguinte procedimento: incorpora-se, artificialmente, um campo de pressões hidrostáticas nas extremidades do elemento, como se o mesmo fosse fechado. Para compensar estaticamente essa modificação, introduz-se um campo de pressões em sentido contrário, também nas extremidades, de sorte que o equilíbrio estático é mantido.

Feito isso, é possível integrar o campo de pressões hidrostáticas ao redor de toda a superfície do elemento, de forma que o empuxo é prontamente introduzido, a partir de sua definição física. Em sentido contrário, atua o peso próprio, no ar, desse elemento, dado por $m \cdot g \cdot d s$. Decorre dessas forças o conceito de peso imerso próprio (ou peso aparente), definido por $q \cdot d s$, onde $q$ é o peso correspondente a uma massa aparante, definida como a diferença entre a massa linear própria $(m)$ do elemento e a correspondente massa de água por ele deslocada $\left(m_{d}\right)^{8}$.

Por outro lado, note-se o aparecimento de novas componentes aditivas às trações atuantes, provenientes do campo de pressões artificialmente introduzido e não considerado na determinação do empuxo. A resultante das forças de tração nas extremidades do elemento de linha é denominada tração efetiva. Segundo Pesce (1997), "é a tração efetiva, e não a tração solicitante que determina, do ponto de vista estrutural, a configuração de equilíbrio estático e rege a rigidez geométrica da linha a deslocamentos transversais, esta última a principal condicionante de sua resposta dinâmica".

\footnotetext{
${ }^{7} \mathrm{~A}$ definição física de empuxo é atribuída a Arquimedes (287 a.C.- 212 a.C., aproximadamente), que formulou o princípio de que todo corpo mergulhado em um fluido sofre a ação de um empuxo vertical, contrário à ação da gravidade (sic), igual ao peso do líquido deslocado por esse corpo.

${ }^{8}$ Desta forma, o peso próprio imerso é dado por $q \cdot\left(m-m_{d}\right) \cdot g \cdot d s$
} 
Tal como definida, a tração efetiva $T_{e f}$ pode ser expressa matematicamente pela Equação 3.2, bastando, para tanto, utilizar as definições de pressão e empuxo.

$$
T_{e f}(s)=F(s)+\rho \cdot g \cdot S(s) \cdot[H-z(s)]
$$

onde $\rho$ é a densidade do meio circundante e $S(s)$ é a área da seção transversal do riser, em $s=s(x)$.

Apresentado o conceito de tração efetiva e as demonstradas as origens do empuxo e do peso próprio imerso de um elemento de linha, considere-se o mesmo elemento de linha agora deformado, devido à atuação das forças em suas extremidades (extensibilidade axial). Suponha-se que o comprimento deformado seja igual a $d \bar{s}$. Os esforços genéricos a que esse elemento está submetido estão ilustrados na Figura 3.2.

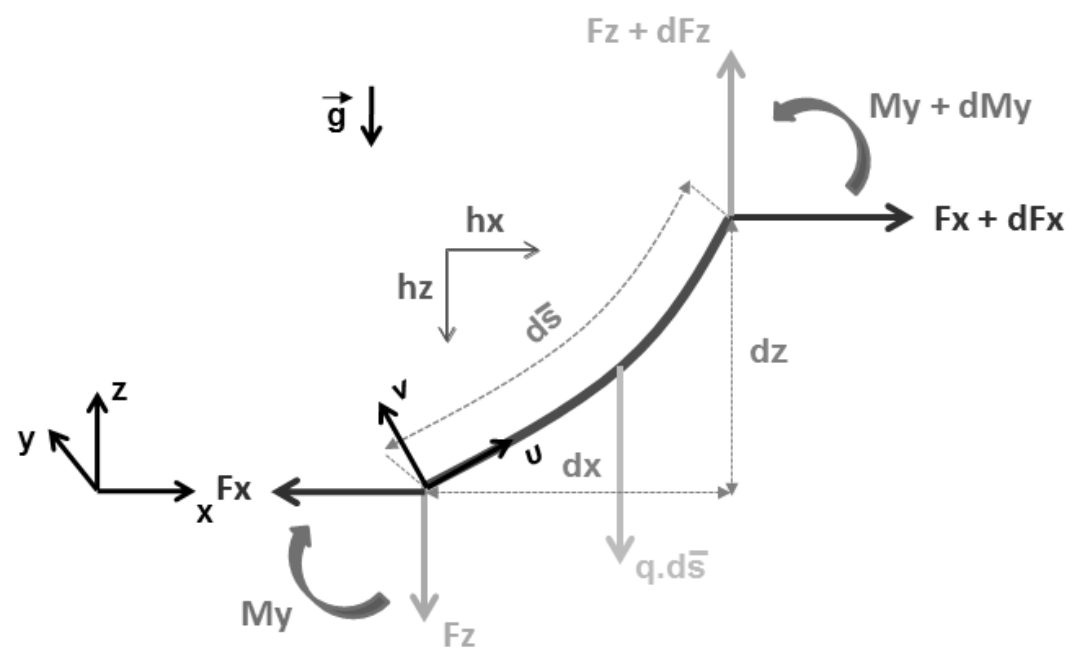

Figura 3.2: Equilíbrio estático de um elemento deformado de comprimento infinitesimal $d \bar{s}$.

Fonte: (Amarante, 2011).

Pretende-se estabelecer as equações de equilíbrio estático relacionadas ao elemento deformado da Figura 3.2, supondo que essa deformação é linear (Lei de Hooke) e isotrópica, de maneira que vale a Equação 3.3.

$$
d \bar{s}=\left(1+\epsilon_{0}\right) \cdot d s
$$

- Segue, então, do equilíbrio das forças horizontais que:

$$
\frac{d}{d \bar{s}} F_{x}=0
$$

o que implica no resultado bastante conhecido de que a força horizontal atuante sobre esse elemento é constante, resultado é extensível a todo o comprimento do riser, $F_{x}=T_{0}$, correspondendo à projeção da tração normal sobre o eixo $x^{9}$.

\footnotetext{
${ }^{9} \mathrm{~A}$ menos que se ressalve em contrário, o sistema global de coordenadas e, portanto, as denominações dos eixos coordenados serão referidos como os apresentados na Figura 3.1.
} 
- Do equilíbrio das forças verticais:

$$
\frac{d}{d \bar{s}} F_{z}=q
$$

levando ao fato de que a resultante das forças verticais corresponde ao peso próprio imerso do elemento deformado; e, por conseguinte, do riser como um todo: se $L_{s}$ é o comprimento suspenso do riser em catenária, então seu peso imerso fica sendo dado por $F_{z}=q \cdot L_{s} \cdot\left(1+\epsilon_{0}\right)$.

Neste ponto, cabe uma observação interessante: dado que a componente horizontal da força atuante sobre um elemento de linha é constante e sua componente vertical é crescente com a coordenada curvilínea $s($ ou $\bar{s}$ ), então vale a seguinte relação:

$$
T(s)=T_{0} \cdot \sec (\theta)
$$

- E do equilíbrio dos momentos:

$$
d M_{y}=\left(1+\epsilon_{0}\right) \cdot\left[F_{x} \cdot d z-F_{z} \cdot d x\right]
$$

Note-se que um termo de ordem igual $(d \bar{s})^{2}$ foi desprezado na equação de equilíbrio dos momentos.

Além do equilíbrio estático estabelecido e apresentado, é necessário explicitar as chamadas equações constitutivas:

- $\epsilon_{0}=\frac{N}{E A}$, advinda diretamente da Lei de Hooke, onde EA é a rigidez axial do elemento de linha e $N=F_{x} \cdot \cos (\theta)+F_{z} \cdot \operatorname{sen}(\theta)$ é o esforço normal atuante sobre o elemento deformado (tração efetiva); e

- $M=\frac{d}{d x} \theta \cdot E I=\chi \cdot E I$, onde El é a rigidez flexional do elemento de linha e $\chi$ representa sua curvatura na coordenada $s=s(x)$.

Ressalte-se que essa última equação constitutiva, relativa ao momento-fletor, é uma aproximação linear.

Em geral, a partir dos resultados das Equações 3.4 a 3.7 são feitas aproximações de maneira a explicitar alguns resultados importantes e de uso corriqueiro.

A primeira dessas simplificações é assumir a ausência de momentos aplicados, ou seja, $M_{y}=0$ na Equação 3.7, e a consideração de inextensibilidade da linha $\left(\epsilon_{0}=0\right.$ ou, ainda, $d \bar{s}=d s$ ) de maneira que a seguinte relação torna-se explícita:

$$
\tan [\theta(s)]=\frac{d z}{d x}=\frac{q \cdot s}{T_{0}}
$$


Tomando a Equação 3.8 e derivando $\theta(s)$ com respeito a $s$, chega-se a:

$$
\frac{d}{d s} \theta(s)=\frac{q}{T_{0}} \cdot \cos ^{2}[\theta(s)]=\frac{q}{T_{0}} \cdot \frac{1}{1+\left(\frac{q \cdot s}{T_{0}}\right)^{2}}
$$

Por outro lado, partindo ainda da Equação 3.8, mas derivando-a com relação a $x$ e usando a Regra da Cadeia, segue que:

$$
\frac{d^{2}}{d x^{2}} z(s)=\frac{d}{d x} \tan [\theta(s)]=\frac{q}{T_{0}} \cdot\left[1+\left(\frac{d z}{d x}\right)^{2}\right]^{\frac{1}{2}}
$$

O objetivo, neste ponto, é estabelecer a relação $z=z(x)$ que determina, neste caso, o formato geométrico de um cabo lançado exclusivamente sob a ação do seu peso próprio (imerso ou não), ou seja, a catenária, dada por:

$$
z(x)=\frac{T_{0}}{q} \cdot\left[\cosh \left(\frac{q}{T_{0}} \cdot x\right)-1\right]
$$

Na extremidade superior do riser (topo), a Equação 3.8 assume a seguinte forma:

$$
\tan \left(\theta_{t}\right)=\left(\frac{F_{z}}{F_{x}}\right)_{s=L_{s}}=\frac{q \cdot L_{s}}{T_{0}}
$$

A Equação 3.12 se configura como uma maneira interesante de se determinar o comprimento suspenso do cabo em catenária:

$$
L_{s}=\frac{T_{0}}{q} \cdot \tan \left(\theta_{t}\right)=\frac{T_{0}}{q} \cdot\left[\left(1+\frac{q \cdot H}{T_{0}}\right)^{2}-1\right]^{\frac{1}{2}}
$$

Definindo a curvatura $\chi_{s}=\frac{d \theta}{d s}$, da Equação 3.10 decorre diretamente que a curvatura da linha em catenária, em qualquer ponto ao longo do seu comprimento é dada por: 


$$
\chi_{s}=\frac{q}{T_{0}} \cdot \cos ^{2}[\theta(s)]=\frac{q}{T_{0}} \cdot \frac{1}{1+\left(\frac{q \cdot s}{T_{0}}\right)^{2}}
$$

Para o TDP, onde $s=0$ :

$$
\chi_{0}=\frac{q}{T_{0}}
$$

Além disso, note-se que as Equações 3.8 e 3.15 compatibilizam, juntas, duas condições de contorno importantes da linha no TDP:

- A condição de tangência nula para abcissas nula (se necessário, relembrar o sistema global de coordenadas definido na Figura 3.1); e

- Sua curvatura característica $\chi_{0}$, caso contrário. Para abcissas negativas, a linha encontra-se repousada sobre o solo.

No contexto do presente trabalho, é interessante explicitar as relações $x(s)$ e $z(s)$, dado que seu uso faz parte da rotina numérica empregada para determinação da estática da linha, conforme ilustrado na primeira etapa do fluxograma da Figura 4.1.

As formulações abaixo foram extraídas de (Pesce, 1997), embora sua determinação seja simples e direta a partir das equações já apresentadas.

$$
\begin{gathered}
x(s)=\frac{T_{0}}{q} \cdot \operatorname{asenh}\left(\frac{q \cdot s}{T_{0}}\right) \\
z(s)=\frac{T_{0}}{q} \cdot\left\{\left[1+\left(\frac{q \cdot s}{T_{0}}\right)^{2}\right]^{\frac{1}{2}}-1\right\}
\end{gathered}
$$

O próximo ponto a se tratar, no que tange à estática bidimensional de um riser lançado sob catenária direta, é a incorporação dos efeitos devidos à extensibilidade da linha. Note-se que, embora considerada inicialmente, a deformação específica $\epsilon_{0}$ não desempenha papel algum na estática em catenária, dada a suposição de inextensibilidade da linha, feita anteriormente à Equação 3.8.

Entretanto, cumpre destacar que, (Patel \& Seyed, 1995) apud Pesce (1997), afirma que "o efeito da extensibilidade será desprezível, em geral, ao menos no que tange à determinação da configuração de equilíbrio da elástica. (...) É evidente que à medida que a rigidez axial decresce, cresce a importância da extensibilidade”. 
A fim de incorporar o efeito da extensibilidade da linha, basta considerar a Equação 3.3 em toda a formulação que se segue a partir (e inclusive) da Equação 3.8.

As principais consequências da incorporação desses efeitos são:

1. A componente horizontal da tração permanece constante ao longo de todo o comprimento da linha;

2. As projeções vertical e horizontal da catenária ficam modificadas, dado que $x(\bar{s})$ e $z(\bar{s})$ passam a incorporar o efeito da deformação específica $\epsilon_{0}$.

Postas essas considerações e tomando por $s_{i}$ a coordenada curvilínea na condição indeformada, chega-se às novas relações para as coordenadas de cada ponto da elástica deformada, dadas por x $\left(s_{d}\right)$ e z $\left(s_{d}\right)$ ), adaptadas das Equações 3.16 e 3.17:

$$
\begin{gathered}
x\left(s_{d}\right)=\epsilon_{0} \cdot s_{i}+\frac{T_{0}}{q} \cdot \operatorname{asenh}\left(\frac{q \cdot s_{i}}{T_{0}}\right) \\
z\left(s_{d}\right)=\frac{1}{2} \cdot \frac{q \cdot s_{i}}{T_{0}} \cdot \epsilon_{0} \cdot s_{i}+\frac{T_{0}}{q} \cdot\left\{\left[1+\left(\frac{q \cdot s_{i}}{T_{0}}\right)^{2}\right]^{\frac{1}{2}}-1\right\}
\end{gathered}
$$

Essas duas últimas equações foram utilizadas para a incorporação da extensibilidade da linha, apresentada no segunda etapa do fluxograma da Figura 4.1, correspondente à correção proposta por Patel \& Seyed (1995).

Essa correção visava justamente ajustar os valores das projeções horizontal $\left(D_{x}\right)$ e vertical $(H)$ da linha distendida, dadas respectivamente pelas Equações 3.20 e 3.21 a seguir:

$$
\begin{gathered}
D_{x}=\epsilon_{0} \cdot L_{s}+\frac{T_{0}}{q} \cdot \operatorname{asenh}\left(\frac{q \cdot L_{s}}{T_{0}}\right) \\
H=\frac{q \cdot L_{s}^{2}}{2 \cdot E A}+\frac{1}{q}\left(T_{s}-T_{0}\right)
\end{gathered}
$$

Nota: $T_{s}$ aqui, e no restante do texto, é a denominação dada à tração efetiva no topo da linha. $T(s)$ representa a tração efetiva em um ponto de coordenada curvilínea $s$. 
Previamente ao estudo da dinâmica de risers em catenária, cabe uma ressalva de evidente importância: ao contrário do que foi feito habilmente por Pesce (1997), a partir do trabalho de Love (1906), os resultados aqui apresentados referem-se exclusivamente à mecânica bidimensional de tubos submersos. Naquele texto, o autor parte do equilíbrio tridimensional, o que por um lado é mais elegante e teoricamente rico. Por outro, o estudo da compressão dinâmica em risers, em termos estritos, prescinde da abordagem levada a cabo por Pesce (1997), embora efeitos tridimensionais relacionados à saída da linha do plano da catenária, bem como a torção na linha sejam absolutamente relevantes.

Optou-se, no presente texto, pela apresentação bidimensional do fenômeno, com discussões pontuais sobre sua tridimensionalidade, baseadas, por exemplo, em (Ramos Jr, 2001) e (Ramos Jr \& Pesce, 2003).

\subsubsection{O papel físico dos adimensionais na estática de risers em catenária}

A fim de relacionar os adimensionais apresentados na seção 3.1.1 com a formulação analítica desenvolvida na seção 3.1.2, cabe recuperar aqui a Equação 3.1, repetida para facilidade do leitor.

$$
\frac{T_{e f}(s)}{T_{0}}=\Psi_{1}\left(\frac{H}{L_{s}}, \frac{L^{\prime}}{L_{s}}, \frac{E I}{T_{0} \cdot L_{s}^{2}}, \frac{T_{0}}{E A}, \frac{q \cdot L_{s}}{T_{0}}, \eta, \frac{s}{L_{s}}\right)
$$

O Teorema de Pi-Buckingham, por si só, não garante a relevância dos adimensionais resultantes da análise dimensional, dado que a própria escolha das variáveis de interessem depende de quem a faz.

$O$ fato de serem gerados adimensionais, permite que os mesmos sejam associados entre si, caso seja conveniente para determinada análise.

Uma rápida verificação da Equação 3.22, permite a elucidação imediata da importância de alguns adimensionais.

A variável de interesse $T_{e f}(s)$ aparece adimensionalizada pela tração no TDP (projeção horizontal de magnitude invariável ao longo do comprimento da linha).

O parâmetro adimensional $\frac{s}{L_{s}}$ nada mais é que uma adimensionalização da coordenada curvilínea. A deformação específica $\epsilon_{0}=\frac{T_{0}}{E A}$ aparece naturalmente, mostrando a importância da extensibilidade da linha para a sua estática.

O adimensional $\Pi_{\lambda}=\sqrt{\frac{E I}{T_{0} \cdot L_{s}^{2}}}=\frac{\lambda_{f}}{L_{s}}$ explicita a rigidez flexional, particularmente importante nas extremidades do riser, pontos onde a teoria de cabos falha ao se tentar modelar um riser a partir dela. Ainda com relação a esse adimensional, de acordo com Pesce (1997), a ausência de momentos aplicados implica no fato de que "o efeito da rigidez flexional é considerado desprezível face à rigidez geométrica". 
Segundo aquele autor, fica evidente que essa condição é necessária, embora não suficiente, para a determinação da geometria inicial da linha como sendo estaticamente uma catenária. Pesce (1997) cita, ainda, que essa suposição é considerada válida nos casos em que o comprimento flexural é tal que $\frac{E I}{T_{0} \cdot L_{s}^{2}} \ll 1$.

Como definido pela Equação 2.2, esse adimensional se caracteriza por ser uma forma adimensionalizada do comprimento de flexão $\lambda_{f}$, cuja importância dinâmica passa por dois pontos: reflete a relação entre as posições instantânea e inicial do TDP; além de fornecer a dimensão típica da região no entorno do TDP influenciada pela rigidez flexional, de acordo com (Aranha et al., 1997).

Seguindo a avaliação dos adimensionais, $\frac{q \cdot L_{s}}{T_{0}}$ se destaca por ser uma das formas adimensionalizadas da curvatura no TDP, dada pela Equação 3.15, $\chi_{0}=\frac{q}{T_{0}}$.

Mais que isso, avaliando a Equação 3.12, é fácil perceber que esse adimensional é exatamente o valor da tangente do ângulo de topo, evidenciando a relevância desse parâmetro para a estática do riser em catenária.

Observe-se que tanto a curvatura no TDP $\chi_{0}$, quanto o comprimento flexural $\lambda_{f}$, foram adimensionalizados pelo comprimento suspenso $L_{s}$.

Assim, é possível, a partir desses dois adimensionais, gerar um terceiro, dado pela expressão $\Pi_{\theta}=\tan (\theta)=\chi_{0} \cdot \lambda_{f}$, que será utilizado nas próximas seções, tanto no estabelecimento da relação adimensional que descreve a tração dinâmica analítica, quanto da carga crítica de flambagem de vigas curvas.

O adimensional $\frac{H}{L_{s}}$ aponta para uma relação que não traz muita explicação física ao problema. É possível perceber a relação direta entre ambas as variáveis pelas Equações 3.13 e 3.21, que apenas são formas implícitas para o cosseno do ângulo entre a tangente à linha e o plano horizontal. A partir da Equação 3.13, é possível determinar:

$$
\left(\chi_{0} \cdot L_{s}\right)^{2}+1=\left(1+\chi_{0} \cdot H\right)^{2}
$$

Essa equação evidencia outra relação importante entre a lâmina d'água $H$ e o comprimento suspenso em catenária $L_{s}$. A grandeza $\frac{L^{\prime}}{L_{s}}$, em primeira análise, apenas mostra uma relação entre o comprimento repousado sobre o leito marinho e o suspenso em catenária. A soma desses dois parâmetros dimensionais, evidentemente, corresponde ao comprimento total da linha.

A utilização do parâmetro $L^{\prime}$ foi feita pela sua associação com o coeficiente de atrito com o solo, $\eta$. Uma grandeza adimensional que se pode obter como combinação das apresentadas na Equação 3.22 é a seguinte: $\eta \cdot \frac{q \cdot L^{\prime}}{T_{0}}$, que corresponde à razão entre a força de atrito estática entre o riser e o solo, dada por $\eta \cdot q \cdot L^{\prime}$ e a tração $T_{0}$ no TDP. É notável, entretanto, que esse adimensional não rege a geometria de catenária assumida pelo riser sob ação exclusiva de seu peso próprio, apenas o equilíbrio da porção 
dele que repousa sobre o leito marinho, podendo, inclusive, ser omitido na análise, de sorte que os parâmetros $\eta$ e $L^{\prime}$ poderiam ter ser suprimidos na função $\Psi_{1}$, desde o início deste estudo. Como a rigidez geométrica prevalece, estaticamente, sobre os efeitos locais da rigidez flexional, esta também pode ser suprimida dessa análise. Assim, de maneira a finalizar a presente seção, é possível rearranjar a expressão que encerra os adimensionais relacionados exclusivamente com a estática de risers em catenária direta, usando as informações anteriores juntamente com a Equação 3.15.

$$
\Pi_{e}=\frac{T_{e f}(s)}{T_{0}}=\Psi_{1}\left(\Pi_{H}=\frac{H}{L_{s}}, \Pi_{s}=\frac{s}{L_{s}}, \Pi_{\theta}=\tan \left(\theta_{t}\right)=\chi_{0} \cdot L_{s}, \epsilon_{0}=\frac{T_{0}}{E A}\right)
$$

Assim, ficam bem estabelecidas, para a elástica deformada, a curvatura e trações ao longo de seu comprimento, além de suas projeções horizontal e vertical, regidas pelos adimensionais apresentados na Equação 3.24, corroborada pelas Equações 3.6 e 3.8, sob consideração implícita da deformação específica devida à rigidez axial.

Por fim, utilizando a Equação 3.14 na Equação 3.6, chega-se à equação adimensionalizada para a tração $T_{s}$ do cabo inextensível, completamente compatível com a Equação 3.24, a menos da consideração da deformação específica $\epsilon_{0}$ :

$$
\Pi_{e}=\sqrt{\left(1+\Pi_{H} \cdot \Pi_{\theta}\right)^{2}-\Pi_{\theta}^{2}+\left(\Pi_{s} \cdot \Pi_{\theta}\right)^{2}}
$$

As Figuras 3.3 e 3.4 corroboram e ilustram os resultados das formulações realizadas na presente seção, mostrando, para dois casos distintos (provenientes, respectivamente, dos trabalhos de Ribeiro et al. (1998) - SCR e de Simos \& Fujarra (2006) - riser flexível), as trações efetivas ao longo da linha estática.

Em ambos os casos, foram confeccionados e ilustrados dois gráficos distintos:

- À esquerda de cada uma das referidas figuras, é apresentada a tração efetiva $T_{e f}(s)$, em $N$, ao longo da coordenada curvilínea $s$ medida em $m$, desde $s=0$ (TDP) até $s=L_{s}$ (topo).

Os casos foram avaliados (i) sem correção elástica [(Pesce, 1997)] e (ii) considerando a deformação específica [(Patel \& Seyed, 1995)]; e,

- À direita, o respectivo resultado da adimensionalização realizada, levando em conta a Equação 3.25, de modo que a tração efetiva adimensionalizada pela tração horizontal constante $\left(\Pi_{e}\right)$ foi ilustrada em função da coordenada curvilínea adimensionalizada $\left(\Pi_{s}\right)$. 
Note-que que, nesses dois exemplos, os resultados mostram-se bastante coerentes, tanto no que tange ao formato de ambas as curvas, apontando para o conhecido resultado de que a tração é praticamente linear após uma certa distância do TDP (preponderantemente para o SCR), quanto à aderência das representações gráficas da tração efetiva dimensional, com e sem correção devida à rigidez axial, mostrando que a correção, em termos estáticos, é de pequena monta, sendo imperceptível no caso da linha flexível, resultado amplamente conhecido.
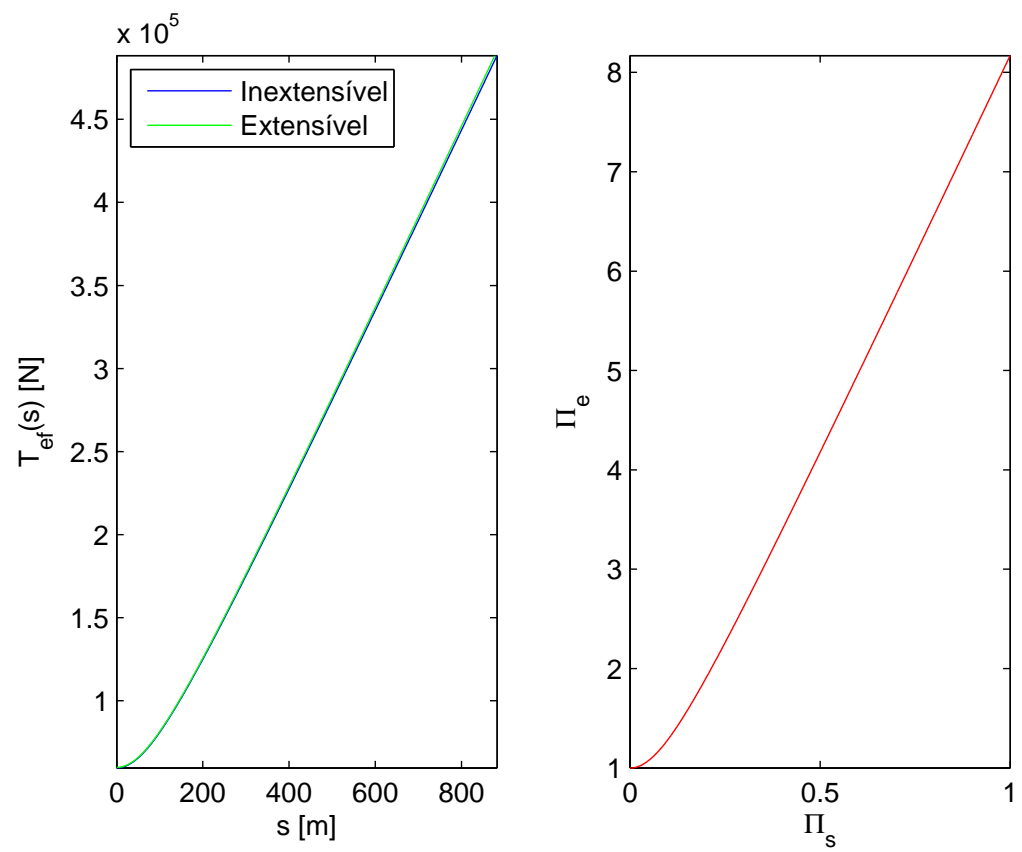

Figura 3.3: Tração efetiva estática ao longo da linha de (Ribeiro et al., 1998).
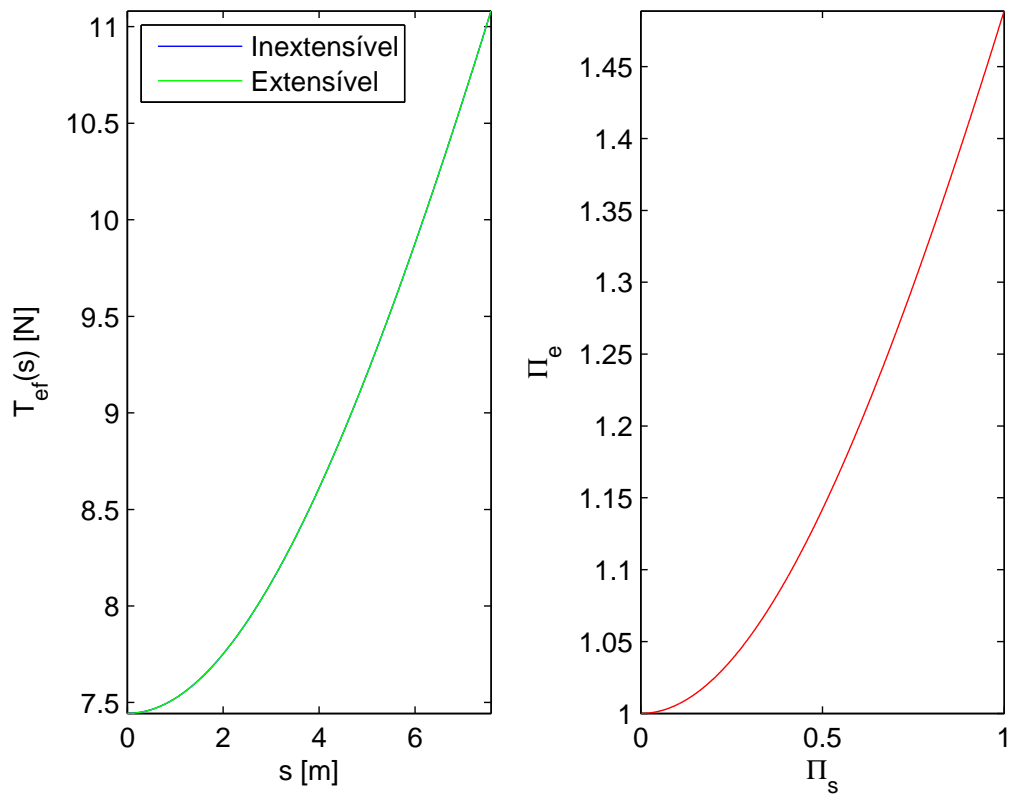

Figura 3.4: Tração efetiva estática ao longo da linha de (Simos \& Fujarra, 2006). 


\subsection{Dinâmica de Risers em Catenária}

A presente seção apresentará o problema da dinâmica de risers em catenária, a partir de uma estrutura semelhante à da seção precedente. A riqueza de detalhes apresentada teve caráter ilustrativo e, portanto, os resultados desta seção e da que a sucede serão feitos de maneira mais direta e resumida.

\subsubsection{Adimensionais que regem a dinâmica de risers em catenária}

O estudo da dinâmica de risers será iniciado com a aplicação do Teorema de Buckingham, com a variável de interesse sendo a tração dinâmica $T_{d}$.

Como será apresentado posteriormente, ainda nesta seção, a dinâmica do riser depende diretamente da sua configuração estática, daí a utilização das mesmas variáveis utilizadas na seção precedente, além dos parâmetros de excitação de topo (amplitude do movimento harmônico imposto, $A_{m}$ e período de excitação, $T$ ).

Adicionalmente, são necessários os coeficientes (adimensionais) de inércia $C_{m}{ }^{10}$ e de arrasto, $C_{d}$, bem como um parâmetro que modele a rigidez do solo, supostamente linear, $k_{s}$ e a massa linear própria submersa $\mu=m+m_{a}{ }^{11}$.

A importância e o significado físico dos coeficientes de massa adicionada e de arrasto serão explorados na próxima sessão. Por fim, foram introduzidas as variáveis relativas à coordenada curvilínea $s$ e ao tempo $t$, de forma que é possível escrever:

$$
T_{d}(s, t)=\Psi_{2}\left(q, T_{0}, E A, E I, L_{s}, L^{\prime}, H, \eta, g, A_{m}, T, C_{m}, C_{d}, k_{s}, \mu, s, t\right)
$$

Então, a partir do Teorema de Pi-Buckingham, é possível mostrar que:

$$
\frac{T_{d}(s, t)}{T_{0}}=\Psi_{2}\left(\frac{H}{L_{s}}, \frac{A_{m}}{L_{s}}, \frac{L^{\prime}}{L_{s}}, \frac{E I}{T_{0} L_{s}^{2}}, \frac{E A}{T_{0}}, \frac{q L_{s}}{T_{0}}, \frac{g T^{2}}{L_{s}}, \frac{k_{s} L_{s}^{2}}{T_{0}}, \frac{\left(m+m_{a}\right) L_{s}^{2}}{T^{2} T_{0}}, \eta, C_{m}, C_{d}, \frac{s}{L_{s}}, \frac{t}{T}\right)
$$

Alguns dos adimensionais que compõem a Equação 3.27 já foram apresentados na seção A.1.2. Assim, reescrevendo a Equação 3.27 utilizando tais adimensionais, bem como aqueles apresentados na seção 3.1.3.

\footnotetext{
${ }^{10}$ Por definição, o coeficiente de inércia de Morison é dado por $C_{m}=1+C_{a}$, onde $C_{a}$ é o chamado coeficiente de massa adicionada, dado pela divisão da massa adicionada pela massa do volume deslocado, ou seja, $C_{a}=\frac{m_{a}}{m}$.

${ }^{11}$ A massa adicionada (ou virtual) $m_{a}$ é a inércia adicional experimentada por um corpo sujeito a uma aceleração de modo que culmina com a movimentação do fluido que o circunda. Essa definição resulta do fato de que dois corpos não podem ocupar o mesmo espaço, ao mesmo tempo. Prof. A. Techet (MIT), em http://web.mit.edu/2.016/www/labs/L01_Added_Mass_050915.pdf
} 


$$
\frac{T_{d}(s, t)}{T_{0}}=\Psi_{2}\left(\Pi_{H}, \frac{A_{m}}{L_{s}}, \frac{L^{\prime}}{L_{s}}, \Pi_{\lambda}, \epsilon_{0}, \Pi_{\theta}, T \sqrt{\frac{g}{L_{s}}}, \frac{k_{s} L_{s}^{2}}{T_{0}}, \frac{c_{0} \cdot T}{L_{s}}, \Pi_{a t}, C_{m}, C_{d}, \Pi_{s}, \Pi_{t}\right)
$$

com $\Pi_{a t}=\frac{\eta q L^{\prime}}{T_{0}} ; \Pi_{t}=\frac{t}{T} ; c_{0}=\sqrt{\frac{T_{0}}{m+m_{a}}} ; \mathrm{e} \Pi_{H}, \Pi_{s}, \Pi_{\theta}, \epsilon_{0}, \Pi_{\lambda}$ definidos anteriormente.

A presença dos adimensionais $\Pi_{H}, \Pi_{s}, \Pi_{\theta}, \epsilon_{0}$ e $\Pi_{\lambda}$, nesta formulação, sugere que a resposta dinâmica do riser depende dos parâmetros estáticos. Esse resultado é bastante conhecido no estudo da Mecânica de Tubos Submersos e será explorado de maneira mais adequada na próxima seção.

A discussão sobre a importância e o papel físico do adimensional $\Pi_{a t}$ já foi feita anteriormente, na seção 3.1.3. Ademais, o quociente $\Pi_{t}$ é tão somente um adimensional para o tempo $t$, com relação ao período de excitação.

É possível definir, ainda, outros três adimensionais que serão utilizados novamente em outras seções da presente tese, quais sejam:

- $\Pi_{K}=\frac{k_{s} L_{s}^{2}}{T_{0}}$, cuja importância é fundamental para a consideração da rigidez do solo, como discutido com propriedade em Bernitsas \& Papalambros (1980), em Pesce (1997) e em Pesce et al. (1998a);

- $\Pi_{T}=T \sqrt{\frac{g}{L_{s}}}$, que remete à analogia com o período de um pêndulo simples, além de ser parcela componente da equação analítica para determinação aproximada das frequências naturais de vibração de cabos em catenária, obtida via método WKB, em Pesce et al. (1999), o que reforça o caráter oscilatório associado a esse adimensional e, consequentemente, à resposta do riser frente a esse tipo de excitação; e

- $\Pi_{c_{0}}=\left(\frac{\omega}{c_{0}}\right) \cdot L_{s}$, obtido a partir de $\frac{c_{0} \cdot T}{L_{s}}$ e da equação que associa a frequência angular e o período de um movimento harmônico dada por $\omega=\frac{2 \pi}{T}$. Esse parâmetro será discutido mais detalhadamente adiante, tanto no Item 3.2.3, quanto na Seção 3.3.

Dessa feita, a Equação 3.28 pode ser assim reescrita:

$$
\Pi_{d}=\frac{T_{d}(s, t)}{T_{0}}=\Psi_{2}\left(\Pi_{H}, \frac{A_{m}}{L_{s}}, \frac{L^{\prime}}{L_{s}}, \Pi_{\lambda}, \epsilon_{0}, \Pi_{\theta}, \Pi_{T}, \Pi_{K}, \Pi_{c_{0}}, \Pi_{a t}, C_{m}, C_{d}, \Pi_{s}, \Pi_{t}\right)
$$

Após a apresentação da formulação para a dinâmica de um riser em catenária, será feita a interpretação física dos parâmetros adimensionais ainda não discutidos, dado que muitos desses grupos serão definidos apenas ao longo do texto da próxima seção, dando indícios importantes de sua relevância na física no problema dinâmico. 


\subsubsection{Formulação analítica da dinâmica risers em catenária}

O principal objetivo desta seção é a apresentação de três tópicos relevantes para a pesquisa que a presente tese encerra: os conceitos gerais concernentes à dinâmica de linhas em catenária, baseado em (Pesce, 1997); a formulação analítica proposta por Aranha \& Pinto (2001) para a tração dinâmica em risers sob a mesma configuração de lançamento; e a forma geral com que os programas baseados no Método dos Elementos Finitos, como é o caso do Anflex, funcionam.

Ressalte-se que o equacionamento para a tração dinâmica formulado por Aranha \& Pinto (2001) é capaz de determinar o valor dessa variável ao longo do comprimento suspenso da catenária, e em função do tempo. Além disso, nos casos em que a carga crítica for ultrapassada pelo valor mínimo da tração efetiva, a citada formulação será complementada e ajustada incorporando esse valor, determinado em (Aranha et al., 2001), para a introdução dos efeitos da compressão dinâmica.

Formulação analítica da dinâmica risers em catenária, elaborada por (Pesce, 1997)

Seguindo a sequência que foi estabelecida, apresente-se a formulação analítica deduzida por Pesce (1997), a partir das Equações de Clebsch-Love. Para maiores detalhes, sugere-se recorrer ao texto citado ou ao trabalho original Love (1906).

Os princípios da formulação dinâmica são baseados na sua dependência com relação à geometria estática inicial ${ }^{12}$, conforme citado anteriormente e em consonância com a equação da catenária, dada pelas equações paramétricas 3.16 e 3.17. Assim:

- As citadas equações foram modificadas, a fim de se referirem ao sistema de coordenadas $u v$ da Figura 3.5, mais usual para problemas de de linhas submersas;

- Dessa feita, as forças nas direções x e $z$ foram projetadas no sistema apresentado naquela figura, de sorte que as equação passassem a ser descritas em função da tração solicitante $T(s)$, tangente à linha em cada ponto; e do esforço cortante $Q(s)$, perpendicular à tração;

- Foram introduzidas: uma parcela inercial a cada equação; e as variáveis fundamentais $\Theta(s, t)$ e $T(s, t)$, dadas pelas Equações 3.30 e 3.31, respectivamente; além da Equação 3.32 para o esforço cortante;

- A incorporação das parcelas inerciais permite o estudo dinâmico do problema plano, enquanto que a introdução das novas variáveis remete à solução por técnica de perturbação;

- As parcelas $h_{x}(s)$ e $h_{z}(s)$ referentes aos esforços hidrodinâmicos também foram projetadas no novo sistema de coordenadas, sob as mesmas hipóteses, passando a ser dadas pelas Equações 3.33 e 3.34;

\footnotetext{
${ }^{12}$ Cumpre destacar que, para a estática inicial, duas variáveis assumem importâncias destacadas: a tração efetiva, $T(s)$; e o ângulo de topo, $\theta(s)$.
} 
- Sob a hipótese de pequenas perturbações, foram feitas algumas aproximações, culminando com as Equações 3.36 e 3.37, que descrevem o problema dinâmico plano de linha em catenária.

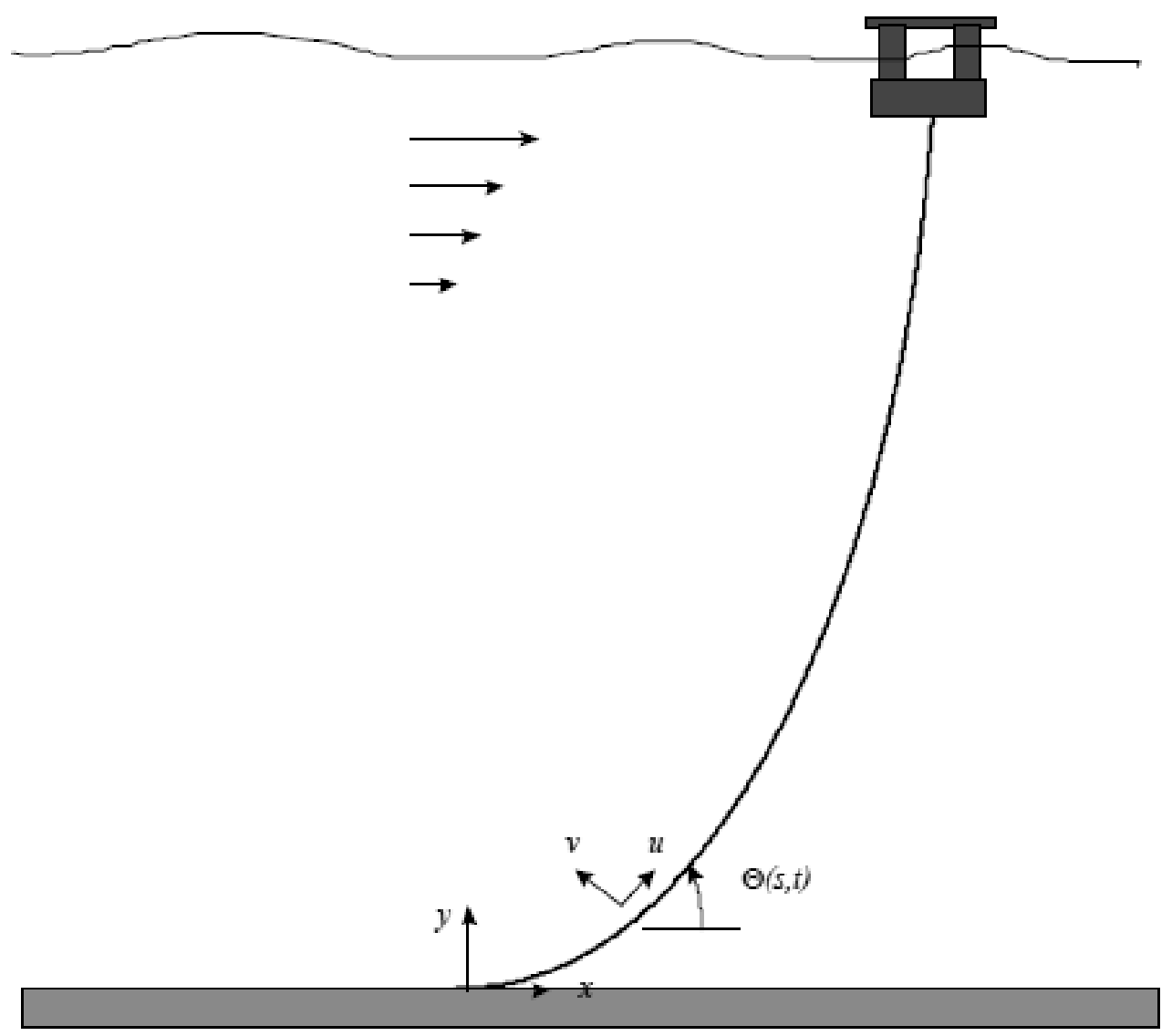

Figura 3.5: Sistemas de coordenadas envolvidos no problema dinâmico. Fonte: Extraído de (Pesce, 1997).

$$
\begin{gathered}
\Theta(s, t)=\theta(s)+\gamma(s, t) \\
T(s, t)=T(s)+\tau(s, t) \\
Q(s, t)=Q(s)+\vartheta(s, t) \\
h_{u}(s, t)=h_{u}(s)+\varpi_{u}(s, t) \\
h_{v}(s, t)=h_{v}(s)+\varpi_{v}(s, t)
\end{gathered}
$$


Nas Equações 3.30 a 3.34, as variáveis $\gamma(s, t), \tau(s, t), \vartheta(s, t), \varpi_{u}(s, t)$ e $\varpi_{v}(s, t)$ correspondem, respectivamente, às perturbações dinâmicas sobre $\theta(s), T(s), Q(s), h_{x}(s)$ e $h_{z}(s)$. A equação relativa ao equilíbrio dinâmico dos momentos foi suprimida propositalmente, por culminar apenas na conhecida relação entre momento-fletor e esforço cortante, embora seus efeitos tenham sido levados em consideração.

Em geral, no estudo da dinâmica de cilindros esbeltos imersos em água, é comum a adoção do modelo proposto por Morison ${ }^{13}$ :

$$
h=C_{m} \cdot \frac{\rho \pi D^{2}}{4} \cdot \dot{u}+\frac{1}{2} C_{D} \cdot \rho D \cdot u \cdot|u|
$$

Cumpre notar que os coeficientes $C_{m}$ e $C_{D}$ foram definidos anteriormente, na Seção 3.2 , onde esses efeitos foram incorporados, preliminarmente à sua definição formal, a fim de permitir a avaliação dos adimensionais relacionados à dinâmica de risers.

Postas essas considerações, o problema dinâmico plano é descrito pelas Equações 3.36 e 3.37, que não correspondem, ainda, às suas formas finais. A escolha por essa apresentação ficará clara logo adiante.

$$
\begin{aligned}
\left(m+m_{a}\right) \frac{\partial^{2} u}{\partial t^{2}}= & {\left[\frac{\partial T}{\partial s}-Q \frac{\partial \theta}{\partial s}-q \cdot \operatorname{sen}(\theta)+h_{u}\right]+} \\
& +\left[\frac{\partial \tau}{\partial s}-(T \gamma+\vartheta) \frac{\partial \theta}{\partial s}-\frac{\partial}{\partial s}(Q \gamma)+\varpi_{u}\right] \\
\left(m+m_{a}\right) \frac{\partial^{2} v}{\partial t^{2}}= & {\left[\frac{\partial Q}{\partial s}+T \frac{\partial \theta}{\partial s}-q \cdot \cos (\theta)+h_{v}\right]+} \\
& +\left[\frac{\partial \vartheta}{\partial s}+(\tau-Q \gamma) \frac{\partial \theta}{\partial s}+\frac{\partial}{\partial s}(T \gamma)+\varpi_{v}\right]
\end{aligned}
$$

A escolha por apresentar as Equações 3.36 e 3.37, nessas formas, foi feita com a finalidade de mostrar que essa formulação incorpora, explicitamente, a solução estática (catenária), nos termos dentro dos primeiros colchetes de cada uma dessas equações (aqueles em que aparecem os esforços hidrodinâmicos $h_{u}$ e $\left.h_{v}\right)^{14}$.

Dada essa consideração, a respeito dos termos estáticos nas Equações 3.36 e 3.37, é possível reescrever:

\footnotetext{
${ }^{13}$ Mais precisamente, o modelo de Morison apresenta forças por unidade de comprimento.

${ }^{14}$ Ressalte-se que os esforços hidrodinâmicos, no contexto da presente tese, não incorporam efeitos de ondas ou correnteza.
} 


$$
\begin{aligned}
& \left(m+m_{a}\right) \frac{\partial^{2} u}{\partial t^{2}}=\frac{\partial \tau}{\partial s}-[(T+\tau) \gamma+\vartheta] \frac{\partial \theta}{\partial s}-\frac{\partial}{\partial s}[(Q+\vartheta) \gamma]+\varpi_{u} \\
& \left(m+m_{a}\right) \frac{\partial^{2} v}{\partial t^{2}}=\frac{\partial \vartheta}{\partial s}+[\tau-(Q+\vartheta) \gamma] \frac{\partial \theta}{\partial s}+\frac{\partial}{\partial s}[(T+\tau) \gamma]+\varpi_{v}
\end{aligned}
$$

Tal como apresentadas, as Equações 3.38 e 3.39 podem ser integradas numericamente, sob as condições de contorno mais adequadas aos vínculos do problema específico que se deseja resolver ${ }^{15}$.

Formulação analítica da dinâmica risers em catenária, elaborada por (Aranha \& Pinto, 2001)

O equacionamento realizado por Aranha \& Pinto (2001) teve como ponto de partida as Equações 3.38 e 3.39, apresentadas no item precedente, considerando suas soluções assintóticas sob as seguintes premissas:

- A massa adicional na direção tangente à linha é desprezível, equivalente a considerar $m_{a}=0$ na Equação 3.38;

- Valem as aproximações $O\left(\frac{\tau}{T}\right) \ll 1$ e $O\left(\frac{\vartheta}{Q}\right) \ll 1$, citadas anteriormente, também utilizadas por Pesce (1997);

- Para o leitor que tiver interesse na solução assintótica para a tração dinâmica, sua formulação pode ser encontrada em (Aranha et al., 1993).

Em Aranha \& Pinto (2001) são tecidas diversas considerações a respeito dos efeitos de eventual presença de correnteza, da não-homogeneidade das propriedades físicas da linha, bem como da influência das variáveis associadas a esses aspectos nos parâmetros estáticos e dinâmicos associados ao problema específica em questão: a resposta dinâmica de um riser lançado em catenária, sujeito a um movimento harmônico $U(t)^{16}$ aplicado no ponto de suspensão da linha, na direção tangente ao cabo (os efeitos globais da rigidez flexional são desconsiderados).

Adicionalmente, cabe citar que as condições de contorno utilizadas no equacionamento correspondem a um cabo biapoiado, com a consideração das componentes harmônicas do movimento prescrito na extremidade superior. Como resultado, foi obtida a sequinte formulação analítica:

\footnotetext{
${ }^{15} \mathrm{Em}$ Pesce (1997), é feita uma aproximação adicional, considerando que $\frac{\tau}{T}$ e $\frac{\vartheta}{Q}$ são de pequena monta, o que, segundo o autor, impossibilita análises decorrentes do termo $\frac{\partial(\tau \gamma)}{\partial s}$ que é desprezado, e que "pode vir a reger fenômenos de instabilidade do tipo que comparecem no estudo da clássica equaçã̃o de Mathieu".

${ }^{16} \mathrm{O}$ movimento harmônico foi suposto como $U(t)=U_{0} \cdot \cos (\omega t)$.
} 


$$
\tau(s)=\frac{1}{d(\Omega)} \cdot\left\{c_{1}(s)[e(\Omega)-b(\Omega)]^{2}+2 c_{2}(s)[e(\Omega)-b(\Omega)]\right\}^{1 / 2}
$$

sob as seguintes definições:

$$
\begin{gathered}
d(\Omega)=\frac{2 \zeta_{0}}{\Omega^{2}} \\
e(\Omega)=\sqrt{[b(\Omega)]^{2}+[d(\Omega)]^{2} a^{2}} \\
b(\Omega)=\left(\frac{1-\Omega^{2}}{\Omega^{2}}\right)^{2}+\zeta_{c}^{2} \\
c_{1}(\Omega)=\left[1-\frac{L_{s}}{L_{t}} \pi^{2}\left(\frac{\omega}{\omega_{e}}\right)^{2} \cdot \frac{s}{L_{s}}\right]^{2} \\
c_{2}(\Omega)=\left[1-\left(\frac{1-\Omega^{2}}{\Omega^{2}}\right) \frac{L_{s}}{L_{t}} \pi^{2}\left(\frac{\omega}{\omega_{e}}\right)^{2} \cdot \frac{s}{L_{s}}\right]^{2}+\zeta_{c}^{2} \cdot c_{1}(s)
\end{gathered}
$$

E complementadas por ${ }^{17}$ :

$$
\begin{gathered}
a=\frac{U_{0}}{\sigma_{U}} \\
\zeta_{0}=\frac{8}{3 \pi} \cdot \frac{2 C_{D, 0}}{\pi} \cdot \frac{\rho D^{2} / 4}{m+m_{a}} \cdot \frac{T_{s}}{q L_{s}} \cdot \frac{I_{3}}{I_{2}^{2}} \cdot \frac{\sigma_{U}}{D} \\
\zeta_{c}=\frac{2 C_{D, c}}{\pi} \cdot \frac{\rho D^{2} / 4}{m+m_{a}} \cdot \frac{2 V_{c}}{\omega D} \cdot \frac{I_{c}}{I_{2}} \\
\Omega=\frac{\pi}{\Lambda}\left(\frac{\omega}{\omega_{c}}\right) \\
\omega_{c}=\frac{\pi}{L_{s}} \sqrt{\frac{T_{s}}{m+m_{a}}} \\
\omega_{e}=\frac{\pi}{L_{t}} \sqrt{\frac{E A}{m}}
\end{gathered}
$$

\footnotetext{
${ }^{17}$ Nessas definições, $L t$ corresponde ao comprimento total do riser, vide Figura 3.1. Além disso, defina-se $L_{g}$, como em (Aranha \& Pinto, 2001), como $L_{g}=\operatorname{mín}\left\{L_{t}-L_{s} ; \frac{T_{0}}{\eta q}\right\} . D$ corresponde ao diâmetro externo do riser; $\rho$ à densidade do meio; $V_{c}$ à intensidade da correnteza, relacionada ao perfil pela curvatura ao longo so comprimento suspenso; e $\sigma_{U}$ é o valor eficaz, ou quadrático médio ou rms, de $U_{0}$. Nota: rms é a sigla, em inglês, para root mean square.
} 
Cumpre notar que as grandezas $\omega_{c}$ e $\omega_{e}$ já haviam sido definidas, indiretamente, pelas Equações A.17 e A.18, bastando, para recuperar essas equações, considerar o primeiro modo de vibração e a posição ao longo da linha (o topo, neste caso). Essas duas definições encerram as escalas de tempo associadas ao problema.

Dessa feita, a frequência reduzida $\Omega$, definida pela Equação 3.43, é um parâmetro adimensional, dado que $\frac{\omega}{\omega_{c}}$ é adimensional e $\Lambda$ é razão entre as forças restauradoras responsáveis pelo mecanismo de reação do cabo qualquer deslocamento imposto, sendo dada por ${ }^{18}$ :

$$
\Lambda=\frac{q L_{s}}{T_{s}} \cdot \sqrt{I_{2}} \cdot \sqrt{\frac{E A}{T_{s}}} \cdot \sqrt{\frac{L_{s}}{L_{t}}}
$$

A fim de complementar as equações apresentadas, resta a introdução de alguns parâmetros, apresentados a seguir nas Equações 3.47 a 3.49 para, por fim, finalizar o presente tópico com a adaptação da Equação 3.40 para as condições dos ensaios realizados nesta tese (desconsideração dos efeitos de correnteza, além da hipótese de homeogeneidade e isotropia dos parâmetros e dinâmicos e propriedades do modelo). Defininam-se, então, as integrais:

$$
I_{n}=\frac{1}{L_{s}} \cdot \int_{0}^{L_{s}}\left|\chi_{1}(s)\right|^{n} d s
$$

onde $n=2,3$.

$$
I_{c}=\frac{1}{L_{s}} \cdot \int_{0}^{L_{s}}\left|\chi_{c} \cdot[z(s)] \cdot \operatorname{sen}[\theta(s)]\right| \cdot \chi_{1}^{2}(s) d s
$$

Ademais, a curvatura do cabo é definida por:

$$
\frac{d}{d s} \theta(s)=\frac{q}{T(s)} \cdot \chi_{1}(s)
$$

Com respeito às hipóteses consideradas para os objetivos do presente trabalho, cumpre citar:

- A homeogeneidade e isotropia dos parâmetros e dinâmicos e propriedades do modelo implicam em $C_{D, 0}=C_{D}$, correspondente ao coeficiente de arrasto;

- Ainda por essas suposições, torna-se desnecessária a apresentação dos parâmetros dinâmicos médios introduzidos em (Aranha \& Pinto, 2001);

\footnotetext{
${ }^{18}$ Esse parâmetro adimensional foi definido por Irvine \& Caughey (1974) e os mecanismos reativos citados se referem (i) à distenção do cabo, relacionada à rigidez axial; e (ii) ao ajustamento da configuração geométrica do cabo (rigidez geométrica).
} 
- Dado que os ensaios realizados para obtenção dos resultados desta tese ocorreram sem correnteza, segue que $\zeta_{c}=0$, dado que $C_{D, c}=0$; além disso, o parâmetro $I_{c}$, segundo (Aranha \& Pinto, 2001), só deve ser utilizado quando o riser estiver sujeito a fortes correntezas oceânicas.

Essas considerações impactam diretamente na formulação apresentada, no que tange às observações pontuadas e as definições de $b(\Omega), e(\Omega)$ e de $c_{2}$; e, portanto, da forma de calcular a amplitude da tração dinâmica $\tau(s)$ definida pela Equação 3.40.

Determinada a amplitude da tração dinâmica, em função da coordenada curvilínea $s$ é necessário incorporar o caráter harmônico da resposta em tração, frente à imposição de um movimento desse tipo. Assim:

$$
\begin{gathered}
\widehat{T}_{D}(s, t)=T_{D}(s) \cdot e^{-i \omega t} \\
\tau_{D}(s)=\frac{T_{D}(s)}{T_{E}}=\tau(s) \cdot e^{-i \phi(\omega ; s)}
\end{gathered}
$$

onde $T_{E}=\frac{E A}{L_{t}} \cdot \sigma_{U}$ é denominada tração elástica.

\section{Sobre as equações resolvidas pelo programa Anflex}

O presente tópico não tem a pretensão de explicitar todas as equações implementadas no programa Anflex, apenas apresentar alguns aspectos básicos gerais que são utilizados por diversos outros programas similares.

Tanto o estabelecimento da estática da linha (a partir de um método iterativo), quanto a resolução do problema dinâmico pelo Métodos dos Elementos Finitos (utilizado pelo Anflex) exigem a discretização da linha em $N$ elementos. Assim, o problema é resolvido de maneira discreta, com cada elemento sendo capaz de realizar movimentos de translação e rotação, cada qual em/ao redor de três direções ( $6 \mathrm{~N}$ graus de liberdade). De maneira geral e simplificada, o programa resolve a Equação 3.52 para cada um desses graus de liberdade, com o problema descrito e resolvido de forma matricial.

$$
\mathbf{M} \cdot \ddot{x}(t)+\mathbf{C} \cdot \dot{x}(t)+\mathbf{K} \cdot x(t)=\mathbf{f}(t)
$$

onde $\mathbf{M}$ é a matriz de inércia dos elementos que compõem a linha, considerando as inércias adicionadas, $\mathbf{C}$ é a matriz de amortecimento, $\mathbf{K}$ é a matriz de rigidez (relacionada à restauração) e $\mathbf{f}(t)$ é matriz das resultantes das forças externas, que incorpora os carregamentos e esforços ambientais. $x(t)$ é vetor de deslocamentos de cada elemento. Por concisão, foram suprimidos os índices subscritos relativos aos graus de liberdade dos elementos discretos da linha.

Dado o caráter experimental do presente trabalho, as formulações e discussões apresentadas são mais que suficientes para o uso que delas será feito. 


\subsubsection{O papel físico dos adimensionais na dinâmica de risers em catenária}

O objetivo deste item é recuperar o resultado da análise dimensional feita para a dinâmica de risers, a partir do Teorema de Pi-Buckingham, a fim de avaliar a importância dos parâmetros adimensionais apresentados e definidos na Equação 3.29. A avaliação será feita tendo como base os resultados analíticos desenvolvidos em (Aranha \& Pinto, 2001). Outros trabalhos poderão ser, eventualmente, citados.

$$
\Pi_{d}=\frac{T_{d}(s, t)}{T_{0}}=\Psi_{2}\left(\Pi_{H}, \Pi_{A}, \Pi_{L}, \Pi_{\lambda}, \epsilon_{0}, \Pi_{\theta}, \Pi_{T}, \Pi_{K}, \Pi_{c_{0}}, \Pi_{a t}, C_{m}, C_{d}, \Pi_{s}, \Pi_{t}\right)
$$

A importância relativa dos adimensionais será avaliada, parâmetro a parâmetro da referida equação, de maneira a avaliar sua função em cada termo para, posteriormente, findar a avaliação em busca de uma associação global entre os coeficientes adimensionais e o comportamento dinâmico do riser.

Neste ponto, cabe uma nota importante: a formulação de Aranha \& Pinto (2001) utilizou a Teoria de Cabos para determinar o equacionamento para a tração dinâmica. Nese sentido, quando necessário, serão recuperados trechos da formulação de Pesce (1997), de maneira a evidenciar o papel de determinados adimensionais.

Além disso, na equação para $\Pi_{d}$, aqui recuperada, é possível perceber a introdução de dois novos parâmetros adimensionais, inexistentes na Equação 3.29 original, $\Pi_{A}=\frac{A_{m}}{L_{s}}$ e $\Pi_{L}=\frac{L^{\prime}}{L_{s}}=\frac{\Pi_{a t}}{\eta \Pi_{\theta}}$, esse último escrito como função de outros adimensinais.

A formulação analítica para a tração dinâmica proposta por Aranha \& Pinto (2001) pode ser resumida pelas Equações 3.40 , para a amplitude da tração dinâmica ao longo da coordenada curvilínea $s ; 3.50$, que incorpora o caráter oscilatório da resposta dinâmica; e 3.51 que modula ajusta a amplitude $\tau(s)$ pela tração elástica definida anteriormente, sob as definições que as acompanham.

Percebe-se, então, das definições da tração elástica e das equações citadas, a relação de proporcionalidade direta entre a amplitude $A_{m}$ do movimento imposto e a magnitude da resposta em tração. Assim, usando os adimensionais $\Pi_{A}$ e $\Pi_{L}$ :

$$
\widehat{T}_{D}(s, t)=\frac{E A}{a} \cdot\left(\frac{\Pi_{A}}{1+\Pi_{L}}\right) \cdot \tau(s) \cdot e^{-i(\omega t+\phi)}
$$

Ademais, o fator $1+\Pi_{L}>1$ corresponde a um termo de redução da amplitude de resposta, visto que, por definição, $\Pi_{L}>0$.

Nos casos em que o riser não estiver ancorado, é possível que o trecho repousado no solo, $L_{g}$, devido ao seu peso próprio imerso e ao coeficiente de atrito entre a linha e o solo, seja suficiente para equilibrar a tração horizontal no TDP. 
Nessa situação, é possível explicitar outra relação para a resposta dinâmica em tração, obtida a partir da Equação 3.54 e da definição dos coeficientes adimensionais obtidos para o problema em questão. Assim:

$$
\widehat{T}_{D}(s, t)=\frac{E A}{a} \cdot\left(\frac{\eta \cdot \Pi_{A} \cdot \Pi_{\theta}}{\Pi_{a t}+\eta \Pi_{\theta}}\right) \cdot \tau(s) \cdot e^{-i(\omega t+\phi)}
$$

Nesses casos, a curvatura no TDP, bem como o citado coeficiente de atrito estático, são diretamente proporcionais a $\Pi_{d}$ e, consequentemente, à tração efetiva ao longo do comprimento suspenso e do tempo.

A frequência reduzida $\Omega$, definida pela Equação 3.43, é uma das variáveis que mais aparece na formulação para a tração dinâmica, o que torna mais complexa a avaliação do seu efeito sobre a resposta dinâmica do riser - vide a dependência de $b(\Omega), c_{2}(s)$, $d(\Omega)$ e $(\Omega)$ com relação a esse parâmetro.

É possível reescrever a expressão para a frequência reduzida, com base nos adimensionais definidos anteriormente:

$$
\Omega=\frac{\Pi_{c_{o}} \cdot\left(1+\Pi_{L}\right)}{\Lambda}=\frac{\Pi_{c_{o}} \cdot \sqrt{\left(1+\Pi_{L}\right)}}{\Pi_{\theta} \cdot \sqrt{I_{2}} \cdot \sqrt{\epsilon_{0}}}
$$

Mesmo diante dessa complexa relação entre $\Omega$ e $\widehat{T}_{D}(s, t)$, é possível deduzir alguns resultados interessantes, a partir dos valores limítrofes da frequência reduzida.

Por exemplo, nos casos em que $\Omega \gg 1$, com $\frac{\omega}{\omega_{e}} \ll 1$, segue que $\tau(s) \rightarrow a$. Tal conclusão é facilmente comprovada, a partir do fato de que, para essa situação particular, $b(\Omega) \rightarrow 0, c_{1}=c_{2}=1$ e $e(\Omega) \rightarrow a$. Substituindo essas relações na Equação 3.40, fica evidente que $\left|\widehat{T}_{D}(s, t)\right| \rightarrow a \cdot T_{E}$.

Na prática, essa situação corresponde a cabos com altas relações entre as projeções horizontal e vertical, sob excitações de baixa frequência, de sorte que os efeitos da rigidez axial prevaleçam sobre a rigidez geométrica. Economicamente, esse caso é pouco provável, embora facilmente verificável em experimentos. Nesse sentido, recomenda-se uma investigação pormenorizada dos resultados de (Simos \& Fujarra, 2006). No limite, um cabo horizontal retesado é capaz de reproduzir esse resultado com bastante fidelidade. Essas deduções são facilmente depreendidas da 3.56, desde que o leitor entenda os efeitos físicos relacionados aos adimensionais envolvidos.

O mesmo resultado para a amplitude da tração dinâmica, $\left|\widehat{T}_{D}(s, t)\right| \rightarrow a \cdot T_{E}$, pode ser recuperado nas situações em que $\frac{\sigma_{U}}{D} \gg 1$, o que implica em $\zeta_{0} \gg 1$. Essa relação é diretamente apresentada na Equação 3.41 e corresponde a casos em que a amplitude de excitação no topo é muito maior que o diâmetro externo da linha, ou seja, $\frac{A_{m}}{D} \gg 1$. Nos ensaios realizados para os objetivos desta tese, $3,4 \lesssim \frac{A_{m}}{D} \lesssim 13,9$. 
Nas situações descritas, a tração dinâmica pode ser considerada constante ao longo da linha. Cumpre notar, adicionalmente, que o parâmetro $\zeta_{0}$ encerra, explicitamente, uma dependência linear com o coeficiente de arrasto $C_{D}$, bem como uma relação ímplicita com o coeficiente de inércia de Morison, $C_{m}$.

Outro adimensional recorrente na formulação da amplitude da tração dinâmica é $\Pi_{s}$, pelo fato de exprimir a posição ao longo do comprimento suspenso do riser. O mesmo poderia ser, facilmente, feito com relação a $\Pi_{t}$, por exemplo. Para os objetivos do presente trabalho, é essencial o conhecimento da série de tração dinâmica no TDP, o que corresponde à nulidade de $\Pi_{s}$ e consequente unidade dos valores de $c_{1} \mathbf{e} c_{2}$. Postas essas considerações, a análise dimensional permitiu a elucidação de diversos termos da formulação para a tração dinâmica. Considerando o trabalho de Aranha \& Pinto (2001) como um todo, apenas alguns dos adimensionais relacionados com a dinâmica de risers não foram explicitados no equacionamento considerado:

- $\Pi_{H}$, dada a suposição de que o movimento imposto é prescrito na linha d'água;

- $\Pi_{\lambda}$, pela aproximação do riser pela "Teoria de Cabos", o que desconsidera os efeitos da rigidez flexional; e

- $\Pi_{K}$, visto que a interação com o solo não foi considerada, no sentido da incorporação de efeitos relacionados à sua rigidez.

O Capítulo 2 apresentou diversos trabalhos em que tais efeitos são considerados, dentre os quais é possível citar: (Aranha et al., 1993), (Aranha et al., 1997), (Pesce et al., 1998b), (Pesce et al., 2006), dentre outros. 


\subsection{Compressão Dinâmica em Risers}

A presente seção apresentará o problema da compressão dinâmica de risers em catenária, a partir da mesma estrutura das seções precedentes, iniciando com a apresentação dos adimensionais que regem o problema, seguida pela apresentação das formulações analíticas para, por fim, discutir a relação entre ambas as abordagens.

\subsubsection{Adimensionais que regem a compressão dinâmica de risers em catenária}

Inicialmente, é possível proceder à adimensionalização da carga crítica de Euler, na forma apresentada na Equação A.15, pela tração horizontal.

$$
\frac{P_{E}}{T_{0}}=\frac{\sqrt{\left(m+m_{a}\right) \cdot E I}}{T_{0}} \cdot \omega=\frac{\lambda_{f} \cdot \omega}{c_{0}}=\Pi_{c_{0}}
$$

Cumpre notar que a relação estabelecida aponta para o significado físico do adimensional $\Pi_{c_{0}}$, que representa a relação entre os efeitos das rijezas flexional e geométrica, a partir dos seus respectivos comprimentos de onda.

Em (Aranha et al., 2001), a dedução da carga crítica para vigas curvas (no caso, um riser em catenária), é feita a partir da formulação para vigas retas, considerando a curvatura no TDP como condição de contorno. Assim, as variáveis escolhidas para a avaliação da carga crítica de flambagem de vigas são $\mu=m+m_{a}$, dado o caráter dinâmico do problema; $T=\frac{2 \pi}{\omega}$ e $A_{m}$, relativas aos parâmetros de excitação; além de $q$ e $T_{0}$, a fim de incorporar a curvatura da catenária no TDP. Assim:

$$
P_{c r}=\Psi_{3}\left(q, T_{0}, E A, E I, A_{m}, T, \mu\right)
$$

De maneira que a aplicação do Teorema de Pi-Buckingham leva a:

$$
\frac{P_{c r}}{T_{0}}=\Psi_{3}\left(T \cdot \sqrt{\frac{T_{0}}{m+m_{a}}} \cdot \sqrt{\frac{T_{0}}{E I}}, A_{m} \cdot \sqrt{\frac{T_{0}}{E I}}, \frac{q}{T_{0}} \cdot \sqrt{\frac{E I}{T_{0}}}, \frac{E A}{T_{0}}\right)
$$

Utilizando os adimensionais definidos anteriormente e estabelecendo, a partir do resultado anterior, $\Pi_{A_{m}}=\frac{A_{m}}{\lambda_{f}}=\frac{\Pi_{A}}{\Pi_{\lambda}}$, é possível reescrever a Equação 3.58. Assim :

$$
\Pi_{c d}=\frac{P_{c r}}{T_{0}}=\Psi_{3}\left(\Pi_{c_{0}}, \Pi_{A}, \Pi_{\lambda}, \epsilon_{0}\right)
$$

Por enquanto, o estabelecimento dos coeficientes adimensionais é suficiente para os propósitos da presente seção. Essa formulação será retomada adiante, no Item 3.3.3. 


\subsubsection{Carga crítica de flambagem para risers em catenária}

A formulação analítica para a carga crítica em barras curvas, a partir da equação para as deflexões de vigas retas deduzida inicialmente por Leonhard Euler, foi desenvolvida, de maneira engenhosa, por Aranha et al. (2001).

Na sequência, os principais resultados daquele trabalho serão apresentados rapidamente e sem detalhes, dado que o objetivo do presente tópico é propiciar ao leitor novos indícios físicos, a partir da continuação do desenvolvimento matemático promovido em (Aranha et al., 2001).

Em (Aranha et al., 2001), os argumentos iniciais para a determinação da carga crítica de flambagem em risers em catenária são simples e diretos: a partir da equação da viga reta (Equação A.1) e sua respectiva carga crítica (Equação A.13), o objetivo era determinar uma solução analítica para a carga crítica em vigas curvas. $O$ uso desse elemento estruturante é capaz de incorporar os efeitos da rigidez flexional no TDP; caso contrário, o uso da teoria de cabos, por exemplo, indicaria que a carga crítica deveria ser nula, dada a impossibilidade de cabos suportarem qualquer nível de compressão axial.

Ressalte-se que toda a formulação desenvolvida e apresentada em (Aranha et al., 2001) pressupõe que o riser pode ser modelado por uma viga biapoiada. Quanto à compressão dinâmica, foi feita uma hipótese ad hoc, fisicamente coerente: no caso de vigas curvas, a onda de flexão deve assumir, naturalmente, um formato compatível com o número de onda $k$, dado pela relação de dispersão:

$$
k^{2}=\sqrt{\frac{m+m_{a}}{E I}} \cdot \omega
$$

Essa relação de dispersão foi deduzida e discutida, implicitamente, a partir da Equação A.20, para a velocidade das ondas em vigas-coluna, associadas à rigidez flexional. A partir daí, uma sucessão de formulações é apresentada e desenvolvida, até culminar com a seguinte equação transcendental:

$$
\tan (\alpha)=\alpha+\frac{\alpha^{3}}{3}-\frac{\alpha^{5}}{\gamma^{2}(\chi)}
$$

Nessa formulação, o parâmetro $\gamma(\chi)$ é adimensional e dependente linearmente da curvatura $\chi=\chi_{0}=\frac{q}{T_{0}}$ no TDP, de sorte que:

$$
\gamma(\chi)=\left(\frac{\pi}{2}\right)^{2} \cdot \chi_{0} \cdot \sqrt{\frac{E A}{k^{4} \cdot E I}}=\left(\frac{\pi}{2}\right)^{2} \cdot \chi_{0} \cdot \sqrt{\frac{E A}{m+m_{a}}} \cdot \frac{1}{\omega}
$$


Essa equação é bastante simples e sua importância reside no fato de que, como demonstrado em (Aranha et al., 2001), a carga crítica $P_{c r}$ para vigas curvas, a partir das Equações A.15 e 3.60, é dada por:

$$
P_{c r}(\chi)=\beta_{c r}^{2}(\chi) \cdot \sqrt{\left(m+m_{a}\right) \cdot E I} \cdot \omega=\beta_{c r}^{2}(\chi) \cdot P_{E}
$$

Com relação à Equação 3.61, Aranha et al. (2001) afirma, em tradução livre, que:

"Observando que $\tan (\alpha)=\alpha+\frac{\alpha^{3}}{3}+\frac{2 \alpha^{5}}{15}$, para $\alpha \ll 1$, é fácil checar que $\tan (\alpha)>\alpha+\frac{\alpha^{3}}{3}-\frac{\alpha^{5}}{\gamma^{2}(\chi)}$ quando $0 \leq \alpha<\frac{\pi}{2}(0 \leq \beta<1)$; assim, a menor raiz da equação transcendental está no intervalo $\frac{\pi}{2} \leq \alpha<\frac{3 \pi}{2}(1 \leq \beta<3)$. No limite em que a curvatura $\chi$ tende a zero (e, portanto, $\gamma(\chi) \rightarrow 0$, o que representa uma viga reta), o lado direito da equação transcendental tende a $-\infty$, o que ocorre para $\beta_{c r}(0)=1$ (ou $\alpha=\frac{\pi}{2}$ ); nesse limite, a carga crítica de Euler é recuperada prontamente. A raiz $\alpha$ da equação transcendental cresce monotonicamente com $\chi$, é igual a $\pi\left(\beta_{c r}=2\right)$ quando $\frac{\gamma}{\pi}=1,517$ e tende ao valor $\frac{3 \pi}{2}(1-0,0055)$ no limite em que $\chi \rightarrow \infty\left(\beta_{c r}(\infty)=2,984\right)$."

Decerto, essas assertivas são corretas e consonantes com experimentos e simulações constantes em (Aranha et al., 2001). Entretanto, pretende-se conferir mais formalidade a essas observações, com o uso de Cálculo Diferencial, principalmente. Ressalte-se, entretanto, que essa opção não pode ser confundida como uma maneira alternativa de se chegar aos mesmos resultados, o que será adiante, no próximo tópico.

Postas as considerações a respeito da Equação 3.61, é imediata a verificação de que o fator $\beta_{c r}(\chi)$ amplifica o valor da carga crítica proposta por Euler, dado que fisicamente o menor valor desse parâmetro é a unidade. Essa asserção será explorada na sequência do texto.

$\mathrm{Na}$ Equação 3.63, por hipótese, $\alpha=\frac{\pi}{2} \cdot \beta_{c r}(\chi)$. Assim, a determinação da menor raiz da Equação 3.61 é condição necessária e suficiente para determinação da carga crítica de flambagem de vigas curvas, a partir da substituição de $\beta_{c r}^{2}(\chi)$ na Equação 3.63.

Postas estas considerações, a determinação analítica da carga de compressão $P_{c r}$, a partir dessa formulação, passa pela resolução da Equação (transcendental) 3.61.

Cabe salientar que, de acordo com Aranha et al. (2001), o objetivo é obter a menor raiz não nula dessa equação ${ }^{19}$, referente ao primeiro modo de flexão da viga.

Equações transcendentais não possuem solução analítica fechada, de modo que, em geral, empregam-se métodos gráficos e/ou numéricos para sua resolução.

Assim, dada uma equação transcendental $f(x)=0$, deseja-se obter numericamente, com precisão $\delta$ pré-determinada, os valores $x_{i}$ para os quais $f\left(x_{i}\right)= \pm \delta$, com $\delta \ll 1$.

\footnotetext{
${ }^{19}$ Obviamente, a solução trivial dessa equação não possui interesse físico relevante.
} 
O primeiro passo para o cálculo dessas raízes é a determinação de um intervalo $[a, b]$, que contenha uma única raiz. Posteriormente, é possível estreitar esse intervalo de modo a facilitar a convergência dos métodos numéricos a serem empregados (em geral, o Método de Newton-Raphson é eficiente). A principal dificuldade para a utilização desses métodos é o estabelecimento do intervalo apropriado que: (i) contenha uma única raiz e (ii) garanta a convergência numérica da solução.

É mister destacar que o objetivo da presente tese não está associado, diretamente, à determinação da carga crítica de flambagem, mas do comprimento das ondas de flexão geradas quando da ocorrência de compressão dinâmica. Assim, recupere-se de (Aranha et al., 2001) a relação entre $\beta_{c r}^{2}$ e o número de onda $k_{c r}$ associado (vide Equação 3.60):

$$
k_{c r}^{2}=\beta_{c r}^{2} \cdot \sqrt{\frac{m+m_{a}}{E I}} \cdot \omega
$$

Dessa feita, a resolução do problema passa pela determinação do número de onda $k$, considerado uma variável de suma importância para o comportamento das ondas de flexão geradas a partir da compressão dinâmica e, por conseguinte, para validar as hipóteses inerentes à presente tese.

\section{Aspectos particulares da carga crítica de vigas curvas formulada por Aranha et al. (2001)}

No trecho de (Aranha et al., 2001) cidado anteriormente, ipsis litteris, é utilizada uma aproximação de ordem 5 para a função tangente, utilizando Séries de Taylor, sob a argumentação de que isso é possível para $\alpha \ll 1$ (ou ainda, no entorno da origem). Os chamados polinômios de Taylor permite que essa aproximação utilizada ao redor de qualquer ponto do domínio válido.

Formalmente, para o caso em questão, essa aproximação é tanto melhor, quanto mais próximo $\alpha$ for de zero. Entretanto, o resultado é estendido para todo o intervalo $0 \leq$ $\alpha<\frac{\pi}{2}$, sem maiores considerações. A ausência de um estudo mais detalhado da equação transcendental, deixa a afirmação carente de fundamentação matemática.

A seguir, é feita a asserção categórica de que a menor raiz da Equação 3.61 encontrase no intervalo correspondente ao segundo e terceiro quadrantes do círculo trigonométrico. Novamente, a proposição é correta, mas nenhuma argumentação formal foi feita em favor do que é afirmado.

Quanto ao comportamento da raiz $\alpha$ nesse intervalo, cabe uma checagem das asserções feitas, sem adiantar nenhum resultado.

Para formalizar todas essas questões, seja $F(\alpha)$ definida por:

$$
F(\alpha)=\tan (\alpha)-\alpha-\frac{\alpha^{3}}{3}+\frac{\alpha^{5}}{\gamma^{2}(\chi)}
$$


Ora, uma raiz da Equação 3.61 é, obrigatoriamente, raiz da Equação 3.65. O primeiro passo, então, é avaliar o comportamento dessa última função, buscando isolar adequadamento um intervalo que contenha, pelo menos, uma raiz de $F(\alpha)$.

Para tanto, note-se que, embora não seja útil para o problema proposto, por se tratar da solução trivial, $\alpha=0$ é uma raiz da Equação 3.65.

Segundo o Teorema de Cauchy-Bolzano, uma função $f$, contínua em um intervalo fechado $[a, b]$, possui pelo menos uma raiz se $f(a) \cdot f(b)<0$, em $[a, b]$.

Em outras palavras, se uma função contínua troca de sinal em um dado intervalo fechado, certamente deve apresentar valor nulo, nesse intervalo, ao menos uma vez. Com exceção dos pontos em que a função tangente não é definida $\left(\alpha=\frac{\pi}{2} \pm n \cdot \pi\right.$, com $n$ inteiro), $F(\alpha)$ é contínua.

Ressalte-se que o caso em que $\gamma(\chi) \rightarrow 0$ representa uma viga reta (Equação 3.62) e, portanto, não interessa aos objetivos da presente discussão. Além disso, a própria Equação 3.61 exige que $\gamma(\chi) \neq 0$.

Considerando o intervalo $\left[-\frac{\pi}{2}+\delta, \frac{\pi}{2}-\delta\right]$, com $\delta \ll 1$, note-se que, como $\gamma^{2}(\chi)>0$ :

$$
\begin{aligned}
& \text { - } F\left(-\frac{\pi}{2}+\delta\right)=\tan \left(-\frac{\pi}{2}+\delta\right)-\left(-\frac{\pi}{2}+\delta\right)-\frac{\left(-\frac{\pi}{2}+\delta\right)^{3}}{3}+\frac{\left(-\frac{\pi}{2}+\delta\right)^{5}}{\gamma^{2}(\chi)} ; \\
& \text { - } \lim _{\delta \rightarrow 0}\left[F\left(-\frac{\pi}{2}+\delta\right)\right]=-\infty ; \\
& \text { - } F\left(\frac{\pi}{2}-\delta\right)=\tan \left(\frac{\pi}{2}-\delta\right)-\left(\frac{\pi}{2}-\delta\right)-\frac{\left(\frac{\pi}{2}-\delta\right)^{3}}{3}+\frac{\left(\frac{\pi}{2}-\delta\right)^{5}}{\gamma^{2}(\chi)} \\
& \text { - } \lim _{\delta \rightarrow 0}\left[F\left(\frac{\pi}{2}-\delta\right)\right]=+\infty
\end{aligned}
$$

Conforme mencionado anteriormente, $\alpha=0$ é raiz. O Teorema de Cauchy-Bolzano, todavia, não garante a unicidade dessa raiz no intervalo $\left[-\frac{\pi}{2}+\delta, \frac{\pi}{2}-\delta\right]$, para valores de $\delta$ arbitrariamente diminutos.

É necessário, então, conhecer melhor o comportamento de $F(\alpha)$. Sejam a primeira e a segunda derivadas de $F(\alpha)$ dadas, respectivamente, pelas Equações 3.66 e 3.67.

$$
\begin{gathered}
F^{\prime}(\alpha)=\tan ^{2}(\alpha)-\alpha^{2}+\frac{5 \cdot \alpha^{4}}{\gamma^{2}(\chi)} \\
F^{\prime \prime}(\alpha)=2 \cdot \tan (\alpha) \cdot\left[\tan ^{2}(\alpha)+1\right]-2 \cdot \alpha+\frac{20 \cdot \alpha^{3}}{\gamma^{2}(\chi)}
\end{gathered}
$$

A partir da Equação 3.66, é fácil verificar que $F^{\prime}(0)=0$, de sorte que, além de raiz, $\alpha=0$ também é um ponto crítico de $F(\alpha)$. Por outro lado, pela Equação 3.67, constatase que $F^{\prime \prime}(0)=0$, de maneira que nada se pode afirmar, a priori, sobre o tipo de ponto crítico representado por $\alpha=0$. 
Entretanto, um importante teorema do Cálculo Diferencial afirma que: se $n$ é impar e $f^{(n)}\left(x^{*}\right) \neq 0, \operatorname{com} x^{*}$ representando um ponto crítico de $f(x)$, e as sucessivas derivadas $f^{(2)}\left(x^{*}\right)=f^{(3)}\left(x^{*}\right)=\ldots=f^{(n-1)}\left(x^{*}\right)=0$, então $x=x^{*}$ é um ponto de inflexão.

Observe-se que $F^{(2)}(0)=F^{(3)}(0)=F^{(4)}(0)=0$, mas $F^{(5)}(0)=16+\frac{120}{\gamma^{2}(\chi)} \neq 0 \mathrm{e}$, portanto, $\alpha=0$ é ponto de inflexão.

Considere-se, por hipótese, que $\alpha$ pertença ao intervalo $\left[0, \frac{\pi}{2}\right]$. Por construção geométrica, $\tan (\alpha)>\alpha$. Rearranjando as Equações 3.66 e 3.67, obtêm-se:

$$
\begin{gathered}
F^{\prime}(\alpha)=[\tan (\alpha)-\alpha] \cdot[\tan (\alpha)+\alpha]+\frac{5 \cdot \alpha^{4}}{\gamma^{2}(\chi)} \\
F^{\prime \prime}(\alpha)=2 \cdot \tan ^{3}(\alpha)+2 \cdot[\tan (\alpha)-\alpha]+\frac{20 \cdot \alpha^{3}}{\gamma^{2}(\chi)}
\end{gathered}
$$

Como resultado direto, as Equações 3.68 e 3.69, mostram que, para o intervalo considerado, $F^{\prime}(\alpha)>0$ e $F^{\prime \prime}(\alpha)>0$, de maneira que a função $F(\alpha)$ é crescente em todo o intervalo, possuindo concavidade voltada para cima.

Isso prova, de maneira irrefutável, a ausência de raízes em $\left(0, \frac{\pi}{2}\right]$. A busca por raízes de interesse passa a recair sobre o intervalo $\left[\frac{\pi}{2}, \frac{3 \pi}{2}\right]$, cujas extremidades são descontinuidades da função tangente.

A existência de raízes no intervalo considerado depende do valor de $\gamma^{2}(\chi)$.

Assim, por exemplo, para $\gamma=1, F(\alpha \approx 1,672)=0$; para $\gamma=4, F(\alpha \approx 2,775)=0$; para $\gamma=5, F(\alpha \approx 3,257)=0$; e para $\gamma=30, F(\alpha \approx 4,685)=0$.

Para os valores de $\gamma$ utilizados, as raízes de $F(\alpha)$ pertencem ao intervalo em questão. Obviamente, para valores em $\left[\frac{\pi}{2}, \frac{3 \pi}{2}\right]$ que não estejam nas proximidades de $\alpha=\pi, a$ priori nada pode ser concluído algebricamente com relação às raízes de $F(\alpha)$.

A resolução da equação transcendental passa a depender de métodos numéricos. Como citado anteriormente, existem diversos métodos para calcular a raiz desejada, dada uma precisão pré-determinada.

Entretanto, optar-se-á pelo estabelecimento de um método alternativo que não dependa da solução da numérica da Equação 3.61, promovendo uma nova forma de solucionar o problema e que se configura como um avanço com relação à formulação proposta por Aranha et al. (2001), no que tange à facilidade de resolução da mesma. A determinação da carga crítica tornar-se-á meramente algébrica. No contexto da presente tese, embora meritória, essa contribuição é marginal.

A fim de sustentar essa escolha, avalie-se geometricamente o comportamento da equação transcendental ou, alternativamente, de $F(\alpha)$. 
Inicialmente, ilustrem-se as Figuras 3.6 e 3.7, equivalentes, embora apresentadas de maneiras distintas.

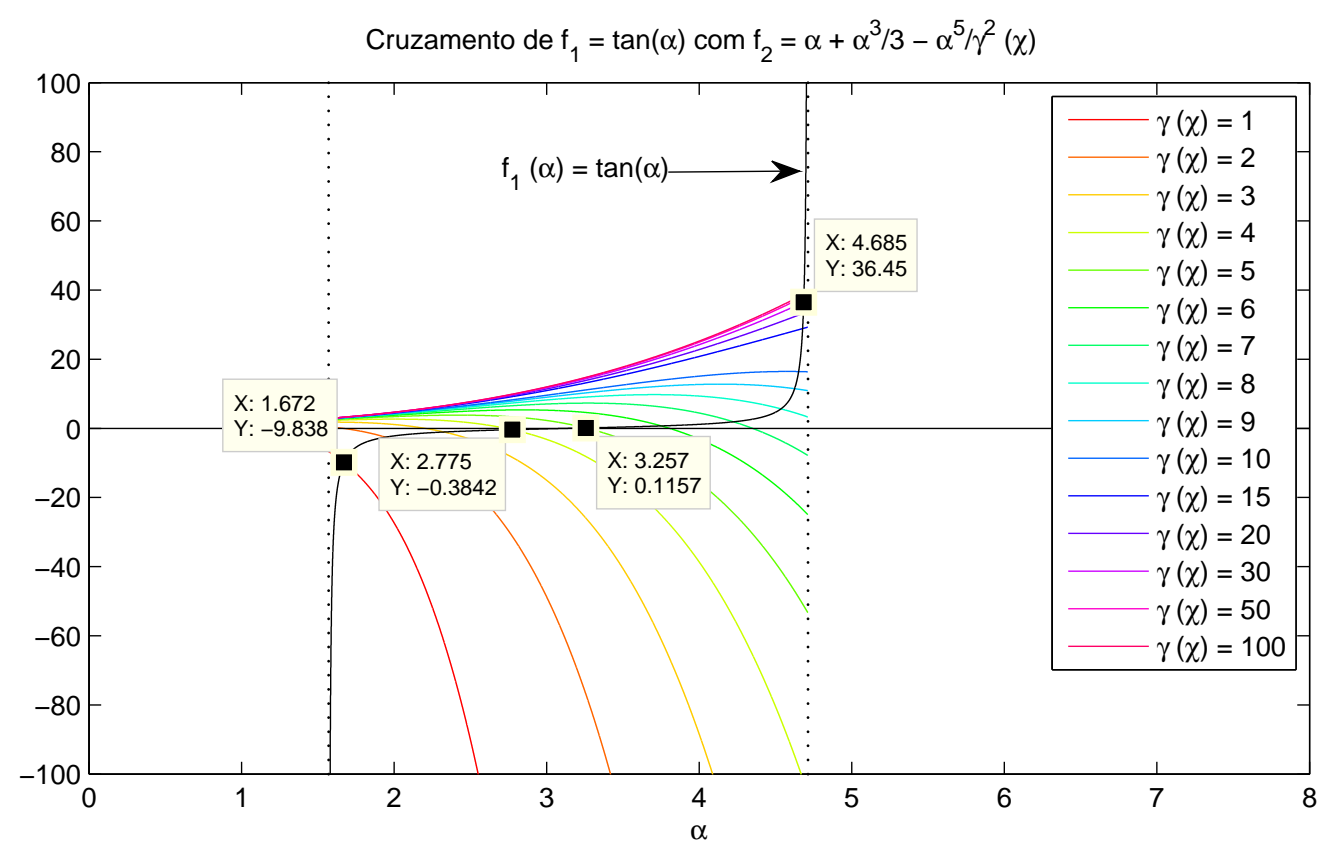

Figura 3.6: Resolução gráfica da equação transcendental.

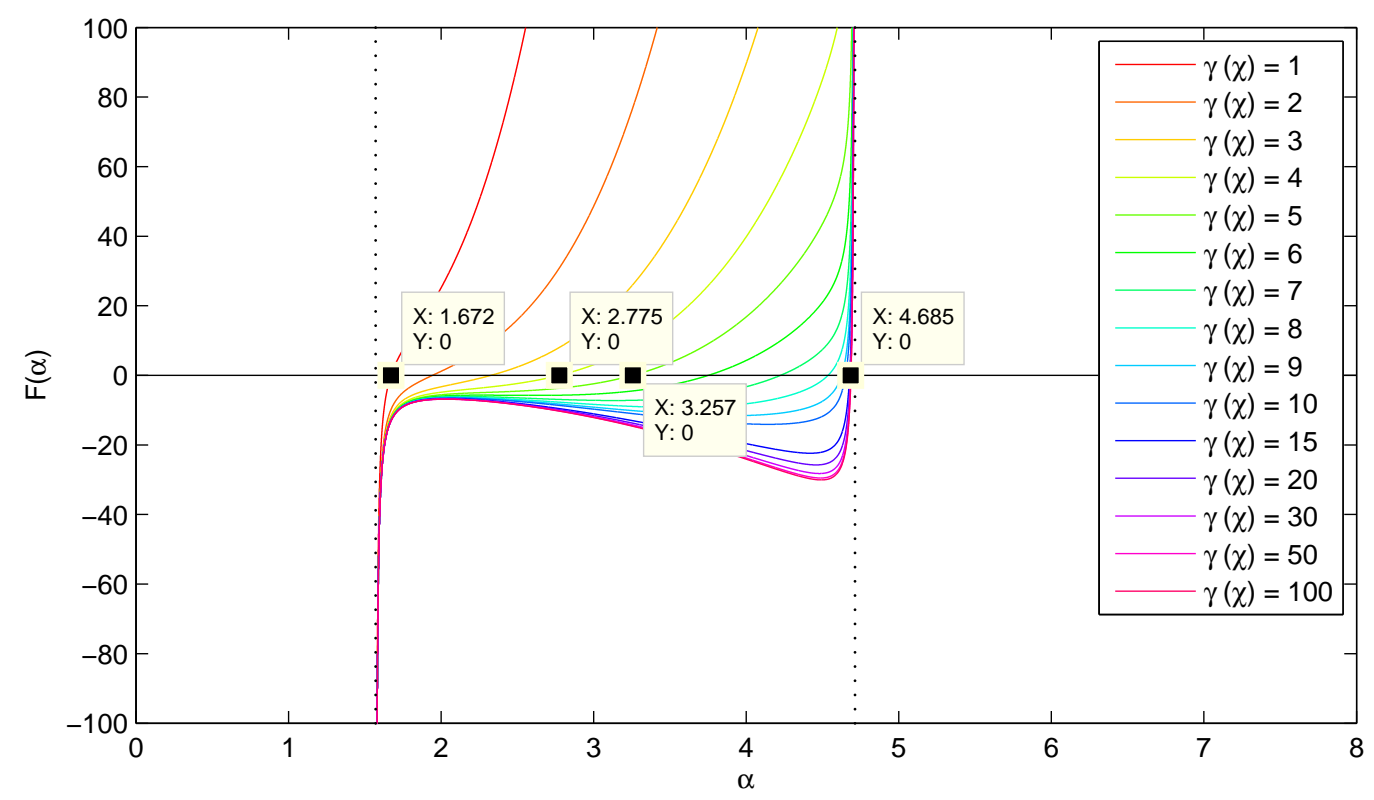

Figura 3.7: Representação gráfica de $F(\alpha)=\tan (\alpha)-\alpha-\frac{\alpha^{3}}{3}+\frac{\alpha^{5}}{\gamma^{2}(\chi)}$.

A Figura 3.6 representa as intersecções da função $f_{1}=\tan (\alpha)$ (curva contínua em preto na figura) com $f_{2}=\alpha+\frac{\alpha^{3}}{3}-\frac{\alpha^{5}}{\gamma^{2}(\chi)}$, obtida para diversos valores de $\gamma(\chi)$ arbitrários, entre $\gamma(\chi)=1$ e $\gamma(\chi)=100$. A utilização desse intervalo ficará clara na sequência.

Em ambas as figuras, os pontilhados em preto representam os extremos do intervalo. 
Algumas observações interessantes podem ser feitas a partir dessas Figuras:

- As funções $f_{2}$ e $F(\alpha)$ são contínuas no intervalo em análise, como argumentado anteriormente;

- Os pares ordenados destacados nas caixas de texto correspondem aos citados citados anteriormente no texto;

- Em ambas as figuras, como era de se esperar, os resultados se equivalem a despeito do seu comportamento geral;

- Nesse intervalo, o número de raízes é infinito; entretanto, cada valor de $\gamma(\chi)$ implica em uma única raiz.

Cumpre destacar que os gráficos ilustrados nas Figuras 3.6 a 3.7 mostram o comportamento da equação transcendental para alguns valores de $\gamma(\chi) \geq 1$, mas as tendências apresentadas apontam para a existência de uma única raiz para a equação, para um dado valor fixo de $\gamma(\chi)$. Para o intervalo $0<\gamma(\chi) \leq 1$, considere-se a Figura 3.8.
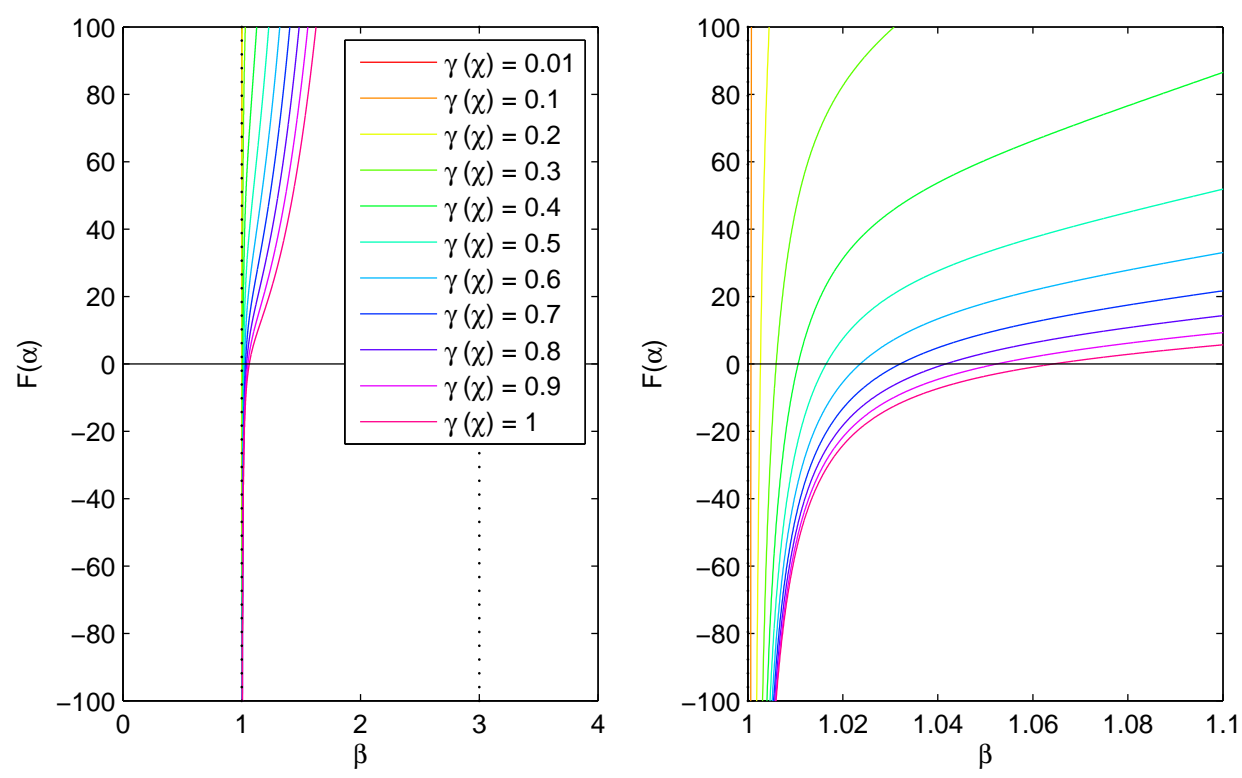

Figura 3.8: Representação gráfica de $F(\alpha)=\tan (\alpha)-\alpha-\frac{\alpha^{3}}{3}+\frac{\alpha^{5}}{\gamma^{2}(\chi)}$, para $0,01<\gamma(\chi) \leq 1$. À esquerda, a representação de $F(\alpha), \frac{\pi}{2}<\alpha<\frac{3 \pi}{2}$. À direita, o intervalo restrito que encerra as raízes.

O comportamento de $F(\alpha)$ é visualmente o mesmo que para a faixa de $\gamma(\chi)$ avaliada anteriormente. Note-se que, nessa figura, $F(\alpha)$ é dada em função de $\beta=\frac{2 \alpha}{\pi}$. Como consequência, esse intervalo parece apontar para situações em que as cargas críticas previstas são muito próximas das previstas por Euler para vigas retas.

llustre-se na Figura 3.9 a correspondente das Figuras 3.7 e 3.8, na qual $F(\alpha)$ é apresentada para uma quantidade muito maior, porém ainda finita, de valores de $\gamma(\chi)$, aumentando a discretização utilizada anteriormente, no intervalo $0<\gamma(\chi) \leq 50$. 


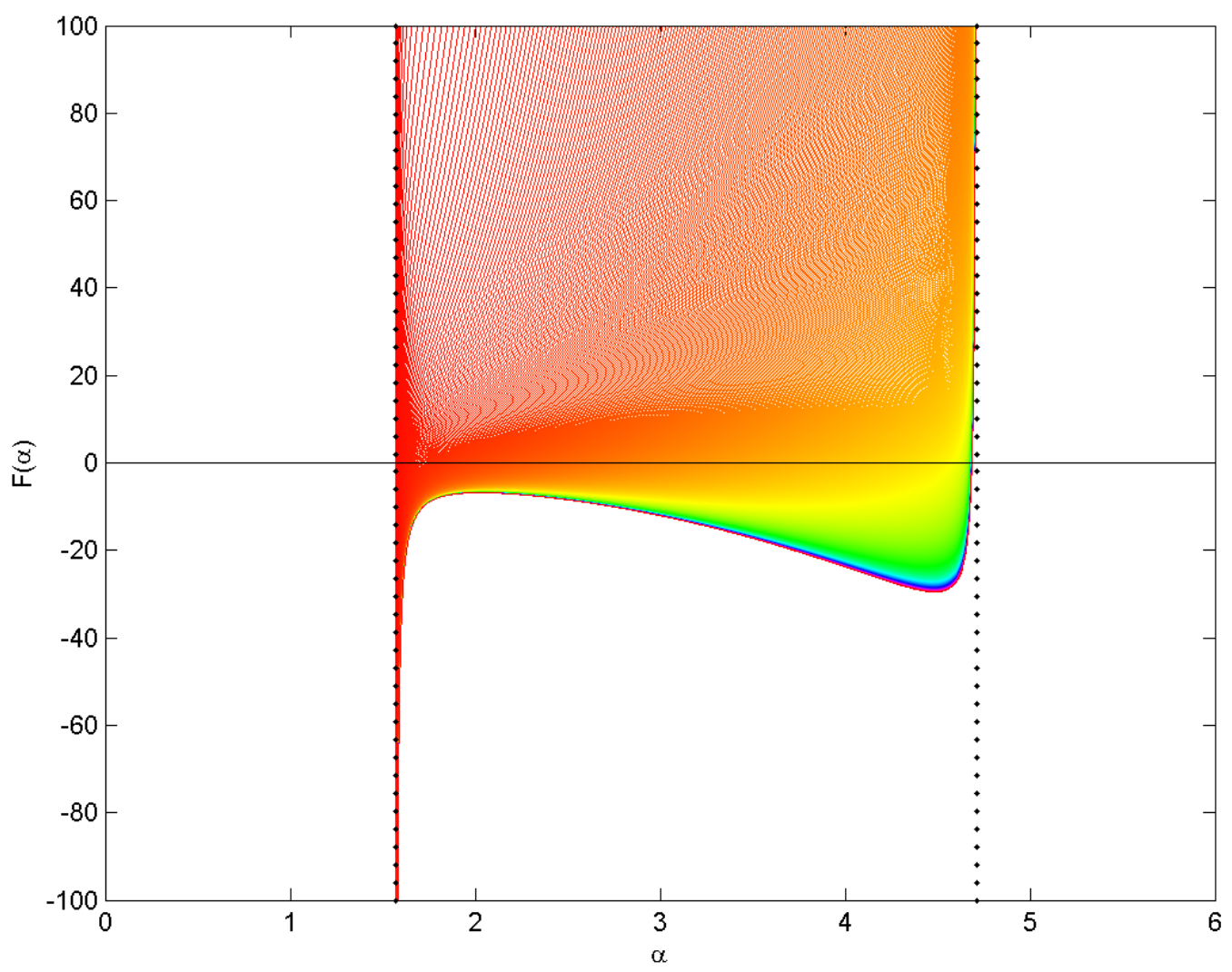

Figura 3.9: Representação gráfica de $F(\alpha)=\tan (\alpha)-\alpha-\frac{\alpha^{3}}{3}+\frac{\alpha^{5}}{\gamma^{2}(\chi)}$, para $0<\gamma(\chi) \leq 50$.

A argumentação apresentada em (Aranha et al., 2001) - de que seria necessária a obtenção da menor das raízes da Equação 3.61 para determinação da carga crítica de flambagem - parece se resumir a encontrar a única raiz no intervalo $\left[\frac{\pi}{2}, \frac{3 \pi}{2}\right]$, para determinado valor de $\gamma(\chi)$, dado pela Equação 3.62.

A fim de corroborar tal afirmação, foi feito um estudo mais detalhado do comportamento da Equação 3.61 que permite checar essa assertiva, bem como as demais feitas por Aranha et al. (2001) e citadas anteriormente nesta seção.

A equação foi avaliada graficamente para a faixa $0<\gamma(\chi) \leq 50$, de 0,1 em 0,1 (gráfico da Figura 3.9). Alternativamente, a Equação (transcendental) 3.61 foi resolvida numericamente, para distintos valores iniciais em $\left[\frac{\pi}{2}, \frac{3 \pi}{2}\right]$, utilizando o Método de NewtonRaphson, variando $\gamma(\chi)$ no mesmo intervalo.

Para determinados valores iniciais, o método não convergiu para nenhuma solução. Para outros, o método confluiu para soluções que não convinham física e matematicamente, recuperadas as considerações tecidas anteriormente para a Equação 3.61. Os demais valores iniciais utilizados convergiram para soluções viáveis (Figura 3.10). Cada ponto da Figura 3.10 representa uma solução $\beta_{c r}$ para a equação transcendental, a partir de diferentes estimativas iniciais $x_{0}$ para $\alpha$, necessárias para as iterações do Método de Newton-Raphson. Cada cor representa um valor diferente de $\gamma(\chi)$. 


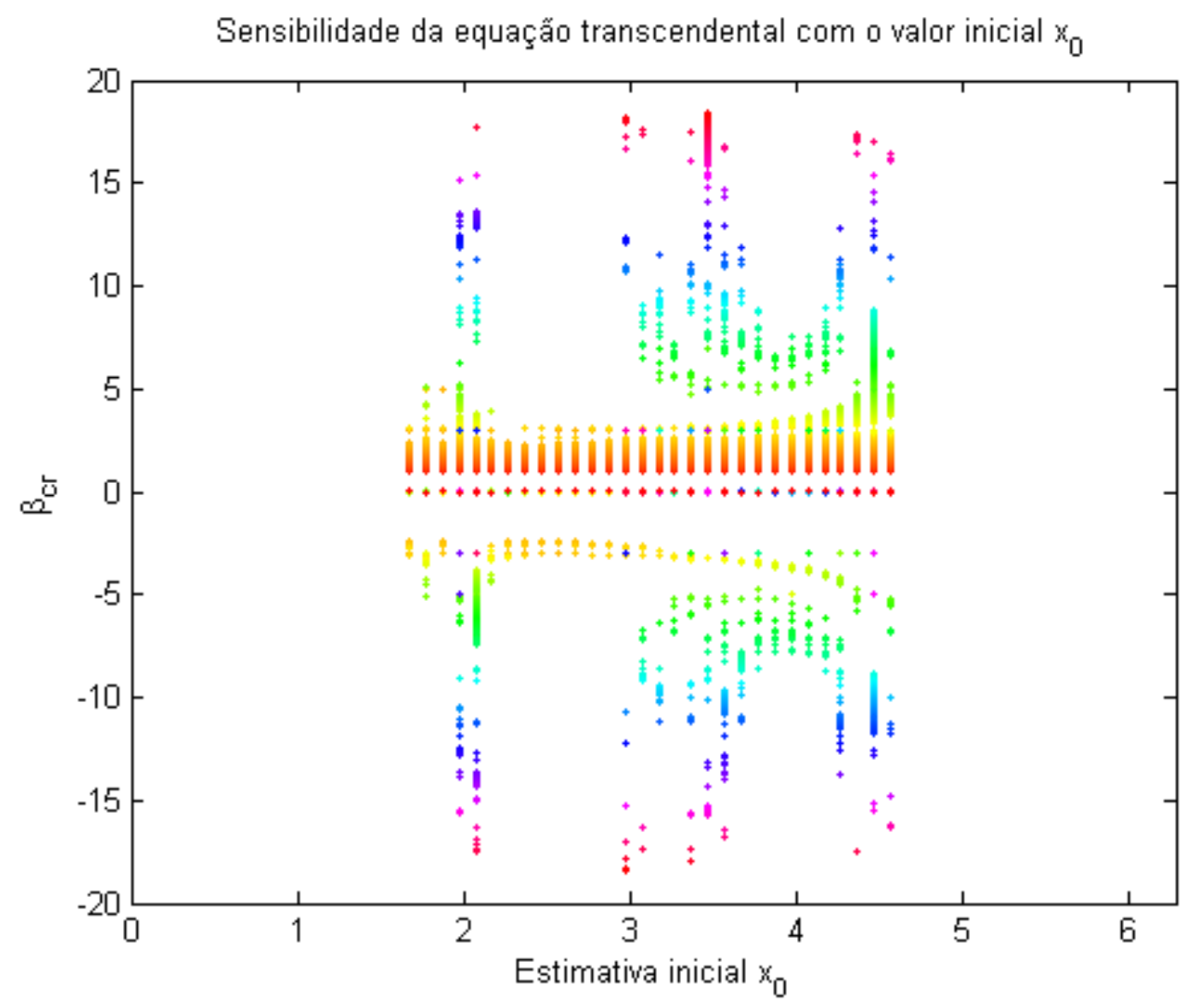

Figura 3.10: Valores de $\beta_{c r}$ em função das estimativas iniciais $x_{0}$ para a equação transcendental.

Note-se que não foi feita nenhuma consideração preliminar restritiva quanto aos possíveis valores de $\beta_{c r}$. A análise da Figura 3.10, permite concluir que é possível determinar diversas soluções distintas a partir de um mesmo valor inicial $x_{0}$. Entretanto, para um dado valor de $\gamma(\chi)$ a solução é sempre a mesma, considerando o intervalo fixado anteriormente e a convergência do método, independentemente do valor inicial. A partir da Equação 3.61, é possível isolar o parâmetro $\gamma(\chi)$, representando-o como uma função de $\alpha$ :

$$
\gamma^{2}(\chi)=\frac{3 \alpha^{5}}{3 \alpha+\alpha^{3}-3 \tan (\alpha)}
$$

A existência de $\gamma(\chi)$ na Equação 3.70 exige que $3 \alpha+\alpha^{3}-3 \cdot \tan (\alpha)>0$ (vide gráfico da Figura 3.11). Por essa figura, nota-se que o valor limite para $\alpha$ é igual a $4,687^{20}$. Essa aproximação, bem como a utilizada em (Aranha et al., 2001), são válidas para efeitos de cálculo; apesar de, a rigor, ambos os valores desrespeitarem os limites da Equação 3.70. Assim, quando necessário, será utilizado o valor máximo $\beta_{c r}=2,98358$, por ser uma aproximação com baixo erro relativo e que recai no domínio de $\gamma^{2}(\chi)$.

\footnotetext{
${ }^{20}$ Para esse valor de $\alpha, \beta_{c r}=2,9835847267$, em uma aproximação com dez casas decimais.
} 


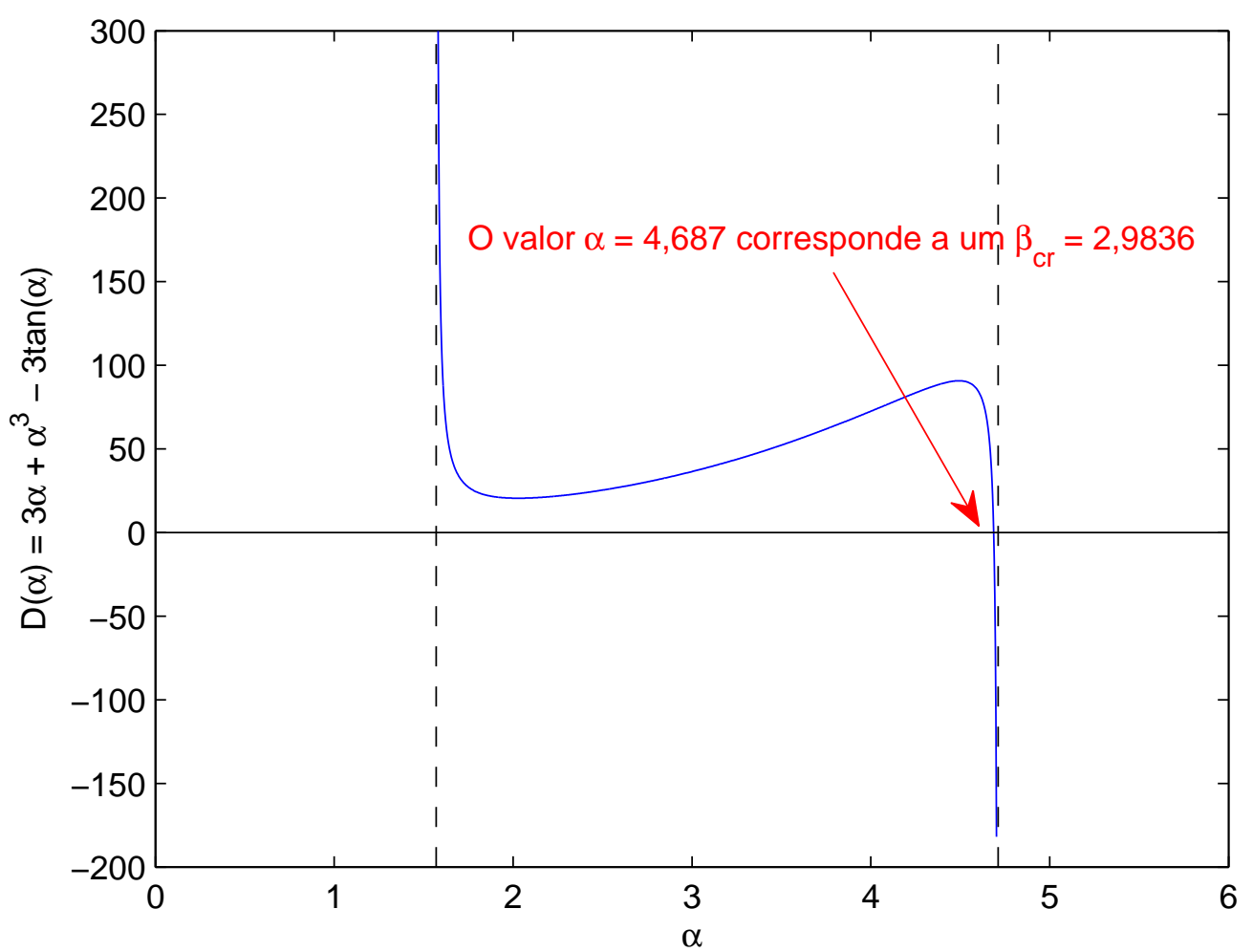

Figura 3.11: Comportamento do denominador de $\gamma^{2}(\chi)$, para $\frac{\pi}{2}<\alpha<\frac{3 \pi}{2}$.

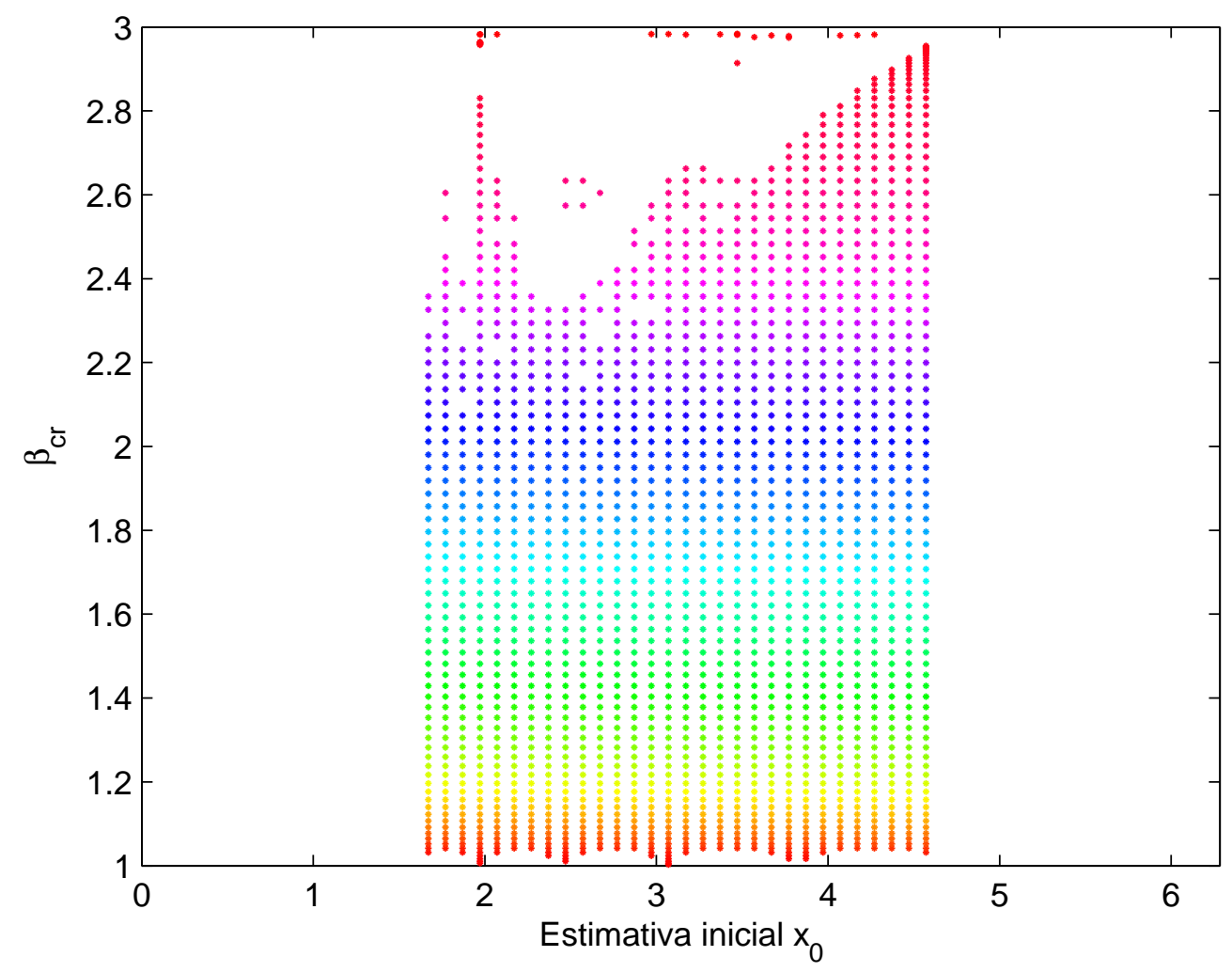

Figura 3.12: Valores de $\beta_{c r}$ em função das estimativas iniciais $x_{0}$, para $1<\beta_{c r} \leq 2,98358$. 
Como consequência direta dessa avaliação, fica claro que o parâmetro $\beta(\chi)$ só é matematicamente definido no intervalo $1<\beta_{c r}(\chi) \lesssim 2,98358^{21}$. Retome-se a Figura 3.10, considerando apenas o intervalo dos possíveis valores que $\beta_{c r}$ pode assumir, representado pela Figura 3.12, nas quais eventuais padrões tornam-se mais claros.

Nota: por concisão, o presente texto utilizará, por vezes, a notação $\beta_{c r}$, ao invés da sua forma mais precisa $\beta_{c r}[\chi(s)]$. Entretanto, deve-se ter em mente que, rigorosamente, 0 valor de $\beta_{c r}$ depende da curvatura $\chi(s)$. A mesma observação é válida para $\Gamma[\chi(s)]$.

As conclusões feitas anteriormente, com relação à unicidade da raiz da equação transcendental para um dado valor de $\gamma(\chi)$, parecem evidentes. A fim de avaliar essa proposição, defina-se $\Gamma(\chi)$, pela Equação 3.72 .

$$
\Gamma(\chi)=\frac{\chi_{0}}{\omega} \cdot \sqrt{\frac{E A}{m+m_{a}}}
$$

Ou seja, pela Equação 3.62:

$$
\gamma(\chi)=\left(\frac{\pi}{2}\right)^{2} \cdot \Gamma(\chi)=\left(\frac{\pi}{2}\right)^{2} \cdot \frac{\chi_{0}}{\omega} \cdot \sqrt{\frac{E A}{m+m_{a}}}
$$

A razão entre os adimensionais $\gamma(\chi)$ e $\Gamma(\chi)$ é meramente uma constante. Entretanto, entender a diferença entre essas relações é extremamente importante.

A vantagem em utilizar $\Gamma(\chi)$ reside no fato de que esse adimensional é composto exclusivamente por variáveis relacionadas ao problema da compressão dinâmica (propriedades físico-geométricas e condições de lançamento e excitação da linha).

O uso da constante $\left(\frac{\pi}{2}\right)^{2}$ na definição de $\gamma(\chi)$ não é arbitrária: ela encerra informações relativas às condições de contorno, confgurando-se como um artifício matemático extremamente perspicaz, a fim de chegar à Equação (transcendental) 3.61 na forma como ela se apresenta.

Por outro lado, um outro aspecto é digno de nota e de grande interesse prático. Todas as considerações analíticas feitas até aqui, com respeito à formulação analítica da carga crítica em vigas curvas, levam a uma conclusão inexorável: a relação entre $\beta_{c r}^{2} \mathrm{e}$ $\Gamma(\chi)$ é bijetora no intervalo correspondente ao domínio de validade física do problema, conforme pode ser visualizado na Figura 3.13.

\footnotetext{
${ }^{21} \mathrm{~A}$ situação em que $\beta_{c r}=1$ não recai no domínio considerado, mas é evidente que recupera o resultado de Euler.
} 


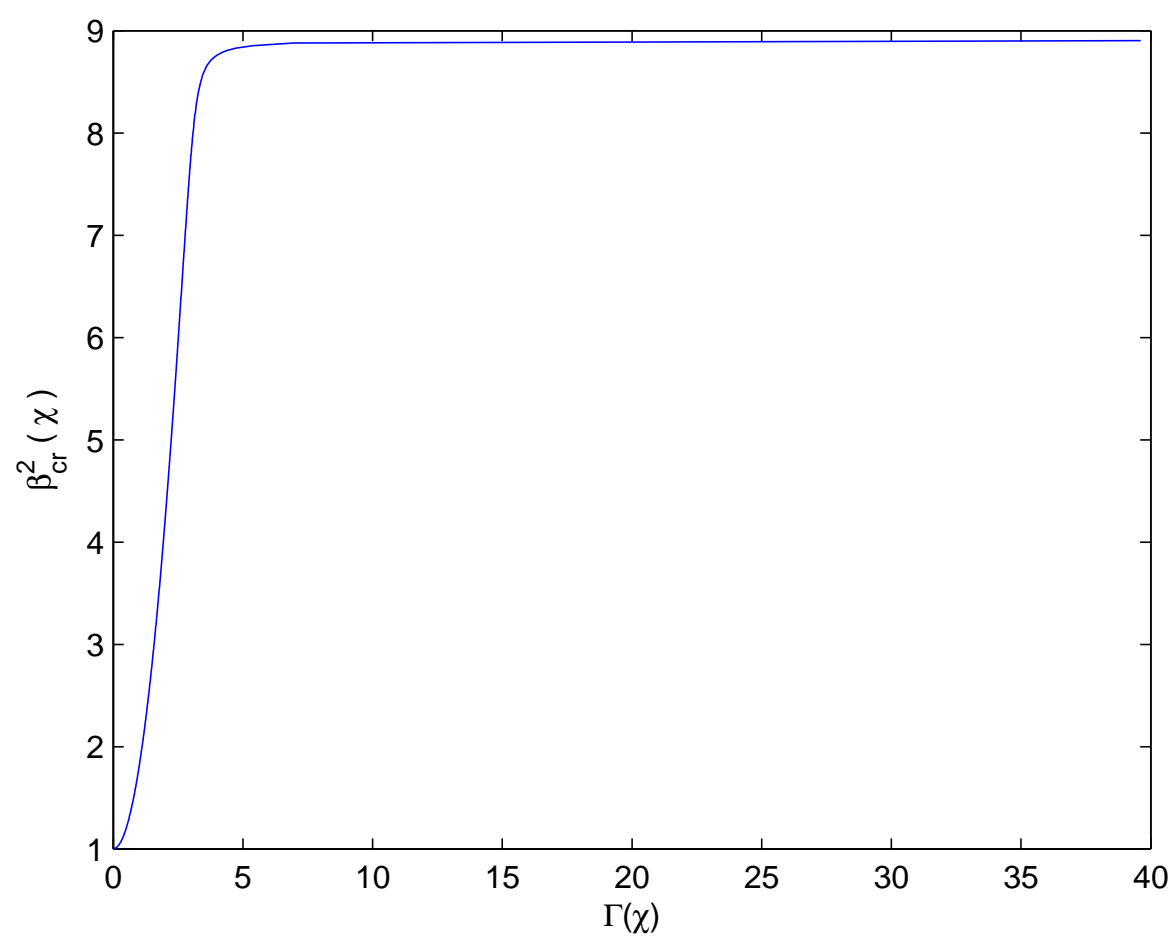

Figura 3.13: Relação gráfica entre $\beta_{c r}^{2}$ e $\Gamma(\chi), 1 \leq \beta_{c r} \leq 2,98358$.

\section{Aproximação algébrica para o cálculo da carga crítica de vigas curvas biapoiadas}

O gráfico ilustrado na Figura 3.13 representa a função que associa $\beta_{c r}^{2}$ e $\Gamma(\chi)$, a qual é bijetora e, portanto, inversível. Essa função foi obtida diretamente das definições dadas nas Equações 3.70 e 3.71 .

Para tanto, os possíveis valores de $\alpha(\chi)$ foram utilizados para determinar o intervalo dos $\gamma(\chi)$ associados. A seguir, foram determinados os respectivos $\Gamma(\chi)$ com o uso da Equação 3.70. Ora, cada $\alpha(\chi)$ está associado a um único $\beta(\chi)$.

Tabulados os valores de $\Gamma(\chi)$ e $\beta(\chi)$ foi possível a confecção do gráfico da Figura 3.13, graças ao fato da função $\gamma(\chi)=\gamma[\alpha(\chi)]$ ser bijetora no intervalo considerado.

Assim, a Equação 3.63 pode ser utilizada em conjunto com o gráfico da Figura 3.13: dados os parâmetros necessários para o cálculo de $\Gamma(\chi)^{22}$, determina-se $\beta_{c r}$ e, portanto, a carga crítica de compressão dinâmica do riser.

Embora válido, o uso da relação gráfica entre $\beta_{c r}^{2}$ e $\Gamma(\chi)$ para todo o domínio de validade de $\beta_{c r}$ (Figura 3.13), não é interessante do ponto de vista prático. A utilização do gráfico ilustrado eliminaria a característica original do trabalho de Aranha et al. (2001), que culminou com uma formulação analítica para a carga crítica.

O objetivo, neste ponto, é a obtenção de uma expressão analítica simples para a carga crítica de flambagem de vigas curvas, sob as mesmas hipóteses, eliminando a necessidade da determinação das raízes de uma equação transcendental.

\footnotetext{
${ }^{22}$ Cumpre recuperar a informação de que o adimensional $\Gamma(\chi)$ é determinado a partir das propriedades físico-geométricas da linha, bem como das suas condições de lançamento e excitação, em particular a frequência do movimento imposto.
} 
Dessa forma, foram avaliadas funções analíticas algébricas que pudessem aproximar adequadamente a curva da referida figura, sem que essa aproximação desrespeitasse as principais características físicas do modelo, quais sejam: o valor mínimo unitário de $\beta_{c r}$, o formato da curva (inclinações, curvaturas e inflexões) e a estabilização de $\beta_{c r}$ no seu valor máximo teórico a partir de determinado valor de $\Gamma(\chi)$.

Para tanto, foi utilizado um programa comercial denominado LABFit $(2011)^{23}$.

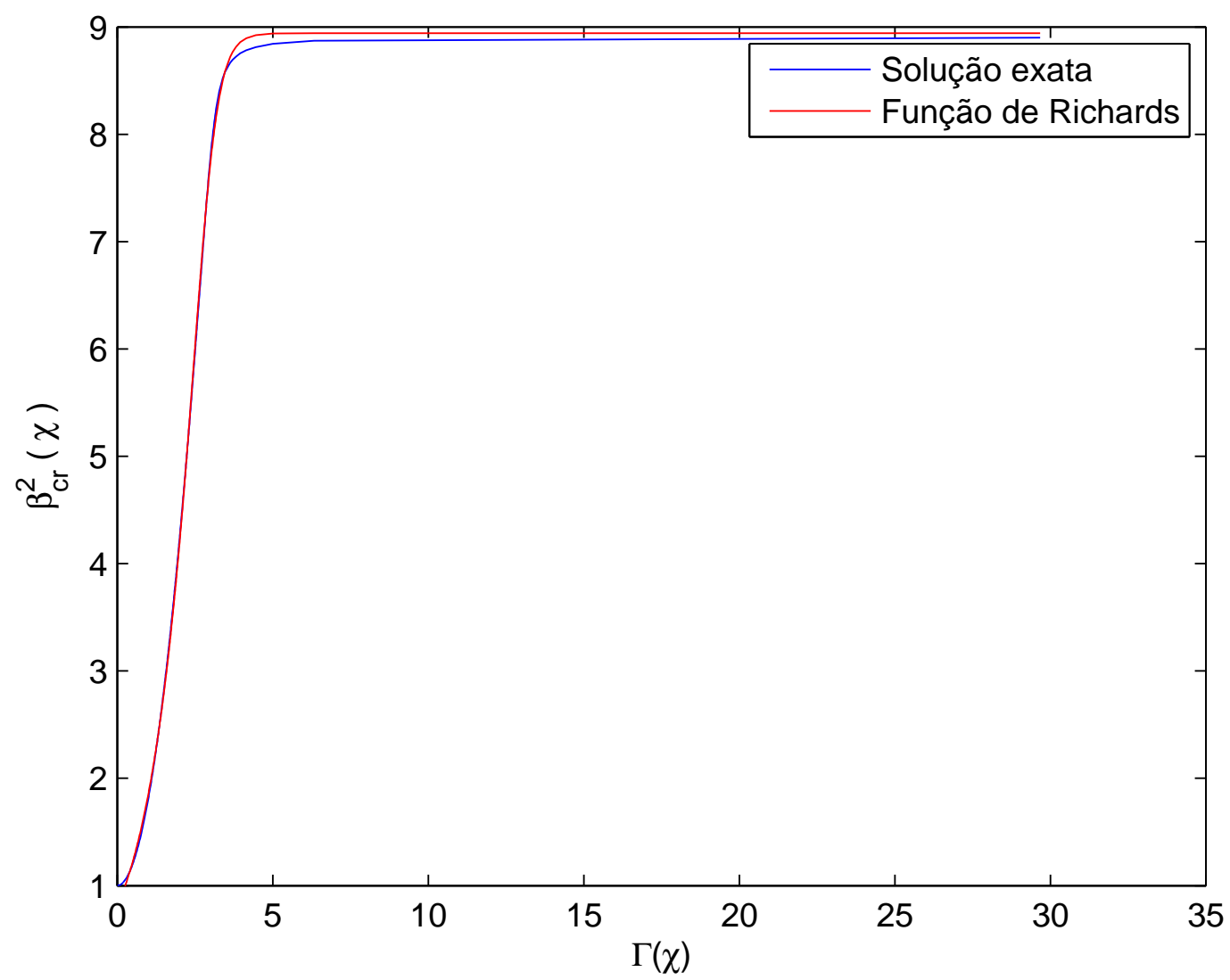

Figura 3.14: Aproximação por função de Richards para $\beta_{c r}^{2}=f[\Gamma(\chi)]$.

Esse programa sugeriu que a melhor aproximação para a relação desejada é representada por uma função de Richards, de sorte que:

$$
f[\Gamma(\chi)]=\frac{1}{\{A+B \cdot \exp [C \cdot \Gamma(\chi)]\}^{D}} \approx \beta_{c r}^{2}
$$

\footnotetext{
${ }^{23}$ LAB Fit é um software desenvolvido para Windows para o tratamento e análise de dados experimentais. Seu uso acadêmico é prmitido, desde que seja feita a seguinte citação, a pedido de seu autor: "Com o LAB Fit existe a possibilidade de: tratar dados similares; tratar dados não-similares; determinar erro propagados; plotar gráficos 2D e 3D; executar cálculos (sistema de equações, as raízes da função, equações diferenciais ordinárias etc); extrair dados $(x, y)$ de um gráfico 2D (digitalização); ajuste de curva (regressão não-linear - método dos mínimos quadrados, o algoritmo de Levenberg-Marquardt). o programa possui quase 500 funções na biblioteca, com uma e duas variáveis independentes, funções finder, opção que permite ao usuário escrever sua própria função com até 150 caracteres, 6 independente variáveis e 10 parâmetros". Disponível em zeus.df.ufcg.edu.br/labfit/index_p.htm, acessado em 28/11/2014.
} 
Especificamente no caso da referida aproximação, as constantes $A, B, C$ e D assumiram os seguintes valores, respectivamente: $2,2200 \cdot 10^{-4} ; 2,2410 ;-3,1780$; e $0,2602^{24}$. Consequentemente:

$$
\beta_{c r}^{2}(\chi) \approx \frac{1}{\left\{2,2200 \cdot 10^{-4}+2,2410 \cdot \exp [-3,1780 \cdot \Gamma(\chi)]\right\}^{0,2602}}
$$

A Figura 3.15 ilustra as diferenças relativas entre a curva original (Figura 3.13) e a utilizada para sua aproximação algébrica por uma função de Richards (Figura 3.14).

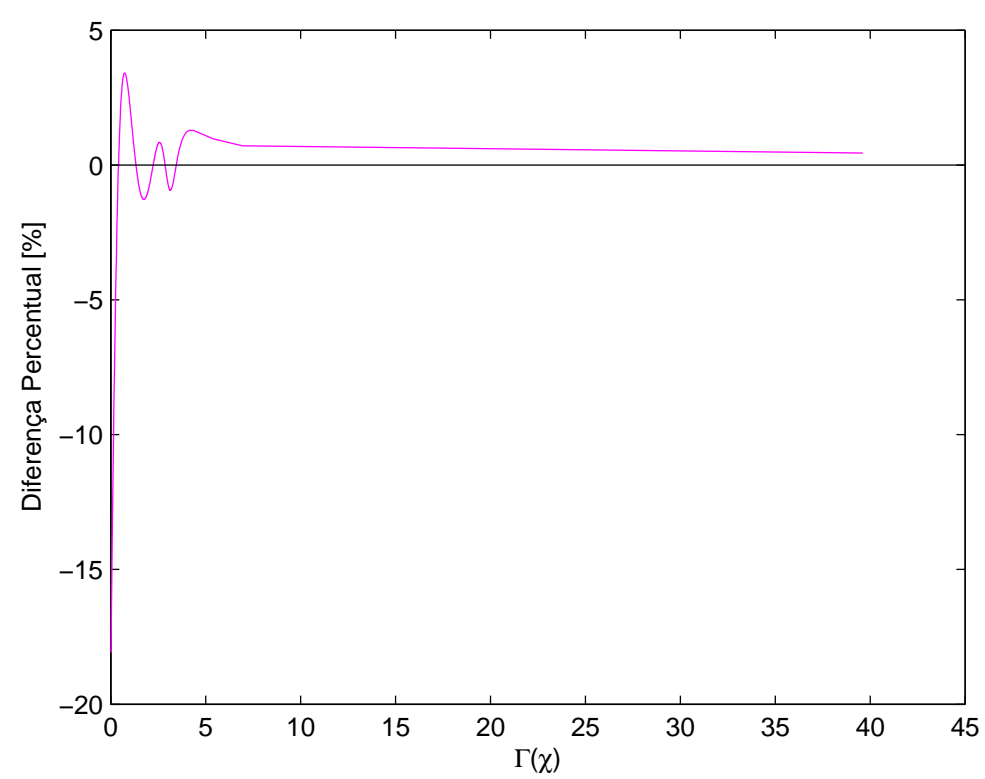

Figura 3.15: Diferenças relativas entre os valores exato e aproximado de $\beta_{c r}^{2}$.

A Equação 3.74, em conjunto com a Figura 3.14, mostra que, a despeito da boa aderência da função de Richards, com os coeficientes determinados, para aproximar algebricamente o valor de $\beta_{c r}^{2}$, cabem algumas notas, relativas às principais características de $\beta_{c r}$ que deveriam ser respeitadas pela aproximação utilizada:

- O valor inicial $\beta_{c r}^{2}=1$ não é recuperado ${ }^{25}$. Para fins práticos, nesse caso, basta que, se $\beta_{c r}^{2}<1$, assuma-se prontamente a unidade como o valor correto;

- A menos do ponto inicial (e seu entorno $\Gamma(\chi) \lesssim 1$ ), a maior diferença apresentada entre a curva original e a aproximada é menor que 3,41\%;

- O comportamento assintótico para os maiores valores de $\Gamma(\chi)$ é recuperado com bastante acurácia (diferenças relativas menores que 0,44\%).

\footnotetext{
${ }^{24} \mathrm{~A}$ aproximação pela função de Richards com os parâmetros explicitados foi avaliada, posteriormente, com o uso da ferramenta cftool do Matlab, a partir da qual foram confirmados os valores de A, B, C e D - dentro de um intervalo de confiança de $95 \%$. A aproximação apresentou um Coeficiente de Correlação de Pearson $R^{2} \approx 0,9997$.

${ }^{25}$ Cumpre lembrar que $\Gamma(\chi)$ não pode assumir valor nulo - o menor valor de $\Gamma(\chi)$ avaliado numericamente é aproximadamente igual a 0,0157 . Para esse valor, $\beta_{c r}^{2} \approx 0,8194$, de sorte que $\beta_{c r} \approx 0,9052$.
} 
Postas essas considerações e assumindo que a aproximação determinada é adequada, é possível determinar a expressão algébrica que permite o cálculo da carga crítica de flambagem de vigas curvas biapoiadas.

$$
P_{c r}(\chi) \approx \frac{\sqrt{\left(m+m_{a}\right) \cdot E I} \cdot \omega}{\left\{2,2200 \cdot 10^{-4}+2,2410 \cdot \exp [-3,1780 \cdot \Gamma(\chi)]\right\}^{0,2602}}
$$

Obviamente, a utilização da Equação 3.75 depende do valor de $\Gamma(\chi)$ e, consequentemente, do erro associado em detrimento da acurácia desejada.

Como conclusão, a determinação de $\beta_{c r}^{2}$ para determinação da carga crítica de flambagem de vigas curvas passa a não depender da resolução da Equação transcendental 3.61: basta o conhecimento das propriedades físicas, de lançamento e de excitação de topo do riser (ou modelo) a ser estudado ou avaliado, e a Figura 3.13.

A partir das Equações $3.74^{26}$ e 3.64 e da definição de número de onda $\left(k=\frac{2 \pi}{\lambda}\right)$, chegase, a uma expressão algébrica que permite o cálculo do comprimento das ondas de flexão associadas à flambagem de vigas curvas biapoiadas:

$$
\lambda_{c r}^{2} \approx \frac{(2 \pi)^{2}}{\omega} \cdot \sqrt{\frac{E I}{m+m_{a}}} \cdot\left\{2,2200 \cdot 10^{-4}+2,2410 \cdot \exp [-3,1780 \cdot \Gamma(\chi)]\right\}^{0,2602}
$$

A celeridade das ondas associadas à rigidez flexional, definida pela Equação A.20, utilizada em conjunto com a Equação 3.76 permite a determinação da relação entre os comprimentos das ondas de flexão da viga curva $\left(\lambda_{c r}\right)$ e da viga reta $\left(\lambda_{f}\right)$, explicitamente apresentada na Equação 3.77.

$$
\frac{\lambda_{c r}}{\lambda_{f}} \approx\left\{2,2200 \cdot 10^{-4}+2,2410 \cdot \exp [-3,1780 \cdot \Gamma(\chi)]\right\}^{0,1301}
$$

A relação aproximada entre os comprimentos de onda de flexão em vigas curvas e retas, dada pela Equação 3.77 está ilustrada graficamente na Figura 3.16.

A partir dessa figura, é possível depreender o comportamento das ondas de flexão na viga curva, em função de $\Gamma(\chi)$ : o comprimento dessas ondas é igual ao de uma viga reta, quando $\Gamma(\chi) \rightarrow 0$; e tende a cerca de $\frac{1}{3}$ desse valor para $\Gamma(\chi) \gtrsim 4$.

Esse resultado é quantitativa e qualitativamente consonante com a formulação analítica de Aranha et al. (2001), apontando mais uma vez para a adequabilidade e acurácia da aproximação desenvolvida.

\footnotetext{
${ }^{26}$ Embora desenvolvida apenas na Seção 3.3.2 do Apêndice $A$, a citada equação é apenas uma aproximação algébrica para a relação entre $\beta_{c r}$ e $\Gamma(\chi)=\left(\frac{2}{\pi}\right)^{2} \cdot \gamma(\chi)=\chi_{0} \cdot \sqrt{\frac{E A}{m+m_{a}}} \cdot \frac{1}{\omega}$, a fim de facilitar a determinação de $\beta_{c r}$.
} 


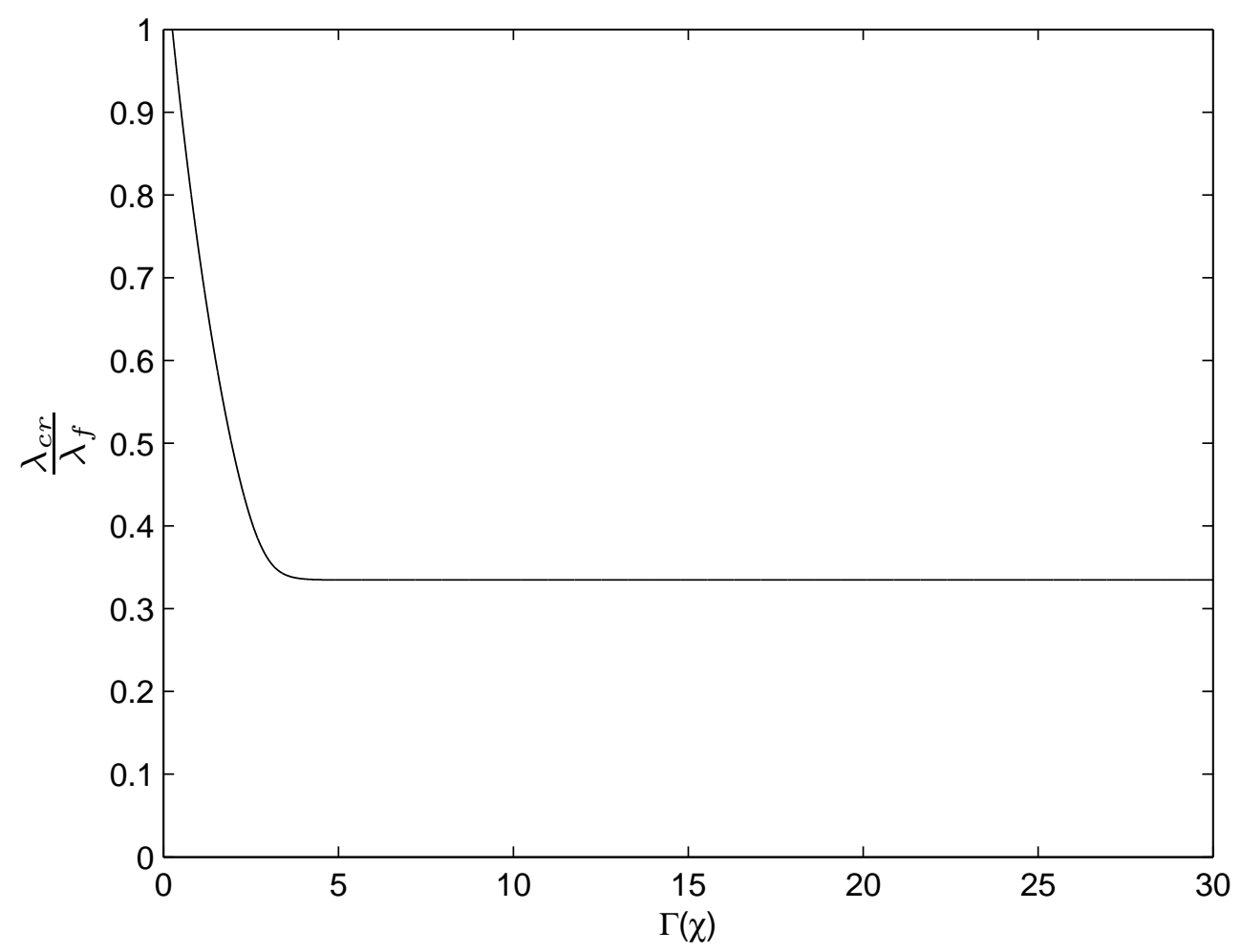

Figura 3.16: Relação aproximada entre os comprimentos das ondas de flexão em vigas curvas e retas.

\subsubsection{O papel físico dos adimensionais na carga crítica de flambagem}

Conforme demonstrado em Aranha et al. (2001), a carga crítica para flambagem de vigas curvas biapoiadas pode ser determinada a partir da Equação 3.63, em que uma correção, $\beta_{c r}^{2}(\chi)$, é utilizada para amplificação do valor da carga crítica de Euler. $\mathrm{Na}$ Seção 3.3.2, foi proposta uma aproximação para a relação entre $\beta_{c r}^{2}(\chi)$ e o adimensional $\Gamma(\chi)$, definido naquela seção e aqui apresentado para familiarização do leitor.

$$
\Gamma(\chi)=\frac{\chi_{0}}{\omega} \cdot \sqrt{\frac{E A}{m+m_{a}}}=\frac{\Pi_{\lambda}}{\Pi_{c_{0}} \cdot \sqrt{\epsilon_{0}}}
$$

O coeficiente adimensional $\Pi_{c d}=\frac{P_{c r}}{T_{0}}$, definido na Equação 3.59, é, portanto, função de $\Gamma(\chi)$ e de $P_{E}$, cuja adimensionalização foi apresentada na Equação 3.57.

Uma primeira conclusão, bastante interessante com relação a esse admensional, como apresentado na Equação 3.78, diz respeito à interdependência entre $\Gamma(\chi)$ e três dos adimensionais definidos anteriormente. Afora o termo $\Pi_{c_{0}}$, é visível a relação de proporcionalidade inversa entre $\Pi_{\lambda}$ e a raiz quadrada da deformação específica $\sqrt{\epsilon_{0}}$, apontando para a possibilidade de que o comprimento das ondas de flexão possam ser influenciadas diretamente pela rigidez axial. 
Conforme citado por Aranha et al. (2001), o comprimento flexural $\lambda_{f}$ seria da mesma ordem que o comprimento das ondas de flexão geradas durante a compressão dinâmica e a relação apresentada pode estabelecer uma correção entre esses comprimentos de onda, compatibilizando ambas as relações. É possível perceber também uma relação de proporcionalidade direta entre a carga crítica de flambagem de vigas curvas e o adimensional $\Pi c_{0}$, cujo significado físico, relacionado à rigidez geométrica, já foi amplamente discutido anteriormente.

Ademais, existe uma relação indireta entre $\Pi_{c d}$ e o próprio adimensional $\Pi c_{0}$, além de $\Pi_{\lambda}$ e $\epsilon_{0}$, todos esses dados pela função que relacionada $\beta_{c r}^{2}(\chi)$ e $\Gamma(\chi)$. No Apêndice A, são propostas aproximações algébricas para $\beta_{c r}^{2}(\chi)=f[\Gamma(\chi)]$, dependentes das condições de contorno consideradas no problema.

Dessa definição, é possível depreender que $\Gamma(\chi)$ depende, por exemplo, da rigidez axial, da curvatura no TDP e do comprimento flexural. Implicitamente, essa relação incorpora a definição da carga crítica de Euler para flambagem de vigas retas.

A fim de tornar essa relação evidente, reescreva-se novamente a Equação 3.71, introduzindo artificialmente a rigidez flexional $E I$.

$$
\Gamma(\chi)=\frac{E I \cdot \chi_{0}}{\sqrt{E I \cdot\left(m+m_{a}\right)} \cdot \omega} \cdot \sqrt{\frac{E A}{E I}}=\frac{M_{f}}{P_{E} \cdot K}
$$

A Equação 3.79 encerra uma analogia bastante interessante: ela respresenta o quociente adimensional entre o momento-fletor linearizado no TDP, $M_{f}=E I \cdot \chi_{0}$, e o produto da carga crítica de Euler por um braço que corresponde ao raio de giração ${ }^{27}$. Uma outra maneira de representar $\Gamma(\chi)$, em uma forma mais sucinta, mas hermética, é dada pela Equação 3.80 .

$$
\Gamma(\chi)=\frac{\sqrt{E A \cdot E I} \cdot \chi_{0}}{\sqrt{E I \cdot\left(m+m_{a}\right)} \cdot \omega}=\frac{\sqrt{E A \cdot E I} \cdot \chi_{0}}{P_{E}}
$$

Por fim, cabe ressaltar que a hipótese feita inicialmente de que a carga crítica pudesse ser função da amplitude de excitação não foi confirmada. A formulação analítica proposta por Aranha et al. (2001), após a análise dimensional realizada, mostra claramente a independência da carga crítica com respeito à amplitude do movimento prescrito ao topo do riser.

${ }^{27} \mathrm{O}$ raio de giração $K$ é definido pela relação $K^{2}=\frac{I}{A}$. Para maiores detalhes, ver, por exemplo, (Gere \& Timoshenko, 2001). 


\subsection{Considerações a respeito do uso de ancoragem nos ensaios}

Conforme será apresentado e discutido no Capítulo 4, e mais detalhadamente na Seção C.1 do Apêndice C, as restições físicas do Calibrador Hidrodinâmico do Tanque de Provas Numérico (CH-TPN), de acordo com simulações numéricas preliminares, impuseram a necessidade do uso de ancoragem durante os ensaios, a fim de permitir as avaliações estática e dinâmica do modelo sob determinados ângulos de topo.

A escolha pela utilização de ancoragem implica, mandatoriamente, em modificações nas condições de contorno e, consequentemente, na formulação proposta por Aranha et al. (2001). De maneira a apresentar subsídios teóricos relevantes e, até certo ponto, inéditos, sem incorrer no desvio de foco do leitor com respeito aos objetivos almejados, serão apresentadas as formulações concernentes a essas alterações nas condições de contorno.

Para que os resultados façam sentido faz-se mister o entendimento de alguns pontos fundamentais, relativos à modelagem empregada:

- Quaisquer que sejam os vínculos utilizados nos modelos matemáticos, a fim de emular a física do problema, há que se compreender que eles são inerentemente ideais, de sorte que nenhum conjunto aventado representará perfeitamente os resultados de observações dinâmicas;

- Para o problema em questão, dados os movimentos prescritos no topo e o uso de ancoragem, a formulação desenvolvida utiliza condições de contorno de engaste para a âncora e rótula deslizante para o topo;

- A escolha pelo engaste para modelar a âncora é bastante razoável, dado que esse tipo de vínculo restringe todos os graus de liberdade possíveis para aquele ponto;

- Entenda-se por rótula deslizante o vínculo que permite a translação (bidimensional) do ponto de fixação, impedindo movimentos na direção perpendicular ao plano a que ele pertence. Toda rótula, por definição, permite rotações. Por concisão, a despeito da nomenclatura imprecisa, esse vínculo será denominado, neste trabalho, por pinado;

- Assim, o problema resolvido em (Aranha et al., 2001) considerou condições de contorno de uma viga biapoiada, enquanto que, para os efeitos desta tese, os vínculos passarão a ser tratados como engastado-pinados. As equações diferenciais que regem a modelagem da viga, entretanto, permanecem as mesmas.

Postas essas considerações, as condições de contorno passar a ser as seguintes:

- Engaste no primeiro vínculo: $v(0)=0$ e $v^{\prime}(0)=0$;

- Rótula deslizante no segundo vínculo: $v^{\prime}(L)=0$ e $v^{\prime \prime \prime}(L)=0$. 
A imposição de que $v(0)=0$ implica em deflexão nula no engaste.

As condições relativas à inclinação da curva de deflexão, $v^{\prime}(0)=0$ e $v^{\prime}(L)=0$, correspondem à imposição de que a extremidade da linha junto à âncora é paralela ao solo (trecho repousado sobre o leito) e ao ângulo de saída do modelo no topo, respectivamente. A rigor, essa última condição é a menos plausível fisicamente ${ }^{28}$, embora permita modelar o topo, a princípio, de maneira mais adequado que um apoio simples. Por fim, a condição $v^{\prime \prime \prime}(L)=0$ exige que a linha, no topo, não apresente mudanças no sinal da curvatura (ou seja, da concavidade), apesar da possibilidade de translações bidimensionais no plano que contém a rótula.

O problema modelado sob essas condições de contorno levam, como pode ser verificado no Apêndice $A$, à seguinte equação característica:

$$
\tan (k L)+\tanh (k L)=0
$$

com $k L=\lambda^{*} \approx 2,36502037$ representando o autovalor para o primeiro modo.

Saliente-se que, para o primeiro modo da viga biapoiada, esse valor é igual a $\pi$.

Ora, como $k$, nessa formulação, é exatamente o número de onda, conclui-se que, para vigas retas de mesmo comprimento, as ondas de flexão são tais que a razão entre seus comprimentos é dada pela Equação 3.82 .

$$
\frac{\lambda_{E P}}{\lambda_{B I}} \approx 1,32835754
$$

Ou seja, quando $\beta_{c r}(\chi) \rightarrow 1$, o comprimento da onda de flexão na viga reta é cerca de $32,8 \%$ maior para a condição engastada-pinada ("EP") que para a "biapoiada" ("BI"). Nesse ponto, cabe adiantar um resultado, relativo à matriz de ensaios elaborada para os fins da presente tese. Em nenhuma das condições experimentais o valor de $\beta_{c r}$ atingiu a unidade; nesse sentido, os experimentos físicos ficaram restritos à faixa $1,24 \lesssim \Gamma(\chi) \lesssim 10,54$ - adimensional esse definido e discutido anteriormente nesse mesmo capítulo, na Seção 3.3.2.

A fim de comparar o resultado mostrado anteriormente para a relação entre os comprimentos de ondas de flexão para vigas retas e curvas biapoiadas (vide Figura 3.16), foi confeccionada a Figura 3.17.

Nas Figuras 3.17 a 3.27, as linhas tracejadas em preto indicam as restrições relativas às condições ensaiadas, $0,07 \lesssim \Gamma(\chi) \lesssim 10,54$.

Maiores considerações e discussões a respeito dessa comparação serão realizadas em momento oportuno, quando da discussão dos resultados obtidos com os ensaios físicos no $\mathrm{CH}$-TPN.

\footnotetext{
${ }^{28}$ Essa condição parece mais adequada para linhas lançadas mais verticalmente, de sorte que talvez a melhor forma de representar esse vínculo fosse $v^{\prime}(L)=\tan \left(\theta_{t}\right)$, por exemplo.
} 


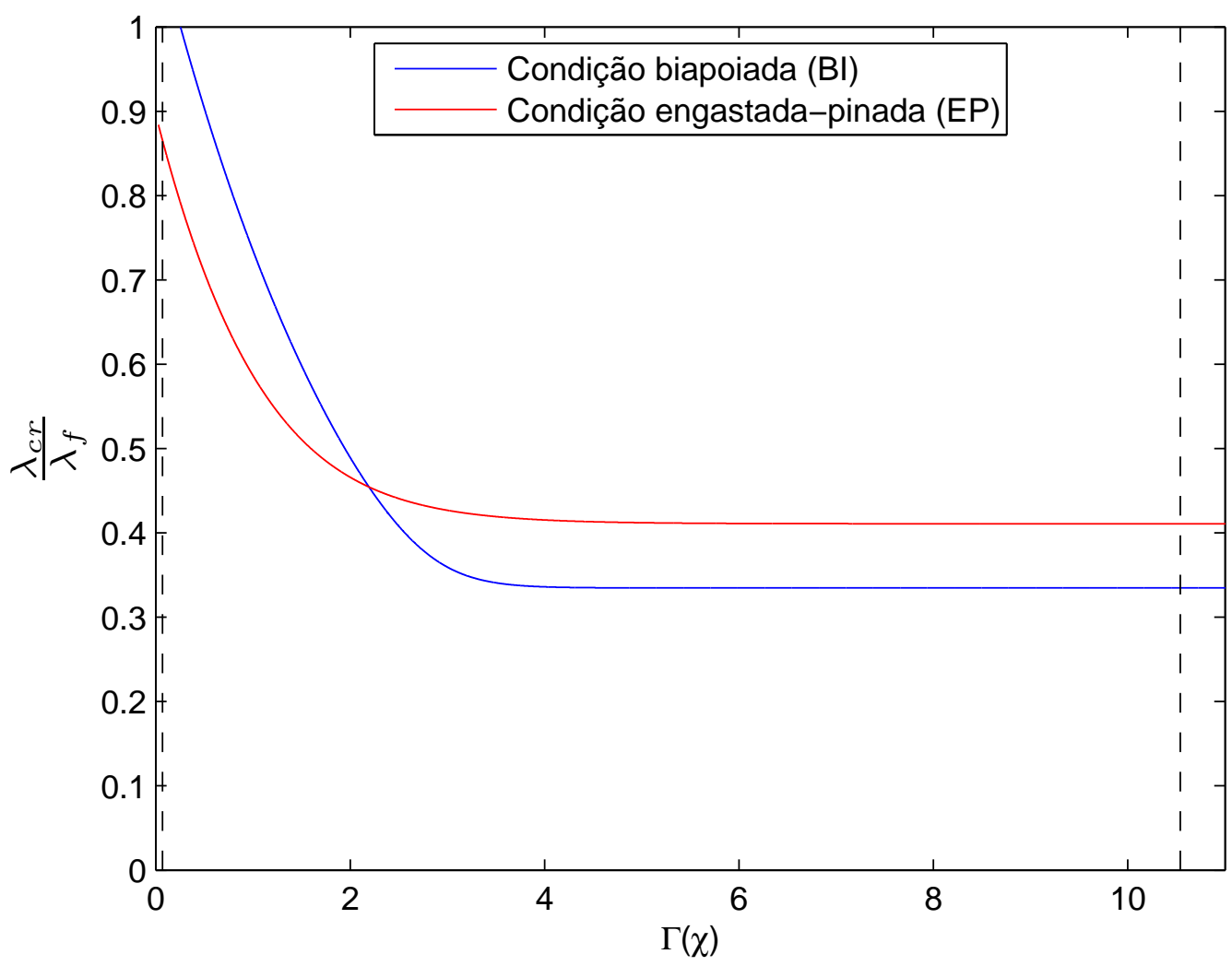

Figura 3.17: Comparação entre as relações de comprimentos de onda para as condições de ensaio.

Continuando o processo de discussões das diferenças esperadas para os resultados dos experimentos, cabe apresentar a equação transcendental (análoga da Equação 3.61, desenvolvida para a condição biapoiada) que permite determinar os valores de $\beta_{c r}$, diretamente responsáveis pela modelagem analítica da carga crítica em vigas curvas.

$$
\cot (\alpha)=\frac{1}{\alpha}-\frac{\alpha}{3}+\frac{\alpha^{3}}{[\gamma(\chi)]_{E P}^{2}}
$$

$\operatorname{com} \alpha=\beta \lambda^{*}$.

A Equação 3.83 é bastante similar à Equação 3.61, em alguns aspectos. $O$ desenvolvimento analítico apresentado no Apêndice A conclui que, para o caso engastadopinado, $1,3284 \lesssim \beta_{\text {cr }}(\chi) \lesssim 2,4369$.

Nese ponto, é interessante notar as semelhanças e diferenças entre as equações transcendentais obtidas em (Aranha et al., 2001) e no presente texto.

A fim de nortear a avaliação dessa nova equação transcendental, avaliem-se inicialmente as Figuras 3.18 e 3.19 , que permitem avaliar o comportamento das funções $f(\alpha)=\cot (\alpha)$ e $g(\alpha)$, onde $g(\alpha)=\frac{1}{\alpha}-\frac{\alpha}{3}+\frac{\alpha^{3}}{[\gamma(x)]_{E P}^{2}}$ e $f(\alpha)=\cot (\alpha)-g(\alpha)$, respectivamente. As raízes dessas equações são idênticas entre si, para dado $[\gamma(\chi)]_{E P}$. 


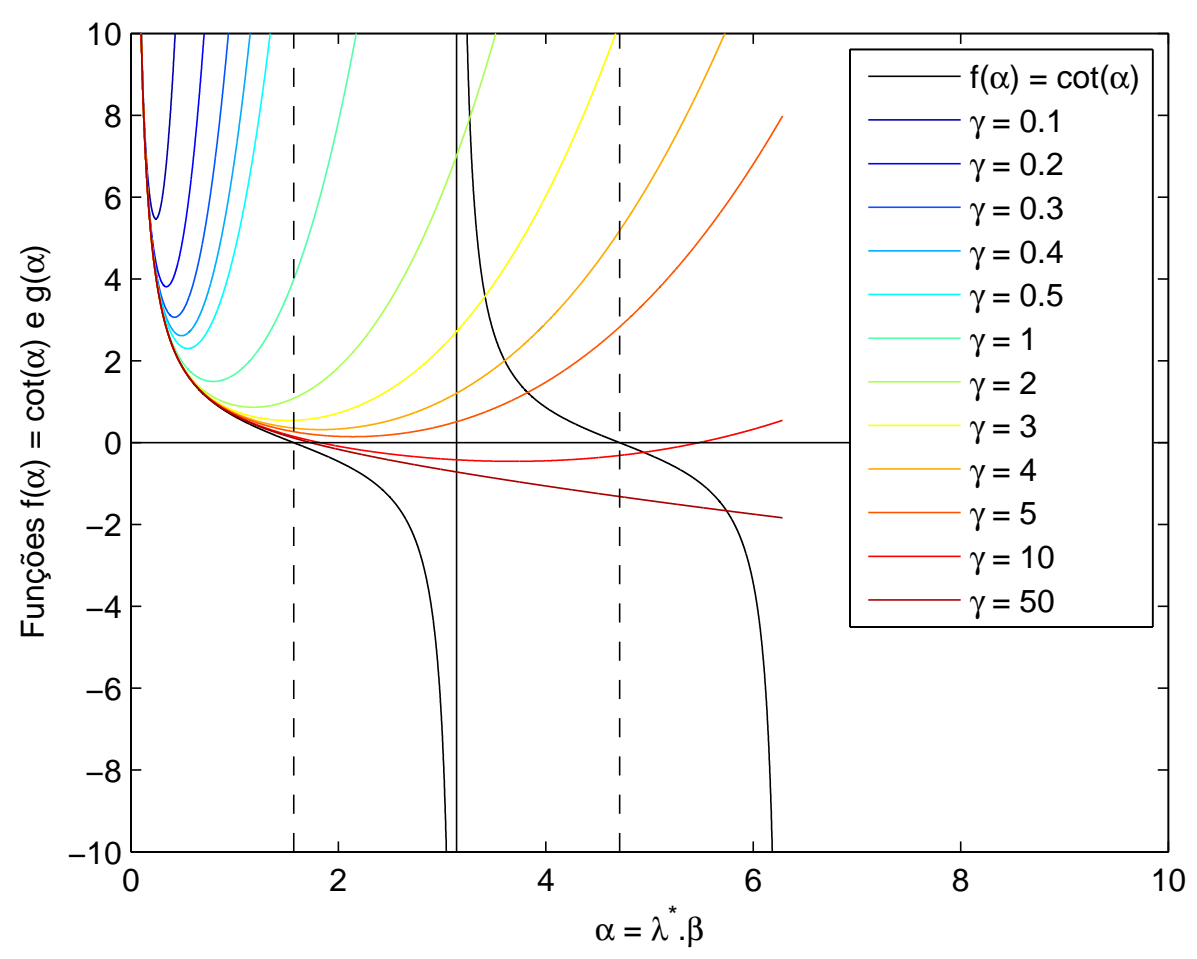

Figura 3.18: Soluções diretas da Equação 3.83 graficamente.

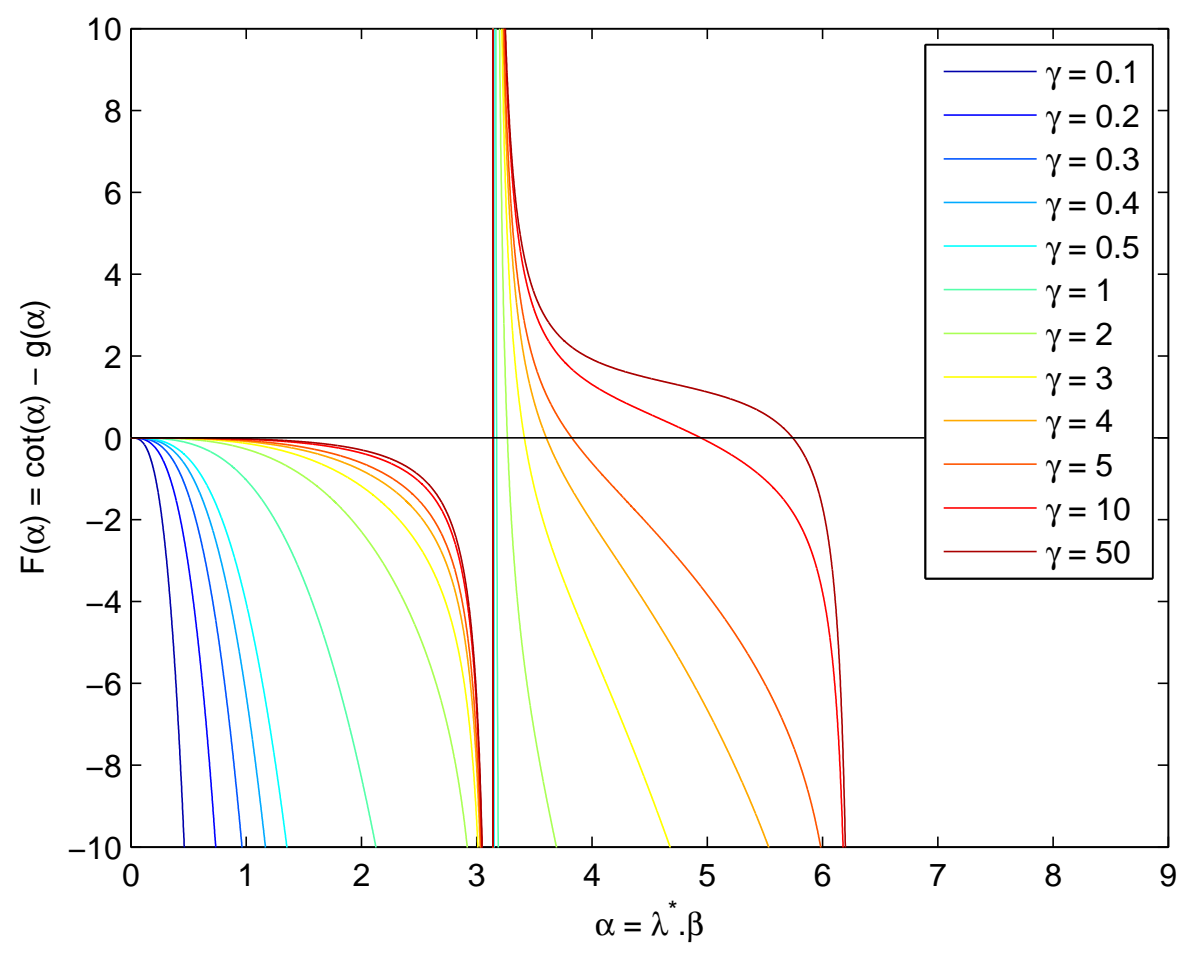

Figura 3.19: Soluções indiretas da Equação 3.83 graficamente.

Essas figuras, similares às geradas para o trabalho de Aranha et al. (2001), sugerem a unicidade das raízes da Equação transcendental 3.83 no intervalo $(\pi, 2 \pi)$, embora essa conclusão não tenha sido formalmente demonstrada. 
Com esse intuito, proceda-se de maneira análoga à realizada anteriormente para a condição de contorno biapoiada. Seja a função $F(\alpha)$ dada pela Equação 3.84 e ilustrada na Figura 3.19.

$$
F(\alpha)=\cot (\alpha)-\frac{1}{\alpha}+\frac{\alpha}{3}-\frac{\alpha^{3}}{[\gamma(\chi)]_{E P}^{2}}
$$

Obviamente, a Equação 3.84 não é definida na origem, nem para valores de $\alpha$ iguais a múltiplos inteiros de $\pi$. O interesse recai, portanto, em determinar inicialmente um intervalo que contenha uma raiz de $F(\alpha)$. A avaliação da Figura 3.20 aponta para o fato de que o intervalo de existência de raízes de $F(\alpha)$ está no intervalo $(\pi, 5,7635]$. As Figuras 3.18 e 3.19 corroboram essa afirmação. Considerando-se esse intervalo, é possível encaminhar uma solução algébrica aproximada para resolução do problema.

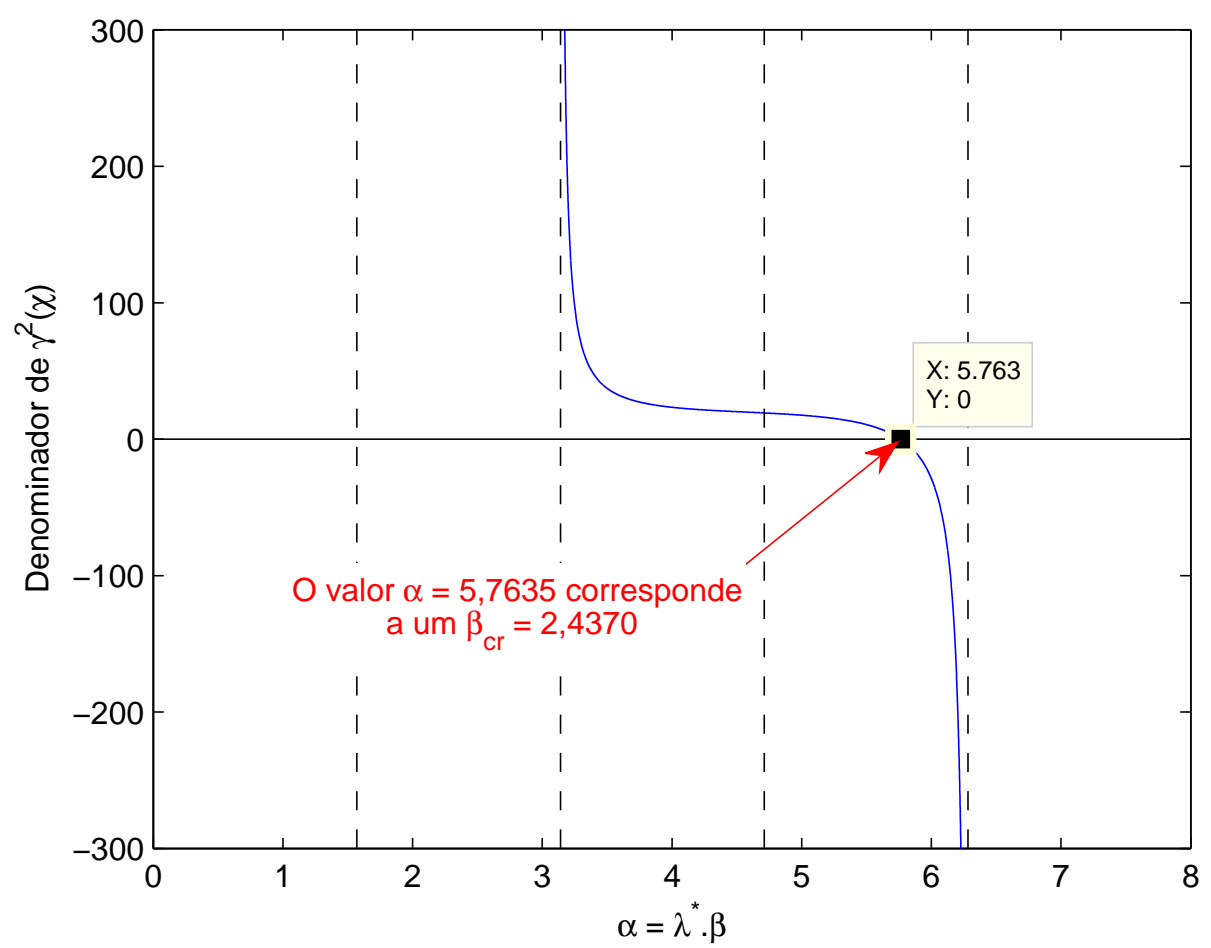

Figura 3.20: Comportamento do denominador da função $F(\alpha)$, para o caso engastado-pinado.

\subsubsection{Aproximação algébrica para o cálculo da carga crítica de vigas curvas engastadas-pinadas}

Utilizando um procedimento similar ao realizado para o caso biapoiado, é possível aproximar algebricamente a função que relaciona $\beta^{2}$ e $\Gamma$. A Figura 3.21 ilustra graficamente o comportamento real dessa função. 


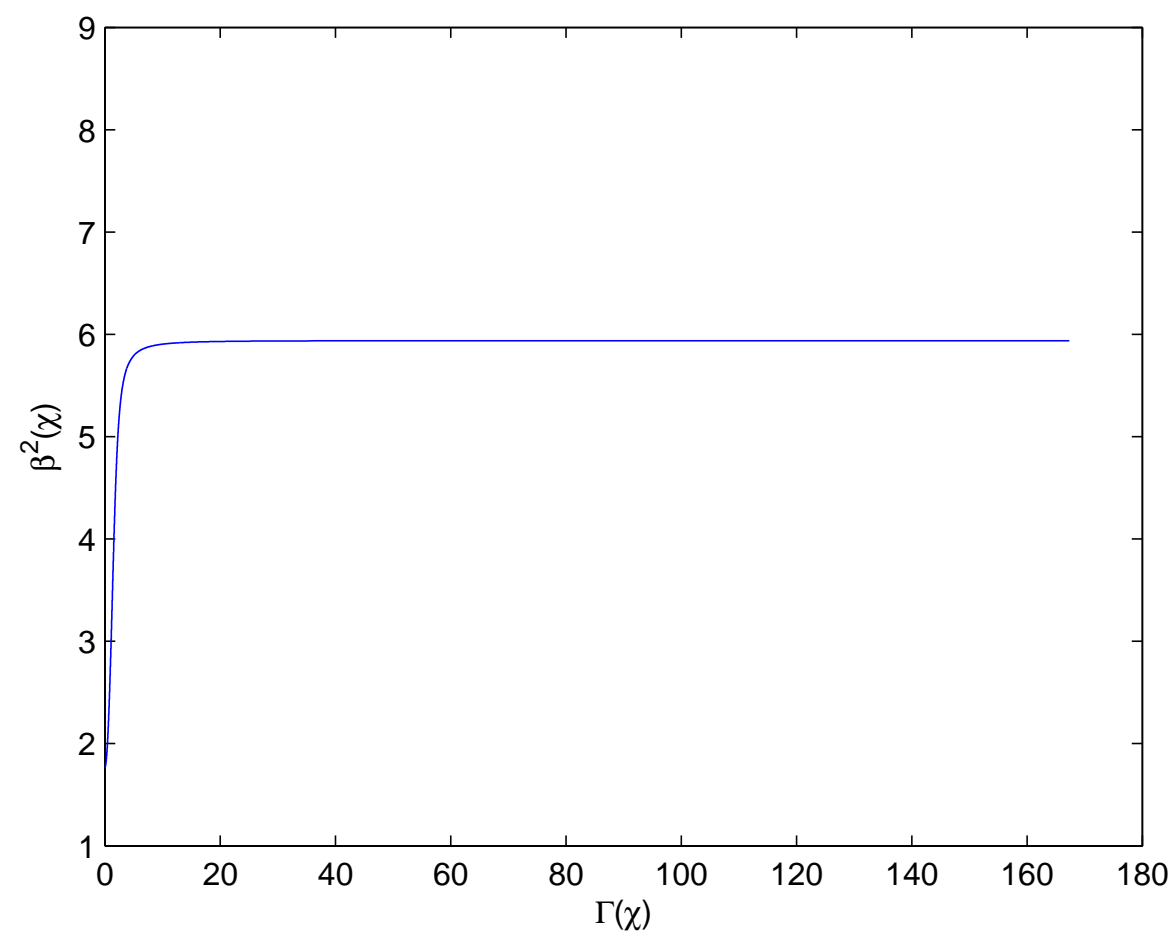

Figura 3.21: Curva que representa $\beta^{2}$ como função de $\Gamma$ para o caso engastado-pinado.

Para o vínculo engaste-pinado foi utilizada a chamada função logística, dada por $f(x)=\frac{A}{1+B \cdot \exp (C * x)}$, com $\mathrm{A} \approx 5,925 ; \mathrm{B} \approx 3,757 ;$ e $\mathrm{C} \approx-1,286$ (vide Figura 3.22).

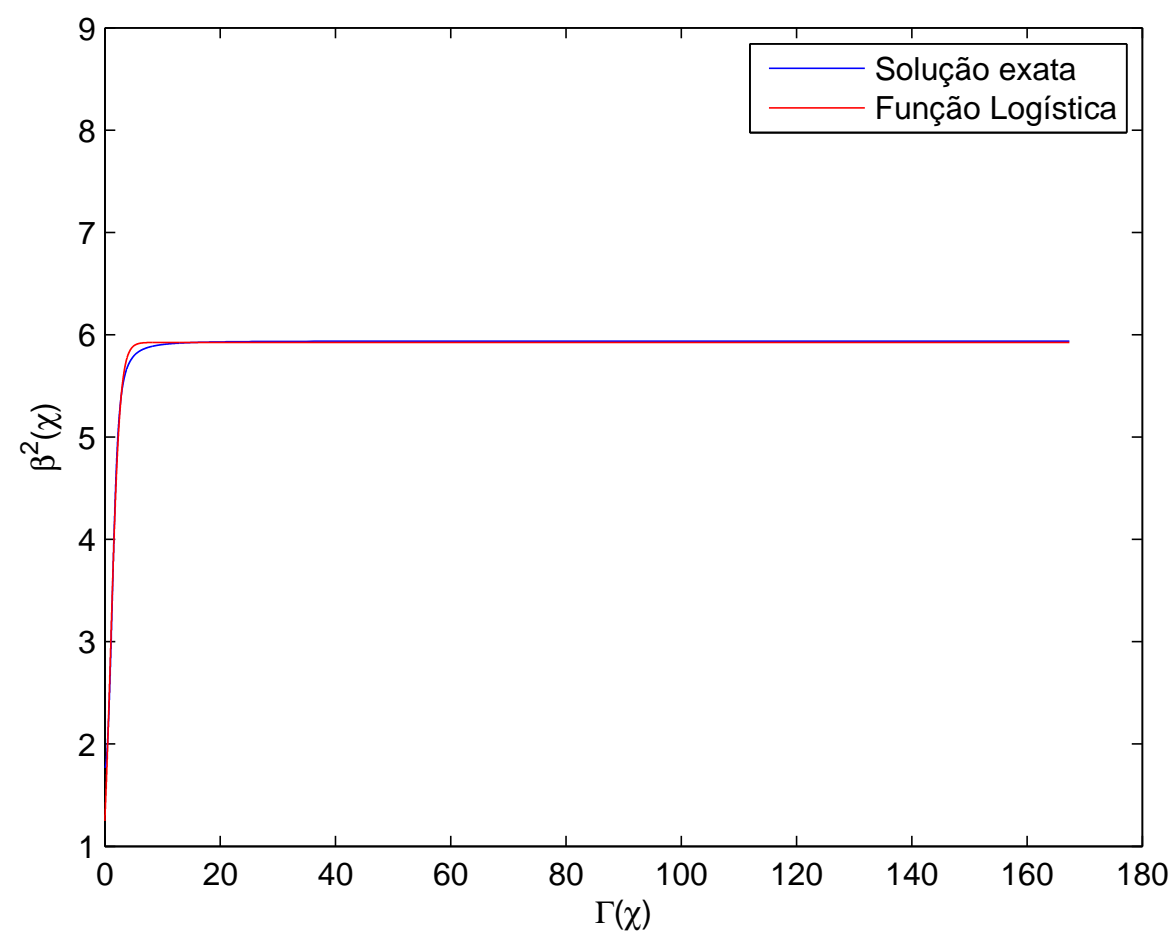

Figura 3.22: Aproximação algébrica de $\beta^{2}=f[\Gamma]$ pela função Logística. 
A Figura 3.23 apresenta as diferenças relativas entre as soluções exata e aproximada, que se mostram bastante satisfatórias, atingindo cerca de $5 \%$ para os menores valores de $\Gamma(\chi)$ e estabilizando em cerca de $0,3 \%$ para o extremo superior do intervalo de $\Gamma(\chi)$.

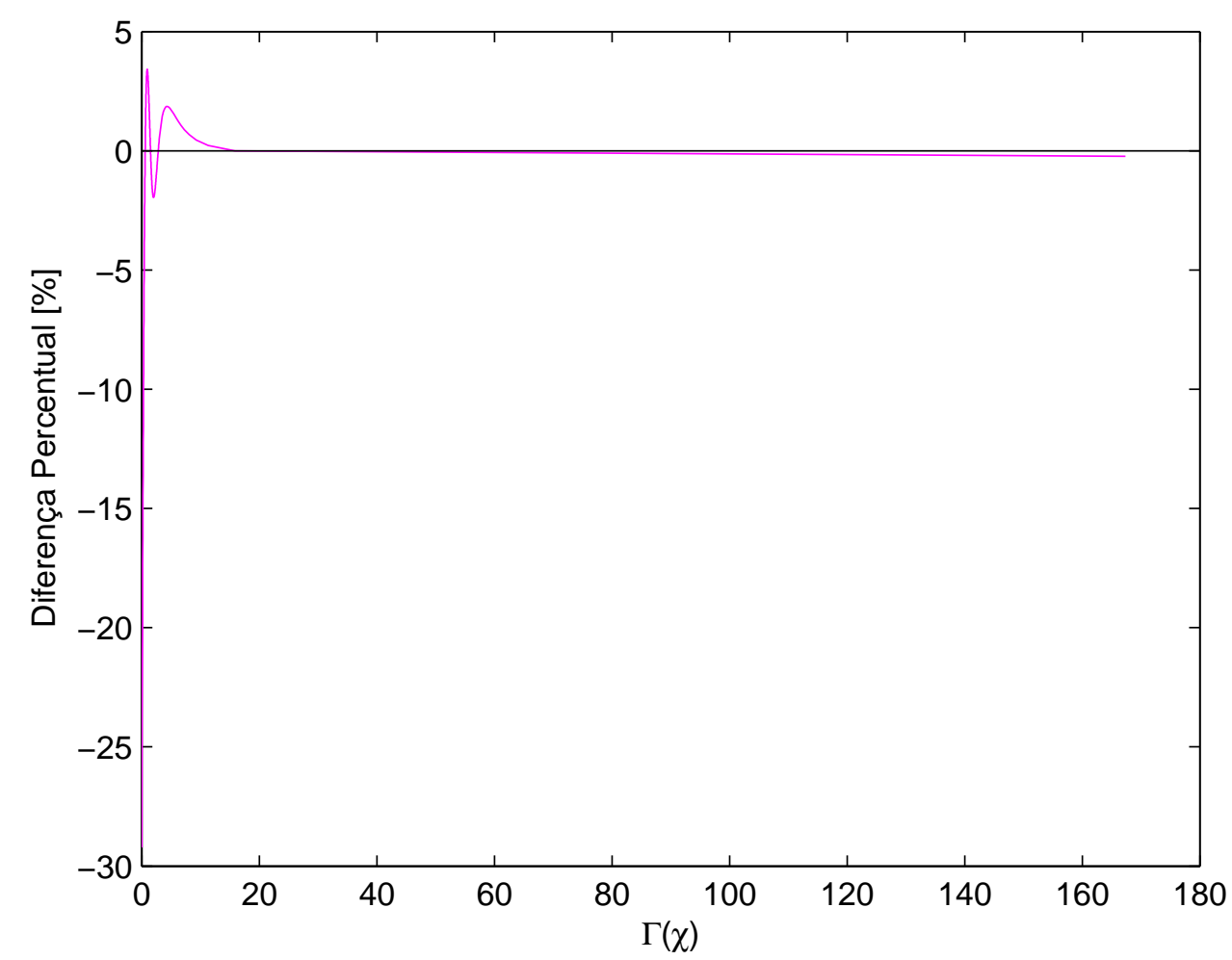

Figura 3.23: Diferenças percentuais entre a função exata e a aproximação pela função Logística.

A Figura 3.24 apresenta a relação entre os comprimentos de onda de flexão na viga curva engastada-pinada e na viga reta, de maneira similar à procedida anteriormente. Como, por definição (Equação 3.63), a carga crítica é proporcional ao valor de $\beta_{c r}(\chi)^{2}$, apresentem-se os gráficos das Figuras 3.25 e 3.26 que ilustram, respectivamente, esses valores para ambas as condições de contorno e suas aproximações algébricas. Saliente-se que esse parâmetro foi aproximado por uma função de Richards para o caso biapoiado. Para o vínculo engaste-pinado foi utilizada a chamada função logística, dada por $f(x)=\frac{A}{1+B \cdot \exp (C * x)}, \operatorname{com} \mathrm{A} \approx 5,925 ; \mathrm{B} \approx 3,757$; e $\mathrm{C} \approx-1,286$.

Embora apresentadas em conjunto, as Figuras 3.25 e 3.26 não permitem, visualmente, claras distinções entre os valores reais e aproximados de $\beta_{c r}(\chi)^{2}$, para a faixa de $\Gamma(\chi)$ relativas às condições dos ensaios, a fim de determinar quão boas são as aproximações realizadas para fins experimentais e, talvez, de projeto.

Para facilitar essa diferenciação, ilustre-se a Figura 3.27.

Com relação à Figura 3.27, algumas observações são dignas de nota. As aproximações para as condições relativas à matriz de ensaios parecem bastante satisfatórias, atingindo cerca de $5 \%$ para os menores valores de $\Gamma(\chi)$ e estabilizando em cerca de, no máximo, $0,3 \%$ para o extremo superior do intervalo de $\Gamma(\chi)$. 


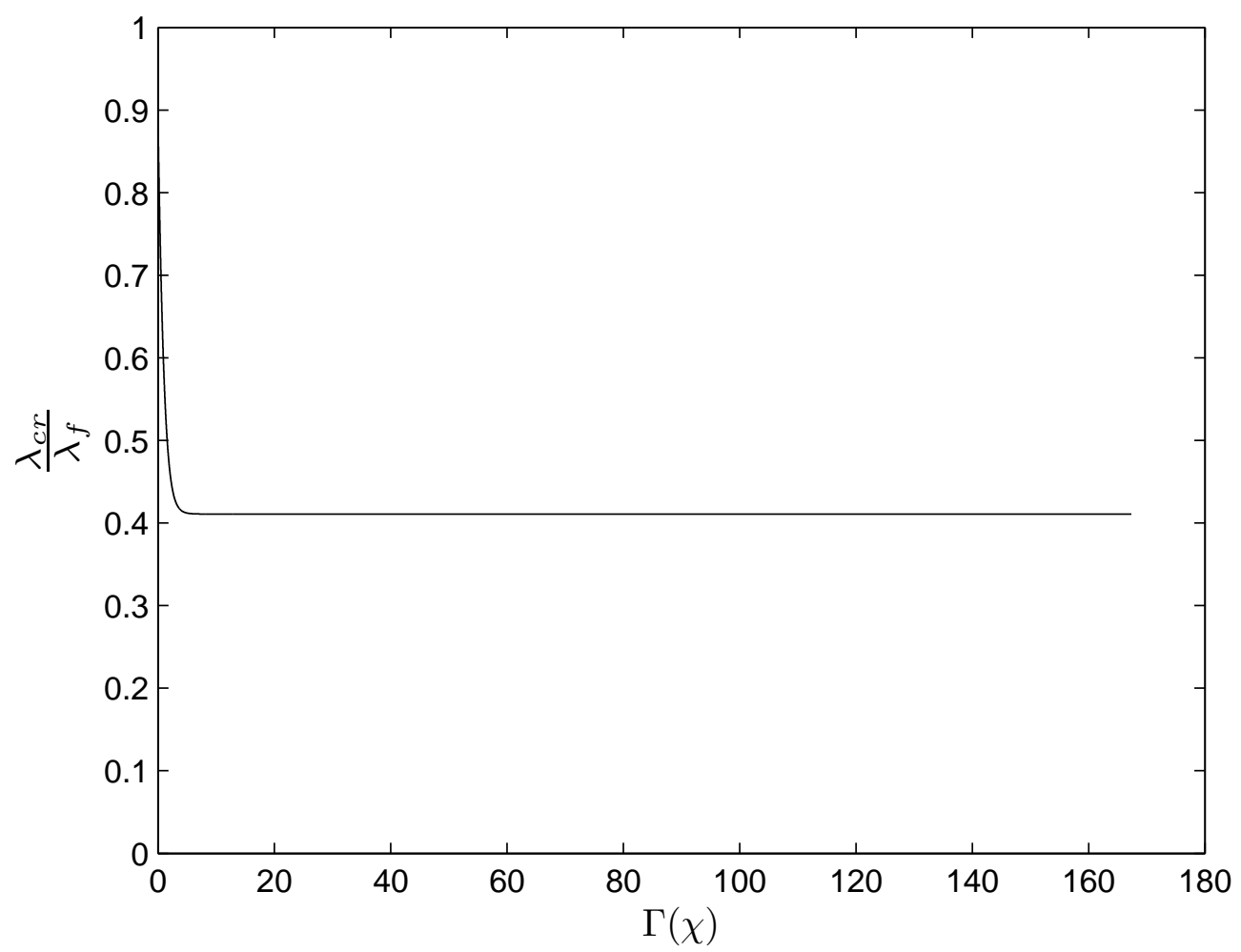

Figura 3.24: Comportamento da relação entre os comprimentos de onda de flexão na viga curva engastada-pinada e na viga reta.

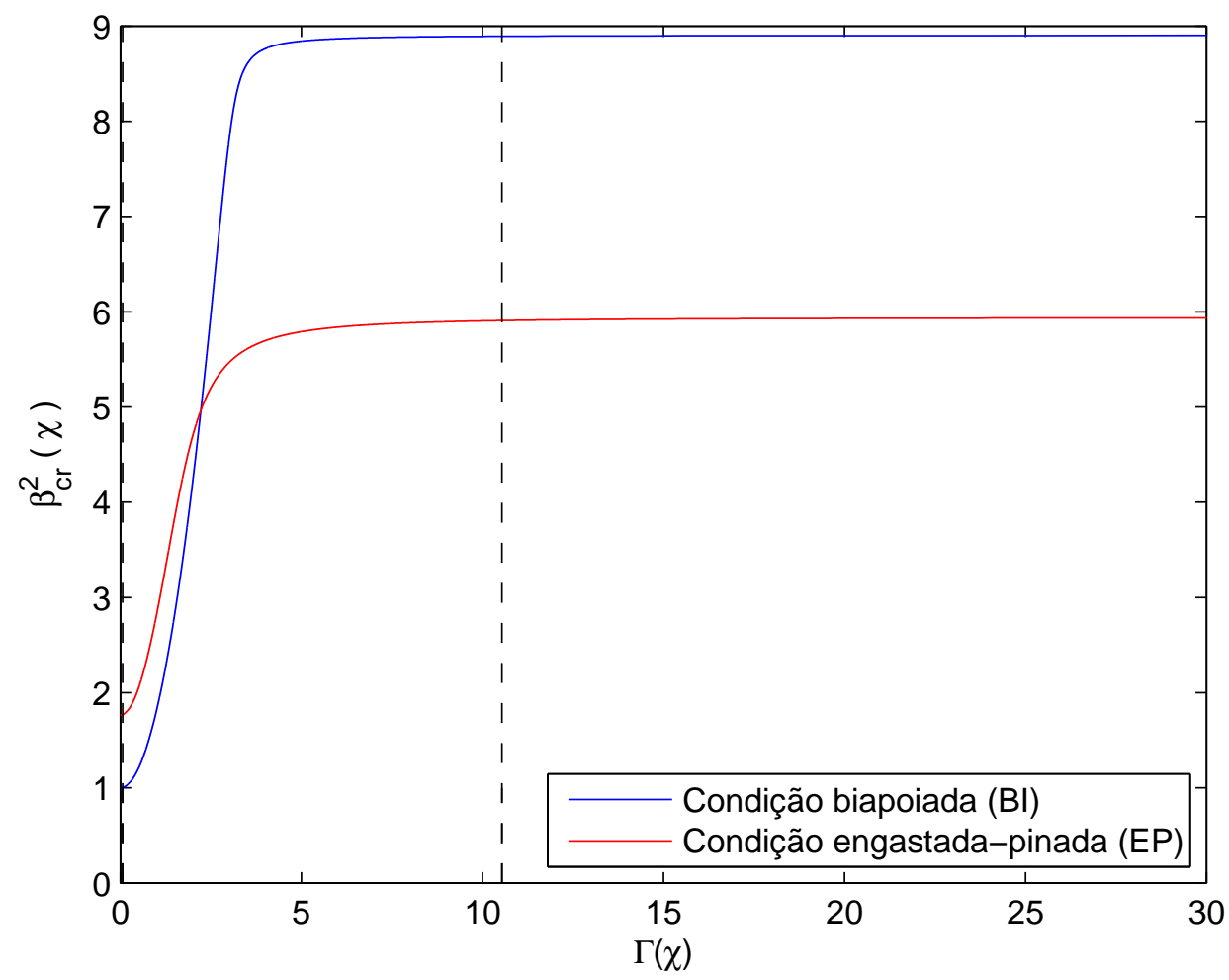

Figura 3.25: Relação gráfica exata entre $\beta_{c r}(\chi)^{2}$ e $\Gamma(\chi)$ para ambas as condições de contorno. 


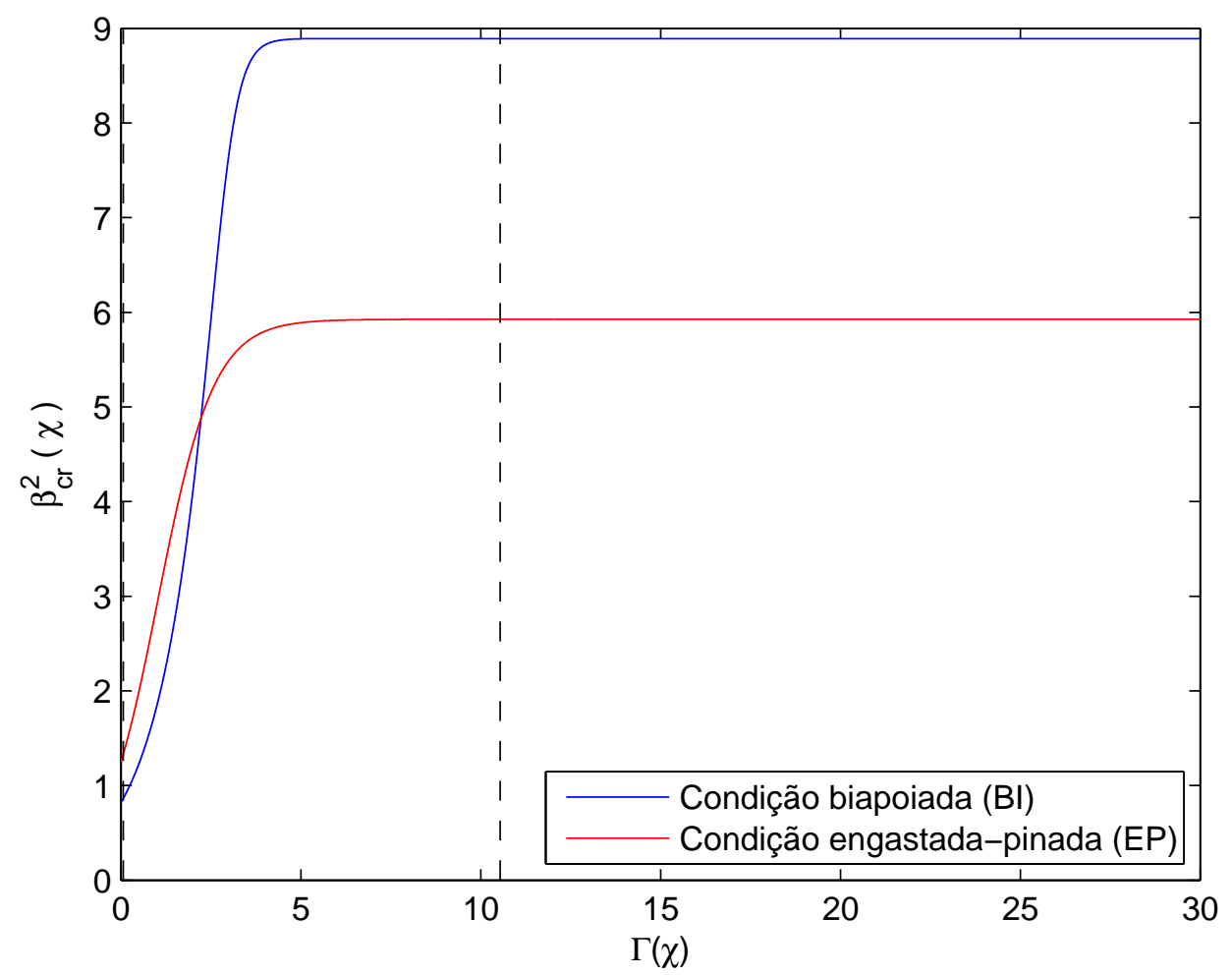

Figura 3.26: Relação gráfica aproximada entre $\beta_{c r}(\chi)^{2}$ e $\Gamma(\chi)$ para ambas as condições de contorno.

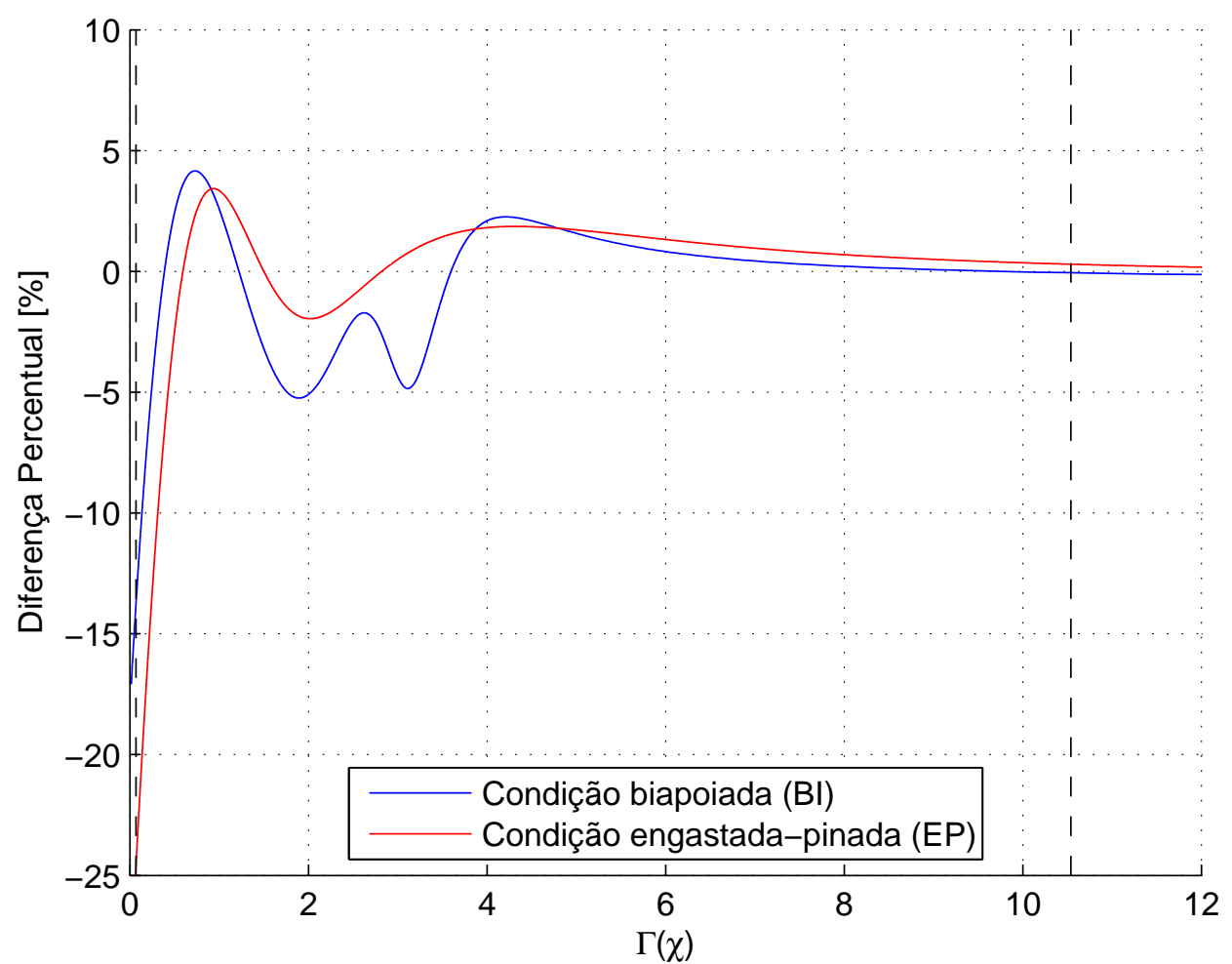

Figura 3.27: Diferenças percentuais entre os valores aproximados de $\beta_{c r}(\chi)^{2}$ em função de $\Gamma(\chi)$. 
Nesse sentido, ressaltem-se as seguintes propriedades de $\Gamma(\chi)$, advindas da definição apresentada na Equação 3.71:

- Como $\Gamma(\chi)$ é inversamente proporcional à frequência do movimento de topo, as maiores diferenças entre $\beta_{c r}(\chi)^{2}$ e sua aproximação algébrica ocorrem para as maiores frequências;

- A dependência direta de $\Gamma(\chi)$ com relação à curvatura no TDP, indica implicitamente uma relação de proporcionalidade inversa com o cosseno no ângulo de topo; assim, as menores diferenças relativas entre $\beta_{c r}(\chi)^{2}$ e as aproximações utilizadas se referem a situações de lançamento menos verticais;

- Essas conclusões foram feitas avaliando-se as diferenças percentuais observadas a partir da análise de duas variáveis, separadamente (ceteris paribus). 


\section{Capítulo 4}

\section{Metodologia}

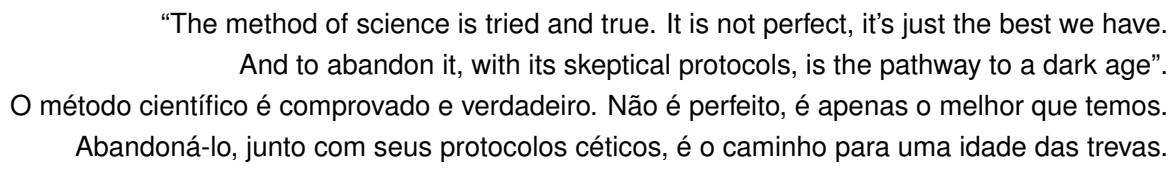

(Carl Sagan)

Conforme destacado, o presente trabalho está calcado no estudo da compressão dinâmica de risers a partir de uma abordagem tríplice, fundamentada em simulações numéricas ${ }^{1}$, formulações analíticas e ensaios físicos, com posterior confrontação e discussão dos resultados advindos de cada uma dessas vertentes.

Assim sendo, apresenta o planejamento dos trabalhos conduzidos para a obtenção dos resultados que serão explicitados e discutidos no Capítulo 6.

$\mathrm{Na}$ ordem, são expostos os métodos empregados e, a seguir, são apresentados os materiais e equipamentos utilizados.

A escolha pela apresentação nessa ordem (métodos, depois materiais) foi baseada no fato de que a escolha do material que compõe a linha flexível utilizada nos ensaios foi feita a partir dos métodos empregados, notadamente via rotina numérica confeccionada a partir de diversas referências bibliográficas de cunho analítico, a qual será apresentada adiante.

O presente capítulo é findado com uma seção adicional, onde é apresentada a caracterização físico-mecânica do modelo flexível, de maneira a permitir que o leitor entenda todo o processo de escolha do material, iniciado com o levantamento bibliográfico, passando por simulações numéricas preliminares e culminando com avaliações pós-caracterização. Essas últimas foram responsáveis pela determinação racional e sistemática da matriz de ensaios, apresentada formalmente, na íntegra, no início do Capítulo 5.

\footnotetext{
${ }^{1}$ Obviamente, todo e qualquer código computacional é baseado na resolução numérica de equações que modelam determinado sistema. Ainda assim, a vertente computacional foi destacada da analítica por se tratar da utilização de um (ou mais) programa(s) comercial (is), cujo funcionamento será explicado oportunamente, ainda neste capítulo.
} 


\subsection{Métodos}

Considerados os fundamentos teóricos constantes da revisão bibliográfica (Capítulo 2) e dos conceitos discutidos no Capítulo 3 , foi necessária a elaboração de uma rotina numérica capaz de predizer os níveis de tração esperados ao longo do comprimento do modelo físico ensaiado, bem como a carga crítica de flambagem para cada situação estudada.

Essa rotina numérica, confeccionada em ambiente Matlab ${ }^{\circledR 2}$, foi utilizada para a determinação do material do modelo e da respectiva matriz de ensaios, bem como nas análises efetuadas a partir dos resultados advindos dos experimentos realizados.

Baseada nos conceitos e predições analíticos apresentados no Capítulo 3, a rotina numérica foi confrontada com dados de experimentos físicos, simulações realizadas por programas específicos para avaliação de linhas flexíveis (Anflex e Poliflex) e outros resultados constantes na literatura especializada, a fim de dar sustentação ao procedimento adotado (explicitado no Item 4.1.2).

Com a rotina validada, o passo seguinte foi sua utilização para a avaliação racional do material a ser utilizado na confecção do modelo físico, a partir de um elenco de opções pré-selecionadas. Posteriormente, essa mesma rotina foi empregada na determinação da matriz de ensaios mais adequada, levando em consideração as limitações de materiais, equipamentos e infraestrutura geral, descritos na Seção 4.2.

A quantidade de dados e resultados gerados torna impraticável - e desnecesária - sua exposição integral, dado que não se configura como um dos objetivos específicos do presente trabalho. Assim, foram escolhidas alguns casos-base para exemplificar esse procedimento. Ademais, como o foco deste trabalho é voltado às análises do TDZ, confrontações e resultados referentes ao topo da linha foram suprimidos do texto.

A escolha do material utilizado para a construção do modelo físico (Item 4.2.4) visou a determinação daquele mais adequado em termos da possibilidades de ocorrência do fenômeno de interesse, sob diversas condições. O Item C.1 apresenta os principais resultados obtidos nas simulações preliminares, apenas para o material escolhido (tubo de silicone).

Os dados utilizados nas simulações para estudo do material selecionado foram extraídos, preliminarmente, de catálogos e publicações especializadas. Desta forma, foram feitas avaliações iniciais para determinar se o material escolhido realmente produziria os resultados desejados, quando da realização dos ensaios físicos.

Na sequência, o modelo flexível foi construído e suas características físico-mecânicas foram validadas a partir de ensaios de caracterização. O procedimento foi, então, utilizado novamente para o modelo confeccionado em silicone, com suas características avaliadas precisamente. Os resultados dessas últimas simulações numéricas permitiram a elaboração da matriz de ensaios utilizada para as investigações desta tese.

\footnotetext{
${ }^{2}$ Uma versão limitada do Matlab é disponibilizada aos alunos, gratuitamente e para fins acadêmicos, fruto de um convênio entre a sua fabricante The Mathworks ${ }^{\mathrm{TM}}$ e a Universidade de São Paulo.
} 
Findadas essas etapas preliminares, o modelo foi ensaiado no $\mathrm{CH}-\mathrm{TPN}$ com a linha imersa em água e monitorada por dois sistemas ópticos de rastreamento (um aéreo, outro aquático), devidamente calibrados, e uma célula de carga na articulação de topo. A prescrição dos movimentos de topo foi feita a partir de um dispositivo atuador, que permitiu a imposição de movimentos circulares com amplitude e frequências conhecidas. Esse equipamento foi previamente aferido, de maneira a garantir que os movimentos supostamente prescritos estivessem sendo efetivamente impostos.

Durante os ensaios realizados, os sistemas de monitoramento e o controlador da célula de carga geravam arquivos digitais individuais dos dados mensurados (deslocamentos e forças, respectivamente). A seguir, foram feitas análises, confrontando esses resultados com simulações numéricas e formulações analíticas.

As seções seguintes têm como objetivo explicitar, sistematicamente e nessa ordem: (i) o software de análise de linhas flexíveis utilizados (Item 4.1.1) e (ii) a elaboração (Item 4.1.2) e validação (Item 4.1.2) do procedimento numérico proposto para o alcance dos objetivos planejados. Esses pontos são expostos nos itens que se seguem nesta mesma seção. O presente capítulo é findado com a apresentação dos principais materiais e equipamentos utilizados no âmbito desta tese, na Seção 4.2.

\subsubsection{Programa de análise de linhas flexíveis}

Existem diversos programas comerciais, ou de uso restrito ${ }^{3}$, para estudo de linhas submersas. De maneira geral, esses programas recebem como dados de entrada as propriedades físicas e geométricas da linha, sua condição de lançamento, as características de processamento a serem utilizadas, tais como intervalo de tempo de integração e incrementos de tempo (ou time step); condições ambientais, como correnteza e ondas; densidade e viscosidade do meio; coeficientes de arrasto e massa adicional; atritos e rijezas relativas ao leito marinho, entre outras.

Esses programas permitem o estudo da estática e da dinâmica dessas linhas, sendo que, para tanto, são empregados métodos numéricos de integração direta das equações diferenciais que regem o equilíbrio da linha.

Normalmente, a avaliação da mecânica de tubos submersos se vale da subdivisão do corpo em elementos de comprimentos fixos, não necessariamente iguais, permitindo que se aumente o número de elementos em suas extremidades para uma análise local mais precisa, por exemplo. Adicionalmente, condições de contorno adequadas permitem que o conjunto desses elementos descreva o corpo como um todo.

Em geral, os códigos numéricos para estudos de linhas permitem que o usuário escolha o tipo de elemento a ser utilizado para a modelagem (treliça, pórtico, barra ou viga), bem como as saídas a serem apresentadas após os cálculos (séries temporais de deslocamentos ou trações, envelopes, frequências naturais, entre outros).

\footnotetext{
${ }^{3}$ São exemplos de programas para avaliação de risers e cabos umbilicais: Orcaflex (Orcina Ltd.), Deeplines (Principia), Flexcom (MCS Kenny), DeepC / Riflex (SESAM - DNV), RiserDyn (Golbal Maritime), Poliflex e Anflex.
} 
Outras funcionalidades comuns a esses programas são: a confrontação dos resultados auferidos com as normas de determinadas Sociedades Classificadoras, estudo de tensões de ruptura e avaliação de fadiga. Nenhuma dessas, entretanto, será utilizada ou discutida no presente texto.

O Anflex (desenvolvido pelo $\mathrm{LACEO}^{4}$ ) é um programa de uso restrito da Petrobras. Para fins acadêmicos, seu uso é permitido para esquisas e estudos relacionados ao TPN-USP, a partir de um convênio específico. Assim, dada a disponibilidade, o Anflex foi escolhido para a elaboração da matriz de ensaios e confrontação com os resultados finais dos experimentos.

O Poliflex 3D é um programa desenvolvido no Departamento de Engenharia Mecânica da Escola Politécnica da Universidade de São Paulo, que permite avaliar a estática e o comportamento dinâmico tridimensionais de cabos umbilicais e risers flexíveis, levando em conta os efeitos decorrentes de carregamentos ambientais e da rigidez flexional. A utilização desse programa foi gentilmente autorizada para os trabalhos inerentes aos objetivos da presente tese, principalmente com relação à estática da linha e a determinação dos modos e frequências naturais de vibração.

Uma diferença importante no que tange ao funcionamento desses dois programas é que o Anflex utiliza análises no domínio do tempo, enquanto que o Poliflex trabaIha com análises no domínio da frequência. A necessidade de obtenção das séries temporais (de trações e deslocamentos, principalmente) culminou na utilização preferencial do Anflex. Entretanto, sempre que possível, o Poliflex foi adotado uma fonte adicional de dados para comparações com os resultados das demais abordagens.

\subsubsection{Procedimento numérico utilizado}

O procedimento para elaboração da matriz de ensaios mereceu uma seção à parte, dado que foi baseado no estudo detalhado e compilação de diversos trabalhos apresentados no levantamento bibliográfico, dentre os quais se destacam os efetuados por Irvine \& Caughey (1974), Chakrabarti \& Frampton (1982), Patel \& Seyed (1995), Pesce (1997), Ribeiro et al. (1998), Aranha \& Pinto (2001), Aranha et al. (2001) e Simos \& Fujarra (2006); em consonância com as recomendações presentes em (ABS, 2008), (DNV, 2010a), (DNV, 2010b), (API, 1993), (API, 2009) e (McCann et al., 2003).

A matriz de ensaios foi elaborada com base em rotinas numéricas confeccionadas a partir do que foi estabelecido por Pesce (1997) para a estática de linhas em catenária, com a correção devida à rigidez axial proposta por Patel \& Seyed (1995). A partir daí, a dinâmica da linha foi estabelecida pelas formulações analíticas fundamentadas em (Aranha \& Pinto, 2001) e (Aranha et al., 2001), resultando, respectivamente, na determinação das séries de tração efetiva no topo e no TDP e no cálculo da carga crítica para cada situação considerada.

\footnotetext{
${ }^{4}$ O LACEO é o Laboratório de Análise e Confiabilidade de Estruturas Offshore da Universidade Federal do Rio de Janeiro.
} 
Portanto, a determinação das condições dos experimentos realizados seguiu o seguinte procedimento:

1. Dadas algumas das características físicas da linha (comprimento total $L_{t}$, diâmetros externo $D_{\text {ext }}$ e interno $D_{\text {int }}$ e massas próprias lineares no ar $m$ e imersa $q$ ) e sua condição de lançamento (lâmina d'água $H$ e ângulo de topo $\theta_{t}$ ou tração no TDP $T_{0}$ ), determina-se sua configuração estática de equilíbrio, incluindo as trações estáticas efetivas ao longo da linha, com base em (Pesce, 1997) e em (Patel \& Seyed, 1995), que incorpora os efeitos da rigidez axial, $E A$;

2. Calcula-se a carga crítica de compressão para cada situação, a partir da equação analítica desenvolvida por Aranha et al. (2001), que demanda o conhecimento prévio da estática da linha, bem como do período de excitação $T$ sobre a linha e sua rigidez flexional $E I$;

3. Em seguida, determinam-se as trações dinâmicas efetivas no topo e no TDP, com a utilização da formulação apresentada em (Aranha \& Pinto, 2001), utilizando os dados anteriormente disponíveis e calculados, além dos coeficientes adimensionais de massa adicional e de arrasto;

4. Nos casos em que a tração efetiva ultrapassar a carga crítica de flambagem durante a compressão, o primeiro valor é substituído por esse último, de maneira que o sinal, antes harmônico, passa a apresentar uma região de "saturação", típica da compressão dinâmica em risers.

Uma rotina numérica integra e controla os cálculos, determinando, ao final, os casos passíveis de ocorrência de compressão dinâmica. A Figura 4.1 ilustra e organiza o procedimento descrito para determinação da matriz de ensaios.

A fim de dar sustentação ao procedimento apresentado, o mesmo foi utilizado para avaliar os resultados decorrentes de Ribeiro et al. (1998), de (Simos \& Fujarra, 2006), de Aranha \& Pinto (2001) e de Aranha et al. (2001). Para tanto, foram utilizadas simulações numéricas (procedimento apresentado na Figura 4.1 e Anflex) e os resultados dos respectivos trabalhos.

Impotante destacar que em todas as simulações numéricas foram respeitados os critérios básicos estabelecidos pelas (API, 1993) e (API, 2009) para os limites superiores de comprimento dos elementos finitos:

- Próximo às extremidades, o comprimento do elemento não pode exceder $C=$ $\sqrt{\frac{E I}{T}}$

- Nos demais trechos, o comprimento do elemento não pode exceder $C=\frac{\pi}{\omega} \cdot \sqrt{\frac{E I}{T}}$, onde $\omega$ é a maior frequência de vibração lateral, a ser incluída na análise;

- A razão entre os comprimentos de dois elementos sucessivos não poder ultrapassar 1:2. 


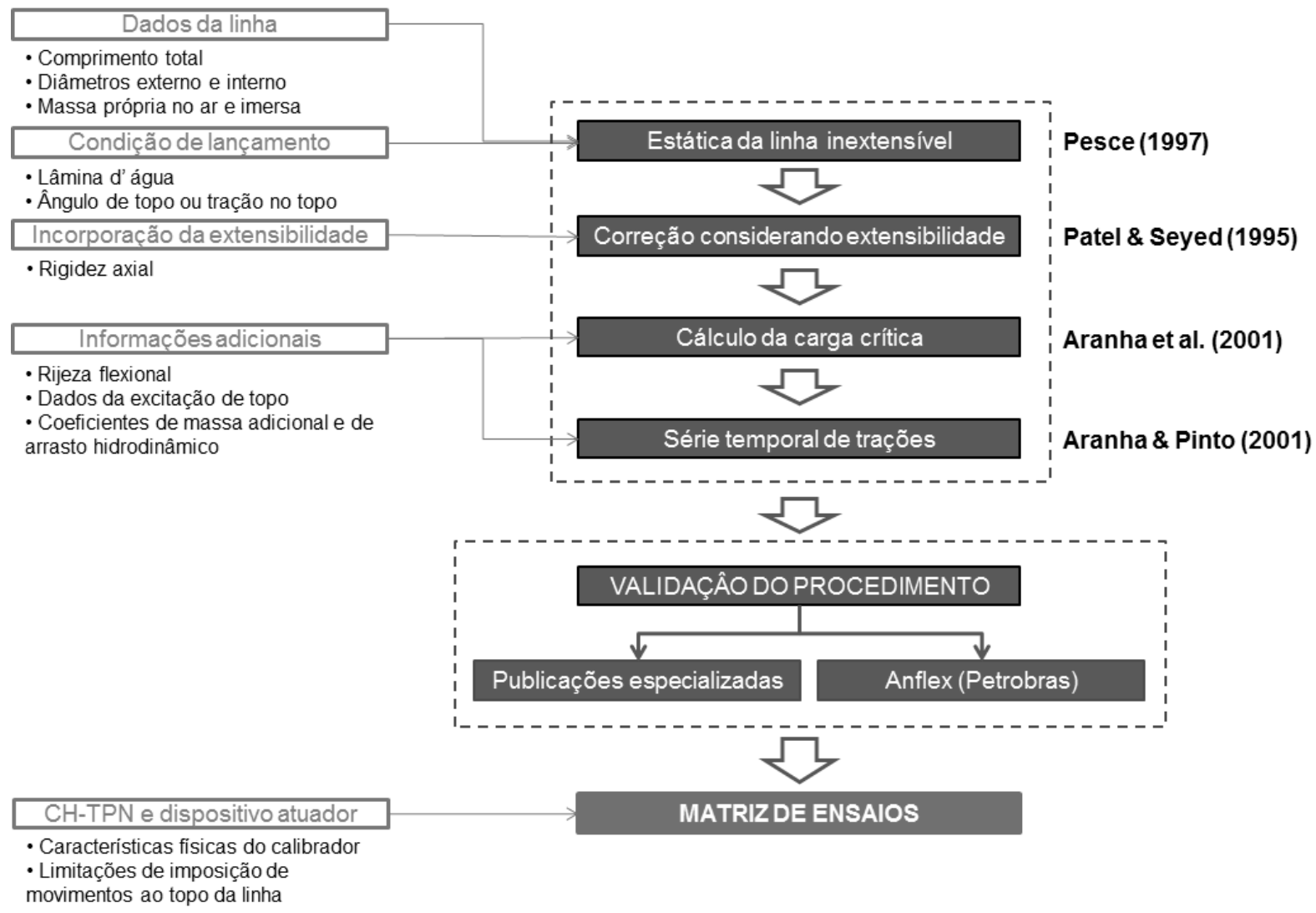

Figura 4.1: Fluxograma do procedimento para elaboração da matriz de ensaios.

De acordo com Leira (2010), "a experiência indica que o incremento de tempo utilizado nas simulações não deve ultrapassar um vigésimo a um décimo do menor período natural do movimento, para qualquer grau de liberdade do modelo" (em casos em que haja risco de instabilidades), prática que também foi utilizada e explicitamente citada por Simos \& Fujarra (2006). Em todos os casos, foram utilizados incrementos temparais que garantissem um mínimo de 20 pontos por período simulado.

A validação do procedimento ilustrado na Figura 4.1 foi feita da seguinte maneira:

- As primeiras comparações ilustradas, seguindo o próprio procedimento apresentado, são relativas à estática de duas linhas completamente distintas, estudadas respectivamente em Ribeiro et al. (1998), um SCR; e em Simos \& Fujarra (2006), modelo de linha flexível;

- Em seguida, resultados referentes à dinâmica de topo de um modelo riser em catenária, cujo experimento foi realizado no ar com o monitoramento de uma célula de carga, são utilizados para comparação;

- Nas demais confrontações foram utilizados os resultados de Ribeiro et al. (1998), via simulações com o Anflex; e de Simos \& Fujarra (2006), via experimentos. Para esses casos, as avaliações foram realizadas para o TDP e para o topo. 


\section{Validação do procedimento proposto}

O procedimento proposto foi verificado a partir dos resultados citados no item precedente. Ao leitor que se interessar por algumas das confrontações realizadas, sugerese a leitura do Apêndice $B$.

Como consequência direta, as avaliações levadas a termo permitem concluir que o modelo utilizado, baseado em (Patel \& Seyed, 1995), em (Aranha \& Pinto, 2001) e em (Aranha et al., 2001) permite, de forma simples, rápida e aparentemente eficiente, a previsão da ocorrência do fenêmeno de interesse. 


\subsection{Materiais}

Essa seção tem como finalidade a apresentação dos principais materiais e equipamentos utilizados no âmbito desta tese: o Calibrador Hidrodinâmico do Tanque de Provas Numérico ( $\mathrm{CH}-\mathrm{TPN}$ ), onde os experimentos foram realizados; a instrumentação utilizada (sistema de rastreamento óptico, para a dinâmica global, e a célula de carga, fixada no topo da linha, a fim de determinar as séries temporais de tração naquele ponto, entre outros); o atuador eletromecânico para prescrição de movimento no topo da linha e o modelo de riser lançado em catenária.

\subsubsection{Calibrador Hidrodinâmico $\mathrm{CH}-\mathrm{TPN}$}

O Tanque de Provas Numérico (TPN), ligado ao Departamento de Engenharia Naval e Oceânica (PNV) da Escola Politécnica da Universidade de São Paulo (EPUSP), possui um Calibrador Hidrodinâmico (CH-TPN) com 14m de comprimento, $14 \mathrm{~m}$ de largura e profundidade de 4m. Embora seja dotado de 148 batedores (flaps), distribuídos em 4 conjuntos de 37 batedores, conforme pode ser visualizado na Figura 4.2 e que podem ser acionados independentemente, de maneira a gerar ondas. $\mathrm{O}$ uso do $\mathrm{CH}-\mathrm{TPN}$ foi limitado à sua função como tanque oceânico, sem a geração/ absorção de ondas.

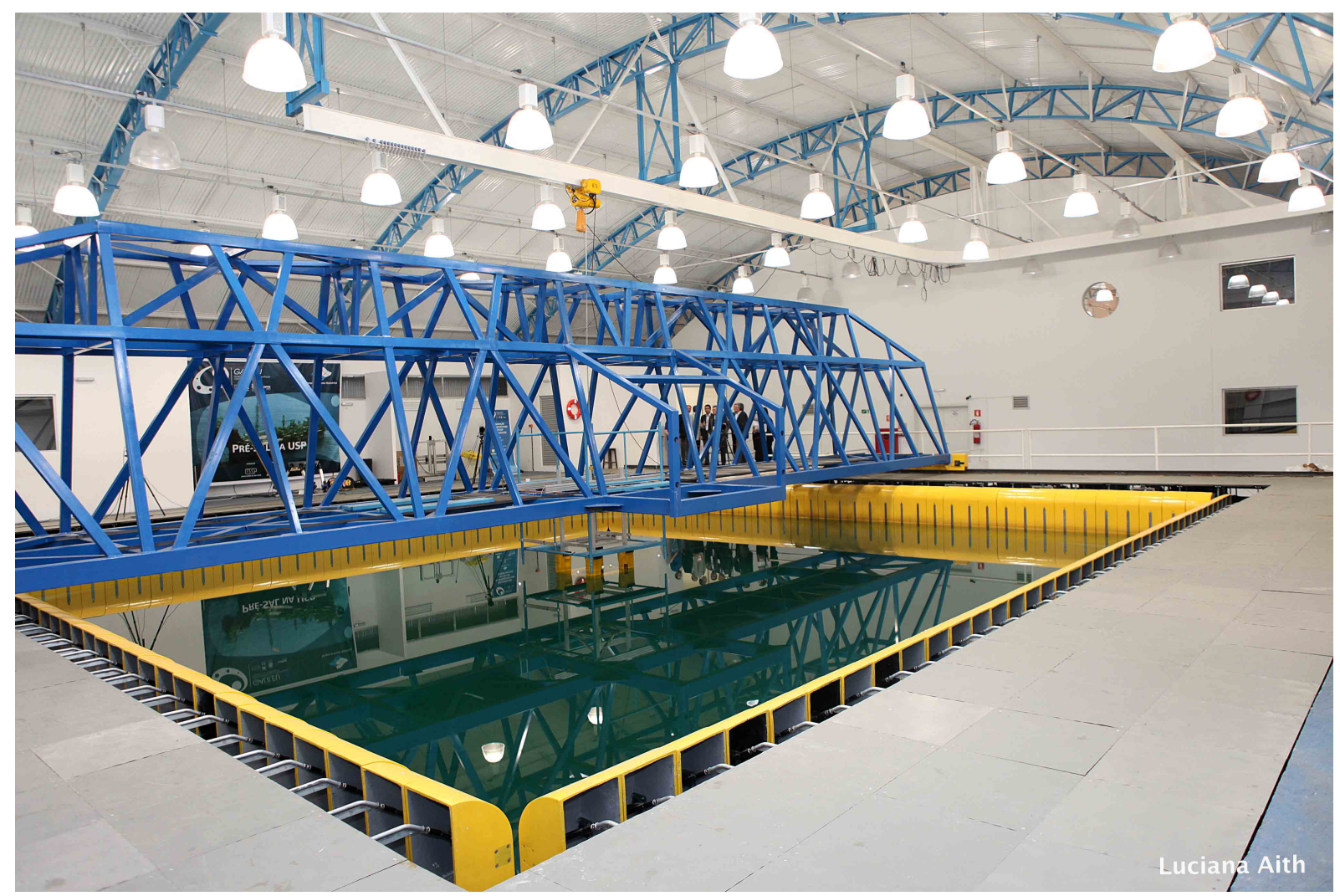

Figura 4.2: Visão geral do $\mathrm{CH}$-TPN.

Foto de Luciana Aith, disponível em www.jornalcanal16.com/?p=14992, acessado em 10/12/2014. 
Em sua concepção original, ensaios de arrasto não são possíveis neste calibrador, dada sua pequena extensão longitudinal. A despeito dessas caracaterísticas, ensaios de linhas sem correnteza e com prescrição de movimento de topo são completamente possíveis, desde que a escala utilizada seja adequada à sua profundidade relativamente pequena. Cabe notar que, hoje, experimentos com correnteza podem ser realizados no $\mathrm{CH}$-TPN, dado que uma estrutura adicional foi recentemente adaptada, o braço giratório ou "rotating arm"); embora seu uso não tenha sido necessário para os ensaios realizados no âmbito desta tese.

\subsubsection{Instrumentação utilizada nos ensaios}

A presente seção não tem por objetivo apresentar e descrever todos os equipamentos utilizados neste trabalho. Equipamentos como computadores, balanças, trenas, massas calibradas, entre outros, serão apenas citados, para que detalhes em demasia não desviem a atenção do leitor. Optou-se, então, pela descrição dos materiais e dos equipamentos fundamentais aos ensaios físicos realizados no $\mathrm{CH}$-TPN.

Um dos grandes problemas comuns aos trabalhos experimentais relacionados a sistemas oceânicos e seus subsistemas, principalmente no tocante ao ensaio de linhas de amarração, risers e umbilicais, está relacionado à escala envolvida.

Em geral (e também nos casos relacionados ao presente trabalho), utiliza-se a similaridade de Froude e também a similaridade dinâmica associada aos fenômenos de interesse, em detrimento da similaridade de Reynolds.

Uma consequência direta dessa característica é que, para os tanques de provas comumente utilizados, a adoção de uma escala de redução para construção de modelos deve ser feita com muito cuidado. Isso porque, no caso de linha esbeltas, respeitandose o comprimento total, fica inviável a similaridade de diâmetros, que se apresentariam extremamente diminutos.

Uma alternativa é a construção de modelos com os menores diâmetros possíveis, desrespeitando a escala escolhida, mantendo a similaridade das demais características relevantes, como rijezas axial e flexional, massas própria e submersa, entre outras. Este procedimento, conhecido como distorção de escala, foi adotado nesta tese.

Dadas essas considerações, a utilização de uma instrumentação conveniente, de maneira a interferir minimamente nas variáveis que se deseja mensurar é de extrema importância. Nesse sentido, foi utilizado um sistema comercial de rastreamento de movimentos por imagens, composto de câmeras (ver Figura 4.3) emissoras e receptoras de luz adequada ao meio em questão (ar ou água).

O TPN-USP possui um conjunto de câmeras aéreas e submersas, integradas a um programa de gerenciamento dedicado, que permite o rastreamento de alvos refletivos. Esses equipamentos foram utilizados nos ensaios desta tese, o que permitiu 0 monitoramento do modelo físico como um todo e não apenas na região do TDZ. 


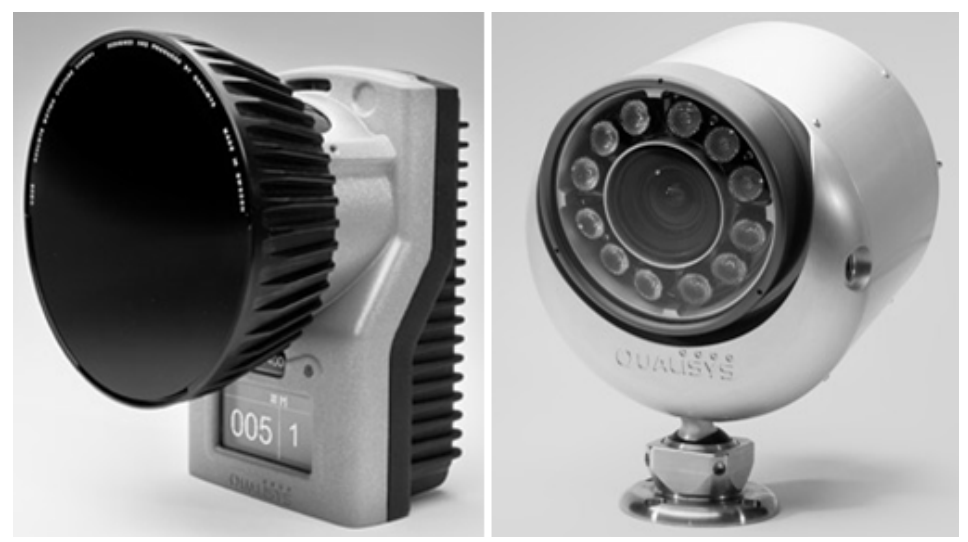

Figura 4.3: Câmeras do sistema óptico de monitoramento. À esquerda, câmera aérea; à direita, câmera subaquática.

Fonte: Site http://www.qualisys.com/products/hardware, acessado em 23/11/2013.

Importante citar que o sistema da Qualisys possui alta precisão, flexibilidade de montagem e facilidade de calibração e uso, além do próprio programa gerenciador, que permite a geração automática dos registros temporais, de deslocamentos, velocidades, acelerações, rotações e/ou ângulos, conforme a necessidade do usuário, no sistema de coordenadas real.

Cabe salientar que é necessário o uso de, no mínimo, duas câmeras para o rastreamento tridimensional de alvos refletivos. Um número maior de câmeras permite a redundância de pontos, melhorando a precisão. Além disso, o uso de um maior número de câmeras mitiga, ou pelo menos diminui, a incidência de problemas como a oclusão dos alvos refletivos ou má identificação dos mesmos.

Como procedimento inicial ao uso desse equipamento como sistema de rastreamento (o que é feito por meio de alvos refletivos dispostos sobre a linha flexível a ser ensaiada, vide Figura 4.4), é necessária a calibração de uma região que contenha o modelo em escala, de maneira que as imagens bidimensionais geradas possam ser utilizadas para a determinação matemática e automática das coordenadas tridimensionais dos alvos rastreados. O sucesso da etapa de calibração é imprescindível para a qualidade dos resultados obtidos, visto que é possível a redução dos erros a ela associados.

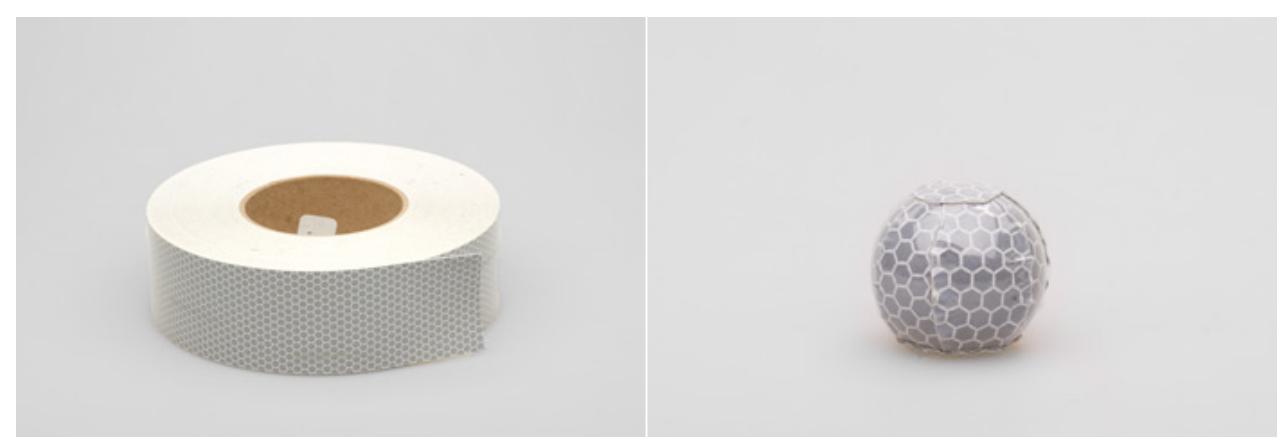

Figura 4.4: Alvos refletivos passivos utilizados pelo sistema de rastreamento óptico.

À esquerda, fita adesiva refletiva; à direita, alvo esférico.

Fonte: Site http://www.qualisys.com/products/accessories/passive-markers, acessado em 23/11/2013. 
O processo de calibração consiste em fixar uma estrutura de referência em formato de "L" (conhecida como cálibre e ilustrada na Figura 4.5 - detalhe A), e movimentar ao seu redor um bastão de calibração em formato de "T" (Figura 4.5 - detalhe B).

O conjunto de todas as posições alcançadas pelos alvos do bastão de calibração delimitam o volume de controle calibrado (em vermelho nessa mesma ilustração).

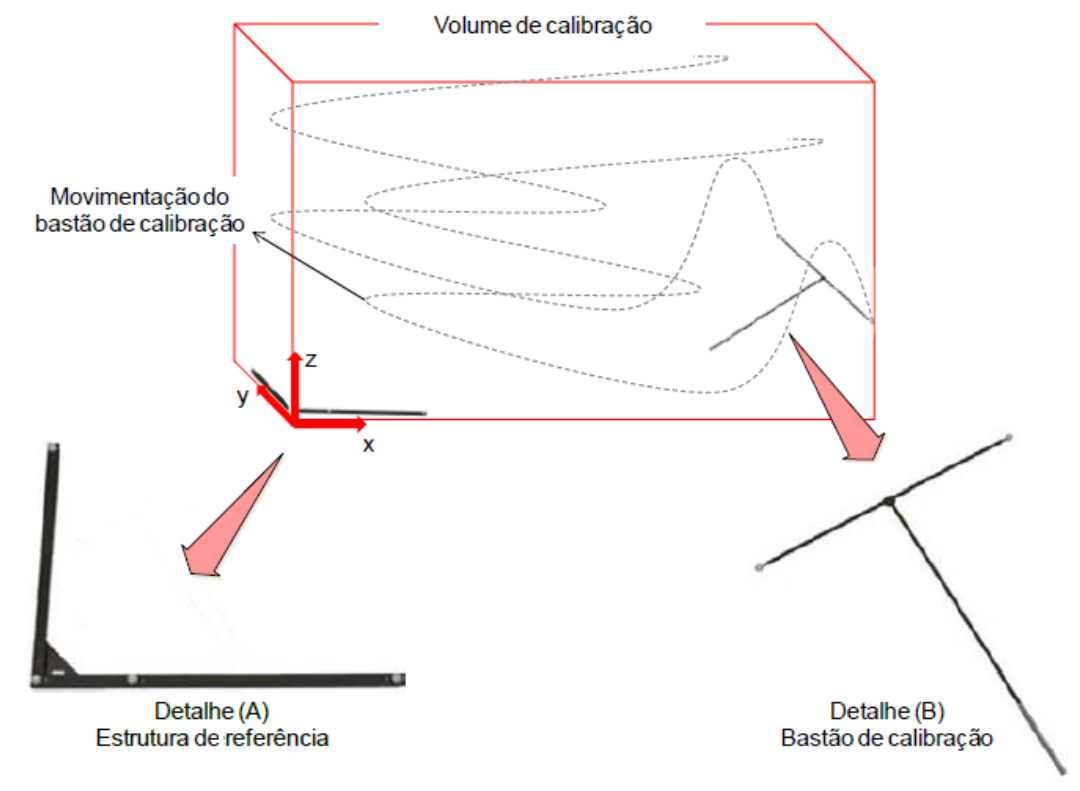

Figura 4.5: Calibração do volume de controle do sistema de rastreamento óptico.

Fonte: (Amarante, 2011).

Após a calibração das câmeras, o programa dedicado determina automaticamente a posição das mesmas em relação ao centro de coordenadas real, fixado no ângulo reto da estrutura de referência. Esse sistema de coordenadas é uma base positiva, na qual o eixo x é paralelo ao maior lado da estrutura de referência e o eixo y é paralelo ao outro lado. $O$ eixo $z$ é perpendicular ao plano que contém os eixos $x$ e y (Figura 4.6).

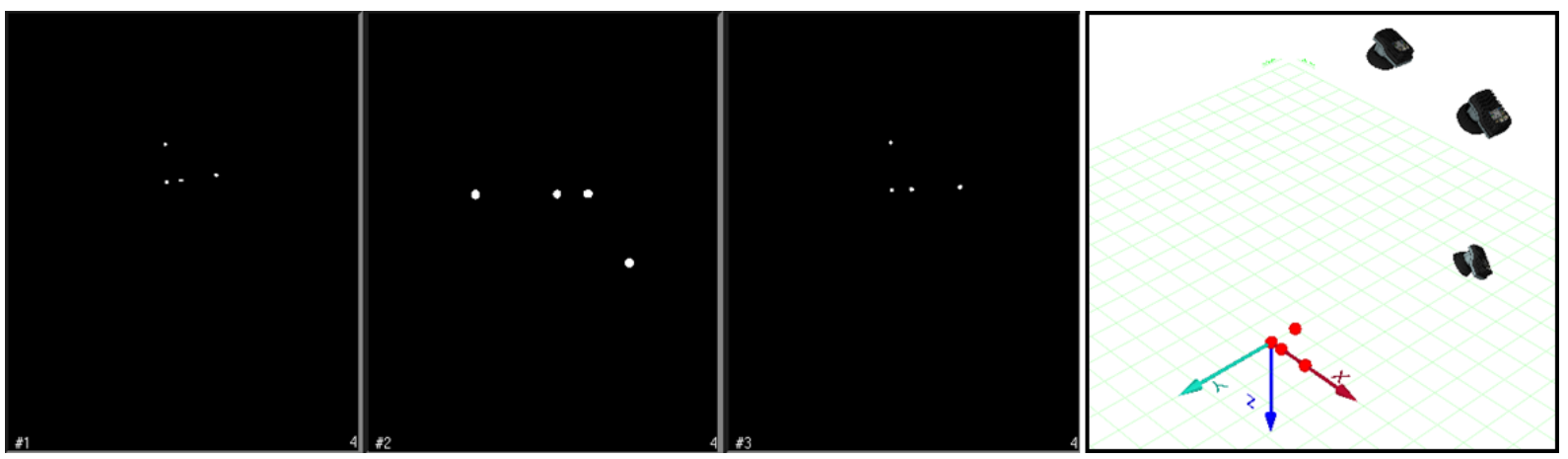

Figura 4.6: Identificação da estrutura de referência pelo software do sistema óptico.

Depois de calibrado, o sistema de câmeras possibilita a identificação e acompanhamento de movimentos dentro do volume de controle estabelecido. Incertezas associadas ao processo de calibração são calculados automaticamente pelo programa do sistema e apresentados ao usuário. 


\subsubsection{Dispositivo atuador}

Neste texto, denominar-se-á por dispositivo atuador o mecanismo utilizado para excitar o topo do modelo flexível ensaiado. De maneira geral, esse equipamento é composto por um conjunto motorredutor ligado a um inversor programável capaz de gerar movimentos circulares com frequência definida pelo usuário. O conjunto ilustrado na Figura 4.7 apresenta o dispositivo montado, tal como foi instalado na ponte rolante do $\mathrm{CH}$ TPN, com o auxílio de barras de alumínio e elementos de fixação.

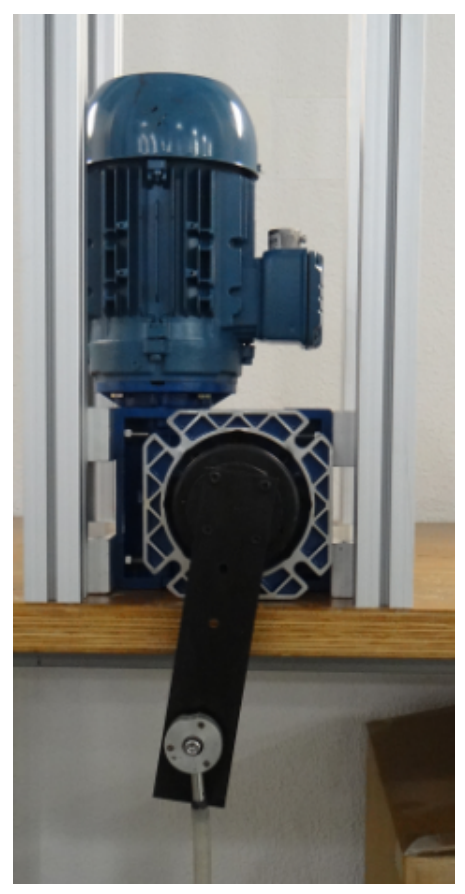

Figura 4.7: Visão geral do dispositivo atuador, sobre a bancada de montagem.

Pela Figura 4.7, é possível perceber a montagem, forçada e parafusada, de um braço rígido na saída do eixo do motorredutor responsável pela transmissão dos movimentos do motor ao topo do modelo. Ao longo desse braço foram feitos furos, colineares entre si e ao centro de rotação, a distâncias pré determinadas, correspondentes às amplitudes prescritas pelo movimento de topo.

A cada um desses furos é possível fixar um rolamento conectado a uma célula de carga, compondo o conjunto que permite manter a linha flexível presa ao dispositivo atuador, de sorte que a linha flexível se movimente solidariamente ao braço do atuador, com mesmas amplitudes e frequências.

Ainda pela Figura 4.7, é possível visualizar o rolamento ao qual a célula de carga foi montada, além de um trecho do modelo flexível, fixado diretamente ao rolamento, apenas para fins ilustrativos.

Os resultados obtidos na aferição do dispositivo atuador são apresentados no Capítulo 5, Seção 5.2, onde detalhes adicionais sobre a montagem do aparato são explicitados. A apresentação da montagem final do aparato experimental naquele capítulo evita a 
antecipação de particularidades que dizem respeito à matriz de ensaios concebida, de modo que, para os fins desta seção, essa descrição é suficiente.

\subsubsection{Modelo de linha flexível}

O modelo físico utilizado foi uma linha flexível ${ }^{5}$ com lançamento em catenária (sob diferentes ângulos de topo), ancorada ${ }^{6}$ ao fundo do $\mathrm{CH}$-TPN e conectada em sua outra extremidade à célula de carga presa pela rótula ao dispositivo atuador.

Conforme já descrito, os movimentos globais da linha foram monitorados por um sistema óptico de rastreamento de alvos refletivos dispostos sobre o modelo flexível (tanto em sua porção submersa, quanto no trecho que ficava fora d'água).

\section{Escolha do material para confecção do modelo físico}

A escolha do material utilizado na confecção do modelo foi feita a partir de um elenco de materiais mais usados em experimentos relacionados à dinâmica de linhas flexíveis.

Dentre todos os materiais aventados, os mais promissores foram o alumínio, a borracha, o nylon, o polietileno e o silicone. Para cada um desses materiais, a rotina numérica confeccionada em consonância com o fluxograma da Figura 4.1 foi utilizada para avaliar os casos possíveis.

Nas simulações, foi feita a avaliação de cada um desses materiais, sob as seguintes possibilidades: cilindros sólidos e tubos de seção circular, preenchidos com ar, água e areia ${ }^{7}$.

As maiores percentagens de ocorrência de compressão dinâmica no modelo foram obtidas para o tubo de silicone preenchido com água ou areia ${ }^{8}$ ).

O Apêndice $C$ apresenta os principais resultados obtidos a partir dessas simulações, para o caso do silicone preenchido com água e com areia, além das suas principais características físico-mecânicas, bem como as condições de lançamento e excitação de topo. O objetivo desse procedimento foi a escolha racional de qual opção utilizar. A escolha em retirar o conteúdo das simulações e experimentos de caracterização do corpo do texto tem a finalidade de dar fluência à leitura dos aspectos mais diretamente relacionados à tese, sem deixar de apresentar, mesmo que em anexo, todos os cuidados tomados para elaboração, preparação e execução dos ensaios finais.

\footnotetext{
${ }^{5}$ Entenda-se por linha flexível um modelo de riser bastante esbelto (no caso do presente texto, a relação entre o comprimento útil total e o diâmetro externo é da ordem de 620), cujo material permite grandes deflexões relativamente ao vão, ou de outra forma, $E A \gg E I$.

${ }^{6} \mathrm{~A}$ utilização de ancoragem é, aqui, antecipada e apresentada sem justificativas. Entretanto, tais justificativas serão explicitadas ainda no presente capítulo.

${ }^{7}$ No caso da areia, foi considerada sua densidade aproximada, sem levar em contar o fator de compactação da mesma, para efeito de cálculos preliminares.

${ }^{8}$ Como será visto posteriormente, o peso imerso próprio do silicone é negativo. As densidades consideradas para a água e a areia foram, respectivamente, $1.000 \mathrm{~kg} / \mathrm{m}^{3}$ e $1.500 \mathrm{~kg} / \mathrm{m}^{3}$. A densidade do silicone, nos catálogos, variava entre $1.100 \mathrm{~kg} / \mathrm{m}^{3} \mathrm{e}$ $1.300 \mathrm{~kg} / \mathrm{m}^{3}$. Optou-se pelo uso do valor médio dessa faixa
} 


\section{Propriedade físico-mecânicas do modelo flexível}

Avaliados os pretensos materiais passíveis de serem utilizados para a confecção do modelo flexível a ser ensaiado, optou-se, ao fim, por uma mangueira de silicone, com preenchimento em areia, dado que, conforme pode ser verificado pela Tabela $4.1 \mathrm{e}$ pelo conteúdo do Apêndice $\mathrm{C}$, as diferenças teóricas esperadas não foram confirmadas pelos ensaios de caracterização, de modo que foi escolhido o modelo com maior peso próprio, de sorte a permitir configurações iniciais com variações de ângulo de topo em uma faixa mais ampla de valores, sob menor projeção horizontal, respeitando as limitações físicas do Calibrador Hidrodinâmico do TPN-USP.

Tabela 4.1: Características do modelo em silicone, dados de ensaios

\begin{tabular}{|c|c|c|}
\hline Característica & Símbolo (Unidade) & Magnitude \\
\hline Diâmetro externo & $D_{\text {ext }}(\mathrm{mm})$ & 14,06 \\
Diâmetro interno & $D_{\text {int }}(\mathrm{mm})$ & 6,86 \\
\hline Módulo de elasticidade & $E\left(\mathrm{MN} / \mathrm{m}^{2}\right)$ & 3,103 \\
Densidade do silicone & $\rho\left(\mathrm{kg} / \mathrm{m}^{3}\right)$ & $1.281,7$ \\
\hline Peso linear no ar (vazio) & $m g(\mathrm{~N} / \mathrm{m})$ & 1,491 \\
Peso linear imerso (vazio) & $q(\mathrm{~N} / \mathrm{m})$ & $-0,029$ \\
Rigidez axial média (vazio) & $E A(\mathrm{~N})$ & 367,08 \\
Rigidez flexional (vazio) & $\left.E I(\mathrm{Nm})^{2}\right)$ & $5,616 \cdot 10^{-3}$ \\
\hline Peso linear no ar (com areia) & $m g(\mathrm{~N} / \mathrm{m})$ & 1,993 \\
Peso linear imerso (com areia) & $q(\mathrm{~N} / \mathrm{m})$ & 0,475 \\
Rigidez axial (com areia) & $E A(\mathrm{~N})$ & $385,54-422,57$ \\
Rigidez flexional (com areia) & $E I\left(\mathrm{Nm}{ }^{2}\right)$ & vide Tabela 4.2 \\
\hline
\end{tabular}

Tabela 4.2: Valores obtidos para rigidez flexional (EI) do modelo com areia

\begin{tabular}{|c|c|c|c|c|}
\hline Fonte do Resultado & Mínimo $\left[\mathrm{Nm}^{2}\right]$ & Média $\left[\mathrm{Nm}^{2}\right]$ & Máximo $\left[\mathrm{Nm}^{2}\right]$ & $\Delta \%$ médias \\
\hline (a) Definição (El) & $5,40 \cdot 10^{-3}$ & $5,90 \cdot 10^{-3}$ & $6,50 \cdot 10^{-3}$ & - \\
\hline (b) Equação C.6 & $3,80 \cdot 10^{-3}$ & $5,25 \cdot 10^{-3}$ & $6,70 \cdot 10^{-3}$ & $-11,0 \%$ \\
\hline \hline
\end{tabular}




\title{
Capítulo 5
}

\section{Planejamento da Matriz de Ensaios e Simulações Numéricas}

\author{
"It doesn't matter how beautiful your theory is, it doesn't matter how smart you are. \\ If it doesn't agree with experiment, it's wrong". \\ Não importa quão bonita é sua teoria, nem quão inteligente você é. \\ Se não concorda com os experimentos, está errada. \\ (Richard P. Feynman)
}

O presente capítulo tem por objetivo apresentar a matriz de ensaios e o planejamento dos experimentos físicos e das simulações numéricas implementadas para confrontação dos resultados seus resultados com aqueles advindos das formulações matemáticas apresentadas e discutidas no Capítulo 3.

A composição da matriz de ensaios merecerá uma seção à parte, dada sua importância no planejamento para a obtenção dos resultados almejados. Na sequência, são apresentados o detalhamento dos ensaios físicos e simulações numéricas realizados. As simulações numéricas referem-se à utilização específica do Poliflex, para determinação da estática e dos modos e frequências naturais de vibrar; e do Anflex, para determinação da estática e dinâmica do modelo - em termos de deslocamentos e tração ao longo da linha.

Além disso, foram feitas simulações a partir de códigos numéricos em Matlab, desenvolvidos pelo autor e baseadas no procedimento sugerido, cuja sustentação teórica foi amplamente discutida nos Capítulos 3 e 4. 


\subsection{Matriz de Ensaios}

Dando continuidade ao que foi proposto no Capítulo 4 e consolidado com os ensaios preliminares realizados, faz-se oportuna a definição precisa da matriz de ensaios.

Como mencionado e discutido anteriormente, optou-se por ensaiar apenas o modelo preenchido com areia. Essa seleção, em detrimento da outra, foi feita a partir da avaliação racional promovida no capítulo 4 . Como ambos os modelos estudados, em tese, produziriam resultados bastante similares, a opção levou em conta o maior peso próprio do modelo com areia, sem justificativas adicionais.

Considerando-se os resultados e os argumentos expostos nos capítulos precedentes, foi definida a matriz de ensaios, apresentada a seguir.

- Amplitudes (nominais) ensaiadas ${ }^{1}: 0,050 \mathrm{~mm} ; 0,100 \mathrm{~mm}$ e 0,200mm;

- Frequências impostas ao topo do modelo²: $0,80 \mathrm{~Hz} ; 1,00 \mathrm{~Hz}$ e 1,25Hz;

- Ângulos de topo nominais no lançamento do modelo ${ }^{3}: 65^{\circ} ; 70^{\circ}, 80^{\circ}$ e $85^{\circ}$;

- Foram prescritos movimentos de topo nos sentidos horário e anti-horário, a fim de avaliar e discutir eventuais diferenças.

Dessa maneira, os ensaios realizados encerram um total de 72 experimentos.

Com a finalidade de organizar o conjunto de experimentos realizados, cada um deles recebeu uma nomenclatura específica, que será utilizada deste ponto em diante.

Cada ensaio realizado foi nomeado como $F_{i} A_{j} T_{k} S$, onde $F, A, T$ e $S$ referem-se, respectivamente, à frequência imposta, à amplitude do movimento prescrito, ao ângulo de topo nominal de lançamento inicial do modelo e ao sentido do referido movimento. Desta forma, pela matriz de ensaios:

- $\mathrm{i}=[0,80 ; 1,00 ; 1,25] \cdot 10^{2}$;

$\cdot j=[0,050 ; 0,100 ; 0,200] \cdot 10^{3}$;

- $\mathrm{k}=[65 ; 70 ; 80 ; 85]$.

A fim de facilitar a leitura dos arquivos digitais gerados pelos equipamentos utilizados na instrumentação dos ensaios, foi adotado o seguinte padrão de nomenclatura: as frequências e as amplitudes são representadas por 3 dígitos, enquanto para $o$ ângulo de topo foram adotados 2 dígitos.

Além disso, o sufixo $S$ citado anteriormente poderia assumir os valores $S H H$ e $S A H$, referindo-se ao sentido do movimento $(S H H$, para o sentido horário e $S A H$, para o sentido anti-horário).

\footnotetext{
${ }^{1}$ A Seção 5.3, apresentada na sequência do texto, caracteriza e explicita os resultados da aferição do dispositivo atuador, em termos das amplitude e frequências reais prescritas ao topo do modelo.

${ }^{2}$ Cabe ratificar que os movimentos prescritos ao topo do modelo foram movimentos circulares uniformes, caracterizados pelas amplitudes e frequências definidas.

${ }^{3} \mathrm{Em}$ um contexto mais oportuno, na Seção 5.4 são apresentados os ângulos de topo reais, medidos direta ou indiretamente.
} 
Assim, por exemplo, o ensaio denominado por F080A050T65_SAH refere-se à imposição de um movimento circular uniforme de frequência $0,80 \mathrm{~Hz}$; raio (amplitude) $0,050 \mathrm{~m}$; ângulo de topo nominal de lançamento igual a $65^{\circ}$, aplicado no sentido antihorário (o referencial para determinação do sentido ficará claro na Seção 5.4).

Quanto à realização dos referidos ensaios, cumpre salientar que os mesmos foram monitorados a partir de uma célula de carga (fundo de escala $100 \mathrm{~N}$ ) conectada ao topo do modelo, bem como com o emprego de dois sistemas de monitoramento óptico a fim de rastrear alvos refletivos dispostos sobre a tubo flexível, permitindo a obtenção de dados referentes aos deslocamentos tridimensionais da linha, no topo e no TDP (um dos sistema era composto por 3 câmeras aéreas, o outro por 4 câmeras aquáticas). Em termos das análises, a serem esmiuçadas no Capítulo 6, o procedimento seguido, ilustrado na Figura 5.1, teve como finalidade permitir as seguintes confrontações:

1. Estaticamente, foram comparados os resultados analíticos (baseados em Pesce (1997) e Patel \& Seyed (1995)), numéricos (programas baseados no Método dos Elementos Finitos, no caso o Anflex e o Poliflex) e aqueles provenientes dos experimentos (alvos dispostos ao longo da linha e monitorados opticamente);

2. As séries temporais de trações obtidas com o uso da célula de carga no topo do modelo foram comparadas, juntamente com suas respectivas densidades espectrais de potência, com as simulações realizadas com o uso do Anflex e do procedimento numérico baseado em Aranha \& Pinto (2001) e Aranha et al. (2001);

3. Para a região do TDP, foram confrontados os resultados referentes às assinaturas temporais versus as trações efetivas obtidas nas simulações numéricas (procedimento proposto e Anflex);

4. A partir dos quadros resultantes do monitoramento óptico do TDZ, foram determinados os comprimentos das ondas de flexão geradas, quando da ocorrência do fenômeno de compressão dinâmica, a fim de comparar com a hipótese ad hoc feita por Aranha et al. (2001) e utilizada por Ramos Jr \& Pesce (2003), que se configura como meta principal do presente texto;

5. Os demais resultados apresentados têm como objetivo conferir alicerce analíticoexperimental para corroborar (e até validar) os resultados relativos aos comprimentos de onda determinados.

As etapas que precederam os ensaios, concernentes à montagem do aparato físico necessário e à aferição do dispositivo atuador são apresentadas nas Seções 5.2 e 5.3, respectivamente.

A Figura 5.1 ilustra, esquematicamente, a forma como as diversas vertentes deste trabalho se interligam, bem como a forma com que cada recurso (equipamento, programa e formulações) foi utilizado e quais os resultados gerados a partir de cada etapa. 
Além disso, essa figura permite identificar a partir de quais resultados as comparações e análises constantes do Capítulo 6 advieram.

\begin{tabular}{|c|c|c|c|c|c|}
\hline \multicolumn{2}{|c|}{ Avaliações Estáticas } & \multicolumn{2}{|c|}{ Ensaios (CH-TPN) } & \multicolumn{2}{|c|}{ Avaliações Dinâmicas } \\
\hline Pesce (1997) & - Catenária inelástica & $\begin{array}{l}\text { Célula de } \\
\text { Carga }\end{array}$ & $\begin{array}{l}\text { - Trações no topo } \\
\text { (estática e dinâmica) }\end{array}$ & $\begin{array}{c}\text { Anflex } \\
\text { (simulações) }\end{array}$ & $\begin{array}{l}\text { - Trações no topo } \\
\text { - Trações no TDP } \\
\text { - Deslocamentos }\end{array}$ \\
\hline $\begin{array}{c}\text { Patel \& Seyed } \\
\text { (1995) }\end{array}$ & - Catenária elástica & & & & \\
\hline & & $\begin{array}{l}\text { Câmeras } \\
\text { Aéreas }\end{array}$ & $\begin{array}{l}\text { - Anguos dé topo } \\
\text { - Alvos Aéreos }\end{array}$ & $\begin{array}{c}\text { Aranha \& Pinto } \\
\text { (1991) }\end{array}$ & $\begin{array}{l}\text { - Trações no topo } \\
\text { - Trações no TDP }\end{array}$ \\
\hline Anflex & $\begin{array}{l}\text { - Catenária elástica } \\
\text { - Considera El e GJ }\end{array}$ & & & & \\
\hline Poliflex & $\begin{array}{l}\text { - Catenária elástica } \\
\text { - Considera El e GJ } \\
\text { - Modos de vibrar }\end{array}$ & $\begin{array}{l}\text { Câmeras } \\
\text { Aquáticas }\end{array}$ & $\begin{array}{l}\text { - Alvos Aquáticos } \\
\text { (estática e dinâmica) }\end{array}$ & $\begin{array}{c}\text { Aranha et al } \\
\text { (1991) }\end{array}$ & $\begin{array}{l}\text { - Carga crítica } \\
\text { - Saturação do sinal }\end{array}$ \\
\hline
\end{tabular}

\begin{tabular}{|l|l|}
\hline$\square$ Alvos aéreos $\rightarrow$ ângulo de topo & $\begin{array}{l}\text { Séries temporais das trações no topo } \\
\text { - Célula de carga } \\
\text { - Anflex }\end{array}$ \\
$\begin{array}{l}\text { - Aranha, considerando carga critica } \\
\text { ângulo de topo }\end{array}$ & $\begin{array}{l}\text { Séries temporais das trações no TDP } \\
\text { - Célula de carga }\end{array}$ \\
- Anflex
\end{tabular}

Figura 5.1: Utilização dos recursos e vertentes para avaliação dos ensaios e simulações.

O detalhamento de cada etapa ilustrada na Figura 5.1 é apresentado nas Seções 5.4 e 5.5. Os resultados referentes aos ensaios físicos levados a cabo e às simulações realizadas serão apresentados e discutidos apenas no Capítulo 6 e concluídos sistematicamente no Capitulo 7. 


\subsection{Aparato Experimental Utilizado nos Ensaios}

A presente seção tem como principal objetivo a apresentação do aparato experimental assim como montado para os ensaios realizados. Os materiais e equipamentos utilizados já foram apresentados anteriormente na Seção 4.2, do Capítulo 4.

O local escolhido para realização dos ensaios foi o $\mathrm{CH}$-TPN que possui lâmina d'água real de $4,12 \mathrm{~m}$. A densidade da água do $\mathrm{CH}-\mathrm{TPN}$ foi assumida como igual a $997 \mathrm{~kg} / \mathrm{m}^{3}$ (valor típico para a água doce a $25^{\circ} \mathrm{C}$ ).

A Figura 5.2 ilustra a forma como o modelo foi lançado no $\mathrm{CH}$-TPN. As medidas que constam nessa figura representam o máximo comprimento útil disponível sem que a ponte rolante fosse movimentada, igual a cerca de $8,40 \mathrm{~m}$; e a lâmina d' água durante os ensaios.

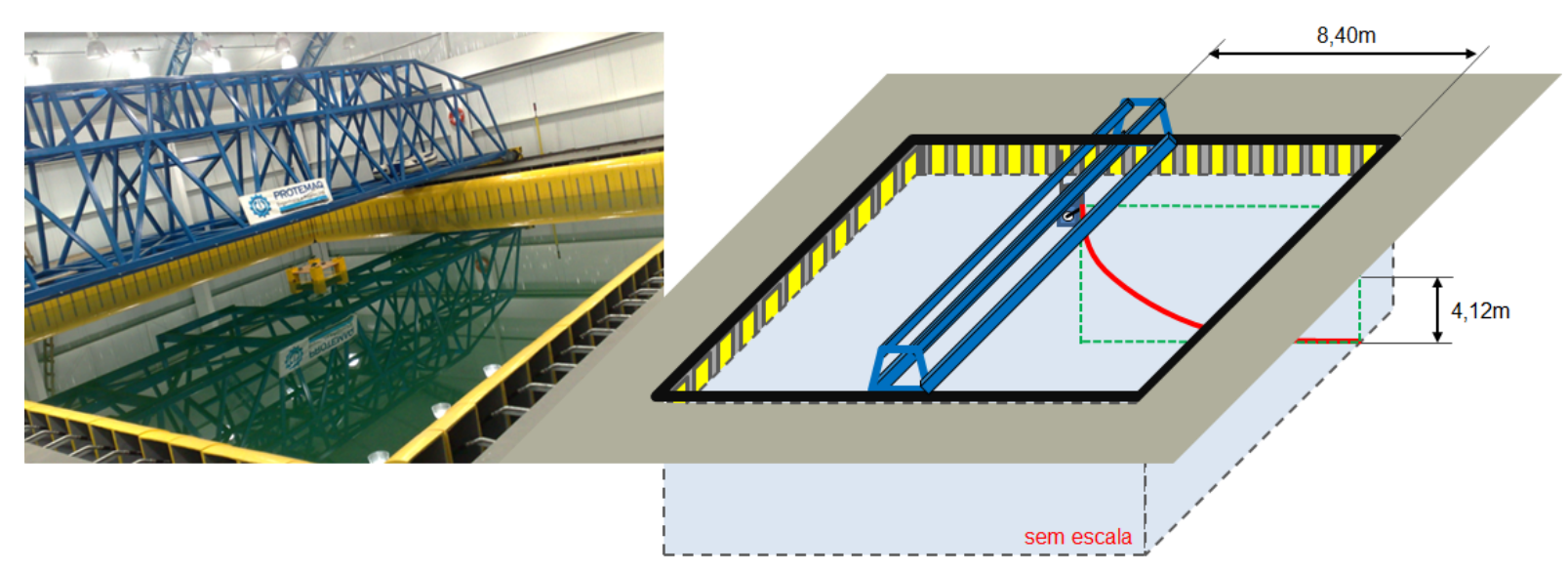

Figura 5.2: Esquema ilustrativo do lançamento do modelo no $\mathrm{CH}$-TPN.

À esquerda, uma foto do tanque; à direita, uma ilustração ilustrativa.

Em azul, as extremidades da ponte rolante, fixa; em vermelho, o modelo físico.

Em verde tracejado, o plano vertical que inicialmente contém a catenária.

A montagem do dispositivo atuador contou com um conjunto motorredutor ${ }^{4}$, uma estrutura de barras de alumínio para suporte e fixação na ponte rolante e um equipamento das rotações do motor.

Detalhes da montagem desse aparato foram ilustrados e descritos na Seção 4.2.3. Na Figura 5.3, a seguir, esse conjunto está destacado em verde. Nessa mesma figura é possível visualizar e identificar as posições das câmeras aéreas utilizadas para o monitoramento dos alvos dispostos na porção emersa do modelo flexível (destacas em vermelho na figura). Essas câmeras foram afixadas solidariamente à ponte rolante, de maneira a possibilitarem que o sistema de monitoramento fosse capaz de definir um sistema referencial inercial.

Cumpre destacar que, na saída do eixo do redutor, foi afixado o braço rígido de ferro, com quatro furos: uma para fixação no eixo e três para posicionamento do rolamento

\footnotetext{
${ }^{4}$ Pelo catálogo do fabricante, a redução promovida seria de 1:25. Esse valor foi indiretamente aferido. Os resultados são apresentados na Seção 5.3.
} 


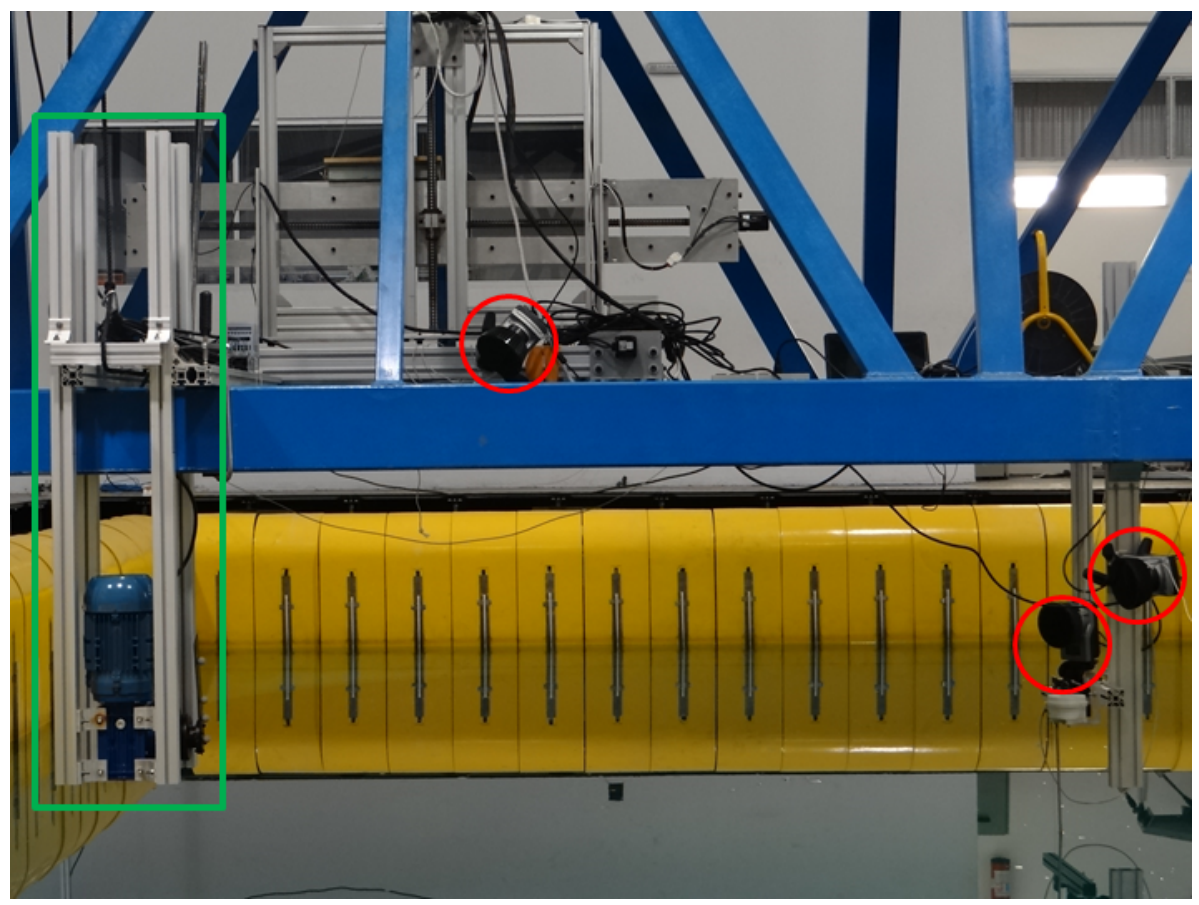

Figura 5.3: Posições relativas entre o dispositivo atuador e as câmeras aéreas utilizadas nos ensaios.

que sustentava a célula de carga e a linha, nessa sequência. A Figura 5.4 mostra esse braço, utilizado para variação das amplitudes dos movimentos, bem como a estrutura em forma de "L" utilizada para calibração das câmeras aéreas.

Note-se, também, pela Figura 5.4, o uso de um nível eletrônico para garantir os paralelismos e perpendicularismos da estrutura montada.

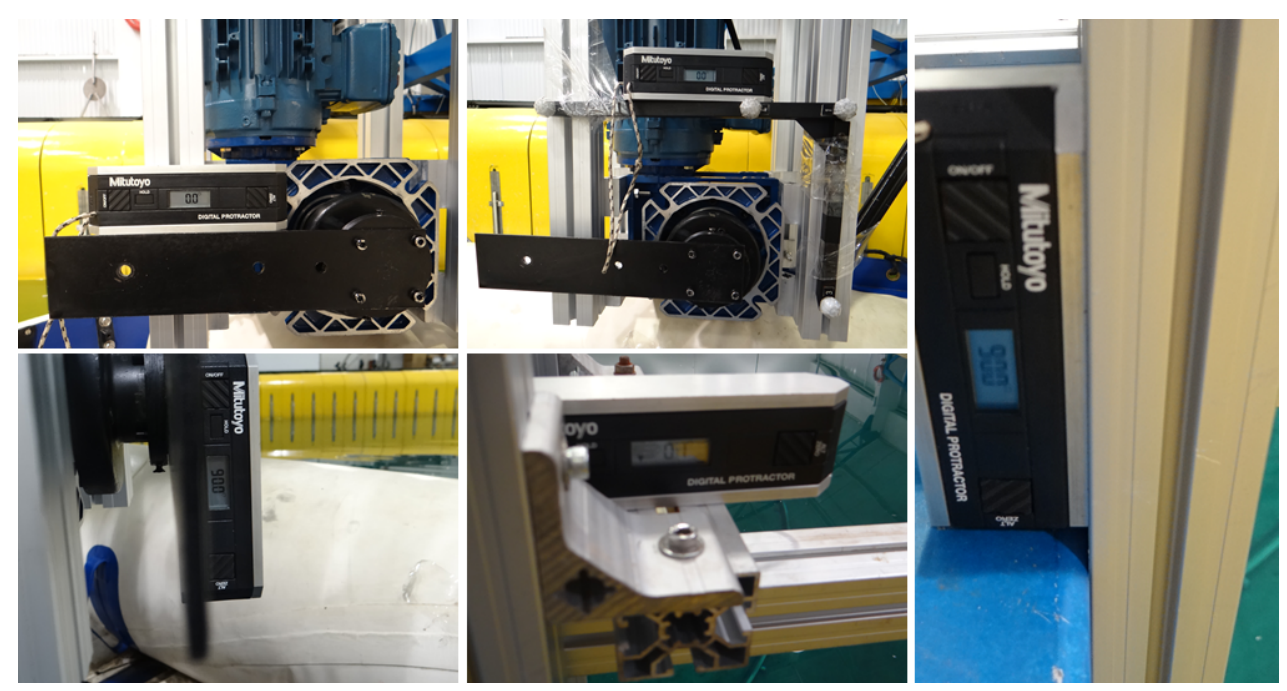

Figura 5.4: Estrutura fixada na saída do eixo do atuador e equipamento de calibração das câmeras. Destaque-se o uso de um nível eletrônico para a montagem do conjunto.

O dispositivo atuador utilizado nos experimentos teve a rotação do motor comandada pelo controlador destacado em vermelho da Figura 5.5.

O controlador de rotações do motor permitiu a variação da frequência de rotação do eixo do motor (não do redutor). Além disso, seu uso propiciou o início e parada dos 


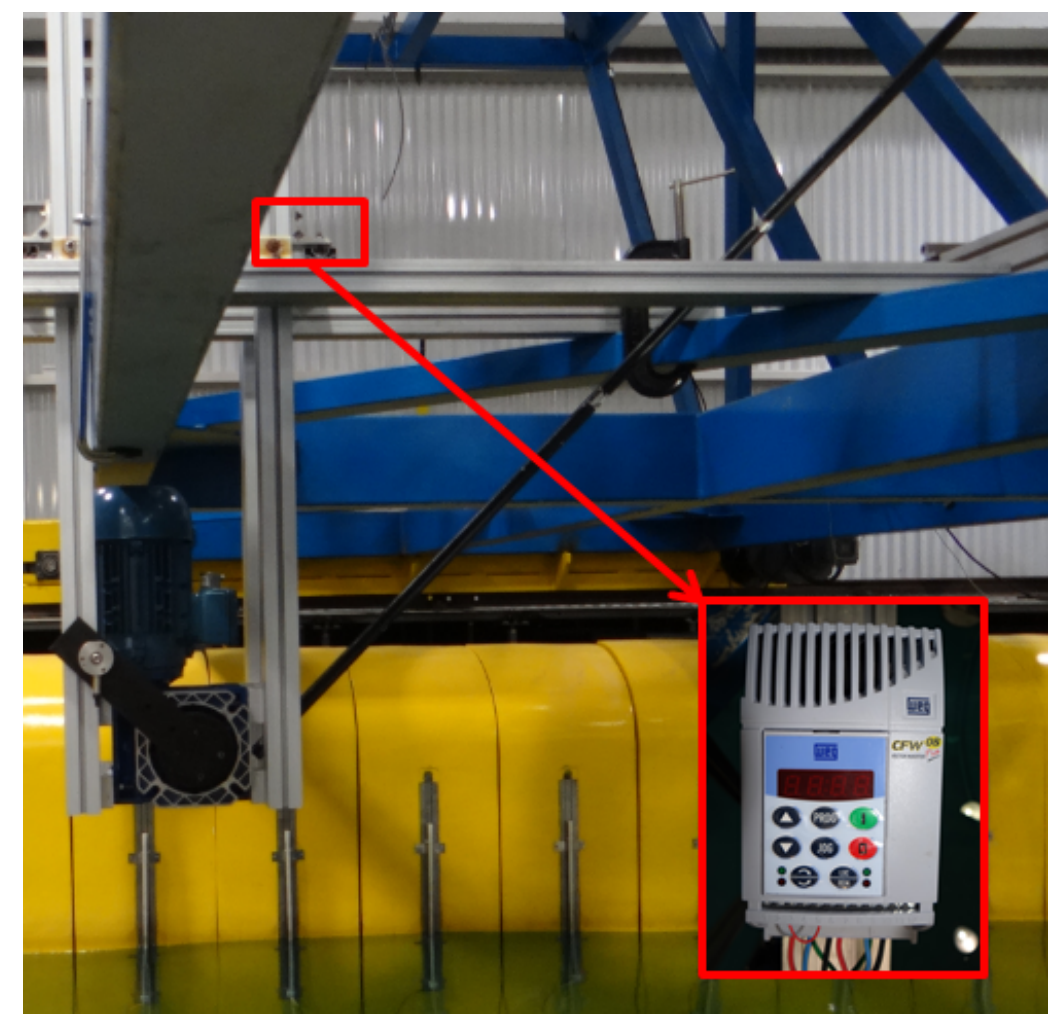

Figura 5.5: Visão frontal do dispositivo atuador montado com a rótula.

No detalhe em vermelho o equipamento usado para controle da rotação do motor.

movimentos, bem como alterar o sentido de rotação ${ }^{5}$.

Foram impostas rotações de $1.200 \mathrm{rpm}, 1.500 \mathrm{rpm}$ e $1.875 \mathrm{rpm}$ ao motor, em ambos os sentidos. Considerando a redução nominal e a alteração da unidade de medida da frequência (em consonância com o chamado Sistema Internacional de Unidades), as frequências equivalentes, na saída do redutor, foram de $0,80 \mathrm{~Hz} ; 1,00 \mathrm{~Hz}$; e $1,25 \mathrm{~Hz}$, conforme determinado pela matriz de ensaios planejada.

$\mathrm{Na}$ sequência de montagem do aparato, foi utilizada uma rótula fixada a um dos três furos da barra rígida, encaixada à saída do eixo do redutor.

Na periferia desssa rótula, foi feito um furo que recebeu um fuso M8 cuja extremidade oposta foi utilizada para fixação da célula de carga. Na saída desta, outro fuso M8 garantiu o encaixe forçado da linha. Lembrando que o diâmetro interno medido era da ordem de $6,86 \mathrm{~mm}$. Além da fixação forçada, foi utilizada uma braçadeira de náilon vide Figura 5.6.

Com o aparato experimental montado desta forma, foi possível prescrever movimentos circulares de topo ao modelo flexível utilizado nos ensaios. A Figura 5.7 ilustra um ciclo completo do braço rígido que suportava o conjunto que sustentava a linha.

$\mathrm{Na}$ Figura 5.7, a trajetória circular tracejada em cinza se refere ao movimento de um dos furos do braço, no caso dessa figura, o que representa a imposição da maior amplitude possível).

\footnotetext{
${ }^{5}$ No âmbito deste trabalho, os sentidos de rotação são descritos como os que seriam percebidos por um eventual observador posicionado frontalmente ao aparato, como ilustrado na Figura 5.5.
} 

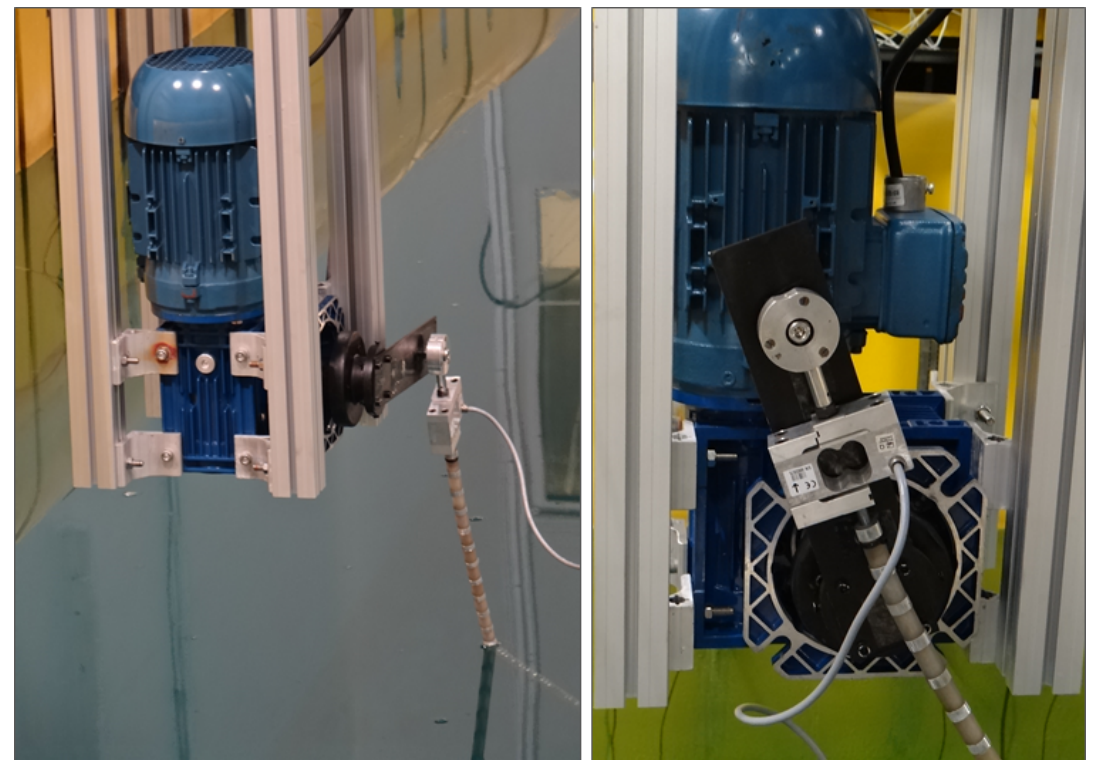

Figura 5.6: Detalhes da fixação do rolamento e célula de carga na saída do eixo do redutor. Por essa figura é possível entender também como o modelo flexível foi fixado ao conjunto.
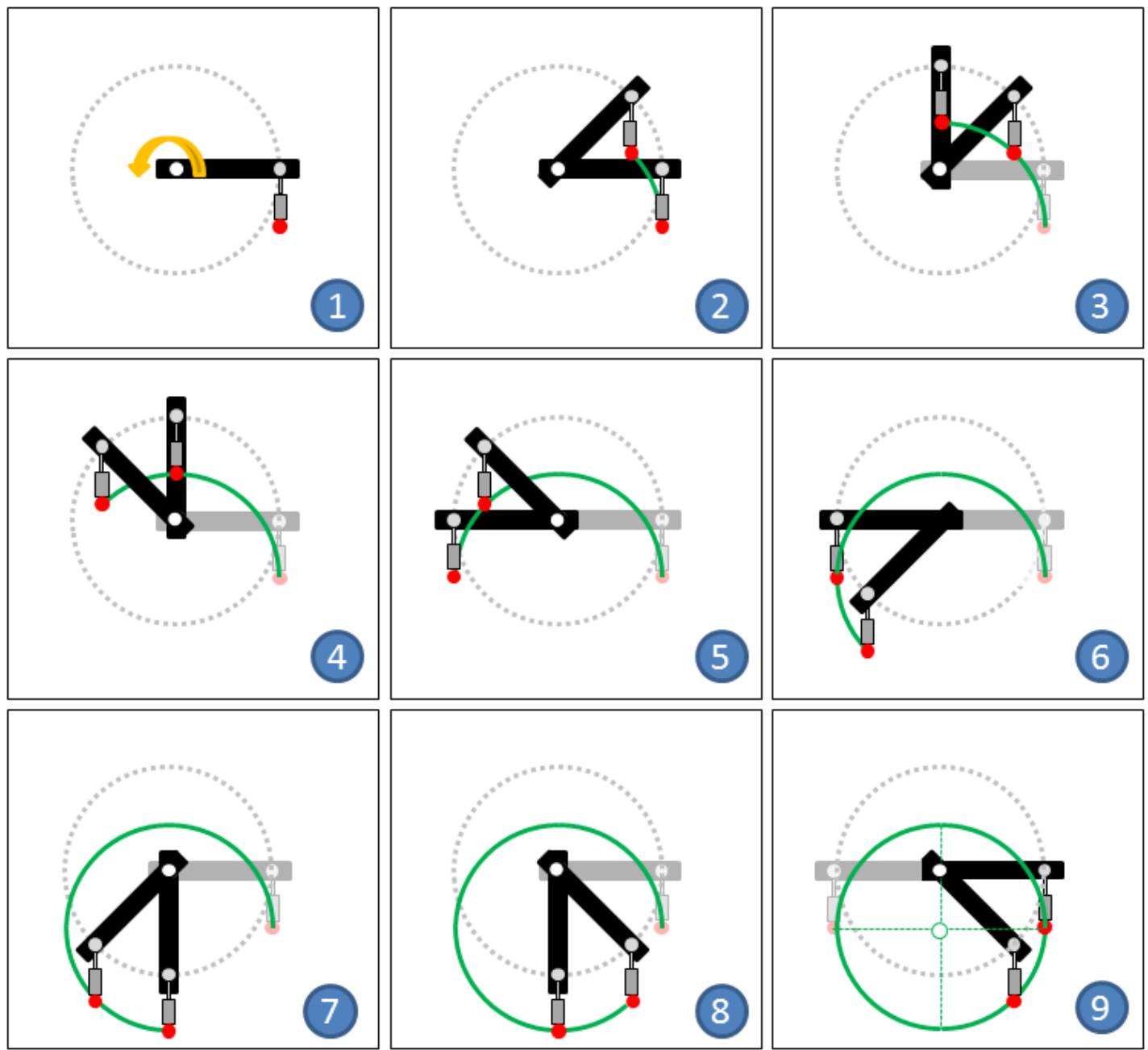

Figura 5.7: Um ciclo de movimento prescrito pelo dispositivo atuador.

Na ponta do braço (em preto), é possível visualizar a rótula e a célula de carga (ambas em cinza). O ponto vermelho representa o topo da linha. 
A trajetória em verde, também circular, ilustra o movimento associado prescrito ao topo da linha pelo conjunto motorredutor. Cumpre destacar que as trajetórias apresentam o mesmo raio (e, portanto, a mesma amplitude de movimento prescrito), com centros defasados de uma distância igual àquela entre o centro do rolamento e parte inferior da célula de carga (aproximadamente $0,12 \mathrm{~m}$ ).

A execução da matriz de ensaios seguiu uma ordem lógica pré-determinada, em função das mudanças não automáticas das amplitudes de movimento: para um dado ângulo de topo, fixava-se o conjunto resposnsável pelas amplitudes do movimentos prescrito em uma determinada posição e efetuavam-se, na sequência, seis experimentos seguidos (três frequências, dois sentidos).

Ainda sem modificar a amplitude dos movimentos impostos, os ângulos de topo eram alterados (quatro ângulos distintos), contabilizando um total de 24 experimentos. Somente após essa sequência a fixação era reposicionada, dando início a uma nova série de experimentos.

Note-se que em (Aranha \& Pinto, 2001), um dos trabalhos utilizados nos procedimentos numéricos deste trabalho, a formulação para a tração dinâmica foi feita sob a hipótese de movimentos harmônicos aplicados ao topo da linha, na direção tangente a ela. A escolha pela imposição do movimento circular ao topo do modelo é, portanto, adequada aos objetivos especificados e equivalente à proposição inicial daquele trabalho analítico.

Na Seção 5.5 será mostrada a forma como essa imposição de movimentos foi adaptada para que as simulações realizadas via Anflex reproduzissem essa situação.

A fim de proporcionar ao leitor uma visão geral da montagem do aparato utilizado nos ensaios, ilustre-se a Figura 5.8, fora de escala, pela qual é possível checar inclusive algumas das distâncias mais importantes no que tange às cotas verticais de cada equipamento.

A utilização do sistema de monitoramento óptico demanda a fixação de alvos refletivos sobre a estrutura em estudo. A Figura 5.9 ilustra um trecho do modelo, na qual é possível estimar a extensão de cada fita adesiva refletiva, bem como o espaçamento médio entre elas (aproximadamente $0,06 \mathrm{~m}$ ).

A Figura 5.10 apresenta duas visões globais do modelo na água. À esquerda, uma vista superior em perspectiva, à direita uma submersa.

Para efeito de documentação, são apresentadas as Figuras de 5.11 a 5.15, a fim de ilustrar o procedimento adotado e os resultados para as câmeras aquáticas e seus respectivos alvos refletivos.

A Figura 5.11 ilustra o cálibre sobre o qual apoiaram-se duas massas concentradas, a fim de promover a manutenção de sua posição durante a calibração. Note-se, à esquerda dessa figura, a posição relativa da âncora (composta por uma massa circular de $10 \mathrm{kgf}$ sobre a qual a extensão não utilizada do tubo de silicone foi enrolada e afixada solidariamente). 


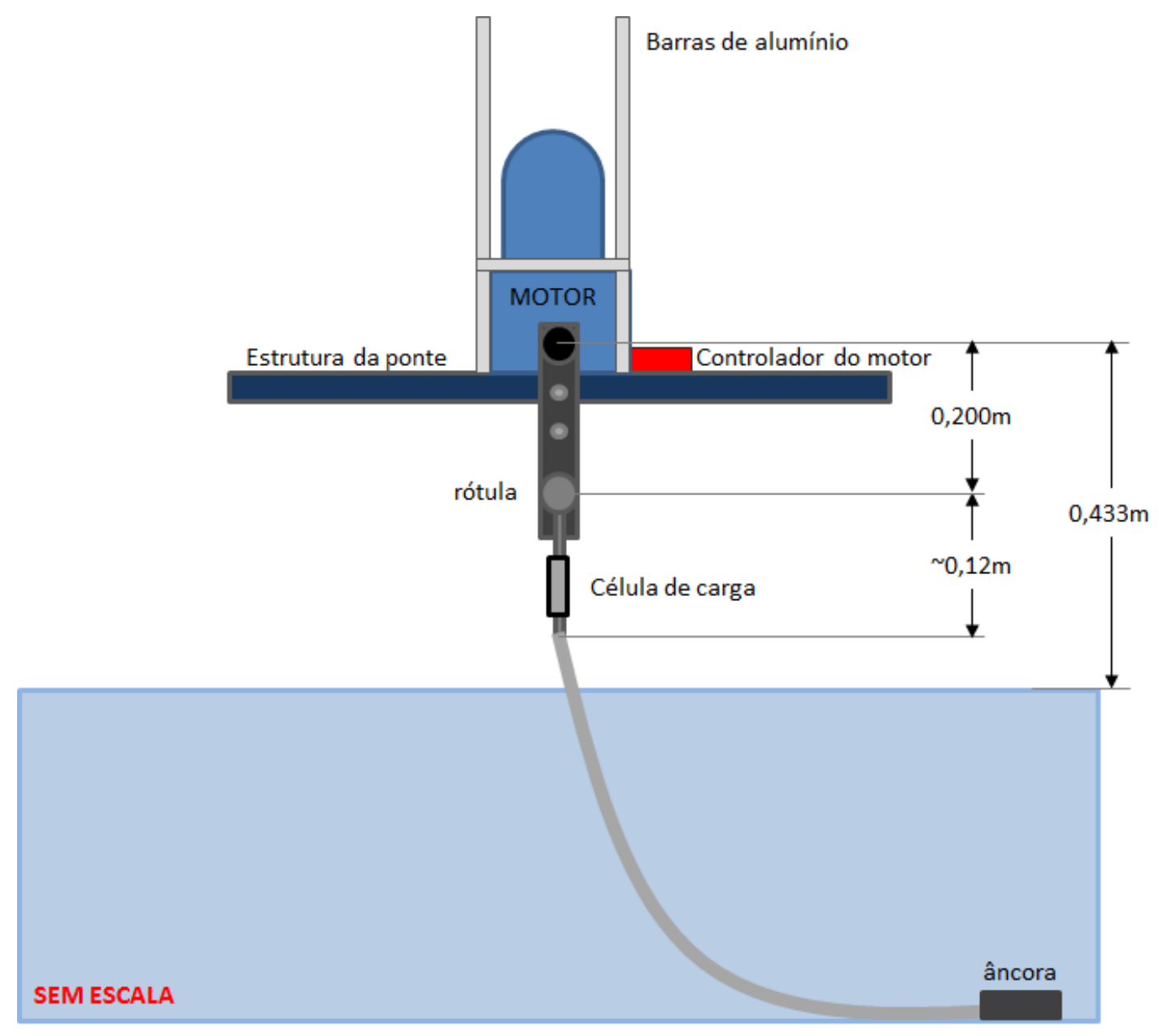

Figura 5.8: Esquema ilustrativo da estrutural utilizada nos ensaios físicos (vista frontal).

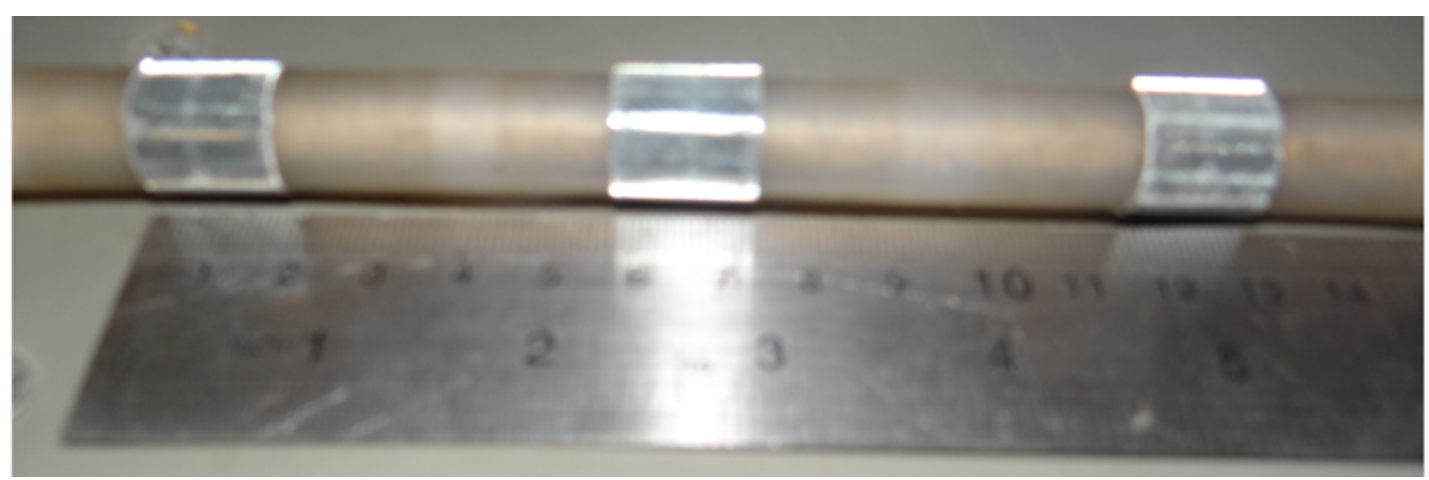

Figura 5.9: Trecho do modelo utilizado com fitas refletivas para rastreamento óptico.

Foram aventados diferentes posicionamentos das câmeras aquáticas até que uma configuração permitiu a determinação de um volume de calibração adequado.

A Figura 5.12 é composta de três fotografias, assim descritas, de cima para baixo: (i) estrutura física composta de barras de alumínio adequadamente afixadas para suportar as quatro câmeras aquáticas, utilizadas; (ii) posicionamento da estrutura descrita à ponte rolante do CH-TPN, de maneira que as câmeras estavam a poucos centímetros da superfície da água; (iii) configuração em que a estrutura, como mostrada na ilustração superior, estava apoiada diretamente sobre o solo do $\mathrm{CH}-\mathrm{TPN}$. 

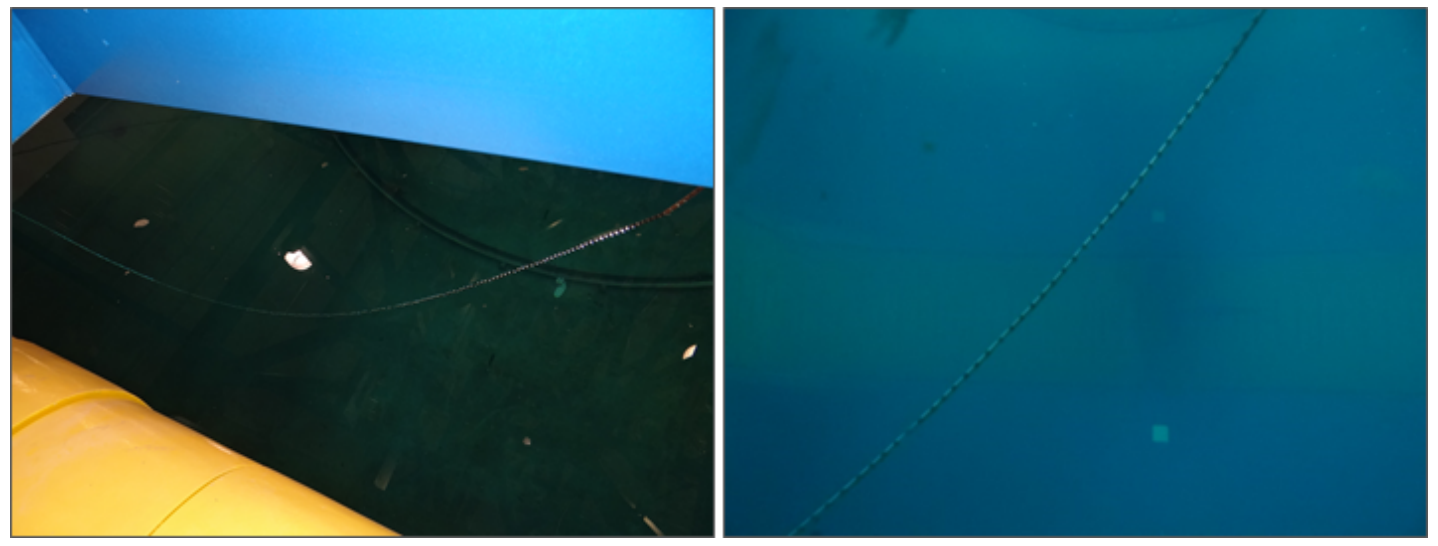

Figura 5.10: Exemplo de lançamento do modelo flexível na água.

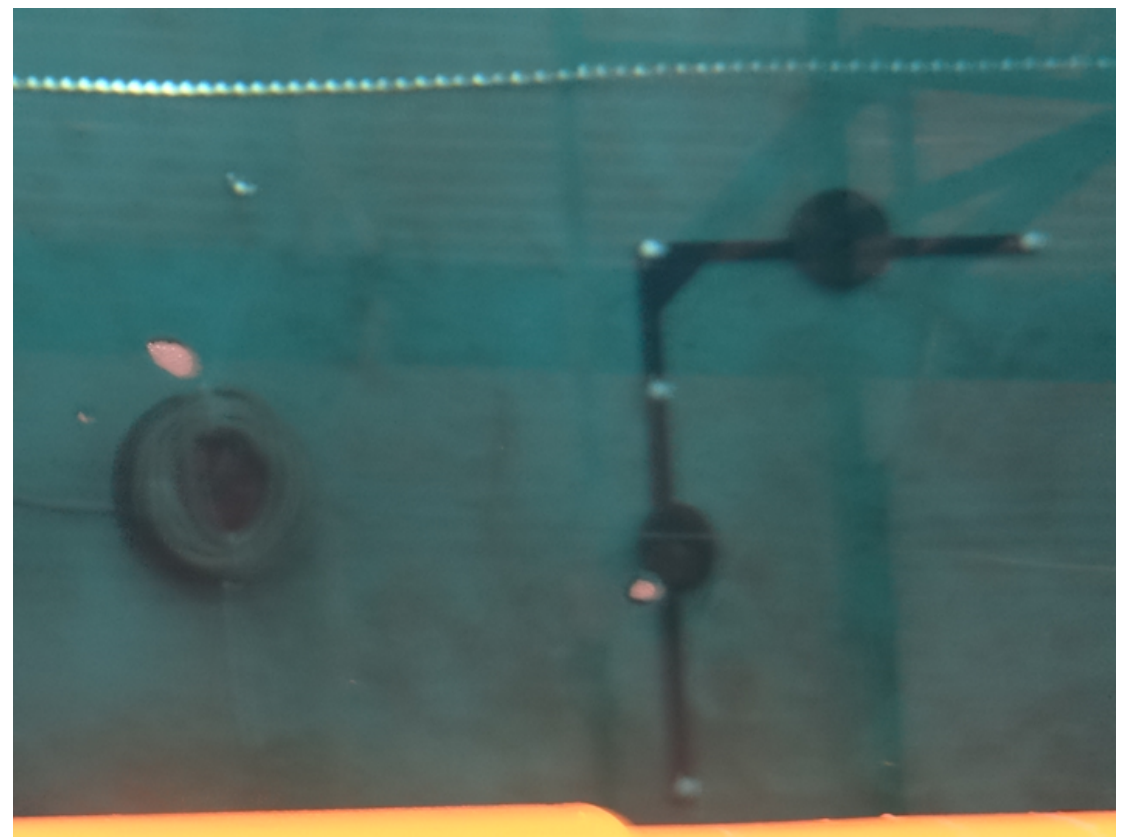

Figura 5.11: Estrutura aquática utilizada para calibração das câmeras.

A configuração da estrutura de sustentação das câmeras utilizada foi praticamente a mesma visualizada na porção inferior da Figura 5.12, a menos de um complemento estrutural que conferia ao sistema uma altura mais adequada, de maneira que a parte inferior de cada câmera permanecia a cerca de $0,40 \mathrm{~m}$ do solo.

A fim de auxiliar o processo de calibração, o sistema de monitoramento permitia a visualização da região delimitada pelo campo de visão de cada uma das câmeras em tempo real, conforme pode ser visto na Figura 5.13.

Como complemento e finalização da presente seção, seguem as Figuras 5.14 e 5.15 que ilustram, respectivamente, o volume de calibração determinado e os campos visuais das câmeras, durante um dos ensaios realizados.

A próxima seção apresentará os resultados dos ensaios de aferição do dispositivo atuador, responsável pela imposição dos movimentos ao topo da linha. 


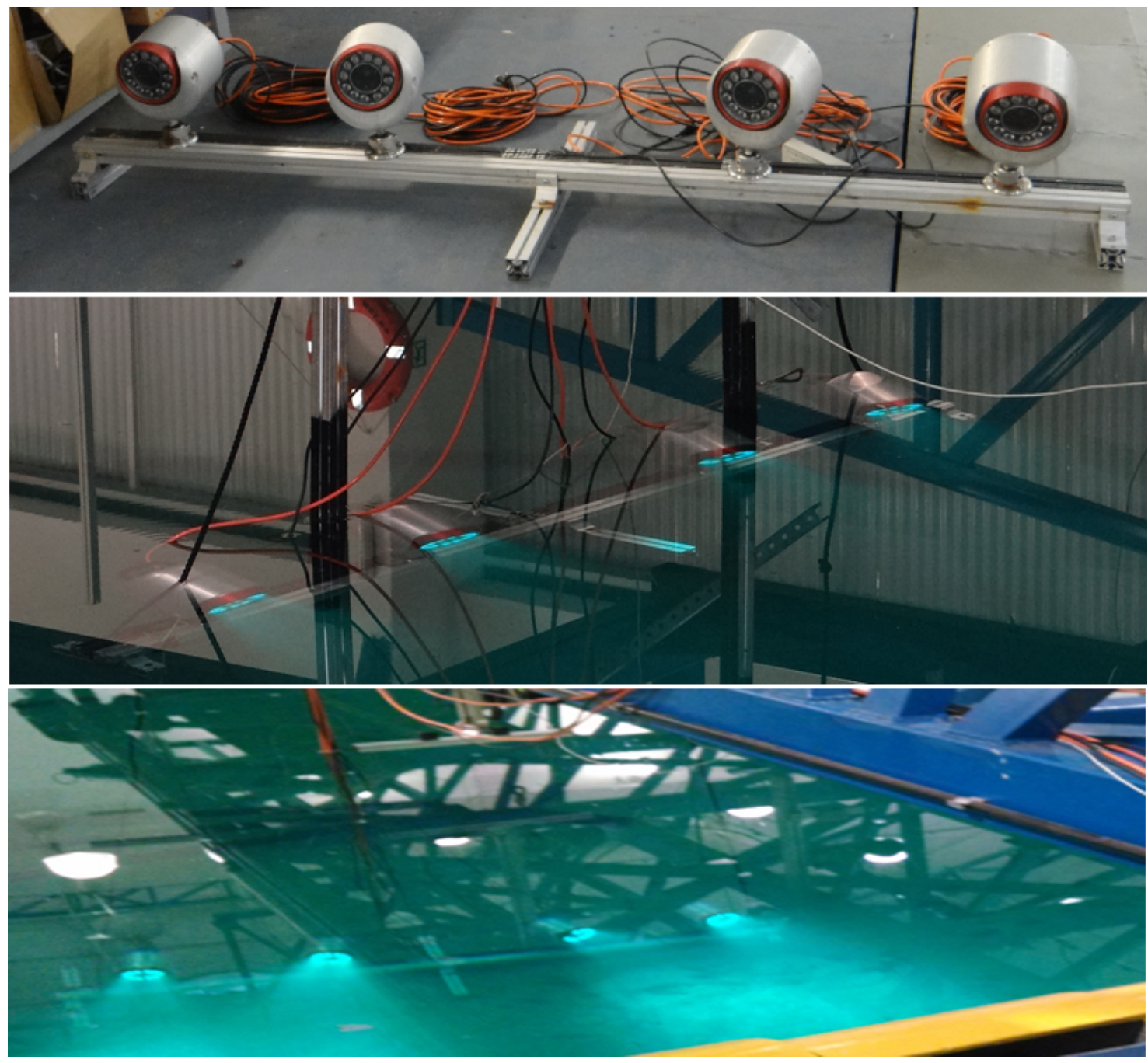

Figura 5.12: Estrutura de sustentação e posicionamento das câmeras aquáticas.

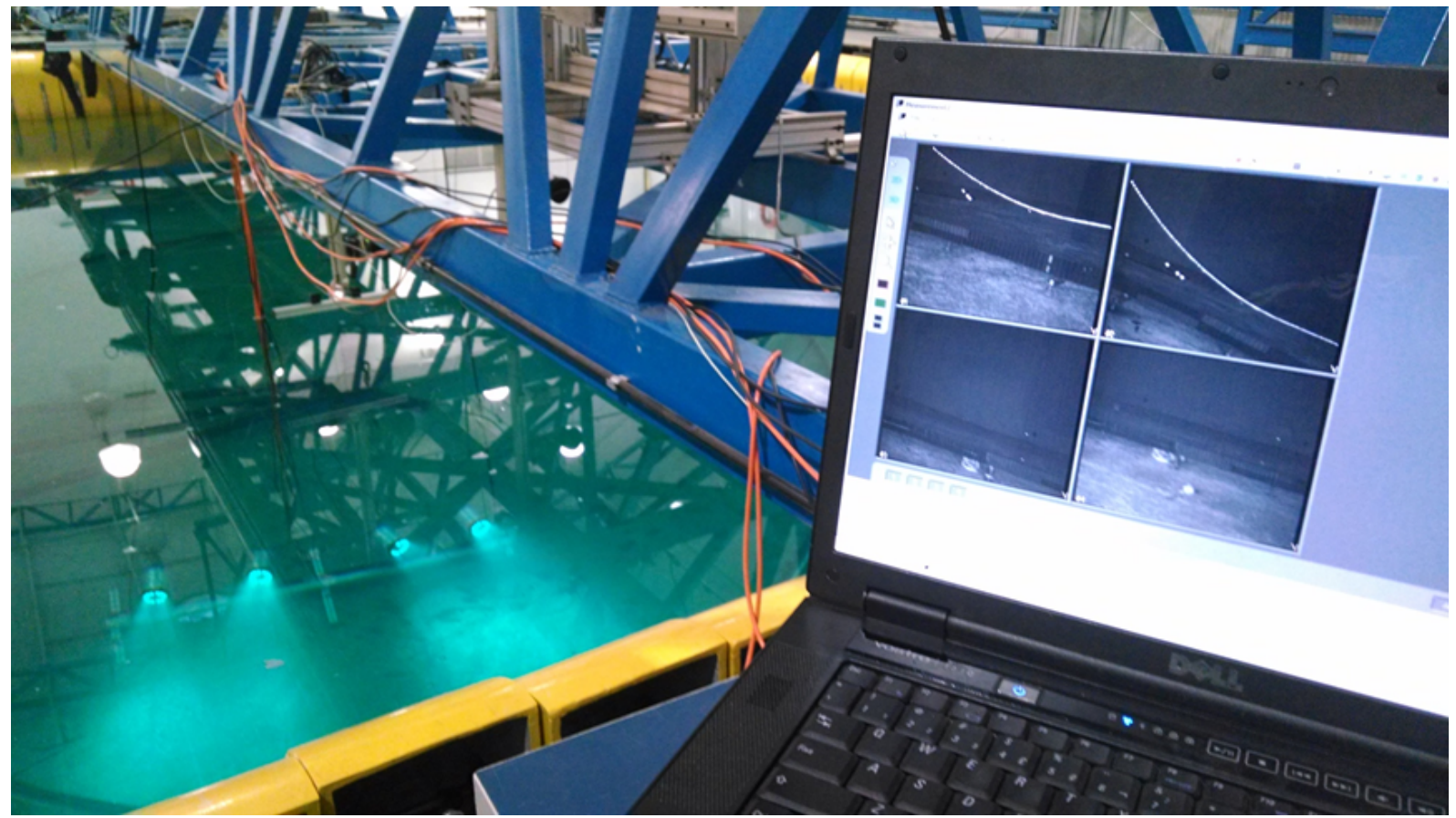

Figura 5.13: Monitoramento em tempo real das câmeras aquáticas, pré-calibração. 


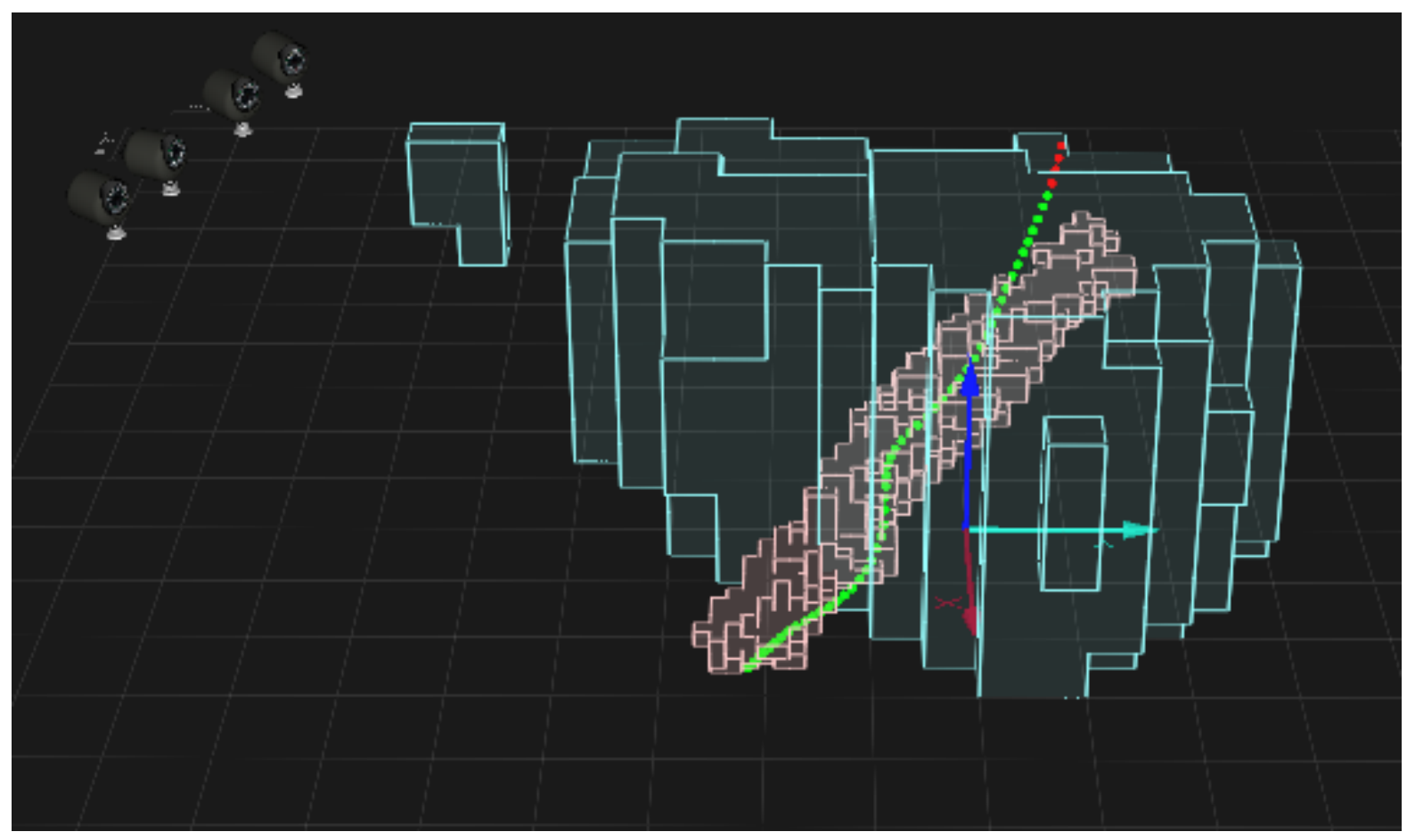

Figura 5.14: Visualização do volume de calibração durante parte de um ensaio.

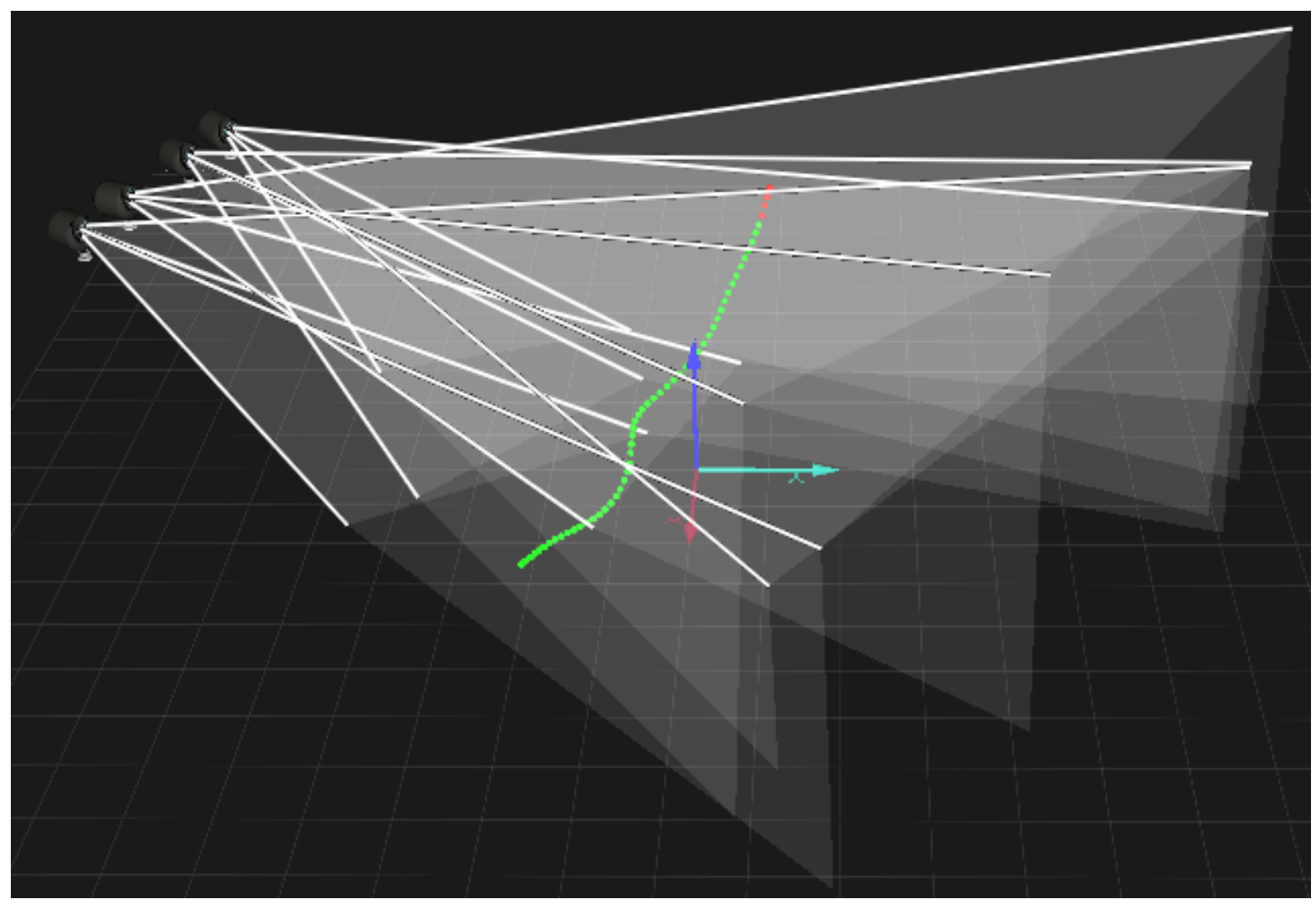

Figura 5.15: Campo visual de cada câmera durante parte de um ensaio. 


\subsection{Aferição do Dispositivo Atuador}

Com a estrutura montada para os ensaios, fez-se necessária a aferição do dispositivo atuador, a fim de garantir que os movimentos prescritos fossem previamente bem determinados e consonantes com os previstos na matriz de ensaios.

Cabe lembrar que, de acordo com os experimentos planejados, os movimentos circulares de topo seriam promovidos a três amplitudes $(0,050 \mathrm{~m} ; 0,100 \mathrm{~m}$; e $0,200 \mathrm{~m})$ e três frequências $(0,80 \mathrm{~Hz} ; 1,00 \mathrm{~Hz} ;$ e $1,25 \mathrm{~Hz})$.

A fim de verificar esses movimentos, alvos refletivos foram afixados nos orifícios feitos na barra rígida que suportaria o conjunto formado pela rótula, célula de carga e elementos de fixação, bem como no centro de rotação da barra (vide Figura 5.16).

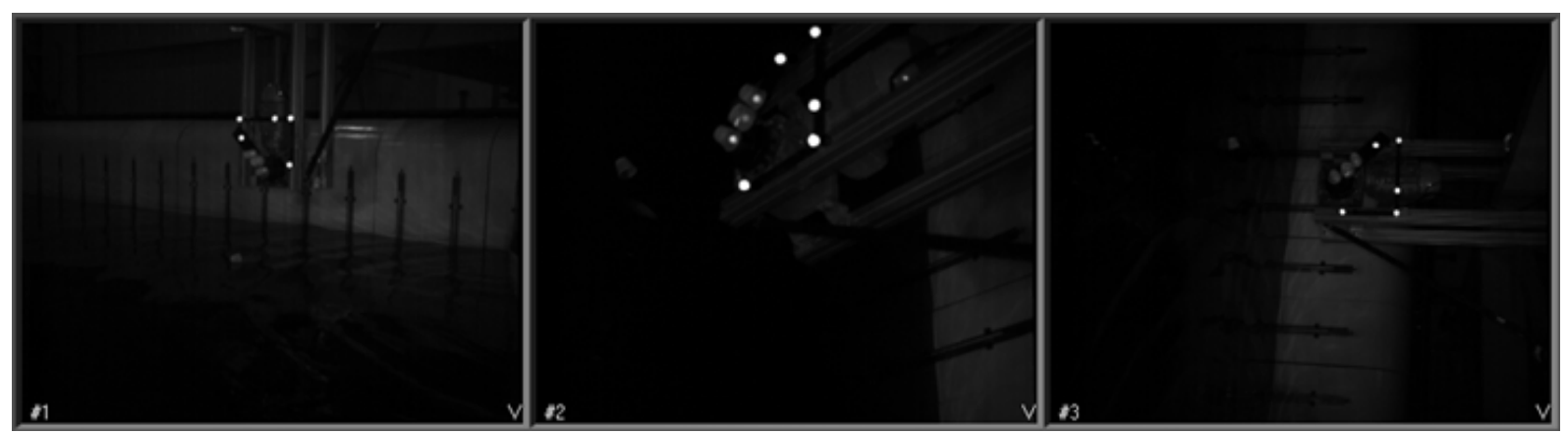

Figura 5.16: Montagem do sistema de monitoramento para aferição do atuador.

As câmeras aéreas foram calibradas e os movimentos circulares impostos, um a um, durante 60,0s - tempo suficiente para a medição de 48 a 75 ciclos completos. Os resultados percebidos pelo sistema de monitoramento óptico foram adequadamente separados, de sorte que foi possível avaliar (i) as séries temporais de deslocamentos de cada alvo, bem como a validação das frequências impostas a partir das densidades espectrais de potência (PSD) daquelas séries; (2) as trajetórias circulares dos alvos no plano da estrutura, com a respectiva determinação dos raios associados a cada movimento. As trajetórias circulares (no plano xy) foram auferidas diretamente.

Cada dupla ordenada foi utilizada para a determinação das amplitudes dos movimentos prescritos. Foram calculados os valores médios e os resultados foram assumidos como os raios efetivamente utilizados nos ensaios. Cada experimento de aferição recebeu uma denominação similar à utilizada nos ensaios principais, apresentada na Seção 5.1: $F_{i} A_{j}$, com $F$ correspondendo à frequência (em centésimos de $\mathrm{Hz}$ ) e $A$ à amplitude (em milímetros).

Com relação às frequências dos movimentos prescritos, todas as avaliações corroboraram os valores esperados, com grande acurácia. O mesmo não pode ser afirmado com respeito às amplitudes, apontando para imprecisões na construção do braço rígido, especialmente nas furações realizados, em termos de distâncias (longitudinal e transversal) relativas ao centro de fixação. 
Nesse sentido, as amplitudes nominais prescritas foram avaliadas e determinadas como sendo iguais a $0,0483 \mathrm{~m} ; 0,0958 \mathrm{~m}$; e $0,1958 \mathrm{~m}$, valores relativamente próximos do planejamento realizado, não demandando a necessidade de alterações no equipamento construído.

Como último resultado desta seção, apresente-se a Figura 5.17, que ilustra o mapeamento bidimensional dos resultados esperados para os ensaios finais.
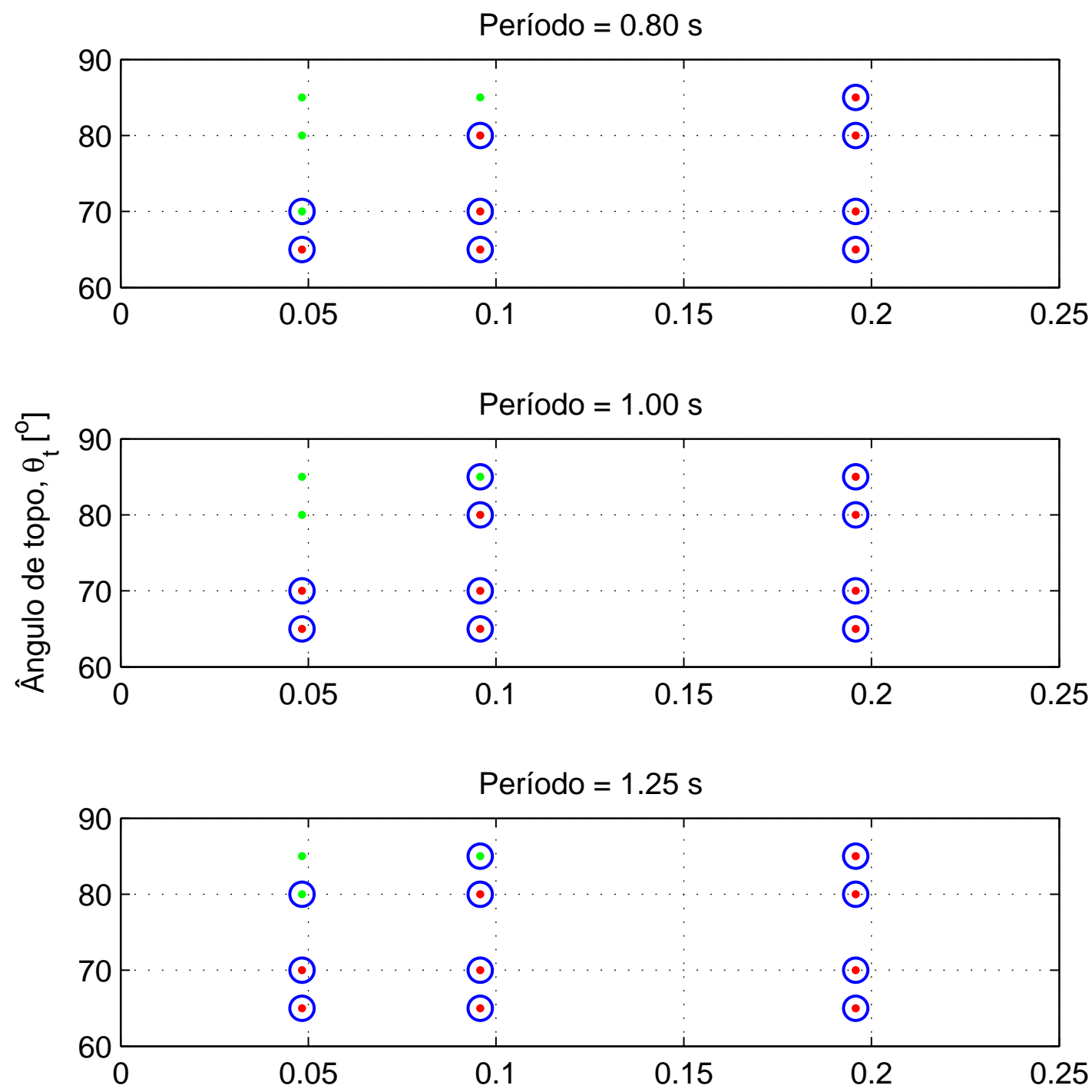

Amplitude, $A_{m}[m]$

Figura 5.17: Mapeamento bidimensional com os resultados esperados para os ensaios.

Nessa figura, pontos vermelhos indicam a previsão de ocorrência do fenômeno de compressão dinâmica para o modelo caracterizado e os movimentos aferidos, utilizando o modelo proposto por Aranha et al. (2001). Da mesma maneira, sob os auspícios da mesma teoria, pontos verdes apontam para a ausência desse fenômeno. 
Ainda com respeito a essa figura, círculos azuis referem-se a prognósticos de ocorrência de compressão dinâmica no modelo, sob a óptica da teoria de vigas curvas, sob as condições de contorno de vínculos do tipo engastado-pinado.

Analisando a Figura 5.17, é possível perceber que para todos os casos em que houve previsão de ocorrência de compressão dinâmica para o vínculo biapoiado houve confirmação do mesmo resultado, considerando-se vínculo engastado-pinado.

Por outro lado, e esse é um ganho secundário do presente trabalho, existem condições em que cada uma das formulações prevê resultados diferentes, em termos de ocorrência do fenômeno em estudo. Esses pontos, em particular, serão investigados experimentalmente, de sorte que será possível avaliar quais as condições de contorno mais adequadas para os ensaios realizados, em termos dos vínculos utilizados. 


\subsection{Ensaios Físicos}

O objetivo da presente seção não é apresentar os resultados dos ensaios físicos, mas apontar para aspectos importantes relativos aos trabalho de cunho experimental.

Definida a matriz de ensaios a ser executada, apresentado o detalhamento dos aparatos utilizados e descritas as etapas preliminares necessárias ao bom encaminhamento dos ensaios, a finalidade desta seção é a apresentação sucinta de alguns aspectos evidenciados durante os experimentos, bem como mencionar um problema ocorrido, de maneira que o leitor compreenda plenamente como as análises foram realizados após a execução dos ensaios e das simulações numéricas.

Por uma questão de praticidade, inerente à etapa de planejamento dos ensaios, uma sequência lógica de tarefas foi programada e seguida à risca.

Conforme mencionado anteriormente, os ensaios foram realizados em grupos de seis experimentos: para uma dada configuração de lançamento e amplitude determinada, variavam-se a frequência (três possibilidades) e o sentido do movimento prescrito (horário ou anti-horário).

Dessa forma, os arquivos digitais de dados gerados pelos equipamentos de aquisição (célula de carga e os dois sistemas de monitoramento óptico) encerraram, cada um, seis séries temporais (de trações ou deslocamentos e todos os sentidos). A Figura 5.18 exemplifica graficamente o conteúdo de um desses arquivos.

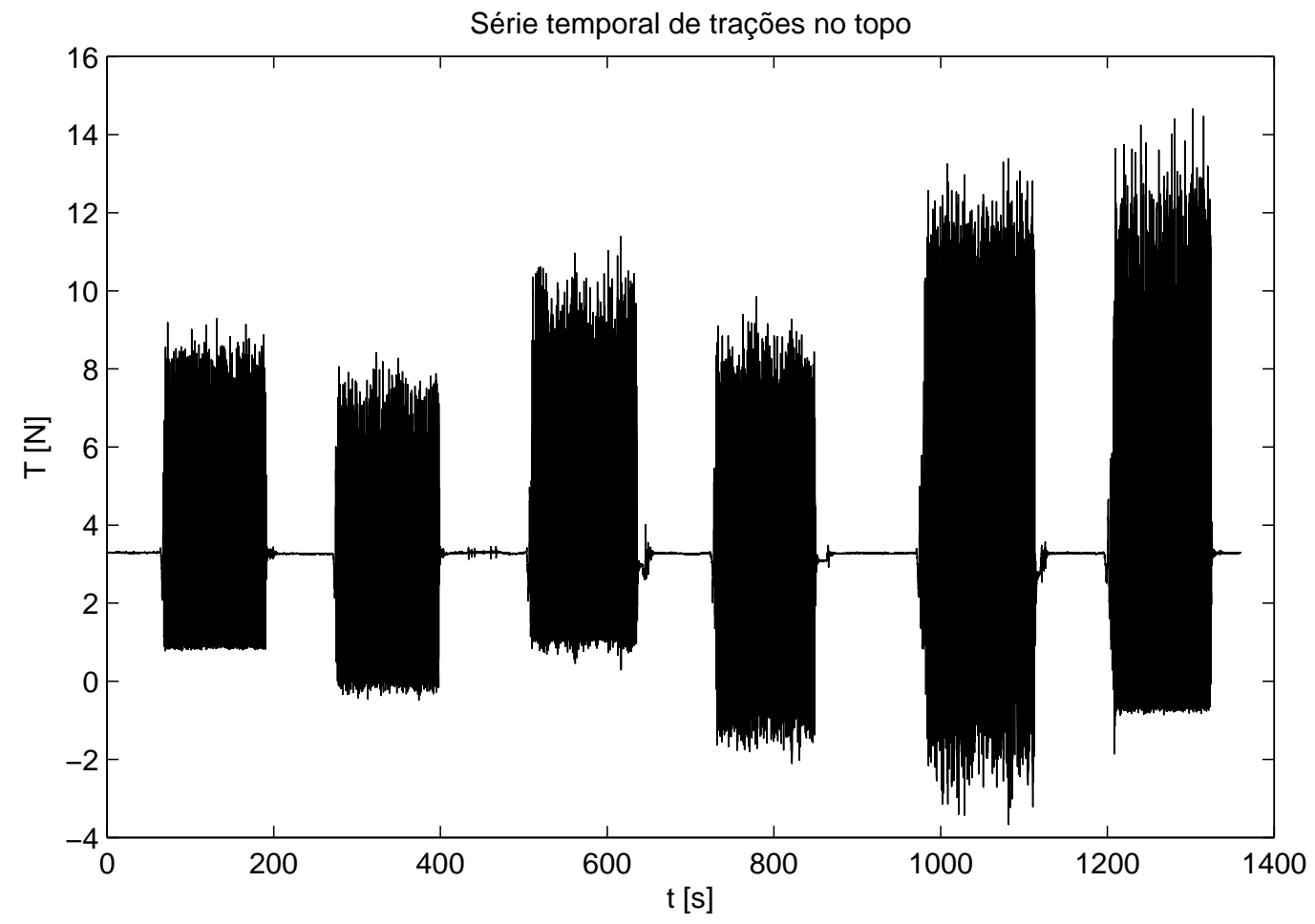

Figura 5.18: Visualização do conteúdo de um dos arquivos de monitoramento da célula de carga.

Com relação à Figura 5.18 cabem algumas observações: 
- Cada experimento foi monitorado por cerca de dois minutos, permitindo a aquisição de informações relativas de 96 a 150 ciclos;

- Antes do primeiro e entre dois experimentos os sistemas permaneciam ligados registrando sinais referentes ao rápido decaimento e posterior configuração estática inicial do ensaio seguinte;

- Na ordem, da esquerda para a direita, cada conjunto de seis aquisições foi gerado da seguinte forma: os movimentos foram impostos ao topo da linha em ordem crescente de frequências, alternando-se os sentidos;

- Assim, o primeiro sinal refere-se a um movimento circular a $0,80 \mathrm{~Hz}$ no sentido anti-horário; o segundo com a mesma frequência no sentido horário; a seguir, imposição de frequência de $1,00 \mathrm{~Hz}$ no sentido anti-horário e assim por diante;

- Como foram ensaiados um total de 72 experimentos distintos, cada sistema de monitoramento gerou 12 arquivos digitais;

- Especificamente com relação ao trecho relativo às medições das trações estáticas, suas médias foram utilizadas para determinar, indiretamente, os ângulos de topo de cada situação ${ }^{6}$.

A fim de padronizar a apresentação dos resultados, optou-se pela exposição de séries temporais de $100 \mathrm{~s}$, dado que o tempo de aquisição variou sensivelmente durante a execução dos experimentos físicos. Essa escolha garante um mínimo de 80 ciclos para cada assinatura temporal a ser apresentada, um número suficiente para os objetivos almejados.

Cada arquivo digital contendo seis séries temporais de experimentos distintos foi, posteriormente, tratado e separado adequadamente, a fim de possibilitar sua análise e comparação de resultados com as demais abordagens.

Com relação ao citado problema ocorrido, cumpre destacar que a célula de carga e o sistema de monitoramento óptico das câmeras submersas geraram todos os 72 arquivos esperados com êxito. Entretanto, o sistema que gerenciava as câmeras aéreas falhou por duas vezes, gerando arquivos vazios, fato que só foi percebido posteriormente, durante a separação e análise dos dados brutos.

Como esses arquivos foram utilizados, primordialmente, para determinação direta do ângulo de topo de cada situação ensaiada, na sua falta foram utilizados os resultados obtidos indiretamente pela célula de carga.

Para que fique devidamente documentado, os arquivos sem conteúdo aproveitável referiam-se aos ensaios (i) com amplitude de $0,100 \mathrm{~m}$ e ângulos de topo de $70^{\circ} \mathrm{e}$ (ii) com amplitude de $0,200 \mathrm{~m}$ e ângulos de topo de $80^{\circ}$ - todos valores nominais.

\footnotetext{
${ }^{6} \dot{E}$ importante citar que a determinação do ângulo de topo a partir das trações efetivas no topo da linha teve por objetivo a comparação com os valores obtidos diretamente pelo sistema de monitoramento óptico das câmeras aéreas.
} 
Cumpre notar que, para os casos passíveis de comparação, os ângulos de topo medidos diretamente e aqueles inferidos a partir das formulações analíticas mostraram-se completamente compatíveis entre si, apontando para uma ótima aderência, de maneira que o procedimento adotado pareceu bastante satisfatório.

$\mathrm{Na}$ Seção 5.5 são apresentadas duas tabelas comparando os resultados dos ângulos de topo.

As Figuras 5.19 e 5.20 ilustram dois aspectos de suma importância para os objetivos da presente tese, evidenciados nos ensaios. O primeiro refere-se à propagação de ondas de flexão geradas pela compressão dinâmica do modelo, o segundo aponta para a importância das modelagens tridimensionais do fenômeno em estudo.

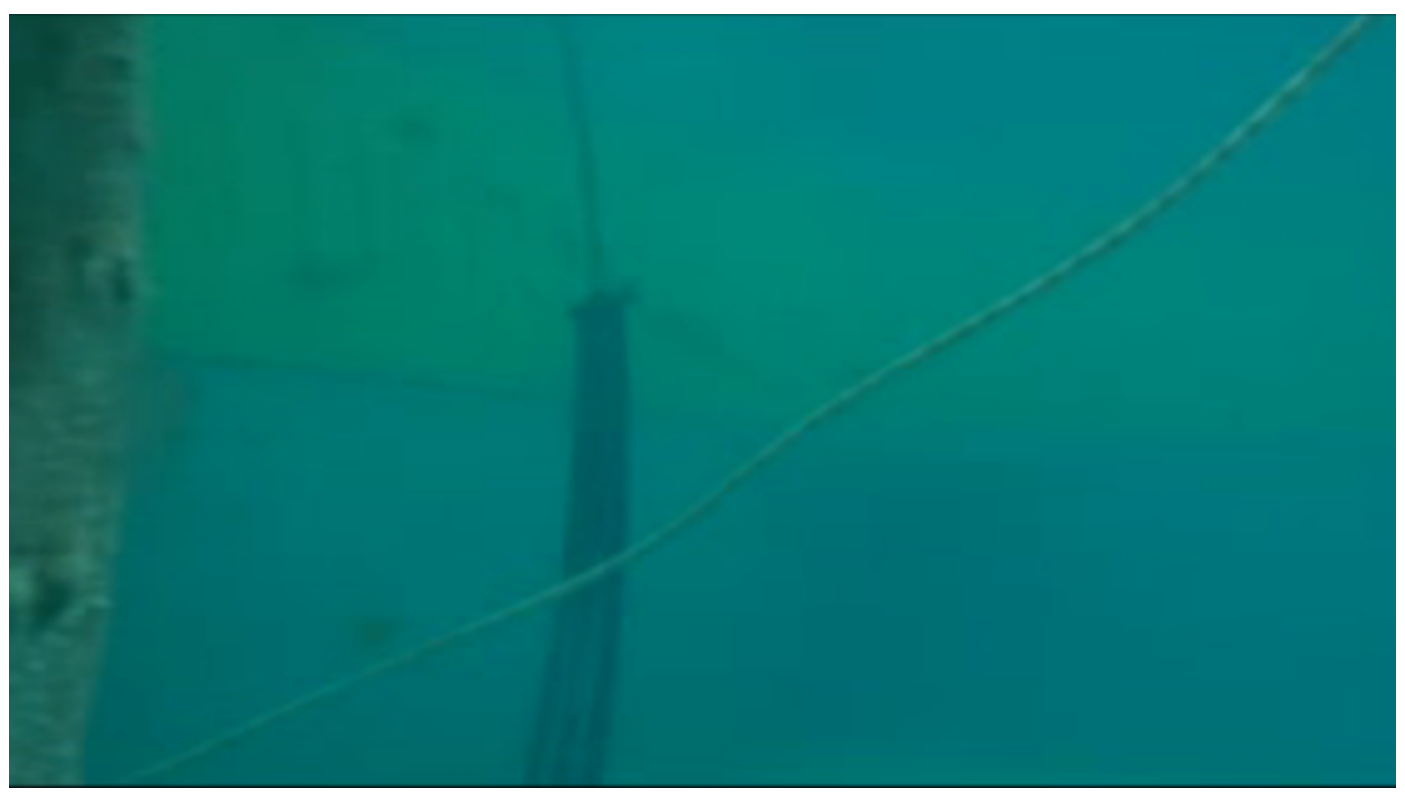

Figura 5.19: Exemplo de propagação de ondas de flexão durante um dos ensaios. Vista aquática, foto capturada pelo autor por uma das janelas laterais do CH-TPN. Essa janela de visualização fica a cerca de $2 \mathrm{~m}$ de profundidade.

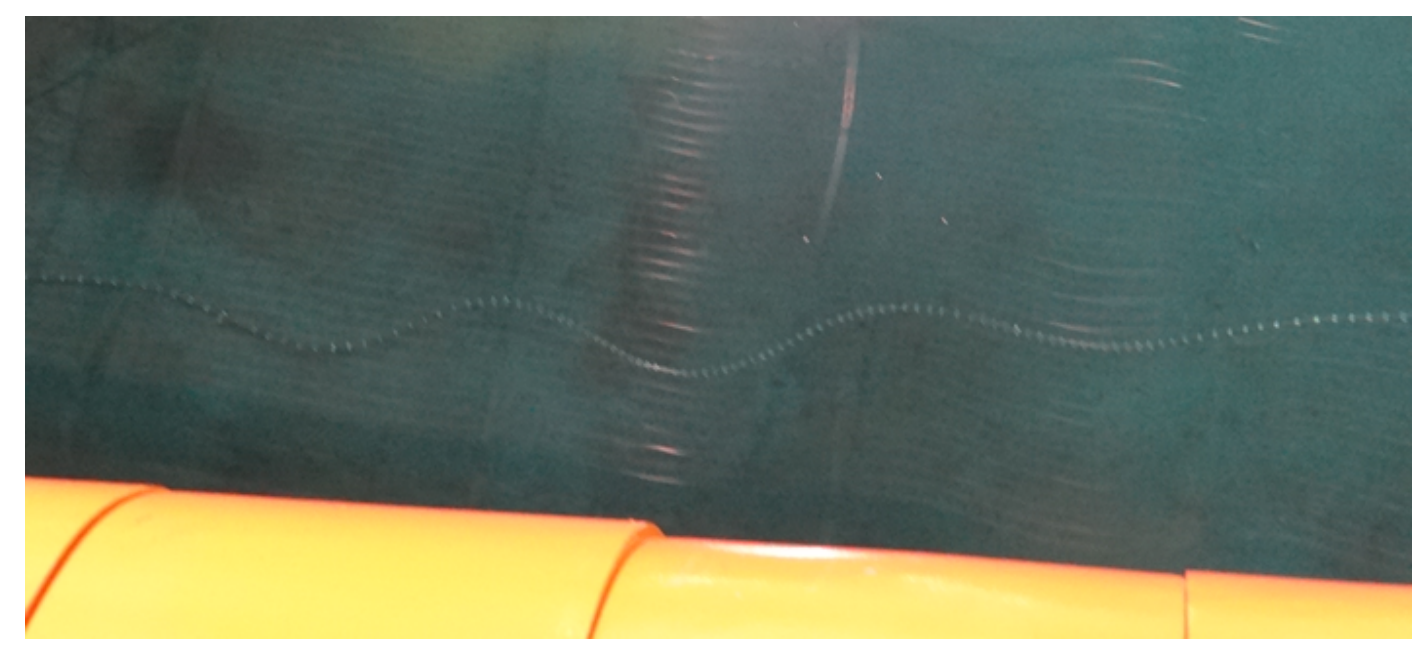

Figura 5.20: Exemplo de movimentação lateral do modelo durante um dos ensaios. Vista aérea, foto capturada pelo autor em uma das laterais do $\mathrm{CH}$-TPN. 


\subsection{Simulações Numéricas}

As simulações numéricas utilizadas no âmbito da presente tese, conforme citado anteriormente, foram realizadas a partir de um conjunto básico de três ferramentas: rotinas elaboradas em Matlab pelo próprio autor (baseadas nas formulações analíticas apresentadas no Capítulo 3 e consonante com o fluxograma da Figura 4.1) e os programas Anflex e Poliflex.

As três vertentes foram utilizadas para a determinação da estática do modelo, a fim de confrontar os resultados gerados com os advindos do sistema de monitoramento óptico.

Nesse sentido, uma das variáveis de maior interesse físico é o ângulo de topo, cujo valor foi determinado diretamente a partir do sistema de câmeras aéreas. As Tabelas 5.1 e 5.2 apresentam uma comparação simples e direta dos resultados auferidos.

$\mathrm{Na}$ coluna denominada "Aéreas" constam os valores dos ângulos de topo medidos diretamente pelo sistema de aquisição das câmeras aéreas. Com relação a esses valores, particularmente, cabem alguns comentários pertinentes.

As linhas dessa coluna assinaladas com um "* " referem-se aos casos, citados na Seção 5 , em que os arquivos resultantes do monitoramento óptico não continham nenhum dado. Os procedimentos de análises que serão explicados no próximo capítulo tornarão claros os motivos pelos quais, para essas situações, as respectivas colunas "P \& S (1995)" encontram-se vazias. Essa denominação foi utilizada como um acrônimo para (Patel \& Seyed, 1995).

Ainda com respeito às Tabelas 5.1 e 5.2, é possível perceber a maior aderência entre os valores das colunas "P\&S (1995)", "Célula de Carga" e "Anflex", o que sugere a conclusão de que o procedimento adotado para determinação indireta dos ângulos de topo, a partir das medidas estáticas das trações no topo, é bastante eficiente.

A Figura 5.21 ilustra esquematicamente a sequência de cálculos utilizada para essa finalidade, sendo autoexplicativa.

Cabe notar, todavia, que os ângulos auferidos diretamente apresentam valores mais aderentes com os resultantes do Poliflex. Como última nota, cite-se a importância das duas últimas colunas ("Poliflex CD" e "Aranha CD") que assinalam os casos de previsão de ocorrência de compressão dinâmica. A última coluna utilizou o fluxograma da Figura 4.1, que aponta para a utilização conjunta das formulações analíticas de Aranha \& Pinto (2001) e Aranha et al. (2001). Os sinais " o " indicam ausência do fenômeno, enquanto que os sinais " $x$ ", sugerem a ocorrência do mesmo. A maioria das previsões concordam entre si e somente a avaliação dos resultados finais poderá dirimir eventuais dúvidas a esse respeito. Cumpre citar que o Poliflex não possibilita a análise do comportamento pós-crítico, posterior à flambagem. Entretanto, suas características são suficientes para promover a comparação com as formulações analíticas citadas e avaliar a existência de compressão dinâmica em risers. 
Tabela 5.1: Comparação entre os ângulos de topo estáticos, sentido anti-horário.

\begin{tabular}{|c|c|c|c|c|c|c|c|}
\hline CASOS & Aéreas & $\begin{array}{l}\text { P \& S } \\
(1995) \\
\end{array}$ & $\begin{array}{c}\text { Célula de } \\
\text { Carga }\end{array}$ & Anflex & Poliflex & $\begin{array}{l}\text { Poliflex } \\
\text { CD }\end{array}$ & $\begin{array}{c}\text { Aranha } \\
\text { CD }\end{array}$ \\
\hline F080A050T65 & $68,6^{\circ}$ & $64,2^{\circ}$ & $64,6^{\circ}$ & $65,1^{\circ}$ & $67,6^{\circ}$ & $\mathrm{x}$ & $\mathrm{x}$ \\
\hline F080A100T65 & $70,6^{\circ}$ & $64,1^{\circ}$ & $64,5^{\circ}$ & $65,1^{\circ}$ & $67,8^{\circ}$ & $\mathrm{x}$ & $x$ \\
\hline F080A200T65 & $71,8^{\circ}$ & $65,5^{\circ}$ & $65,8^{\circ}$ & $65,1^{\circ}$ & $69,7^{\circ}$ & $x$ & $x$ \\
\hline F080A050T70 & $72,9^{\circ}$ & $68,5^{\circ}$ & $68,8^{\circ}$ & $69,4^{\circ}$ & $71,5^{\circ}$ & $x$ & 0 \\
\hline F080A100T70 & * & & $69,5^{\circ}$ & $69,3^{\circ}$ & $72,4^{\circ}$ & $x$ & $x$ \\
\hline F080A200T70 & $77,8^{\circ}$ & $70,0^{\circ}$ & $70,3^{\circ}$ & $69,3^{\circ}$ & $73,7^{\circ}$ & $x$ & $\mathrm{x}$ \\
\hline F080A050T80 & $82,9^{\circ}$ & $78,8^{\circ}$ & $79,0^{\circ}$ & $79,8^{\circ}$ & $80,6^{\circ}$ & 0 & 0 \\
\hline F080A100T80 & $83,5^{\circ}$ & $79,6^{\circ}$ & $79,8^{\circ}$ & $79,3^{\circ}$ & $81,6^{\circ}$ & $x$ & $x$ \\
\hline F080A200T80 & * & & $79,8^{\circ}$ & $79,6^{\circ}$ & $81,8^{\circ}$ & $x$ & $x$ \\
\hline F080A050T85 & $83,9^{\circ}$ & $82,0^{\circ}$ & $82,2^{\circ}$ & $83,0^{\circ}$ & $83,4^{\circ}$ & 0 & 0 \\
\hline F080A100T85 & $83,3^{\circ}$ & $80,6^{\circ}$ & $80,8^{\circ}$ & $82,9^{\circ}$ & $82,4^{\circ}$ & $x$ & 0 \\
\hline F080A200T85 & $-39,8^{\circ}$ & $85,9^{\circ}$ & $86,1^{\circ}$ & $82,8^{\circ}$ & $\mathrm{N} / \mathrm{C}$ & $\mathrm{N} / \mathrm{C}$ & $x$ \\
\hline F100A050T65 & $68,6^{\circ}$ & $64,2^{\circ}$ & $64,5^{\circ}$ & $64,7^{\circ}$ & $67,6^{\circ}$ & $\mathrm{x}$ & $\bar{x}$ \\
\hline F100A100T65 & $70,7^{\circ}$ & $64,2^{\circ}$ & $64,5^{\circ}$ & $64,7^{\circ}$ & $67,9^{\circ}$ & $\mathrm{x}$ & $\mathrm{x}$ \\
\hline F100A200T65 & $71,4^{\circ}$ & $65,1^{\circ}$ & $65,4^{\circ}$ & $64,6^{\circ}$ & $69,3^{\circ}$ & $\mathrm{x}$ & $x$ \\
\hline F100A050T70 & $72,9^{\circ}$ & $68,4^{\circ}$ & $68,7^{\circ}$ & $69,7^{\circ}$ & $71,4^{\circ}$ & $\mathrm{x}$ & $\mathrm{x}$ \\
\hline F100A100T70 & * & & $69,7^{\circ}$ & $69,9^{\circ}$ & $72,6^{\circ}$ & $x$ & $x$ \\
\hline F100A200T70 & $77,8^{\circ}$ & $70,1^{\circ}$ & $70,4^{\circ}$ & $69,9^{\circ}$ & $73,8^{\circ}$ & $\mathrm{x}$ & $\mathrm{x}$ \\
\hline F100A050T80 & $82,7^{\circ}$ & $78,4^{\circ}$ & $78,6^{\circ}$ & $79,8^{\circ}$ & $80,3^{\circ}$ & $x$ & 0 \\
\hline F100A100T80 & $83,6^{\circ}$ & $79,5^{\circ}$ & $79,7^{\circ}$ & $79,9^{\circ}$ & $81,4^{\circ}$ & $x$ & $x$ \\
\hline F100A200T80 & * & & $79,8^{\circ}$ & $79,9^{\circ}$ & $81,9^{\circ}$ & $x$ & $x$ \\
\hline F100A050T85 & $86,2^{\circ}$ & $81,9^{\circ}$ & $82,1^{\circ}$ & $81,0^{\circ}$ & $83,4^{\circ}$ & $x$ & 0 \\
\hline F100A100T85 & $83,5^{\circ}$ & $80,3^{\circ}$ & $80,5^{\circ}$ & $84,4^{\circ}$ & $82,1^{\circ}$ & $\mathrm{x}$ & 0 \\
\hline F100A200T85 & $-32,9^{\circ}$ & $85,2^{\circ}$ & $85,4^{\circ}$ & $80,8^{\circ}$ & $\mathrm{N} / \mathrm{C}$ & $\mathrm{N} / \mathrm{C}$ & $x$ \\
\hline F125A050T65 & $68,6^{\circ}$ & $64,2^{\circ}$ & $64,5^{\circ}$ & $65,2^{\circ}$ & $67,5^{\circ}$ & $\mathrm{x}$ & $\bar{x}$ \\
\hline F125A100T65 & $70,6^{\circ}$ & $64,1^{\circ}$ & $64,4^{\circ}$ & $64,8^{\circ}$ & $67,8^{\circ}$ & $x$ & $x$ \\
\hline F125A200T65 & $71,7^{\circ}$ & $65,2^{\circ}$ & $65,5^{\circ}$ & $64,9^{\circ}$ & $69,4^{\circ}$ & $x$ & $x$ \\
\hline F125A050T70 & $72,8^{\circ}$ & $68,4^{\circ}$ & $68,7^{\circ}$ & $69,6^{\circ}$ & $71,4^{\circ}$ & $x$ & $x$ \\
\hline F125A100T70 & * & & $69,7^{\circ}$ & $69,7^{\circ}$ & $72,6^{\circ}$ & $x$ & $x$ \\
\hline F125A200T70 & $77,9^{\circ}$ & $70,0^{\circ}$ & $70,2^{\circ}$ & $69,6^{\circ}$ & $73,7^{\circ}$ & $x$ & $\mathrm{x}$ \\
\hline F125A050T80 & $82,5^{\circ}$ & $78,6^{\circ}$ & $78,8^{\circ}$ & $79,0^{\circ}$ & $80,5^{\circ}$ & $x$ & 0 \\
\hline F125A100T80 & $83,4^{\circ}$ & $79,4^{\circ}$ & $79,6^{\circ}$ & $79,0^{\circ}$ & $81,4^{\circ}$ & $x$ & $x$ \\
\hline F125A200T80 & ${ }^{*}$ & & $80,2^{\circ}$ & $79,4^{\circ}$ & $82,2^{\circ}$ & $x$ & $x$ \\
\hline F125A050T85 & $86,3^{\circ}$ & $81,8^{\circ}$ & $82,0^{\circ}$ & $85,2^{\circ}$ & $83,3^{\circ}$ & $x$ & 0 \\
\hline F125A100T85 & $83,4^{\circ}$ & $80,3^{\circ}$ & $80,5^{\circ}$ & $84,5^{\circ}$ & $82,2^{\circ}$ & $x$ & 0 \\
\hline F125A200T85 & $-43,7^{\circ}$ & $84,9^{\circ}$ & $85,1^{\circ}$ & $84,2^{\circ}$ & $\mathrm{N} / \mathrm{C}$ & $\mathrm{N} / \mathrm{C}$ & $x$ \\
\hline
\end{tabular}


Tabela 5.2: Comparação entre os ângulos de topo estáticos, sentido horário.

\begin{tabular}{|c|c|c|c|c|c|c|c|}
\hline CASOS & Aéreas & $\begin{array}{l}\text { P \& S } \\
(1995)\end{array}$ & $\begin{array}{c}\text { Célula de } \\
\text { Carga }\end{array}$ & Anflex & Poliflex & $\begin{array}{l}\text { Poliflex } \\
\text { CD }\end{array}$ & $\begin{array}{c}\text { Aranha } \\
\text { CD }\end{array}$ \\
\hline F080A050T65 & $68,6^{\circ}$ & $64,2^{\circ}$ & $64,5^{\circ}$ & $65,1^{\circ}$ & $68,3^{\circ}$ & $x$ & $x$ \\
\hline F080A100T65 & $70,7^{\circ}$ & $64,2^{\circ}$ & $64,5^{\circ}$ & $65,1^{\circ}$ & $67,9^{\circ}$ & $x$ & $x$ \\
\hline F080A200T65 & $71,6^{\circ}$ & $65,3^{\circ}$ & $65,6^{\circ}$ & $65,2^{\circ}$ & $69,5^{\circ}$ & $x$ & $x$ \\
\hline F080A050T70 & $72,8^{\circ}$ & $68,3^{\circ}$ & $68,6^{\circ}$ & $69,3^{\circ}$ & $71,3^{\circ}$ & $x$ & 0 \\
\hline F080A100T70 & * & & $69,8^{\circ}$ & $69,3^{\circ}$ & $72,7^{\circ}$ & $x$ & $x$ \\
\hline F080A200T70 & $77,2^{\circ}$ & $69,6^{\circ}$ & $69,9^{\circ}$ & $69,3^{\circ}$ & $73,4^{\circ}$ & $\mathrm{x}$ & $\mathrm{x}$ \\
\hline F080A050T80 & $82,8^{\circ}$ & $78,7^{\circ}$ & $78,9^{\circ}$ & $79,6^{\circ}$ & $80,5^{\circ}$ & 0 & 0 \\
\hline F080A100T80 & $83,4^{\circ}$ & $79,4^{\circ}$ & $79,6^{\circ}$ & $79,6^{\circ}$ & $81,4^{\circ}$ & $x$ & $x$ \\
\hline F080A200T80 & ${ }^{*}$ & & $80,1^{\circ}$ & $79,6^{\circ}$ & $82,1^{\circ}$ & $x$ & $x$ \\
\hline F080A050T85 & $84,0^{\circ}$ & $82,0^{\circ}$ & $82,1^{\circ}$ & $82,9^{\circ}$ & $83,4^{\circ}$ & 0 & 0 \\
\hline F080A100T85 & $83,6^{\circ}$ & $80,3^{\circ}$ & $80,5^{\circ}$ & $82,7^{\circ}$ & $82,1^{\circ}$ & $x$ & 0 \\
\hline F080A200T85 & $-43,8^{\circ}$ & $83,8^{\circ}$ & $84,0^{\circ}$ & $82,8^{\circ}$ & $\mathrm{N} / \mathrm{C}$ & $\mathrm{N} / \mathrm{C}$ & $x$ \\
\hline F100A050T65 & $68,6^{\circ}$ & $64,2^{\circ}$ & $64,5^{\circ}$ & $64,7^{\circ}$ & $67,6^{\circ}$ & $\mathrm{x}$ & $\bar{x}$ \\
\hline F100A100T65 & $70,8^{\circ}$ & $64,2^{\circ}$ & $64,5^{\circ}$ & $64,7^{\circ}$ & $67,8^{\circ}$ & $x$ & $x$ \\
\hline F100A200T65 & $71,7^{\circ}$ & $65,2^{\circ}$ & $65,6^{\circ}$ & $64,7^{\circ}$ & $69,5^{\circ}$ & $x$ & $x$ \\
\hline F100A050T70 & $72,8^{\circ}$ & $68,4^{\circ}$ & $68,7^{\circ}$ & $70,1^{\circ}$ & $71,4^{\circ}$ & $x$ & $x$ \\
\hline F100A100T70 & * & & $69,8^{\circ}$ & $70,0^{\circ}$ & $72,7^{\circ}$ & $\mathrm{x}$ & $\mathrm{x}$ \\
\hline F100A200T70 & $77,1^{\circ}$ & $69,5^{\circ}$ & $69,8^{\circ}$ & $69,9^{\circ}$ & $73,2^{\circ}$ & $\mathrm{x}$ & $\mathrm{x}$ \\
\hline F100A050T80 & $82,6^{\circ}$ & $78,6^{\circ}$ & $78,9^{\circ}$ & $79,8^{\circ}$ & $80,5^{\circ}$ & $x$ & 0 \\
\hline F100A100T80 & $83,3^{\circ}$ & $79,4^{\circ}$ & $79,6^{\circ}$ & $79,8^{\circ}$ & $81,3^{\circ}$ & $x$ & $x$ \\
\hline F100A200T80 & * & & $80,1^{\circ}$ & $79,8^{\circ}$ & $82,1^{\circ}$ & $x$ & $x$ \\
\hline F100A050T85 & $85,5^{\circ}$ & $81,7^{\circ}$ & $81,9^{\circ}$ & $80,8^{\circ}$ & $83,2^{\circ}$ & $x$ & 0 \\
\hline F100A100T85 & $83,0^{\circ}$ & $80,1^{\circ}$ & $80,4^{\circ}$ & $80,4^{\circ}$ & $82,0^{\circ}$ & $x$ & 0 \\
\hline F100A200T85 & $-45,9^{\circ}$ & $84,9^{\circ}$ & $85,1^{\circ}$ & $80,6^{\circ}$ & $\mathrm{N} / \mathrm{C}$ & $\mathrm{N} / \mathrm{C}$ & $x$ \\
\hline F125A050T65 & $68,7^{\circ}$ & $64,3^{\circ}$ & $64,6^{\circ}$ & $65,0^{\circ}$ & $67,7^{\circ}$ & $\mathrm{x}$ & $\bar{x}$ \\
\hline F125A100T65 & $70,6^{\circ}$ & $64,2^{\circ}$ & $64,5^{\circ}$ & $64,9^{\circ}$ & $67,9^{\circ}$ & $x$ & $x$ \\
\hline F125A200T65 & $71,5^{\circ}$ & $65,1^{\circ}$ & $65,4^{\circ}$ & $64,8^{\circ}$ & $69,3^{\circ}$ & $\mathrm{x}$ & $\mathrm{x}$ \\
\hline F125A050T70 & $72,7^{\circ}$ & $68,4^{\circ}$ & $68,7^{\circ}$ & $69,3^{\circ}$ & $71,4^{\circ}$ & $\mathrm{x}$ & $\mathrm{x}$ \\
\hline F125A100T70 & * & & $69,7^{\circ}$ & $69,1^{\circ}$ & $72,6^{\circ}$ & $\mathrm{x}$ & $\mathrm{x}$ \\
\hline F125A200T70 & $77,1^{\circ}$ & $70,1^{\circ}$ & $70,4^{\circ}$ & $69,7^{\circ}$ & $73,8^{\circ}$ & $x$ & $x$ \\
\hline F125A050T80 & $82,5^{\circ}$ & $78,6^{\circ}$ & $78,8^{\circ}$ & $79,3^{\circ}$ & $80,5^{\circ}$ & $x$ & 0 \\
\hline F125A100T80 & $83,4^{\circ}$ & $79,4^{\circ}$ & $79,6^{\circ}$ & $79,3^{\circ}$ & $81,3^{\circ}$ & $x$ & $x$ \\
\hline F125A200T80 & * & & $80,0^{\circ}$ & $79,2^{\circ}$ & $82,0^{\circ}$ & $x$ & $x$ \\
\hline F125A050T85 & $85,7^{\circ}$ & $81,9^{\circ}$ & $82,0^{\circ}$ & $83,1^{\circ}$ & $83,3^{\circ}$ & $x$ & 0 \\
\hline F125A100T85 & $83,4^{\circ}$ & $80,1 \mathrm{v}$ & $80,3^{\circ}$ & $84,2^{\circ}$ & $82,0^{\circ}$ & $x$ & 0 \\
\hline F125A200T85 & $-43,8^{\circ}$ & $84,1^{\circ}$ & $84,3^{\circ}$ & $84,7^{\circ}$ & $\mathrm{N} / \mathrm{C}$ & $\mathrm{N} / \mathrm{C}$ & $\mathrm{x}$ \\
\hline
\end{tabular}




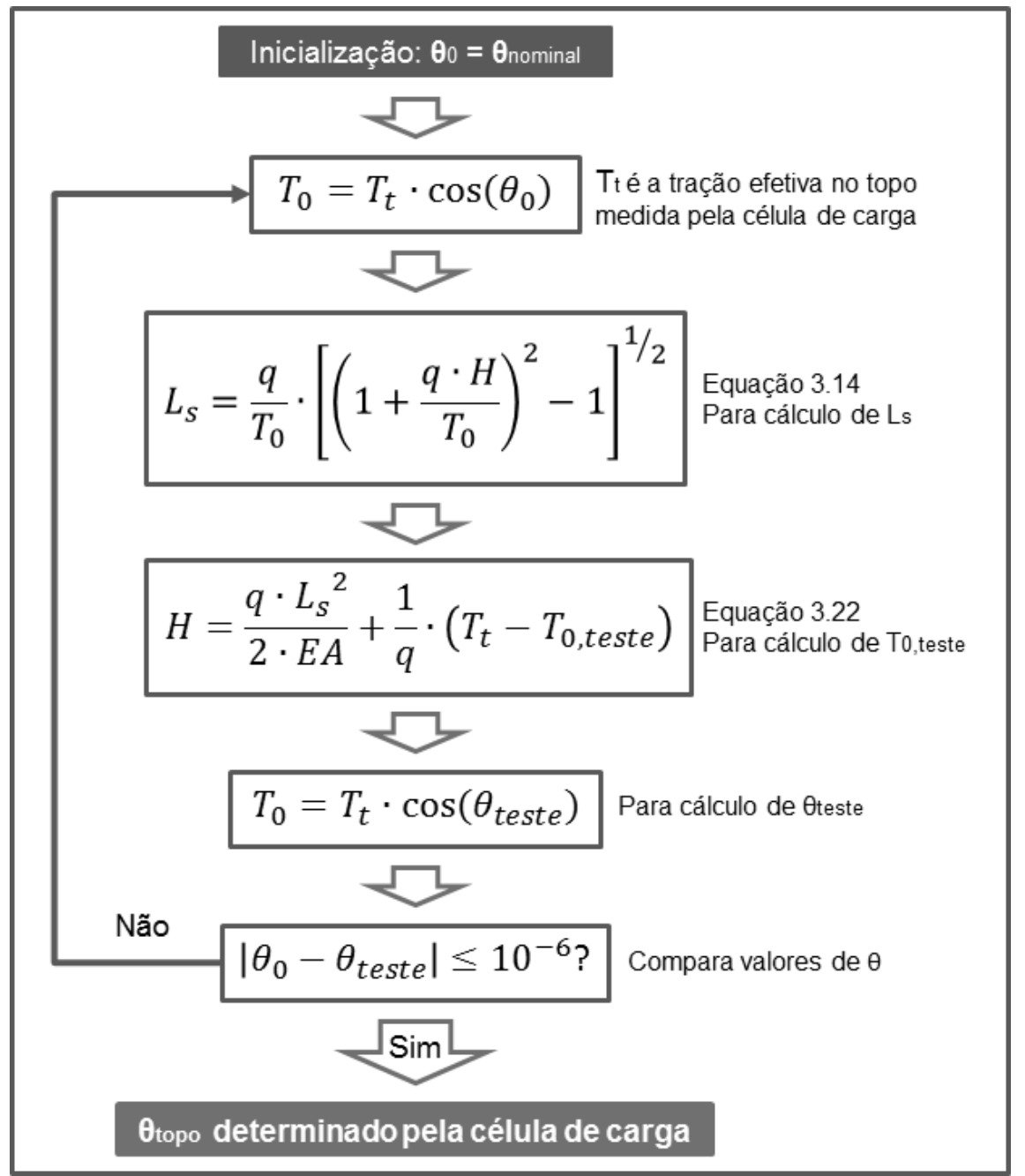

Figura 5.21: Determinação iterativa do ângulo de topo a partir das trações medidas pela célula de carga.

Nos casos em que o Poliflex identifica a ocorrência do fenômeno em estudo, o programa apresentava uma mensagem de erro, reproduzida na Figura 5.22.

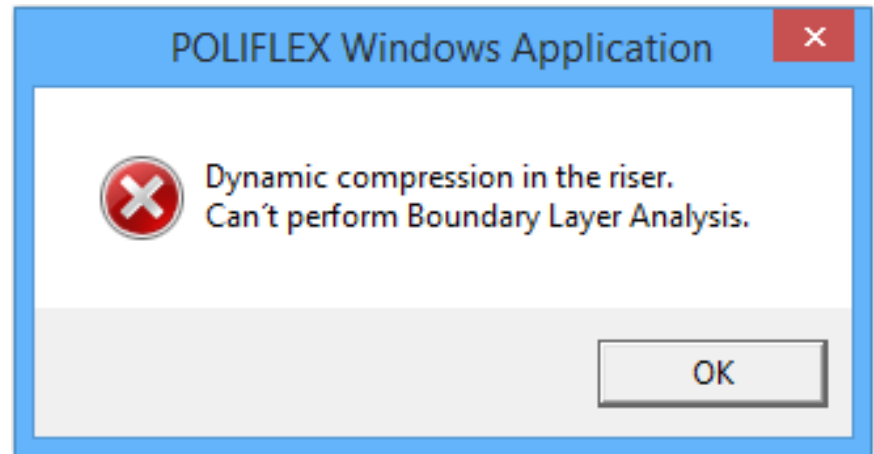

Figura 5.22: Mensagem de erro do Poliflex quando da ocorrência de compressão dinâmica.

Além das funcionalidades apresentadas, o Poliflex permite a determinação das frequências naturais de vibração do modelo caracterizado, o que foi feito para os ângulos de topo nominais, dada a grande variedade de valores mensurados dos mesmos, bem como as diferenças apresentadas para seus resultados. 
A Tabela 5.3 apresenta as frequências relativas aos primeiros vinte modos de vibrar do modelo flexível utilizado nos ensaios, para cada um dos quatro ângulos de topo determinados pela matriz de ensaios. O Poliflex determina as frequências de modos naturais no plano da catenária e também na direção perpendicular a esse. Os valores da tabela anotados com um " * " correspondem a modos no plano da catenária. Dessa forma, é preciso cuidado ao comparar os valores para, assim, perceber a aderência entre o método analítico e os resultados do Poliflex.

Os valores obtidos com o uso do Poliflex são apresentados juntamente com os calculados a partir da formulação analítica de Pesce et al. (1999), solução analítica fechada para o problema de autovalor associado. O problema foi modelado sob a hipótese de inextensibilidade da linha, que a rigor é fisicamente inadequada. A presença de correnteza também não é contemplada por essa solução, baseada no método WKB ${ }^{7}$, que consiste na determinação aproximada de equações diferenciais parciais.

Cumpre destacar que a solução proposta em (Pesce et al., 1999) é de uma simplicidade analítica impressionante, expressão pela Equação 5.1, em conjunto com a definição do parâmetro $\Lambda_{n}$ apresentada na Equação 5.2.

$$
\Omega_{n} \cong \Lambda n \cdot \sqrt{\frac{1-a}{1+a} \cdot \tan \left(\theta_{t}\right)} \cdot \sqrt{\frac{g}{L}}=\Lambda n \cdot \sqrt{\frac{1-a}{1+a}} \cdot \sqrt{\frac{1-\cos \left(\theta_{t}\right)}{\cos \left(\theta_{t}\right)}} \cdot \sqrt{\frac{g}{H}}
$$

onde $a=\frac{m_{a}}{m}, L$ é o comprimento suspenso do riser e $H$ é a lâmina d' água.

$$
\Lambda_{n}=\Lambda_{n}\left(\theta_{t}\right) \cong \frac{n \cdot \pi}{\int_{0}^{\theta_{t}} \frac{d \theta}{[\cos (\theta)]^{\frac{3}{2}}}}
$$

A despeito das aproximações e hipóteses utilizadas para determinação da solução analítica formulada por Pesce et al. (1999), é evidente a capacidade dessa formulação em termos de acurácia, reltivamente aos valores resultantes da utlização do Poliflex, com a versatilidade da mesma, em termos de facilidade de cálculo e a rapidez em fazê-lo com o conhecimento prévio de poucas variáveis.

Cabe, ainda, uma citação com respeito aos resultados referentes às frequências naturais associadas aos modos de vibrar do modelo. Em Morooka et al. (2008) apud (Tsukada, 2009), afirmou-se, tacitamente, que:

"Cilindros com termos de tração predominantes no comportamento dinâmico (Cabos): esta configuração de experimento geralmente é utilizada para estudar o comportamento dinâmico de risers longos. Como a tração predomina sobre a rigidez flexional no comportamento dinâmico da estrutura, é esperado que o espaçamento entre as freqüências naturais diminua".

Esse trecho é completamente corroborado pelos dados compilados na Tabela 5.3.

\footnotetext{
${ }^{7}$ O nome desse método é um acrônimo para Wentzel-Kramers-Brillouin e também é conhecido como método LG - acrônimo de Liouville-Green.
} 
Tabela 5.3: Comparação entre as frequências naturais obtidas para o modelo ensaiado.

\begin{tabular}{c|c|c|c|c||c|c|c|c|}
\hline & \multicolumn{3}{|c|}{ WKB, Pesce (1999) - frequência em Hz } & \multicolumn{4}{|c|}{ POLIFLEX - frequência em Hz } \\
\hline \hline $\mathrm{n}$ & $65^{\circ}$ & $70^{\circ}$ & $80^{\circ}$ & $85^{\circ}$ & $65^{\circ}$ & $70^{\circ}$ & $80^{\circ}$ & $85^{\circ}$ \\
\hline 1 & 0,1852 & 0,1829 & 0,1739 & 0,1649 & 0,1815 & 0,1782 & 0,1670 & 0,1550 \\
\hline 2 & 0,3704 & 0,3658 & 0,3478 & 0,3297 & $0,3291^{*}$ & $0,3135^{*}$ & $0,2662^{*}$ & $0,2281^{*}$ \\
\hline 3 & 0,5555 & 0,5488 & 0,5217 & 0,4946 & 0,3601 & 0,3534 & 0,3328 & 0,3129 \\
\hline 4 & 0,7407 & 0,7317 & 0,6955 & 0,6594 & $0,4838^{*}$ & $0,4817^{*}$ & $0,4482^{*}$ & $0,4131^{*}$ \\
\hline 5 & 0,9259 & 0,9146 & 0,8694 & 0,8243 & 0,4954 & 0,4906 & 0,4754 & 0,4639 \\
\hline 6 & 1,1111 & 1,0975 & 1,0433 & 0,9891 & $0,5400^{*}$ & $0,5303^{*}$ & $0,5004^{*}$ & $0,4737^{*}$ \\
\hline 7 & 1,2962 & 1,2804 & 1,2172 & 1,1540 & 0,6977 & 0,6883 & 0,6402 & 0,6002 \\
\hline 8 & 1,4814 & 1,4634 & 1,3911 & 1,3188 & $0,7212^{*}$ & $0,7085^{*}$ & $0,6716^{*}$ & $0,6408^{*}$ \\
\hline 9 & 1,6666 & 1,6463 & 1,5650 & 1,4837 & 0,7372 & 0,7608 & 0,7346 & 0,7071 \\
\hline 10 & 1,8518 & 1,8292 & 1,7389 & 1,6485 & $0,7692^{*}$ & $0,8124^{*}$ & $0,8132^{*}$ & $0,7818^{*}$ \\
\hline \hline 11 & 2,0370 & 2,0121 & 1,9128 & 1,8134 & $0,9037^{*}$ & $0,8886^{*}$ & 0,8471 & 0,8155 \\
\hline 12 & 2,2221 & 2,1950 & 2,0866 & 1,9782 & 0,9288 & $0,9768^{*}$ & $1,0079^{*}$ & $0,9745^{*}$ \\
\hline 13 & 2,4073 & 2,3780 & 2,2605 & 2,1431 & 1,0793 & 1,0626 & 1,0277 & 0,9984 \\
\hline 14 & 2,5925 & 2,5609 & 2,4344 & 2,3079 & $1,0877^{*}$ & $1,0709^{*}$ & $1,0538^{*}$ & $0,9984^{*}$ \\
\hline 15 & 2,7777 & 2,7438 & 2,6083 & 2,4728 & $1,1240^{*}$ & $1,1063^{*}$ & 1,1765 & 1,1661 \\
\hline 16 & 2,9628 & 2,9267 & 2,7822 & 2,6377 & 1,2732 & 1,2555 & $1,2138^{*}$ & $1,1898^{*}$ \\
\hline 17 & 3,1480 & 3,1096 & 2,9561 & 2,8025 & 1,2779 & 1,2671 & 1,3875 & 1,3195 \\
\hline 18 & 3,3332 & 3,2926 & 3,1300 & 2,9674 & $1,4529^{*}$ & 1,4341 & $1,3987^{*}$ & $1,3740^{*}$ \\
\hline 19 & 3,5184 & 3,4755 & 3,3038 & 3,1322 & $1,4605^{*}$ & $1,4426^{*}$ & $1,4058^{*}$ & $1,3901^{*}$ \\
\hline 20 & 3,7036 & 3,6584 & 3,4777 & 3,2971 & 1,5071 & 1,4802 & 1,4394 & 1,5737 \\
\hline
\end{tabular}

O Anflex foi utilizado para determinação das séries temporais de trações (no TDP e no topo) e de deslocamentos (de diversos pontos, escolhidos ao longo da linha, a fim de permitir a comparação com os resultados advindos do sistema de monitoramento óptico, além de oferecer informações a respeito dos trechos não monitorados).

Além das considerações tecidas, cabe um último comentário com respeito às simulações feitas com o uso do Anflex e do Poliflex: esses programas são bastante parecidos em termos dos dados de entrada exigidos para análise das linhas submersas.

Ao longo do presente texto, particularmente no Item 4.1.1, várias dessas variáveis de entrada foram descritas e, inclusive, detalhadas. Entretanto, uma delas não foi citada anteriormente, por se tratar de um efeito pouco considerado nas formulações analíticas: a rigidez torsional. Exceções a essa afirmação são os trabalhos de Ramos Jr (2001) e Ramos Jr \& Pesce (2003), nos quais esse efeito é considerado, inclusive no que tange aos seus efeitos sobre a carga crítica de flambagem.

Ambos os programas citados e utilizados no contexto desta tese exigem a introdução, por parte do usuário, do valor da rigidez torsional equivalente.

Dado que nenhum ensaio específico foi levado a cabo de maneira a permitir a determinação experimental dessa propriedade, recorreu-se à literatura. 
Na realidade, é mister entender a classe de materiais a que o silicone pertence.

O silicone, por definição, é um elastômero viscoelástico de origem mineral.

A classificação do silicone como um elastômero implica no fato de que esse material possui propriedades elásticas que são bem representadas estatisticamente, diferentemente de metais, por exemplo, cujas propriedades físico-mecânicas são muito bem estabelecidas. Ademais, os elastômeros suportam grandes deformações relativas préruptura.

Essas características foram decisivas para a realização dos ensaios de caracterização. Além disso, cabe lembrar a grande variedade de equacionamentos, resultados e dados de literatura utilizados como base de comparação com os resultados auferidos a partir desses experimentos específicos.

A viscoelasticidade, por seu turno, confere ao silicone propriedades combinadas de materiais elásticos e viscosos.

Sinteticamente, as equações diferenciais que regem o comportamento dos materiais viscoelásticos são compostas de três parcelas que somadas permitem determinar a tensão total atuante sobre o corpo ou material: (i) a deformação elástica; (ii) a taxa de deformação viscosa; e (iii) um termo inercial proporcional à aceleração.

Por outro lado, uma propriedade bastante interessante dos materiais viscoelásticos é a sua incompressibilidade. Para entender a importância dessa propriedade na determinação do Módulo de Torção (ou Cisalhamento), retomem-se algumas definições da Mecânica dos Sólidos e Resistência dos Materiais, com a finalidade de apontar a maneira como a rigidez torsional foi considerada nas simulações numéricas realizadas:

- O Coeficiente de Poisson $\nu$ mede a deformação transversal (em relação à direção longitudinal) de um material homogêneo e isotrópico;

- O chamado Módulo Volumétrico $K$ descreve a elasticidade volumétrica de um material, ou seja, a capacidade de um material de deformar em tordas as direções quando submetido a cargas uniformes em todas as direções. Pode-se relacionar o Módulo Volumétrico como o inverso da compressibilidade;

- A relação entre os dois parâmetros citados e o Módulo de Young (ou de elasticidade) é bem determinada e dada pela Equação 5.3;

- Ora, a incompressibilidade implica em altos valores de $K$. Quando $\nu \rightarrow 0,5$, $K \rightarrow \infty$;

- Assim, é muito comum a adoção do Coeficiente de Poisson como 0,5 para o silicone. Alguns trabalhos experimentais apontam para valores entre 0,48 e 0,49, o que implica em diferenças percentuais bastante reduzidas para o Módulo Volumétrico.

$$
K=\frac{E}{3 \cdot(1-2 \nu)}
$$


Além disso, a relação entre o Módulo de Cisalhamento $(G)$ e o Módulo de Young $(E)$ também é bastante conhecida:

$$
G=\frac{E}{2 \cdot(1+2 \nu)}
$$

Portanto, como para o silicone $\nu \rightarrow 0,5$, então uma boa aproximação para o valor do Módulo de Cisalhamento é $G \cong \frac{E}{3}$. Essa relação foi utilizada para determinação da rigidez torsional $(G J)^{8}$, a partir do cálculo do momento de inércia da seção transversal do tubo de silicone utilizado como modelo para os ensaios.

Outras variáveis importantes para as simulações são:

1. os coeficiente adimensionais de massa e arrasto;

2. as propriedades do solo (atritos e rijezas);

3. os parâmetros intrinsecamente relacionados às simulações em si (erros absolutos/relativos permitidos para trações, momentos e deslocamentos; tempo total de simulação; intervalo entre cada iteração - time step; discretização da linha (número de elementos discretos que representam o modelo contínuo; etc.).

A determinação desses parâmetros é essencial para o sucesso das simulações, no sentido de que elas representem o mais fielmente possível as situações reais ou de experimentos em escala, daí sua importância no contexto do presente trabalho.

Como descrito na Seção 3.2.2, as forças hidrodinâmicas inerentes ao problema de linhas submersas costumam ser modeladas pela chamada Equação de Morison, composta de duas parcelas (vide Equação 3.35):

- A primeira parcela aditiva corresponde a um termo inercial, onde $C_{m}=1+C_{a} \mathrm{e}$ $u$ é a velocidade normal relativa do fluxo oscilatório existente entre o fluido e o corpo;

- $C_{m}$ é conhecido como coeficiente de inércia, que incorpora a massa própria do sistema, além da chamada massa adicionada, através de seu coeficiente homônimo $C_{a}$;

- A segunda parcela é um termo de arrasto, proporcional ao quadrado do módulo da velocidade $u$, na qual $C_{D}$ é o chamado coeficiente de arrasto.

Um dos problemas mais importantes na resolução da dinâmica de risers é a determinação dos valores dos coeficientes da Equação 3.35, o que é feito experimentalmente ou com base em dados da literatura especializada. Neste ponto, cabem algumas considerações dignas de nota.

${ }^{8}$ Utilizou-se $J=I_{x}+I_{y}=\frac{\pi}{64} \cdot\left(D_{\text {ext }}^{4}-D_{\text {int }}^{4}\right)+\frac{\pi}{64} \cdot\left(D_{\text {ext }}^{4}-D_{\text {int }}^{4}\right)=\frac{\pi}{32} \cdot\left(D_{\text {ext }}^{4}-D_{\text {int }}^{4}\right)$. Logo, $G J \cong \frac{\pi \cdot E}{96} \cdot\left(D_{\text {ext }}^{4}-D_{\text {int }}^{4}\right)$. 
- No estudo dinâmico de risers, é comum a utilização desses coeficientes dentro de faixas teóricas recomendadas, por exemplo, em (Veritas, 1991), de sorte que, para valores supercríticos de Número de Reynolds, como é o caso dos ensaios em questão $\left(R e \approx 10^{6}\right), C_{D}=1,0-1,2$ e $1,5 \leq C_{m} \leq 2,0$;

- Em (API, 2009), recomenda-se que $0,65 \leq C_{D} \leq 1,6$ e $1,2 \leq C_{m} \leq 1,6$, mas essas faixas podem ser diferentes de acordo com o ano de referência da publicação do American Petroleum Institute;

- Sarpkaya (1995); Khalak \& Williamson (1999); e Blevins (2001), entre outros, apud Franzini (2013), são tácitos ao afirmar que "o movimento do cilindro acaba por amplificar o coeficiente de arrasto médio";

- O coeficiente de arrasto depende do Número de Reynolds e do Número de KeuleganCarpenter (KC), definido como $K C=\frac{V T}{L}=\frac{2 \pi \cdot A}{L}$, onde $V, T, A$ e $L$ são, respectivamente, a máxima velocidade do fluxo oscilatório, seu período, sua amplitude e uma dimensão característica do corpo. Fisicamente, Re determina a relação entre as forças de inércia sobre um corpo com respeito às viscosas, enquanto KC expressa a importância relativa das forças de arrasto frentes às forças inerciais;

- Por fim, cabe salientar que os valores desses coeficientes dependem da estrutura em questão e também do nível de rugosidade apresentado pelo material.

Em (DNV, 2010b) recomenda o uso de uma formulação empírica clássica para determinação de $C_{a}$, ilustrada na Figura 5.23.

\begin{tabular}{|c|c|c|c|c|c|}
\hline \multicolumn{2}{|r|}{ Body shape } & \multirow[t]{2}{*}{$\begin{array}{c}\text { Direction of of } \\
\text { motion }\end{array}$} & \multicolumn{2}{|c|}{$C_{A}$} & $V_{R}$ \\
\hline & & & $b / 2 a$ & $C_{A}$ & \\
\hline $\begin{array}{l}\text { Right circular } \\
\text { cylinder }\end{array}$ & & Vertical & $\begin{array}{l}1.2 \\
2.5 \\
5.0 \\
9.0 \\
\infty\end{array}$ & $\begin{array}{l}0.62 \\
0.78 \\
0.90 \\
0.96 \\
1.00\end{array}$ & $\pi a^{2} b$ \\
\hline
\end{tabular}

Figura 5.23: Recomendação da DNV para cálculo de $C_{a}$. $\mathrm{Na}$ figura, $V_{R}$ é o chamado volume de referência.

Essa mesma publicação sugere valores típicos para o coeficiente de arrasto $C_{d}$, de acordo com a Figura 5.24. Outra boa referência para valores típicos dos coeficientes de inércia e arrasto a serem utilizados na Equação de Morison é (Clauss et al., 1992). A Tabela ilustrada na Figura 5.25 apresenta um resumo desses valores.

Essas poucas citações mostram que a escolha dos valores desses coeficientes (ou sua determinação experimental) é de suma importância no que tange o estudo da dinâmica assumida pelo riser. 


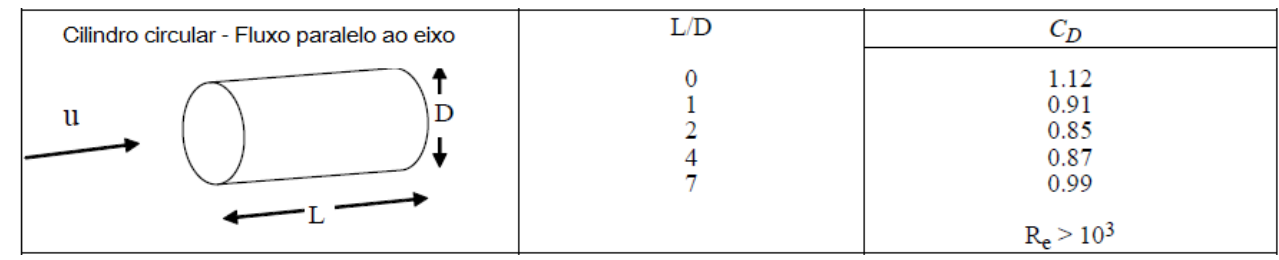

Figura 5.24: Recomendação da DNV para valores do coeficiente de arrasto $C_{d}$.

\begin{tabular}{|c|c|c|c|c|}
\cline { 2 - 5 } \multicolumn{1}{c|}{} & \multicolumn{2}{c|}{$\operatorname{Re}<10^{5}$} & \multicolumn{2}{c|}{$\operatorname{Re} \geq 10^{5}$} \\
\hline $\mathrm{KC}$ & $\mathrm{C}_{\mathrm{D}}$ & $\mathrm{C}_{\mathrm{m}}$ & $\mathrm{C}_{\mathrm{D}}$ & $\mathrm{C}_{\mathrm{m}}$ \\
\hline$<10$ & 1,2 & 2,0 & 0,6 & 2,0 \\
\hline$\geq 10$ & 1,2 & 1,5 & 0,6 & 1,5 \\
\hline
\end{tabular}

Figura 5.25: Sugestão de coeficientes para a Equação de Morison. Adaptado de (Clauss et al., 1992).

No contexto da presente tese, essas considerações impactam diretamente as simulações realizadas com o auxílio do programa Anflex, descrito anteriormente no Item 4.1.1, dado que os valores desses coeficientes são essenciais para a execução das mesmas, com a finalidade posterior das confrontações propostas nos objetivos.

Como mencionado anteriormente, o valor de KC é a relação entre as forças de arrasto e as forças inerciais. Para valores "pequenos" desse adimensional, a força de inércia é dominante; para "grandes" valores, o arrasto predomina.

Para uma explicação mais minuciosa, serão citadas as faixas de valores apresentadas em (Journèe \& Massie, 2001), Capítulo 12. Para $K C<3$, a força de inércia predomina, de maneira que o fluxo permanece bem aderido ao corpo e a teoria potencial é válida. $\mathrm{O}$ arrasto pode ser desprezado.

Já para a faixa $3<K C<15$, o arrasto pode ser considerado linear. Em $15<K C<45$ é necessário a consideração do arrasto não-linear da Equação de Morison.

Por fim, para $K C>45$ a força de arrasto é dominante sobre a inércia. A frequência de emissão de vórtices torna-se alta, relativamente à frequência do fluxo (ou ondas), e o comportamento do fluxo aseemelha-se a um regime uniforme. A inércia pode ser desprezada. O limite $K C \rightarrow \infty$ corresponde a correnteza constante.

A relação entre o regime de escoamento e o número de Keulegan-Carpenter é ilustrado na Figura 5.26, na qual esse adimensional é representado por $K$.

Sarpkaya (1976) apud (Burcharth \& Frigaard, 1989), definiu um parâmetro adimensional de frequência, $\beta$, dado pela Equaçao 5.5.

O principal intuito dessa definição é expressar os coeficientes de arrasto $C_{D}$ e de inérica $C_{m}$, em função de $\beta$.

$$
\beta=\frac{R e}{K C}=\frac{L^{2}}{\nu T}
$$




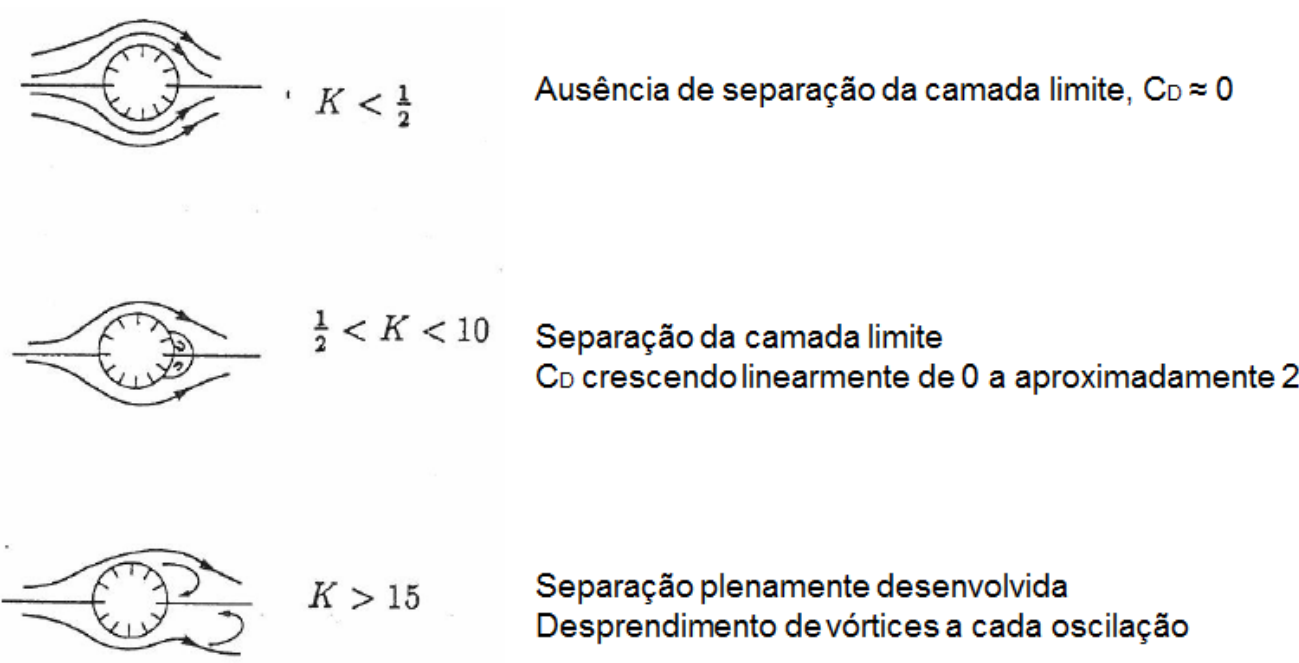

Figura 5.26: Regimes de escoamento em função de KC. Adaptado de (Freds $\phi e, 1985)$ in (Burcharth \& Frigaard, 1989).

Para a faixa de frequências das excitações que utilizadas no contexto deste trabalho e considerando: (i) a viscosidade cinemática $\nu$ da água igual a $8,936 \cdot 10^{-7} \mathrm{~m}^{2} \cdot \mathrm{s}$ e (ii) 0 diâmetro externo como sendo a dimensão característica do modelo de riser; os valores de $\beta$ de interesse situam-se no intervalo aproximado $155<\beta<245$, com números de Keulegan-Carpenter em $114<K C<180$.

Embora não tenha avaliado essa faixa de valores de $\beta$, Sarpkaya (1976) determinou em laboratório curvas dos coeficientes de inércia e arrasto em função de KC, como ilustrado na Figura 5.27.

Além da adequação dos valores teóricos e os referenciados aqui no texto, cabe ressaltar que os amortecimentos estruturais determinados experimentalmente na Seção C.2.5 devem ser considerados adequadamente, em conjunto com as respectivas frequencias de excitação.

Os valores determinados naquela seção são condizentes com as recomendações encontradas na literatura, como por exemplo em (Pereira, 2010) e (Gonçalves, 2009), que consideraram valores de cerca de 5\% e 10\%, respectivamente.

Com respeito às características do solo, dois parâmetros são considerados mais importantes: os atritos entre a linha e o solo (axial e lateral) e a rigidez do solo. A determinação experimental desses parâmetros é mais difícil e, em geral, é feita a partir de adimensionais de literatura em conjunto com testes de valores que auxiliem a recuperação das características dinâmicas experimentais.

Nesse sentido, no que tange à utilização do Anflex, utilizou-se como base teórica os resultados de Datye (2010) e o próprio manual do programa.

As Figuras 5.28 e 5.29 ilustram os parâmetros de simulação utilizados.

Os resultados provenientes das simulações com o Anflex e o Poliflex serão apresentados no próximo capítulo, em conjunto com os provenientes das demais abordagens. 

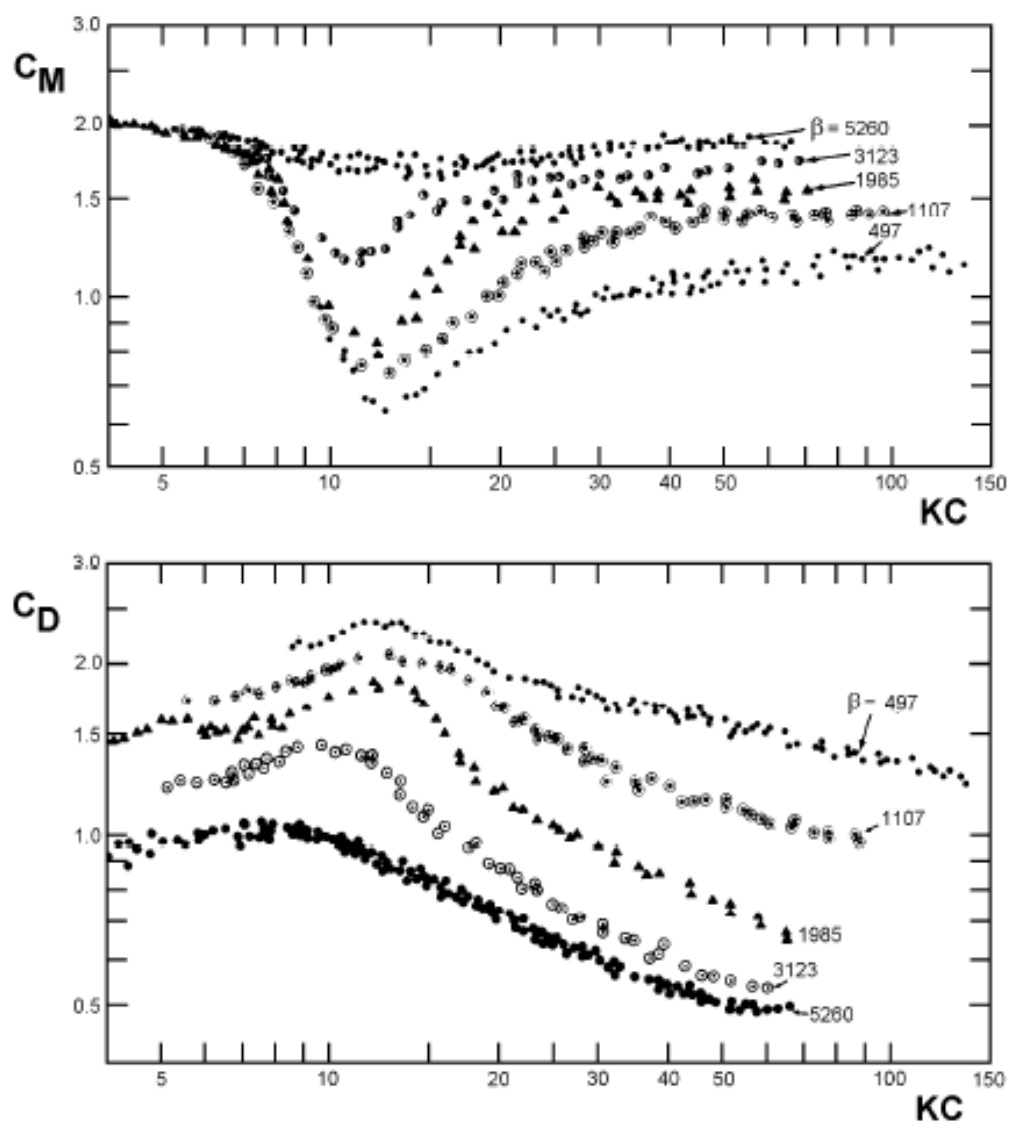

Figura 5.27: Coeficientes de inércia e arrasto em função de KC, para vários valores de $\beta$. Extraído de Sarpkaya (1976) apud (Burcharth \& Frigaard, 1989).

A finalidade é permitir uma base de comparação numérica para o cumprimento das etapas ilustradas no procedimento da Figura 5.1, bem como ensejar discussões e embasar as análises. 


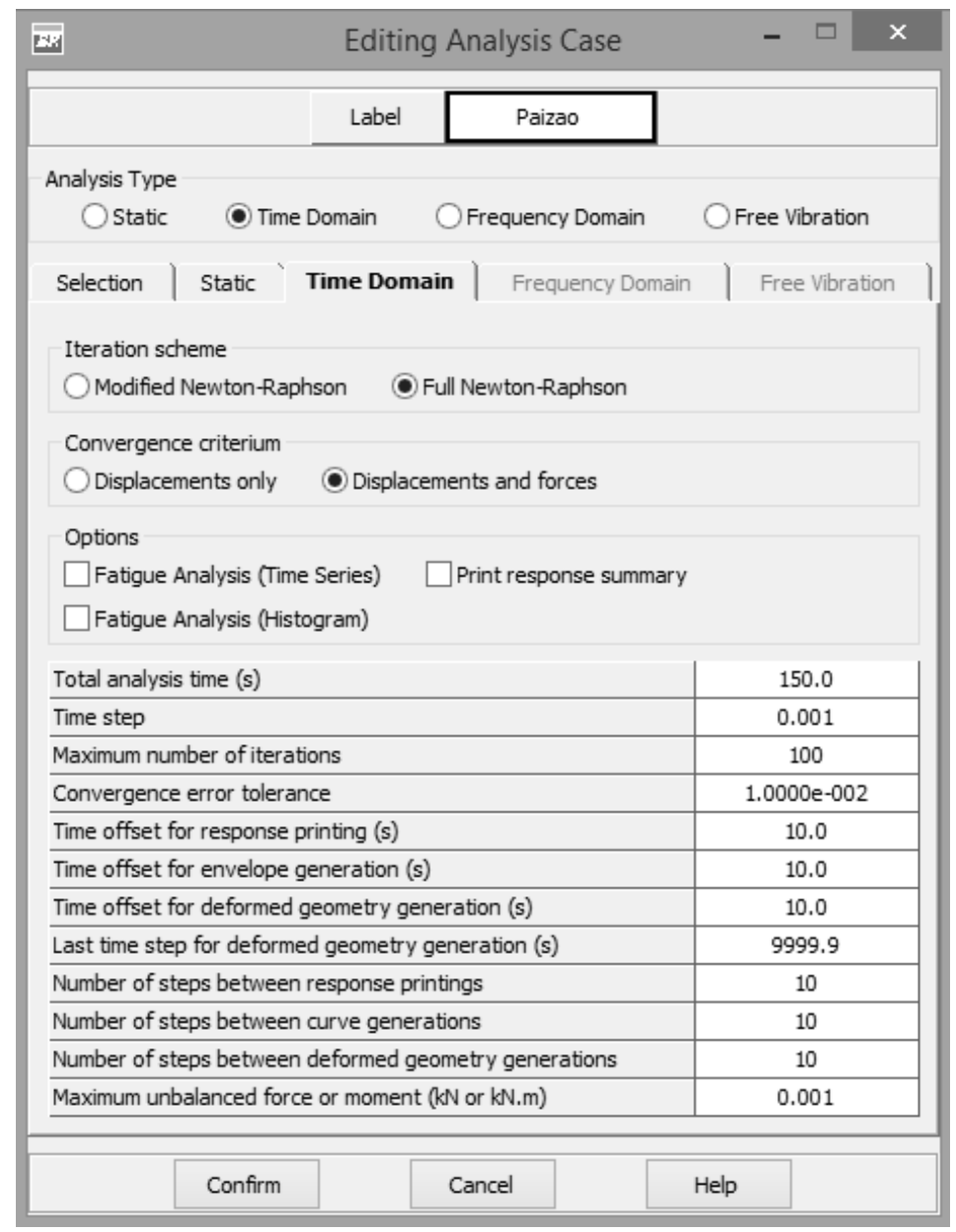

Figura 5.28: Parâmetros de simulação do Anflex.

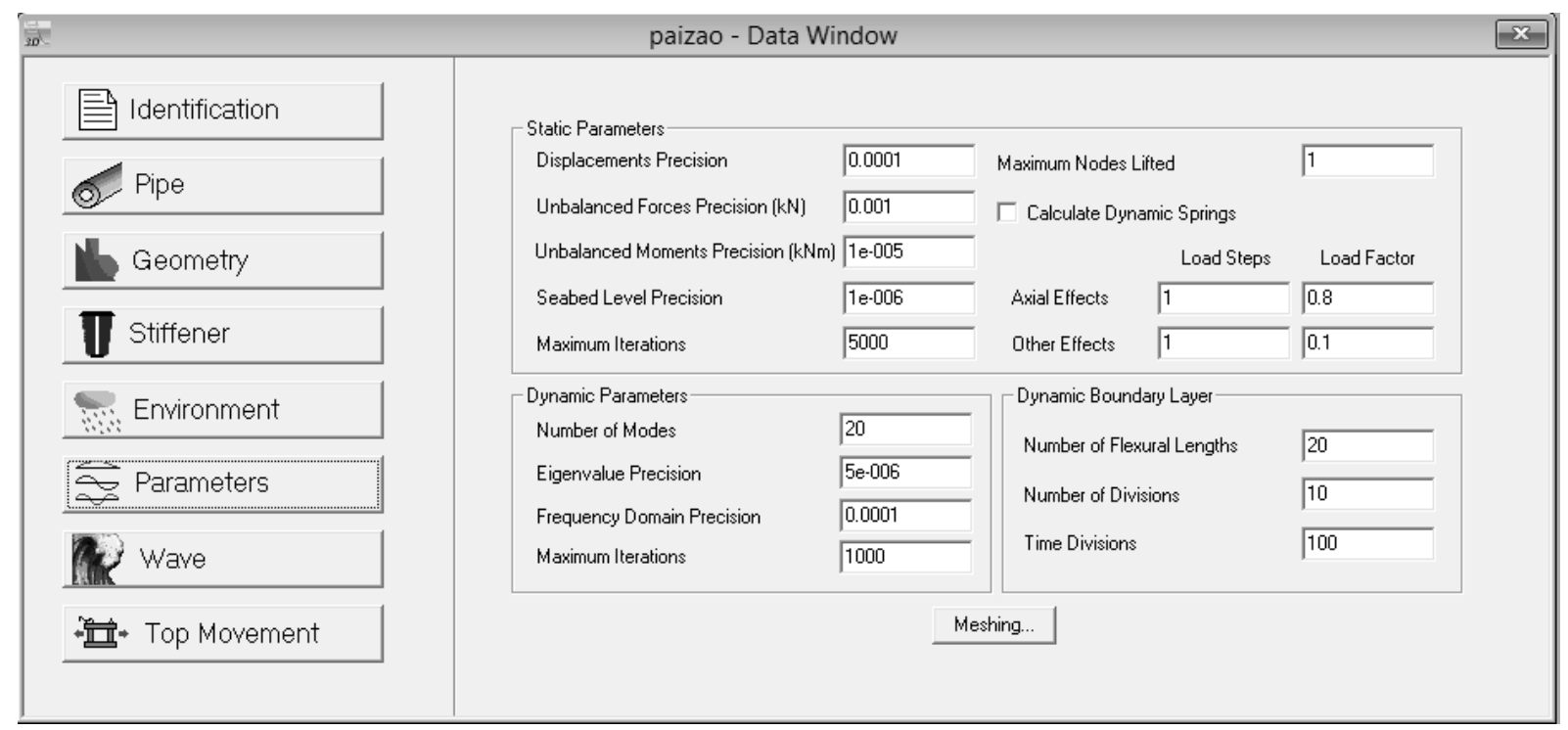

Figura 5.29: Parâmetros de simulação do Poliflex. 


\section{Capítulo 6}

\section{Resultados e Análises}

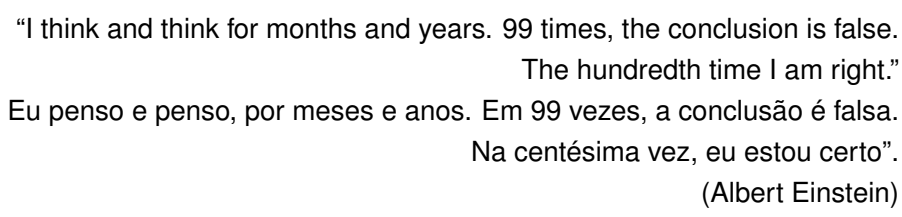

O presente capítulo tem por finalidade a apresentação dos resultados e discussões relativas aos ensaios realizados.

Inicialmente, é apresentada uma compilação dos resultados auferidos, em comparação com os esperados (mapeamento da Figura 5.17). Realizados os experimentos, assim como planejados, é possível recuperar essa figura, incorporando graficamente as observações feitas durante os ensaios, no que se refere à ocorrência do fenômeno de compressão dinâmica. O resultado desse procedimento, ilustrado na Figura 6.1, será utilizado para definição dos casos a serem apresentados e discutidos, visto que a exposição integral dos resultados obtidos é inviável e desnecessária.

Na sequência, são apresentados alguns casos de interesse particular, racionalmente escolhidos com vistas aos objetivos da presente tese para, em seguida, comparar os resultados experimentais com os advindos das demais vertentes.

Embora sejam apresentados alguns resultados de importância secundária, salientese que o objetivo é embasar algumas das conclusões experimentais, principalmente nos pontos em que diferentes abordagens preveem resultados distintos.

Cumpre salientar que, dados os objetivos do presente texto, as informações contidas na Figura 6.1 são meramente indicativas, não se configurando como um fim em si mesmas. Nesse sentido, os resultados relativos aos comprimentos das ondas de flexão geradas no TDP, nos casos em que a compressão dinâmica foi verificada, serão apresentados, oportunamente, na seção reservada para apesentação e discussão de alguns casos justificadamente selecionados. 
O mapeamento ilustrado na Figura 6.1 apresenta alguns resultados interessantes. Assim como previsto, para as amplitudes de excitação nominais de $0,200 \mathrm{~m}$, foram confirmadas a ocorrência de compressão dinâmica, prevista pelas formulações analíticas considerando-se as duas possibilidades de condições de contorno estudadas.

A consonância entre os resultados experimentais e os esperados pelas duas formulações utilizadas também ocorreu para os ângulos de topo de $65^{\circ}$ e $70^{\circ}$, com exceção do caso F080A050T70; assim como para os casos F080A100T80, F100A100T80, F100A100T85 e F125A100T80. Todas essas situações são relativas a casos de ocorrência de compressão dinâmica no modelo ensaiado.
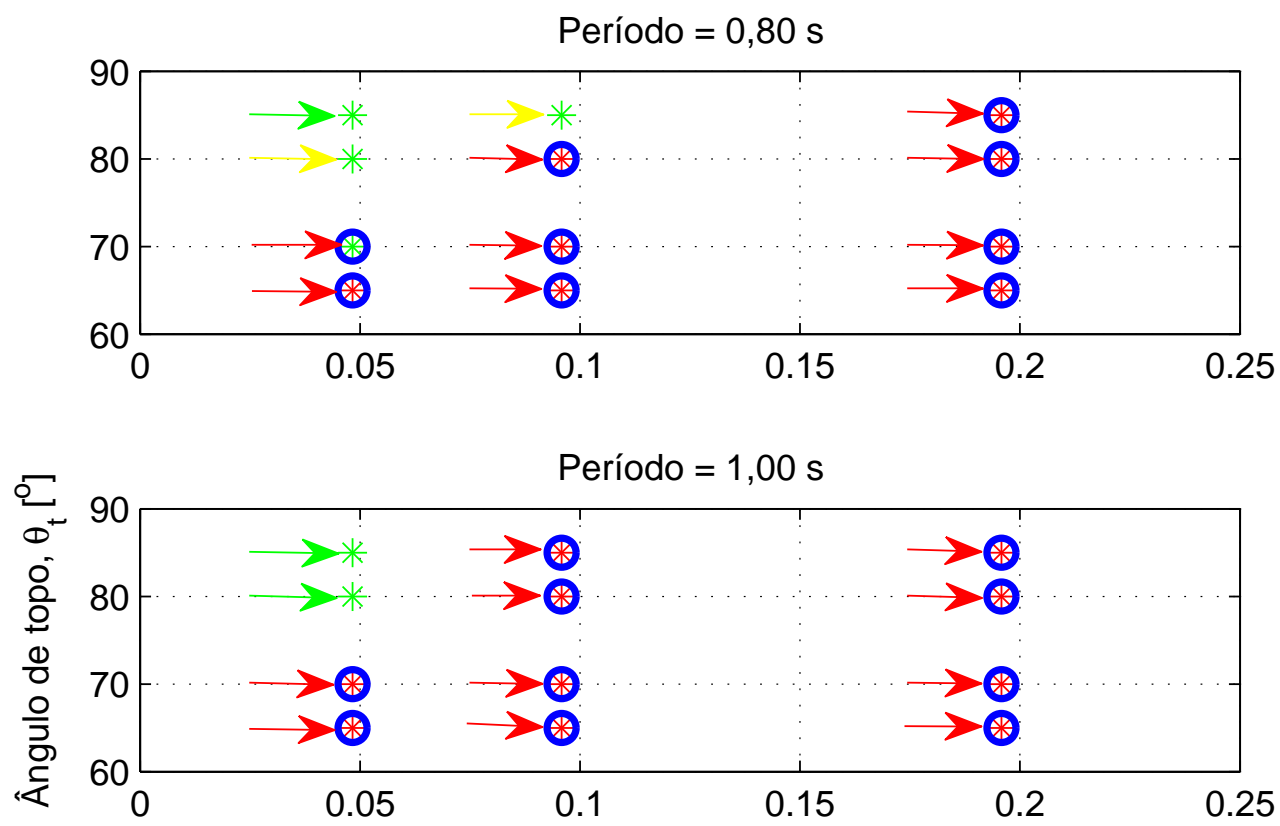

Período $=1,25 \mathrm{~s}$

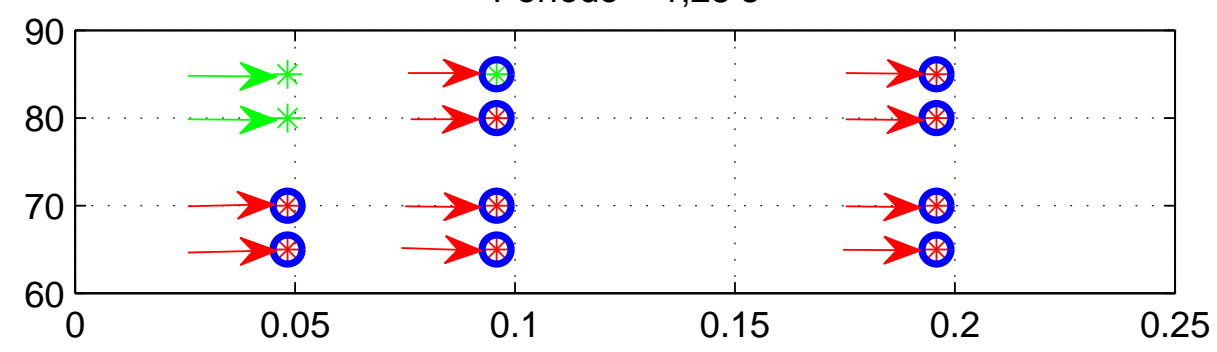

Amplitude, $A_{m}[m]$

Figura 6.1: Mapeamento bidimensional dos resultados dos ensaios finais.

Asteriscos verdes indicam previsão de ausência de compressão dinâmica por (Aranha et al., 2001).

Asteriscos vermelhos apontam para ocorrência do fenômeno, a partir da mesma formulação.

Os círculos azuis sugerem ocorrência de compressão dinâmica, considerando a condição engaste-pinado. As setas representam os resultados advindos do sistema de monitoramento óptico, mantendo o mesmo padrão de cores: verdes, ausência; e vermelhos, ocorrência de compressão.

As setas amarelas se referem a situações particulares a serem discutidas mais adiante. 
Quanto ao casos de não-ocorrência de compressão dinâmica, considerando ambas as formulações, as previsões confirmadas referem-se aos casos de amplitude nominal $0,050 \mathrm{~m}$, sob lançamentos a ângulos de topo de $65^{\circ}$ e $70^{\circ}$, com exceção do caso F080A050T80, que será um dos casos discutidos na Seção 6.2, dadas particularidades que merecem ser apresentadas sob um nível maior de detalhes. $O$ caso F080A100T85 demanda o mesmo tipo de estudo detalhado, embora por razões distintas, o que ficará claro na citada seção.

Além desses, o interesse por uma análise mais detalhada também recai sobre outros dois casos, F080A050T70 e F125A200T85, já citados anteriormente. A característica comum a esses dois experimentos, que desperta interesse em suas avaliações diferenciadas, se refere ao fato de que, pela formulação de Aranha et al. (2001), ambos não deveriam apresentar compressão dinâmica. Entretanto, a formulação para carga crítica em vigas curvas engastadas-pinadas apontou para resultados diferentes daquela expectativa. Os experimentos comprovaram que esta última previsão era a mais adequada, para os casos citados.

Um dos objetivos da Seção 6.2 será discutir esses casos particulares, a fim de verificar as diferenças e semelhanças, na prática, entre as duas condições de contorno aventadas.

Cumpre destacar que essa discussão consiste apenas em uma parte dos objetivos almejados no presente trabalho, dado que a avaliação da eficácia do procedimento proposto para predição de ocorrência de compressão dinâmica em risers, com o uso de experimentos físicos, é notadamente secundária, embora necessária.

Na sequência do presente capítulo é feita a exposição da metodologia de análise dos ensaios, a apresentação dos resultados deles advindos, sua comparação com as demais vertentes e posteriores análises e discussões. 


\subsection{Metodologia de Análise dos Resultados}

Após a determinação das coordenadas dos alvos em todos os ensaios realizados, inclusive nos testes de decaimento, foi necessário proceder a transformações de rotação e translação do sistema global de coordenadas XYZ (determinado pelo programa), a fim de que a catenária identificada estivesse contida no plano vertical xz da Figura 3.1, cuja origem é o TDP estático. Esse procedimento foi feito para facilitar a visualização dos resultados e para estabelecer um padrão de visualização, consonante com o sistema de referências utilizado nas modelagens feitas no Capítulo 3. O emprego dessas transformações, descritas na sequência, foi utilizado em todas as análises de dados brutos provenientes do sistema de monitoramento.

A Figura 6.2 ilustra a perspectiva dos alvos dispostos sobre o modelo flexível no espaço, bem como as respectivas vistas frontal (plano $X Y$ ), lateral (plano $Y Z$ ) e superior (plano XY), com relação ao sistema global de coordenadas original.

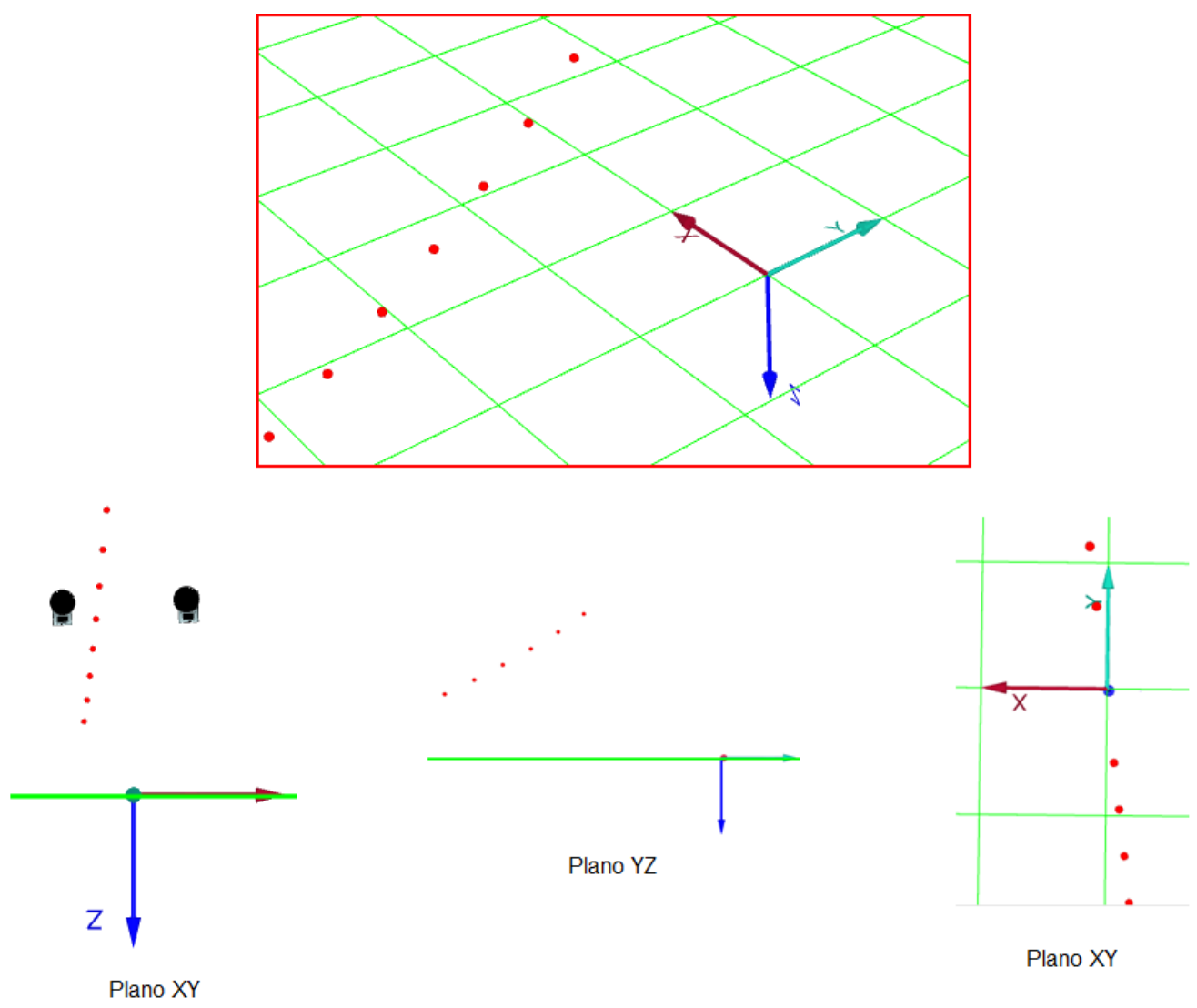

Figura 6.2: Vistas frontal, lateral e superior dos alvos, a partir do sistema de coordenadas das câmeras.

As transformações de coordenadas do sistema XYZ (das câmeras) para o 0xyz, permite a pronta utilização dos equacionamentos apresentados no Capítulo 3, quando necessário. A fim de promover maior compreensão desse procedimento e dos resultados auferidos a partir de um conjunto de dados brutos qualquer (provenientes do sistema de monitoramento óptico), utilize-se o exemplo que se segue, ilustrado sequencialmente pelas Figuras 6.3 a 6.5 . 
Os detalhes matemáticos foram suprimidos, dados que são de uso corriqueiro.

O primeiro passo foi a promoção de uma rotação de $180^{\circ}$ do sistema $X Y Z$, ao redor do eixo Y. Naturalmente, isso foi feito apenas pela determinação dos opostos dos valores das coordenadas $\mathrm{X}$ e $\mathrm{Z}$, que se apresentavam negativas (apenas nos testes de decaimento).

Tal situação foi evitada nos ensaios finais, pela utilização de um sistema de coordenadas mais adequado, escolhido durante configuração do programa dedicado que controla o sistema de monitoramento óptico.

Como a estrutura de calibração (apresentada anteriormente na Figura 4.5, detalhe A) foi colocada sobre o solo, suposto plano e horizontal, então a transformação do sistema de coordenadas XYZ para o sistema xyz consiste apenas em uma rotação ao redor do eixo $Z$ (paralelo a $z$ e paralelo à atuação do campo gravitacional) e uma translação da origem para uma posição mais adequada.

Para tanto, foi feita a suposição, bastante plausível, de que as coordenadas $Z$ são coincidentes com os valores $z$, do sistema global 0xyz.

Dados os alvos graficamente dispostos sobre a linha e descritos a partir do sistema de coordenadas XYZ (Figura 6.3), definido após a calibração das câmeras, identificouse, pelo Método dos Mínimos Quadrados, a reta que melhor aproxima esses alvos no plano XY. Essa reta é representada por uma linha preta na referida figura.
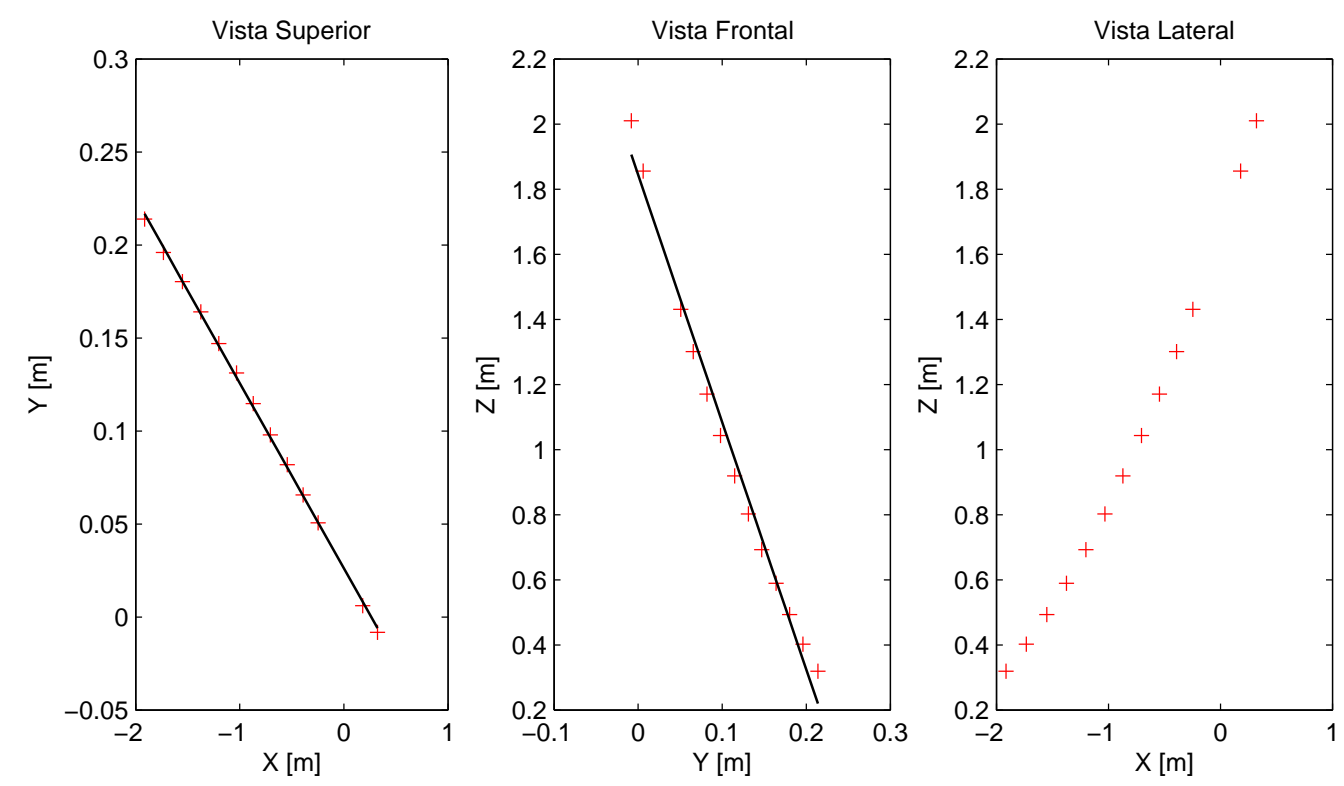

Figura 6.3: Exemplo de tranformações de coordenadas, vistas originais.

Note-se que, naturalmente, os alvos (representados por "+" vermelhos), observados na vista do plano $Y Z$, acabam por ser interpolados por essa mesma reta.

O plano de referência escolhido para essa aproximação linear é consistente com a hipótese de manutenção das cotas dos alvos com relação ao solo. Prodecida a aproximação linear citada, o sistema $X Y Z$ foi rotacionado ao redor de $Z$. 
Dessa maneira, os pares de eixos $\mathrm{X}$ / $\mathrm{x}$ e $\mathrm{Y}$ / y passassem a ser paralelos, dois a dois e perpendiculares entre si. $O$ resultado das novas coordenadas obtidas é ilustrado na Figura 6.4, onde as coordenadas de cada alvo, no novo sistema, são representadas por círculos verdes. Nessa figura, os alvos passam a pertencer ao plano xy, possuindo, na média, valores nulos para a coordenada y, sem alteração nos valores de $z$.
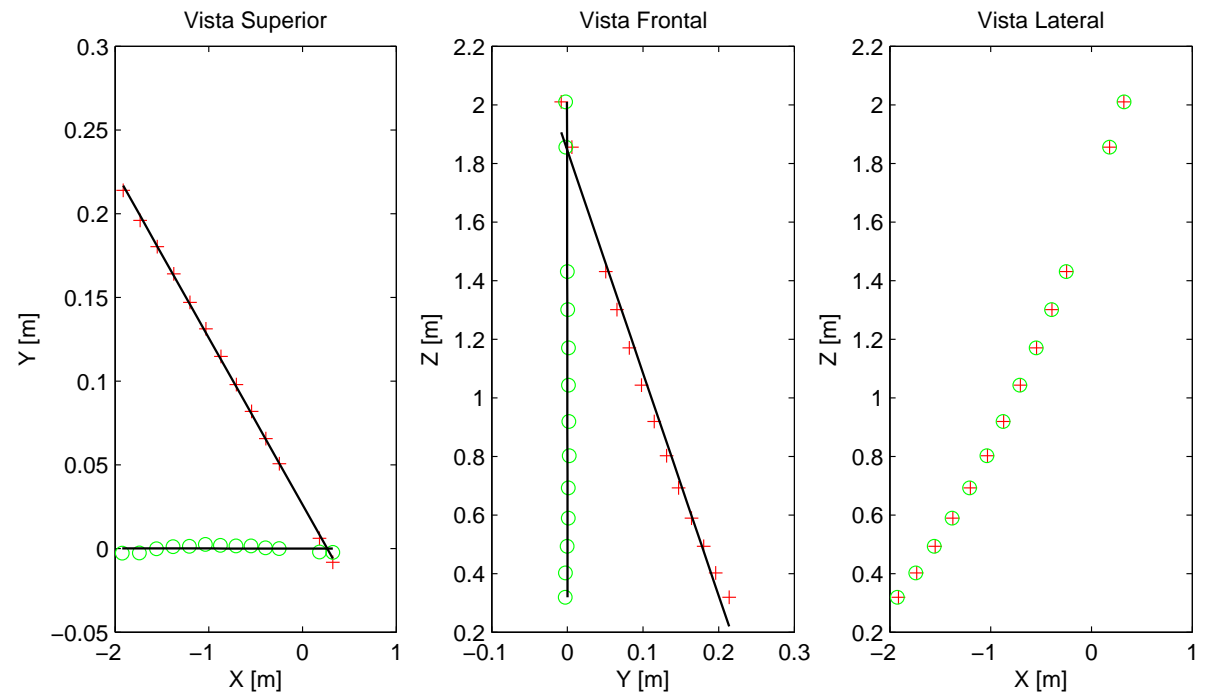

Figura 6.4: Vistas frontal, lateral e superior dos alvos, após rotação em torno de Z.

A vista lateral apresentada corrobora a afirmação feita sobre os valores de Z e Z (notese a coincidência entre os "+" vermelhos e os "o" verdes). O passo seguinte, como citado anteriormente, foi a translação do novo sistema de modo a tornar os eixos $X$ e $x$ coincidentes. Para tanto, utilizou-se a Equação 3.11, da função que representa a catenaria inelástica $z=z(x)$, de modo a encontrar o deslocamento médio das coordenadas $\mathrm{X}$, com respeito a $\mathrm{X}$. Esse foi o valor utilizado para promover a translação das coordenadas dos alvos identificados. Os resultados obtidos, após a translação precedida de rotação, estão ilustrados na Figura 6.5, para o exemplo em questão.
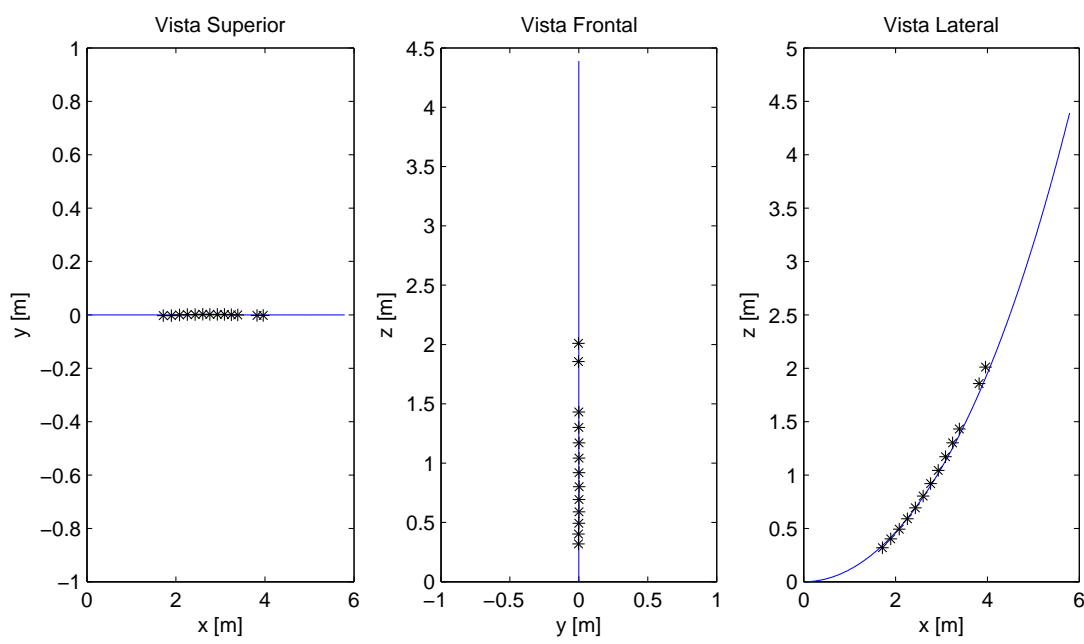

Figura 6.5: Vistas frontal, lateral e superior dos alvos, após rotação e translação (sistema xyz). 
Nessa figura, a linha azul representa a catenária elástica, obtida a partir das propriedades físicas do modelo e condições de lançamento da linha. A curva azul obtida foi representada parametricamente pelas Equações 3.16 e 3.17, deduzidas no Capítulo 3, Seção 3.1, em concordância com (Patel \& Seyed, 1995).

Apenas como forma de visualização, em perspectiva, dos resultados obtidos, ilustra-se na Figura 6.6 a representação dos alvos identificados pelo sistema de monitoramento no novo sistema de coordenadas, tornando possível perceber mais claramente o resultado final obtido posteriormente às tranformações realizadas.

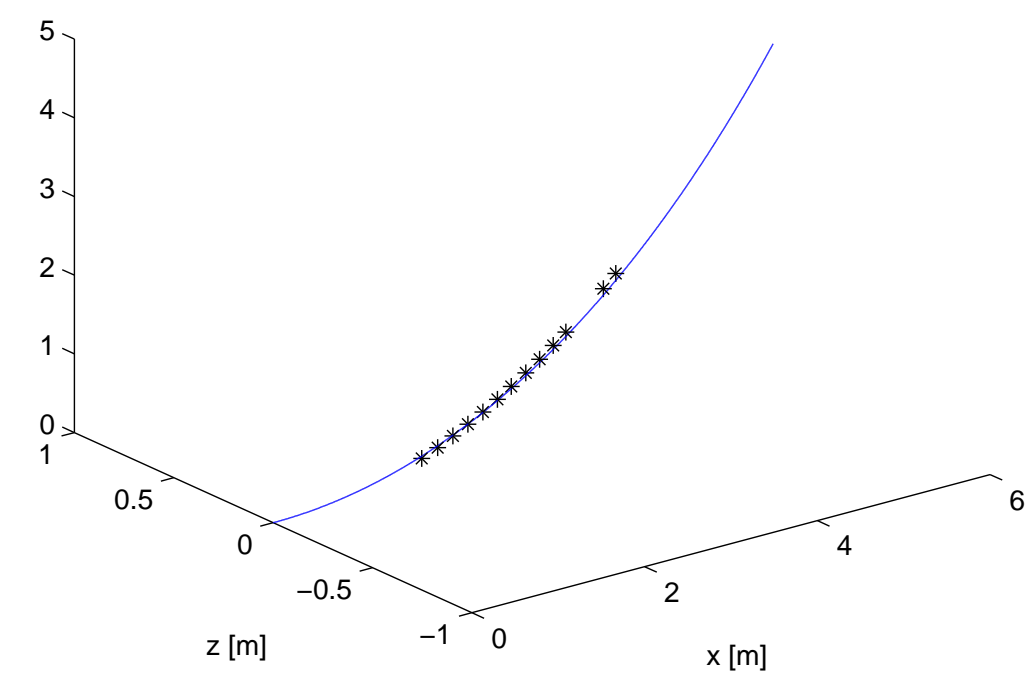

Figura 6.6: Visualização, em perspectiva, dos alvos identificados, após rotação e translação.

A utilização das transformações citadas, tanto para os dados brutos estáticos, quanto para os dinâmicos, permite dar sequência aos trabalhos preliminares às análises realizadas. Feito isso, todas as coordenadas passaram a ser descritas em função do sistema 0xyz.

Em algumas situações, durante os ensaios, dependendo da configuração inicial (ângulo de topo), o trecho do modelo que repousava no fundo do $\mathrm{CH}$-TPN podia ser relativamente curto ou não ${ }^{1}$. Por motivos que serão explicitados na sequência, a avaliação dos comprimentos de onda podia demandar a eliminação de alguns dos alvos repousados no solo, para efeito de análise.

Os alvos eliminados são aqueles que não apresentavam movimentos apreciáveis durante determinado ensaio. Dessa forma, avaliaram-se todas as séries temporais, de cada alvo reconhecido pelo sistema de monitoramento, em cada ensaio. Essas assinaturas temporais foram centralizadas para determinar quais alvos possuíam amplitudes de movimento desprezíveis (menores que um diâmetro do modelo, por exemplo).

\footnotetext{
${ }^{1}$ Uma posível forma de definição de "curto", nesse caso, pode ser baseada na definição de comprimento de flexão, parâmetro relacionado ao passeio do TDP.
} 
As figuras 6.7 e 6.8 ilustram duas situações distintas: na primeira, não houve a necessidade de retirada de nenhum alvo para a determinação das elásticas assumidas pelo modelo; na segunda, uma rotina numérica definia quais alvos deveriam ser eliminados para determinação dos comprimentos de onda de flexão, quando necessário.

Para compreender os motivos dessa etapa da análise, é mister o entendimento dos detalhes da rotina numérica elaborada para a determinação dos comprimentos de ondas de flexão, quando essas eram geradas durante a ocorrência do fenômeno de compressão dinâmica.

A forma instantânea da elástica é de difícil previsão e modelagem. Dessa forma, foram utilizadas aproximações polinomiais, $P_{n}$, de graus variáveis, a fim de descrever os formatos aproximados das curvas assumidas pelo modelo durante os ensaios.

A aproximação polinomial de grau variáveis permitia a aproximação bastante fidedigna dos pontos de interesse (alvos), desde que fosse utilizada apenas para o comprimento suspenso instantâneo. Tal fato justifica a necessidade, apresentada anteriormente, de eliminação de alvos com baixos (ou nenhum) movimento relativo.

Além disso, esse tipo de aproximação facilita sobremaneira o cálculo de suas derivadas sucessivas ou a determinação da cota de determinado ponto, por exemplo.

Essa característica foi aproveitada para a determinação automática, via rotinas numéricas confeccionadas em Matlab, dos comprimentos de onda de flexão.

Assim, dada uma sequência de alvos, adequadamente interpolada por um polinômio de ordem $n$, era possível a determinação, via segunda derivada, de sua curvatura ao longo do comprimento suspenso. De posse da curva que representa as curvaturas locais da elástica deformada, eram calculadas, algebricamente, suas raízes, que representam pontos de mudança de concavidade, propriedades intrínsecas de ondas (senoidais ou cossenoidais).

Cada onda completa possui, instantaneamente, ponto(s) de máximo (crista); ponto(s) de mínimo (vale); e ponto(s) de inflexão (mudanças de concavidade). Assim, o código numérico elaborado buscava, em cada quadro (frame), os pontos de inflexão e determinava a distância euclidiana entre eles (quando existia mais de um), dois a dois. Essa distância, calculada pelo Teorema de Pitágoras, aplicado aos pontos correspondentes às inflexões gráficas, poderiam representar semicomprimentos de ondas.

A rotina ignorava valores menores a distância média entre três alvos consecutivos (ou cerca de $0,18 \mathrm{~m}$ ), por questões óbvias: (i) em nenhuma das previsões, havia a previsão de ondas com comprimentos dessa magnitude; (ii) distância menores que a considerava implicariam em curvaturas excessivas, impossíveis de ocorrência, na prática, devido à combinação entre as trações efetivas envolvidas, em detrimento da rigidez flexional considerada; e (iii) a percepção de curvas, pelas aproximações polinômiais, com um baixo número de pontos poderia levar a distorções indesejavéis.

As Figuras de 6.9 a 6.12, apresentadas após as Figuras 6.7 e 6.8, ilustram esse procedimento, a partir de exemplos de casos reais avaliados nesta tese. 

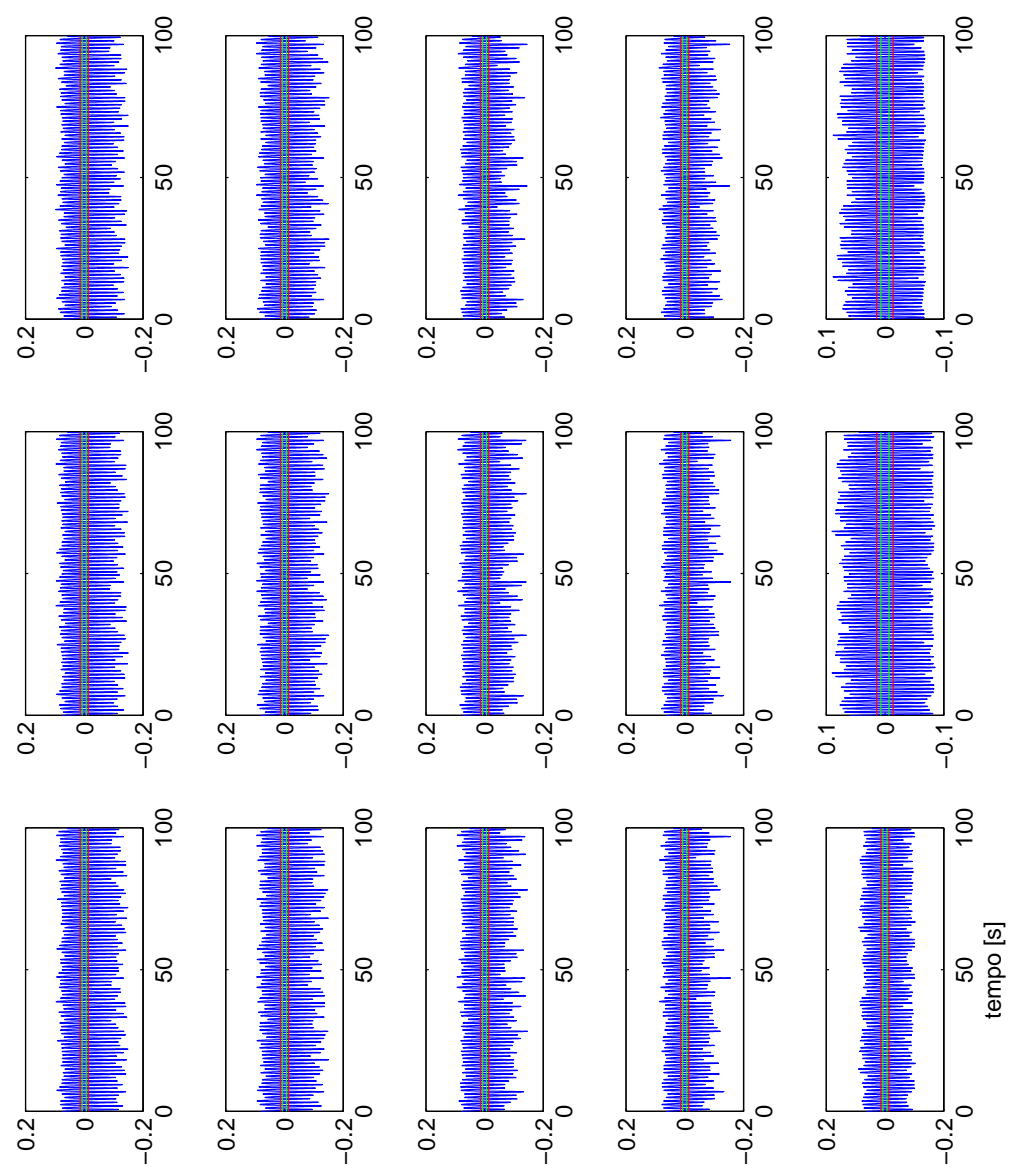

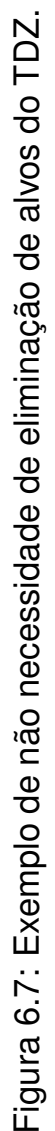
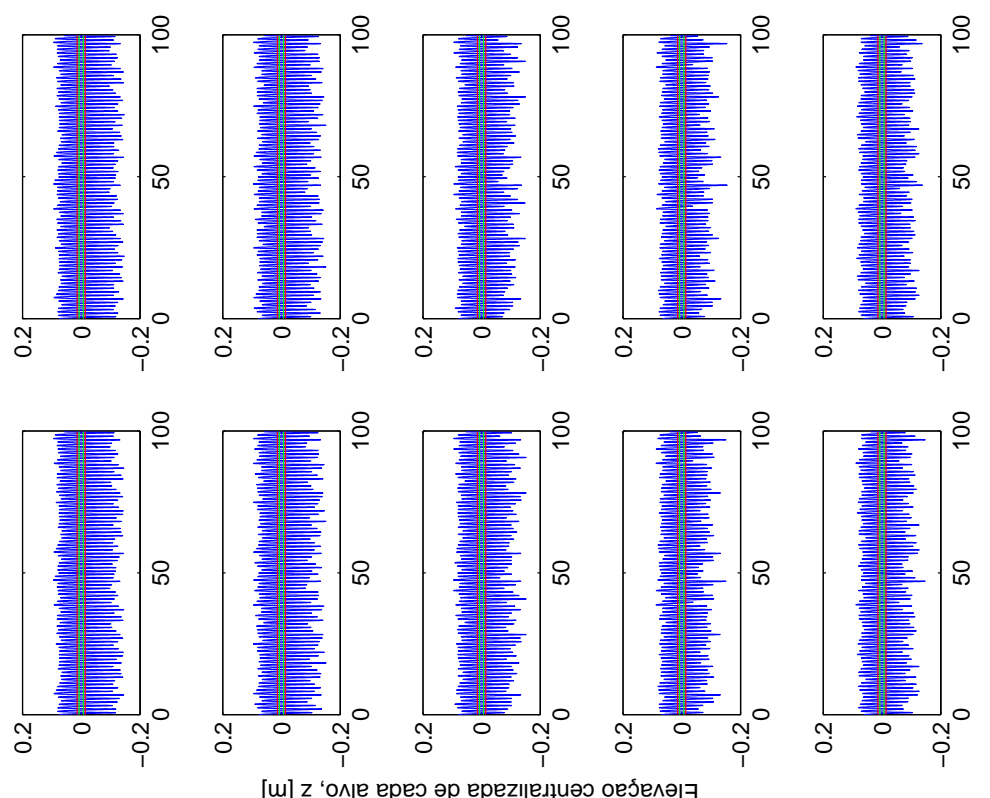

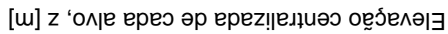


Elevação centralizada de cada alvo, z [m]

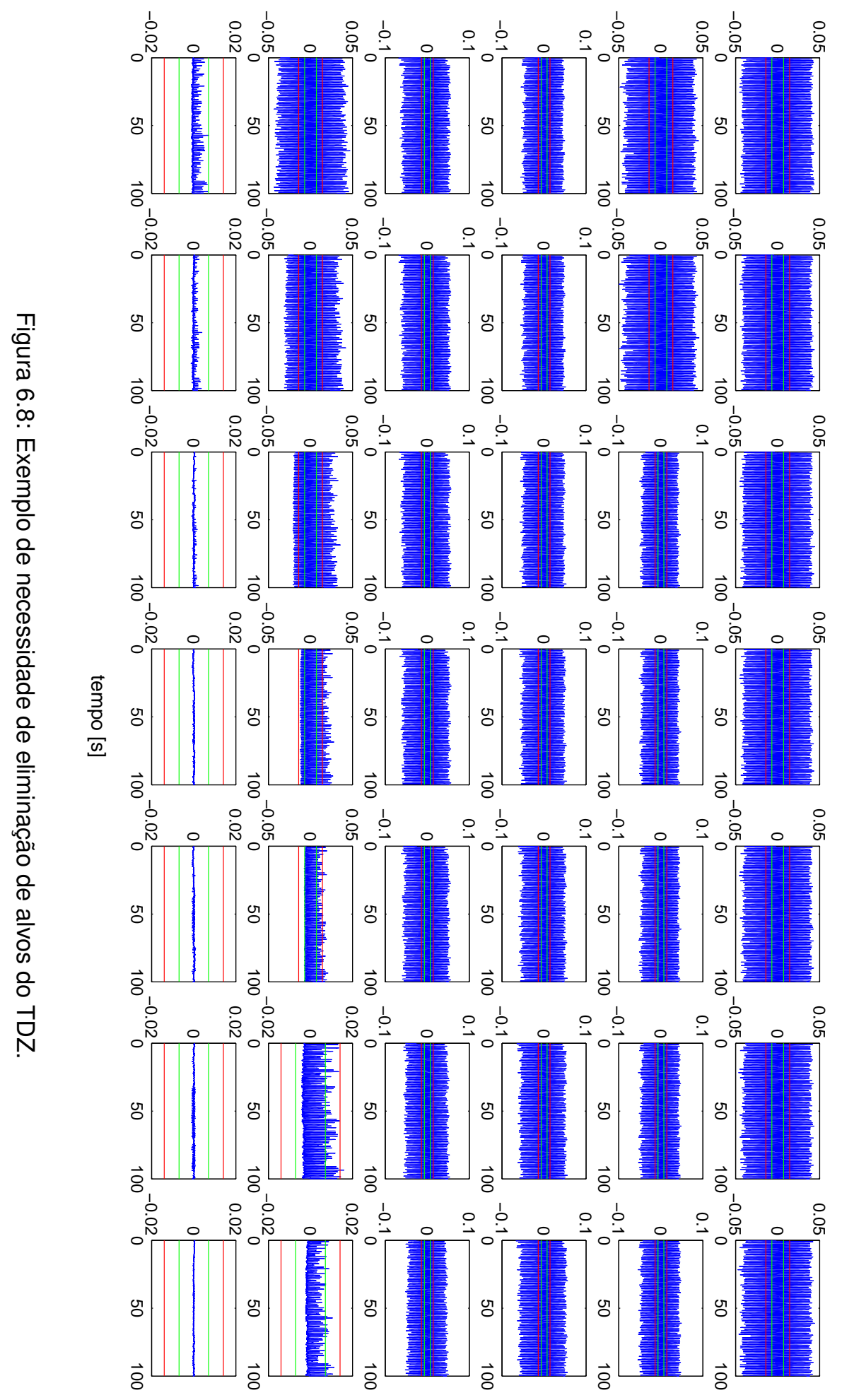


O primeiro passo das análises, após as transformações descritas na seção anterior, consistia na verificação de ocorrência (ou não) de compressão dinâmica em cada caso ensaiado. Esse procedimento era feito de duas maneiras: pelas séries temporais de deslocamentos, obtidas via sistema de monitoramento óptico; e a partir das séries temporais de trações efetivas no TDP (simulações numérica, via Anflex).

As figuras a seguir, referentes ao caso F080A100T80, ilustram as etapas para determinação dos comprimentos de ondas de flexão, geradas no modelo flexível estudado, nos casos de compressão dinâmica. Note-se, pela Figura 6.1, que, para esse caso específico, ambas as formulações utilizadas previam a ocorrência desse fenômeno.

Na Figura 6.9 é possível visualizar a aproximação polinomial utilizada, bem como a determinação das curvaturas e pontos de inflexão.
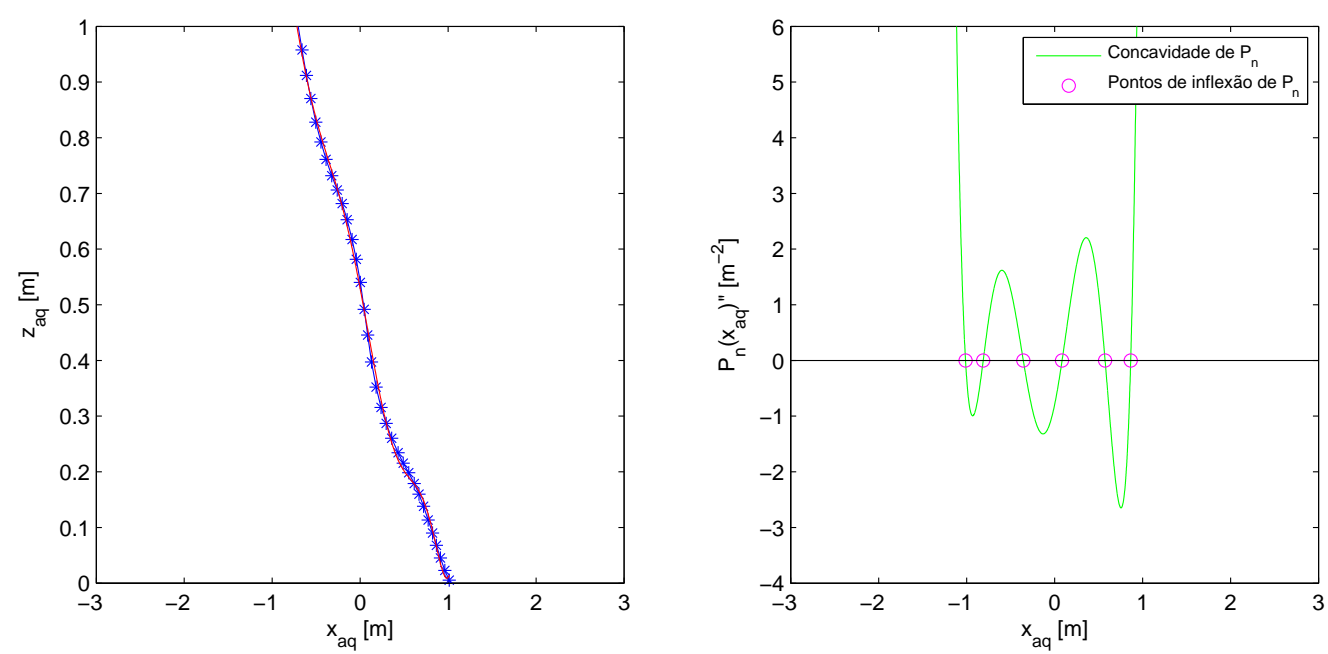

Figura 6.9: Exemplo de aproximação polinomial para a elástica instantânea.

À esquerda, aproximação polinomial (em vermelho) dos alvos aquáticos (em azul). à direita, a concavidade da aproximação polinomial, em verde; e os pontos de inflexão, em magenta.

A Figura 6.9 ilustra um caso de determinação automática dos comprimentos de ondas de flexão, a partir da aproximação polinomial e determinação dos pontos de inflexão citadas anteriormente. A elástica apresentada nessa figura explicita, claramente, a formação de ondas sobre o modelo.

A Figura 6.10 permite a identificação das ondas de flexão, de maneira ainda mais nítida. Por essa figura, nota-se uma linha verde, determinada automaticamente pela rotina numérica confeccionada para esse fim, correspondente a um semicomprimento de onda. A escolha pela identificação de meias ondas foi feita pelo fato de que, ao se propagar do TDP para o topo, a energia carregada pelas ondas de flexão é dissipada para o meio, de maneira que sua amplitude diminui, concomitantemente a um aumento no seu comprimento. Essa opção permite a identificação mais precisa do comprimento da onda de flexão, no instante em que ela é gerada. Obviamente, a opção poderia ter sido feita, sob esse argumento, pela determinação de um quarto de onda, por exemplo. Entretanto, em termos matemáticos, a escolha feita é mais facilmente implementável. 


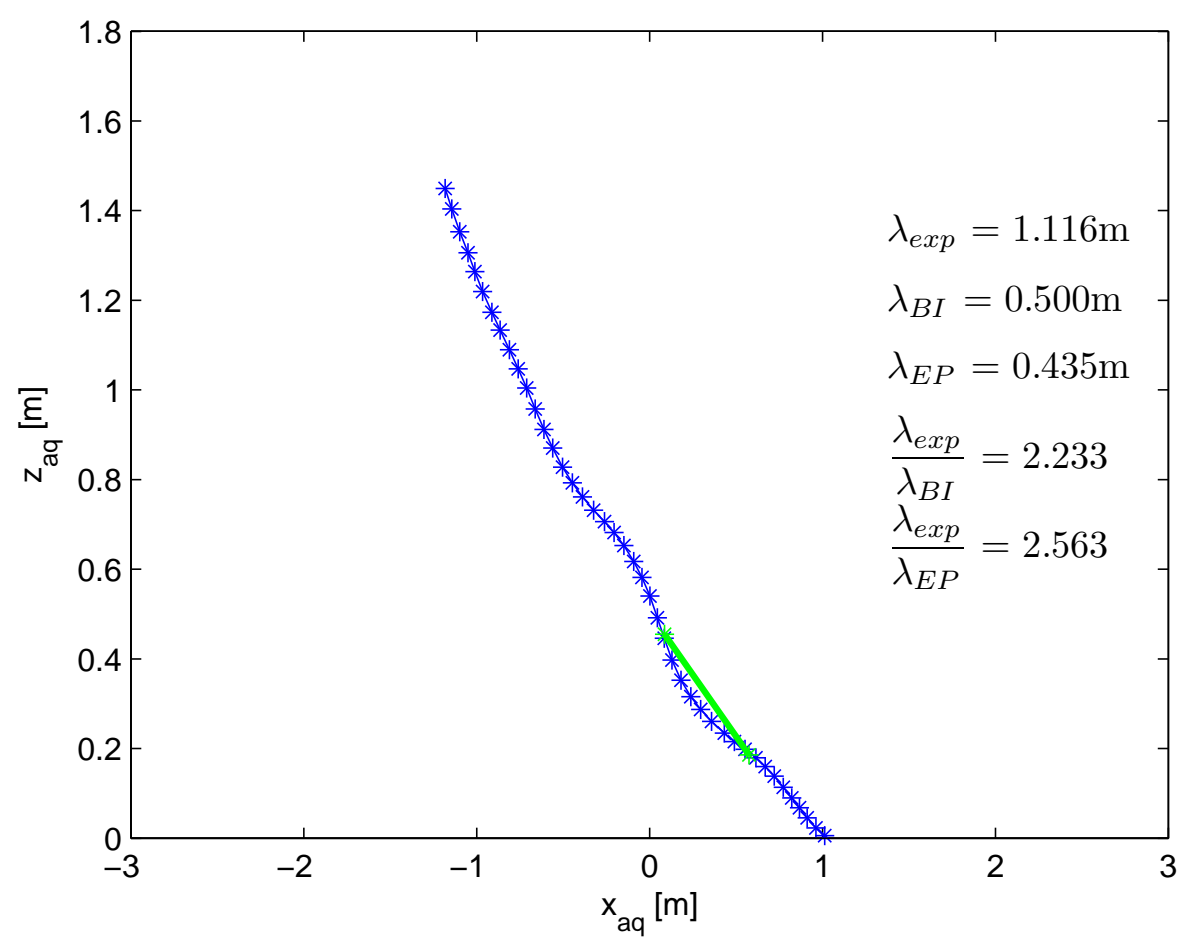

Figura 6.10: Exemplo de determinação do comprimento de onda de flexão.

Os índices subescritos exp, $B I$ e $E P$ referem-se, respectivamente, a valores experimentais e previsões para os vínculos biapoiado e engastado-pinado.

A Figura 6.11 a seguir é meramente ilustrativa. Nela, é possível verificar uma sequência de quadros, equiespaçados no tempo, das geometrias assumidas pelo modelo flexível, em instantes de tempo nos quais compressão dinâmica não foi percebida. Essa condição se refere, ainda, ao caso F080A100T80. Para que seja possível a utilização dessa estrutura de apresentação de resultados (Figura 6.11), sempre que se fizer necessária, é mister o entendimento de algumas características:

- Em cada quadro são sempre apresentadas duas elásticas: uma em cinza (quadro de referência, sempre o último da sequência apresentada), outra em azul (quadro no instante considerado), o que permite a comparação entre uma condição estática e a deformada instantânea;

- O quadro central, com a elástica destacada em vermelho, corresponde ao instante utilizado naquela avaliação particular, sendo os demais apenas indicativos da sequência de geometrias assumidas pelo modelo, sempre e apenas em sua porção submersa;

- Essa figura sempre trará algumas informações pertinentes: no alto, o nome do caso, conforme a nomenclatura adotada e explicada anteriormente, juntamente com o total de quadros avaliados dinamicamente; em cada quadro, será explicitada a numeração do mesmo (indicando, indiretamente, o instante de tempo considerado) e a do quadro de referência. 
Caso em análise: F080A100T80-SAH / Total de frames: 10001
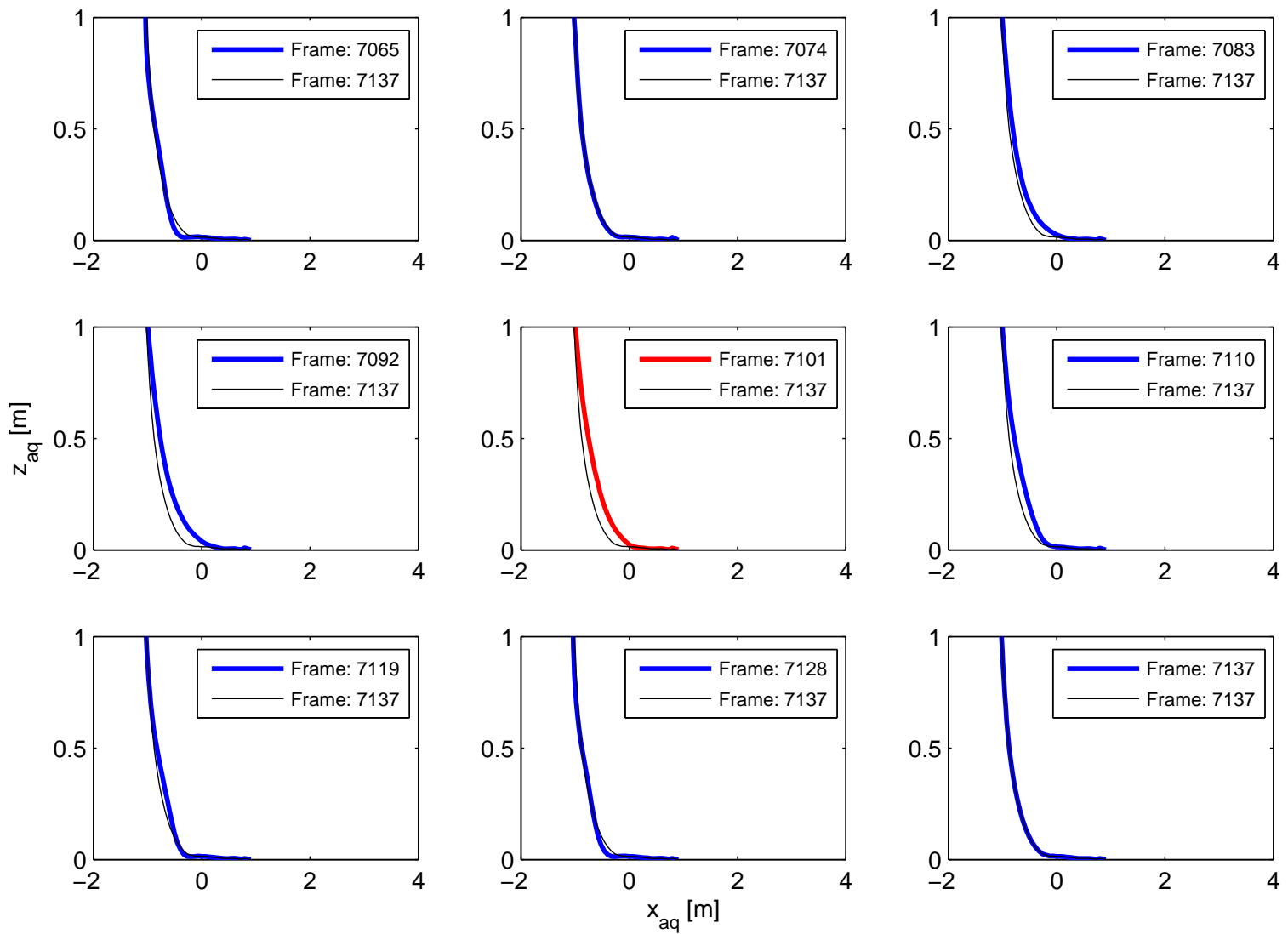

Figura 6.11: Sequência de quadros sem ocorrência de compressão dinâmica.

Nas situações em que a compressão dinâmica não era percebida (seja durante alguns intantes ou em um experimento como um todo), o procedimento de determinação automática do comprimento de ondas de flexão era interrompido, visto que não ocorriam mudanças de concavidade, condição ilustrada na Figura 6.12, a título de exemplo.
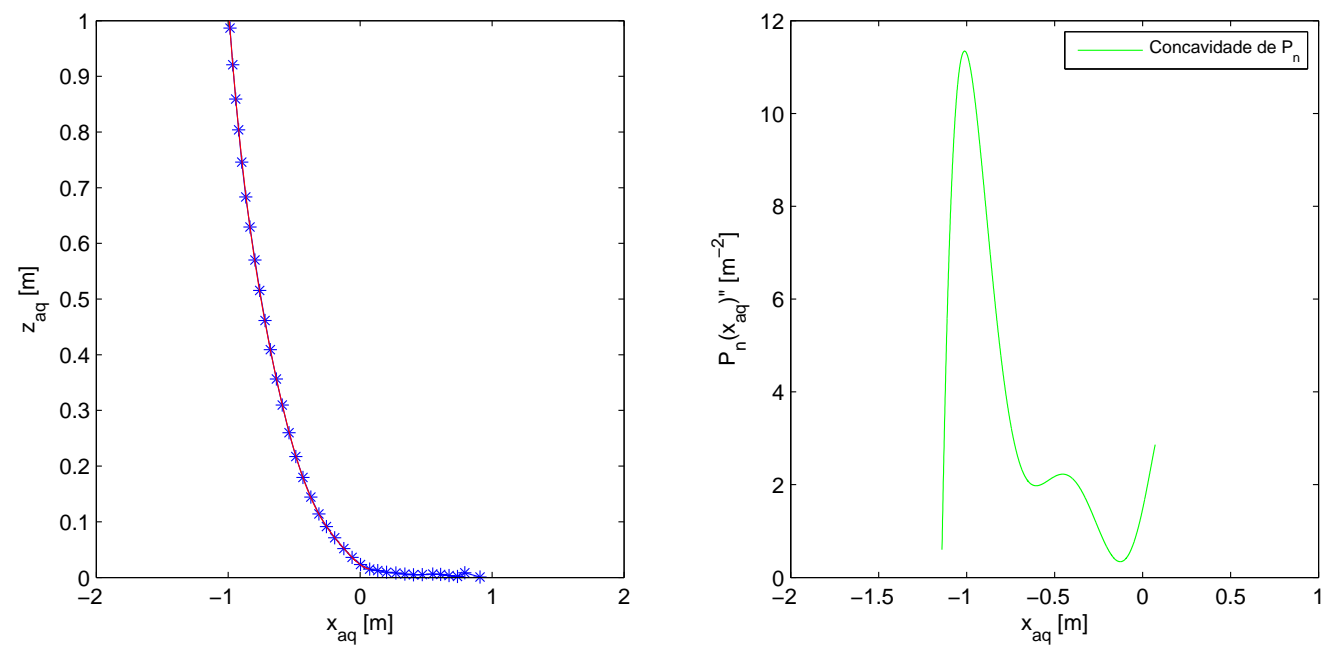

Figura 6.12: Exemplo de procedimento para determinação do comprimento de onda. Caso F080A100T80, instante de ausência de compressão dinâmica. 
Após a utilização dos dados provenientes do sistema de monitoramento óptico, o que já seria suficiente para os fins desta tese, uma checagem era promovida, com a verificação das séries temporais de tração (e respectivas densidades espectrais de potência), a fim de comparar os resultados obtidos com os esperados pelo procedimento proposto. A Figura 6.13 ilustra esa checagem.

Para o caso utilizado como exemplo nesta descrição da metodologia de análise, cumpre notar que as três cargas críticas teóricas foram ultrapassadas pelo mínimo valor das trações efetivas. Além disso, ainda que discretamente, o PSD da série temporal de trações determinada pelo Anflex exibe um pico bastante proeminente sob a frequência de excitação, além de outro pico, com intensidade muito menor, na frequência igual ao dobro da primeira, não sendo possível extrair nenhuma informação adicional da referida figura.
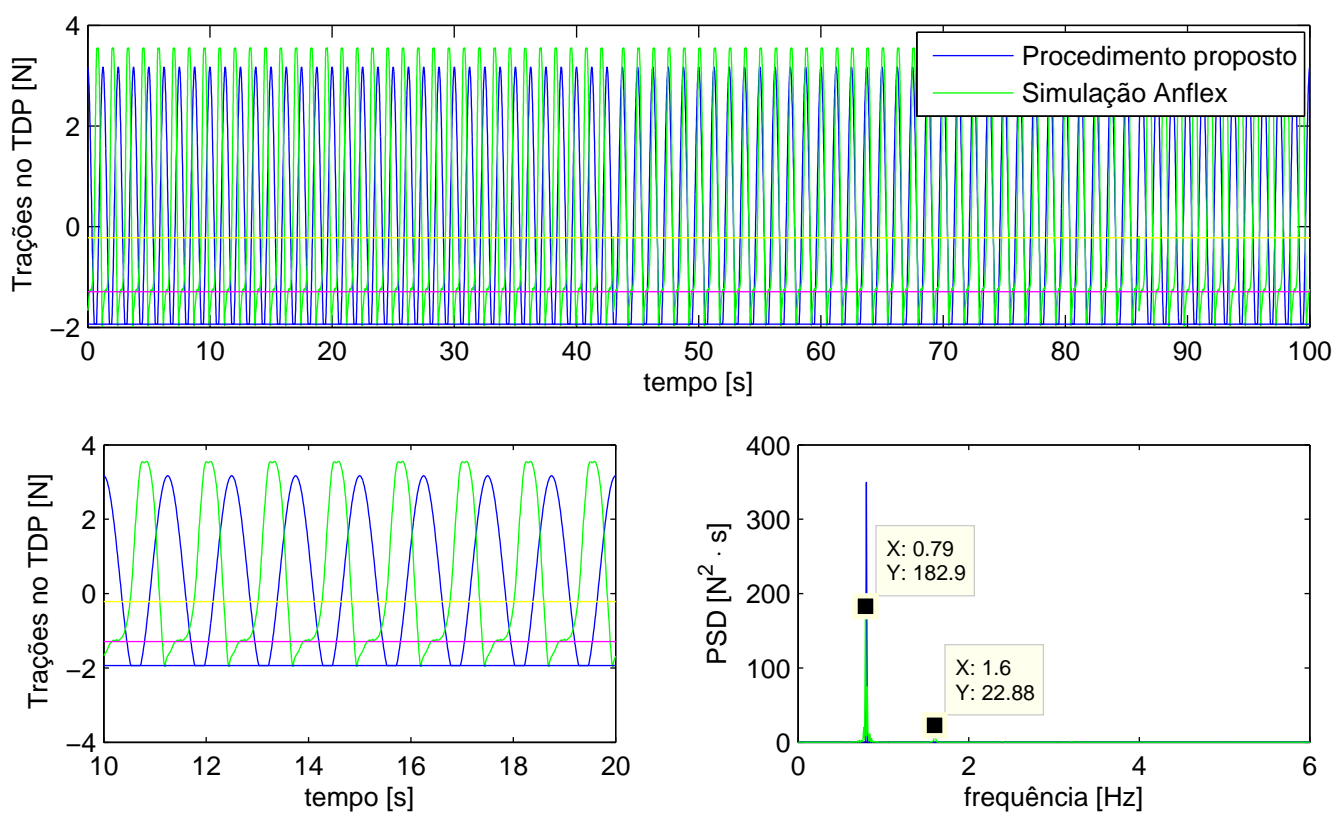

Figura 6.13: Série de trações no TDP e respectivo PSD para o caso F080A100T80. $\mathrm{Na}$ figura, as linhas horizontais representam as cargas críticas calculadas; em amarelo, pela definição de Euler; em azul, pela formulação de Aranha et al. (2001); em magenta, engaste-pinado.

A próxima seção é iniciada com a justificativa racional dos casos a serem estudados em detalhe, seguida pela apresentação e discussão dos respectivos resultados, em consonância com o padrão apresentado até aqui. Ressalte-se que, em alguns casos particulares, avaliações diferentes das apresentadas poderão ser feitas, a fim de explorar especificidades de um dado caso, ou por se tratarem de padrões dos comumente encontrados na literatura. Nesse sentido, cabe uma nota importante: para cada caso estudado foram gerados um total de vinte figuras, dentre as mostradas ao longo deste texto, além de outras como vistas e perspectivas estáticas, trajetórias dos alvos submersos, retratos de fase e evolução temporal das elásticas, que serão eventualmente apresentadas, a título de exemplo ou quando se fizer necessário. 


\subsection{Principais Resultados}

A presente seção tem por finalidade a apresentação dos resultados obtidos para alguns casos particulares, dentre os ensaiados, seguida de breves discussões. Por uma questão de concisão textual, optou-se pela exposição do menor número de casos, evitando-se perdas de informações que possam prejudicar os objetivos desejados.

Para tanto, foram definidos alguns critérios a serem respeitados, a fim de permitir uma escolha racional dos casos apresentados ao leitor. O conjunto assim determinado deve conter exemplos de todas as frequências, amplitudes e ângulos de topo ensaiados, bem como encerrar os casos assinalados por setas amarelas na Figura 6.1 (denominados "casos especiais") e aqueles em que foram verificadas divergências nas previsões feitas a partir das formulações analíticas consideradas.

Avaliados os casos ensaiados, sob essas hipóteses restritivas, restaram seis casos a serem explicitados ao leitor, conforme ilustrado na Figura 6.14. Embora pequeno, esse conjunto de casos pretende abarcar grande parte das discussões necessárias.

\begin{tabular}{|c|c|c|c|c|c|c|}
\hline CASOS & 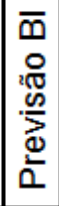 & 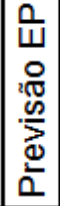 & 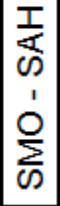 & 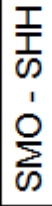 & 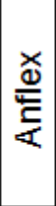 & 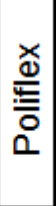 \\
\hline F080A050T80 & & & & NA & & \\
\hline F080A100T85 & & & & NA & & \\
\hline F100A200T65 & & & & & & \\
\hline F125A050T70 & & & & NA & & \\
\hline F125A050T80 & & & & $\mathrm{NA}$ & & \\
\hline F125A100T85 & & & & NA & & \\
\hline
\end{tabular}

(1) sobre as denominações das colunas, "Previsão BI" refere-se à formulação para deflexões em vigas curvas biapoiadas; "Previsão EP", idem para engastes-pinados; "SMO-SAH", Sistema de Monitoramento Óptico, sentido anti-horário; "SMO-SHH", idem, sentido horário; e "Anflex" e "Poliflex" correspondem às simulações numéricas feitas com o uso dos respectivos programas; (2) células verdes, ausência de compressão dinâmica; células vermelhas, previsão de ocorrência de compressão dinâmica; (3) casos assinalados em amarelo correspondem aos denominados "casos especiais"; em azul, divergências analíticas. (4) Não avaliado.

Figura 6.14: Seleção preliminar dos casos para detalhamento.

A Figura 6.14 possui uma pequena descrição com a finalidade de esclarecer a forma de apresentação escolhida. Nesse sentido, cabe, ainda, uma pequena observação: os dois casos denominados como "casos especiais", demarcados em amarelo naquela figura, apresentaram resultados que podem ser considerados limítrofes para as simulações via Anflex, como será apresentado adiante.

Além disso, é importante citar que, dos 72 casos ensaiados, o Poliflex previu a ocorrência de compressão dinâmica para 64 casos, um número muito superior ao aventado pelas demais abordagens (formulações analíticas e simulações via Anflex) e confirmado pelos ensaios. O motivo para essa diferença é que o Poliflex, como citado anteriormente, não permite o estudo do comportamento pós-crítico. 
Uma possível explicação para essa característica pode ser a utilização de elementos de cabo, desconsiderando os efeitos da rigidez flexional do TDP ou, simplesmente, impedindo trações negativas pela imposição de carga crítica nula. Embora equivalentes, em termos de efeitos, o funcionamento interno do código numérico é desconhecido, nem disponibilizado no manual do programa².

Postas todas essas considerações iniciais, são apresentados, na sequência, os casos escolhidos para análise, na ordem em que aparecem na Figura 6.14.

\subsubsection{Apresentação e discussão dos resultados do caso F080A050T80}

A presença do caso F080A050T80 é justificada pelo interesse em apresentar um caso em que todas as abordagens previram ausência de compressão dinâmica no modelo ensaiado, o que foi confirmado pelas simulações realizadas e pelos resultados obtidos com a utilização do sistema de monitoramento óptico.

Nesse caso, não faz sentido nenhuma discussão relacionada às previsões do comprimento de ondas de flexão. Ainda assim, a apresentação dos demais resultados gráficos pode fornecer subsídios importantes para os demais casos escolhidos para análise. Assim, são apresentadas as séries temporais de trações (e respectivos PSD); as séries temporais de deslocamentos nas direções tangente e normal (e respectivos PSD); e os retratos de fase dos alvos submersos identificados, nessas direções.
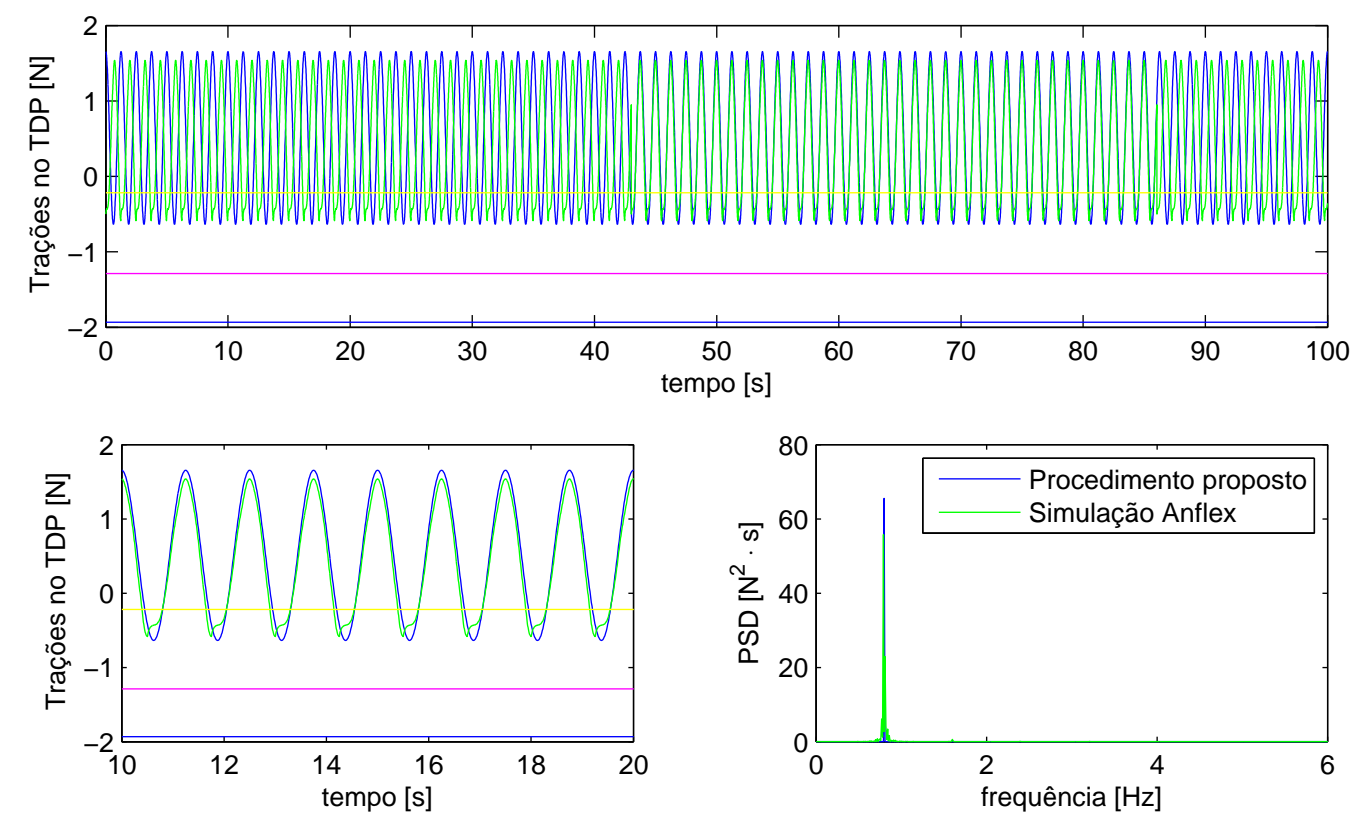

Figura 6.15: Série de trações no TDP e respectivo PSD para o caso F080A050T80. $\mathrm{Na}$ figura, as linhas horizontais representam as cargas críticas calculadas; em amarelo, pela definição de Euler; em azul, pela formulação de Aranha et al. (2001); em magenta, engaste-pinado.

\footnotetext{
${ }^{2}$ Nesse ponto, uma observação é digna de nota: o manual do Poliflex cita correções devidas à rigidez flexional apenas para o topo, tratando o restante da linha como um cabo. Frente a essa consideração, as duas hipóteses aventadas tornam-se equivalentes em causa e efeito. Segundo o próprio manual "(...) o programa não aceita um número de comprimentos de flexão nulo, nem simula casos em que haja compressão dinâmica (...)".
} 
Com respeito à Figura 6.15 cumpre notar a aderência das assinaturas temporais apresentadas, fato bastante comum na ausência de compressão dinâmica. No que tange às Figuras 6.16 e 6.17 é possível notar o caráter meramente oscilatório, típico das respostas provenientes de excitações harmônicas. Saliente-se o baixo nível de movimentos na direção tangente, em comparação à direção normal à linha, o que é completamente condizente com o esperado.

Nota: em todos os gráficos apresentados na sequência, cada cor representa um alvo distinto situado sobre determinada posição da porção submersa do modelo flexível.
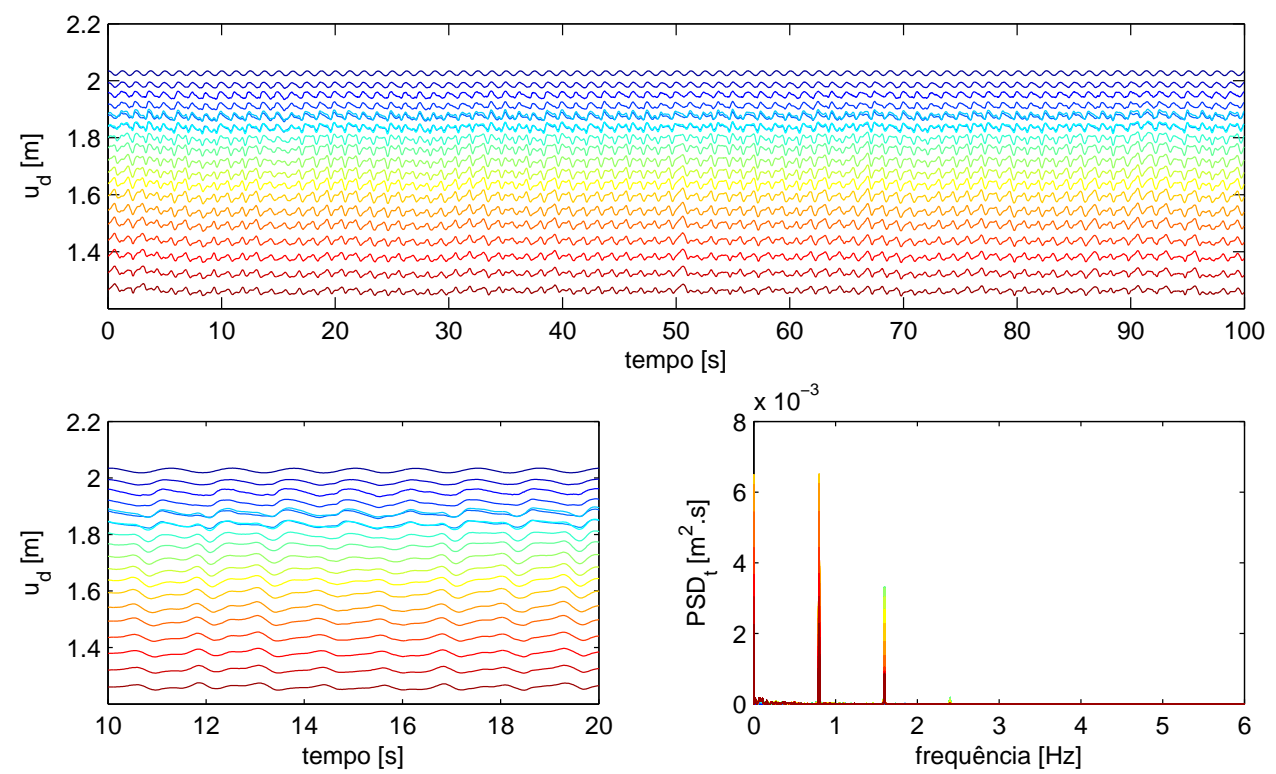

Figura 6.16: Série de deslocamentos na direção tangente e respectivo PSD para o caso F080A050T80.
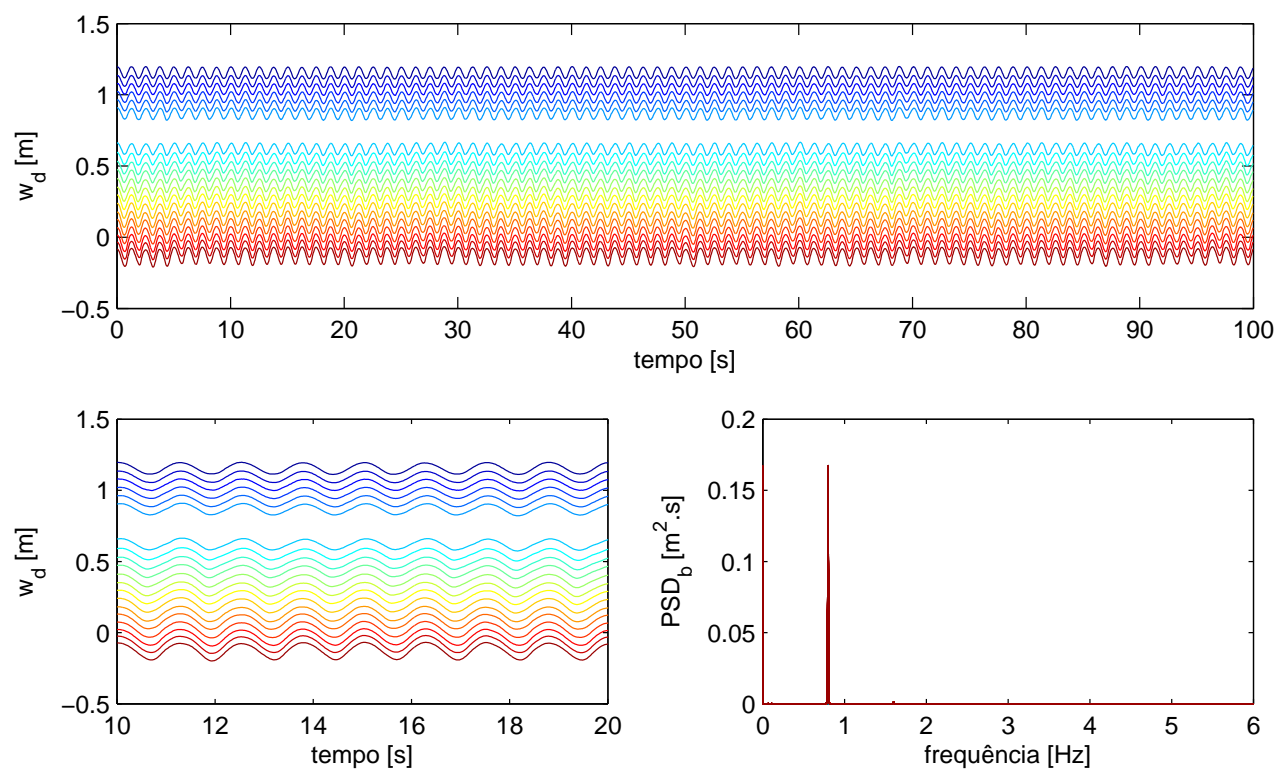

Figura 6.17: Série de deslocamentos na direção normal e respectivo PSD para o caso F080A050T80. 
Por fim, com relação aos retratos de fase, é possível notar a existência de órbitas fechadas, associadas aos movimentos de cada alvo.

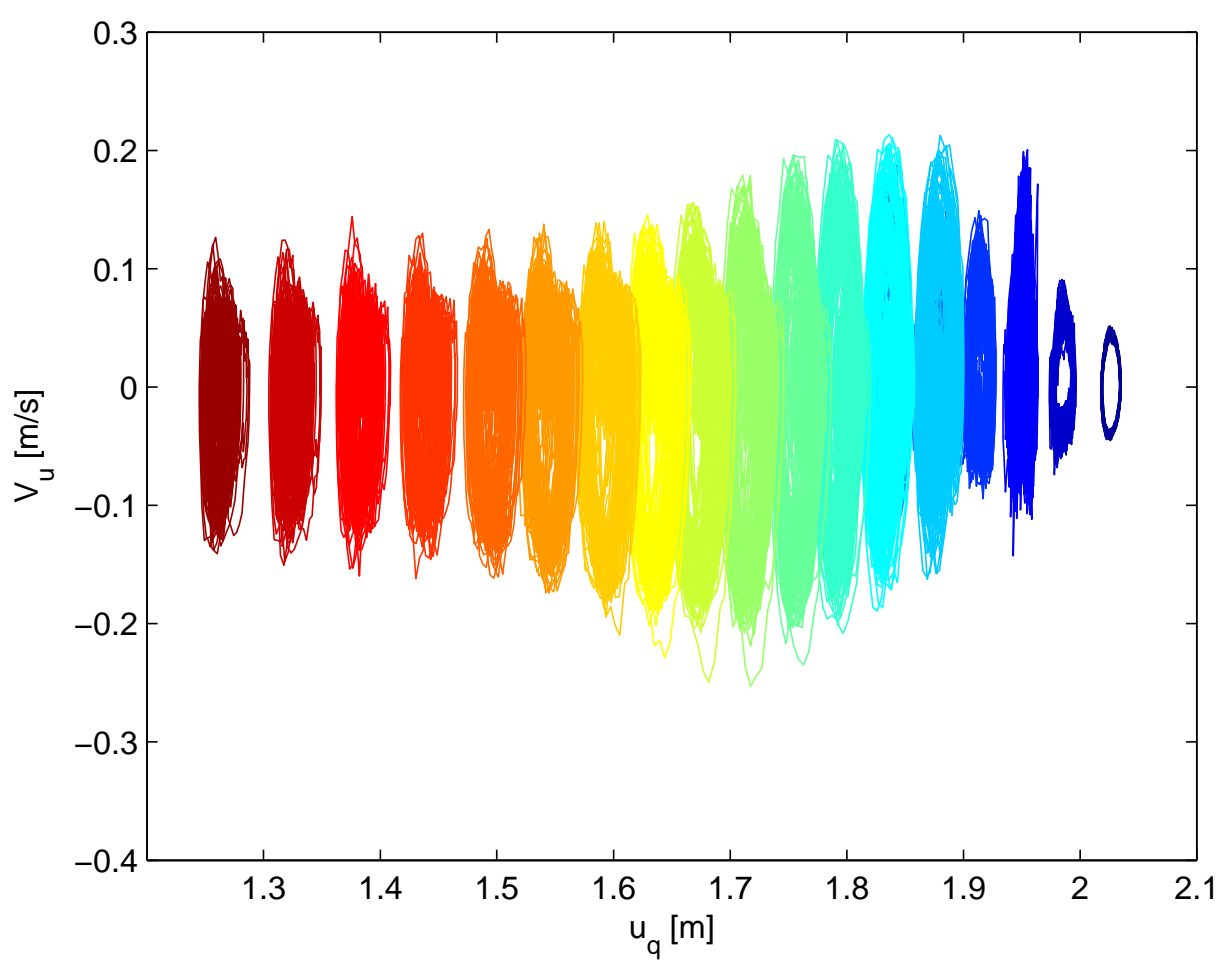

Figura 6.18: Retratos de fases dos alvos submersos, caso F080A050T80, direção tangente.

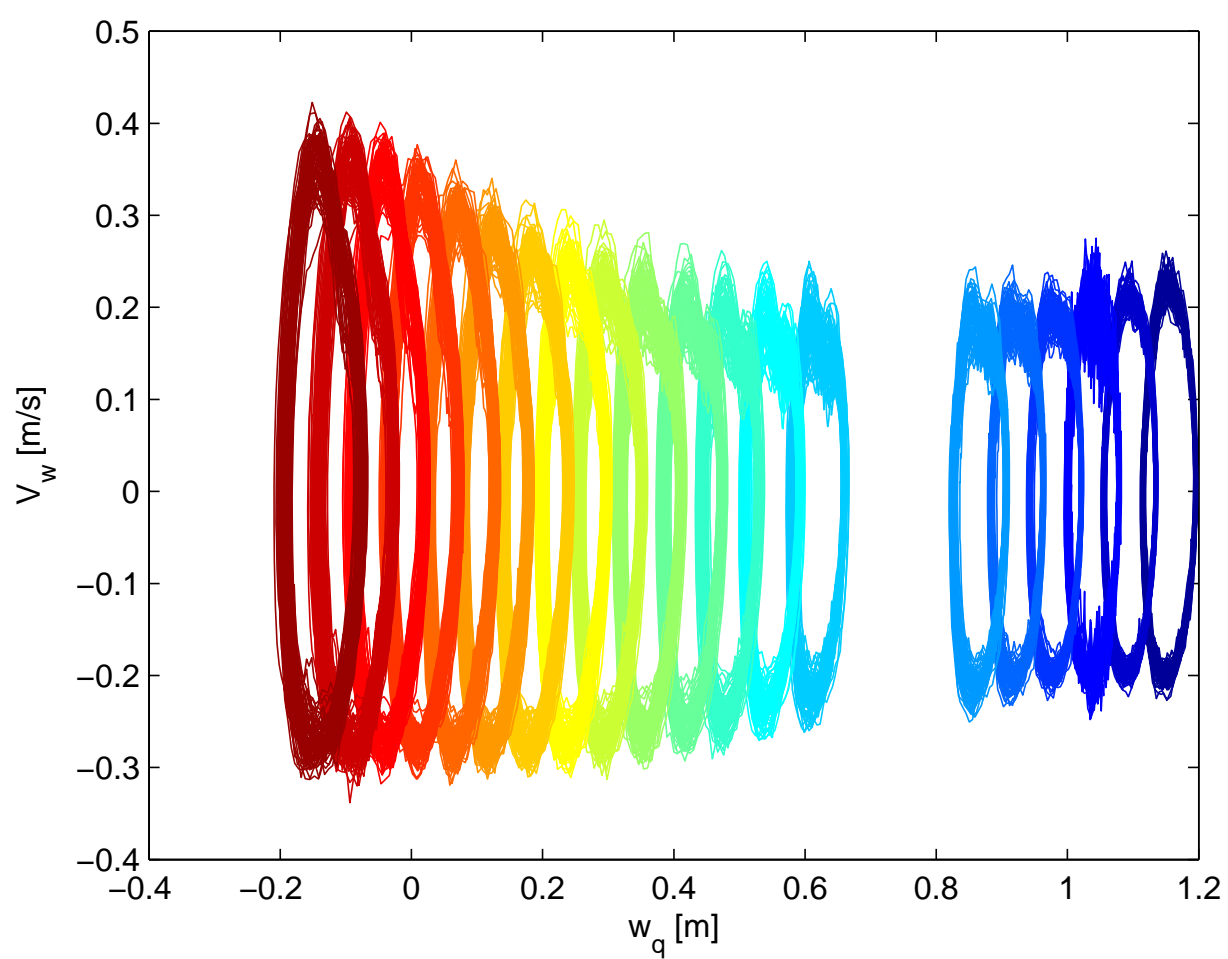

Figura 6.19: Retratos de fases dos alvos submersos, caso F080A050T80, direção normal. 


\subsubsection{Apresentação e discussão dos resultados do caso F080A100T85}

O caso F080A100T85 foi um dos que apresentou divergências com respeito às formulações consideradas, levando em conta as duas possibilidades aventadas para as condições de contorno da viga curva.

Esse caso é particularmente interessante pelos resultados auferidos. Primeiramente, destaque-se a Figura 6.20, na qual é possível perceber que a assinatura temporal de trações, via Anflex, ultrapassa a carga crítica para o caso engastado-pinado, mas não a carga crítica prevista por Aranha et al. (2001); entretanto, é possível perceber a presença de um patamar, ainda que sutil, na séries de trações via Anflex, nas proximidades da carga crítica para o caso ancorado, sem, no entanto, atingir a carga crítica formulada para o vínculo biapoiado.
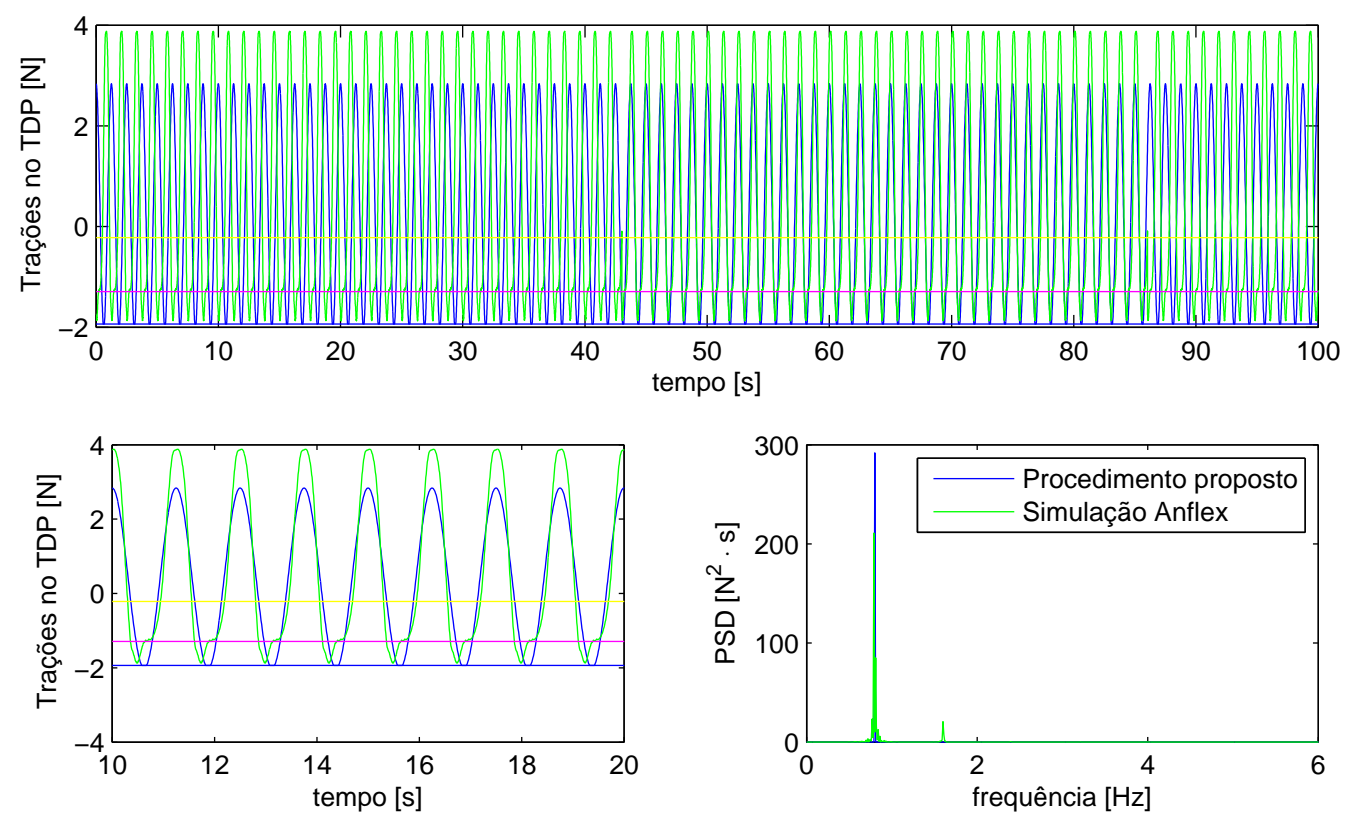

Figura 6.20: Série de trações no TDP e respectivo PSD para o caso F080A100T85. $\mathrm{Na}$ figura, as linhas horizontais representam as cargas críticas calculadas; em amarelo, pela definição de Euler; em azul, pela formulação de Aranha et al. (2001); em magenta, engaste-pinado.

Tendo em mente os resultados apresentados para o caso anterior, em que a compressão dinâmica não ocorria, nem sequer era prevista por nenhuma das formulações analíticas utilizadas, é interessante visualizar as diferenças gráficas, resultantes dos ensaios. Apresente-se, na sequência, as séries temporais de deslocamentos nas direções tangente e normal, acompanhadas de suas respectivas densidades espectrais de potência. Nesse sentido, aponte-se as diferenças mais evidentes: o caráter oscilatório não é mantido durante todo o intervalo de tempo considerado, de sorte que, em alguns instantes específicos, aparecem picos, para os mesmos alvos ou alvos próximos entre si, nas direções tangencial e normal. Note-se, em particular, os comportamentos diferenciados dos alvos representados por tons de azul mais claro. 

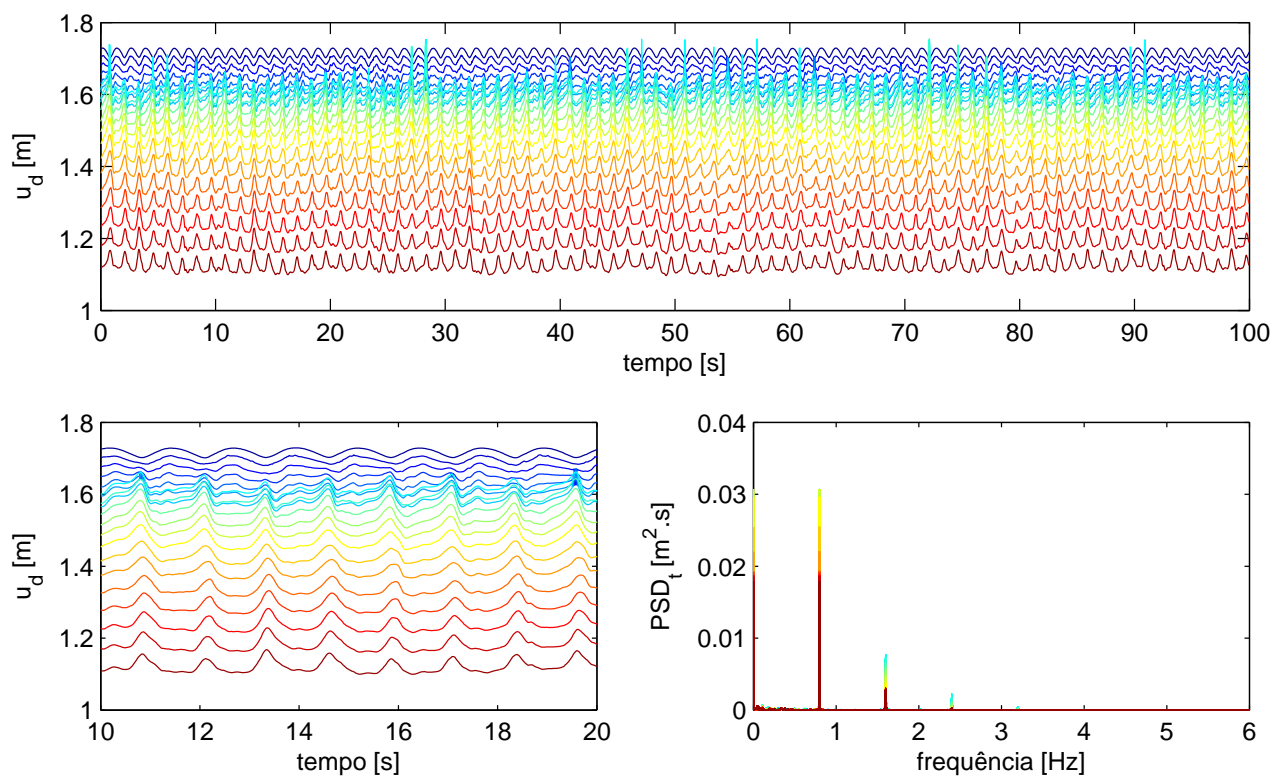

Figura 6.21: Série de deslocamentos na direção tangente e respectivo PSD para o caso F080A100T85.

É importante notar que o comportamento oscilatório é tão destacado que o conjunto dos movimentos faz com que pretensos movimentos de períodos extremamente longos podem ser visualizados no PSD.

Por outro lado, a presença desses picos, associados a frequências múltiplas inteiras da frequência de excitação, concorrem para a conclusão de presença de compressão dinâmica durante o experimento em questão. Nesse sentido, é possível recorrer a uma ilustração diferenciada, não mostrada anteriormente (Figura 6.23).
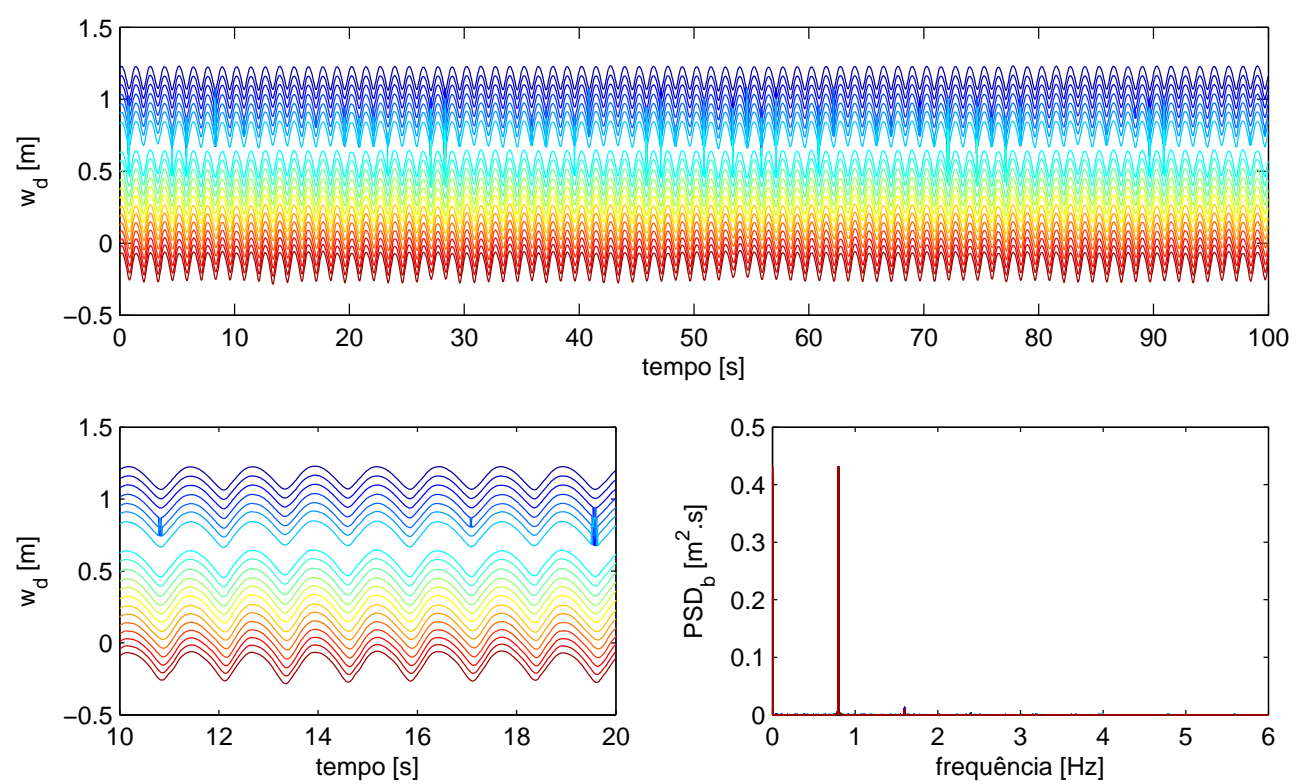

Figura 6.22: Série de deslocamentos na direção normal e respectivo PSD para o caso F080A100T85. 
A hipótese utilizada nas formulações, envolvendo pequenos deslocamentos ao redor da posição de equilíbrio estático, continua compatível com os resultados observados, considerando o experimento como um todo. Todavia, os picos diferenciados presentes nas Figuras e parecem estar relacionados à formação das ondas de flexão durante a compressão dinâmica.

A fim de checar essa hipótese, considere-se a Figura 6.23. Nela, são apresentados os deslocamentos de cada alvo do modelo (com relação ao instante de tempo imediatamente anterior), em função do tempo. Nos casos em que a compressão dinâmica não é observada, esses deslocamentos tendem a ser extremamente baixos, o que ocorre na maior parte do ensaio em questão, a menos de instantes bem específicos, nos quais os mesmos alvos citados anteriormente (representados em tons de azul), apresentam variações substanciais em seus deslocamentos, o que parece corroborar a assertiva relativa à formação das ondas de flexão nos referidos instantes de tempo. Esse padrão percebido na Figura 6.23 não apenas mostra, claramente, uma alteração importante nos deslocamentos de determinados alvos, apontando para a ocorrência de compressão dinâmica e a formação das chamadas ondas de flexão, como reflete diretamente no padrão dos retratos de fase percebidos no estudo do caso anterior. Essas diferenças podem ser visualizadas nas Figuras 6.24 e 6.25, sempre relacionadas aos alvos representados por tons de azul.

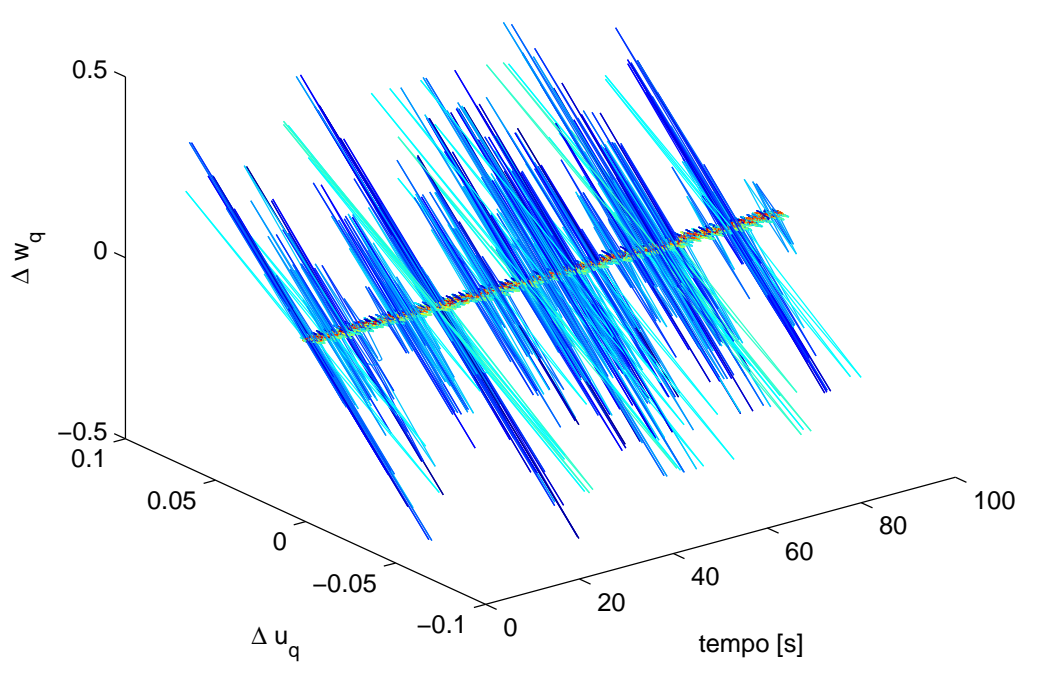

Figura 6.23: Evolução temporal dos deslocamentos tangencial e normal para o caso F080A100T85. Os deslocamentos da figura são apresentados em metros.

Os retratos de fase das referidas figuras apresentam, para a maior parte dos alvos identificados pelo sistema de monitoramento, o mesmo comportamento percebido anteriormente. Entretanto, para os alvos com comportamento diferenciado, as órbitas fechadas apresentam variações abruptas de velocidade, evidenciando a escala de tempo associada às ondas de flexão. 


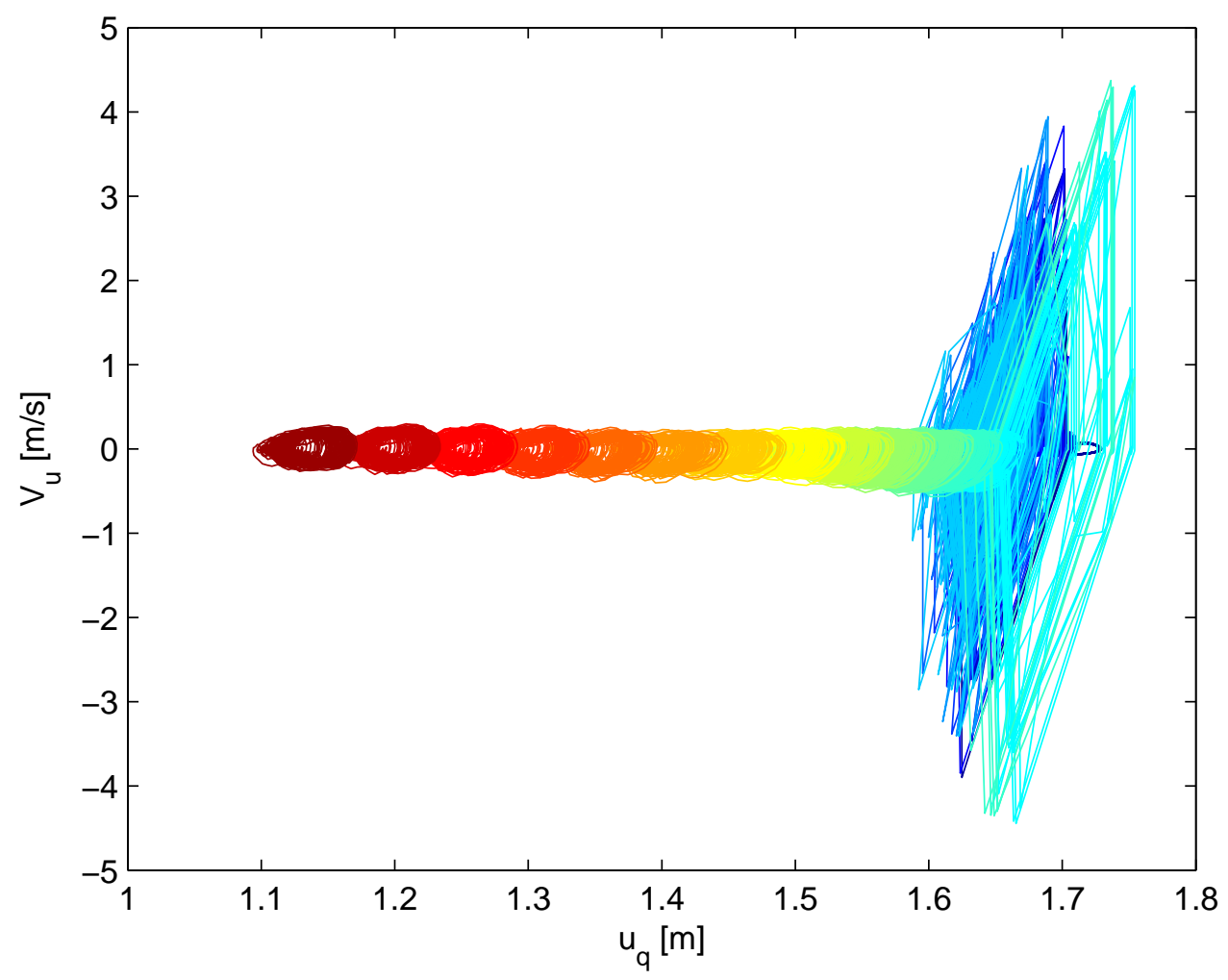

Figura 6.24: Retratos de fases dos alvos submersos, caso F080A100T85, direção tangente.

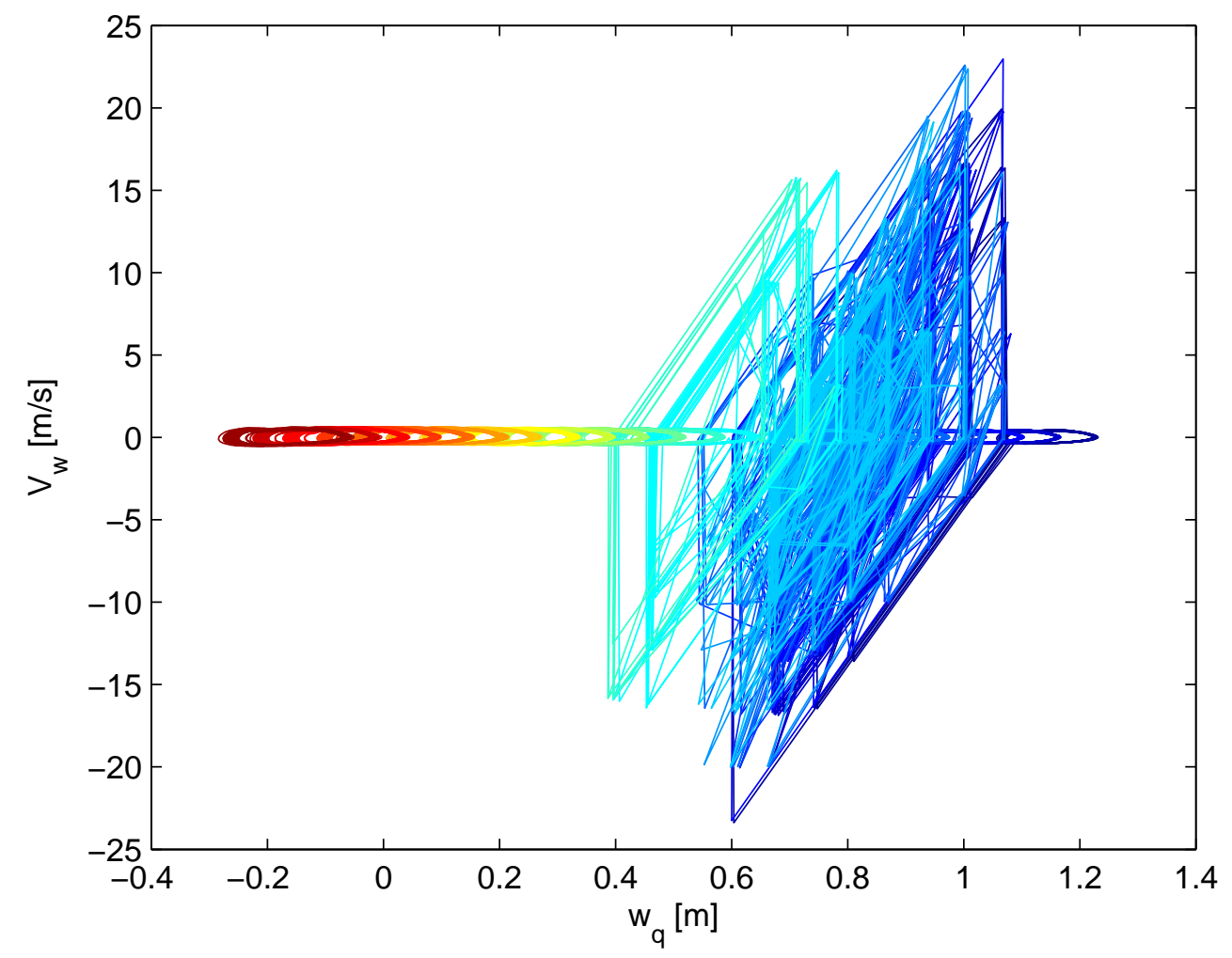

Figura 6.25: Retratos de fases dos alvos submersos, caso F080A100T85, direção normal. 
Dado que o presente ensaio apresentou compressão dinâmica, com a geração das chamadas ondas de flexão, foi possível sua determinação, a partir do procedimento descrito anteriormente. Os valores dos comprimentos de onda medidos, comparados com os esperados pelas formulações analíticas, estão compilados da Tabela 6.1, para os sentidos anti-horário e horário.

Nas tabelas em que os comprimentos de onda são compilados, cumpre notar que:

- $\lambda_{\text {exp }}$ é o comprimento de onda medido nos experimentos;

- $\lambda_{B I}$ é o comprimento de onda esperado para o caso biapoiado;

- $\frac{\lambda_{e x p}}{\lambda_{B I}}$ é a razão entre os comprimentos de onda descritos;

- $\lambda_{E P}$ é o comprimento de onda esperado para o caso engastado-pinado;

- $\frac{\lambda_{e x p}}{\lambda_{E P}}$ é a razão entre os comprimentos de onda descritos;

- "BI Torção" utiliza o fator de correção de $\sqrt{\frac{9}{4}}=1,5$ proposto por Ramos Jr \& Pesce (2003), com a inclusão de efeitos da torção crítica (subescrito "T");

- $\frac{\lambda_{e x p}}{\lambda_{B I_{T}}}$ é a razão entre os comprimentos de onda descritos;

- "EP Torção" utiliza o fator de correção de $\sqrt{\frac{9}{4}}=1,5$ proposto por Ramos Jr \& Pesce (2003), com a inclusão de efeitos da torção crítica (subescrito "T");

- $\frac{\lambda_{e x p}}{\lambda_{E P_{T}}}$ é a razão entre os comprimentos de onda descritos.

Tabela 6.1: Comprimentos de onda de flexão medidos do caso F080A100T85

\begin{tabular}{|c|c|c|c|c|c|c|c|c|c|}
\hline Caso/Sentido & $\begin{array}{c}\lambda_{\exp } \\
{[\mathrm{m}]}\end{array}$ & $\begin{array}{c}\lambda_{B I} \\
{[\mathrm{~m}]}\end{array}$ & $\frac{\lambda_{\exp }}{\lambda_{B I}}$ & $\begin{array}{c}\lambda_{E P} \\
{[\mathrm{~m}]}\end{array}$ & $\frac{\lambda_{\exp }}{\lambda_{E P}}$ & $\begin{array}{c}\mathrm{Bl} \\
\text { torção } \\
{[\mathrm{m}]}\end{array}$ & $\frac{\lambda_{\exp }}{\lambda_{B I} I_{T}}$ & $\begin{array}{c}\mathrm{EP} \\
\text { torção } \\
{[\mathrm{m}]}\end{array}$ & $\frac{\lambda_{\exp }}{\lambda_{E P_{T}}}$ \\
\hline F080A100T85SAH & 0,402 & 0,327 & 1,229 & 0,401 & 1,003 & 0,491 & 0,819 & 0,601 & 0,669 \\
F080A100T85SHH & 0,399 & 0,327 & 1,219 & 0,401 & 0,996 & 0,491 & 0,813 & 0,601 & 0,664 \\
\hline \hline
\end{tabular}

Cumpre destacar, por fim, a relação praticamente unitária entre os comprimentos de onda medidos experimentalmente e a previsão da aproximação para vigas curvas engastadas-pinadas. Tal semelhança pode ser explicada pelo fato do lançamento quase vertical do modelo, o que leva a duas condições que concorrem para o valor determinado: (i) a influência da ancoragem nesse ensaio em particular; (ii) nessa configuração, as saídas laterais da linha, bem como os efeitos associados à rigidez torcional são menores que em outras situações.

O próximo item apresentará um ensaio em que a configuração de lançamento do modelo flexível é bem diferente da apresentada neste caso, culminando em resultados bem diferentes dos aqui auferidos. 


\subsubsection{Apresentação e discussão dos resultados do caso F100A200T65}

O caso F100A200T65 é particularmente interessante por se tratar de uma configuração de lançamento bastante distinta das avaliadas até aqui, dado que o ângulo de topo nominal de $65^{\circ}$ faz com que o trecho repousado sobre o solo seja substancialmente menor, comparativamente às configurações mais verticais. Como resultado, a projeção horizontal é maior e, portanto, a âncora fica mais afastada da vertical que passa pelo topo do modelo, diminuindo sua influência na dinâmica da linha.

A sequência de quadros ilustrada na Figura 6.26 mostra a formação de ondas de flexão no modelo, durante os ensaios, de maneira que os comprimentos de onda podem ser calculados e comparados com os resultados das formulações analíticas.

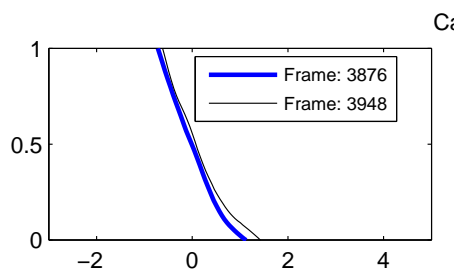

Caso em análise: F100A200T65-SAH / Total de frames: 6553
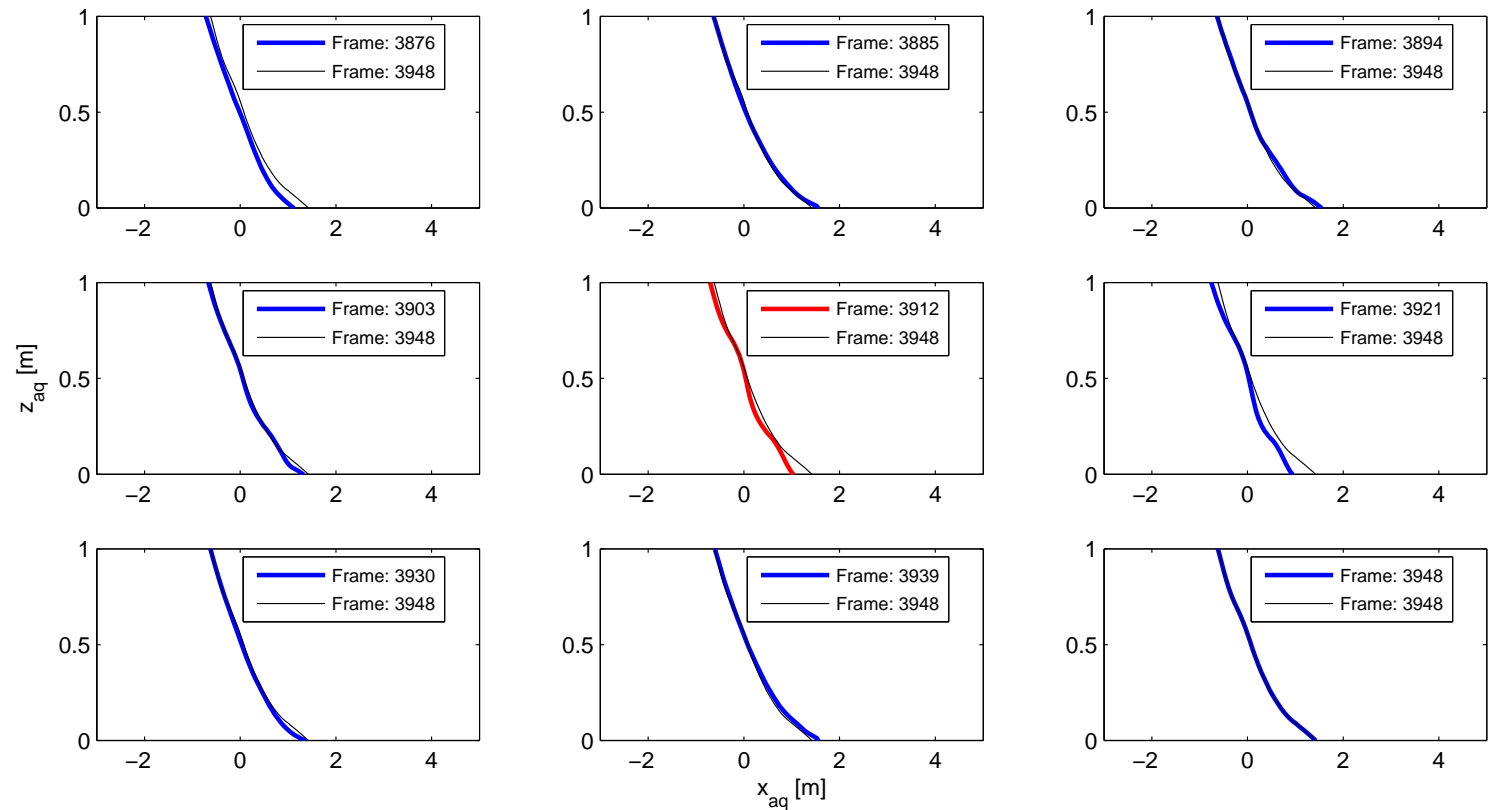

Figura 6.26: Sequência de quadros do caso F100A200T65, com ocorrência de compressão dinâmica.

A Tabela 6.2 apresenta os valores dos comprimentos de onda medidos nesse ensaio, bem como os valores esperados a partir da utilização das formulações analíticas, considerando-se as condições de contorno "BI" e "EP".

Tabela 6.2: Comprimentos de onda de flexão do caso F100A200T65

\begin{tabular}{|c|c|c|c|c|c|c|c|c|c|}
\hline Caso/Sentido & $\begin{array}{c}\lambda_{\exp } \\
{[\mathrm{m}]}\end{array}$ & $\begin{array}{c}\lambda_{B I} \\
{[\mathrm{~m}]}\end{array}$ & $\frac{\lambda_{\text {exp }}}{\lambda_{B I}}$ & $\begin{array}{c}\lambda_{E P} \\
{[\mathrm{~m}]}\end{array}$ & $\frac{\lambda_{\exp }}{\lambda_{E P}}$ & $\begin{array}{c}\mathrm{BI} \\
\text { torção } \\
{[\mathrm{m}]}\end{array}$ & $\begin{array}{c}\frac{\lambda_{\text {exp }}}{\lambda_{B I_{T}}} \\
\begin{array}{c}\mathrm{EP} \\
\text { torção } \\
{[\mathrm{m}]}\end{array}\end{array}$ & $\frac{\lambda_{\exp }}{\lambda_{E P_{T}}}$ \\
\hline F100A200T65SAH & 1,023 & 0,497 & 2,059 & 0,435 & 2,350 & 0,745 & 1,373 & 0,653 & 1,567 \\
F100A200T65SHH & 1,116 & 0,497 & 2,246 & 0,435 & 2,564 & 0,745 & 1,498 & 0,653 & 1,709 \\
\hline \hline
\end{tabular}


Os resultados compilados na Tabela 6.2 são bem distintos dos apresentados anteriormente para o caso F080A100T85, o que é explicado diretamente pelas diferentes configurações de lançamento. A influência da ancoragem, por exemplo, afeta menos a dinâmica, de sorte que a previsão de Aranha et al. (2001) é mais adequado que a utilização da condições "EP". Ainda mais: o fator de correção que incorpora os efeitos da torção são de grande valia, apresentado-se menor que o obtido experimentalmente.

Apenas para fins ilustrativos, apresenta-se a Figura 6.27, na qual é possível identificar o comprimento de uma das ondas de flexão geradas nos experimentos do caso F100A200T65.

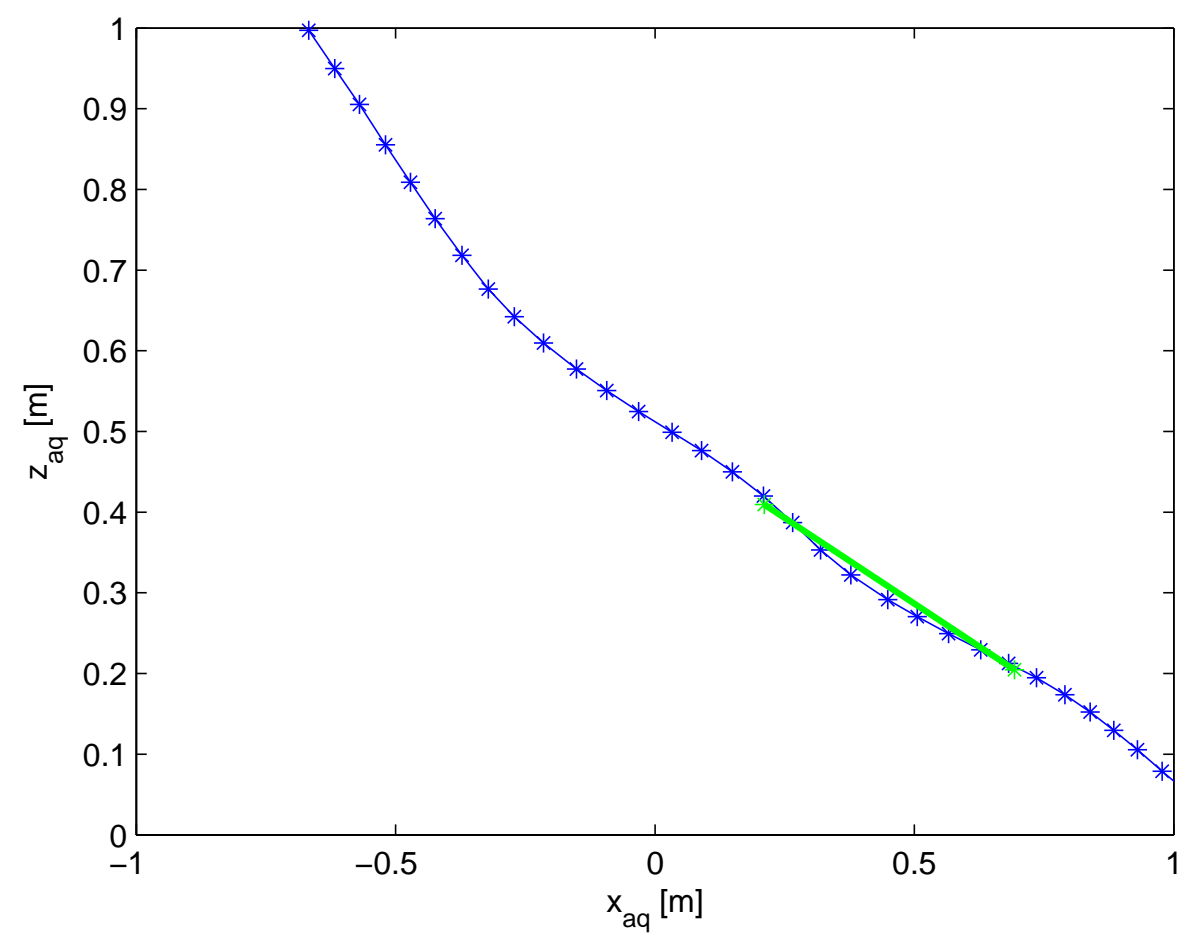

Figura 6.27: Determinação do comprimento de onda de flexão, caso F100A200T65.

Por fim, é interessante verificar o comportamento da série de trações para o presente caso, bem como seu respectivo PSD. Para tanto, recorra-se à Figura 6.28.

Essa figura apresenta três características particularmente interessantes: (i) o patamar referente ao atingimento da carga crítica é de fácil percepção, embora não se configure exatamente como um patamar; (ii) os níveis de tração mínima ultrapassam todas as cargar críticas aventadas, atingindo o nível referente ao vínculo "Bl" antes do "EP"; (iii) mesmo ficando evidente que a carga de compressão mais adequada para o presente caso é a proveniente da formulação de Aranha et al. (2001), a diferença para o vínculo engastado-pinado parece ser diminuta; (iv) a sequência de picos proeminentes, em frequência múltiplas inteiras da de excitação, no PSD é uma característica comum a esse tipo de ensaio, conforme citado por Simos \& Fujarra (2006). Esse exemplo é bastante característico pela quantidade de picos passíveis de avaliação. 

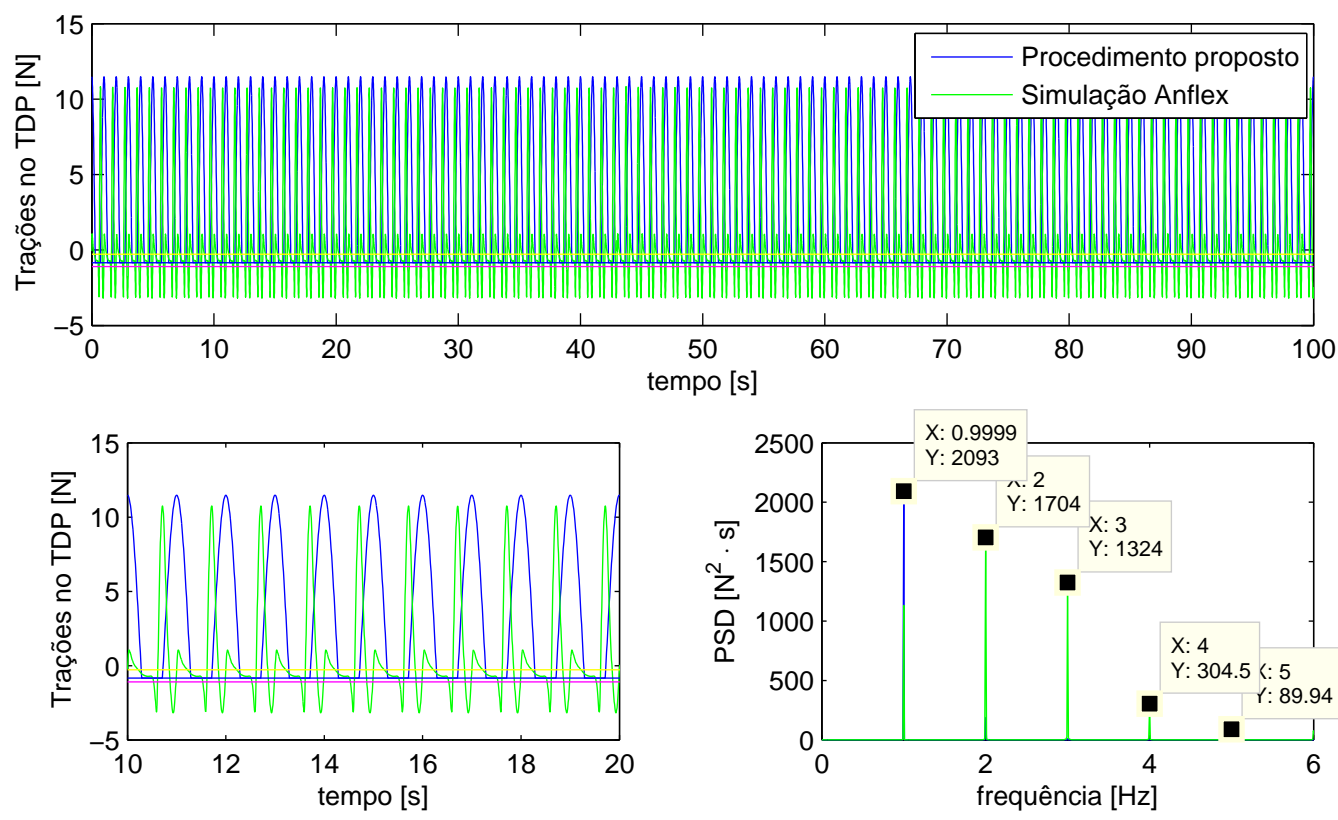

Figura 6.28: Série de trações no TDP e respectivo PSD para o caso F100A200T65.

\subsubsection{Apresentação e discussão dos resultados do caso F125A050T70}

A presença do caso F125A050T70 (ver Figura 6.29) nas análises dos resultados é fruto da escolha racional apresentada no início desta seção. Todavia, essa condição é bastante similar à explicitada anteriormente no Item 6.2.2, no sentido de se tratar de um caso em que as previsões de compressão dinâmica, a partir das formulações consideradas, são distintas. Por outro lado, o ângulo de topo é consideravalmente menor, de maneira que os resultados são bastante diferentes, guardando relação com a condição estudada no Item 6.2.3, em termos dos comprimentos de ondas.

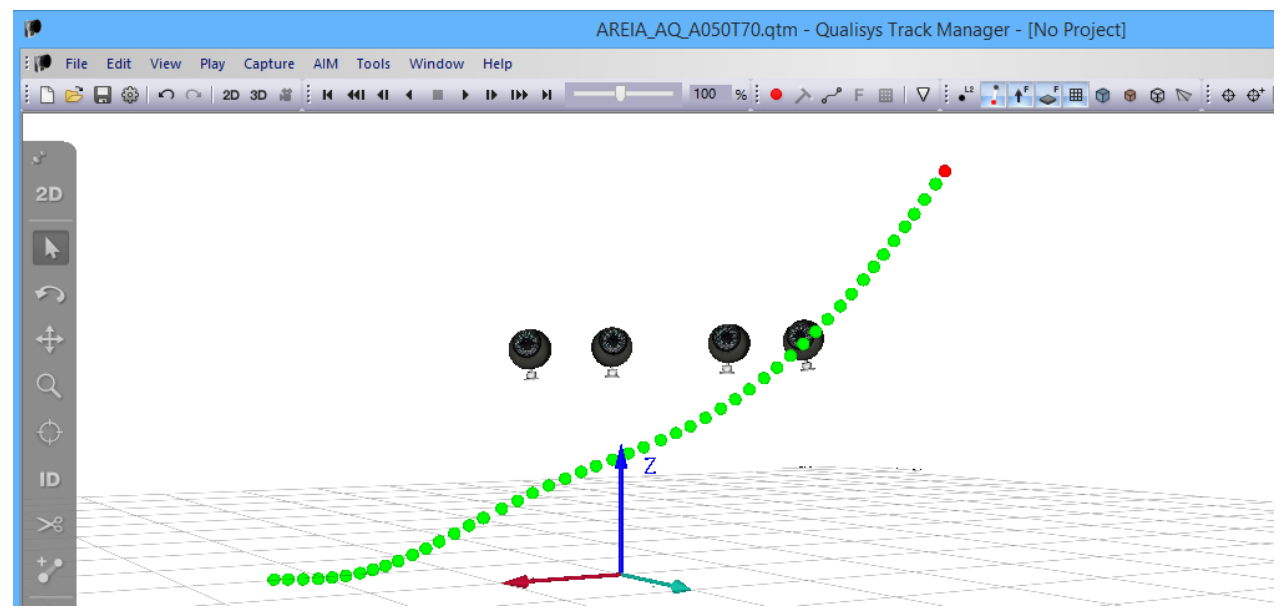

Figura 6.29: Visualização do caso F125A050T70 pelo programa dedicado.

Dados os resultados anteriores, é possível apresentar os resultados gráficos mais rapidamente para, posteriormente, tecer os comentários pertinentes. Desta forma, a 
Figura 6.30 ilustra um exemplo de determinação do comprimento da onda de flexão em um quadro específico. Os resultados médios são apresentados na Tabela 6.3.

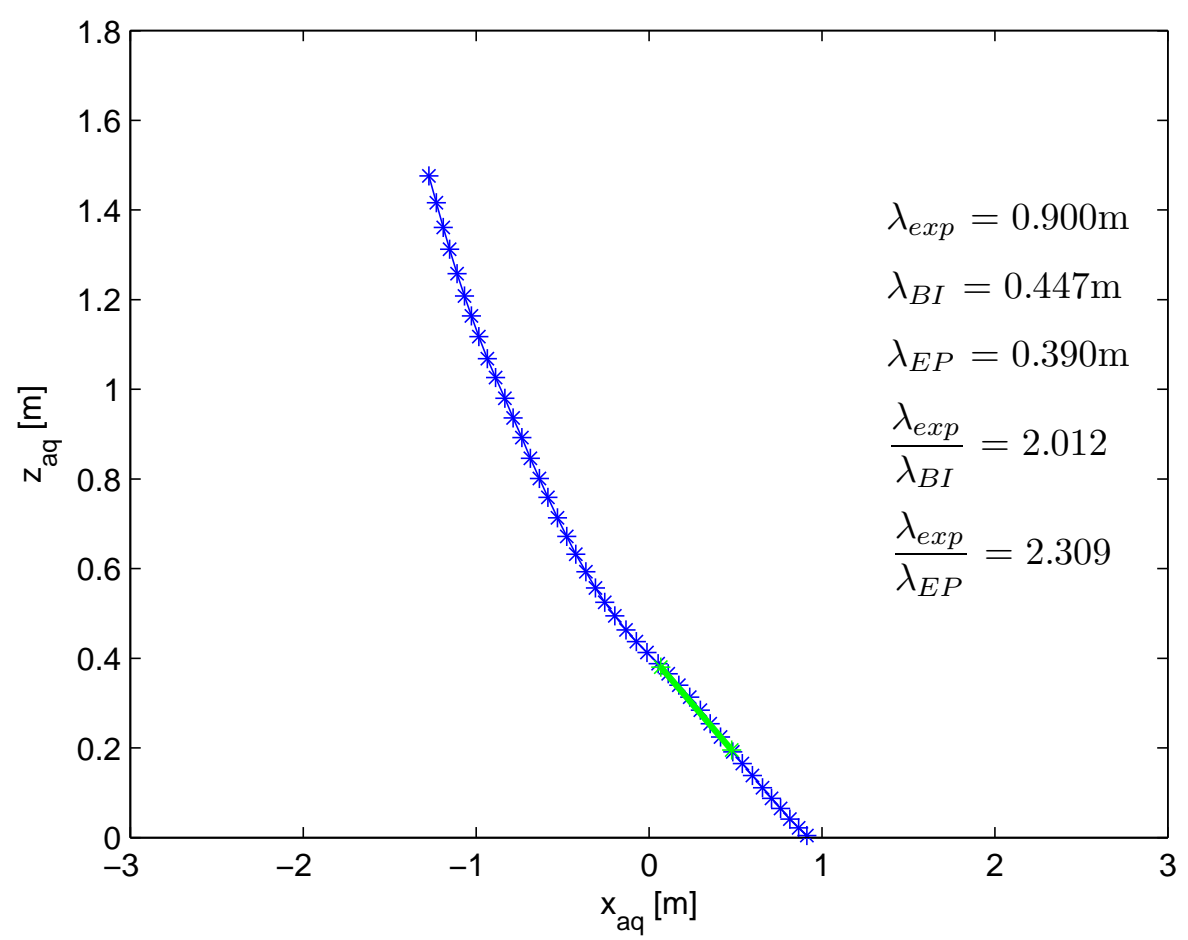

Figura 6.30: Exemplo de determinação do comprimento de onda de flexão, caso F125A050T70.

A Tabela 6.3 sugere a mesma conclusão do caso do item anterior, referente a um lançamento similar à da presente condição, no que tange ao ângulo de topo, cuja importância foi descrita naquele item.

Note, portanto, a relação praticamente de 2:1 entre o comprimento de onda medido diretamente a partir dos ensaios e o resultado previsto pela formulação analítica desenvolvida em (Aranha et al., 2001), o que implica em uma relação de $\approx \frac{4}{3}$, quando 0 resultado auferido é comparado com a previsão de Ramos Jr \& Pesce (2003).

Tabela 6.3: Comprimentos de onda de flexão do caso F125A050T70

\begin{tabular}{|c|c|c|c|c|c|c|c|c|c|}
\hline Caso/Sentido & $\begin{array}{c}\lambda_{\exp } \\
{[\mathrm{m}]}\end{array}$ & $\begin{array}{c}\lambda_{B I} \\
{[\mathrm{~m}]}\end{array}$ & $\frac{\lambda_{\exp }}{\lambda_{B I}}$ & $\begin{array}{c}\lambda_{E P} \\
{[\mathrm{~m}]}\end{array}$ & $\frac{\lambda_{\exp }}{\lambda_{E P}}$ & $\begin{array}{c}\mathrm{BI} \\
\text { torção } \\
{[\mathrm{m}]}\end{array}$ & $\frac{\lambda_{\exp }}{\lambda_{B I_{T}}}$ & $\begin{array}{c}\mathrm{EP} \\
\text { torção } \\
{[\mathrm{m}]}\end{array}$ & $\frac{\lambda_{\exp }}{\lambda_{E P_{T}}}$ \\
\hline F125A050T70SAH & 0,889 & 0,445 & 1,999 & 0,390 & 2,282 & 0,667 & 1,333 & 0,584 & 1,522 \\
\hline \hline
\end{tabular}

Os dois próximos casos que serão apresentados, e que findam o presente capítulo, foram denominados "casos especiais", dadas as diferenças apresentadas entre os resultados dos ensaios e as previsões analíticas, principalmente pelas dificuldades encontradas na determinação dos valores experimentais das ondas de flexão (embora as formulações não apontassem para a possibilidade de ocorrência de compressão dinâmica), bem como a confirmação de ocorrência do fenômeno, via Anflex. 


\subsubsection{Apresentação e discussão dos resultados do caso F125A050T80}

Preliminarmente à apresentação dos resultados auferidos nos ensaios, cabe recuperar as previsões analítico-numéricas de compressão dinâmica no modelo flexível, referente ao presente caso (vide Figuras 6.1 e 6.14).

Ambas as formulações analíticas consideradas, previram a não-ocorrência de compressão dinâmica para o caso F125A050T80, o que é condizente com os casos para as mesmas frequência e amplitude, para os ângulos de topo iguais a $70^{\circ} \mathrm{e} 85^{\circ}$.
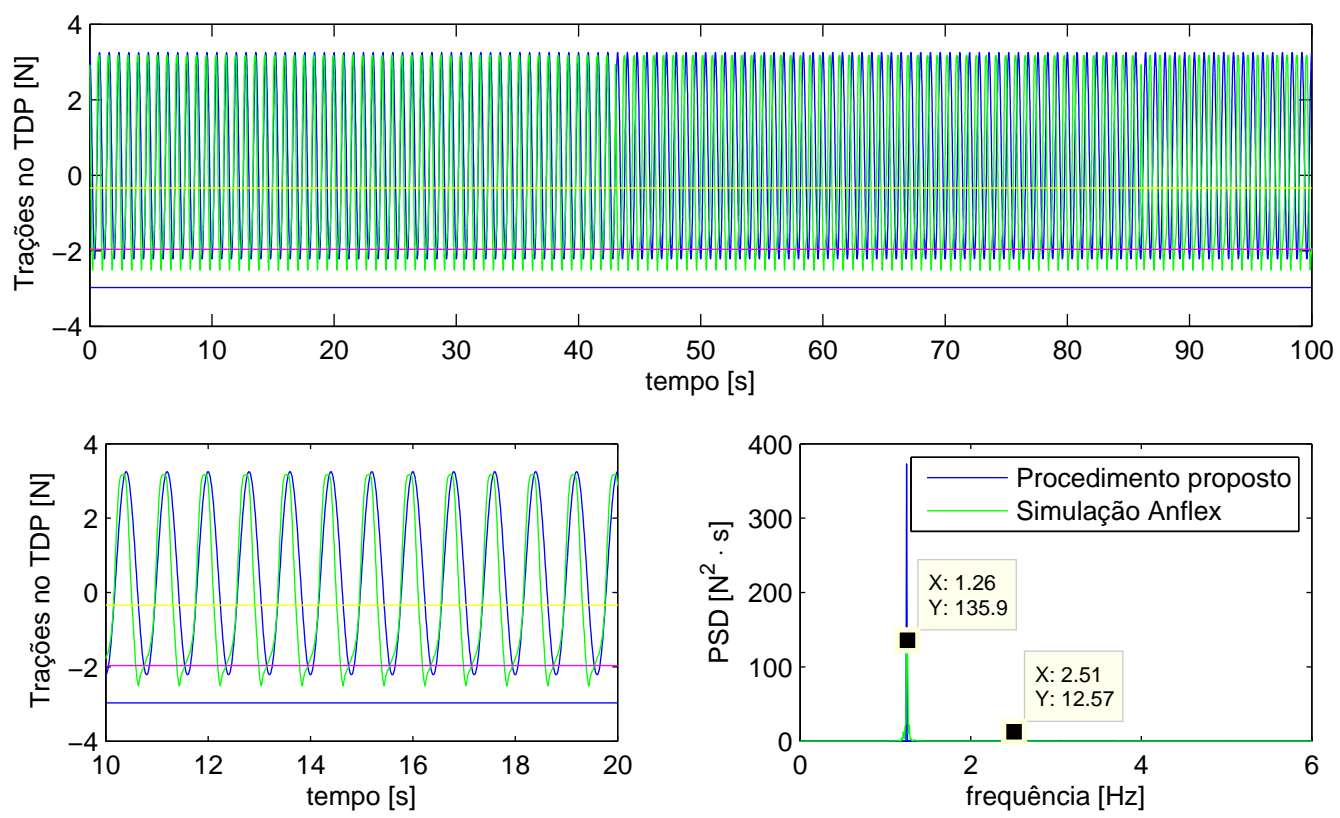

Figura 6.31: Série de deslocamentos na direção normal e respectivo PSD para o caso F125A050T80.

Pela Figura 6.31 é possível afirmar que, dadas as condições de lançamento do modelo e as avaliações apresentadas anteriormente, a linha apresentou compressão dinâmica, mesmo que de maneira sutil:

1. embora a tração dinâmica, proposta por Aranha \& Pinto (2001) e utilizada no procedimento proposto, não ultrapasse a respectiva carga crítica (vínculo biapoiado), seu valor mínimo ultrapassou a carga crítica para vigas curvas engastadaspinadas (que, pelo exemplos anteriores, é mais adequada para esse caso);

2. os mínimos valores da série temporal de trações obtidas via Anflex apresentamse no mesmo nível das previsões teóricas, também ultrapassando a carga crítica da condição "EP";

3. o PSD apresenta um pico bastante proeminente e associado a grandes energias na frequência de excitação, além de um pico bem menor na frequência correspondente ao primeiro super-harmônico, embora a uma energia cerca de dez vezes menor. 
Ainda que esses resultados possam induzir à conclusão de que houve compressão dinâmica no modelo, é necessária a confirmação pelo sistema de monitoramento.

Nesse sentido, cabe uma nota importante: mesmo sem a previsão de ocorrência do fenômeno a partir do procedimento proposto, as formulações analíticas podem ser utilizadas para determinação da suposta carga crítica, sob as condições de lançamento e excitação do presente caso. Assim, considerando as condições vinculares "Bl" e "EP", as previsões apontariam para comprimentos de onda de flexão, respectivamente, de $0,263 \mathrm{~m}$ e $0,325 \mathrm{~m}$ - os menores valores aventados nas situações avaliadas.

Posto isso, a determinação dos comprimentos das ondas de flexão, a partir dos experimentos, demandou a modificação da rotina elaborada para esse fim, de maneira que o procedimento anteriormente descrito passasse a buscar por comprimento de onda, ao invés de semicomprimentos de onda. O resultado obtido, para um quadro específico, é apresentado na Figura 6.32.

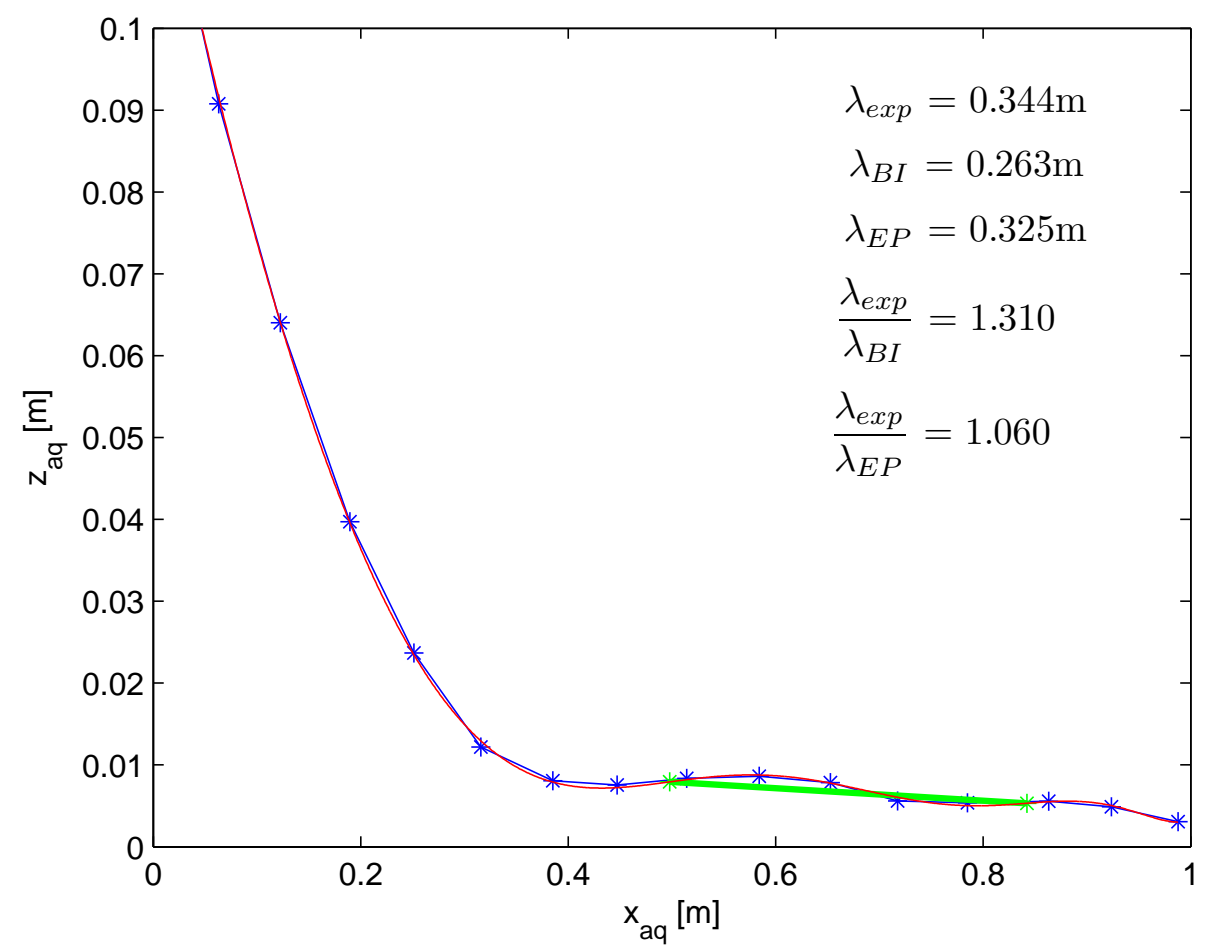

Figura 6.32: Determinação do comprimento de onda de flexão, caso F125A050T80.

Embora o resultado auferido seja condizente com as conclusões dos casos anteriores, em que, para lançamentos aproximadamente verticais, os comprimentos de onda de flexão esperados guardam uma relação próxima da unidade com relação à previsão para a condição de vínculo "EP", a proximidade da onda identificada com relação ao solo e ao ponto de ancoragem não permite que aquelas conclusões sejam estendidas ao presente caso, ainda que a possibilidade pareça bastante razoável. 


\subsubsection{Apresentação e discussão dos resultados do caso F125A100T85}

O último caso a ser apresentado e avaliado, F125A100T85, também foi denominado um "caso especial", pelos mesmos motivos do caso F125A050T80, mostrado no item anterior. Por esse motivo, inicie-se a presente análise pela série temporal de trações no TDP, a fim de avaliar se alguma das cargas críticas de flambagem foi ultrapassada pelas trações mínimas analítica ou determinadas via Anflex.
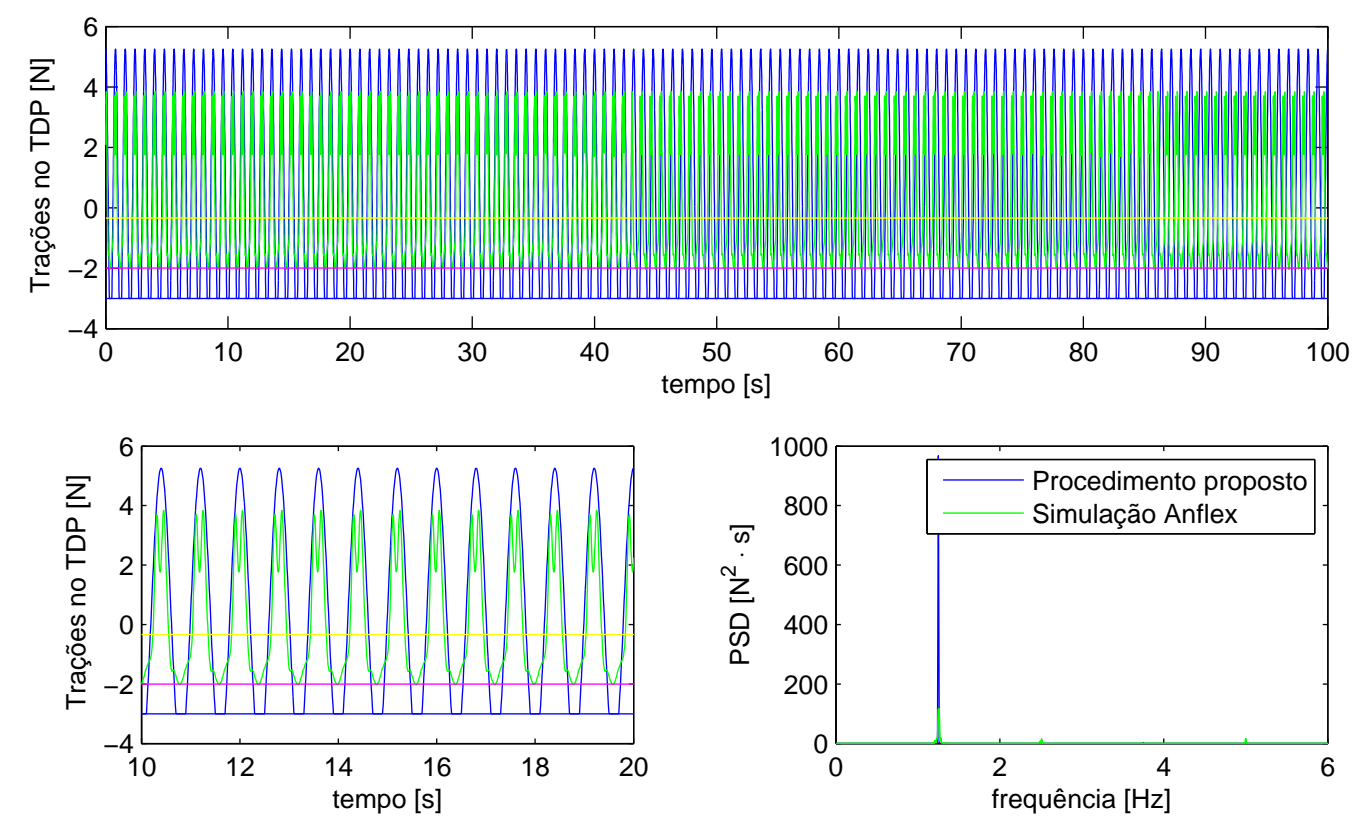

Figura 6.33: Série de deslocamentos na direção normal e respectivo PSD para o caso F125A100T85.

Conforme se pode depreender da Figura 6.33, os valores mínimos das trações obtidos via Anflex não ultrapassaram nenhuma das cargas críticas analíticas, embora tenham ficado bastante próximas do valor estabelecido pela formulação para o vínculo "EP", como era esperado. Dessa feita, é possível considerar que o modelo, nesse caso, estava na iminência de sofrer compressão dinâmica.

A despeito do fato de aproximações numéricas serem passíveis de erros, por exemplo de truncamento, tal hipótese, a priori, não será considerada. Cumpre lembrar que a determinação das cargas críticas demandavam, obrigatoriamente, a determinação aproximada de raízes de equações transcendentais. A Figura 6.33, tal como elaborada, utilizou, propositalmente, a aproximação desenvolvida na Seção 3.3.2, baseada em uma Função de Richards, para determinação da carga crítica de flambagem para vigas curvas biapoiadas. Por esse motivo, essa figura apresenta saturação do sinal temporal teórico das trações no TDP, o que foi conseguido artificialmente e não corresponde à solução exata proposta por Aranha et al. (2001), conforme apresentado na Figura 6.1 (mapeamento de possibilidades de compressão dinâmica para os casos ensaiados, em conjunto com os resultados das observações pelo sistema de monitoramento óptico). 
A despeito dessas considerações, a princípio, nenhum caso de compressão dinâmica foi observado para o presente caso. Entretanto, nesse sentido, cabem algumas observações pertinentes. Pelas formulações teóricas, os valores esperados para os comprimentos das ondas de flexão, sob as condições vinculares "Bl" e "EP", seriam iguais a, respectivamente, $0,263 \mathrm{~m}$ e $0,322 \mathrm{~m}$. Sob um ângulo de topo inicial de cerca de $85^{\circ}$, existe uma dificuldade intrinseca em registrar esses valores, mesmo com a demonstrada eficácia do procedimento proposto.

Ora, os resultados e argumentações apresentados até aqui seriam suficientes para considerar que, sob quaisquer meios de avaliação, o modelo não apresentou compressão dinâmica nos ensaios relativos ao presente caso. Entretanto, essas considerações não explicam os padrões observados para as Figuras 6.34 a 6.36.

Observando-se a Figura 6.34, por exemplo, é possível perceber que, em alguns poucos instantes, alguns alvos dispostos sobre o modelo apresentaram deslocamentos bastante apreciáveis, o que seria indicativo de possibilidade de ocorrência de compressão dinâmica, nos primeiros 20s da amostra apresentada.

Os retratos de fase dos movimentos nas direções tangente e normal à linha central do modelo, apresentados nas Figuras 6.35 e 6.36, sugerem o mesmo indício: o de que ocorreu compressão dinâmica no ensaio em questão, em níveis bastante sutis, praticamente imperceptíveis, o que poderia sugerir que os resultados são inconclusivos.

Neste ponto, um comentário é digno de nota: os níveis de velocidades e deslocamentos atingidos correspondem aos mesmo verificados para o caso F080A100T85, para o qual foi verificada compressão dinâmica (vide Figuras 6.24 e 6.25).

A fim de suportar tal asserção, foi confeccionada a Figura 6.37, uma ampliação seletiva da Figura 6.33, contendo apenas as séries temporais de trações no TDP e respectivas densidades espectrais de potência, obtidas somente via Anflex, para o caso considerado. Com relação à carga crítica de compressão, apenas a determinada pela formulação referente ao vínculo "EP" é apresentada.

Nessa situação, bastante específica, pode ser percebido um certo nível de compressão dinâmica. Mesmo sem apresentar sinais claros de saturação da assinatura temporal das trações no TDP, o respectivo PSD apresenta, em níveis relativamente baixos de energia, picos na frequência de excitação, bem como nas suas frequências múltiplas inteiras, típicas da ocorrência de compressão dinâmica.

Por esses motivos, é prudente considerar os resultados para o presente caso como inconclusivos. 


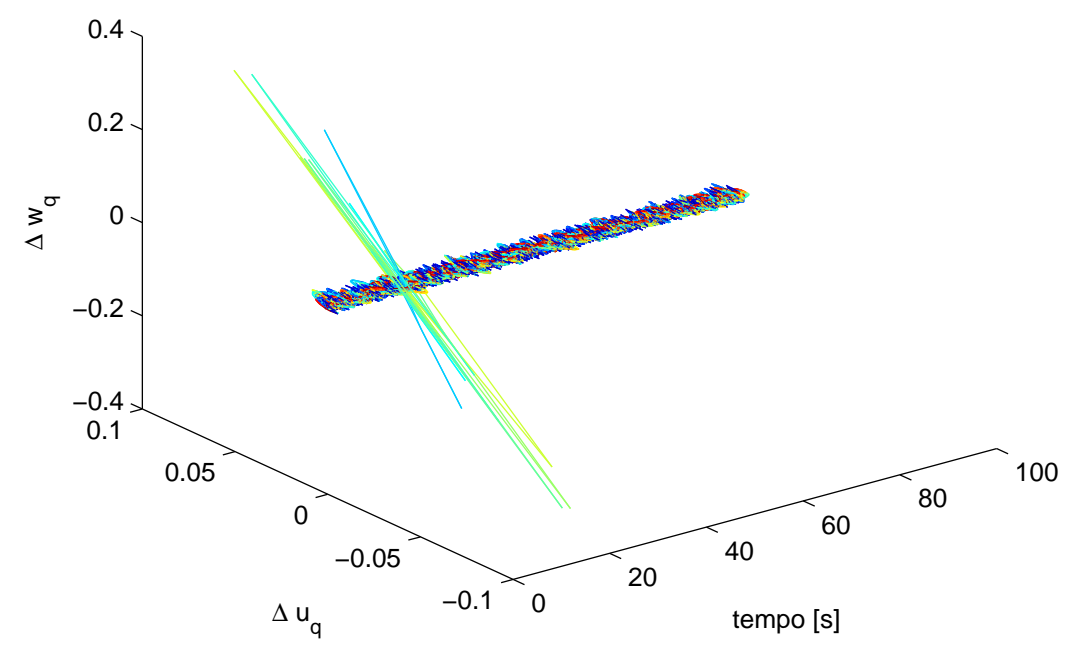

Figura 6.34: Evolução temporal dos deslocamentos tangencial e normal para o caso F125A100T85.

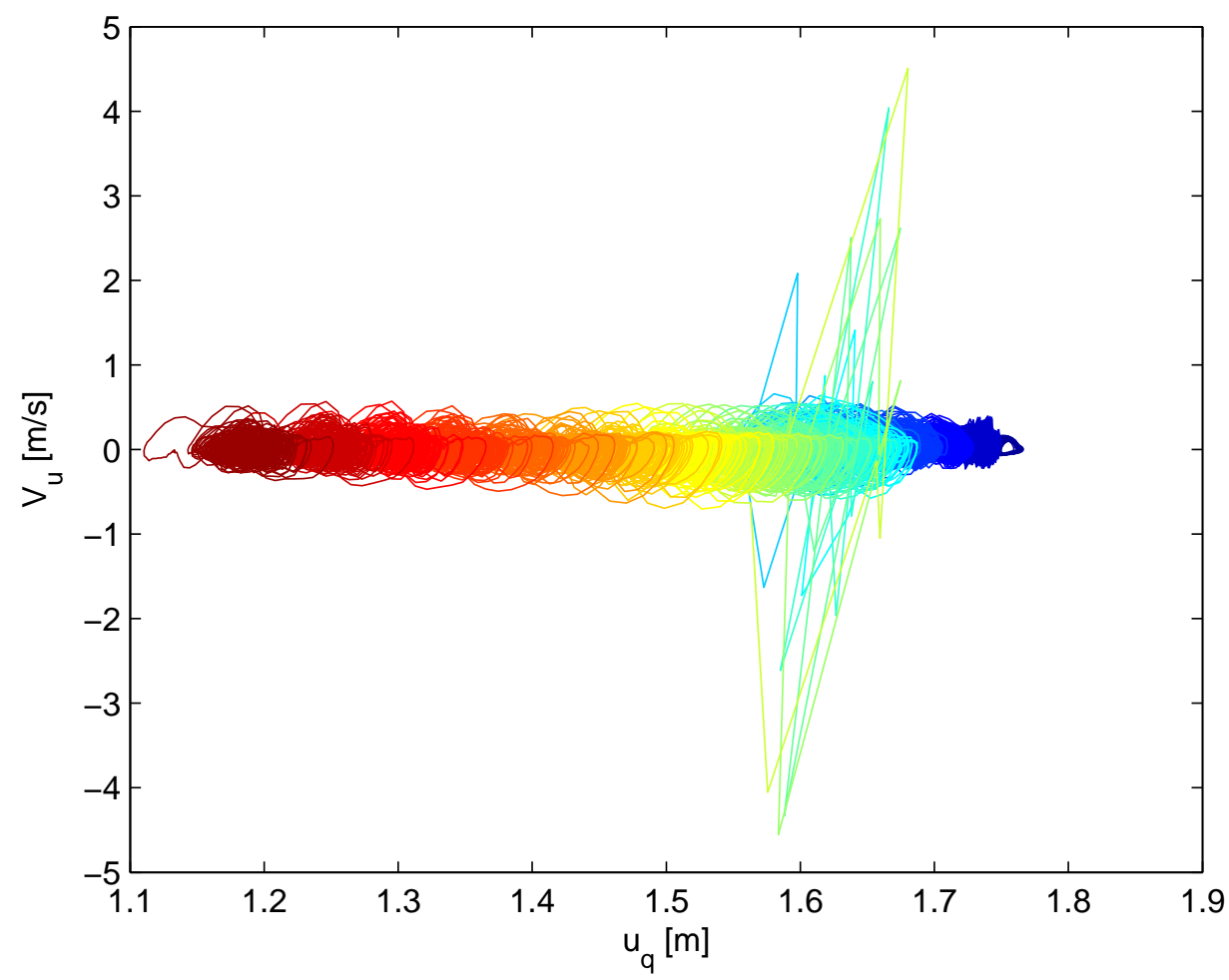

Figura 6.35: Retratos de fases dos alvos submersos, caso F125A100T85, direção tangente. 


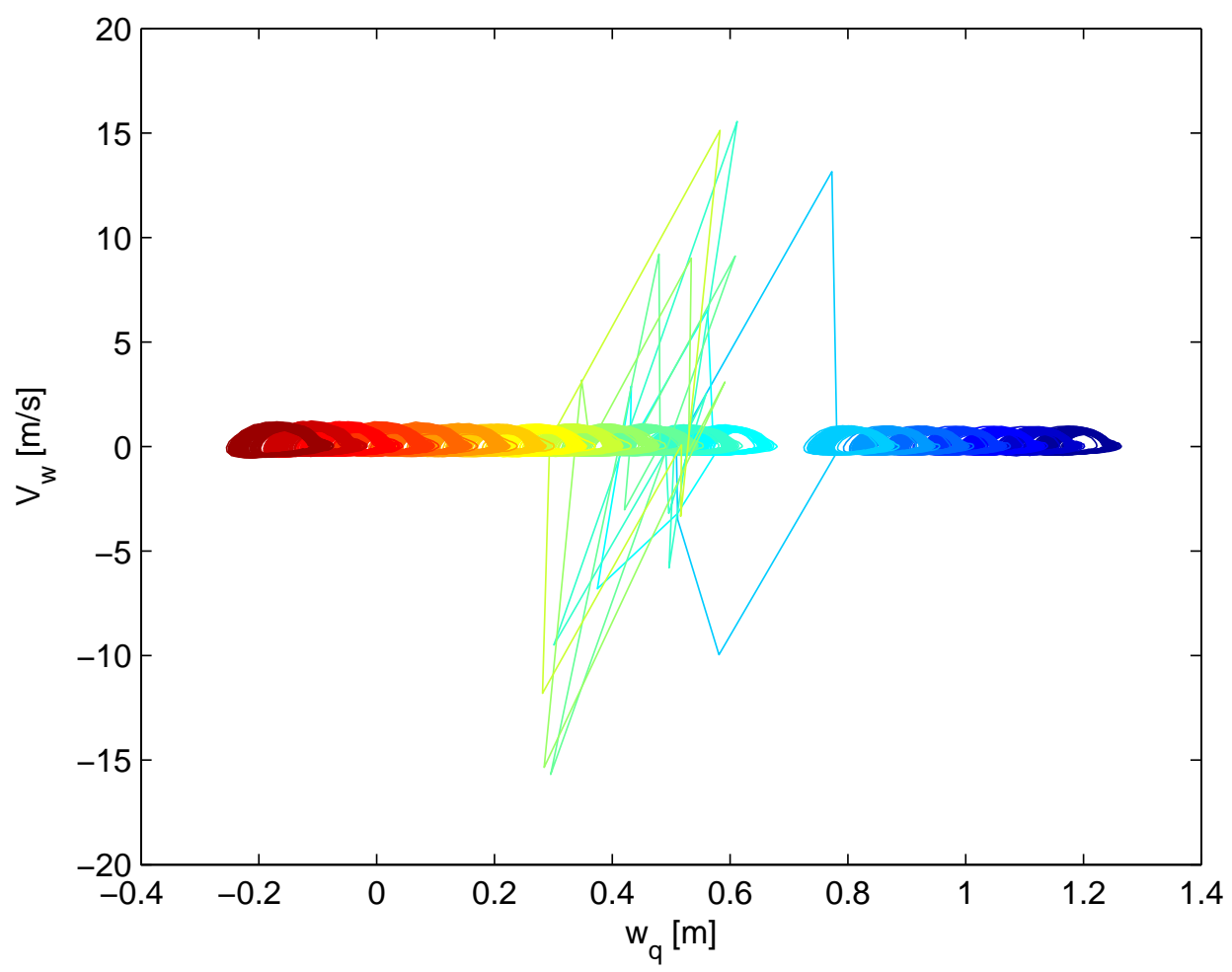

Figura 6.36: Retratos de fases dos alvos submersos, caso F125A100T85, direção normal.
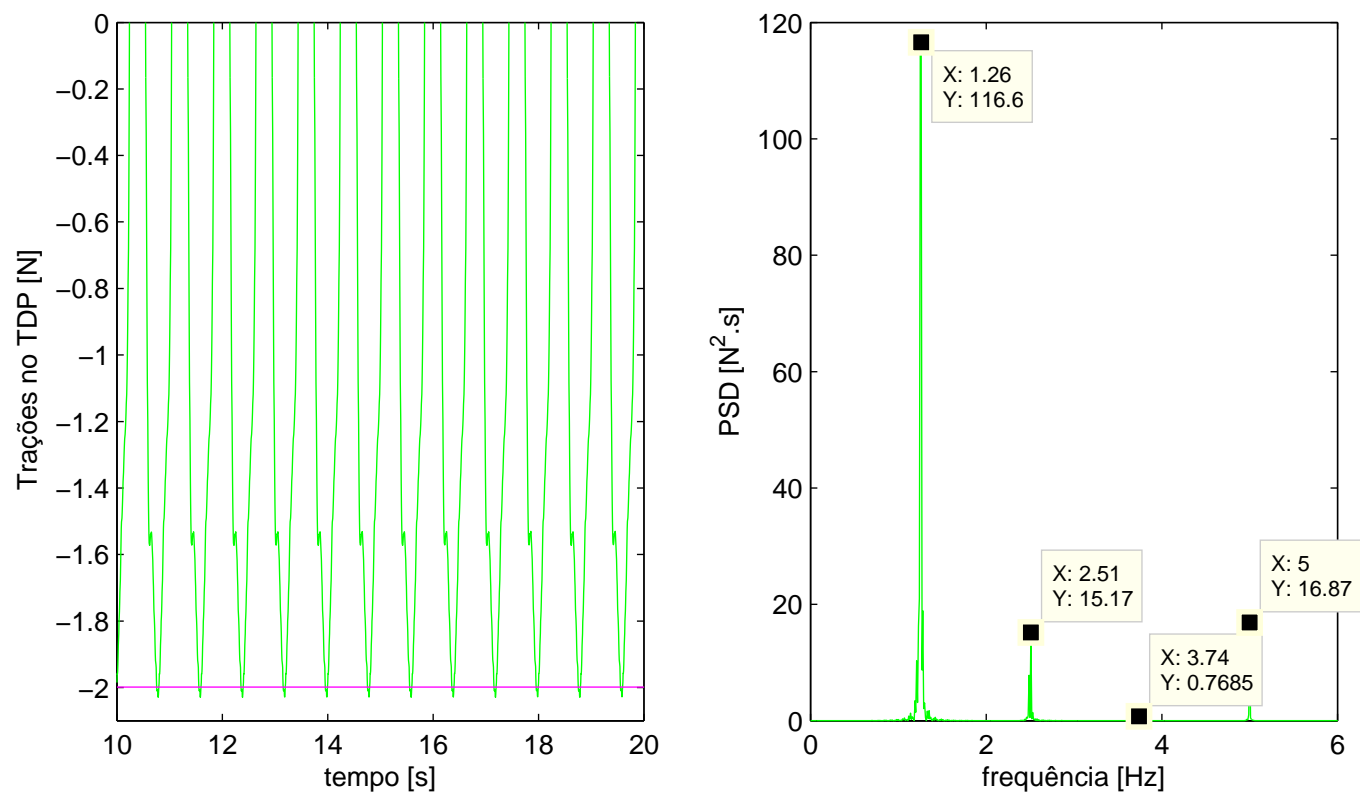

Figura 6.37: Detalhe das séries temporais de trações, caso F125A100T85, via Anflex. 



\title{
Capítulo 7
}

\section{Conclusões e Perspectivas}

\author{
"Não busques a vaidade de ter o melhor que os outros. \\ Contenta-te com a tarefa gloriosa de tentares ser melhor que és. \\ Que tu não sejas o teu limite de crescimento, \\ mas o teu grande questionamento, o teu grande interrogador". \\ (Henrique de Souza Filho, o Henfil)
}

Previamente à apresentação das conclusões relativas ao presente trabalho, cabe fazer um breve relato do texto como um todo.

O principal objetivo da presente tese era a elaboração de um conjunto de procedimentos que permitisse a determinação experimental dos comprimentos das ondas de flexão, geradas em um modelo de riser flexível lançado em catenária direta, durante a ocorrência do fenômeno conhecido como compressão dinâmica.

Para atingir esse objetivo, além do levantamento bibliográfico realizado, foram utilizados programas específicos para as avaliações estática e dinâmica de risers (Anflex e Poliflex), bem como rotinas numéricas próprias, confeccionadas a partir das formulações relativas ao tema estudado. Nesse sentido, um ganho marginal deste trabalho consistiu no desenvolvimento de uma formulação analítica, baseada em trabalhos de outros autores, para determinação da carga crítica de flambagem de vigas curvas, sob as condições de contorno mais adequadas aos vínculos físicos utilizados nos ensaios realizados.

Após a determinação racional e sistemática de uma matriz de ensaios que propiciou o estudo adequado de um grande número de casos de compressão dinâmica, os resultados experimentais foram comparados com as demais abordagens citadas.

Foram realizados 72 ensaios que combinavam 3 frequências de excitação de topo $(0,80 \mathrm{~Hz} ; 1,00 \mathrm{~Hz} ;$ e $1,25 \mathrm{~Hz}), 3$ amplitudes de movimento prescrito $(0,050 \mathrm{~m} ; 0,100 \mathrm{~m}$; e $0,200 \mathrm{~m}), 4$ ângulos de topo estáticos $\left(65^{\circ} ; 70^{\circ} ; 80^{\circ}\right.$; e $\left.85^{\circ}\right)$ e 2 sentidos de rotação (anti-horário e horário). O procedimento elaborado foi utilizado para a elaboração da matriz de ensaios, para a previsão do número de ocorrências de compressão dinâmica nos experimentos realizados e para as confrontações com os resultados auferidos. 
Realizados os ensaios, é possível concluir que os objetivos planejados foram cumpridos com êxito. A determinação dos comprimentos das ondas de flexão, a partir do uso de um sistema de monitoramento óptico pouco invasivo, permitiu a obtenção direta desses valores, o que, de per si, pode ser considerado como um resultado inédito.

No que tange as hipóteses consideradas, foi comprovada a tese de que essas ondas de flexão podem ser descritas pela equação de dispersão formulada, ad hoc, por Aranha et al. (2001), mesmo que com algumas ressalvas.

Para lançamentos mais verticais ( $80^{\circ}$ e $85^{\circ}$, principalmente, mas também para diversos dos casos a $70^{\circ}$ ), o equacionamento original para determinação da carga crítica de flambagem de vigas curvas mostrou-se menos eficiente que a formulação desenvolvida no âmbito da presente tese, corroborando sua importância, mesmo que marginal. Nos casos em que a formulação desenvolvida se apresentou como mais adequada, os valores dos comprimentos das ondas de flexão obtidos experimentalmente apresesentaram diferenças relativas menores que $2 \%$, em média. Nessas situações, os efeitos relacionados com a tridimensionalidade intrínseca ao fenômeno mostraram ser de pequena monta e os valores previstos por Aranha et al. (2001) raramente foram superiores a $10 \%$.

Por outro lado, para lançamentos sob os menores ângulos de topo considerados $\left(65^{\circ}\right.$ e $70^{\circ}$ ), a formulação original pareceu mais adequada, principalmente pela influência da rigidez geométrica e os efeitos dinâmicos relacionados à ancoragem utilizada.

Ainda assim, cabem algumas ressalvas e considerações. Sob lançamentos a ângulos de topo de $65^{\circ}$ e $70^{\circ}$, os feitos da tridimensionalidade do fenômeno apresentaramse mais evidentes, de sorte que nem a correção proposta por Ramos Jr \& Pesce (2003) foi capaz de recuperar os valores determinados experimentalmente para os comprimentos das ondas de flexão.

Tomando como base os valores previstos na formulação desenvolvida em (Aranha et al., 2001), a correção proposta em (Ramos Jr \& Pesce, 2003), que considera os feitos relativos à rigidez torcional, prevê comprimentos das ondas de flexão $50 \%$ maiores. Os resultados obtidos a partir dos experimentos realizados mostraram que uma eventual correção, levando em conta outros fatores, como os relacionados a movimentos laterais do modelo, deveria ser da ordem de $100 \%$.

Postas todas essas considerações, é possível afirmar tacitamente que os objetivos da presente tese foram integralmente cumpridos, trazendo novas discussões e resultados com relação ao entendimento do fenômeno de compressão dinâmica.

A originalidade inerente ao presente trabalho consistiu na mensuração direta das ondas de flexão geradas durante a compressão dinâmica.

Com respeito às hipóteses aventadas, foi demonstrada a tese de que, consideradas as devidas ressalvas e correções, os comprimentos dessas ondas podem ser determinados analiticamente, a partir da equação de dispersão que, anteriormente era suposta verdadeira, e que, com este trabalho, adquiriu suporte experimental. 
Para futuros trabalhos, realizados a partir da presente tese, é possível sugerir alguns caminhos possíveis.

As formulações utilizadas no âmbito deste trabalho foram, essencialmente, bidimensionais, quando o fenômeno é, claramente, afetado por aspectos tridimensionais. As correções promovidas, nesse sentido, foram baseadas em um equacionamento que leva em consideração apenas os efeitos de torção na linha. A promoção de correções ou formulações adicionais, incorporando esses efeitos, bem como a interação com o solo e estudos a respeito da interação entre os meios, ar e água, devem enriquecer ainda mais o trabalho.

Com relação à intrumentação, mesmo que incorporando efeitos indesejáveis, seria interessante a utilização de extensometria, principalmente na região do TDZ, tomando os devidos cuidados com relação à definição das propriedades exatas do modelo assim confeccionado.

No que tange ao fenômeno em si, sugere-se a averiguação da influência de correnteza atuando sobre o modelo, bem como da pressurização interna, comum aos risers reais. Nesse sentido, formulações que levem em consideração esse último fator ainda são necessárias.

Ainda com respeito às condições de ensaio, a generalização dos movimentos de topo pode trazer maior clareza aos mecanismos que regem o fenômeno de compressão dinâmica, bem como aproximam o modelo físico-matemático da realidade das operações de produção de petróleo e gás.

Por fim, a consideração de efeitos relativos à interação com a unidade flutuante, bem como a coexistência de outros fenômenos, por exemplo o VIV, tornarão a modelagem mais rica e próxima da realidade. 



\section{Bibliografia}

Abramowitz, M. \& Stegun, I. A. (1965). Handbook of mathematical functions: with formulas, graphs, and mathematical tables, volume 55. Dover publications.

ABS (2008). Guide for building and classing: subsea riser systems. American Bureau of Shipping, 2008.

Amarante, R. M. (2011). Estudo da estática e dinâmica de linhas, sob configuração de catenária, através da identificação geométrica, processamento e análise de imagens digitais. Master's thesis, Mestrado (Dissertação), Escola Politécnica, Universidade de São Paulo, São Paulo, SP, Brasil.

Andrade, B. L. R. (1993). Aproximação algébrica para tensão dinâmica em linhas de amarração. Sociedade Brasileira de Engenharia Naval.

API (1993). Recommended Practice for Design, Selection, Operation and Maintenance of Marine Drilling Riser Systems. American Petroleum Institute, 1993.

API (2009). Recommended Practice 2RD. American Petroleum Institute, 2009.

Aranha, J. A. P., Martins, C. A., \& Pesce, C. P. (1997). Analytical approximation for the dynamic bending moment at the touchdown point of a catenary riser. International Journal of Offshore and Polar Engineering, 7(4).

Aranha, J. A. P., Pesce, C. P., Martins, C. A., \& Andrade, B. L. R. (1993). Mechanics of submerged cables: asymptotic solution and dynamic tension. In The Third International Offshore and Polar Engineering Conference: International Society of Offshore and Polar Engineers.

Aranha, J. A. P. \& Pinto, M. O. (2001). Dynamic tension in risers and mooring lines: an algebraic approximation for harmonic excitation. Applied ocean research, 23(2), 63-81.

Aranha, J. A. P., Pinto, M. O., \& Da Silva, R. M. C. (2001). On the dynamic compression of risers: an analytic expression for the critical load. Applied ocean research, 23(2), 83-91.

Bernitsas, M. (1981). Static analysis of marine risers. Technical report, University of Michigan. 
Bernitsas, M., Kokarakis, J., \& Imron, A. (1985). Large deformation three-dimensional static analysis of deep water marine risers. Applied ocean research, 7(4), 178-187.

Bernitsas, M. M. \& Papalambros, P. (1980). Design optimization of risers under generalized static load. International Marine Technology (IMT 80-109).

Bertram, V. (2012). Practical ship hydrodynamics. Elsevier.

Bortolan Neto, L. (2009). Análise numérica de dutos sujeitos à flambagem. Master's thesis, Dissertação (Mestrado), Escola de Engenharia, Universidade Federal do Paraná, Paraná, Brasil.

Buckingham, E. (1914). On physically similar systems; illustrations of the use of dimensional equations. Physical Review, 4(4), 345-376.

Burcharth, H. F. \& Frigaard, P. (1989). Wave loads on cylinders. In CEEC COMETT Seminar on Wave and lce Forces on offshore structures.

Burgess, J. J. \& Triantafyllou, M. S. (1988). The elastic frequencies of cables. Journal of sound and vibration, 120(1), 153-165.

Burke, B. (1974). An analysis of marine risers for deep water. Journal of petroleum technology, 26(4), 455-465.

Campos, L. A. \& Martins, C. (2001). Nonlinear dynamic response of a steel catenary riser at the touch-down point. In Proceedings of the 11th International Offshore and Polar Engineering Conference, volume 6 (pp. 234-238).

Carbo, R. M., Smith, R. W. M., \& Poese, M. E. (2010). Stability of the parametrically excited damped inverted pendulum: Theory and experiment. The Journal of the Acoustical Society of America, 128, 1623.

Chakrabarti, S. \& Frampton, R. (1982). Review of riser analysis techniques. Applied Ocean Research, 4(2), 73-90.

Chang, S. P., Park, J. I., \& Lee, K. C. (2008). Nonlinear dynamic analysis of spatially suspended elastic catenary cable with finite element method. KSCE Journal of Civil Engineering, 12(2), 121-128.

Chatjigeorgiou, I. K. \& Mavrakos, S. A. (2009). The 3d nonlinear dynamics of catenary slender structures for marine applications. Nonlinear Dynamics. ISBN, (pp. 978953).

Clauss, G., Lehmann, E., \& Östergaard, C. (1992). Offshore structures. Springer.

Conway, H. D. \& Lo, C. F. (1967). Further studies on the elastic stability of curved beams. International Journal of Mechanical Sciences, 9(10), 707-718. 
Costa, S. N. J. (2006). O modelo de timoshenko em vigas elásticas, estruturas offshore e nanotubos de carbono através da resposta fundamental de valor inicial. Master's thesis, Doutorado (tese), Instituto de Matemática, Universidade Federal do Rio Grande do Sul, Porto Alegre, RS, Brasil.

Datye, D. V. (2010). On the calibration of coefficients of friction for pipeline-seabed interaction. In ASME 2010 29th International Conference on Ocean, Offshore and Arctic Engineering (OMAE) (pp. 539-543).: American Society of Mechanical Engineers (ASME).

De Sousa, J. R. M., Ellwanger, G. B., \& Lima, E. C. P. (2004). Modelo tridimensional de elementos finitos para el análisis de esfuerzos de tubos flexibles. In IMME Proceedings, Caracas, v. 42, n. 2.

DNV (2010a). Global permormance analysis of deepwater floating structures. Det Norske Veritas, 2010.

DNV (2010b). Offshore Standard - Dynamic Risers. Det Norske Veritas, 2010.

El-Bassiouny, A. F. \& Abdel-Khalik, A. (2009). Periodic solutions and stability for a weakly damped nonlinear mathieu equation. Physica Scripta, 81(1), 015008.

Emam, S. A. \& Nayfeh, A. H. (2004). On the nonlinear dynamics of a buckled beam subjected to a primary-resonance excitation. Nonlinear Dynamics, 35(1), 1-17.

Fischer, W. (1966). Design of floating vessel drilling riser. Journal of Petroleum Technology, 18(3), 272-280.

Franzini, G. R. (2013). Investigação experimental do escoamento ao redor de cilindros inclinados, sujeitos a condiõees de contorno assimétricas nas extremidades. PhD thesis, Universidade de São Paulo, 2013.

Fujarra, A. L. C., Simos, A. N., \& Yamamoto, N. Y. (2003). Dynamic compression of rigid and flexible risers: Part i-experimental results. In ASME 2003 22nd International Conference on Offshore Mechanics and Arctic Engineering (pp. 359-364).: American Society of Mechanical Engineers.

Gay Neto, A. (2012). Estabilidade estrutural da configuração estática de risers em catenária. PhD thesis, Escola Politécnica, Universidade de São Paulo.

Gere, J. \& Timoshenko, S. (2001). Mechanics of materials. brooks. Cole, Pacific Grove, $C A$, (pp. 187-270).

Gonçalves, A. A. (2009). Análises globla e local de umbilicais com tubos de aço. PhD thesis, Mestrado (Dissertação), COPPE, Universidade Federal do Rio de Janeiro, Rio de Janeiro, RJ, Brasil. 
Han, S. M., Benaroya, H., \& Wei, T. (1999). Dynamics of transversely vibrating beams using four engineering theories. Journal of Sound and Vibration, 225(5), 935-988.

Harris, L. M. (1972). An introduction to deepwater floating drilling operations. Office of Scientific and Technical Information, U.S. Department of Energy.

Hobbs, R. E. (1981). Pipeline buckling caused by axial loads. Journal of Constructional Steel Research, 1(2), 2-10.

Irvine, H. M. \& Caughey, T. K. (1974). The linear theory of free vibrations of a suspended cable. Proceedings of the Royal Society of London. A. Mathematical and Physical Sciences, 341(1626), 299-315.

Journèe, J. M. J. \& Massie, W. W. (2001). Offshore hydrodynamics. Delft University of Technology, 4, 38.

Kamel, M. M. \& Hamed, Y. S. (2010). Nonlinear analysis of an elastic cable under harmonic excitation. Acta mechanica, 214(3), 315-325.

LABFit (2011). Lab fit curve fitting software (nonlinear regression and treatment of data program) v 7.2.48. Disponível em www. labfit.net, acessado em 28/11/2014.

Larsen, C. M., Troesch, A., Pesce, C. P., \& Chatjigeorgiou, I. K. (2012). Mathematical modeling of marine structures. Journal of Applied Mathematics.

Leira, B. J. (2010). Review and verification of marine riser analysis programs. PhD thesis, Norwegian University of Science and Technology (NTNU), Department of Marine Technology, Norway, 2010.

Lenci, S. \& Rega, G. (2000). Periodic solutions and bifurcations in an impact inverted pendulum under impulsive excitation. Chaos, Solitons \& Fractals, 11(15), 24532472.

Lestari, W. \& Hanagud, S. (2001). Nonlinear vibration of buckled beams: some exact solutions. International journal of solids and structures, 38(26), 4741-4757.

Lo, C. \& Conway, H. (1967). The elastic stability of curved beams. International Journal of Mechanical Sciences, 9(8), 527-538.

Love, A. E. H. (1906). A treatise on the mathematical theory of elasticity. University Press.

Macagno, E. O. (1971). Historico-critical review of dimensional analysis. Journal of the Franklin Institute, 292(6), 391-402.

Mansur, A. L. (2011). Análise dinâmica não-linear de viga esbelta semi-infinita sob flexão composta com contato unilateral em apoio elástico: uma aplicação ao estudo de vibrações de risers em catenária. Master's thesis, Mestrado (Dissertação), Escola Politécnica, Universidade de São Paulo, São Paulo, SP, Brasil. 
Mazzilli, C. E. N. \& Sanches, C. T. (2010). Non-linear normal modes of a fixed-moored offshore catenary riser. ODEA 2010, Università Politecnica delle Marche.

McCann, D., Smith, F., \& O'Brien, P. (2003). Guidelines for compression modeling in flexible risers for deepwater applications. In Offshore Technology Conference.

Merino, H. E. M., de Sousa, J. R. M., Magluta, C., \& Roitman, N. (2010). Numerical and experimental study of a flexible pipe under torsion. In ASME 2010 29th International Conference on Ocean, Offshore and Arctic Engineering (pp. 911-922).: American Society of Mechanical Engineers.

Nayfeh, A. H. \& Mook, D. T. (2008). c. Wiley-VCH.

Newman, J. N. (1977). Marine hydrodynamics. MIT press.

Oliveira, W. C. (2004). Um processo de refinamento do método dos elementos finitos para análise de vibrações livre de vigas. SIMMEC 2004, VI Simpósio Brasileiro de Mecânica Computacional.

Patel, M. H. \& Seyed, F. B. (1995). Review of flexible riser modelling and analysis techniques. Engineering structures, 17(4), 293-304.

Pereira, F. R. (2010). Confrontação numérico-experimental da dinâmica de sistema flutuante, considerando seu acoplamento com linhas de produção. PhD thesis, Mestrado (Dissertação), Escola Politécnica, Universidade de São Paulo, São Paulo, SP, Brasil.

Perkins, N. C. (1992). Modal interactions in the non-linear response of elastic cables under parametric/external excitation. International Journal of Non-Linear Mechanics, 27(2), 233-250.

Pesce, C., Aranha, J., Martins, C., Ricardo, O., \& Silva, S. (1998a). Dynamic curvature in catenary risers at the touch down point region: an experimental study and the analytical boundary-layer solution. International Journal of Offshore and Polar Engineering, 8(4).

Pesce, C., Fujarra, A., Simos, A., \& Tannuri, E. (1999). Analytical and closed form solutions for deep water riser-like eigenvalue problem. In The Proceedings of the International Offshore and Polar Engineering Conference: International Society of Offshore and Polar Engineers.

Pesce, C. P. (1997). Mecânica de Cabos e Tubos Submersos Lançados em "Catenária": uma abordagem analítica e experimental. PhD thesis, Tese de Livre Docência. EPUSP, 1997.

Pesce, C. P., Aranha, J. A. P., \& Martins, C. A. (1998b). Soil rigidity effect in the touchdown boundary-layer of a catenary riser: static problem. In The 19988 th International Offshore and Polar Engineering Conference. Part 2(of 4) (pp. 207-213). 
Pesce, C. P. \& Martins, C. (2005). Chapter 7: Numerical computation of riser dynamics. In: Numerical Models in Fluid Structure Interaction, Chakrabarti, S. K., Vol. 42, pp. 253-309.

Pesce, C. P., Martins, C. d. A., \& da Silveira, L. M. (2006). Riser-soil interaction: Local dynamics at tdp and a discussion on the eigenvalue and the viv problems. Journal of offshore mechanics and Arctic engineering, 128(1), 39-55.

Porciuncula, S., Ribeiro, J., \& Gonçalves, R. (1999). Marlim field: risers, flowlines and umbilicals developed. In Offshore Technology Conference.

Quéau, L. M., Kimiaei, M., \& Randolph, M. F. (2013). Dimensionless groups governing response of steel catenary risers. Ocean Engineering.

Ramos Jr, R. (2001). Modelos analíticos no estudo do comportamento estrutural de tubos flexíveis e cabos umbilicais. PhD thesis, Tese de Doutorado. EPUSP, 2001.

Ramos Jr, R. \& Pesce, C. P. (2003). A stability analysis of risers subjected to dynamic compression coupled with twisting. Journal of Offshore Mechanics and Arctic Engineering, 125, 183.

Rateiro, F., Pesce, C. P., Gonçalves, R. T., Franzini, G. R., Fujarra, A. L. C., Salles, R., \& Mendes, P. (2012). Risers model tests: Scaling methodology and dynamic similarity. In Proceedings of the 22nd International Ocean and Polar Engineering Conference (ISOPE 2012), Rhodes: ISOPE-2012-TPC-06633.

Ribeiro, E., Roveri, F., \& Mourelle, M. (1998). Dynamic compression buckling in flexible riser. In Offshore Technology Conference.

Savi, M. A. (2006). Dinâmica não-linear e caos. Editora E-papers.

Sertã, O. B., Longo, C. E. V., \& Roveri, F. E. (2001). Riser systems for deep and ultra-deepwaters. In Offshore Technology Conference.

Si-Yu, C. \& Jin-Yuan, T. (2008). Study on a new nonlinear parametric excitation equation: Stability and bifurcation. Journal of Sound and Vibration, 318(4), 1109-1118.

Simos, A. \& Pesce, C. (1997). Mathieu stability in the dynamics of tip tether considering variable tension along the length. Transactions on Built Environment, 29, 175-186.

Simos, A. N. \& Fujarra, A. L. C. (2006). Dynamic compression of rigid and flexible risers: experimental and numerical results. Journal of offshore mechanics and Arctic engineering, 128, 233.

Simos, A. N., Fujarra, A. L. C., \& Alves, K. H. (2003). Dynamic compression of rigid and flexible risers: Part ii-comparison of theoretical and experimental results. In ASME 2003 22nd International Conference on Offshore Mechanics and Arctic Engineering (pp. 351-357).: American Society of Mechanical Engineers. 
Starossek, U. (1994). Cable dynamics-a review. Structural Engineering International, 4(3), 171-176.

Takafuji, F. C. M. (2011). Dinâmica tridimensional de risers. Master's thesis, Tese (Doutorado), Escola Politécnica, Universidade de São Paulo, São Paulo, SP, Brasil.

Taylor, N. \& Gan, A. B. (1984). Regarding the buckling of pipelines subject to axial loading. Journal of Constructional Steel Research, 4(1), 45-50.

Timoshenko, S. P., Gere, J. M., \& Prager, W. (1962). Theory of elastic stability. Journal of Applied Mechanics, 29, 220.

Torres, A. L., Mourelle, M., Senra, S., Gonzalez, E., \& Lima, J. M. (2008). Influence of fatigue issues on the design of scrs for deepwater offshore brazil. In Offshore Technology Conference.

Tsukada, R. I. (2009). Comportamento dinâmico de riser rígido em catenária devido ao VIV em águas profundas. $\mathrm{PhD}$ thesis, Unicamp.

Veritas, N. (1991). Environmental conditions and environmental loads. Det Norske Veritas.

Wei, P., Bingnan, S., \& Jinchun, T. (1999). A catenary element for the analysis of cable structures. Applied Mathematics and Mechanics, 20, 220. 



\section{Apêndice A}

\section{Sobre os vigas, cabos e colunas}

O objetivo deste apêndice é apresentar algumas das equações e aproximações teóricas muito utilizadas na estática de risers, em geral como forma de facilitar desenvolvimentos analíticos. Além disso, tais elementos estruturais são comumente empregados em rotinas e programas computacionais para avaliação da dinâmica de risers, baseados na discretização em elementos desses subsistemas oceânicos.

\section{A.1 Deflexões em vigas, cabos e colunas}

Seja uma viga-coluna, de comprimento $L$ e rigidez flexional $E I$, inicialmente reta, sujeita a uma carga compressiva $P$ e a um carregamento lateral distribuído e constante $q(x)=q$, conforme ilustrado na Figura A.1. A equação diferencial que rege seu equilíbrio, na situação ilustrada, é dada pela Equação A.1. A dedução dessa equação é bastante conhecida. Para o leitor que deseje maiores detalhes, consultar, por exemplo, (Timoshenko et al., 1962).

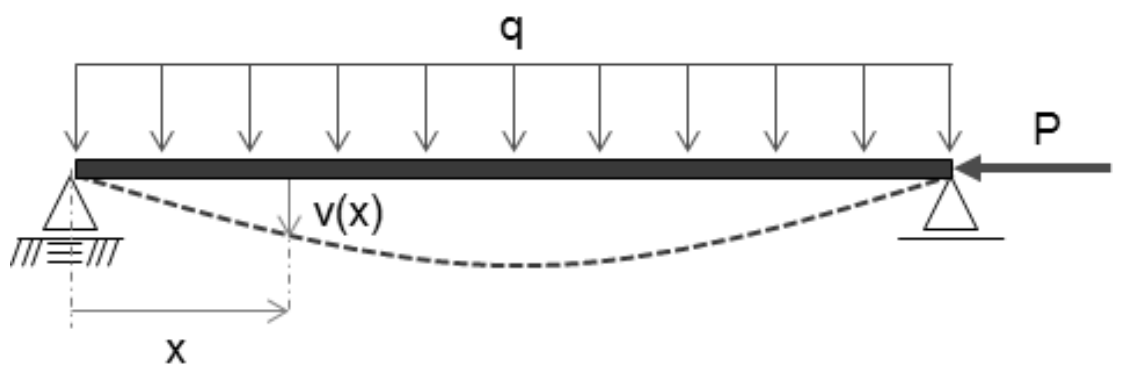

Figura A.1: Viga-coluna sob carregamento axial compressivo e carga lateral distribuída.

$$
E I \cdot \frac{d^{4}}{d x^{4}} v(x)+P \cdot \frac{d^{2}}{d x^{2}} v(x)=q
$$


Dado que a Equação A.1 não é homogênea, sua solução é apresentada pela combinação linear de duas soluções: uma referente à parcela homogênea dessa equação, outra relativa a uma solução particular, polinomial (sugerida pelo fato de $q$ ser constante). Assim, a solução geral da Equação A.1, considerando as condições de contorno de uma viga biapoiada, é dada pela Equação A.2.

$$
v(x)=\frac{q}{k^{2} P} \cdot \frac{1-\cos (k L)}{\operatorname{sen}(k L)} \cdot \operatorname{sen}(k x)+\frac{q}{k^{2} P} \cdot \cos (k x)-\frac{q L}{2 P} \cdot x-\frac{q}{k^{2} P}+\frac{q}{2 P} \cdot x^{2}
$$

onde $k=\sqrt{\frac{P}{E I}}$.

Nesse ponto, cabe uma nota. As situações em que $P=0$ (ausência de compressão), $q=0$ (compressão pura sem carregamento distribuído, definição de viga) e/ou $E I=0$ (definição de cabo) são casos singulares da Equação A.1 e, portanto, não são contemplados pela solução expressa em A.2, necessitando de estudos à parte.

Os resultados para cada um desses casos são apresentados a seguir.

- Solução da Equação A.1, para $P=0, E I \neq 0$ e $q \neq 0$ (deflexão de viga sob carregamento lateral constante, na ausência de carga compressiva):

$$
v(x)=\frac{q \cdot x}{24 E I} \cdot\left(L^{3}-2 L \cdot x^{2}+x^{3}\right)
$$

- Solução da Equação A.1, para $q=0, E I \neq 0$ e $P \neq 0$ (deflexão de viga sem carregamento lateral sob compressão):

$$
v(x)=A \cdot \operatorname{sen}\left(\frac{\pi}{L} \cdot x\right)
$$

Essa solução é válida somente para o primeiro modo de flambagem, que ocorre quando a carga de compressão $P$ ultrapassa o valor crítico ${ }^{1} P_{c r}=\frac{\pi^{2} E I}{L^{2}}$.

- Solução da Equação A.1, para $E I=0, P=0$ e $q \neq 0$ (geometria de um cabo sob carregamento lateral constante):

$$
v(x)=\frac{1}{A} \cdot[\cosh (A x)-1]
$$

onde $A=\frac{q}{T_{0}}$ e $T_{0}$ é a tração horizontal constante a que o cabo fica sujeito.

\footnotetext{
${ }^{1}$ Nos casos em que existe carga de compressão, seja de uma viga-coluna ou uma coluna, a carga crítica assume os mesmos valores, para cada modo natural de vibração específico.
} 
A solução dada pela Equação A.5 corresponde à equação da catenária inextensível, ou seja, sem a consideração dos efeitos devidos à rigidez axial $E A$.

Note que não faz sentido estudar um cabo sob compressão axial, dada sua rigidez flexional desprezível.

Entretanto, se a compressão for substituída por uma tração suficientemente grande para que o peso próprio (carregamento lateral $q$ ) provoque uma deflexão ínfima, o elemento estrutural passa a ser denominado por cabo (ou corda), cujo equilíbrio é dado pela Equação A.7, solução da Equação A.6, que rege o equilíbrio de um cabo.

$$
T_{0} \cdot \frac{d^{2}}{d x^{2}} v(x)=\left(m-m_{a}\right) \cdot g
$$

onde $m$ é a massa linear própria (no ar), enquanto $m_{a}$ é a chamada massa adicional, se for o caso de um cabo imerso.

Integrando analiticamente a Equação A.6 duas vezes e utilizando as condições de contorno apresentadas anteriormente, determina-se a deflexão do cabo biapoiado em questão, dadas as considerações feitas ${ }^{2}$ :

$$
v(x)=\frac{\left(m-m_{a}\right) \cdot g}{2 T_{0}} \cdot x^{2}-\left[\frac{\left(m-m_{a}\right) \cdot g}{2 T_{0}} \cdot L\right] \cdot x
$$

Um caso que, para os efeitos deste trabalho, apresenta interesse particular, é o cabo sujeito às seguinte condições de contorno: $v(0)=0$ e $v(L)=L D A$, onde $L$ é o vão entre os apoios e $L D A$ é a lâmina d'água (ou cota vertical do segundo apoio). Nesse caso:

$$
v(x)=\frac{\left(m-m_{a}\right) \cdot g}{2 T_{0}} \cdot x^{2}+\left[\frac{L D A}{L}-\frac{\left(m-m_{a}\right) \cdot g}{2 T_{0}} \cdot L\right] \cdot x
$$

\section{A.1.1 Validade da aproximação de um riser pela teoria de cabos}

A apresentação dos equacionamentos do item precedente, permite uma breve discussão a respeito da validade da aproximação de um riser em catenária direta (free hanging) pelas soluções de deflexões apresentadas, a partir de dois exemplos retirados da literatura, quais sejam: Ribeiro et al. (1998) e Simos \& Fujarra (2006).

No que tange à vertente analítica, é comum a modelagem do riser como um cabo (extensível ou não), principalmente para o estudo da sua estática, embora com algumas ressalvas. Ressalte-se, por exemplo, o fato de que um cabo possui rigidez flexional desprezível, o que implica na sua incapacidade de resistir a qualquer carga compressão axial.

\footnotetext{
${ }^{2} \mathrm{~A}$ possível utilização da condição de contorno $\frac{d}{d x} v(0)=0$, só faz sentido para deflexões muito pequenas, em que a flecha é diminuta, com relação ao comprimento indeformado do cabo, de maneira que o resultado obtido é uma aproximação parabólica do caso geral (catenária). A validade dessa aproximação é discutida, por exemplo, em (Irvine \& Caughey, 1974), para relações flecha-vão menores ou iguais 1:8.
} 
De acordo com Bernitsas (1981), nos casos em que a tração efetiva é negativa, a aproximação do riser por um cabo não é válida. Até para valores positivos de tração efetiva, a aproximação pode ser inadequada no entorno de suas extremidades. A correção proposta por Bernitsas (1981) consiste na aplicação pontual de momentos nessas extremidades, a fim de adequar os valores de curvatura nesses pontos.

Um riser, por seu turno, resiste naturalmente a um certo nível de compressão até flambar, dado que possui rigidez flexional, cuja importância é mais notadamente importante em suas extremidades (topo e TDP), de maneira que, nessas regiões, a teoria de vigas é mais adequada, por incorporar esse efeito.

A título de informação, a correção proposta por Bernitsas (1981), consiste na incorporação de momentos pontuais às extremidades, o que corresponde, em última análise, à consideração de rijezas flexionais nessas regiões. Esse procedimento é equivalente à aproximação do riser, nessas regiões, por elementos de vigas.

As Figuras A.2 e A.3 ilustram, respectivamente, a geometria estática de um SCR (o mesmo utilizado no estudo de Ribeiro et al. (1998)) e de um riser em catenária direta (estudo realizado por Simos \& Fujarra (2006), em uma escala de 100:1).

Para ambos os casos, a estática foi avaliada a partir de seis métodos distintos, quais sejam: a catenária inextensível, ver (Pesce, 1997); a catenária extensível, vide (Patel \& Seyed, 1995); uma aproximação parabólica para pequenas relações flecha-vão, apresentada em (Irvine \& Caughey, 1974); uma aproximação parabólica menos robusta que a anterior (Teoria de Cabos); uma solução numérica, via Anflex; e a incorporação local, nas extremidades, do efeito da rigidez flexional (Teoria de Vigas).

As Figuras A.2 e A.3 permitem algumas conclusões interessantes, referentes ao presente tópico, além de outras que serão melhor discutidas na seção 2.2.

Primeiramente, note-se que, em ambos os casos, as diferenças devidas à rigidez axial são de pequena monta: as curvas em azul e vermelho (relativas respectivamente às formulações de Pesce (1997) e Patel \& Seyed (1995)) são praticamente coincidentes, apresentando pequenas diferenças apenas no topo.

O motivo para tanto é facilmente explicável. Em (Patel \& Seyed, 1995) a elasticidade da linha é introduzida de maneira a corrigir a cota vertical do topo, a partir do TDP. Assim, naturalmente, a maior diferença apresentar-se-á no topo da linha.

Como esperado, tantos os resultados provenientes da Teoria de Cabos, quanto os da aproximação parabólica sugerida por Irvine \& Caughey (1974), são menos aderentes às demais curvas, embora sejam tanto melhores, quanto menos verticais forem as linhas.

Na Figura A.2, a a solução obtida a partir da Teoria de Cabos é a menos precisa, seguida pela solução obtida com a abordagem proposta por Irvine \& Caughey (1974). Já na Figura A.3, os resultados de ambas as abordagens apresentam maior aderência com as demais curvas.

Cabe notar que as Figuras A.2 e A.3 não são representações gráficas em uma mesma 


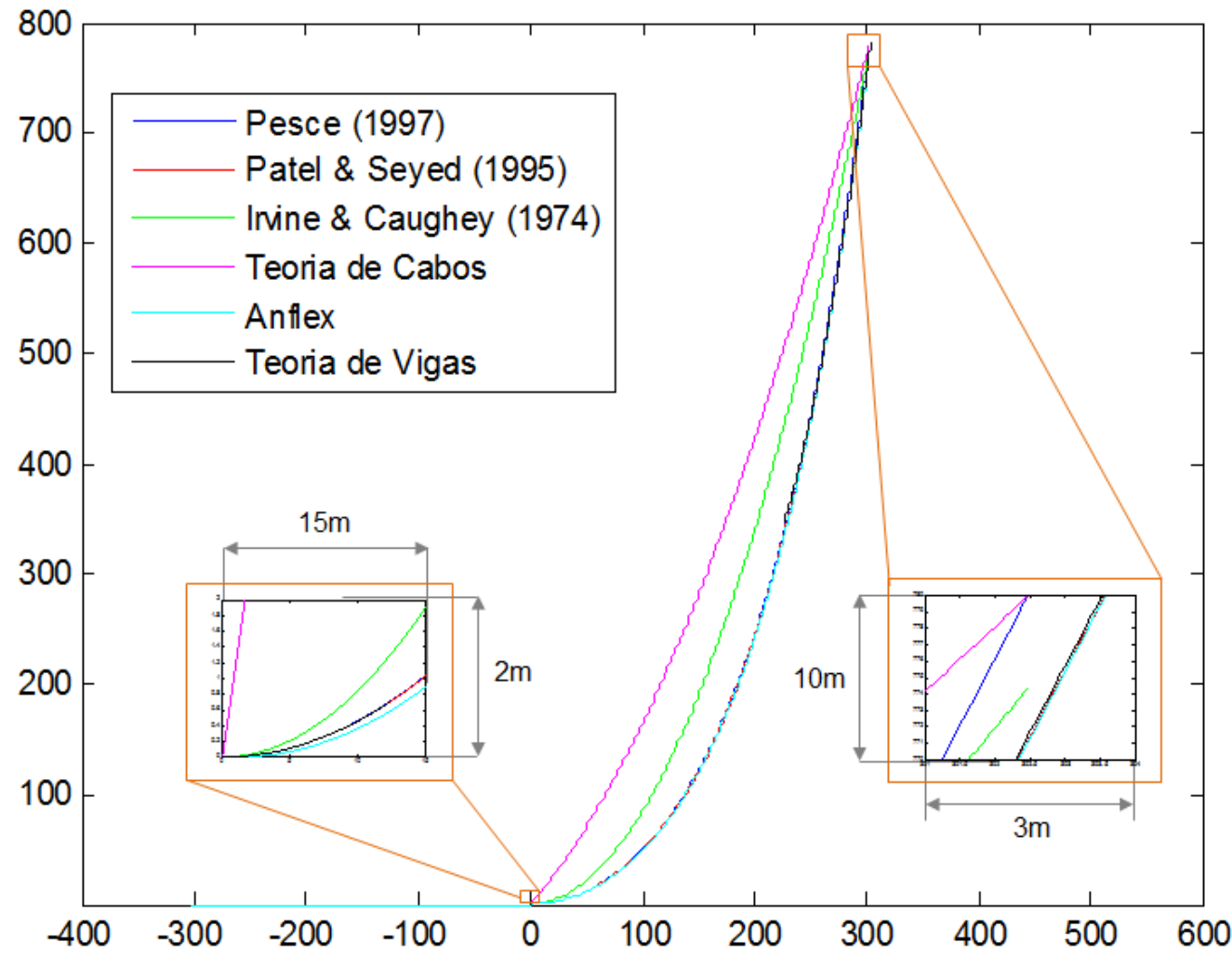

Figura A.2: Comparação da geometria estática de um SCR, por 6 métodos distintos. Baseado no SCR estudado em (Ribeiro et al., 1998).

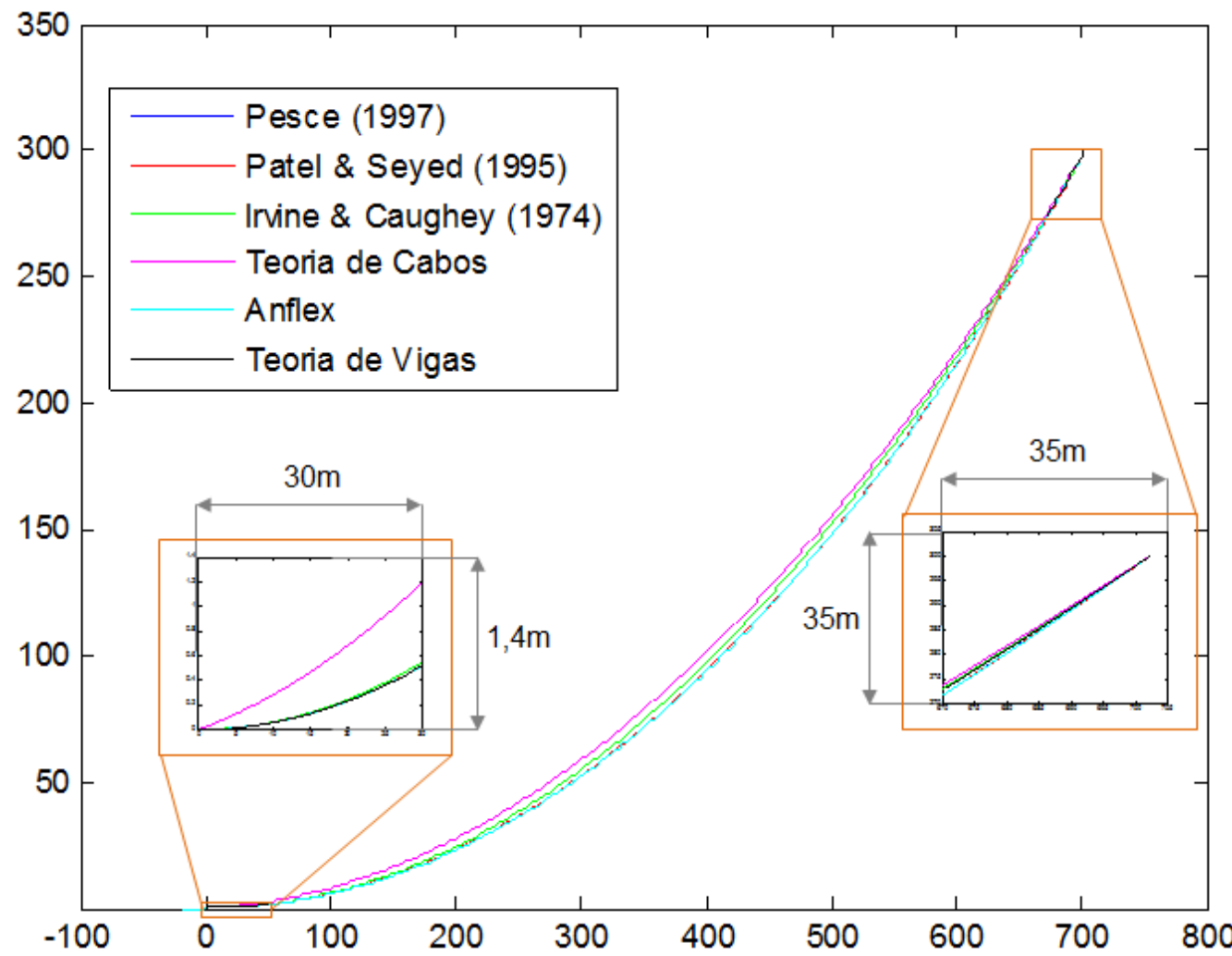

Figura A.3: Comparação da geometria estática de um riser em catenária direta, por 6 métodos distintos. Baseado no riser estudado em (Simos \& Fujarra, 2006). 
escala, o que leva a um maior cuidado ao avaliar na avaliação dos resultados.

Além disso, as abordagens teóricas referentes às aproximações parabólicas da Teoria de Cabos e de (Irvine \& Caughey, 1974) não são solução da equação proposta pela teoria de vigas, por exemplo, sendo capaz de suprir apenas duas das quatro condições de contorno da solução exata.

Essas aproximações são tanto melhores, quanto menos vertical for a linha, ou seja, quando o ângulo de topo, com respeito à horizontal, for menor (vide o exemplo da Figura A.3), de maneira que a relação flecha-vão seja menor.

Segundo Irvine \& Caughey (1974), a validade de sua aproximação se restringe aos casos em que essa relação é menor ou igual a $\frac{1}{8}(=0,125)$, o que não é o caso de nenhuma das duas situações representadas graficamente pelas Figuras A.2 e A.3, cujas relações flecha-vão são, respectivamente, iguais a 1,34 e 0,21.

A Teoria de Vigas (retome-se a Equação A.3), por outro lado, foi utilizada apenas como aproximação da estática de ambas as linhas avaliadas nas suas extremidades, mostrando bastante aderência nessas regiões.

O programa Anflex foi utilizado para modelar ambos os casos estáticos avaliados, servindo como referência para as comparações realizadas.

Com respeito às comparações entre todas as abordagens utilizadas, valem, portanto, as seguintes notas:

- As abordagens de Pesce (1997) e Patel \& Seyed (1995) pouco diferem entre si e com relação ao Anflex, destacando-se como as mais precisas, em termos de assumir esse último como base mais confiável;

- A modelagem pelo Anflex depende, em demasia, das condições de rigidez do solo, podendo justificar as discrepâncias apresentadas na região do TDZ. Cabe citar que, no caso da Figura A.2, a rigidez do solo utilizada foi a mesma apresentada em (Ribeiro et al., 1998);

- Mesmo para relações flecha-vão maiores que $\frac{1}{8}$ as aproximações parabólicas não são severamente discrepantes com relação às demais, principalmente no caso da Figura A.3, na qual esse relação é muito menor que a do outro caso. Ainda assim, seu uso deve se restringir às hipóteses previstas;

- A Teoria de Vigas aproxima de forma bastante acurada as extremidades da linha, de modo que sua representação é praticamente coincidente com a obtida com o Anflex. Em todos os casos apresentados neste trabalho foram utilizados elementos de viga nas modelagens consideradas;

- Especificamente com relação ao topo, as abordagens consideradas apresentaram pequenas diferenças entre si, da ordem de $20 \mathrm{~cm}$ para o caso avaliado por Ribeiro et al. (1998) e 10cm para o caso estudado por Simos \& Fujarra (2006). 
Essas avaliações e conclusões serão de grande auxílio para a elaboração do procedimento proposto para a determinação racional da matriz de ensaios referente à vertente experimental da presente tese, bem como no uso desse procedimento para as avaliações dos resultados provenientes dos experimentos realizados, daí sua presença neste contexto.

A seguir, serão apresentados os equacionamentos para as vibrações de cada um dos elementos estruturais apresentados, a fim de antecipar algumas conclusões interessantes no que tange à dinâmica de risers, mesmo partindo de relações relativamente simples.

\section{A.1.2 Vibrações em vigas, cabos e colunas}

O presente tópico tem como objetivo apresentar o problema das vibrações em vigas, cabos e colunas. Para tanto, incorpore-se um termo inercial à Equação A. $1^{3}$, de maneira que a deflexão passe a ser uma função não apenas da posição relativa, mas também do tempo, ou seja, $v=v(x, t)$.

Alternativamente, também é possível a introdução de um termo de dissipação (modelagem de Rayleigh ou, mais usualmente no âmbito da Engenharia Oceânica, o modelo de Morrison), o que foge ao escopo da presente seção, dado que não interfere no principal objetivo do estudo de vibrações livres (avaliação dos modos e frequências naturais de vibração). Decorre, então, que:

$$
\mu \cdot \frac{\partial^{2}}{\partial t^{2}} v(x, t)+E I \cdot \frac{\partial^{4}}{\partial x^{4}} v(x, t)+P \cdot \frac{\partial^{2}}{\partial x^{2}} v(x, t)=q(x, t)
$$

onde $\mu$ pode ser a massa própria da viga-coluna ou sua massa própria imersa, considerando a respectiva massa adicionada.

Utilizando a hipótese de movimento síncrono ${ }^{4}$, é possível utilizar o método da separação de variáveis, de maneira que, é possível escrever:

$$
v(x, t)=V(x) \cdot T(t)
$$

A substituição da Equação A.10 nas correspondentes equações homogêneas de deflexão apresentadas na seção anterior resulta em:

$$
\frac{-\frac{d^{2}}{d t^{2}} T(t)}{T(t)}=f[V(x)]=C=\text { constante }
$$

\footnotetext{
${ }^{3}$ Essa possibilidade é permitida graças ao Princípio de d’Alembert, postulado pelo físico e matemático francês Jean le Rond d'Alembert (1717-1783), que, em uma de suas formas, afirma que a soma do trabalho virtual total realizado pelas forças que agem sobre um dado corpo com as forças inerciais atuantes sobre o mesmo é nula para deslocamentos reversíveis.

${ }^{4} \mathrm{O}$ movimento é considerado síncrono se todas as seções transversais da viga-coluna vibram na mesma frequência.
} 
Da Equação A.11 decorrem duas equações diferenciais ordinárias e independentes, uma em função da posição $x$ ao longo da viga-coluna, outra como função do tempo t. A análise da primeira delas, função de $t$, é imediata e trivial, mostrando o caráter harmônico da resposta, em função do tempo:

$$
\frac{d^{2}}{d t^{2}} T(t)+\omega^{2} \cdot T(t)=0
$$

$\operatorname{com} \omega^{2}=C$.

A outra parcela da Equação A.11 resulta na expressão para carga crítica, dada por:

$$
P_{E}=k^{2} \cdot E I
$$

O uso do símbolo $P_{E}$ para a carga de compressão, em detrimento do usual $P_{c r}$, tem por objetivo distingui-lo de outra expressão que será apresentada adiante e utilizada ao longo do restante deste trabalho, além da associação mnemônica que pode ser feita com relação à sua autoria original, atribuída a Leonhard P. Euler:

$$
P_{E}=\left(\frac{n \pi}{L}\right)^{2} \cdot E I
$$

onde $n=1,2,3, \ldots$ corresponde ao n-ésimo modo natural de vibração e $L$ é o comprimento da coluna.

Para o caso específico de vigas, a carga de compressão assume outra expressão, dada pela Equação A.15:

$$
P_{c r}=\sqrt{\left(m+m_{a}\right) \cdot E I} \cdot \omega
$$

onde $m$ e $m_{a}$ correspondem, respectivamente, às massas própria e imersa da viga, por unidade de comprimento e $\omega$ é a frequência (angular) associada à vibração da viga.

Nese ponto, cabe explicitar as frequências naturais de oscilações de vigas e cabos, dada sua importância para a aproximação para a catenária ${ }^{5}$. Assim:

- Frequência de vibração transversal livre de vigas-colunas:

$$
\omega_{f}=\left(\frac{n \pi}{L}\right)^{2} \cdot \sqrt{\frac{E I}{\left(m+m_{a}\right)}}
$$

\footnotetext{
${ }^{5} \mathrm{~A}$ dedução dessas equações é consequência direta da definição do número de onda $k$, que aparece na Equação A.13.
} 
- Frequência de vibração tranversal livre de cabos:

$$
\omega_{g}=\frac{n \pi}{L} \cdot \sqrt{\frac{T_{0}}{m+m_{a}}}
$$

- Frequência de vibração axial livre de cabos:

$$
\omega_{a}=\frac{n \pi}{L} \cdot \sqrt{\frac{E A}{m}}
$$

Explicitando a relação de dispersão, em uma de suas formas:

$$
\omega=k \cdot c
$$

onde $c$ é a celeridade da onda.

Dessa forma, é possível apresentar as velocidades de propagação dessas ondas, dadas respectivamente por:

- Velocidade de propagação de ondas transversais em vigas-colunas, associada à rigidez flexional (considerando $n=1$ e $L=\frac{\lambda_{f}}{2}$ ):

$$
c_{f}=\frac{2 \pi}{\lambda_{f}} \cdot \sqrt{\frac{E I}{\left(m+m_{a}\right)}}
$$

- Velocidade de propagação de ondas transversais em cabos, associada à rigidez geométrica:

$$
c_{0}=\sqrt{\frac{T_{0}}{m+m_{a}}}
$$

- Velocidade de propagação de ondas longitudinais em cabos, associada à rigidez axial:

$$
c_{a}=\sqrt{\frac{E A}{m}}
$$

Essas são exatamente as expressões para as frequências e celeridades das ondas que se propagam em risers. Mais que isso, esse resultado aponta claramente para as distintas escalas de tempo associadas ao problema dinâmica de catenárias. 



\section{Apêndice $B$}

\section{Validação do Procedimento Numérico Sugerido}

\section{B.1 Comparação com os resultados estáticos de Ribeiro et al. (1998) e de Simos \& Fujarra (2006)}

O primeiro passo para avaliação da ocorrência de compressão dinâmica em risers é a avaliação da configuração estática da linha. No que concerne a presente tese, os lançamentos serão sempre em catenária direta.

De maneira a apresentar resultados para risers SCR e flexível, seguem os gráficos ilustrados nas Figuras B.1 e B.2, confeccionados a partir dos dados retirados respectivamente de Ribeiro et al. (1998) - (SCR), e de Simos \& Fujarra (2006) - (flexível). Esses gráficos foram originalmente apresentados no Capítulo 2, mas estão aqui explicitados por uma questão de praticidade para o leitor.

As diferenças apresentadas entre as formulações de Pesce (1997) e Patel \& Seyed (1995), a despeito da incorporação da rigidez flexional neste último, são relativamente diminutas traduzindo-se, principalmente, em pequenas diferenças percentuais nas extremidades (em particular no topo).

A avaliação pelo Anflex recuperou, com bastante fidelidade, os resultados analíticos concebidos a partir dessas duas formulações.

Tanto a Teoria de Cabos, quanto a formulação proposta por Irvine \& Caughey (1974), são mais aderentes aos resultados das demais abordagens no caso do riser flexível lançado menos verticalmente, pelas próprias hipóteses que aqueles modelos abarcam: a relação entre flecha e vão assume um valor muito menor no estudo de Simos \& Fujarra (2006) que em (Ribeiro et al., 1998).

Além disso, nenhum desses modelos incorpora a rigidez axial, de sorte que é possível depreender que, nesse caso, essa propriedade deve assumir importância destacada na estática da linha. 


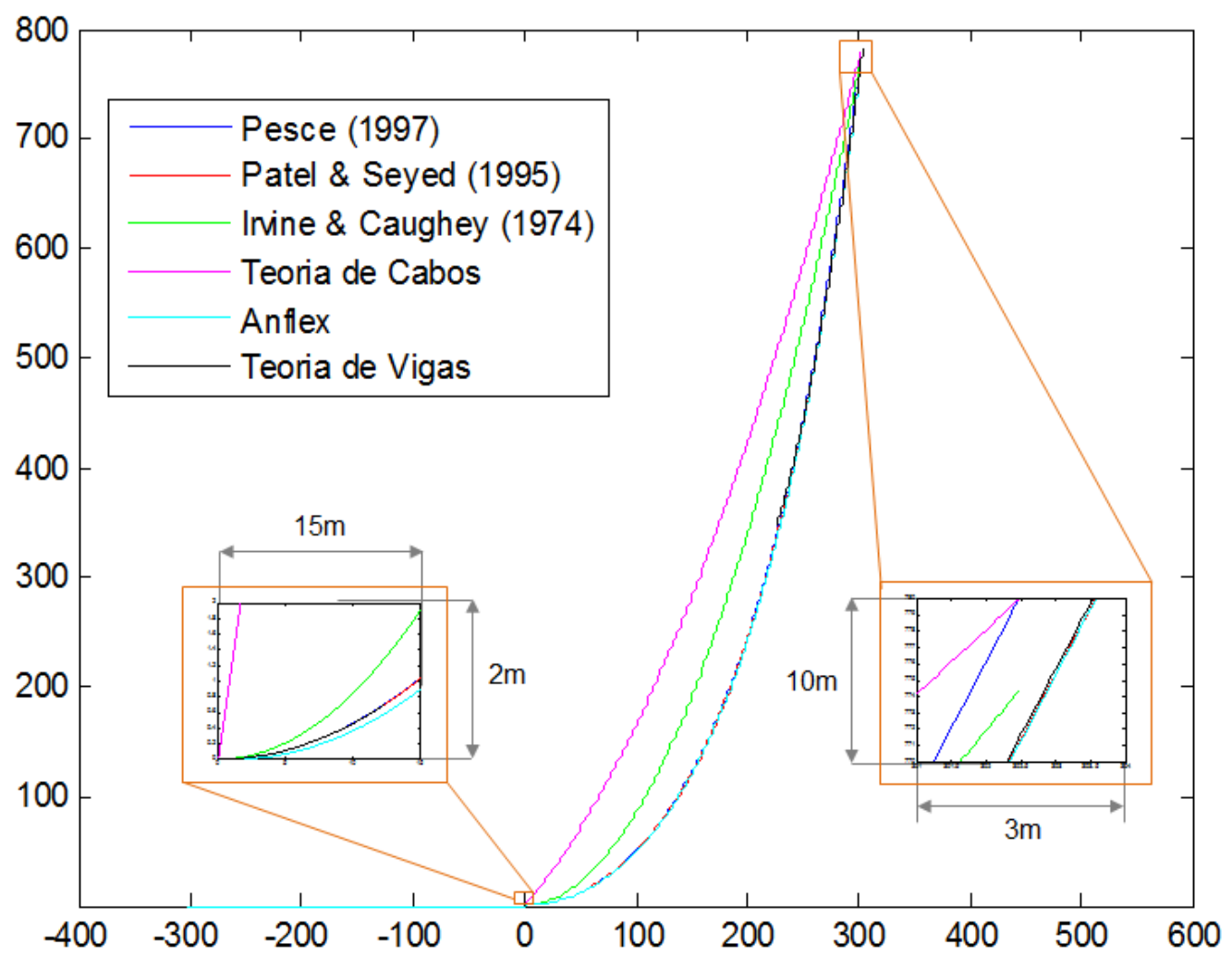

Figura B.1: Comparação da geometria estática de um SCR, utilizando o Anflex. Baseado no SCR estudado em (Ribeiro et al., 1998).

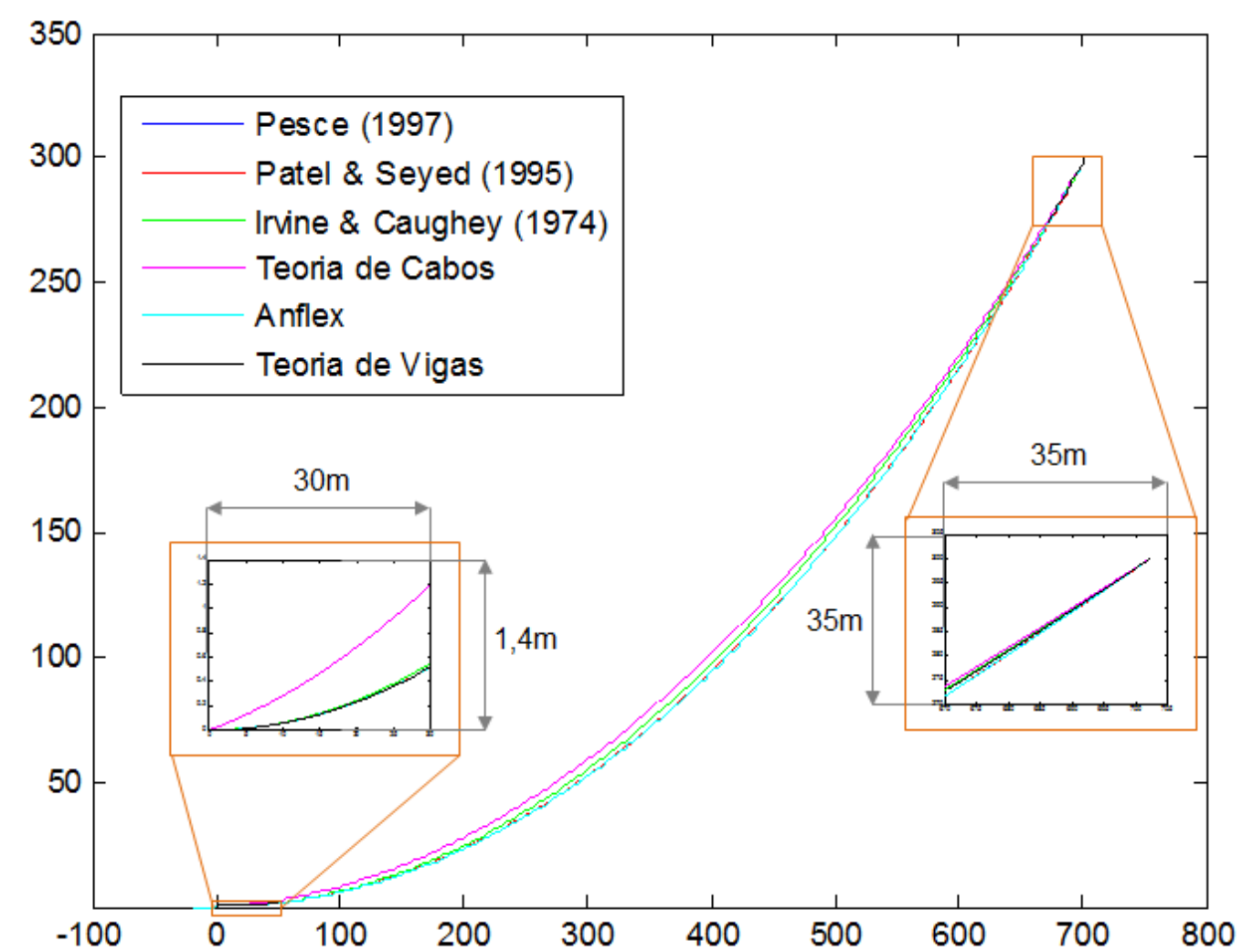

Figura B.2: Comparação da geometria estática de um riser em catenária direta, utilizando o Anflex. Baseado no riser estudado em (Simos \& Fujarra, 2006), em uma escala de 100:1. 
Outras observações e resultados importantes já foram apresentados e discutidos anteriormente na Seção A.1.1, que trata da validade da aproximação das geometrias estáticas assumidas por risers pela Teoria de Cabos. Apresenta-las, nesse ponto, seria desnecessário, visto que o objetivo das figuras aqui ilustradas visa apenas a comparação dos resultados obtidos com o procedimento proposto.

\section{B.2 Comparação com resultados dinâmicos de Ribeiro et al. (1998)}

Embora a quantidade de resultados comparáveis, advindos de (Ribeiro et al., 1998), seja relativamente pequena, as conclusões a respeito da possibilidade de ocorrência de compressão dinâmica na linha flexível utilizada naquele trabalho, juntamente com os dados referentes ao riser em questão e à sua excitação de topo, motivam sua utilização para os objetivos da presente seção.

Ressalte-se que nenhuma série temporal foi apresentada em (Ribeiro et al., 1998); por outro lado, essa publicação cita o uso do Anflex para as simulações realizadas e afirma tacitamente a presença de compressão dinâmica na linha, o que obviamente se configura como outra motivação para o uso das informações nele contidas.

A Tabela B.1 compila alguns dos dados referentes à linha flexível e sua posição de equilibrio estático, referente ao trabalho desenvolvido por Ribeiro et al. (1998). As simulações que se deseja comparar se referem a excitações de topo, com movimento circular de amplitude 7,80m e período 11,5s.

A Figura B.3, obtida a partir da modelagem desse riser com uso do Anflex, mostra a concordância com os resultados apresentados para a estática da linha naquele trabaIho, a partir da adequação dos dados de entrada.

Tabela B.1: Características do modelo SCR de (Ribeiro et al., 1998)

\begin{tabular}{|c|c|c|}
\hline Característica & Símbolo $($ Unidade) & Magnitude \\
\hline Diâmetro externo & $D_{e x t}(\mathrm{~mm})$ & 29,2 \\
Comprimento total & $L_{t}(\mathrm{~m})$ & 1183,9 \\
Rigidez axial & $E A_{e q}(\mathrm{kN})$ & $4,47 \cdot 10^{5}$ \\
Rigidez flexional & $E I_{e q}\left(\mathrm{kNm}{ }^{2}\right)$ & 36,3 \\
Peso por unidade de comprimento (no ar) & $q(\mathrm{~N} / \mathrm{m})$ & 1223 \\
Peso por unidade de comprimento (na água) & $\mu(\mathrm{N} / \mathrm{m})$ & 550 \\
\hline Lâmina d' água & $h(\mathrm{~m})$ & 780 \\
Comprimento suspenso & $L_{s}(\mathrm{~m})$ & 3,36 \\
Comprimento do riser sobre o leito & $L^{\prime}(\mathrm{m})$ & 295 \\
Tração horizontal & $T_{0}(k N)$ & 60,4 \\
\hline \hline
\end{tabular}

A concordância entre os dados da Tabela B.1 (dados provenientes do trabalho original) e da Figura B.3 (simulação realizada no Anflex) é essencial para a análise realizada.

Segundo Ribeiro et al. (1998), o ângulo de topo estático da linha flexível estudada, com respeito à vertical, seria de $7^{\circ}$, o que é condizente com o 0 valor constante na Figura B.3. 
Outros valores, presentes na Tabela B.1, auxiliam na validação da estática do riser em questão. Uma nota importante: o valor apresentado em um campo com fundo de cor laranja representa o dado de entrada utilizado pelo usuário do Anflex. No caso da Figura B.3, o valor de entrada corresponde à tração horizontal atuante sobre a linha.

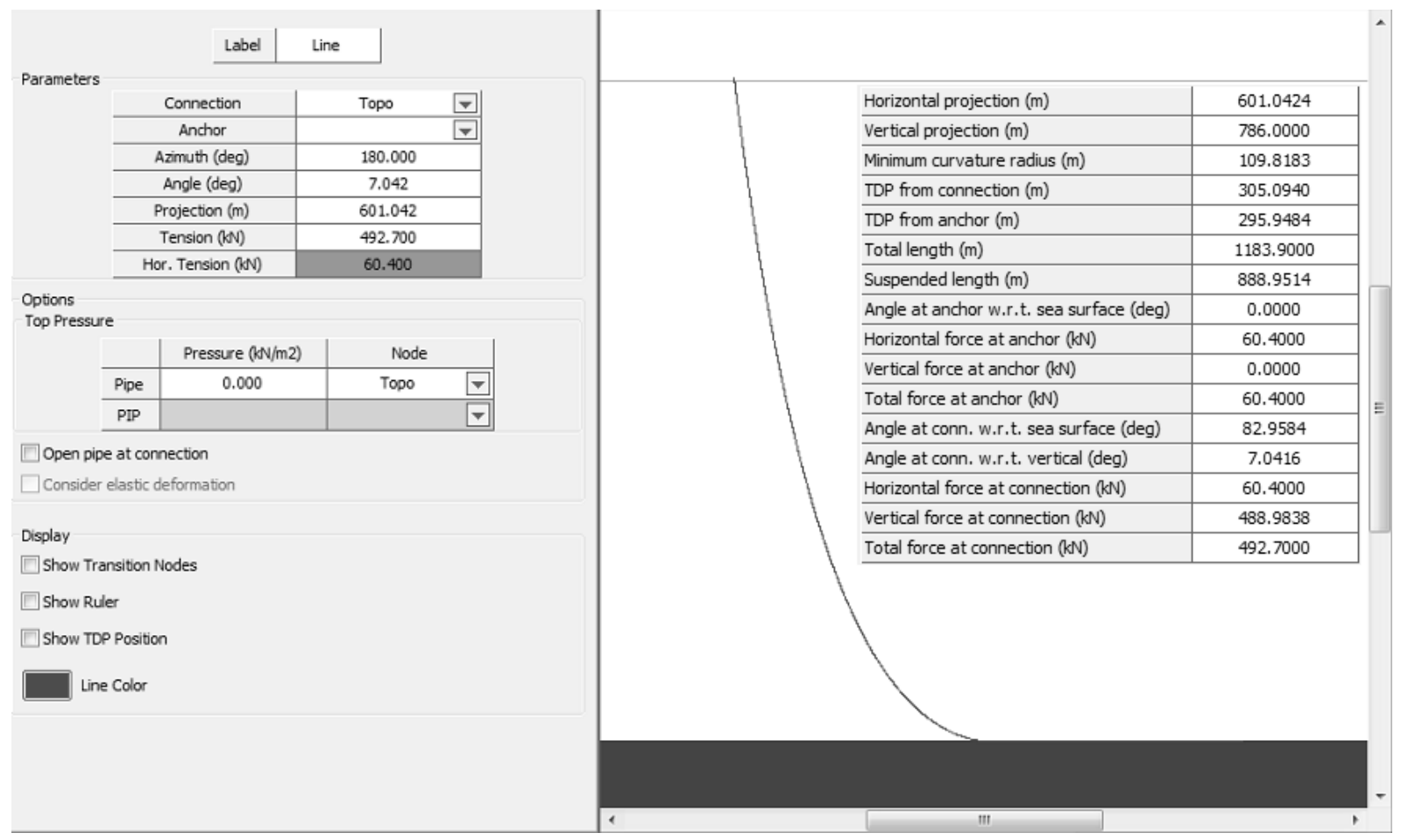

Figura B.3: Modelo numérico em Anflex, baseado na linha flexível apresentada em (Ribeiro et al., 1998).

Dinamicamente, os resultados foram obtidos a partir da simulação da prescrição de movimento ao topo da linha, segundo as considerações da própria publicação, utilizando o Anflex, com tempo de simulação de 70 s e time step de 0,0125 s, além da discretização da linha em elementos de 1m de comprimento, ou seja, 1185 nós (e, portanto, 1184 elementos).

Saliente-se que a discretização utilizada nessa simulação foi a mesma descrita em (Ribeiro et al., 1998). Entretanto, ela não é condizente com as recomendações da (API, 1993) e da (API, 2009) citadas anteriormente. A despeito dessa ressalva os resultados parecem condizentes com os obtidos com as formulações analíticas.

O trabalho cita a utilização dessas configurações, mantidas nas simulaçoes realizadas neste trabalho, a fim de propiciar comparações adequadas. Ribeiro et al. (1998) também apresentam os valores para as fricções laterais a serem consideradas, bem como dos coeficiente de massa adicional e arrastos.

Com os dados apresentados e os demais constantes naquele trabalho, as simulações foram realizadas. Além disso, foram gerados resultados a partir do procedimento proposto na seção 4.1.2, com base em Aranha \& Pinto (2001) e Aranha et al. (2001). Com relação à região próxima ao TDP, os resultados são bastante consistentes, conforme pode ser visualizado na Figura B.4. 

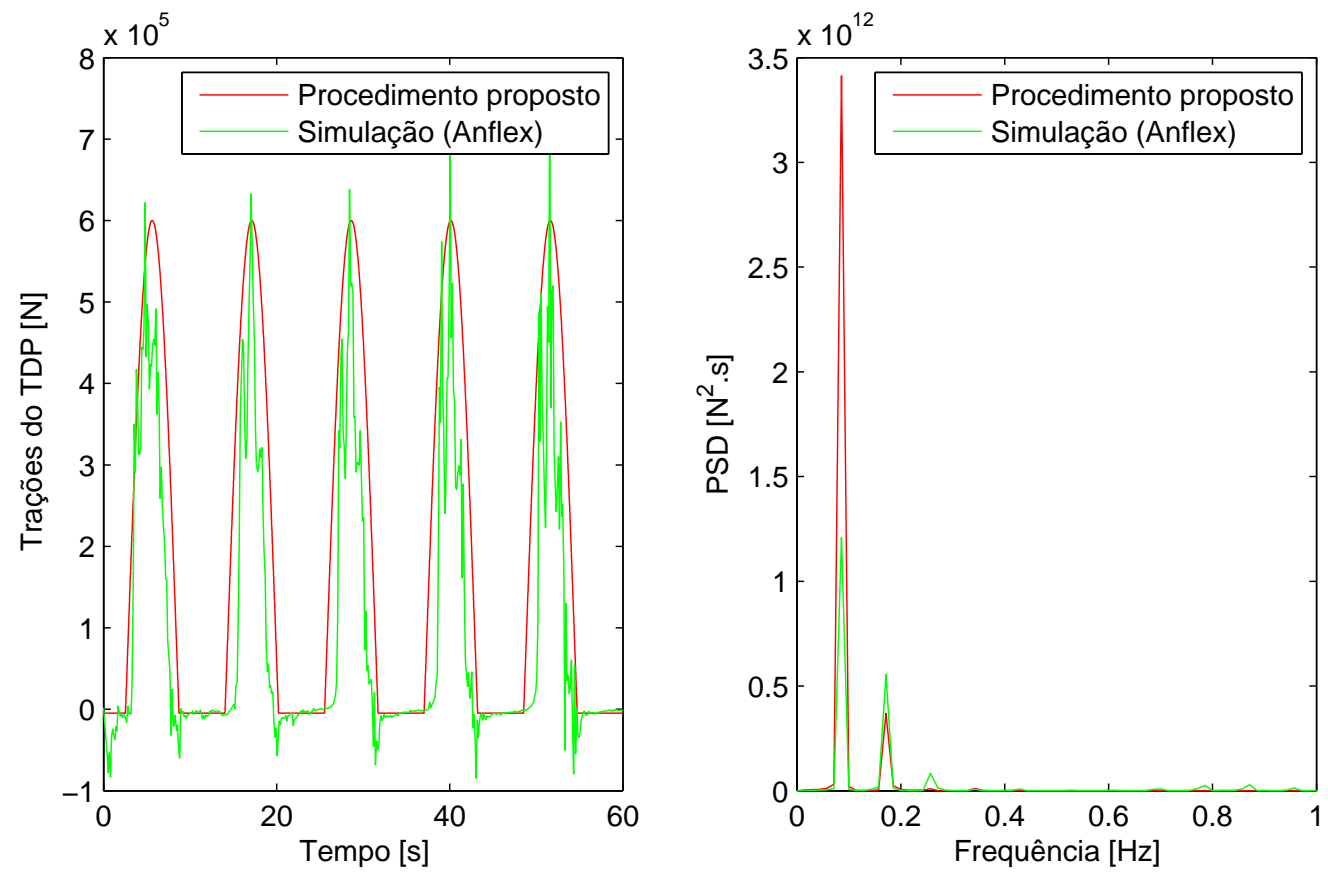

Figura B.4: Excertos das séries temporais de tração no TDP.

Comparação entre o procedimento proposto e resultados de simulações para Ribeiro et al. (1998).

No TDZ, a ocorrência de compressão dinâmica fica evidente, e os resultados provenientes do Anflex e da rotina numérica elaborada com base no procedimento proposto apresentam similaridades fortes em termos de frequência, amplitude do sinal de tração, dos instantes em que ocorrem saturações na série temporal de trações e do valor da carga crítica atingida. Com relação a esse último valor, cabe uma observação importante: a saturação da assinatura temporal de trações é clara e, mesmo que em um valor muito próximo de zero, mostra que esse SCR suporta um certo nível de compressão antes de flambar, resultante da importância da rigidez flexional.

As respectivas densidades espectrais de potência (PSD) dos sinais temporais de trações apresentam picos proeminentes na frequência de excitação, bem como em seus múltiplos inteiros, remetendo à asserção feita em (Simos \& Fujarra, 2006) com respeito à relação entre esse comportamento e a ocorrência de compressão dinâmica.

Cumpre notar que a energia contida nos sinais artificialmente gerados é substancialmente maior que dos sinais provenientes de ensaios ou de simulações com o uso do Anflex, como o presente caso em estudo.

Uma possível explicação para esse comportamento, é justamente o fato de que o sinal gerado a partir da formulação proposta por Aranha \& Pinto (2001) é construído a partir de um sinal harmônico, enquanto que os picos percebidos pelas demais vertentes (ensaios e simulações) são bem mais proeminentes, o que é mais condizente fisicamente com o fenômeno de compressão dinâmica. Basta lembrar que após a linha "congelar" ocorre a propagação instantânea de um pulso (onda de compressão), o que aumenta consideravelmente o valor da tração, em um pequeno intervalo de tempo. 
Por fim, de maneira a corroborar a ocorrência de compressão dinâmica no riser avaliado em (Ribeiro et al., 1998), bem como mostrar a capacidade do software Anflex em evidenciar tal fenômeno, recorra-se à Figura B.5, na qual é possível visualizar no canto superior direito ondas de compressão se propagando a partir do TDP, nas simulações referentes ao caso em estudo.

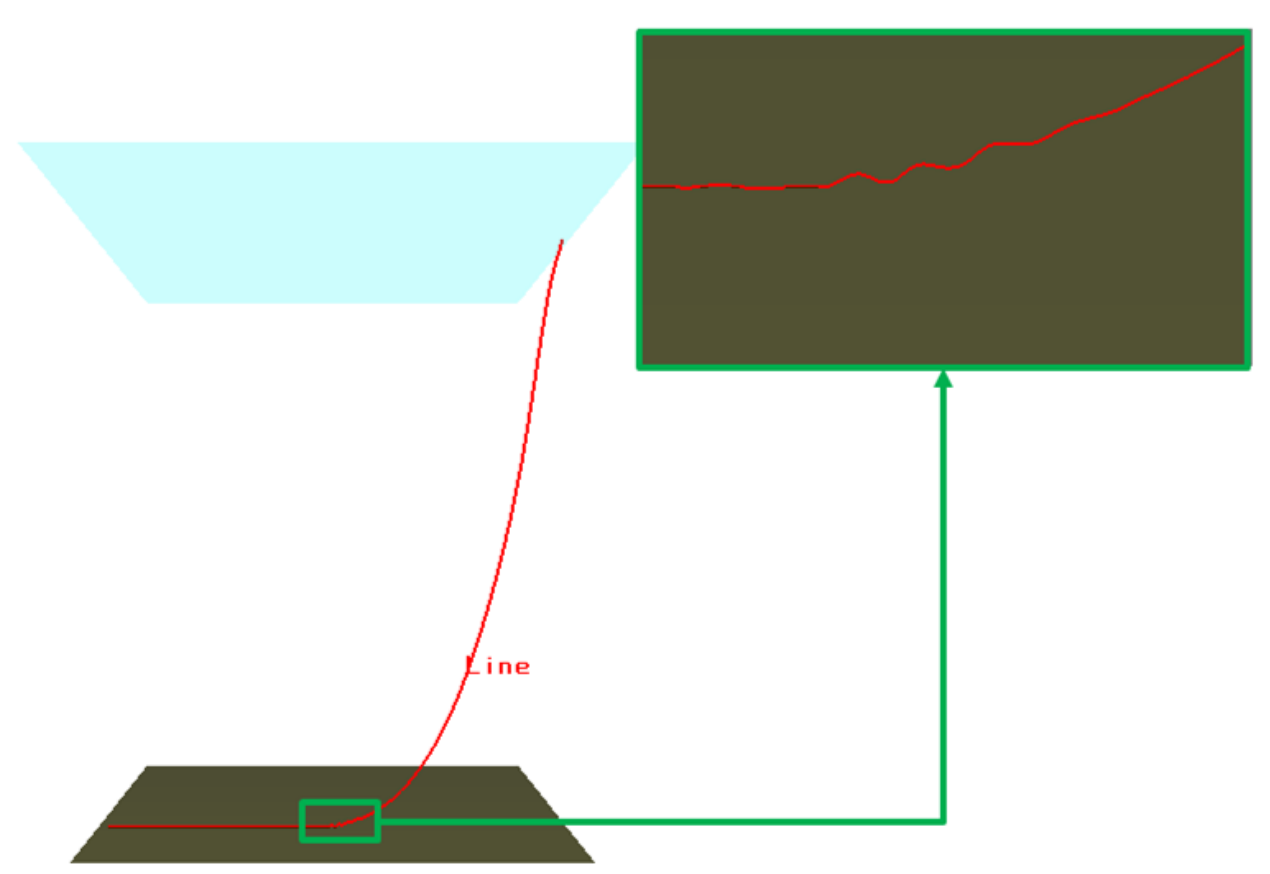

Figura B.5: Snapshot de vídeo gerado pelo Anflex evidenciando ondas de compressão. Obtido a partir de simulações no Anflex para Ribeiro et al. (1998).

\section{B.3 Comparação com resultados dinâmicos de Simos \& Fujara (2006)}

O presente tópico, que finaliza a seção referente à validação dos procedimentos a serem empregados neste trabalho, tem como objetivo apresentar resultados de simulações numéricas realizadas a partir do procedimento proposto, e as confrontações com os resultados experimentais realizados por Simos \& Fujarra (2006).

Para fins de validação, utilizou-se também o software Anflex, dando um exemplo da abordagem tríplice na qual a presente tese se apoia.

A seguir serão apresentados os ensaios realizados por Simos \& Fujarra (2006).

Os estudos realizados geraram dois conjuntos de 16 resultados (excitações a 4 frequências $^{1}$ e 4 amplitudes ${ }^{2}$, sem correnteza), cada um deles referente ao topo e ao TDP da linha flexível ensaiada por Simos \& Fujarra (2006), cujas características estão compiladas na Tabela B.2.

\footnotetext{
${ }^{1}$ As frequências utilizadas para a excitação no topo foram: $0,75 \mathrm{~Hz} ; 1,00 \mathrm{~Hz} ; 1,25 \mathrm{~Hz}$; e $1,50 \mathrm{~Hz}$.

${ }^{2}$ As amplitudes de excitação conferidas ao topo da linha foram: 0,050m; 0,075m;0,100m; e 0,150m.
} 
Tabela B.2: Características do modelo flexível de (Simos \& Fujarra, 2006)

\begin{tabular}{|c|c|c|}
\hline Característica & Símbolo (Unidade) & Magnitude \\
\hline Diâmetro externo & $D_{\text {ext }}(\mathrm{mm})$ & 12,0 \\
Comprimento total & $L_{t}(\mathrm{~m})$ & 8,0 \\
Rigidez axial & $E A_{e q}(\mathrm{kN})$ & 265,25 \\
Rigidez flexional & $\left.E I_{e q}(\mathrm{kNm})^{2}\right)$ & $2,6834 \cdot 10^{-4}$ \\
Peso por unidade de comprimento (no ar) & $q(\mathrm{~N} / \mathrm{m})$ & 2,193 \\
\hline Lâmina d' água & $h(\mathrm{~m})$ & 3,0 \\
Cota vertical do ponto de suspensão & $H(\mathrm{~m})$ & 3,36 \\
Distância horizontal âncora-topo & $D_{x}(\mathrm{~m})$ & 7,0 \\
Ângulo de topo & $\theta_{\text {topo }}\left({ }^{\circ}\right)$ & 47,8 \\
\hline
\end{tabular}

Embora com algumas diferenças sutis, o modelo estático produzido com o auxílio do Anflex (vide montagem ilustrativa na Figura B.6) apresenta características bastante aderentes às apresentadas na Tabela B.2.

É interessante notar a proximidade da âncora relativamente ao TDP.
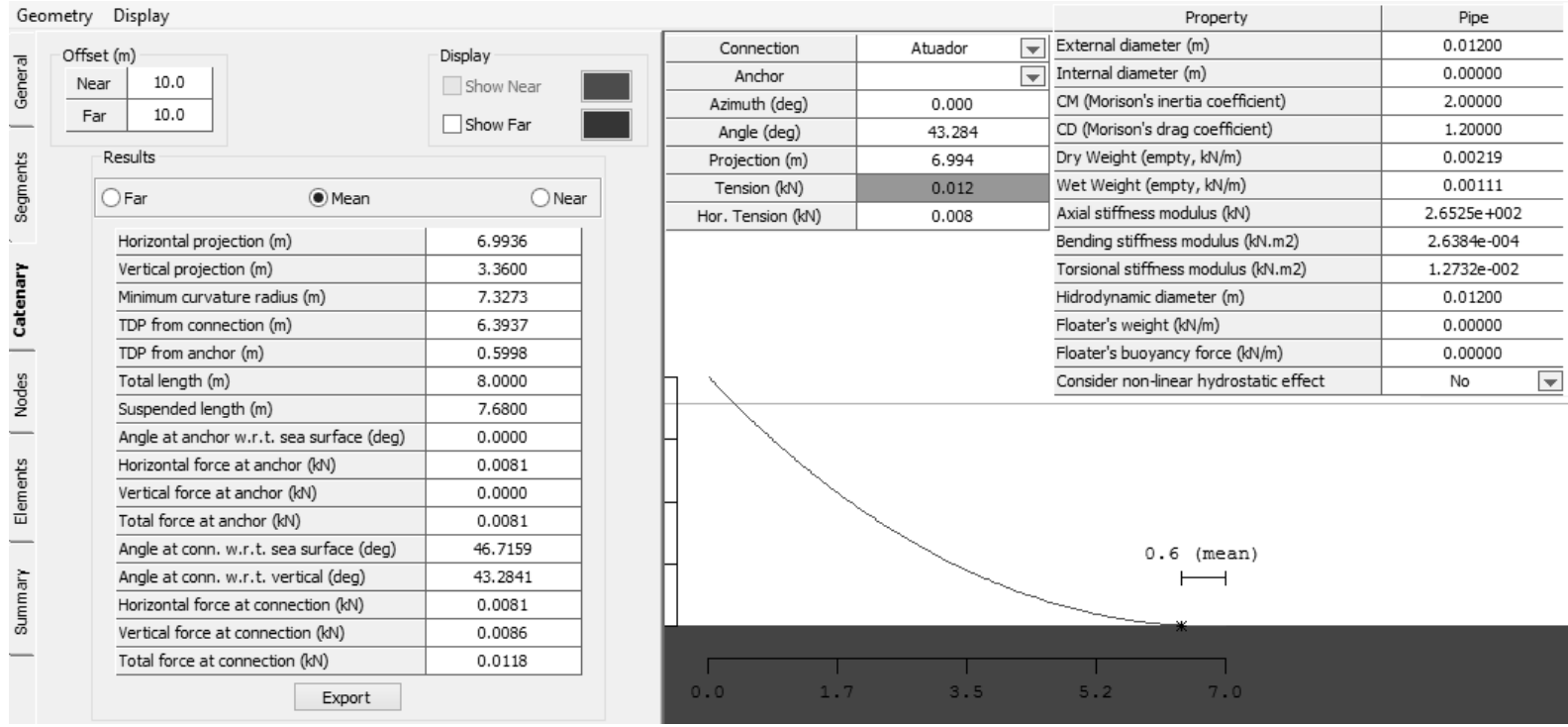

Figura B.6: Configuração de lançamento e estática da linha de Simos \& Fujarra (2006) no Anflex.

O arranjo esquemático do aparato e da linha utilizados nos ensaios realizados por Simos \& Fujarra (2006), extraídos do próprio texto, são ilustrados na Figura B.7, respectivamente demarcados por "A" e "B".

Ao longo do comprimento do modelo foram afixadas massas pontuais distribuídas, a fim de aumentar seu peso próprio. Um esquema ilustrativo de sua aparência e medidas é apresentada na Figura B.7B.

Nos experimentos físicos realizados e descritos em (Simos \& Fujarra, 2006), uma linha flexível, com as características dadas pela Tabela B.2, foi construída a partir de uma fita metálica de $10 \mathrm{~mm} \times 1 \mathrm{~mm}$, recoberta por silicone.

A estrutura metálica interna conferia ao modelo uma rigidez flexional diferenciada na direção perpendicular ao plano vertical de lançamento do mesmo, a fim de confina-lo pretensamente nesse plano, mitigando saídas laterais da linha. 


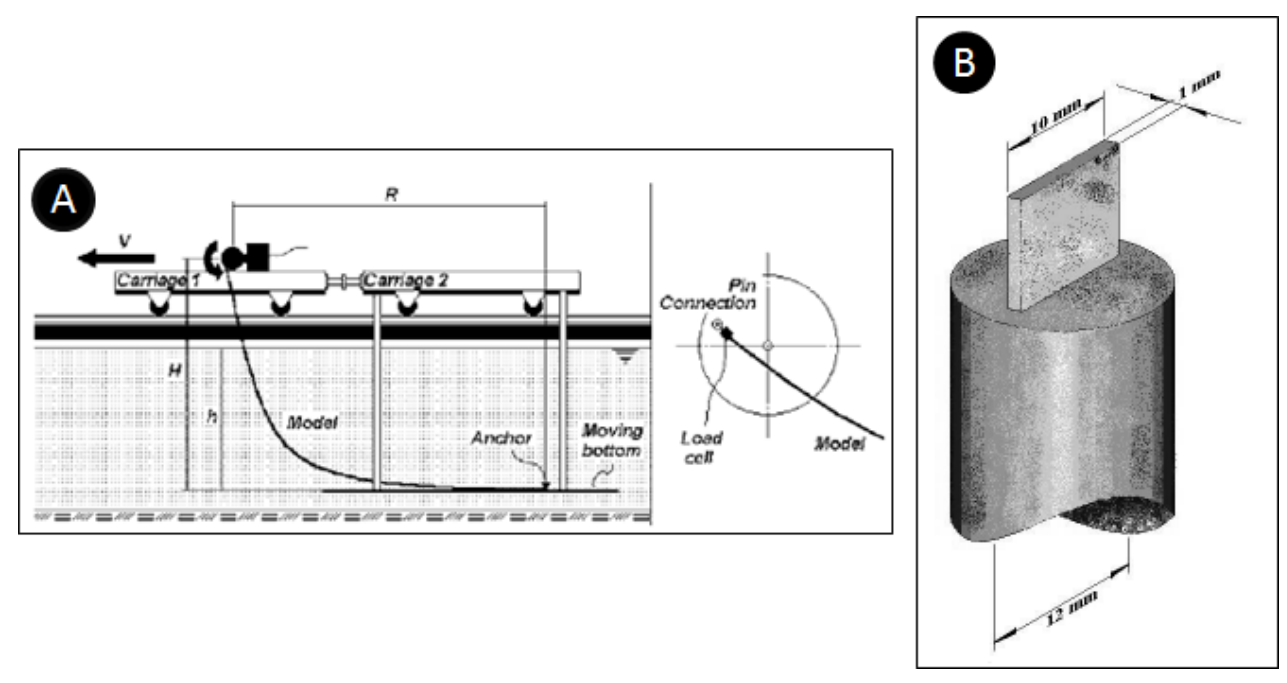

Figura B.7: Esquema ilustrativo do aparato experimental utilizado por Simos \& Fujarra (2006).

A linha foi lançada, com seu topo rotulado e a outra extremidade ancorada, sobre uma plataforma fixada em um carro dinamométrico do tanque de provas do Instituto de Pesquisas Tecnológicas do Estado de São Paulo (IPT-SP).

O conjunto (vide Figura B.7A) podia se movimentar na direção longitudinal do tanque, de modo a simular incidência de corrente no plano do modelo de riser em catenária direta, em ambos os sentidos. Tais resultados são apresentados naquele trabalho, mas omitidos aqui, pelas premissas do presente texto (estudo da compressão dinâmica em riser na ausência de correnteza).

O número de ensaios e simulações realizados por (Simos et al., 2003) foi demasiado grande. Assim, por concisão textual, a íntegra das simulações não é apresentada.

Um ponto importante a se salientar, previamente à e e discussão dos resultados, refere-se à instrumentação utilizada por Simos \& Fujarra (2006): o topo da linha (rotulado) estava conectado a uma célula de carga.

Com o objetivo de comparar e discutir os resultados obtidos, escolheu-se o conjunto dos principais casos apresentados e discutidos em (Simos \& Fujarra, 2006) ${ }^{3}$, como sendo os mais relevantes. São eles:

1. Amplitude $0,050 \mathrm{~m}$ e frequência $0,75 \mathrm{~Hz}$ (não ocorrência de compressão dinâmica);

2. Amplitude $0,100 \mathrm{~m}$ e frequência $1,00 \mathrm{~Hz}$ (ocorrência do fenômeno, com percepção no topo pela célula de carga); e

3. Amplitude $0,150 \mathrm{~m}$ e frequência $1,50 \mathrm{~Hz}$ (ocorrência significativa do fenômeno, com percepção visual das ondas de flexão).

A região de contato com o solo, nas proximidades do TDP, foi monitorada por extensômetros dispostos internamente à linha.

\footnotetext{
${ }^{3}$ Esse trabalho, comumente citado na presente tese, é uma compilação dos resultados de Simos et al. (2003) e Fujarra et al. (2003), os quais também foram utilizados, dadas algumas particularidades inerentes a cada um deles.
} 
A despeito da utilização desses dois instrumentos de monitoramento, os resultados disponibilizados ao autor são relativos apenas ao topo da linha, a partir das séries temporais de trações avaliadas naquele ponto. Ainda assim, a procedimento foi utilizado para previsao das trações efetivas para o TDP, em conformidade com os objetivos almejadas no presente texto.

O primeiro caso analisado (A50F75TDP) refere-se à excitação de topo com amplitude de $0,050 \mathrm{~m}$ e frequência $0,75 \mathrm{~Hz}$. A Figura B.8 ilustra-se essa situação. Salvo exceções em que a apresentação dos resultados de topo se fizerem necessárias, as demais ilustrações referentes a esse ponto foram retiradas do texto.
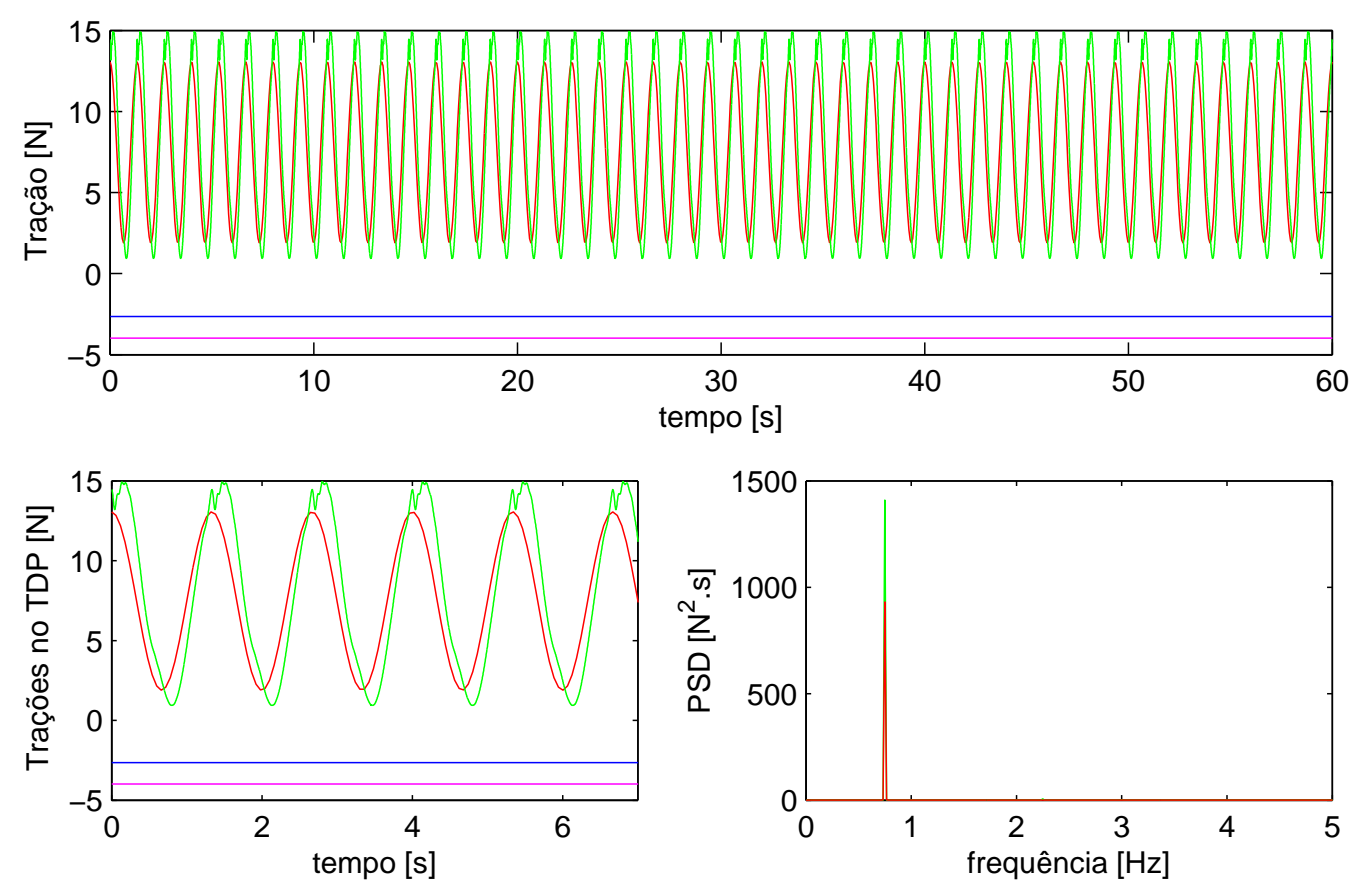

Figura B.8: Série temporal de tração e respectivo PSD do caso A50F75TDP. Em verde, Anflex; em vermelho, procedimento sugerido; em magenta, a carga crítica formulada em (Aranha et al., 2001); em azul, a carga crítica para vigas curvas engastadas-pinadas.

Para esse experimento (A50F75TDP), no qual não se evidenciou a compressão dinâmica do modelo flexível, não cabem maiores discussões.

Cumpre salientar apenas que a formulação analítica para a tração efetiva no TDP, proposta por Aranha \& Pinto (2001) é bastante aderente aos valores obtidos nos ensaios físicos realizados por Simos \& Fujarra (2006), embora apresente picos de trações maiores que as apresentadas na série temporal resultante das simulações realizadas com o software Anflex, em consonância com as explicações feitas anteriormente, a respeito do fato das séries harmônicas envolverem os sinais experimentais.

Os resultados obtidos para a excitação com movimento circular de topo de amplitude $0,100 \mathrm{~m}$ e frequência $1,00 \mathrm{~Hz}$ serão utilizados para efeitos ilustrativos, e comparativos, avaliando o topo e o TDP, ilustrados respectivamentes nas Figuras B.10 (caso A100F100TOP) e B.9 (caso A100F100TDP). 
Pela Figura B.9 é possível verificar que as trações no TDP, obtidas via Anflex, são relativamente mais elevadas que as obtidas com o prodecimento adotado, embora isso ocorra em picos bastante proeminentes, quase impulsivos. Os dados provenientes dos ensaios realizados por Simos \& Fujarra (2006) apresentam esses picos, que são recuperados pelo Anflex (vide Figura B.10, referente ao topo do mesmo caso).
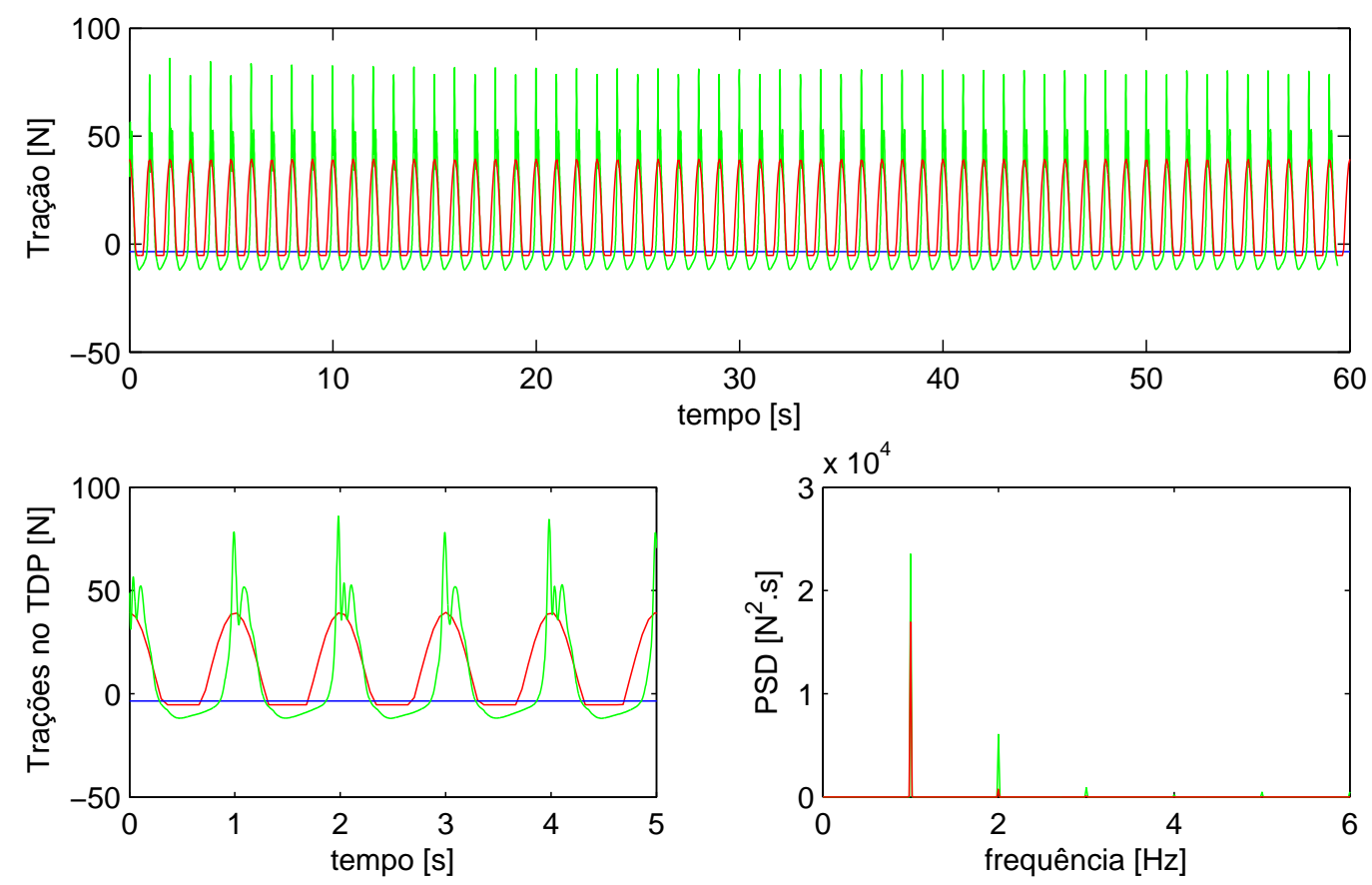

Figura B.9: Série temporal de tração e respectivo PSD do caso A100F100TDP.

Em verde, Anflex; em vermelho, procedimento sugerido; em azul, a carga crítica para vigas curvas engastadas-pinadas (Seção 3.4).

Note-se, pelas respectivas densidades espectrais de potência (PSD, porção inferior direita das respectivas figuras), que o padrão de presença de múltiplos inteiros da frequência de excitação é passível de ser visualizado, conforme se espera nos casos de ocorrência de compressão dinâmica, como citado por Simos \& Fujarra (2006) e ilustrado na Figura 2.6. Esses picos no PSD são recuperados na Figura B.9 pelo Anflex e na Figura B.10 por esse programa e pelos dados provenientes do ensaio.

A menos desses ressaltos agudos e da já citada majoração da energia relacionada à frequência de excitação por parte do procedimento sugerido, a rotina elaborada é capaz de emular o padrão das demais vertentes.

A Figura B.10, refere-se aos resultados das trações no topo da linha, para o modelo ensaiado por Simos \& Fujarra (2006). è de fácil percepção a capacidade do Anflex e do procedimento em avaliação em recuperar os resultados globais desse experimento. Pela Figura B.10, nota-se que o patamar referente à carga crítica experimental é da mesma ordem de grandeza daquelas obtidas pelas demais abordagens. Com respeito a esse ponto, é imperioso um comentário: a carga crítica para vigas curvas engastadas-pinadas apresenta um valor muito mais próximo do resultado expeimen- 

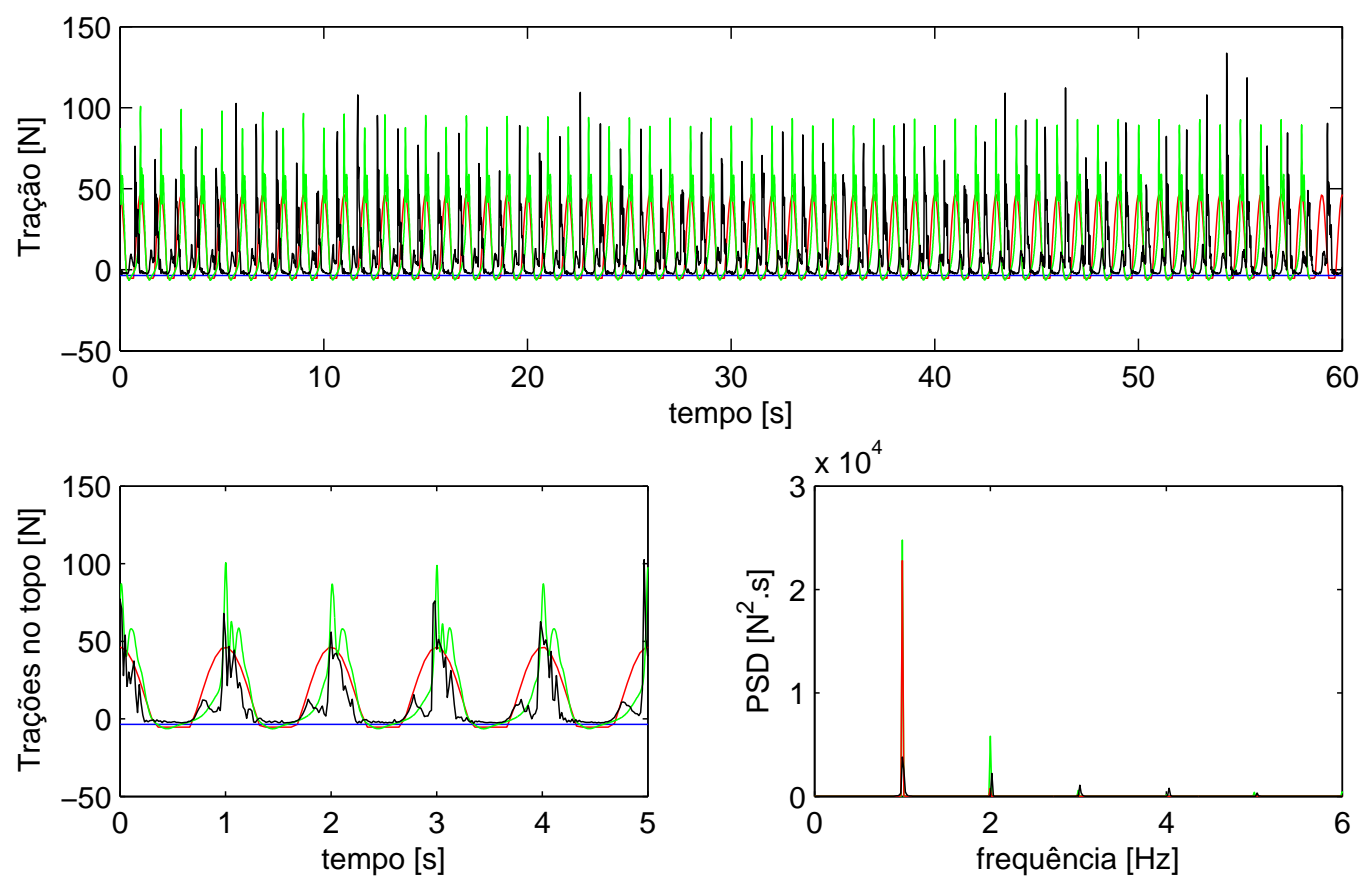

Figura B.10: Série temporal de tração e respectivo PSD do caso A100F100TOP.

Em preto, (Simos \& Fujarra, 2006); em verde, Anflex; em vermelho, procedimento sugerido; em azul, a carga crítica para vigas curvas engastadas-pinadas (Seção 3.4).

tal, apontando para a adequação dessa modelagem quando os experimentos ocorrem com ancoragem do modelo. A Figura B.11, ilustra um excerto da série temporal da Figura B.10 e corrobora peremptoriamente essa asserção.

Ressalte-se, todavia, a dificuldade em se definir visual e numericamente o patamar relativo à carga crítica experimental, dadas as oscilações locais em alta frequência e baixa energia presentes no respectivo PSD.

Cumpre lembrar, ainda, que em (Ramos Jr \& Pesce, 2003), são discutidos os efeitos relativos à torção da linha sobre a carga crítica de flambagem. Naquele trabalho, conclui-se que a utilização da Equação de Greenhill é maos adequada para estudos desse tipo, o que culminaria com a redução da carga crítica por um fator de $\frac{4}{9}$.

Dessa feita, é possível considerar esse fator, relativo aos efeitos torsionais.

Assim, com respeito aos resultados gráficos ilustrados na Figura B.11:

- Os resultados provenientes da análise numérica pelo Anflex não evidencia um patamar nítido, relativo à saturação do sinal temporal de trações do caso A100F100, embora o patamar esperado seja evidente na Figura B.12 (caso A150F150);

- Aplicando o fator de $\frac{4}{9}$ à carga crítica de Aranha et al. (2001), em vermelho nessa figura, chega-se ao valor $-2,359 \mathrm{~N}$;

- Utilizando o mesmo procedimento para a carga crítica deduzida na Seção 3.4, o valor calculado é aproximadamente $-1,572 \mathrm{~N}$; 


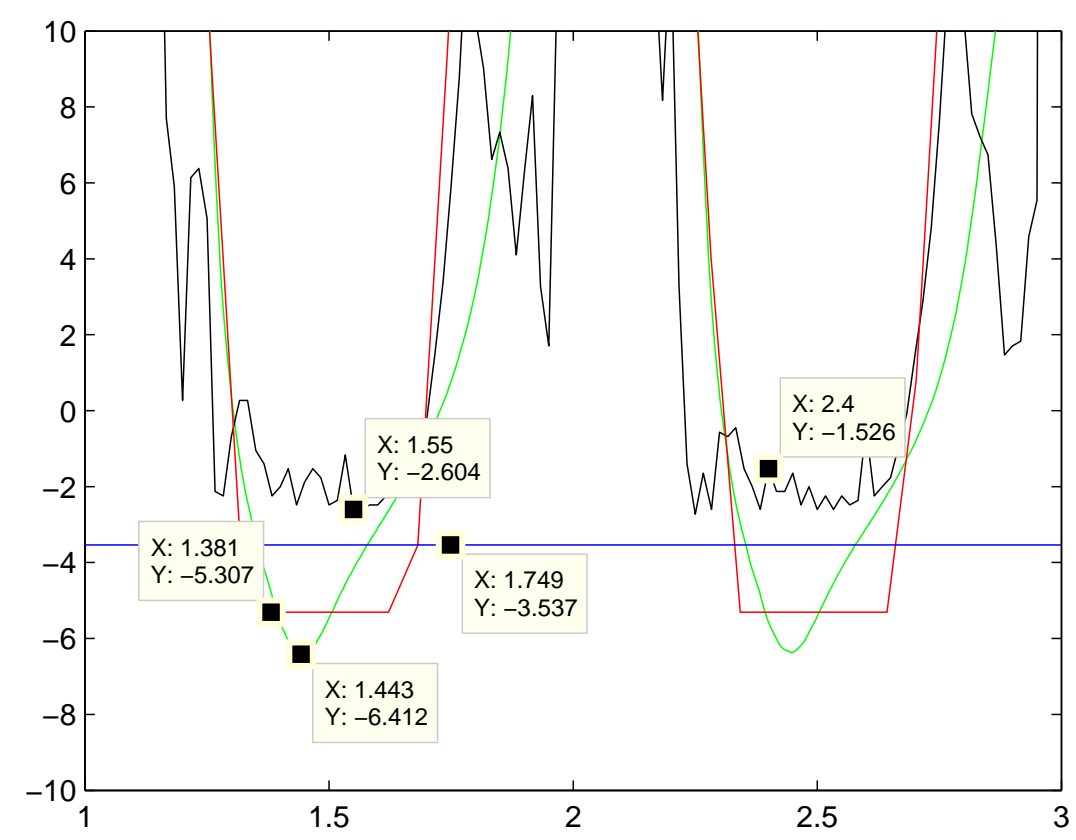

Figura B.11: Excerto da série temporal de tração do caso A100F100TOP.

Em preto, (Simos \& Fujarra, 2006); em verde, Anflex; em vermelho, procedimento sugerido; em azul, a carga crítica para vigas curvas engastadas-pinadas (Seção 3.4).

- Se o valor -2,604N (destacado à esquerda dessa figura) for tomado como média de saturação do sinal, o valor previsto por Aranha et al. (2001) parece mais adequado, com uma diferença de cerca de 10,6\%;

- Por outro lado, se for utilizado o valor destacado à direita dessa mesma figura, a aderência com o previsto para vigas curvas engastadas-pinadas é ainda maior, apontando para uma diferença de apenas $3,0 \%$.

Apresente-se, por fim, a Figura B.12 que ilustra o último dos casos de (Simos \& Fujarra, 2006) utilizados para fins de comparação com o programa Anflex.

Esse caso (A150F150), dentre os apresentados para discussão é, sem dúvidas, o exemplo mais evidente de ocorrência de compressão dinâmica no modelo estudado.

A saturação da assinatura temporal de trações é nítida, bem como os picos no PSD, em frequências múltiplas da de excitação. A Figura B.13 corrobora essa asserção, na qual se pode visualizar a excitação do $1^{\circ}$ ao $5^{\circ}$ harmômico da série de $1,50 \mathrm{~Hz}$.

Considerando-se os resultados apresentados no presente item, a despeito das eventuais discrepâncias apresentadas nos casos avaliados, o procedimento apresentado parece ser bastante adequado para a determinação do material para confecção do modelo físico, bem como para a elaboração da matriz de ensaios e posteriores confrontações com as demais vertentes utilizadas no âmbito desta tese.

A fim de finalizar a presente seção, ilustre-se a Figura B.14, onde é representado 0 mapeamento bidimensional do modelo ensaiado por Simos \& Fujarra (2006). 

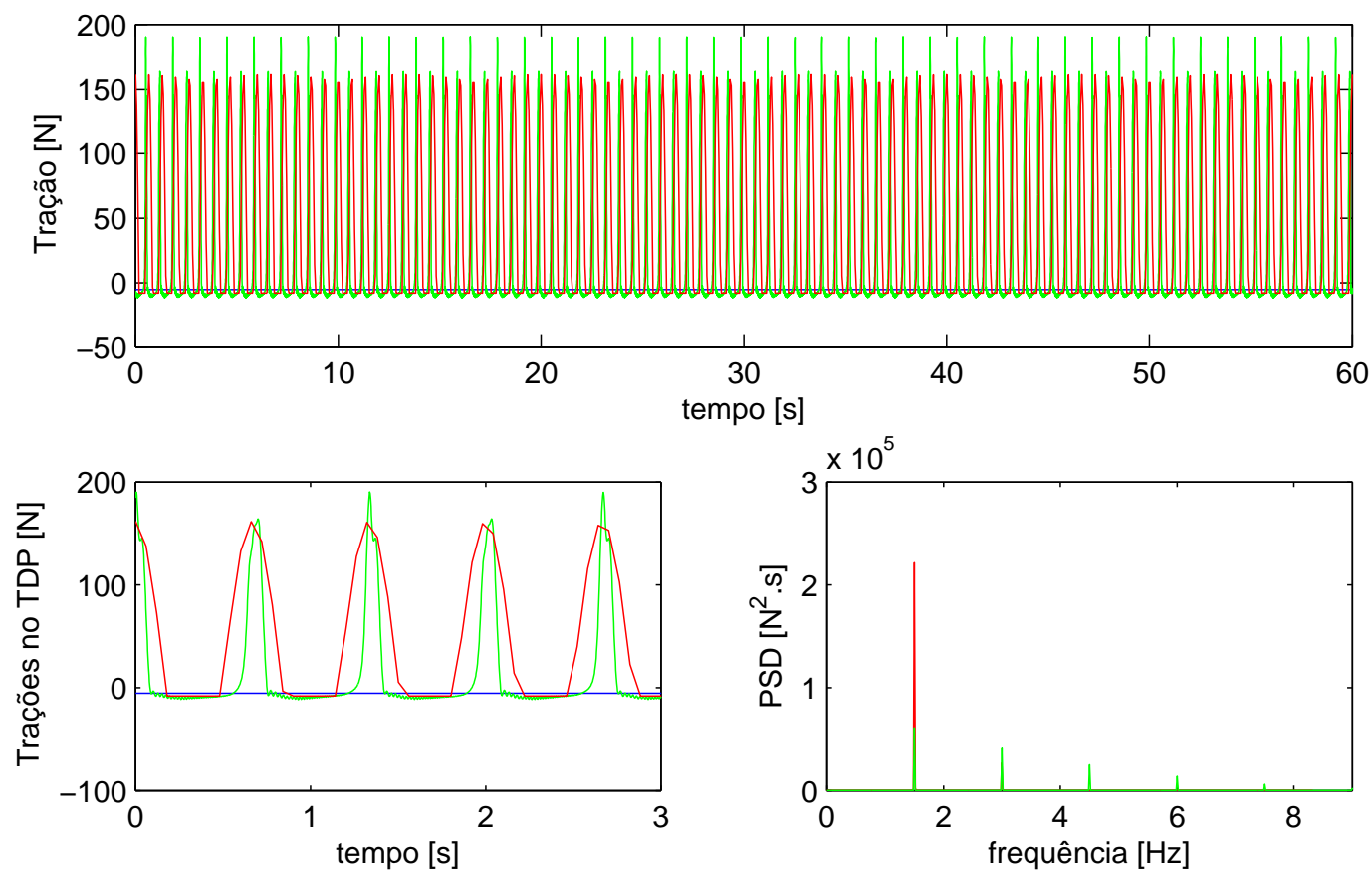

Figura B.12: Série temporal de tração e respectivo PSD do caso A150F150TDP.

Em verde, Anflex; em vermelho, procedimento sugerido; em magenta, a carga crítica formulada em (Aranha et al., 2001); em azul, a carga crítica para vigas curvas engastadas-pinadas.
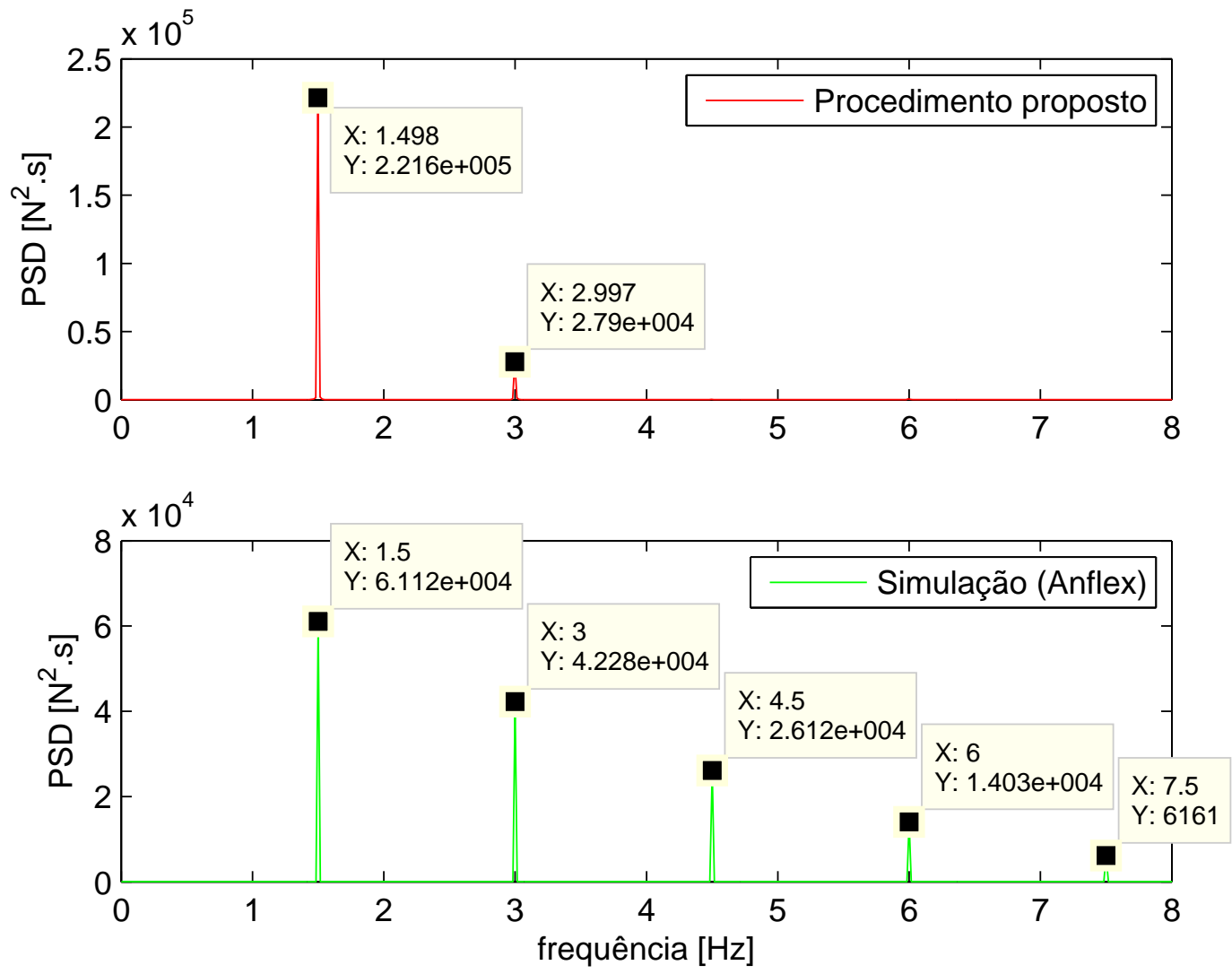

Figura B.13: Excerto da série temporal de tração do caso A150F150TDP. 
Essa figura é composta de quatro gráficos, um para cada frequência avaliada. Cada gráfico representa pares ordenados de amplitudes $(0,050 \mathrm{~m} ; 0,075 \mathrm{~m} ; 0,100 \mathrm{~m} ; 0,200 \mathrm{~m})$ e ângulos de topo (no intervalo de $40^{\circ}$ a $88^{\circ}$ de $2^{\circ}$ em $2^{\circ}$ ). Nela, os marcadores (pontos) em vermelho indicam ocorrência do fenômeno, segundo o procedimento proposto, enquanto que os em verde indicam ausência do mesmo. Nos gráficos apresentados, as linhas em azul indicam o ângulo de topo utilizado nos experimentos de (Simos \& Fujarra, 2006), conforme explicitado na Tabela B.2.

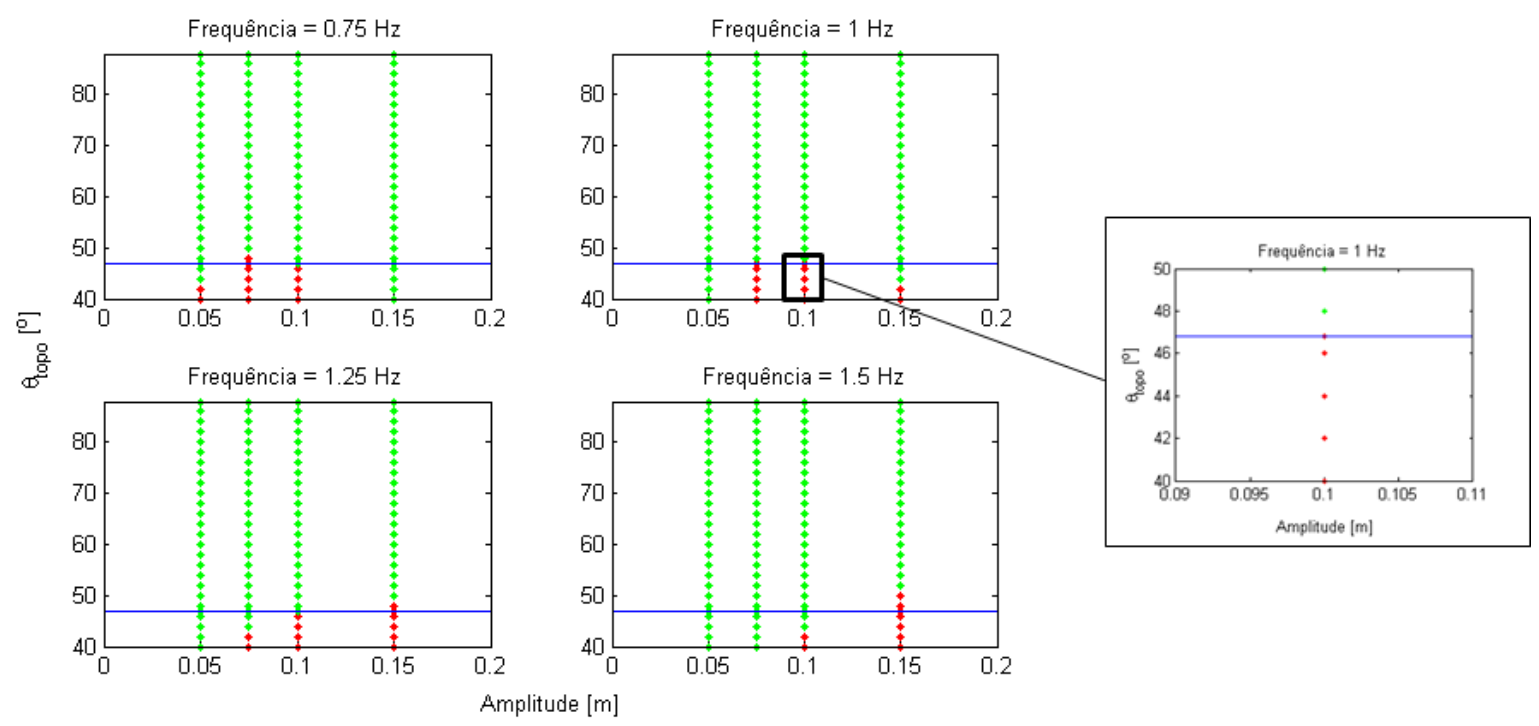

Figura B.14: Mapeamento da compressão dinâmica no TDP da linha de Simos \& Fujarra (2006).

É possível inferir, a partir da , que para as condições experimentais o modelo proposto no fluxograma da Figura 4.1, permite predizer a ocorrência do fenômeno de compressão dinâmica no TDP, para algumas poucas situações, considerando todo 0 mapeamento ilustrado.

Entretanto, é possível verificar que o foco dos trabalhos de Simos \& Fujarra (2006) se restringiu de maneira bastante perspicaz às regiões em que a compressão é prevista e seu entorno. Essa característica permitiu que a matriz de ensaios planejada encerrasse situações abrangentes, possibilitando as discussões levadas a cabo.

A Figura B.14 possui uma região destacada (um retângulo preto), ao redor da amplitude de excitação de $0,100 \mathrm{~m}$ mostrando que o ângulo ensaiado era limítrofe na relação de ocorrência de compressão dinâmica para a frequência de $1,0 \mathrm{~Hz}$, daí a visualização das ondas de compressão observadas durante o ensaio (vide Figura 2.5).

As figuras apresentadas no presente item corroboram algumas das asserções feitas em (Simos \& Fujarra, 2006), dentre as quais se podem destacar: a não ocorrência do fenômeno para o experimento com as menores amplitude e frequência de excitação $(0,050 \mathrm{~m}$ e $0,75 \mathrm{~Hz})$; a percepção visual da compressão dinâmica na situação destacada na Figura B.14; e o aumento considerável do número de ocorrências para as maiores amplitudes em conjunto com as maiores frequências de excitação. 
Como consequência direta, as avaliações realizadas nesta seção permitem concluir que modelo teórico proposto baseado em (Patel \& Seyed, 1995), em (Aranha \& Pinto, 2001) e em (Aranha et al., 2001) permite, de forma simples, rápida e aparentemente eficiente, a previsão da ocorrência do fenêmeno de interesse.

Postas todas essas considerações, parece que o procedimento proposto é capaz de ser utilizado, com certa segurança, a fim de determinar a matriz de ensaios e, posteriormente, como forma de comparação dos resultados obtidos nos ensaios finais com o modelo de linha flexível utilizado. 



\section{Apêndice C}

\section{Caracterização Física do Modelo Flexível}

O presente apêndice apresenta os principais resultados obtidos a partir de simulações numéricas preliminares realizadas para um modelo flexível de silicone preenchido com água e com areia, além das suas principais características físico-mecânicas, condições de lançamento e excitação de topo. O objetivo desse procedimento foi a escolha racional de qual opção utilizar. A escolha em retirar o conteúdo das simulações e experimentos de caracterização do corpo do texto tem a finalidade de dar fluência à leitura dos aspectos mais diretamente relacionados à tese, sem deixar de apresentar, mesmo que em anexo, todos os cuidados tomados para elaboração, preparação e execução dos ensaios finais.

$\mathrm{Na}$ sequência, são apresentadas a construção dos modelos físicos e suas respectivas caracterizações físico-mecânicas, obtidas a partir de ensaios específicos para, por fim, escolher de maneira sistemática e racional o modelo mais apropriado para o atendimento das condições necessárias à consecução dos objetivos desta dese.

\section{C.1 Validação numérica preliminar do modelo}

O modelo de linha flexível escolhido para os objetivos experimentais desta tese consiste em um tubo de silicone, com as características físicas e mecânicas compiladas na Tabela C.1.

As características relativas à excitação circular de topo e coeficientes (de arrasto e atrito entre a linha e o solo) usados nas simulações encontram-se na Tabela C.2. Os valores constantes nesta tabela, bem como a lâmina d'água real, foram posteriormente verificados por experimentos específicos de caracterização, descritos na Seção C.2.6. Para as faixas de valores constantes da Tabela C.2, os ângulos de topo foram variados de $2^{\circ}$ em $2^{\circ}$, os períodos de $0,1 \mathrm{~s}$ em $0,1 \mathrm{~s}$ e as amplitudes de $0,050 \mathrm{~m}$ em $0,050 \mathrm{~m}$. 
Tabela C.1: Características do modelo em silicone, dados de catálogos

\begin{tabular}{|c|c|c|}
\hline Característica & $\begin{array}{c}\text { Símbolo } \\
\text { (Unidade) }\end{array}$ & Magnitude \\
\hline Diâmetro externo & $D_{\text {ext }}(\mathrm{mm})$ & 14 \\
Diâmetro interno & $D_{\text {int }}(\mathrm{mm})$ & 7 \\
\hline Módulo de elasticidade & $E\left(\mathrm{MN} / \mathrm{m}^{2}\right)$ & 1,5 \\
Densidade média & $\rho\left(\mathrm{kg} / \mathrm{m}^{3}\right)$ & 1.200 \\
\hline Peso linear no ar (vazio) & $q(\mathrm{~N} / \mathrm{m})$ & 1,3587 \\
Peso linear imerso (vazio) & $\mu(\mathrm{N} / \mathrm{m})$ & $-0,1509$ \\
\hline Peso linear no ar (com areia) & $q(\mathrm{~N} / \mathrm{m})$ & 1,9248 \\
Peso linear imerso (com areia) & $\mu(\mathrm{N} / \mathrm{m})$ & 0,4152 \\
\hline Peso linear no ar (com água) & $q(\mathrm{~N} / \mathrm{m})$ & 1,7361 \\
Peso linear imerso (com água) & $\mu(\mathrm{N} / \mathrm{m})$ & 0,2265 \\
\hline \hline
\end{tabular}

Tabela C.2: Características gerais utilizadas nas simulações

\begin{tabular}{|c|c|c|}
\hline Característica & $\begin{array}{c}\text { Símbolo } \\
\text { (Unidade) }\end{array}$ & Magnitude \\
\hline Lâmina d'água & $h(\mathrm{~m})$ & 4,0 \\
Ângulos de topo & $\theta_{t}\left({ }^{\circ}\right)$ & $40-88$ \\
\hline Períodos de excitação & $T(\mathrm{~s})$ & $0,7-1,4$ \\
Amplitudes & $A_{m}(\mathrm{~m})$ & $0,050-0,250$ \\
\hline Coeficiente de arrasto & $C_{d}(-)$ & 1,2 \\
Coeficiente de atrito linha-solo & $\eta(-)$ & 0,4 \\
\hline \hline
\end{tabular}

De maneira a antecipar eventuais problemas e correções a serem feitas, foram realizadas simulações numéricas que resultaram na verificação da densidade de possibilidades de ocorrência de compressão dinâmica para as situações aventadas.

A quantidade de simulações realizadas foi bastante numerosa e, portanto, apenas alguns resultados são apresentados a fim de fornecer indicativos para a avaliação do material de preenchimento mais adequado e, ao mesmo tempo, antecipar a forma de apresentação dos resultados finais. Assim:

- Os resultados se referem aos pares de amplitude e período: 0,050m e 1,20s; $0,100 \mathrm{~m}$ e $1,00 \mathrm{~s}$; e $0,200 \mathrm{~m}$ e $0,80 \mathrm{~s}$, apresentados apenas como forma de exemplificar os resultados e perceber determinadas tendências e propriedades do fenômeno de interesse ${ }^{1}$;

- São apresentados: as possíveis condições de lançamentos; as trações no TDP em função do ângulo de topo; mapeamentos indicando para quais amplitudes, frequências e ângulos de topo a ocorrência do fenômeno é mais provável; e os comprimentos de onda esperados;

- Os resultados para os tubos preenchidos com areia e água são apresentados concomitantemente, a fim de permitir ao leitor a pronta comparação de ambos;

- Como esses resultados são preliminares, os mesmo serão apresentados sem explicações prolongadas.

\footnotetext{
${ }^{1}$ Essas condições foram as escolhidas por serem as mais próximas das propostas na matriz de ensaios, vide Seção 5.1.
} 
De antemão, cumpre destacar que as mesmas simulações foram refeitas após a construção do modelo físico e validação experimental de suas propriedades físicomecânicas, e os resultados obtidos são apresentados na Seção C.2.6.

\section{C.1.1 Resultados preliminares dos modelos de silicone com areia e com água}

Os resultados apresentados neste item foram obtidos a partir do procedimento numérico apresentado no fluxograma da Figura 4.1, para o modelo de linha flexível definido anteriormente, considerando os preenchimentos com areia e com água. O primeiro resultado apresenta os comprimentos mínimo $\left(L_{m i n}\right)$, suspenso $\left(L_{s}\right)$ e total $\left(L_{t}\right)$ dos modelos, além de suas projeções horizontais (Figuras C.1 e C.2).

Nesse caso, as condições de excitação não são relevantes, pois as variáveis avaliadas dependem exclusivamente da configuração estática da linha.

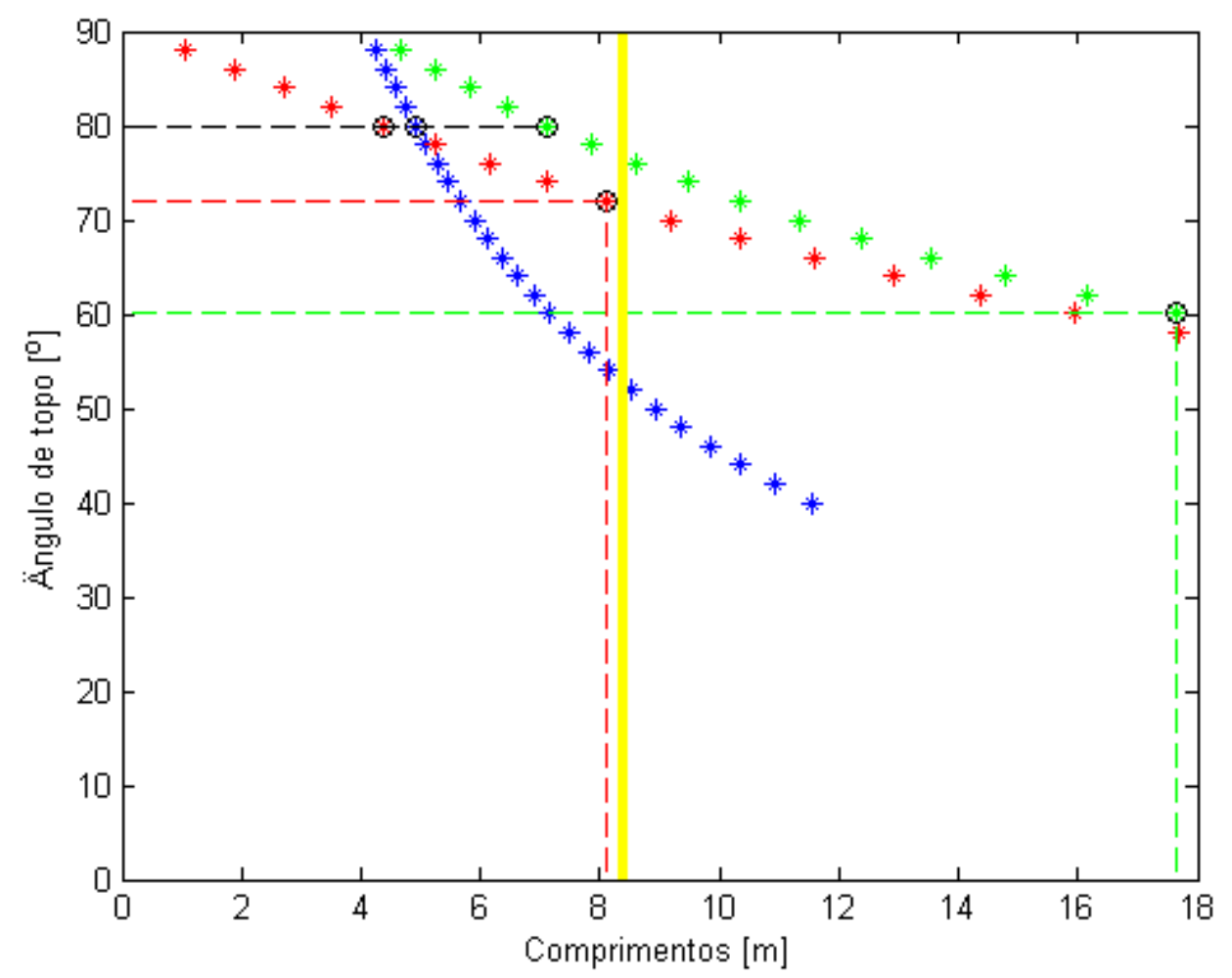

Figura C.1: Comprimentos pré-caracterização do modelo em água, preenchimento com areia. Dos marcadores: em verde, o comprimento total mínimo da linha; em azul, seu comprimento suspenso; em vermelho, sua projeção horizontal (total). A linha amarela representa o máximo comprimento útil do tanque.

Para a confecção das referidas figuras, foi utilizada a formulação de Patel \& Seyed (1995), que incorpora os efeitos da rigidez axial. Essas figuras são extremamente importantes, pois indicam os casos passíveis de serem ensaiados, considerando os comprimentos máximos do modelo e do $\mathrm{CH}$-TPN, sem que seja necessário o uso de ancoragem do modelo ao solo. 


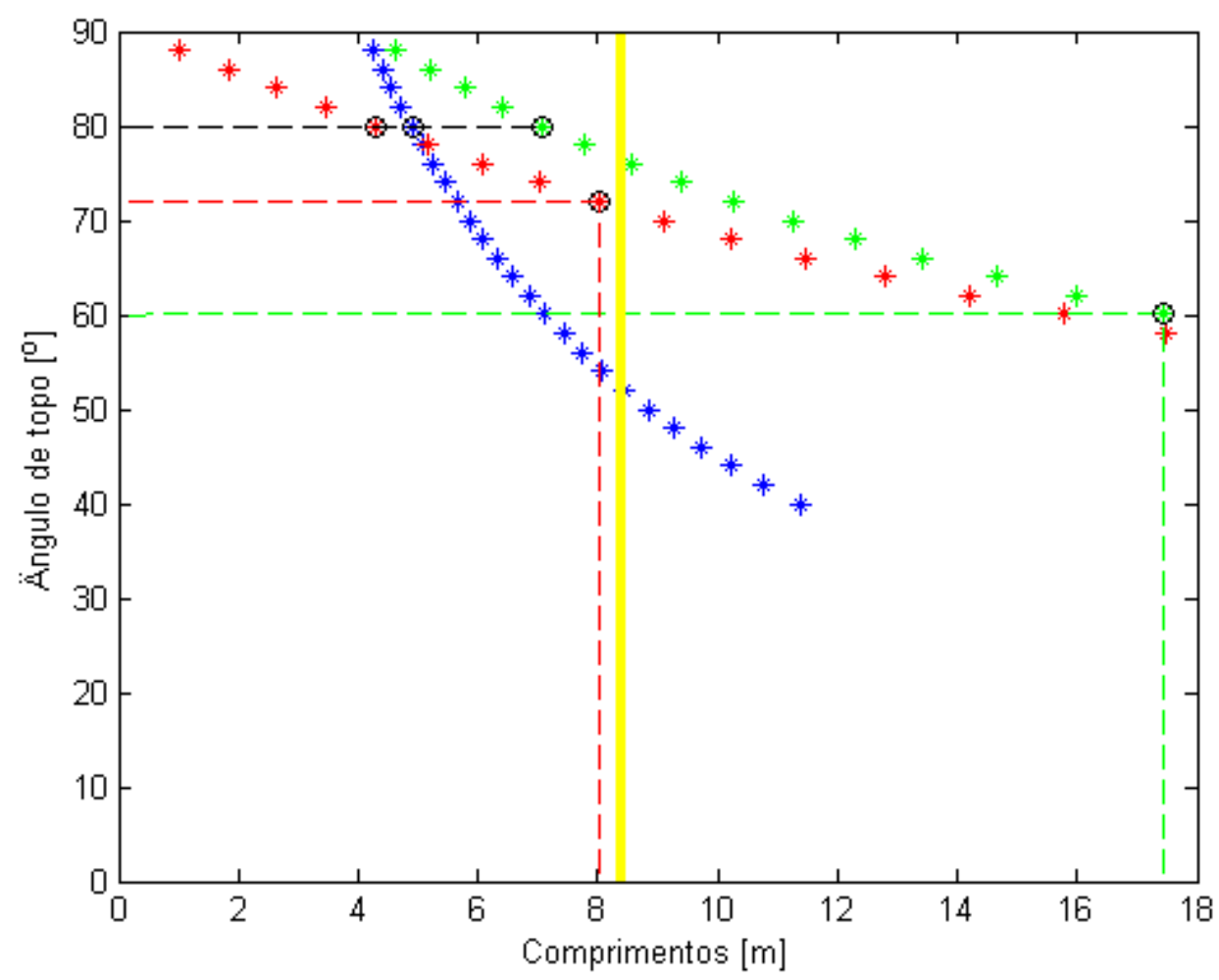

Figura C.2: Comprimentos pré-caracterização do modelo em água, preenchimento com água. Dos marcadores: em verde, o comprimento total mínimo da linha; em azul, seu comprimento suspenso; em vermelho, sua projeção horizontal (total). A linha amarela representa o máximo comprimento útil do tanque.

Convencionou-se que o comprimento mínimo $L_{\min }$ é tal que o peso do trecho que repousa no fundo ${ }^{2}$ seja responsável por uma força de atrito (uma percentagem $\eta$ da força normal) que equilibra a tração horizontal no TDP $\left(T_{0}\right)$.

Assim, define-se $L_{\min }=\frac{T_{0}}{\eta q}$, onde $q$ corresponde ao peso linear submerso da linha. O comprimento total $L_{t}$ do modelo é, então, dado por $L_{t}=L_{s}+L_{\min }$. Para melhor entendimento das situações ilustradas nas Figuras C.1 e C.2, explica-se que:

- A linha amarela representa o máximo comprimento disponível no CH-TPN, sem que haja a necessidade de movimentação da ponte rolante situada a meio comprimento do tanque;

- Os asteriscos vermelhos indicam, para diferentes ângulos de topo, as projeções horizontais do modelo em dada situação. Pontos à esquerda da linha amarela são passíveis de serem ensaiados, dada a consideração do item anterior (nesse caso, situações em que ângulo de topo seja maior que $72^{\circ}$ );

- Os asteriscos verdes representam os comprimentos totais do modelo. Como o maior comprimento de tubo disponível é de aproximadamente $18 \mathrm{~m}$, não poderão ser efetuados experimentos sob ângulos de topo menores que $60^{\circ 3}$; 
- Os asteriscos azuis referem-se aos comprimentos suspensos da linha, em cada lançamento.

Arbitrariamente, escolheu-se o ângulo de topo de $80^{\circ}$ para evidenciar a relação entre as curvas apresentadas: para a linha lançada sob essa configuração inicial, seu comprimento total mínimo é de cerca de $7,13 \mathrm{~m}$ para o modelo com areia e 7,07m para o preenchimento com água. Os comprimentos suspensos resultaram em 4,88m (e projeção horizontal de 4,50m, para o modelo com areia) e 4,84m (e projeção horizontal de $4,47 \mathrm{~m}$, para o preenchimento com água). Assim, em termos de lançamentos iniciais, ambos os modelos resultariam em situações semelhantes.

Saliente-se que, embora o comprimento máximo disponível do $\mathrm{CH}$-TPN possa ser alterado pela movimentação da ponte rolante, o uso de ancoragem permite reduzir o valor de $L_{\text {min }}$, de modo que sejam ensaiadas configurações com ângulos de topo menores que $72^{\circ}$.

Em termos da instrumentação necessária, é imprescindível o conhecimento prévio dos níveis de tração efetiva ao longo da linha ${ }^{4}$, para escolha adequada da célula de carga, bem como dos comprimentos das ondas de flexão gerados no TDP, a fim de discretizar a região do TDZ adequadamente, em termos da distribuição dos alvos refletivos sobre o modelo.

As Figuras C.3 a C.8 ilustram os envelopes de trações no TDP, em função do ângulo de topo da catenária no lançamento. É perceptível a influência das condições de excitação na resposta dinâmica: conforme essas condições se tornam mais severas (maiores amplitudes e frequências), maiores são os níveis das trações observadas. Entretanto, esses valores não chegam a $8 \mathrm{~N}$ para ambos os preenchimentos. Vale ressaltar que, no topo dos modelos, os valores das trações efetivas chegaram a $50 \mathrm{~N}$, indicando a necessidade de uma célula de carga com um fundo de escala adequado para esses níveis.

Cabe citar que, em todas essas figuras, e nas demais que ilustram as trações efetivas, as cargas críticas calculadas estão representadas por uma linha verde, para o caso biapoiado, e na cor magenta para o caso engastado-pinado. Além disso, nos pontos em que as cargas críticas teóricas são ultrapassadas pela tração mínima, existe a previsão de ocorrência teórica de compressão dinâmica e o marcador "asterisco vermelho" é circunscrito por outro marcador: um "círculo vermelho".

A despeito da grande semelhança entre os resultados gráficos mostrados para ambos os preenchimentos, essa similitude não é verificada ao longo de toda a faixa de valores simulados com o Anflex. A fim de corroborar essa assertiva, os resultados relativos às expectativas de ocorrência de compressão dinâmica para os modelos, foram confeccionadas as Figuras C.9 e C.10, apresentadas na sequência.

eventual possibilidade física, dado que se configuram como situações com grande comprimento total da linha, o que torna a situação tecnicamente difícil de ser monitorada na prática.

${ }^{4} \mathrm{~A}$ despeito da importância dos níveis de tração no topo para a escolha da célula de carga, por exemplo, os resultados dos estudos feitos para essa extremidade da linha foram retirados do texto da presente tese, a fim de não desviar o leitor do foco principal do presente trabalho. 
A partir dessas figuras, é possível notar que existe uma diferença apreciável no número esperado de ocorrências do fenômeno em estudo, considerando os modelos construídos e preenchidos com areia e água.

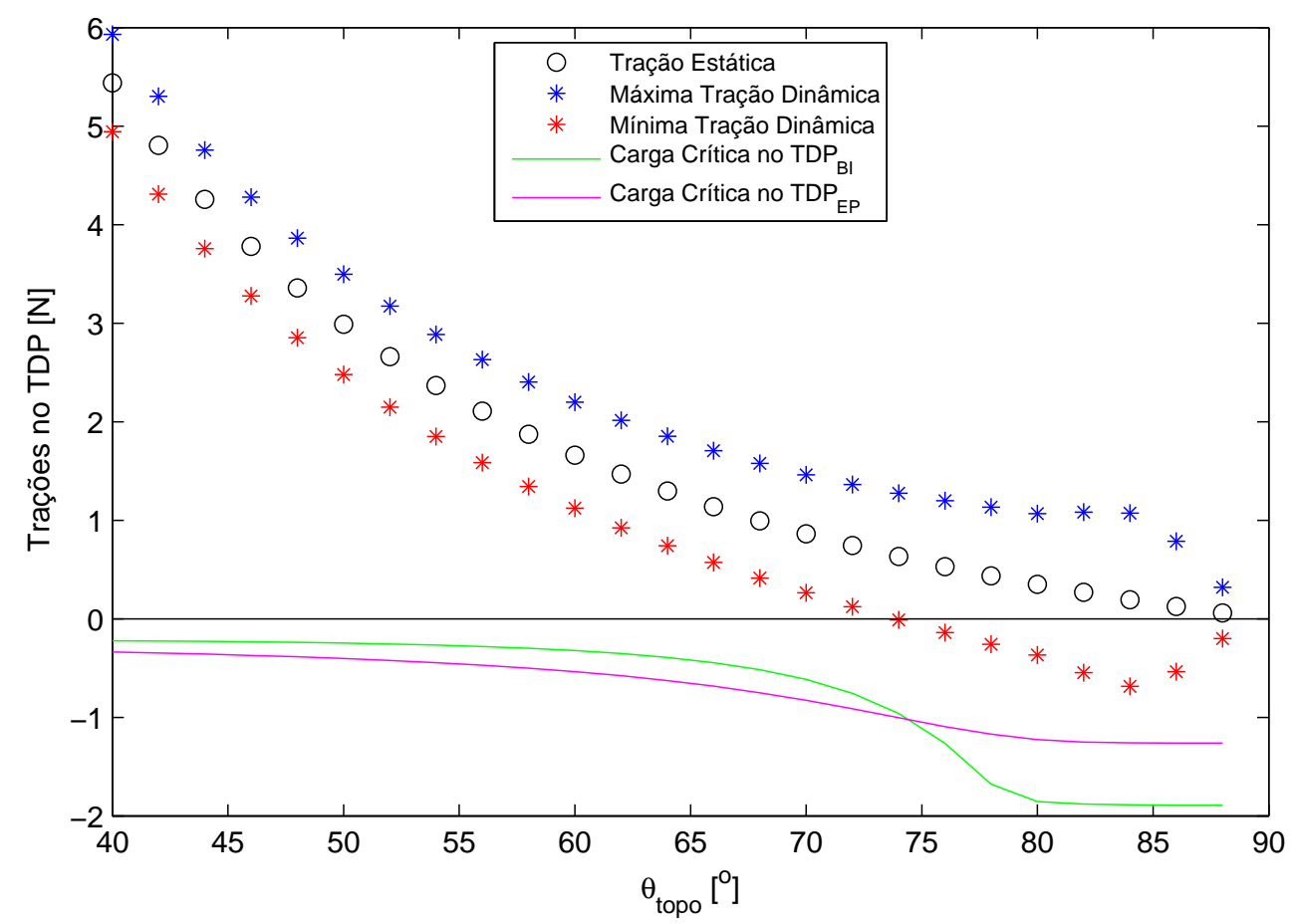

Figura C.3: Envelope de trações no TDP, $A=50 \mathrm{~mm}, T=1,20 \mathrm{~s}$ (modelo com areia pré-caracterização).

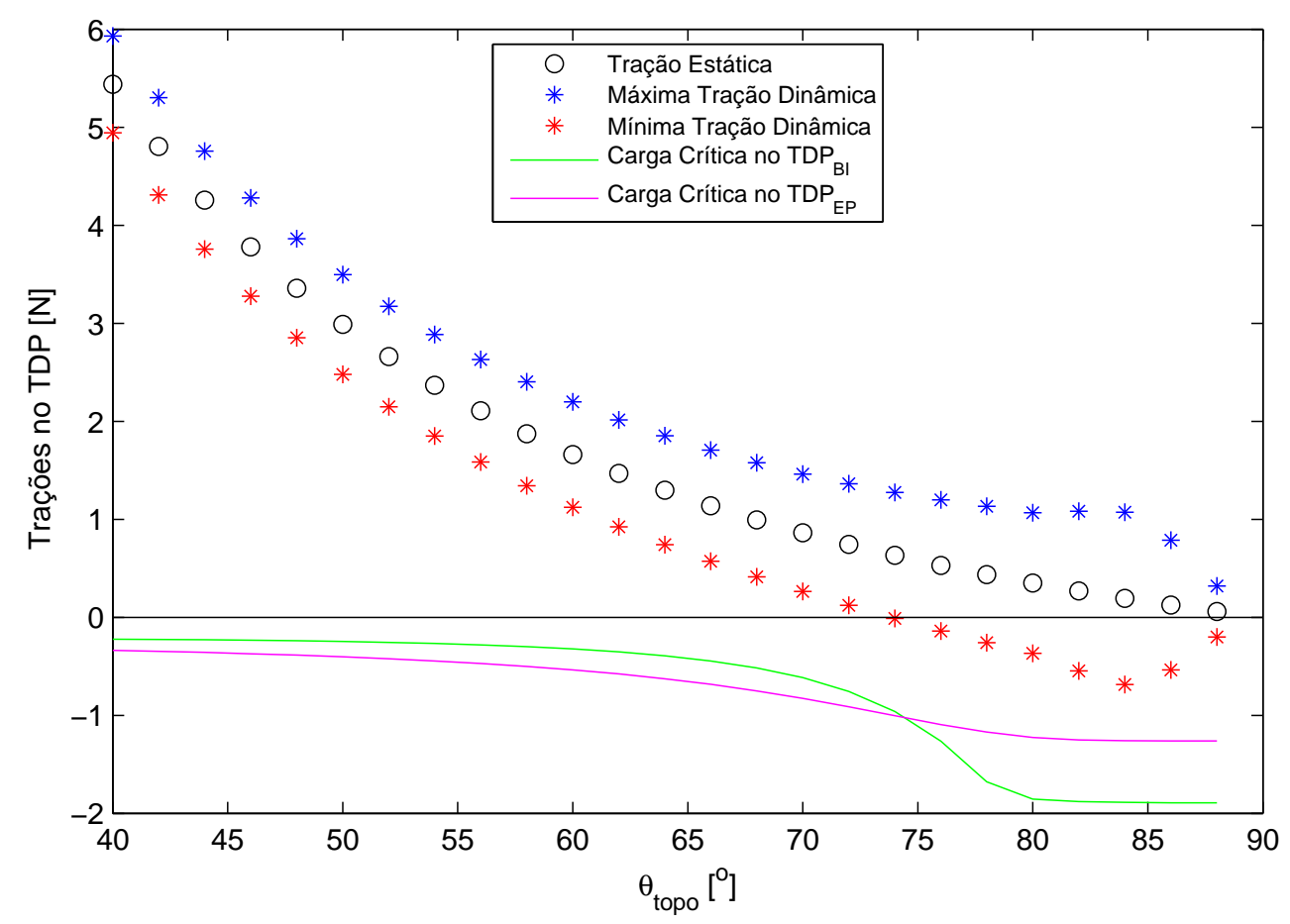

Figura C.4: Envelope de trações no TDP, $A=50 \mathrm{~mm}, T=1,20 \mathrm{~s}$ (modelo com água pré-caracterização). 


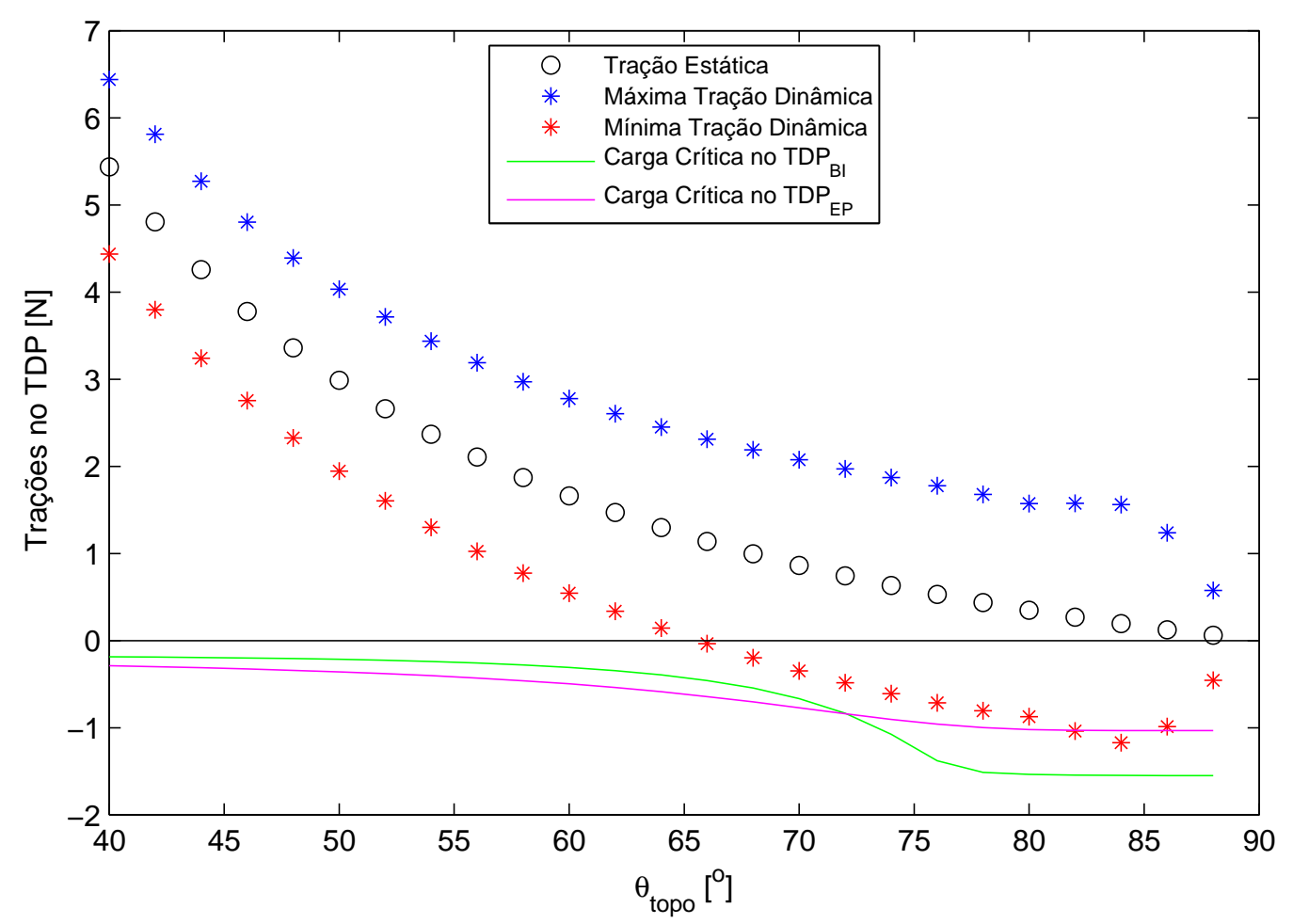

Figura C.5: Envelope de trações no TDP, $A=100 \mathrm{~mm}, T=1,00$ s (modelo com areia pré-caracterização).

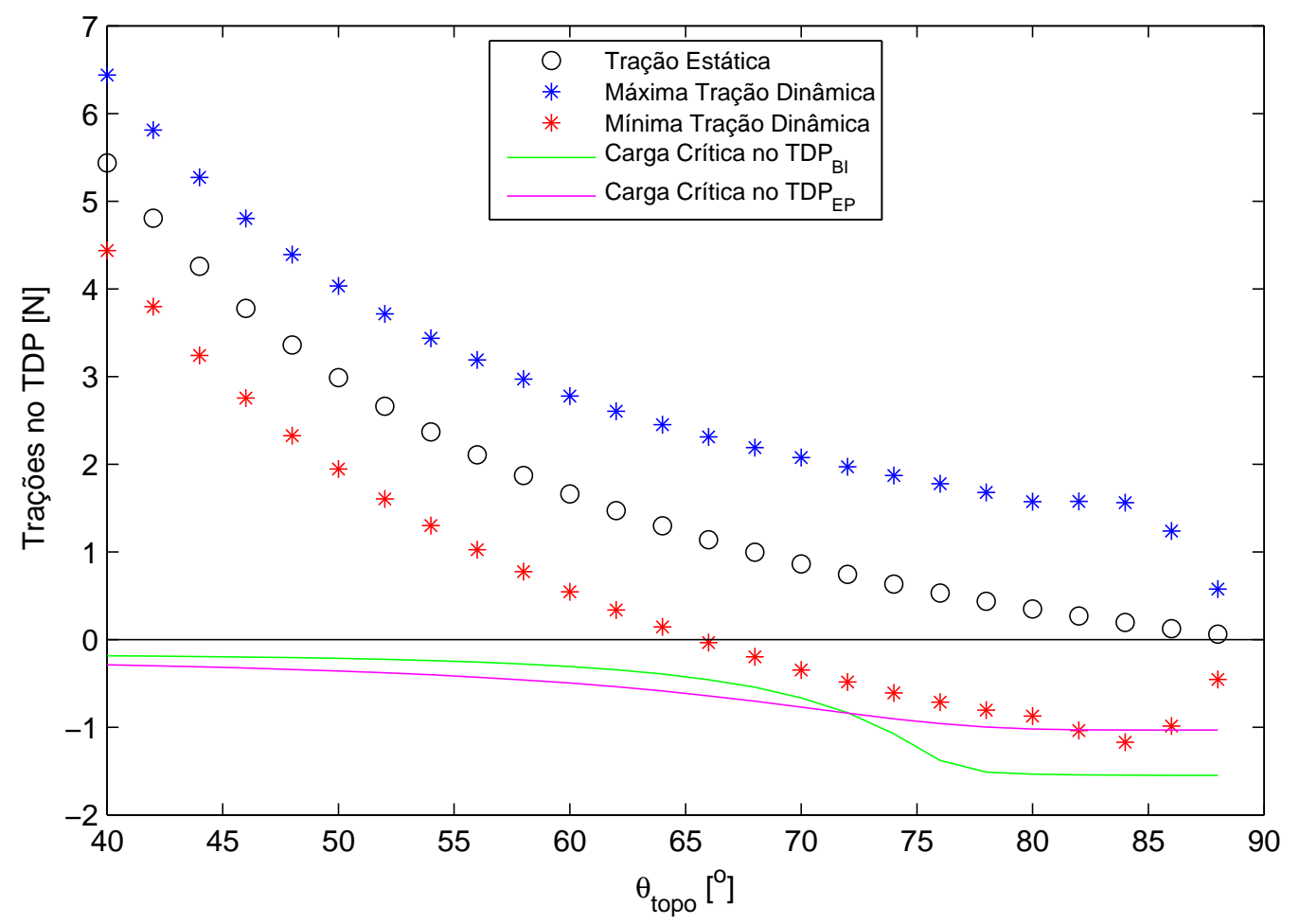

Figura C.6: Envelope de trações no TDP, $A=100 \mathrm{~mm}, T=1,00$ s (modelo com água pré-caracterização). 


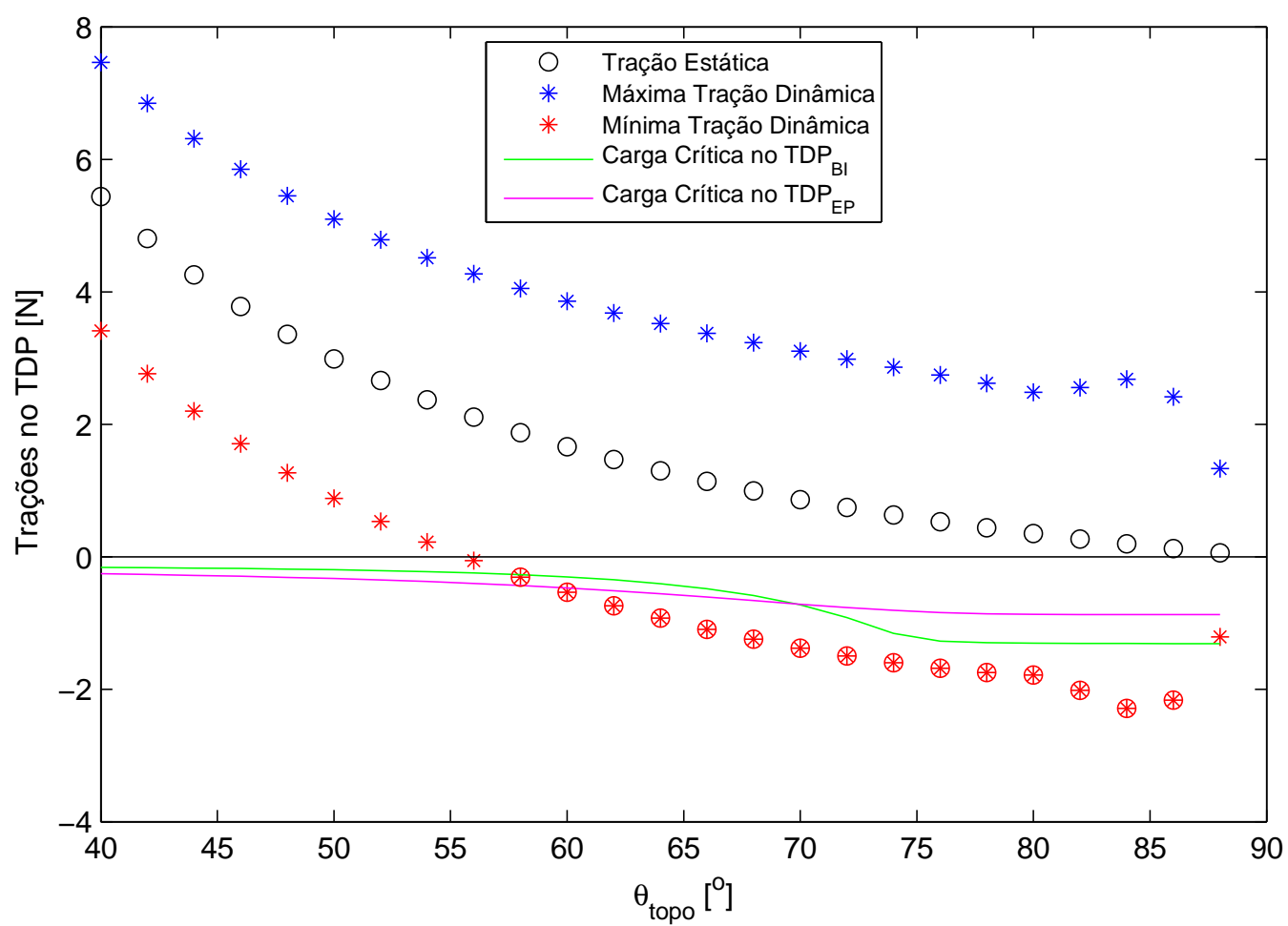

Figura C.7: Envelope de trações no TDP, $A=200 \mathrm{~mm}, T=0,80$ s (modelo com areia pré-caracterização).

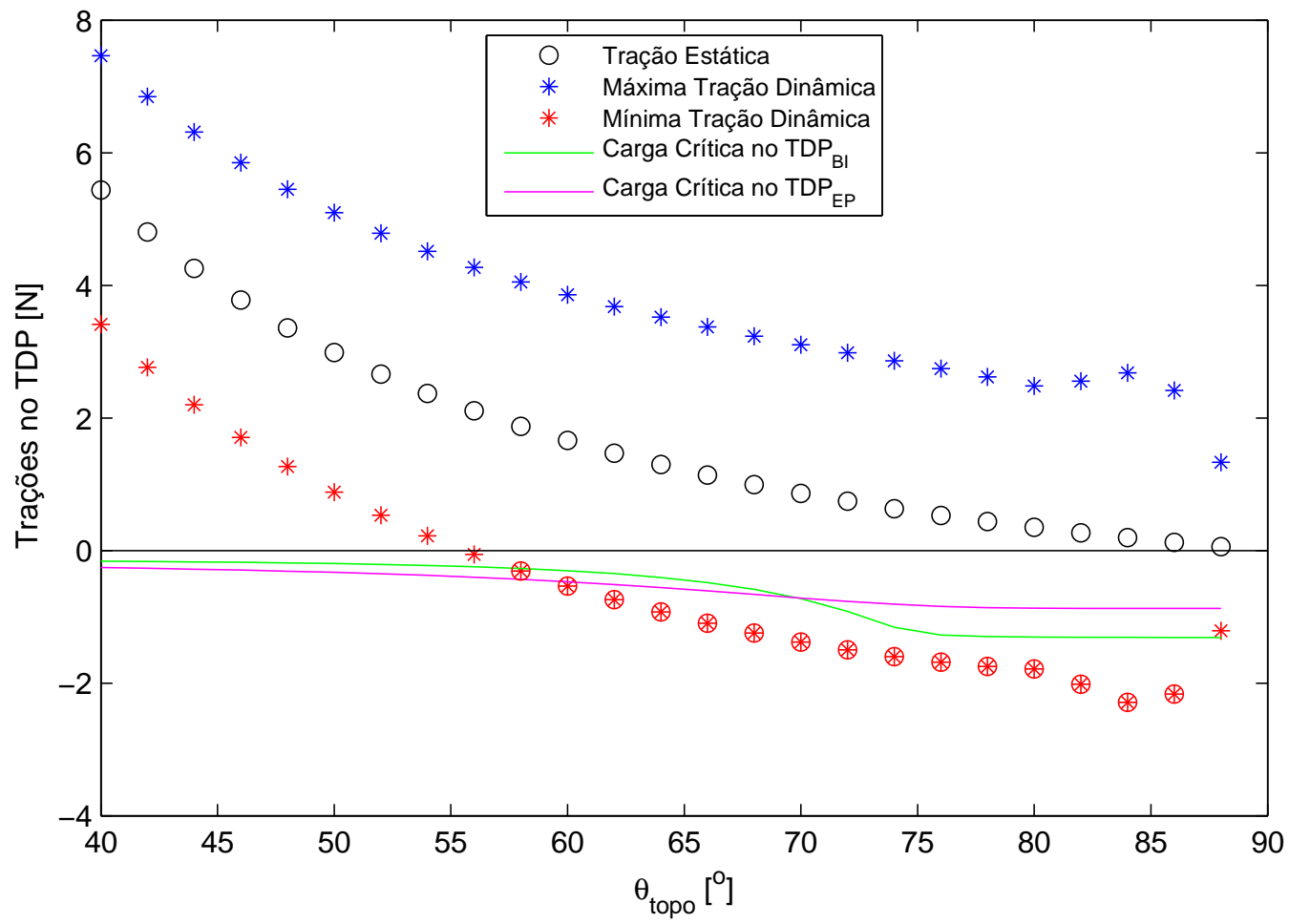

Figura C.8: Envelope de trações carga crítica no TDP, $A=200 \mathrm{~mm}, T=0,80 \mathrm{~s}$ (modelo com água précaracterização). 
Os resultados apresentados nas Figuras C.9 e C.10, facilitam a percepção dos comportamentos das previsões de compressão para ambos os modelos. Note-se que, para cada uma dessas figuras, o máximo número possível de ocorrências de compressão dinâmica é 25 (quantidade de ângulos de topo avaliada).

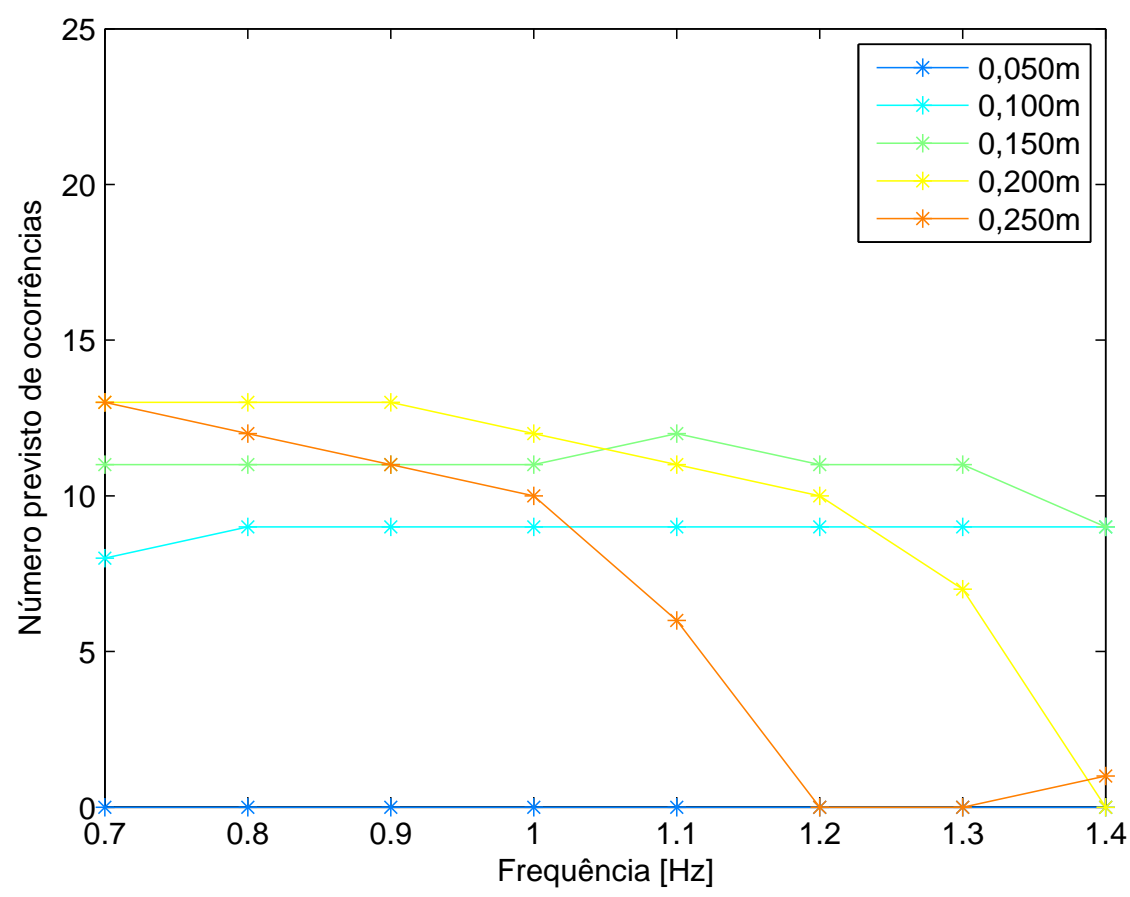

Figura C.9: Número de casos de compressão previstos para o TDP, modelo com areia.

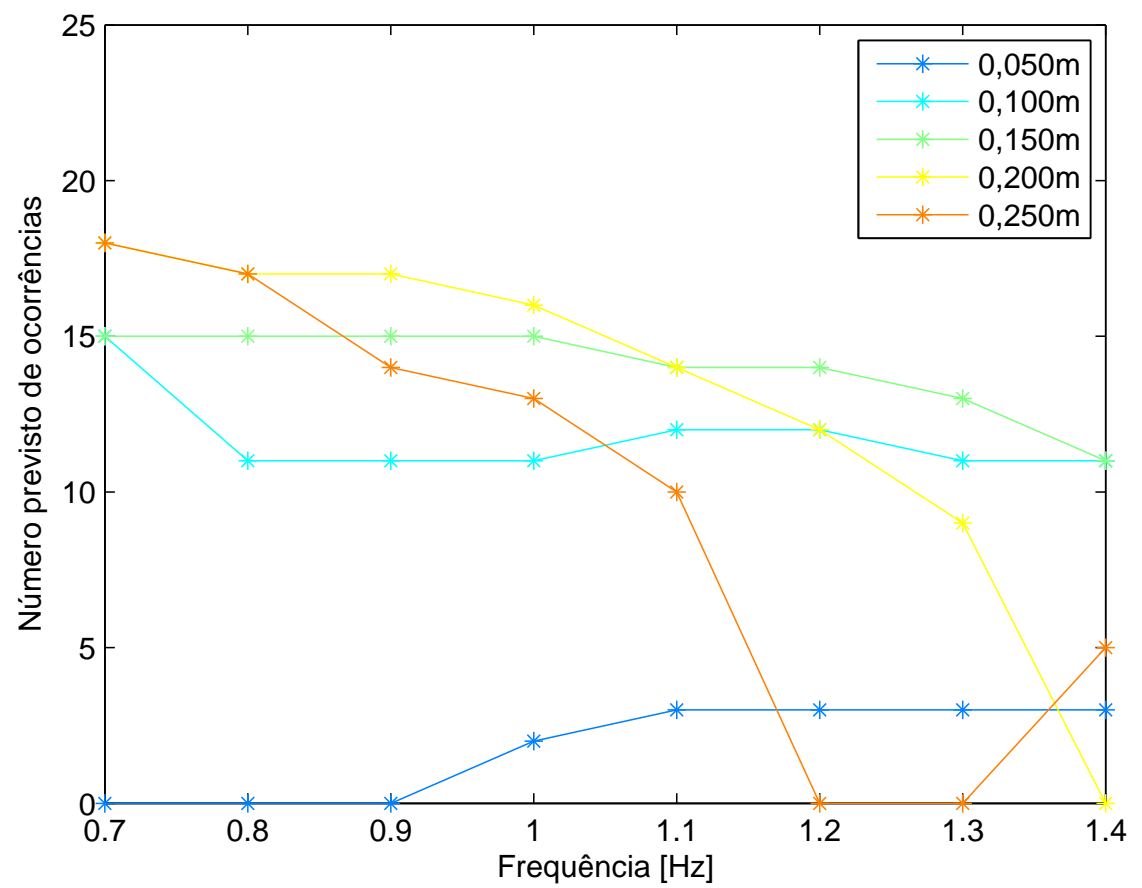

Figura C.10: Número de casos de compressão previstos para o TDP, modelo com água. 
Avaliando-se as situações simuladas, as expectativas quanto à quantidade de casos em que ocorre a compressão dinâmica indicam maior percentagem de ocorrência no modelo preenchido com água. A fim de investigar com maior nível de detalhes esses resultados, foi construída a Tabela C.3, onde as quantidades de ocorrência esperadas estão compiladas, caso a caso. Excepcionalmente, para efeito de comparação, apresentar-se-ão também os mesmos resultados para o topo da linha (Tabela C.4).

Tabela C.3: Compilação dos resultados das simulações pré-caracterização para o TDP.

\begin{tabular}{|c|c|c|c|c|c|c|c|c|c|}
\hline \multirow{2}{*}{\multicolumn{2}{|c|}{ AREIA (TDP) }} & \multicolumn{8}{|c|}{ Período [s] } \\
\hline & & 0,7 & 0,8 & 0,9 & 1,0 & 1,1 & 1,2 & 1,3 & 1,4 \\
\hline \multirow{5}{*}{ 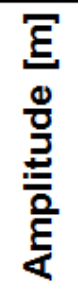 } & 0,050 & 0 & 0 & 0 & 0 & 0 & 0 & 0 & 0 \\
\hline & 0,100 & 8 & 9 & 9 & 9 & 9 & 9 & 9 & 9 \\
\hline & 0,150 & 11 & 11 & 11 & 11 & 12 & 11 & 11 & 9 \\
\hline & 0,200 & 13 & 13 & 13 & 12 & 11 & 10 & 7 & 0 \\
\hline & 0,250 & 13 & 12 & 11 & 10 & 6 & 0 & 0 & 1 \\
\hline
\end{tabular}

\begin{tabular}{|c|c|c|c|c|c|c|c|c|c|}
\hline \multirow{2}{*}{\multicolumn{2}{|c|}{ ÁGUA (TDP) }} & \multicolumn{8}{|c|}{ Período [s] } \\
\hline & & \multirow{2}{*}{$\frac{0,7}{0}$} & \multirow{2}{*}{$\frac{\mathbf{0 , 8}}{0}$} & \multirow{2}{*}{$\frac{0,9}{0}$} & \multirow{2}{*}{$\frac{1,0}{2}$} & \multirow{2}{*}{$\frac{1,1}{3}$} & \multirow{2}{*}{$\frac{1,2}{3}$} & \multirow{2}{*}{$\frac{1,3}{3}$} & \multirow{2}{*}{$\frac{1,4}{3}$} \\
\hline $\boldsymbol{g}$ & 0,050 & & & & & & & & \\
\hline 0 & 0,100 & 12 & 11 & 11 & 11 & 12 & 12 & 11 & 11 \\
\hline$\stackrel{5}{د}$ & 0,150 & 15 & 15 & 15 & 15 & 14 & 14 & 13 & 11 \\
\hline$\overline{0}$ & 0,200 & 18 & 17 & 17 & 16 & 14 & 12 & 9 & 0 \\
\hline$\frac{5}{4}$ & 0,250 & 18 & 17 & 14 & 13 & 10 & 0 & 0 & 5 \\
\hline
\end{tabular}

Tabela C.4: Compilação dos resultados das simulações pré-caracterização para o topo.

\begin{tabular}{|c|c|c|c|c|c|c|c|c|c|}
\hline \multirow{2}{*}{\multicolumn{2}{|c|}{ AREIA (TOP) }} & \multicolumn{8}{|c|}{ Período [s] } \\
\hline & & \multirow{2}{*}{$\begin{array}{c}0,7 \\
0\end{array}$} & \multirow{2}{*}{$\begin{array}{c}\mathbf{0 , 8} \\
0\end{array}$} & \multirow{2}{*}{$\begin{array}{c}0,9 \\
0\end{array}$} & \multirow{2}{*}{$\begin{array}{c}1,0 \\
0\end{array}$} & \multirow{2}{*}{$\begin{array}{c}1,1 \\
4\end{array}$} & \multirow{2}{*}{$\begin{array}{c}1,2 \\
5\end{array}$} & \multirow{2}{*}{$\begin{array}{l}\mathbf{1 , 3} \\
11 \\
\end{array}$} & \multirow{2}{*}{$\begin{array}{l}1,4 \\
25\end{array}$} \\
\hline$\underline{\Xi}$ & 0,050 & & & & & & & & \\
\hline \multirow{4}{*}{ 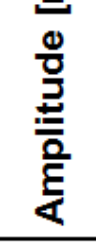 } & 0,100 & 5 & 5 & 5 & 6 & 20 & 25 & 25 & 25 \\
\hline & 0,150 & 6 & 6 & 6 & 21 & 25 & 25 & 25 & 25 \\
\hline & 0,200 & 7 & 7 & 17 & 21 & 25 & 25 & 25 & 25 \\
\hline & 0,250 & 7 & 6 & 6 & 7 & 5 & 4 & 0 & 25 \\
\hline
\end{tabular}

\begin{tabular}{|c|c|c|c|c|c|c|c|c|c|}
\hline \multirow{2}{*}{\multicolumn{2}{|c|}{ ÁGUA (TOP) }} & \multicolumn{8}{|c|}{ Período [s] } \\
\hline & & 0,7 & 0,8 & 0,9 & 1,0 & 1,1 & 1,2 & 1,3 & 1,4 \\
\hline \multirow{5}{*}{ 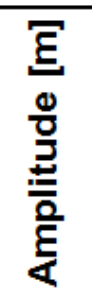 } & 0,050 & 1 & 5 & 6 & 6 & 6 & 20 & 25 & 25 \\
\hline & 0,100 & 8 & 8 & 19 & 24 & 25 & 25 & 25 & 25 \\
\hline & 0,150 & 16 & 21 & 25 & 25 & 25 & 25 & 25 & 25 \\
\hline & 0,200 & 20 & 23 & 25 & 25 & 25 & 25 & 25 & 25 \\
\hline & 0,250 & 20 & 22 & 25 & 25 & 24 & 12 & 0 & 25 \\
\hline
\end{tabular}


Um comportamento interessante refere-se à região no entorno dos períodos de excitação de 1,10s a 1,30s (vide Figuras C.13 e C.14), particularmente para a maior das amplitudes avaliadas: o número previsto de compressões decai drasticamente para a amplitude de $0,250 \mathrm{~m}$, enquanto cresce ou se mantém aproximadamente constante para as demais. A conclusão é válida para o TDP e o topo, com qualquer um dos preenchimentos. Outra tendência que pode ser verificada é o número esperado de ocorrência de compressão dinâmica, sempre maior no topo que no TDP. Uma possível explicação para isso reside no fato de que, embora as trações solicitantes no topo sejam as maiores ao longo da linha, esse ponto apresenta cargas críticas bem menores que as determinadas para o TDP.

Cabe ressaltar que, conquanto esses resultados se referem à simulações numéricas para os modelos pré-caracterização, qualquer conclusão a partir dessas figuras e tabelas seria precipitada. Reafirme-se que a apresentação dos resultados preliminares tem três objetivos: evidenciar eventuais diferenças, optando pelo modelo mais adequado; planejar os ensaios de maneira mais ajustada às particularidades dos resultados esperados; e familiarizar o leitor com a forma de apresentação dos resultados.

Com vistas nesse último objetivo, apresentam-se dois mapeamentos confeccionados a partir das condições avaliadas nas simulações realizadas.

Em ambos os mapeamentos, asteriscos vermelhos indicam a ocorrência de instabilidade dinâmica por flambagem, enquanto que os verdes ilustram as situações em que o fenômeno não ocorre, de acordo com as previsões teóricas baseadas no modelo bidimensional utilizado.

O primeiro mapeamento (Figuras C.11 e C.12) é uma perspectiva tridimensional, que ilustra concomitantemente as amplitudes e períodos de excitação e os ângulos de topo, com suas respectivas discretizações, tais como apresentados na Tabela C.2.

Sua interpretação não é trivial, dada a quantidade de informações que um gráfico deste tipo encerra. Entretanto, ele possui uma particularidade interessante: ilustra a densidade de ocorrências de compressão dinâmica (asteriscos vermelhos), dando indícios de qual região escolher para determinação da matriz de ensaios. Pontos circundados em azul apontam para indícios de compressão quando aventadas as condições de contorno do vínculo engastado-pinado.

Por essas figuras, a escolha mais adequada para avaliação de casos de compressão dinâmica nos modelos parece ser a sub-região caracterizada pelos maiores períodos de excitação, em conjunto com os maiores ângulos de topo e maiores amplitudes. 


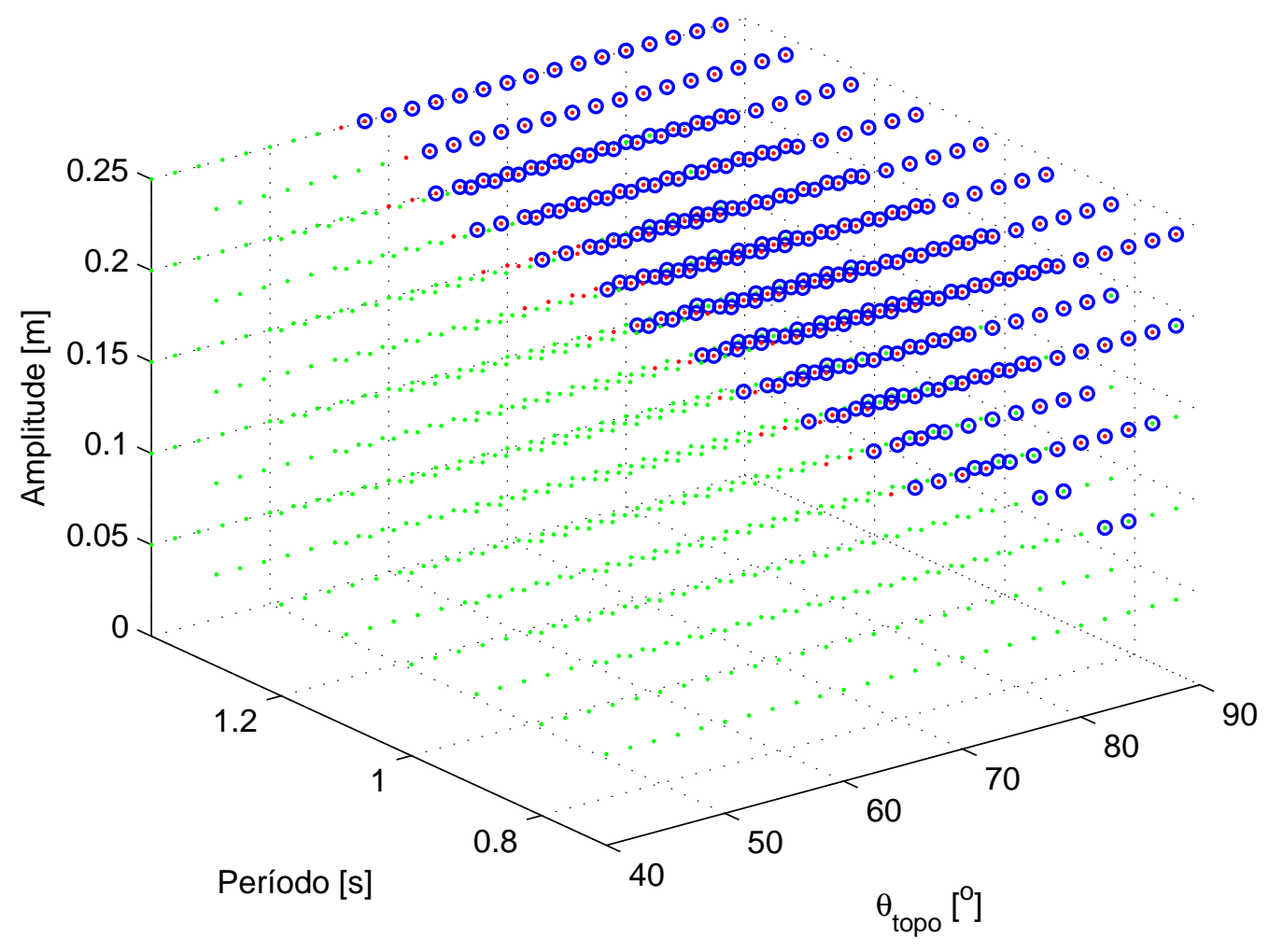

Figura C.11: Mapeamento 3D preliminar da linha de silicone com preenchimento com areia, para o TDP. Em vermelho, ocorrência de compressão; em verde, não ocorrência.

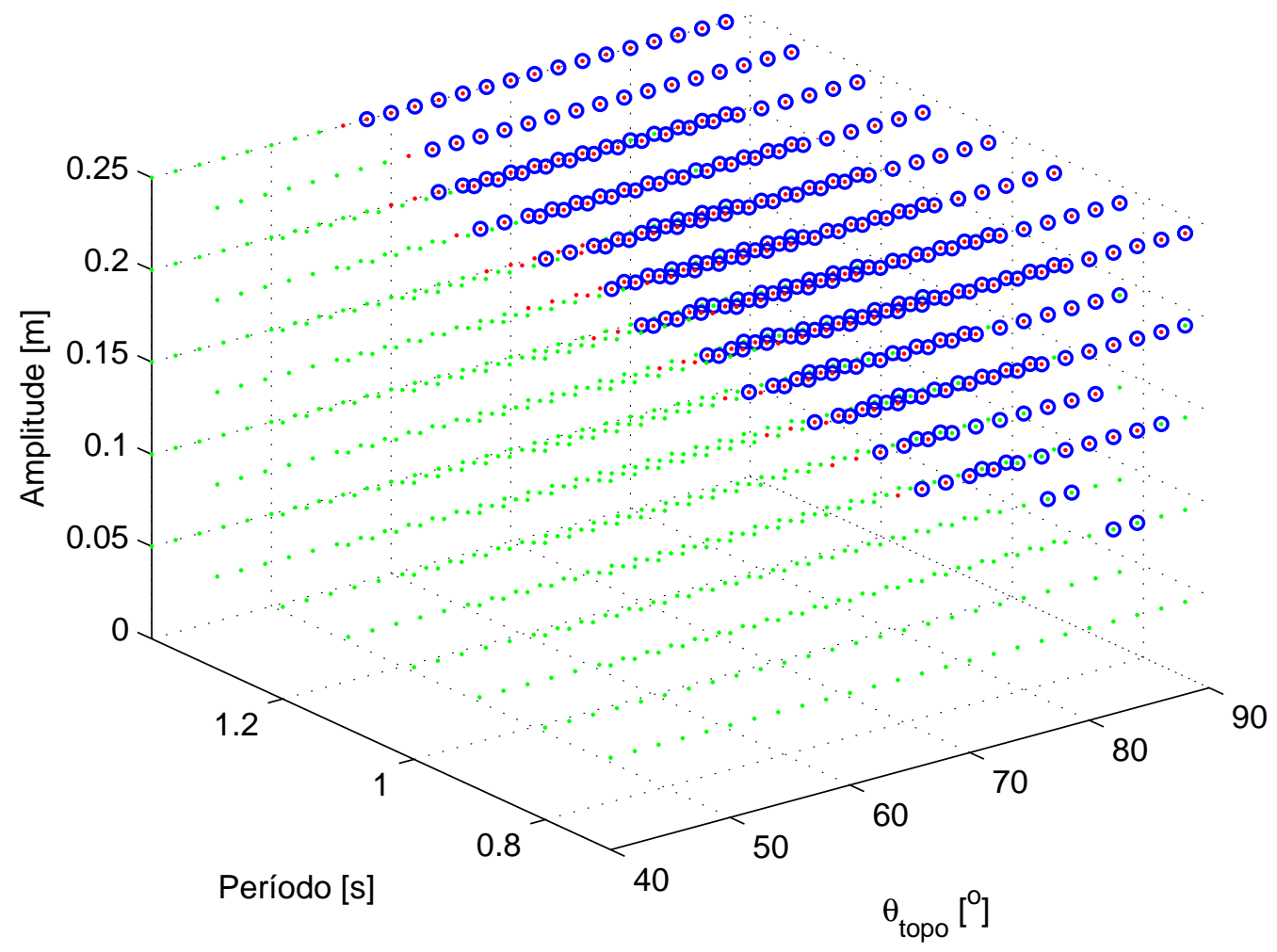

Figura C.12: Mapeamento 3D preliminar da linha de silicone com preenchimento com água, para o TDP. Em vermelho, ocorrência de compressão; em verde, não ocorrência. 
As Figuras C.13 e C.14 foram desenvolvidas de maneira a permitir que, fixando-se o período de excitação, cada situação (ângulos de topo e amplitudes) seja prontamente avaliada em termos da possibilidade de ocorrência de compressão dinâmica.
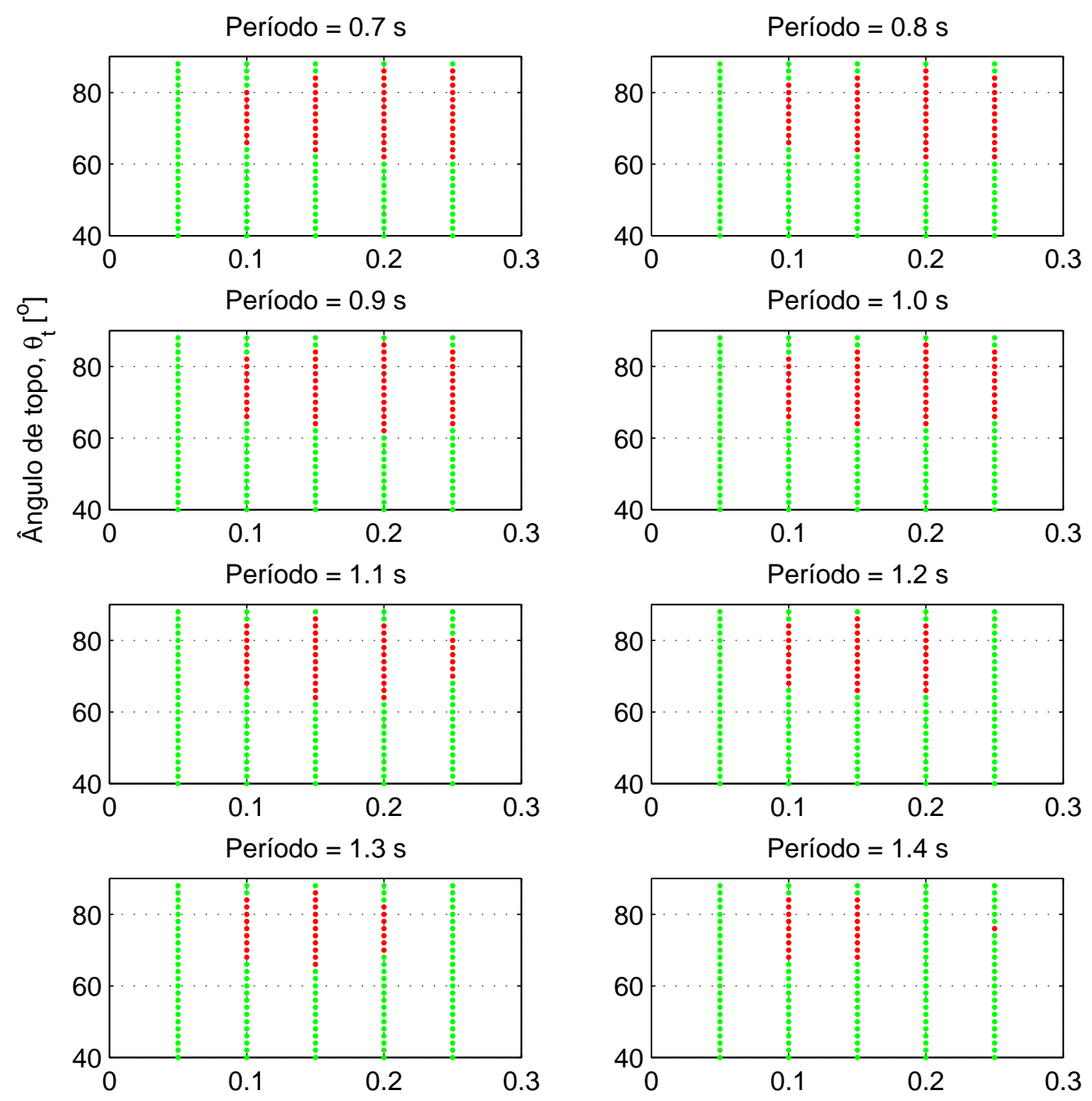

Amplitude [m]

Figura C.13: Amplitudes de excitação por ângulo de topo da linha de silicone com areia, para o TDP.

Em vermelho, ocorrência de compressão; em verde, não ocorrência - (Aranha et al., 2001).

Os círculos azuis foram suprimidos desse mapeamento, a fim de não confundir o leitor.

A escolha por fixar o período em cada ilustração da Figura C.13 pareceu a mais interessante por duas razões principais:

1. Na fase de projeto de um sistema oceânico, as características da locação, entre elas os períodos típicos, são bem definidas estatisticamente, de maneira que essa ilustração pode ser útil a fim de evitar ângulos de topo de instalação que comprometam sua integridade estrutural, baseada na ocorrência de compressão dinâmica; 
2. Durante a operação, esse mapeamento pode ser útil em situações ambientais atípicas (distintas das de projeto). Nesse caso, uma alteração no ângulo de topo poderia fazer com que o fenômeno pudesse ser evitado ou mitigado, ao invés de interroper a produção ou confiar que o riser suporte os carregamentos associados a essas condições inesperadas.
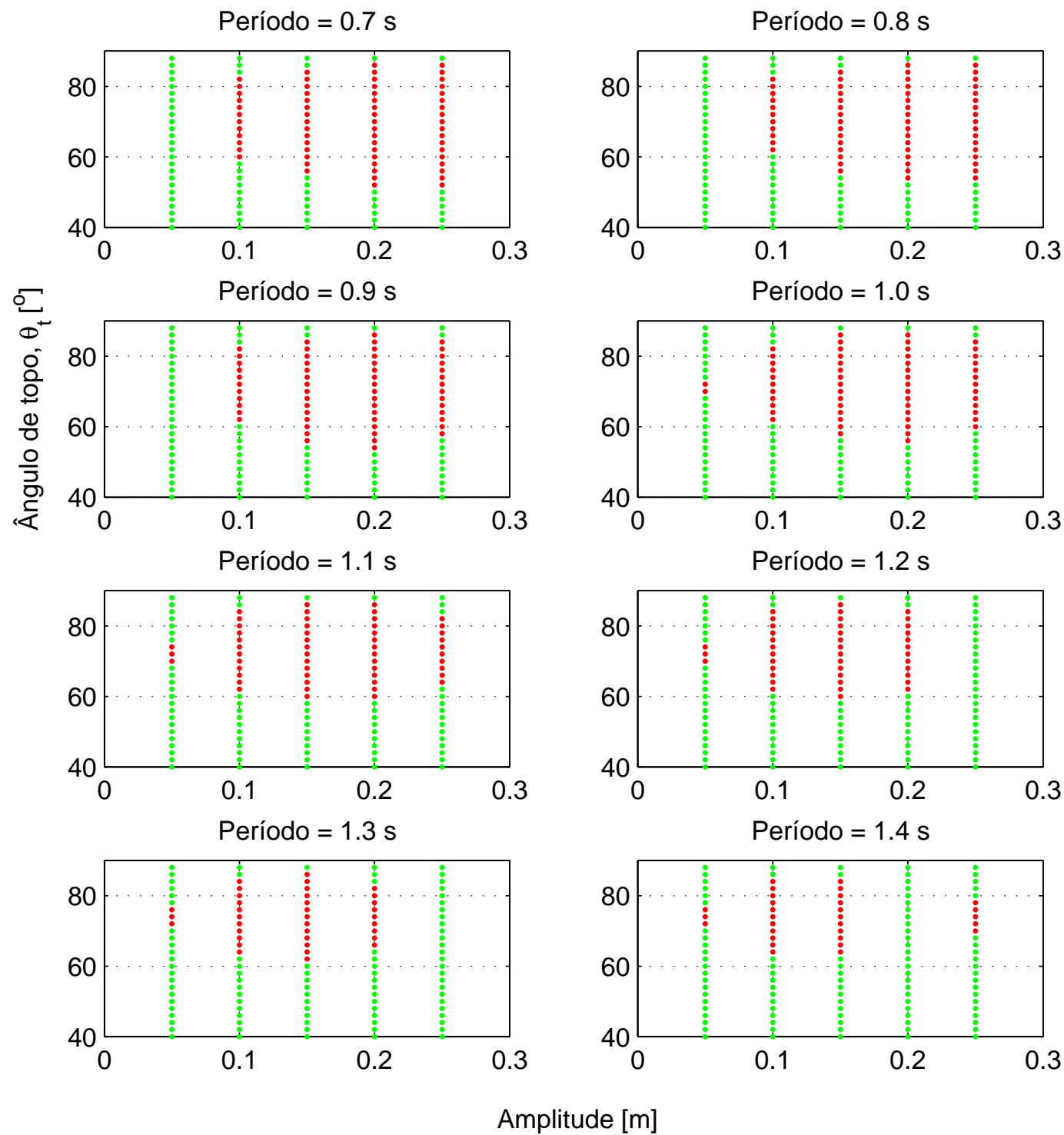

Figura C.14: Amplitudes de excitação por ângulo de topo da linha de silicone com água, para o TDP. Em vermelho, ocorrência de compressão; em verde, não ocorrência - (Aranha et al., 2001).

Os círculos azuis foram suprimidos desse mapeamento, a fim de não confundir o leitor.

O uso desses mapeamentos como ferramenta de projeto ou de operação demandariam a incorporação dos efeitos dinâmicos tridimensionais sobre a linha, principalmente os relativos à torção e seu não-confinamento a um plano vertical fixo, bem como a generalização das características de excitação, com a utilização dos espectros de mar da locação escolhida, como entrada de dados das simulações, por exemplo. 
Nesse sentido, os trabalhos de Ramos Jr \& Pesce (2003) e Aranha \& Pinto (2001) são de importância vital: o primeiro por prover as definições e equacionamentos tridimensionais do problema; o segundo, por prever a consideração de parâmetros estatísticos ambientais na formulação das trações analíticas.

A fim de por termo à presente seção, são apresentadas as Tabelas C.5 e C.6, nas quais estão compiladas os valores máximo e mínimo dos comprimentos de ondas de flexão esperados, para as duas condições de vínculos avaliadas e para o modelo com areia e água.

As referidas tabelas são sucedidas pelas Figuras C.15 e C.16 que ilustram o comportamento esperado para os comprimentos de onda de ambos os modelos, em função do ângulo de topo. Cabe lembrar que, por premissa, não serão ensaiados casos em que os ângulos de topo sejam menores que $60^{\circ}$. Dessa forma, é interessante perceber a simetria das curvas no entorno desse ângulo.

Tabela C.5: Previsões analíticas dos comprimentos das ondas de flexão (modelo com areia, précaracterização)

\begin{tabular}{|c|c|c|c|c|}
\hline Caso & $\lambda_{\text {máx }}^{B I}[\mathrm{~m}]$ & $\lambda_{\text {máx }}^{E P}[\mathrm{~m}]$ & $\lambda_{\min }^{B I}[\mathrm{~m}]$ & $\lambda_{\min }^{E P}[\mathrm{~m}]$ \\
\hline Amplitude 0,050m e período 1,20s & 0,4825 & 0,4573 & 0,3269 & 0,4007 \\
\hline Amplitude 0,100m e período 1,00s & 0,5051 & 0,4390 & 0,2925 & 0,3584 \\
\hline Amplitude 0,200m e período 0,80s & 0,5177 & 0,4239 & 0,2617 & 0,3205 \\
\hline \hline
\end{tabular}

Tabela C.6: Previsões analíticas dos comprimentos das ondas de flexão (modelo com água, précaracterização)

\begin{tabular}{|c|c|c|c|c|}
\hline Caso & $\lambda_{\text {máx }}^{B I}[\mathrm{~m}]$ & $\lambda_{\text {máx }}^{E P}[\mathrm{~m}]$ & $\lambda_{\text {mín }}^{B I}[\mathrm{~m}]$ & $\lambda_{\text {mín }}^{E P}[\mathrm{~m}]$ \\
\hline Amplitude 0,050m e período 1,20s & 0,7775 & 0,6204 & 0,2715 & 0,3328 \\
\hline Amplitude 0,100m e período 1,00s & 0,7185 & 0,5807 & 0,2478 & 0,3038 \\
\hline Amplitude 0,200m e período 0,80s & 0,6492 & 0,5328 & 0,2217 & 0,2717 \\
\hline
\end{tabular}

A respeito desses resultados, cabe uma observação importante: os comprimentos esperados para as ondas no modelo com areia são sensivelmente menores e, portanto, mais fáceis de serem visualizadas, o que justificaria, eventualmente, a escolha por esse material de preenchimento. 

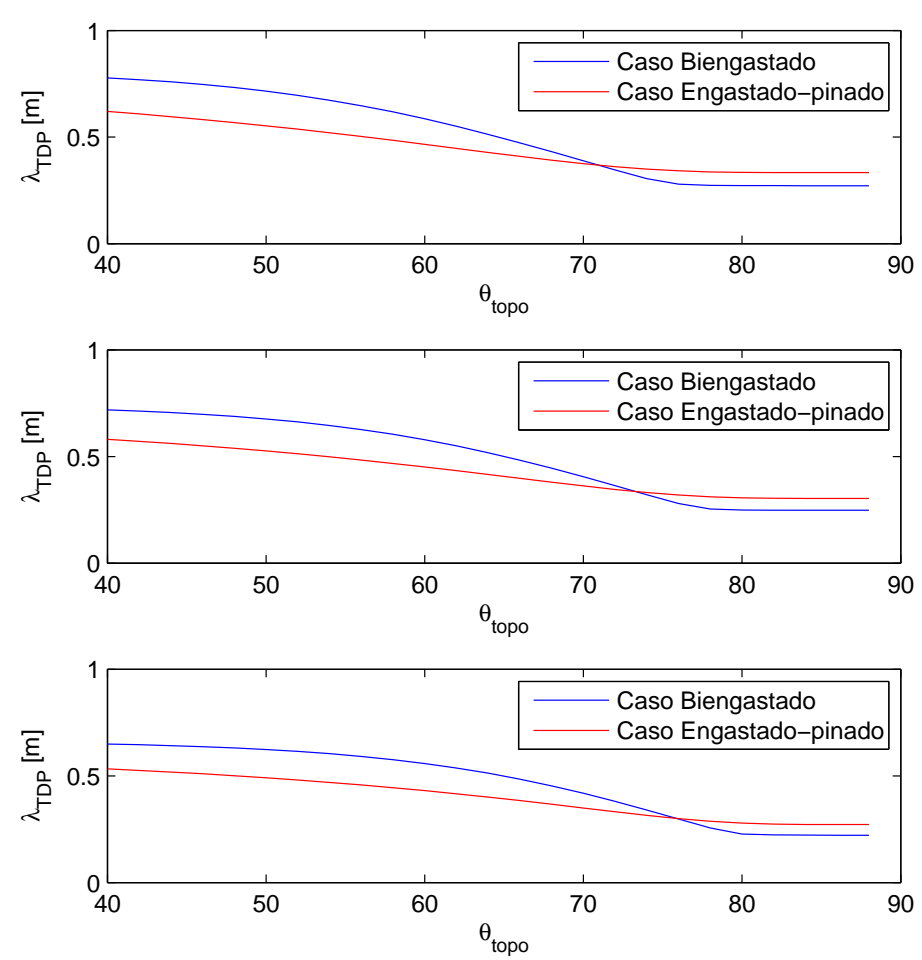

Figura C.15: Comprimentos de ondas de flexão no TDP esperados para o modelo com areia. Acima: $A=50 \mathrm{~mm}, T=1,20 \mathrm{~s}$; no meio: $A=100 \mathrm{~mm}, T=1,00 \mathrm{~s}$; abaixo: $A=200 \mathrm{~mm}, T=0,80 \mathrm{~s}$.
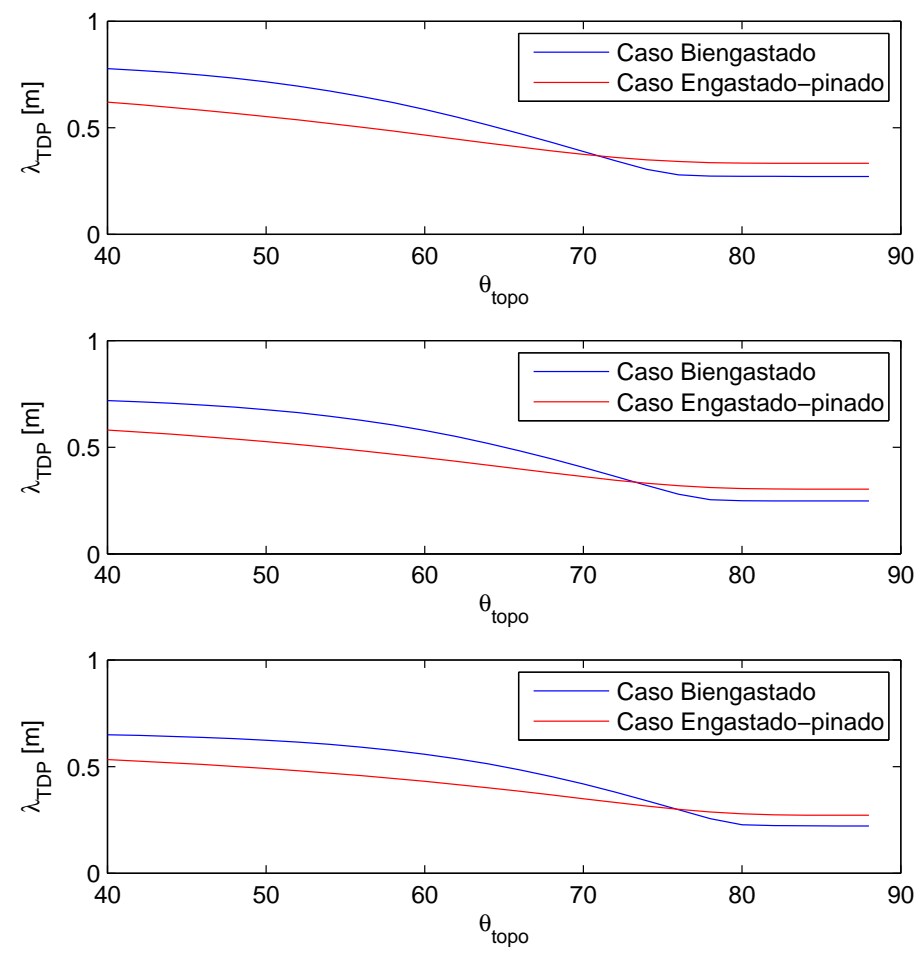

Figura C.16: Comprimentos de ondas de flexão no TDP esperados para o modelo com água. Acima: $A=50 \mathrm{~mm}, T=1,20 \mathrm{~s}$; no meio: $A=100 \mathrm{~mm}, T=1,00 \mathrm{~s}$; abaixo: $A=200 \mathrm{~mm}, T=0,80 \mathrm{~s}$. 


\section{C.2 Caracterização físico-mecânica do modelo flexível}

De maneira a verificar as propriedades físico-mecânicas do tubo de silicone, vazio e com preenchimentos com areia ou água, foram realizadas uma série de experimentos, aqui descritos como ensaios de caracterização. O objetivo principal é verificar a influência dessas propriedades na dinâmica esperada para o modelo nos ensaios principais.

\section{C.2.1 Checagem dos diâmetros interno e externo do tubo}

Como primeiro teste, foram utilizados diversos trechos da mangueira para determinar os diâmetros interno e externo, a partir de medições feitas com o uso de um paquímetro digital.

Como resultado, foram obtidos os seguintes valores:

- Diâmetro interno: $D_{i n t}=(6,86 \pm 0,07) \mathrm{mm}$;

- Diâmetro externo: $D_{e x t}=(14,06 \pm 0,11) \mathrm{mm}$.

Foram feitas 79 medições do diâmetro interno (nas extremidades de várias amostras) e 89 do diâmetro externo (ao longo dos comprimentos das mesmas amostras) para chegar a esses valores. Consideraram-se, para efeito de apresentação dos resultados, o desvio-padrão das amostras e as incertezas associadas aos instrumentos de medição.

Com os valores dos diâmetros foi possível calcular a área da seção transversal do modelo (coroa circular), através da equação $A=\frac{\pi}{4} \cdot\left(D_{e x t}^{2}-D_{\text {int }}^{2}\right)$, bem como inércia de área $I$ do mesmo, com respeito à sua seção transversal, dada por $I=\frac{\pi}{64} \cdot\left(D_{\text {ext }}^{4}-D_{\text {int }}^{4}\right)$ e a inércia polar com relação ao eixo central do tubo, dada por $J=\frac{\pi}{32} \cdot\left(D_{\text {ext }}^{4}-D_{\text {int }}^{4}\right)$. Os resultados auferidos foram:

- Área da seção transversal: $A=(1,183 \pm 0,013) \cdot 10^{-4} \mathrm{~m}^{2}$;

- Inércia de área: $I=(1,810 \pm 0,001) \mathrm{m}^{-9}$;

- Inércia polar de área: $\mathrm{J}=(3,619 \pm 0,001) \mathrm{m}^{-9}$;

Os erros e incertezas associados a essas propriedades, calculadas diretamente a partir dos diâmetros medidos, são bastante sensíveis a esses valores, mas de pequena monta em termos absolutos; por isso sua omissão na apresentação de seus valores. Além disso, esses últimos valores, juntamente com o módulo de elasticidade $E$, a ser determinado posteriormente por ensaios específicos apresentados na Seção C.2.3, permitem verificar os valores empíricos obtidos para as rijezas axial (EA), flexional (EI) e torcional (GJ), este último calculado a partir do módulo de cisalhamento teórico $G$ (relacionado com o módulo de elasticidade e o coeficiente de Poisson). 


\section{C.2.2 Massas lineares no ar e pesos submersos}

O ensaio seguinte foi realizado com o objetivo de medir a massa linear própria da linha flexível no ar. Para tanto, mediu-se a massa de um trecho de $(1,0000 \pm 0,0005) \mathrm{m}$ com o uso de uma trena, obtendo-se como resultado o valor $(0,152 \pm 0,001) \mathrm{kg}$. A divisão da massa dessa amostra de silicone pelo seu respectivo comprimento resultou na massa linear própria, $(0,152 \pm 0,001) \mathrm{kg} / \mathrm{m}$ e seu peso linear próprio $(1,491 \pm$ $0,001) \mathrm{N} / \mathrm{m}$.

- Massa linear própria: $m=(0,152 \pm 0,001)^{5} \mathrm{~kg} / \mathrm{m}$;

- Peso linear próprio: $\mathrm{mg}=(1,491 \pm 0,003) \mathrm{N} / \mathrm{m}$.

Sempre que necessário, adotou-se o valor $g=9,8067 \mathrm{~m} / \mathrm{s}^{2}$ como sendo a magnitude do campo gravitacional local. Esse valor foi verificado junto ao Instituto de Física (IF) da Universidade de São Paulo (USP).

A fim de averiguar e constatar a coerência dos dados coletados, optou-se por checar o volume $V$ da amostra de tubo, a partir de dois conjuntos independentes de resultados:

- Com o uso da equação $V=A$. $L$, onde $L$ é o comprimento da amostra e $A$ a área da seção transversal determinada na seção anterior;

- E sua comparação com o resultado obtido pela equação $V=\frac{M}{\rho_{m}}$, onde $M$ é a massa do comprimento $L$ do tubo de silicone, de sorte que $M=m \cdot L$, e $\rho_{m}$ é a densidade do material, no caso, silicone.

Assumiu-se que as propriedades do silicone utilizado para confecção do tubo são homogêneas e isotrópicas, o que sabidamente não é verdade, embora pareça uma aproximação razoável.

Os valores calculados para o volume da amostra, a partir dos dois equacionamentos citados, apresentaram diferença relativa menor que $0,01 \%$, o que reforça a coerência dos dados colhidos nesses primeiros ensaios de caracterização.

Considerando-se as incertezas das medidas tomadas, é possível afirmar que os volumes calculados são identicamente iguais, com valor aproximado $V=1,183 \cdot 10^{-4} \mathrm{~m}^{3}$.

O valor inicialmente adotado para a densidade foi, posteriormente validado, obtendo valor muito próximo de $1.210 \mathrm{~kg} / \mathrm{m}^{3}$. Também segundo o fabricante, o material possui dureza Shore $A^{6}$ de $(65 \pm 5)$.

Foram preparadas dez amostras do tubo de silicone, com comprimentos variando entre $40 \mathrm{~mm}$ e $65 \mathrm{~mm}$ para testes em laboratório. Cada teste consistia em duas etapas distintas a serem comparadas a posteriori: (i) medição de massa em uma balança de precisão ${ }^{7}$, seguida pela divisão de cada valor pelo volume calculado a partir dos

\footnotetext{
${ }^{5} \mathrm{~A}$ massa linear própria, mais precisamente, foi determinada como sendo igual a 151,62 g/m

${ }^{6}$ Essa dureza foi obtida a partir de ensaios de acordo com a norma ASTM D2240, da American Society for Testing and Materials

${ }^{7}$ Gentilmente cedida pelo LFS-USP - Laboratório de Fenômenos de Superfície, dedicado ao estudo da tribologia de materiais.
} 
diâmetros medidos anteriormente; (ii) imersão das amostras em um béquer graduado, contendo um volume de água conhecido, para determinação do volume de cada amostra. Dessa forma, com a massa medida precisamente, foi possível comparar os volumes determinados diretamente com os obtidos a partir dos diâmetros medidos, determinando o nível de incertezas associado a essas medições.

Os valores obtidos para a densidade, considerando-se os dois tipos de estimativas realizadas, variaram entre $1.196,8 \mathrm{~kg} / \mathrm{m}^{3}$ e $1.295,9 \mathrm{~kg} / \mathrm{m}^{3}$, com valor médio igual a $1.281,7 \mathrm{~kg} / \mathrm{m}^{3}$ - valor esse adotado como o padrão para efeito de quaisquer cálculos necessários.

A fim de avaliar a consistência dos valores determinados para a densidade, foi feita uma análise de sensibilidade com relação às incertezas associadas às medidas dos diâmetros interno $\left(D_{\text {int }}\right)$ e externo $\left(D_{\text {ext }}\right)$, de sorte que $\left(6,80 \lesssim D_{\text {int }} \lesssim 7,20\right) \mathrm{mm}$ e $\left(13,80 \lesssim D_{\text {ext }} \lesssim 14,20\right) \mathrm{mm}$, ambos variando de $0,01 \mathrm{~mm}$ em $0,01 \mathrm{~mm}$. O valor das densidades foi obtido pela divisão da massa por unidade de comprimento pela área determinada a partir de cada par de diâmetros.

Foram avaliados 1.681 casos, dos quais 625 foram considerados possíveis, sob a restrição de que $(1.160<\rho<1.300) \mathrm{kg} / \mathrm{m}^{3}$ - intervalo que contempla os valores obtidos nos catálogos, nas publicações especializadas, nos experimentos e a partir dos cálculos realizados. O resultado dessas simulações é ilustrado na Figura C.17.

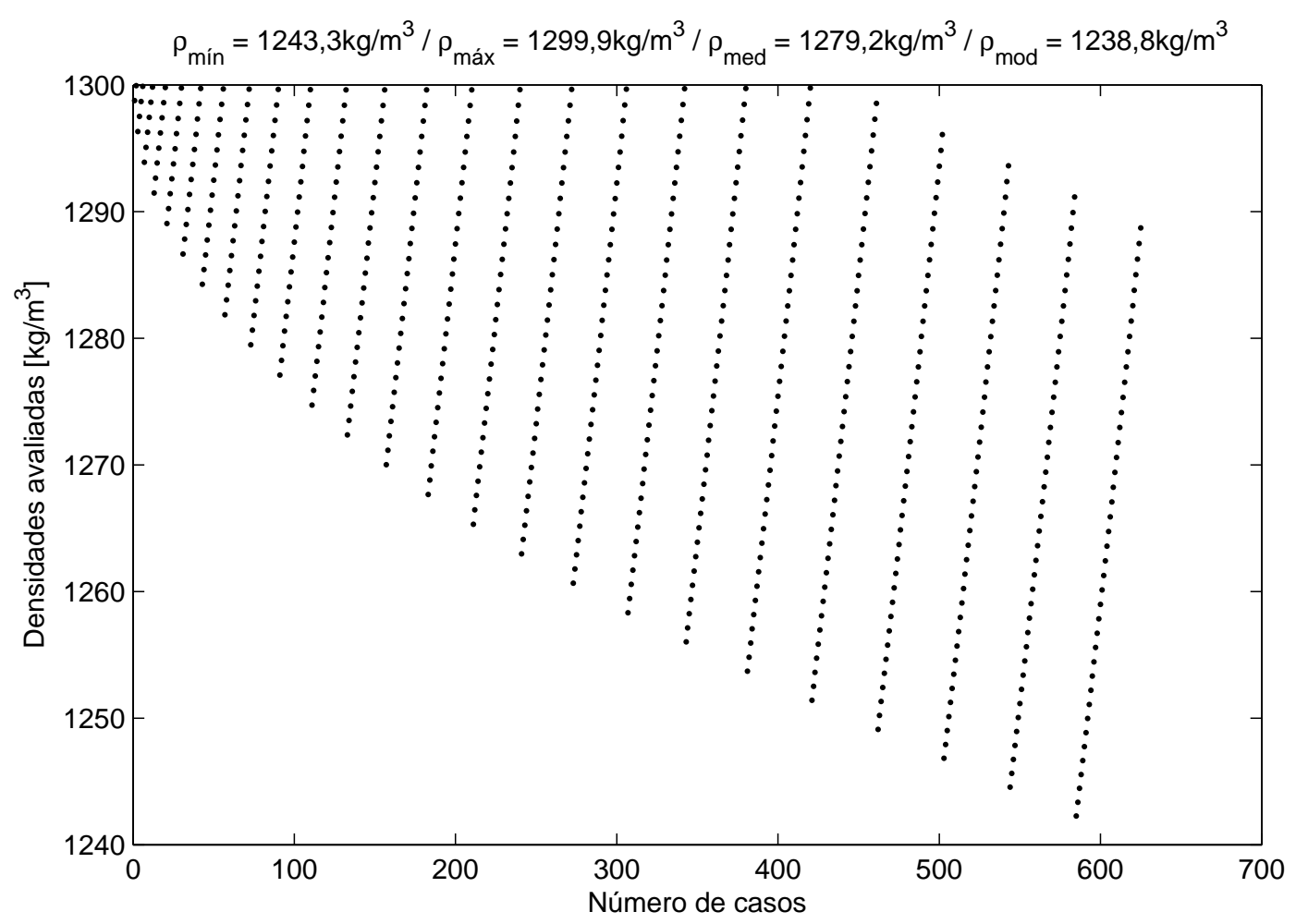

Figura C.17: Análise de sensibilidade da densidade em função dos diâmetros e incertezas associadas. Legenda: $\rho_{\min }$ corresponde ao menor valor obtido; $\rho_{\max }$, ao máximo; $\rho_{\text {med }}$, à média; e $\rho_{\text {mod }}$, à moda. 
Com os dados obtidos até o presente ponto desta tese, foi possível também determinar a massa adicionada por unidade de comprimento, através da equação, extraída de (Newman, 1977), $m_{a}=C_{a} \cdot \rho \cdot \pi \cdot \frac{D_{e x t}^{2}}{4}$, onde $\rho$ é a densidade da água do $\mathrm{CH}-\mathrm{TPN}^{8}$, adotada como sendo aproximadamente igual a $997,05 \mathrm{~kg} / \mathrm{m}^{3}$ e $C_{a}$ é o coeficiente de massa adicionada, suposto igual à unidade.

Além disso, foi possível determinar o peso linear submerso do tubo, por unidade de comprimento, dado por $q=\left(m-m_{d}\right) \cdot g$, onde $m_{d}$ é a massa de fluido correspondente ao volume deslocado. Assim, para o tubo de silicone vazio, $m_{a}=(0,155 \pm 0,001) \mathrm{kg} / \mathrm{m}$ e $q=-(0,029 \pm 0,001) \mathrm{N} / \mathrm{m}$.

Cumpre notar que o peso linear submerso é negativo, indicando que o tubo de silicone, por si só, flutua na água.

Assim, mais uma vez, demonstra-se a necessidade de preenchimento do modelo com um material que promova o aumento da massa linear (sem, no entanto, alterar a massa adicionada, que depende exclusivamente da geometria).

Conforme justificado anteriormente, escolheram-se água e areia como os materiais de preenchimento do tubo de silicone.

Utilizando o mesmo equacionamento apresentado para o tubo vazio, chegou-se aos seguintes valores:

- $m=(0,203 \pm 0,001) \mathrm{kg} / \mathrm{m}$, para o tubo com preenchimento com areia;

- $q=(0,475 \pm 0,001) \mathrm{N} / \mathrm{m}$, para o tubo com preenchimento com areia;

- $m=(0,189 \pm 0,001) \mathrm{kg} / \mathrm{m}$, para o tubo com preenchimento com água;

- $q=(0,334 \pm 0,001) \mathrm{N} / \mathrm{m}$, para o tubo com preenchimento com água.

Com essas três amostras do material (tubo vazio, com água e com silicone), foram feitos, ainda, experimentos para determinação das rijezas axial e flexional e, consequentemente, dos módulos de elasticidade desses trechos de mangueira.

\section{C.2.3 Determinação da rigidez axial do tubo de silicone}

O objetivo do presente tópico é descrever os experimentos para determinação da rigidez axial do modelo ensaiado, com preenchimentos em areia e água, e discutir os resultados obtidos, a fim de compará-los com os valores de catálogo utilizados para as simulações preliminares.

O intuito é utilizar os valores obtidos experimentalmente nas novas simulações para determinação da matriz de ensaios final, a partir da escolha do preenchimentomaterial de preenchimento mais adequado para os fins desta tese.

Como a área da seção transversal já foi determinada experimentalmente, a suposição de que ela permaneça constante e perpendicular à linha neutra da linha, mesmo após

\footnotetext{
${ }^{8}$ Fonte: http://www.cetesb.sp.gov.br/userfiles/file/servicos/normas/pdf/E2166.pdf, acessado em 28/10/2014.
} 
as deformações que ocorrerão naturalmente nos ensaios, torna possível a determinação do Módulo de Young equivalente do modelo, bem como uma estimativa preliminar para a rigidez flexional, dado que a inércia de área também foi previamente calculada, a partir das medidas feitas para os diâmetros interno e externo.
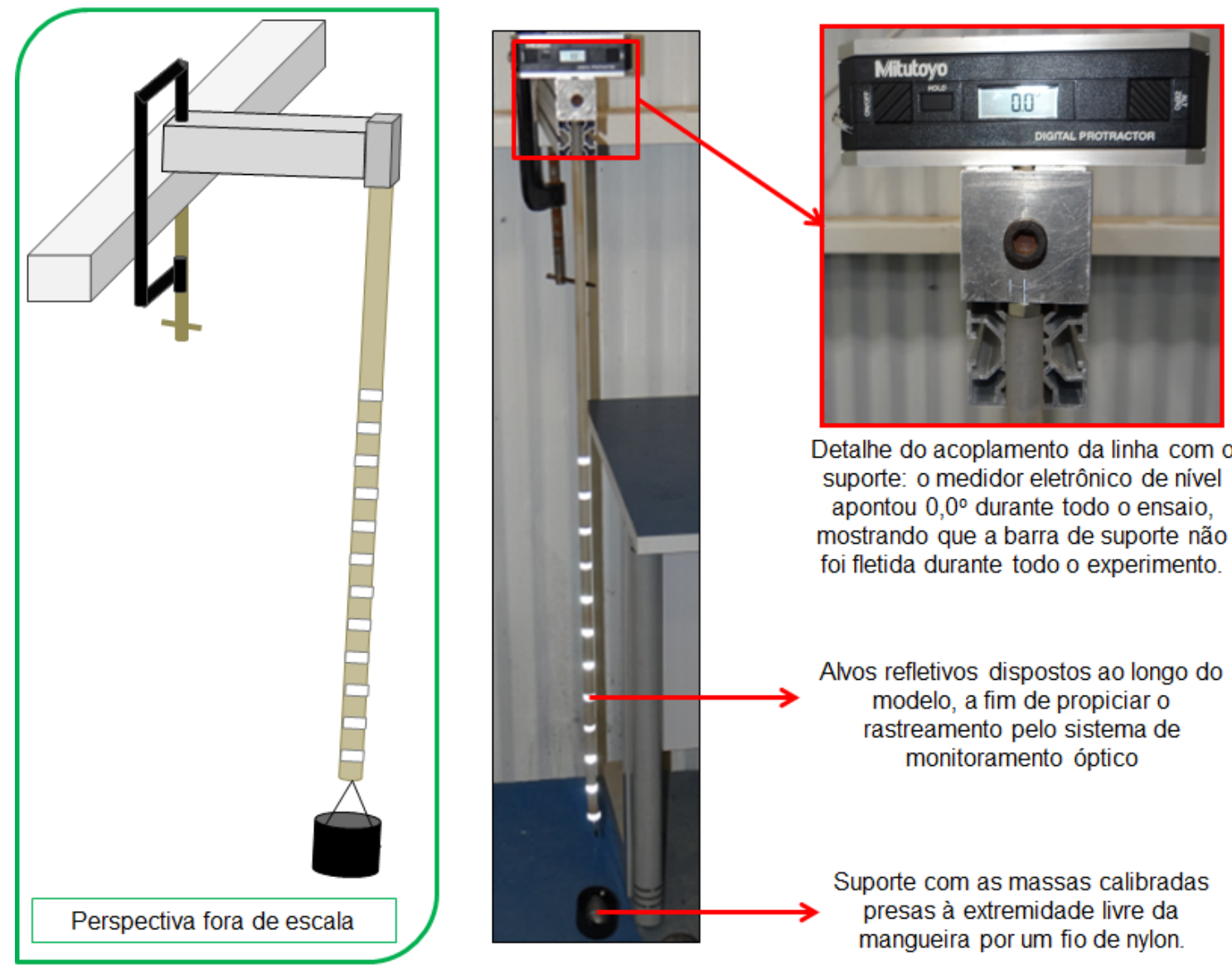

Detalhe do acoplamento da linha com o suporte: o medidor eletrônico de nivel apontou $0,0^{\circ}$ durante todo o ensaio, mostrando que a barra de suporte não foi fletida durante todo o experimento.

Alvos refletivos dispostos ao longo do modelo, a fim de propiciar o rastreamento pelo sistema de monitoramento óptico

Suporte com as massas calibradas presas à extremidade livre da mangueira por um fio de nylon.

Figura C.18: Aparato experimental utilizado para determinação da rigidez axial do modelo.

Para a determinação da rigidez flexional, utilizou-se um trecho da mangueira, que foi fixada a um suporte preso a uma viga solidária a uma das paredes do CH-TPN e dependurada, de modo a permanecer verticalmente disposta, pela atuação do campo gravitacional local.

Massas calibradas foram sucessivamente colocadas, promovendo a elongação do tubo de silicone (vazio ou preenchido). Na sequência, as massas foram sucessivamente retiradas, até que a configuração inicial fosse novamente atingida.

Ao longo da mangueira de silicone, foram dispostos alvos refletivos, separados por uma distância de aproximadamente $5 \mathrm{~cm}$ uns dos outros. O conjunto foi monitorado por três câmeras do sistema de monitoramento óptico, descrito anteriomente.

O sistema de monitoramento óptico foi capaz de perceber todos os doze alvos dispostos sobre o modelo, durante todo o ensaio. A cada carregamento imposto, foi realizado um monitoramento (estático) com duração de 5,0s, a uma taxa de aquisição de $100 \mathrm{~Hz}$. As posições de cada alvo foram tomadas como a média dos valores obtidos a partir de cada conjunto de 500 imagens (frames). A Figura C.19 ilustra uma dessas situações. 


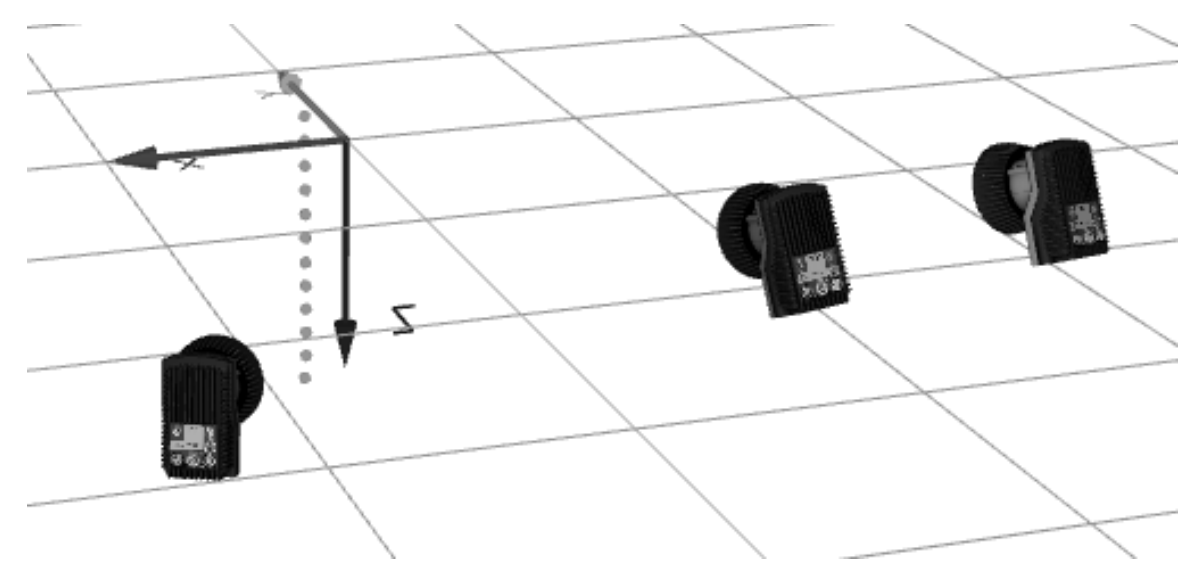

Figura C.19: Visualização em tempo real dos alvos sobre a linha durante o ensaio de tração. Condição de máximo carregamento, utilizando uma massa de $2,541 \mathrm{~kg}$ na extremidade inferior da linha dependurada. O eixo Z é perpendicular ao plano horizontal (solo).

As massas utilizadas para esse ensaio foram de 0,541kg; 1,051kg; 2,030kg; e 2,541kg. Elas foram adicionadas, nesta ordem, a um suporte inferior afixado à extermidade livre do modelo (vide Figuras C.20 e C.21, obtidas a partir das médias dos valores das posições dos alvos refletivos, determinada pelo sistema de monitoramento óptico).

Em cada uma dessas figuras, vale a seguinte legenda: em preto, o suporte de suspensão do modelo físico; em azul, a representação dos alvos dispostos sobre o modelo; em vermelho, a cota do centro do alvo inferior com o modelo sob o menor carregamento; em verde, idem ao anterior para o maior carregamento.

A seguir, essas massas foram retiradas, uma a uma, da última para a primeira situação, de modo a aliviar a linha, o que se configura como uma checagem dos resultados obtidos durante o tracionamento.

Visualmente, os resultados apresentados nas Figuras C.20 e C.21 são, praticamente, indistinguíveis, mas sua presença no escopo desta tese é meramente ilustrativa. Os gráficos mais relevantes são mostrados adiante nas Figuras C.22 a C.27.

Nas Figuras C.22 a C.24 é possível visualizar o comportamento de cada alvo sobre o modelo testado, no que tange aos seus deslocamentos verticais frente à tração efetiva atuante sobre cada um, considerando a carga e descarga das massas calibradas utilizadas. A partir dessas figuras, foram determinadas as curvas tensão-deformação para cada um dos casos: vazio (Figura C.25) e com preenchimentos com areia (Figura C.26) e com água (Figura C.27).

A linha de tendência média foi igualmente determinada nas situações descritas, e o valor do coeficiente angular de cada uma delas, como é sabido, corresponde ao valor do módulo de elasticidade equivalente do modelo em cada situação descrita.

Como esperado, foi observado um certo nível de histerese nos gráficos das tensões pela deformações, o que é típico nesse tipo de ensaio, mais visível, particularmente, para o experimento realizado com o modelo sem preenchimento.

Pelo gráfico da Figura C.25, é possível visualizar o valor do módulo de elasticidade médio determinado como sendo igual a $3,103 \cdot 10^{6} \mathrm{~N} / \mathrm{m}^{2}$. 

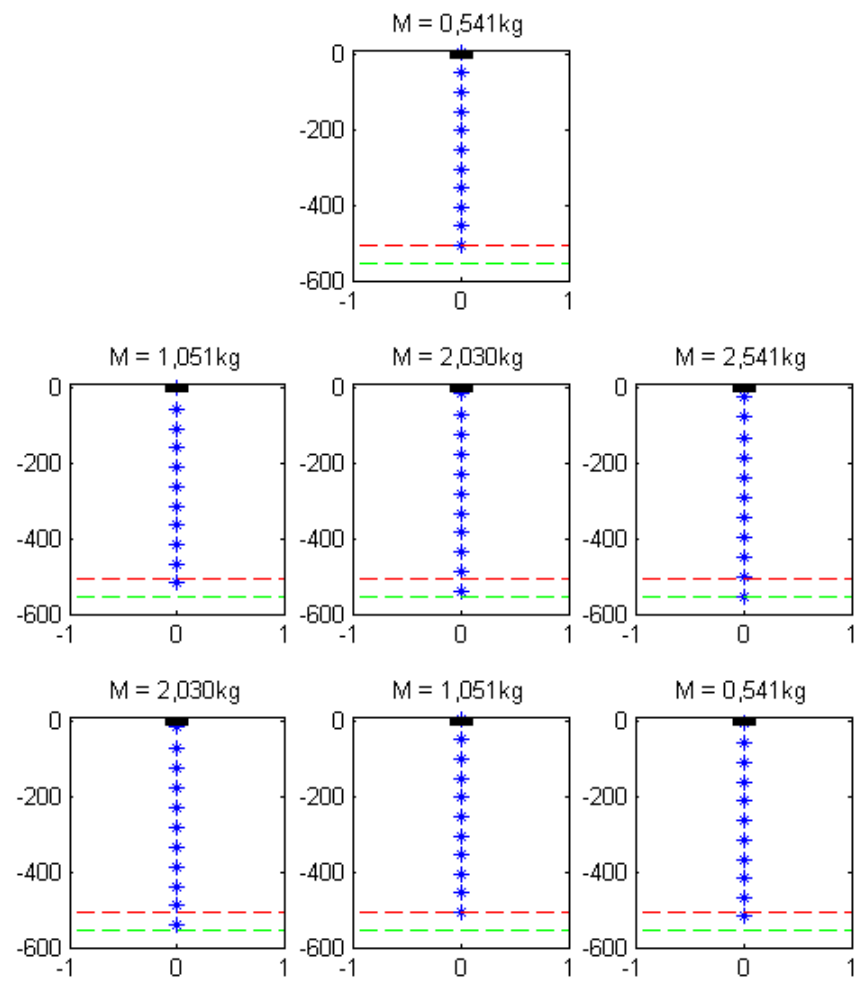

Figura C.20: Visualização dos alvos refletivos sobre o modelo no ensaio de tração (modelo com areia).
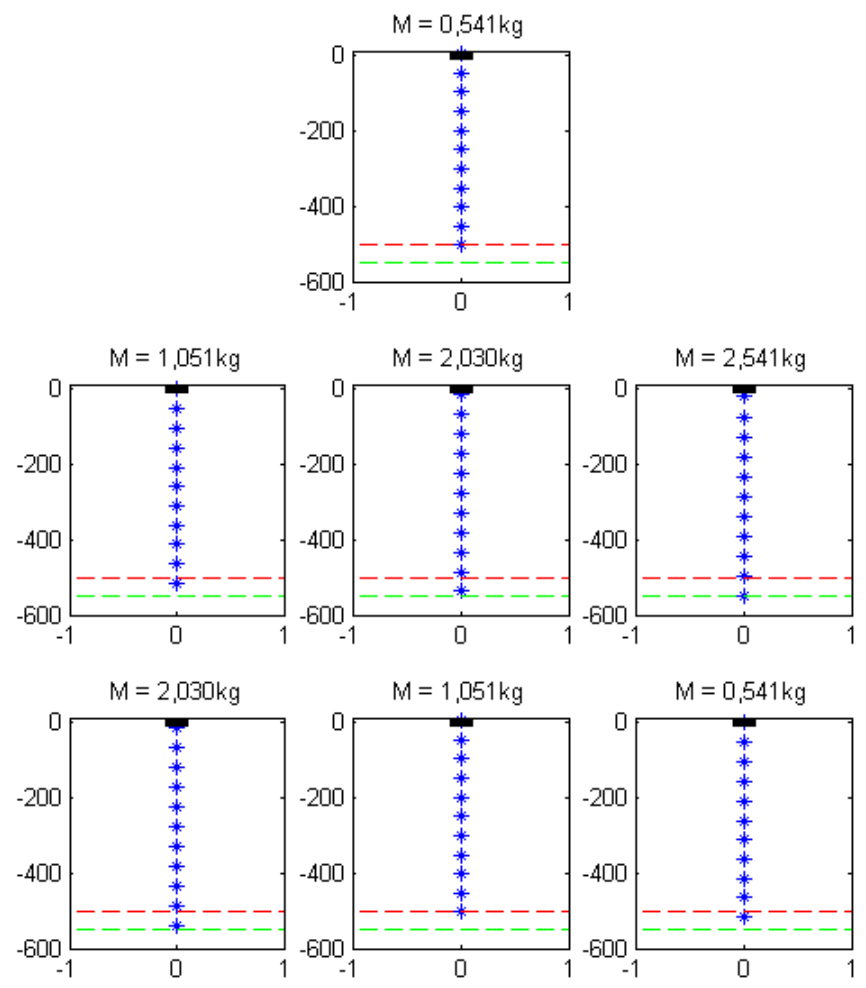

Figura C.21: Visualização dos alvos refletivos sobre o modelo no ensaio de tração (modelo com água). 
O Módulo de Young assim determinado pode ser utilizado para estimar a rigidez axial do tubo vazio. Entretanto, tal resultado não seria de grande valia prática para o conjunto de ensaios e simulações finais, cerne da presente tese, dado que os valores obtidos para os modelos preenchidos serão os utilizados.
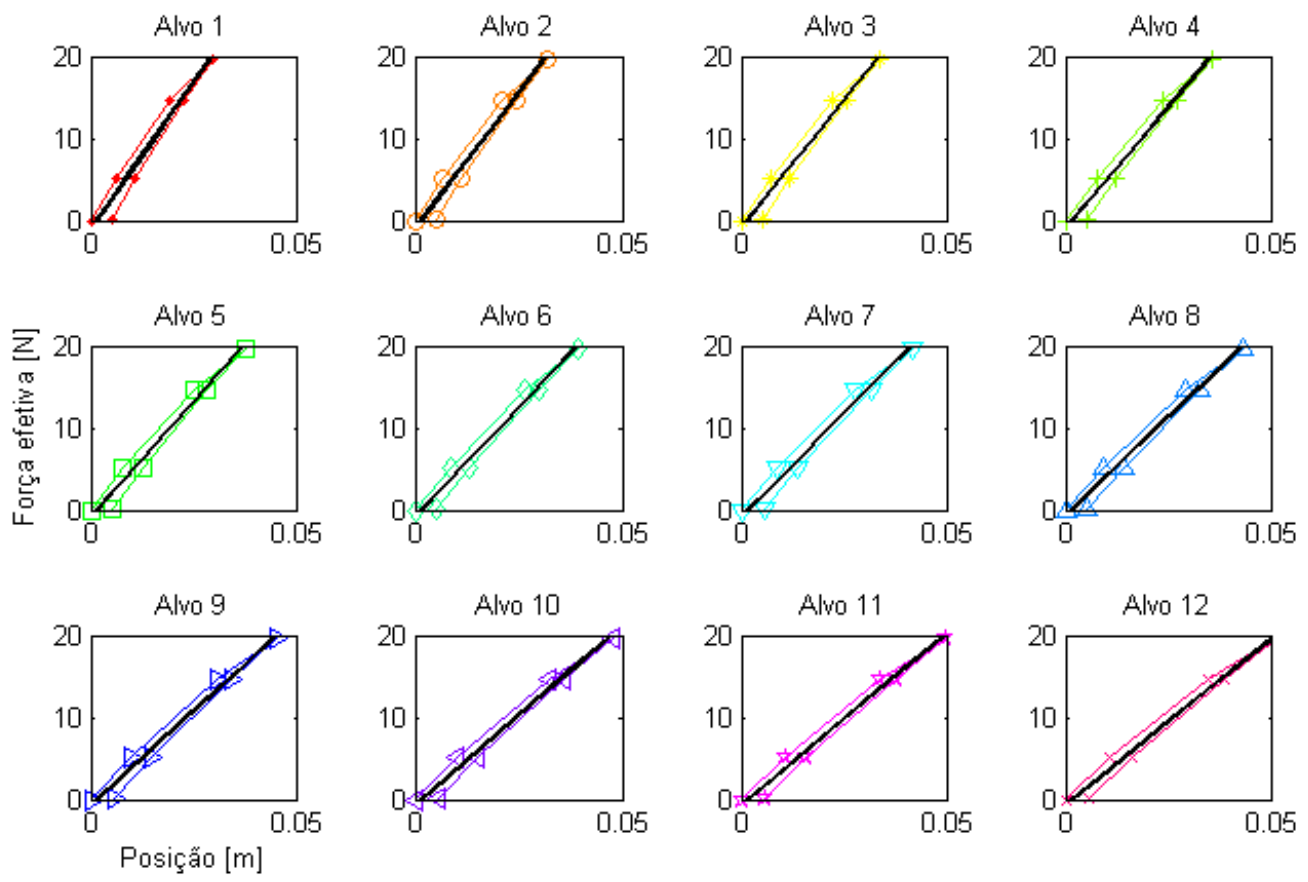

Figura C.22: Forças efetivas medidas ao longo do modelo vazio durante o teste de tração.
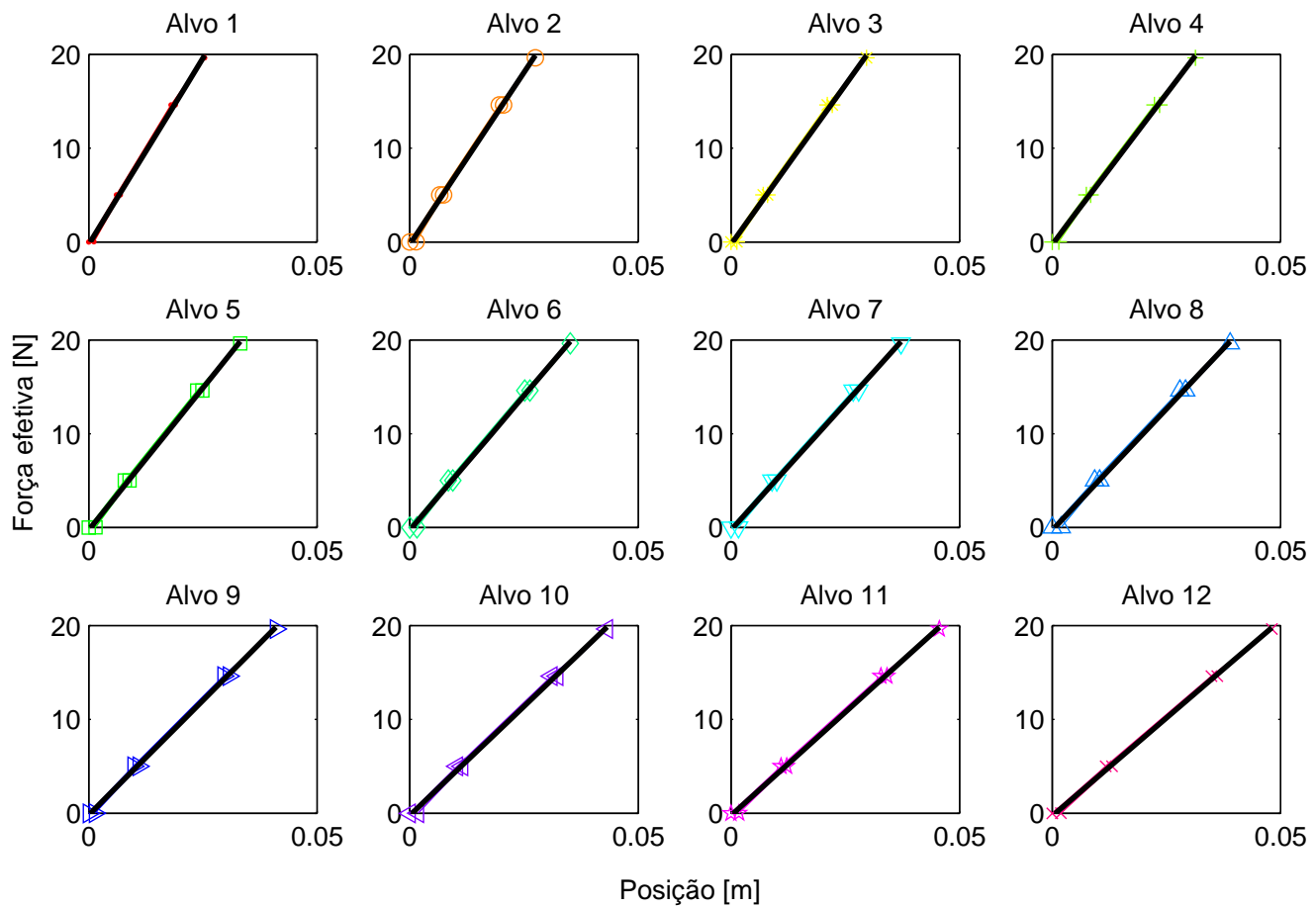

Figura C.23: Forças efetivas medidas ao longo do modelo com areia durante o teste de tração. 

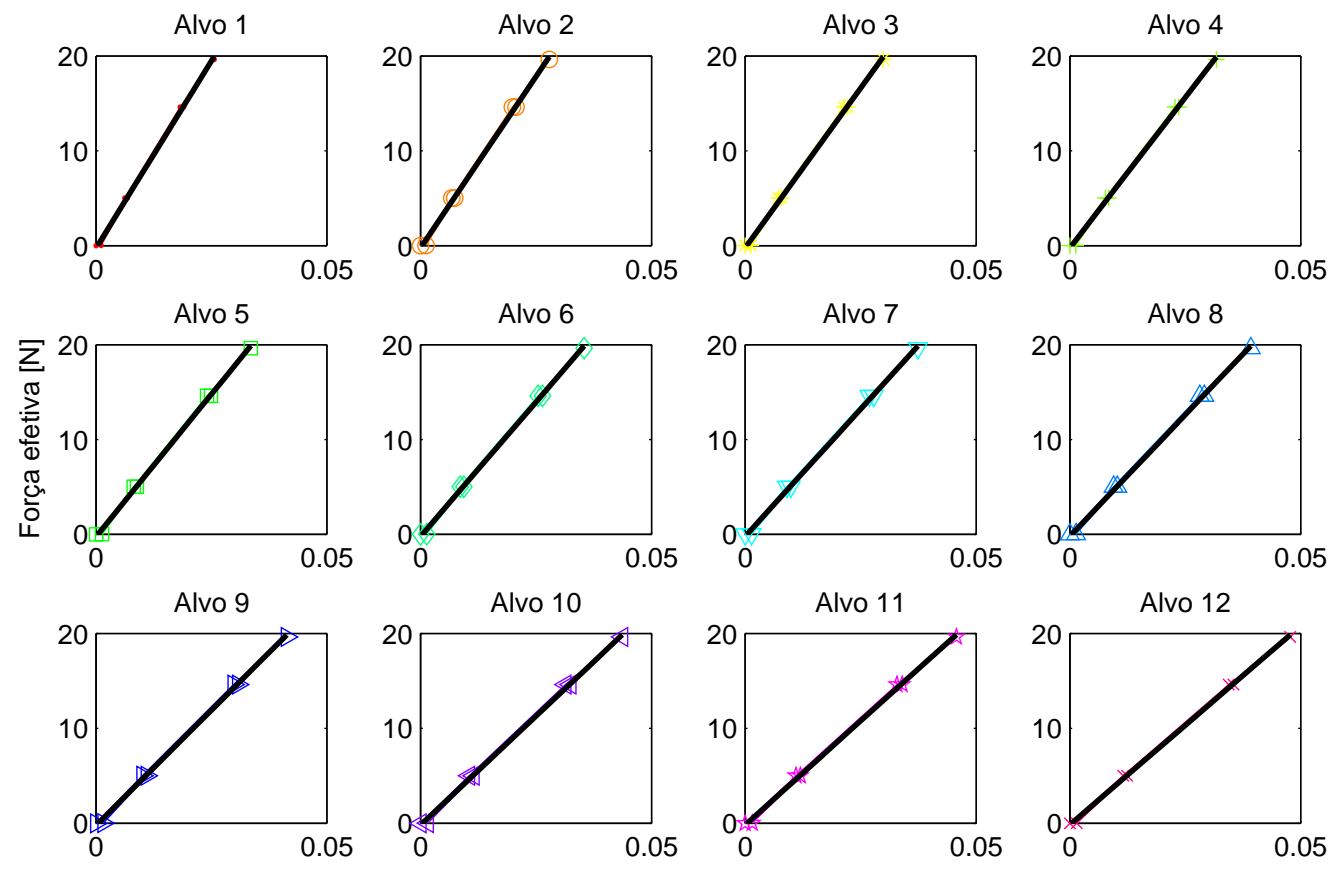

Posição $[\mathrm{m}]$

Figura C.24: Forças efetivas medidas ao longo do modelo com água durante o teste de tração.

Para as demais figuras (C.26 e C.27), além dos módulos de elasticidade, é possível determinar as rijezas axial e flexional, multiplicando aqueles resultados, respectivamente, pela área da seção circular e pela inércia de área determinadas anteriormente.

A partir da Figura C.26, é possível perceber uma pequena variação relativa no módulo de elasticidade do modelo com areia em comparação com o tubo vazio, com valores entre $2,997 \cdot 10^{6} \mathrm{~N} / \mathrm{m}^{2}$ e $3,572 \cdot 10^{6} \mathrm{~N} / \mathrm{m}^{2}$, com valor médio igual a $3,259 \cdot 10^{6} \mathrm{~N} / \mathrm{m}^{2}$, considerando o conjunto completo de situações e alvos.

Esse último valor será utilizado, para efeitos de cálculo e outras aplicações, deste ponto em diante e, portanto, é o valor compilado na Tabela C.14.

A partir desse valor e da área previamente determinada, calculou-se a rigidez axial do tubo com areia como sendo igual a $E A_{e q}^{\text {areia }}=385,54 \mathrm{~N}$.

Usando o valor da inércia de área determinada anteriormente, foi possível estimar a rigidez flexional do modelo preenchido com areia como sendo aproximadamente igual a $E I^{\text {areia }}=5,899 \cdot 10^{-3} \mathrm{Nm}^{2}$, cerca de $5,0 \%$ do valor médio determinado experimentalmente (vide Item C.2.4) e constante da Tabela C.14.

O mesmo procedimento foi feito com a mangueira de silicone preenchida com água. Os resultados são ilustrados na Figura C.27, a partir da qual é possível constatar uma diferença relativa diminuta no módulo de elasticidade do modelo com água com relação ao preenchido com areia, com valor médio de $3,241 \cdot 10^{6} \mathrm{~N} / \mathrm{m}^{2}$, mínimo de $2,971 \cdot 10^{6} \mathrm{~N} / \mathrm{m}^{2}$ e máximo de $3,565 \cdot 10^{6} \mathrm{~N} / \mathrm{m}^{2}$.

Esse último valor foi adotado como o módulo de elasticidade equivalente do modelo com preenchimento de areia, conforme apresentado na Tabela C.14. 


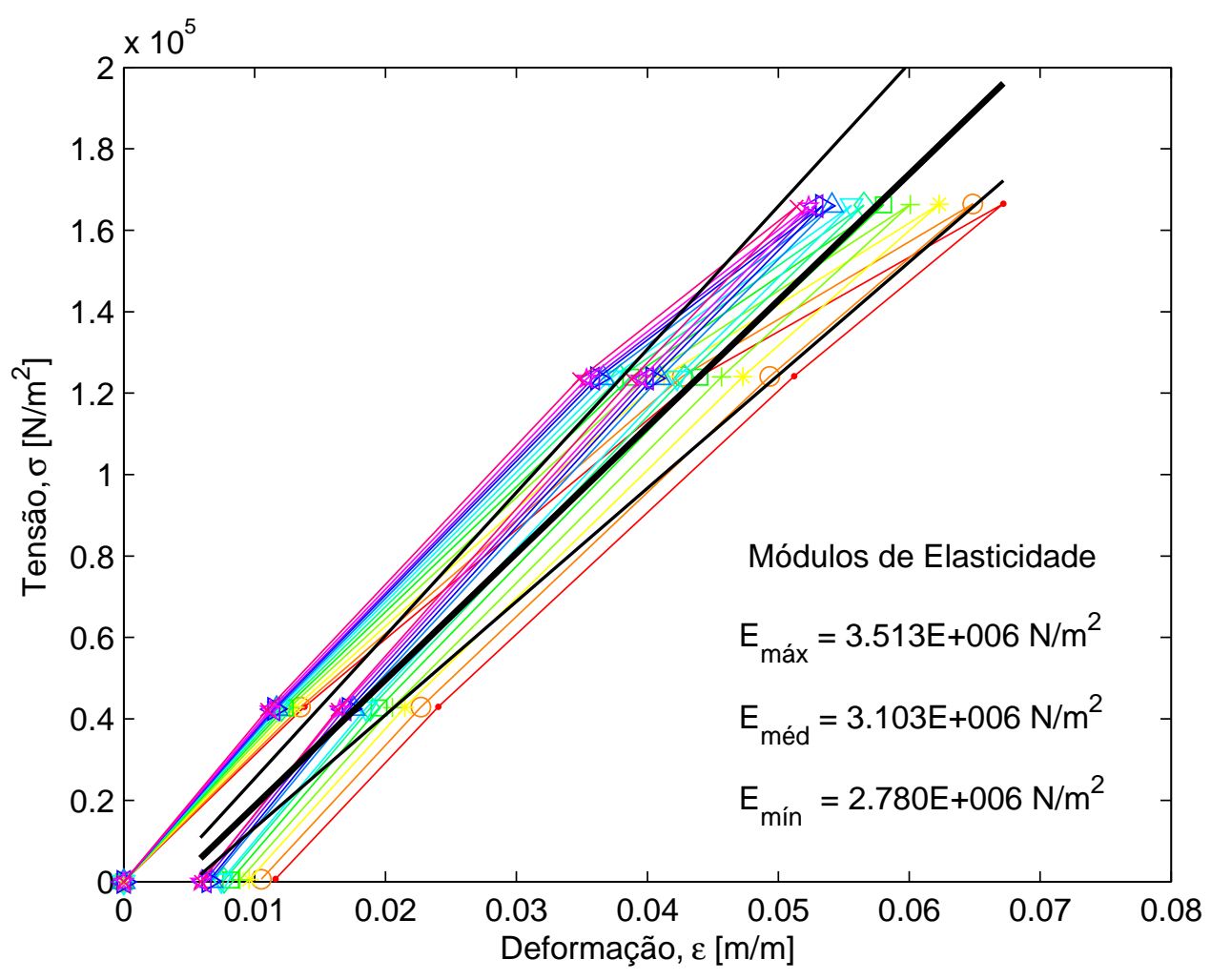

Figura C.25: Diagrama tensão $x$ deformação para o modelo ensaiado sem preenchimento. A linha pendendo verticalmente foi carregada e descarregada com pesos conhecidos.

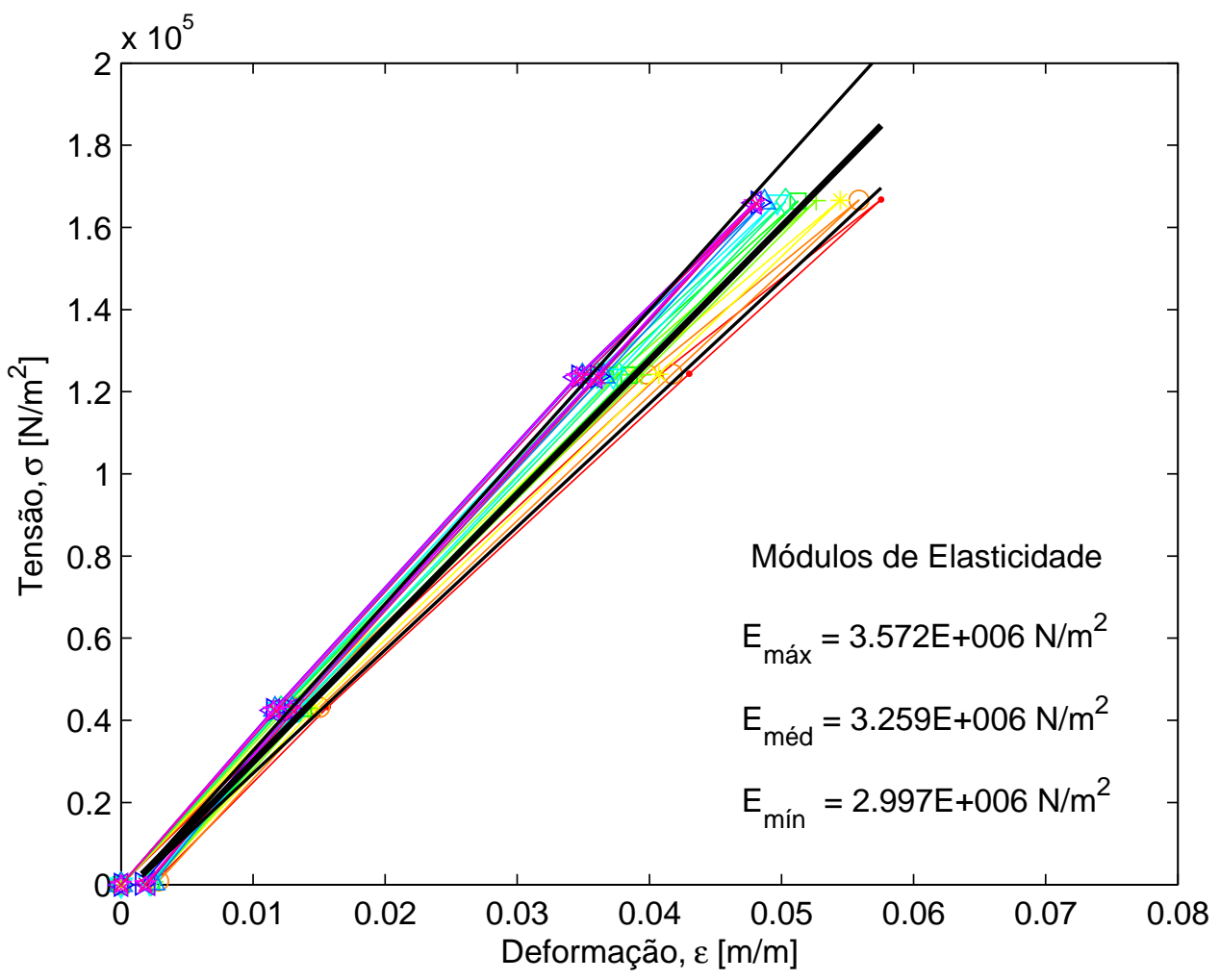

Figura C.26: Diagrama tensão x deformação para o modelo ensaiado com areia. A linha pendendo verticalmente foi carregada e descarregada com pesos conhecidos. 


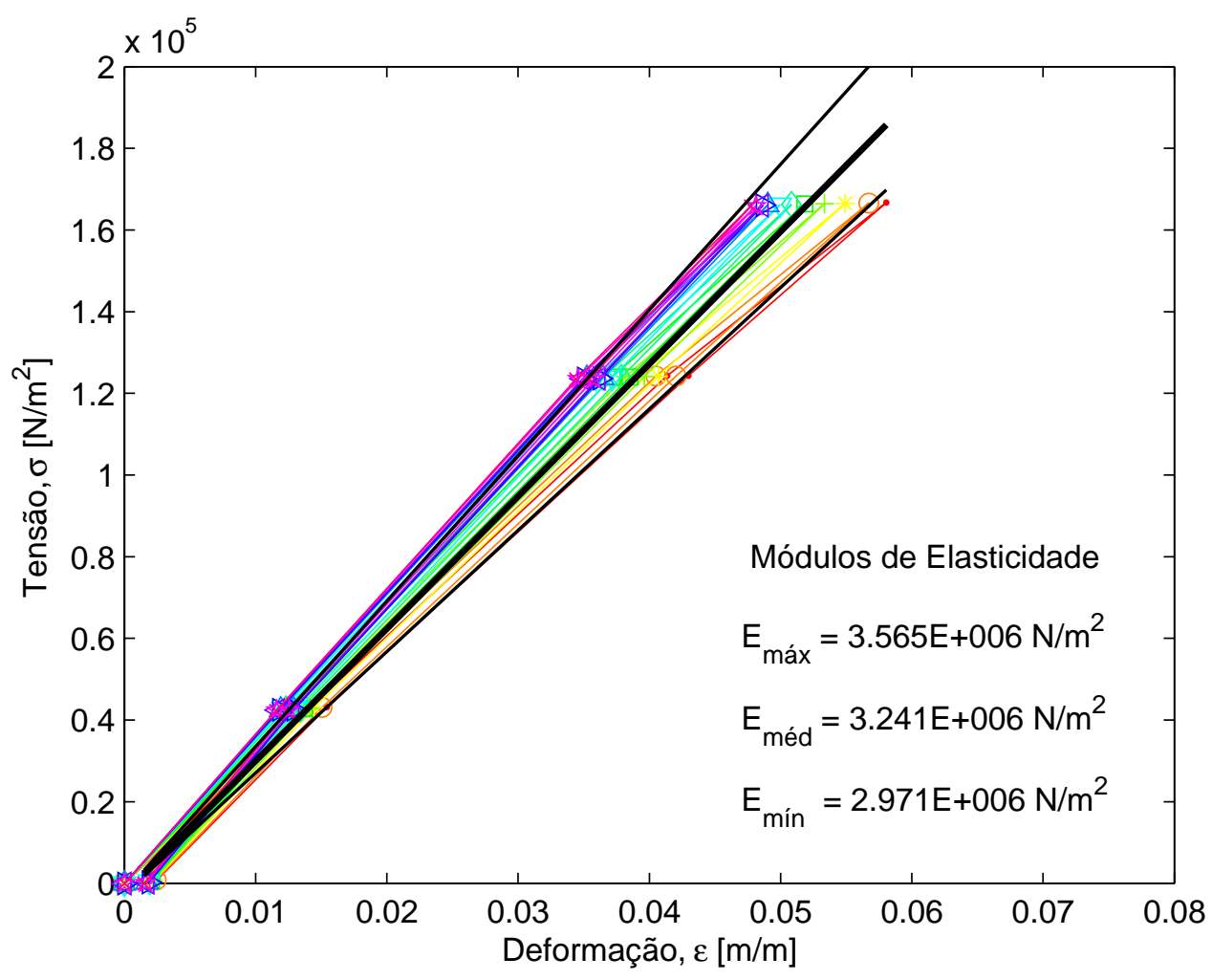

Figura C.27: Diagrama tensão x deformação para o modelo ensaiado com água. A linha pendendo verticalmente foi carregada e descarregada com pesos conhecidos.

A partir desse valor e da área previamente determinada, calculou-se a rigidez axial do tubo com água como sendo igual a $E A_{e q}^{\text {água }}=383,41 \mathrm{~N}$.

Estimou-se a rigidez flexional do modelo com água como sendo aproximadamente igual a $E I^{\text {água }}=5,866 \cdot 10^{-3} \mathrm{Nm}^{2}$, o que representa uma diferença relativa menor que $0,6 \%$ com relação ao valor determinado para o preenchimento com areia, e cerca de $4,5 \%$ diferente do valor obtido para o tubo vazio.

Após a realização dos ensaios de tração para determinação dos módulos de elasticidade e das rijezas axiais equivalentes dos modelos com areia e água, além o cálculo indireto da rigidez flexional, constatou-se que os valores obtidos apresentaram-se bastante próximos entre si, com diferenças sem grande relevância prática.

Os valores obtidos para os módulos de elasticidade do modelo testado mostraram-se compatíveis com valores encontrados na literatura especializada, diferindo sensivelmente do valor fornecido pelo fabricante $\left(2,7 \cdot 10^{6} \mathrm{~N} / \mathrm{m}^{2}\right)$.

Segundo a PSP Inc. - Problem Solving Products ${ }^{9}$, a partir de testes utilizando as normas ISO48 (IRHD), ISO7619 (Shore A), ASTM D1415 (IRHD) e ASTM D2240 (Shore A), é possível estabelecer uma relação entre a dureza Shore A e o módulo de elasticidade de tubos de silicone com características semelhantes ao modelo utilizado. Para uma dureza Shore A 60, o módulo de elasticidade associado é igual a $3,45 \cdot 10^{6} \mathrm{~N} / \mathrm{m}^{2}$.

${ }^{9}$ Fonte: http://www.pspglobal.com/properties-hardness.html, acessado em 28/10/2014 
De acordo com a empresa Chevalier-Cleret ${ }^{10}$, o módulo de elasticidade para uma dureza Shore A 70 e elongação de $100 \%$ é cerca de $3,3 \cdot 10^{6} \mathrm{~N} / \mathrm{m}^{2}$.

Ainda segundo esse fabricante, formulações empíricas que relacionam a dureza Shore A e o Módulo de Young podem ser utilizadas, dependendo da faixa de elongação em que a medida é feita. Exemplos desses equacionamentos são mostrados nas Equações C.1 a C.4.

$$
\begin{gathered}
E=\frac{15,75+2,15 \cdot \operatorname{Sh} A}{100-\operatorname{Sh} A} \cdot\left(1+0.3 \cdot \frac{S h A}{100}\right) \\
\log _{10} E=0,0235 \cdot \operatorname{Sh} A-0,6403 \\
E=0,0981 \cdot \frac{56+7,62336 \cdot \operatorname{Sh} A}{0,137505 \cdot(254-2,54 \cdot S h A)} \\
E=\exp (0,0235 \cdot \operatorname{Sh} A-0,6403)
\end{gathered}
$$

A partir da utilização dessas formulações, para a faixa $60<S h A<70-$ conforme indicação do fabricante do tubo utilizado nos ensaios -, obtiveram-se as seguintes faixas de valores para o Módulo de Young: 4,27 - 6,70; 5,88-10,11; 3,60 - 5,52; e $2,16-2,73$, em $\mathrm{MPa}\left(=10^{6} \mathrm{~N} / \mathrm{m}^{2}\right)$.

Um documento da linha Viton da DuPont sugere o uso de 3MPa como o módulo de elasticidade padrão de artefatos de borracha de silicone com características semeIhantes às utilizadas no ensaio ${ }^{11}$.

Por fim, segundo a Silco Products ${ }^{12}$, os tubos de silicone de uso geral FR60R (Shore A 61) e FR70R (Shore A 68) possuem, respectivamente, as seguintes propriedades: densidade $1.440 \mathrm{~kg} / \mathrm{m}^{3}$ e $1.280 \mathrm{~kg} / \mathrm{m}^{3}$; e módulo de elasticidade $4,5 \mathrm{MPa}$ e $3,6 \mathrm{MPa}$.

A despeito das simulações preliminares apontarem para diferenças de maior monta nos comportamentos dinâmicos dos modelos, foram realizados experimentos para determinação das rijezas flexionais equivalentes, para ambos os preenchimentos, a fim de confirmar a necessidade e interesse de que os ensaios finais sejam realizados com a linha flexível contendo areia ou água.

\footnotetext{
${ }^{10}$ Fonte: http://www.chevalier-cleret.com/event/young-modulus-for-rubber.html, acessado em 28/10/2014.

${ }^{11}$ Fonte: site do MIT, http://www.psfc.mit.edu/ sscott/MSEmemos/mse-memo-101b.pdf, acessado em 29/10/2014.

${ }^{12}$ Fonte: http://www.siliconerubberproducts.co.uk/Technical\%20Data\%20Sheet.pdf, acessado em 28/10/2014.
} 
Esses últimos experimentos, relativos à caracterização empírica do modelo de linha flexível, são apresentados adiante. Saliente-se que esses se referem à determinação experimental das rijezas flexionais dos dois modelos construídos (preenchimento com areia e água).

\section{C.2.4 Determinação da rigidez flexional do tubo de silicone}

Existem duas maneiras distintas, embora equivalentes, de se realizar um ensaio para determinação da rigidez flexional de um modelo em balanço, tendo em vista as formulações para vigas apresentadas anteriormente: para materiais mais rígidos à flexão, mantém-se o vão constante e acrescenta-se massas concentradas conhecidas à extremidade livre; para materiais menos rígidos à flexão, varia-se o vão, de sorte que a deflexão é provocada pela sua massa própria.

Como os tubos ensaiados foram preenchidos com areia/água, houve a necessidade de isolar as extremidades para que o conteúdo do modelo permanecesse internamente ao tubo. Para tanto, foram utilizados cilindros metálicos confeccionados para esse fim e introduzidos, sob ajuste forçado, no interior da mangueira de silicone, após o seu preenchimento.

Dessa maneira, foi necessária a utilização do modelo híbrido de viga em balanço com a consideração de seu peso próprio e presença de massa concentrada na extremidade livre, sob a suposição de superposição linear dos efeitos.

A equação que determina a deflexão da viga, a partir das posições ao longo de uma viga em balanço de comprimento $L$ é dada pela Equação C.5. Pela convenção adotada, $x=L$ corresponde ao ponto de engaste, enquanto que $x=0$ refere-se à posição limite da extremidade livre.

$$
v(x)=-\frac{1}{E I} \cdot\left[q \cdot \frac{x^{4}}{24}+P \cdot \frac{x^{3}}{6}-\left(\frac{q L^{3}}{6}+\frac{P L^{2}}{2}\right) \cdot x+\left(\frac{3 q L^{4}+8 P L^{3}}{24}\right)\right]
$$

Assim considerado, a determinação da elástica do modelo permite o cálculo direto da rigidez flexional equivalente $E I_{\text {eq }}$, a partir da Equação C.5.

Os experimentos realizados utilizaram amostras do tubo de silicone, de cerca de $1 \mathrm{~m}$ de comprimento, dispostas sobre uma superfície plana e com uma de suas extremidades presa à superfície e a outra pendendo sob a ação do campo gravitacional local.

O modelo foi monitorado pelo sistema de rastreamento óptico da mesma maneira que o procedimento descrito para a determinação das rijezas axiais: nesses ensaios, foram utilizadas três câmeras e os modelos confeccionados foram demarcados com o uso de 12 alvos refletivos, conforme ilustrado na Figura C.28. 


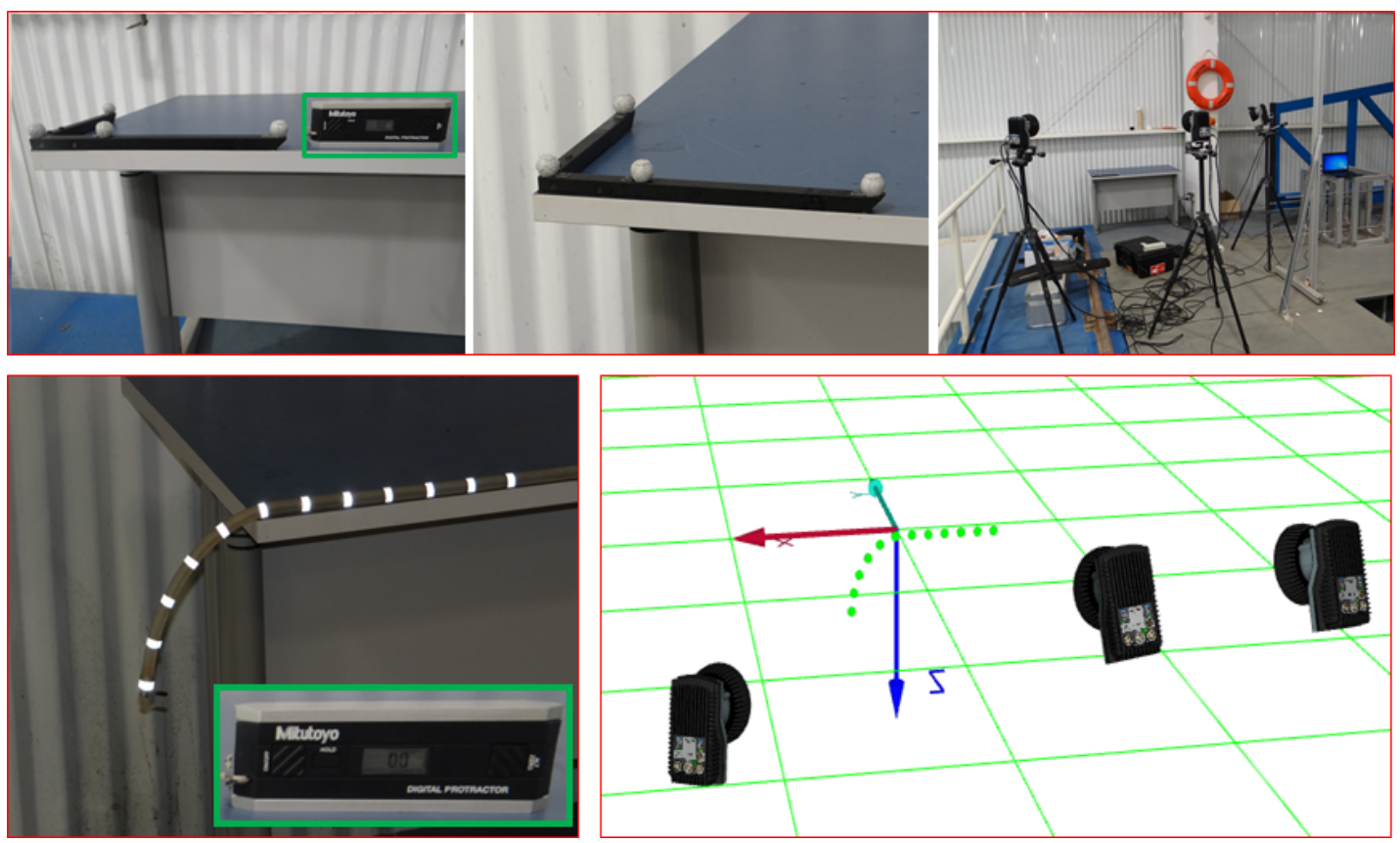

Figura C.28: Aparato experimental utilizado para determinação da rigidez flexional.

A partir dessa figura, é possível verificar diversas características do aparato experimental utilizado na determinação das rijezas flexionais dos modelos preenchidos com areia e com água. A superfície suposta plana foi nivelada, de maneira que nenhuma inclinação pudesse ser percebida pela instrumentação utilizada (medidor eletrônico de nível, em destaque no detalhe em verde nessa figura).

Essa mesma figura permite identificar o conjunto de câmeras utilizado, bem como suas posições relativamente ao modelo. Também é possível identificar os doze alvos refletivos dispostos sobre o tubo de silicone.

Das análises dos resultados provenientes do sistema de monitoramento óptico, foi possível reconstruir as elásticas assumidas pelos modelos durante o ensaio.

Esses resultados são apresentados, respectivamente, nas Figuras C.29 (areia) e C.30 (água). Nelas, cada marcador azul ilustra um alvo refletivo em sua posição real, com relação ao sistema de coordenadas determinado pelo equipamento de rastreamento óptico, após sua calibração. A linha vermelha representa a superfície plana sobre a qual a linha foi ensaiada.

Assim como ilustrado nas figuras referentes aos ensaios para determinação das rijezas axiais, as Figuras C.29 e C.30 não permitem distinguir diferenças substanciais nas posições dos alvos, relativamente aos dois modelos experimentados.

Ao utilizar o Método dos Mínimos Quadrados (MMQ), a fim de obter a melhor aproximação polinomial das posições do alvo, usando a equação de deflexão representada pela Equação C.5, o nível de incertezas associado apresentou-se relativamente grande, visto que apenas uma incógnita $(E I)$ é indeterminada, o que levou a resultados notadamente discrepantes com relação aos demais, mesmo tendo sido considerado um intervalo de confiança de $95 \%$ para a média. 

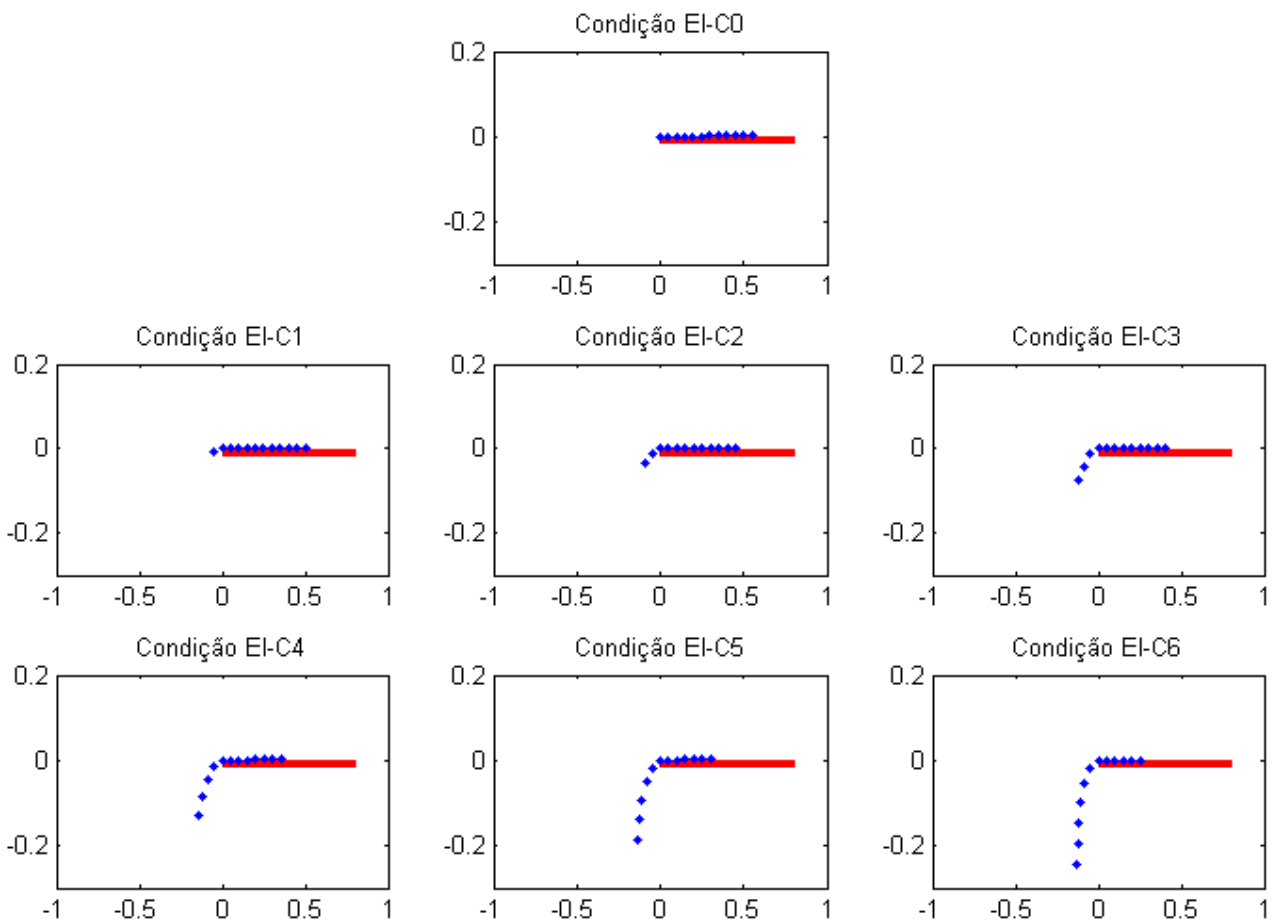

Figura C.29: Visualização dos alvos sobre a linha no ensaio de flexão (modelo com areia). Em vermelho, a superfície plana em azul, a posição de cada alvo refletivo.
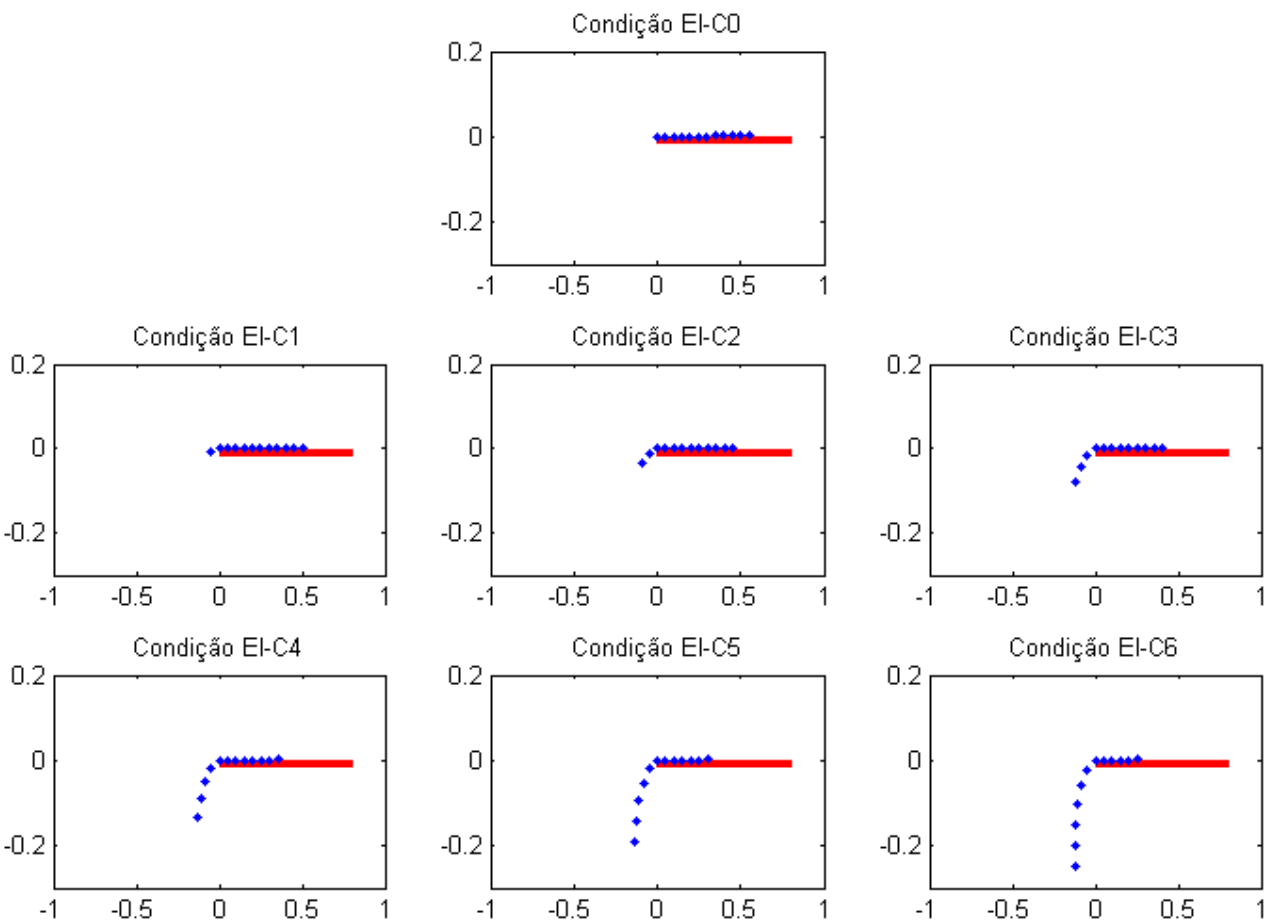

Figura C.30: Visualização dos alvos sobre a linha no ensaio de flexão (modelo com água). Em vermelho, a superfície plana em azul, a posição de cada alvo refletivo. 
A curvatura de vigas é intrinsecamente não-linear. Vale lembrar, entretanto, que a Equação C.5 é deduzida a partir da hipótese de pequenas deflexões ${ }^{13}$.

Tendo em vista que a condição de contorno relativa à máxima deflexão da viga em sua extremidade livre, optou-se por utilizar a Equação C.6, a fim de comparar esses valores com os resultados obtidos anteriormente, a partir do uso da equação de deflexão da viga sujeita a esforços combinados (carga pontual na extremidade livre e carregamento linearmente distribuído ao longo de todo o comprimento).

Assim, assumindo $x=0$ na Equação C.5, determina-se a deflexão máxima $v_{m a ́ x}$ da viga em questão, como sendo:

$$
v_{m a ́ x}=-\frac{q L^{4}}{8 E I}-\frac{P L^{3}}{3}
$$

A Equação C.6 foi, então, utilizada com os dados provenientes do sistema de monitoramento óptico. Os resultados obtidos foram:

- Rigidez flexional equivalente, modelo com areia: $\mathrm{EI}=(3,80-6,70) \cdot 10^{-3} \mathrm{Nm}^{2}$;

- Rigidez flexional equivalente, modelo com água: $\mathrm{EI}=(3,60-6,50) \cdot 10^{-3} \mathrm{Nm}^{2}$.

Os resultados obtidos estão compilados, na íntegra, nas Tabelas C.7 e C.8. Cumpre salientar que as Figuras C.28 a C.30 são ilustrativas com respeito aos experimentos levados a cabo; entretanto, apenas os primeiros alvos em balanço foram utilizados, respeitando a hipótese de pequenas deflexões, o que é coerente fisicamente com os resultados esperados para os ensaios finais, em consonância com os efeitos percebidos em situações reais de campo.

Como visto na Seção 2.3, a rigidez flexional desempenha um papel de suma importância na carga crítica de flambagem e, portanto, sua determinação acurada é essencial para os resultados principais relacionados ao cerne da presente tese.

Tabela C.7: Valores obtidos para rigidez flexional (EI) do modelo com areia

\begin{tabular}{|c|c|c|c|c|}
\hline Fonte do Resultado & Mínimo $\left[\mathrm{Nm}^{2}\right]$ & Média $\left[\mathrm{Nm}^{2}\right]$ & Máximo $\left[\mathrm{Nm}^{2}\right]$ & $\Delta \%$ médias \\
\hline (a) Definição (El) & $5,40 \cdot 10^{-3}$ & $5,90 \cdot 10^{-3}$ & $6,50 \cdot 10^{-3}$ & - \\
\hline (b) Equação C.6 & $3,80 \cdot 10^{-3}$ & $5,25 \cdot 10^{-3}$ & $6,70 \cdot 10^{-3}$ & $-11,0 \%$ \\
\hline \hline
\end{tabular}

Nas Tabelas C.7 e C.8, as colunas denominadas " $\Delta \%$ médias" referem-se às diferenças percentuais entre as médias dos valores obtidos com o uso da Equação C.6, relativamente ao valor obtido a partir da definição.

\footnotetext{
${ }^{13}$ É comum a consideração de que a curvatura $\chi(s)$ é dada por $\chi(s)=-\frac{d^{2}}{d s^{2}} v(s)$ quando esta é, em realidade, uma aproximação da expressão exata $\chi(s)=-\frac{\frac{d^{2}}{d s^{2}} v(s)}{\left\{1+\left[\frac{d}{d s} v(s)\right]^{2}\right\}^{\frac{3}{2}}}$. Entretanto, essa aproximação só é válida para $\frac{d}{d s} v(s) \rightarrow 0$.
} 
Tabela C.8: Valores obtidos para rigidez flexional (EI) do modelo com água

\begin{tabular}{|c|c|c|c|c|}
\hline Fonte do Resultado & Mínimo $\left[\mathrm{Nm}^{2}\right]$ & Média $\left[\mathrm{Nm}^{2}\right]$ & Máximo $\left[\mathrm{Nm}^{2}\right]$ & $\Delta \%$ médias \\
\hline (a) Definição (El) & $5,40 \cdot 10^{-3}$ & $5,90 \cdot 10^{-3}$ & $6,50 \cdot 10^{-3}$ & - \\
\hline (b) Equação C.6 & $3,60 \cdot 10^{-3}$ & $5,05 \cdot 10^{-3}$ & $6,50 \cdot 10^{-3}$ & $-14,0 \%$ \\
\hline \hline
\end{tabular}

Cabe citar que as diferenças percentuais dos valores médios, quando comparados ao valor da rigidez flexional do tubo vazio, representam variações de cerca de 5,0\% / $4,4 \%$; e - $6,5 \% /-10,1 \%$, respectivamente, com relação às fontes (a) e (b) de cálculo (areia / água), o que reforça a hipótese de que o preenchimento pode levar a diferenças significativas nessa propriedade física tão importante para o fenômeno em estudo.

\section{C.2.5 Decaimentos no ar e frequências naturais de vibração}

Para os ensaios de decaimento, o tubo de silicone foi lançado em catenária direta, no ar, a partir de uma altura de aproximadamente $4,390 \mathrm{~m}$, pendendo sob ação de seu peso próprio. Foram utilizados três ângulos de topo distintos ${ }^{14}$, para cada preenchimento utilizado. $O$ topo do modelo foi fixado a uma célula de carga (com fundo de escala de $100 \mathrm{~N}$ ) e esta a um rolamento parafusado a barras de alumínio, solidárias à estrutura física do prédio do TPN-USP.

A outra extremidade do modelo físico foi ancorada a distâncias variáveis do primeiro ponto de contato com o solo, de maneira a não influenciar nos movimentos impostos à linha. Um trecho da linha permaneceu suspenso, enquanto outro repousava sobre $o$ solo, que pode ser considerado infinitamente rígido. $\mathrm{O}$ aparato experimental utilizado e seus detalhes são ilustrados na Figura C.31.

A partir da Figura C.31, é possível visualizar a célula de carga (destacada em vermeIho), o rolamento (no detalhe em amarelo), o posicionamento das câmeras e uma das situações de lançamento.

Impulsos pontuais foram aplicados manualmente à linha ${ }^{15}$, de maneira que foram realizados um total de trinta experimentos, correspondendo a dois preenchimentos distintos, três ângulos de topo e cinco excitações impulsivas pontuais.

O monitoramento foi realizado por cinco câmeras do sistema de rastreamento óptico, a fim de assegurar que o maior número de alvos pudesse ser acompanhado.

Dezenas de alvos refletivos foram distribuídos ao longo da linha, com espaçamentos, entre si, da ordem de $5 \mathrm{~cm}$ nas proximidades das extremidades e $20 \mathrm{~cm}$ no restante do seu comprimento suspenso.

Em cada um desses testes de decaimento, ao menos dez alvos foram identificados pelo conjunto de câmeras, o que torna inviável a apresentação de todos os resultados.

\footnotetext{
${ }^{14}$ Os ângulos serão referidos, ao longo do texto, como sendo nominalmente iguais a $65^{\circ}, 75^{\circ}$ e $85^{\circ}$; entretanto, os ângulos mensurados indiretamente foram da ordem de $66,2^{\circ}, 77,7^{\circ}$ e $88,1^{\circ}$, para o preenchimento com areia; e $63,5^{\circ}, 74,1^{\circ}$ e $85,2^{\circ}$, para o preenchimento com água

${ }^{15}$ Para cada ângulo de topo, foram aplicados três impulsos paralelamente ao plano da catenária e dois impulsos perpendicularmente àquele plano.
} 

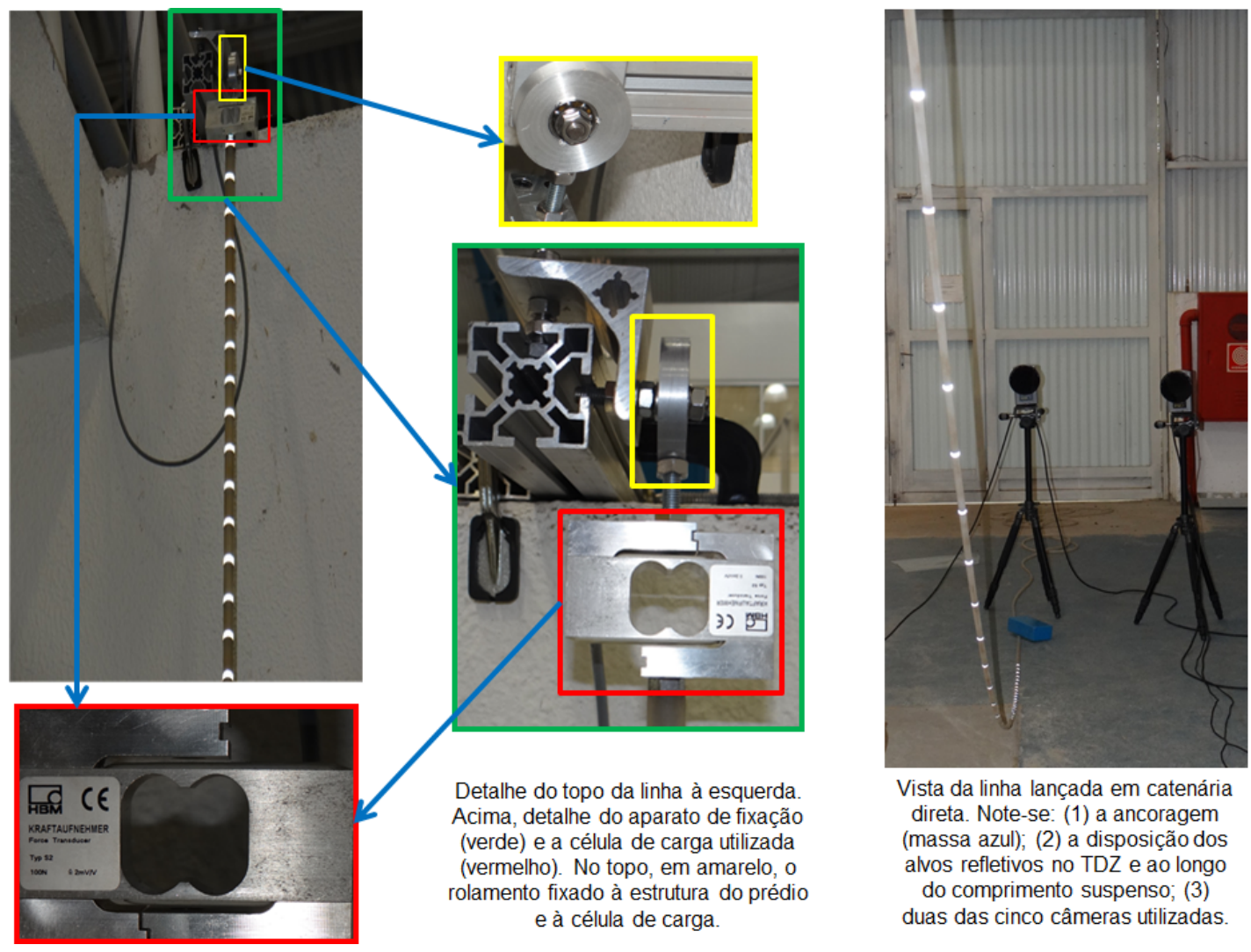

Figura C.31: Aparato experimental utilizado nos ensaios de decaimento.

Desta forma, apenas alguns resultados serão apresentados, de sorte que o procedimento realizado possa ser compreendido e documentado adequadamente.

Os gráficos da Figura C.32 ilustram um exemplo das trajetórias assumidas pelos alvos identificados pelo sistema de monitoramento, durante os testes de decaimento.

A seguir, são mostrados os resultados para o cálculo dos amortecimentos estruturais. O modelo utilizado foi o do decremento logarítmico $\left(e^{-\zeta \cdot \omega_{n} \cdot t}\right)$ como envoltória da assinatura temporal das amplitudes máximas identificadas em cada direção. Para ilustrar esses resultados, foi escolhido apenas um exemplo para cada preenchimento considerado (ângulo de topo nominal de $65^{\circ}$ ), apresentados nas Figuras C.33 e C.34.

A apresentação gráfica dos demais casos foi suprimida da presente tese; entretanto, os valores obtidos estão compilados nas Tabelas C.9 a C.11, no tópico subsequente a este, onde os resultados dos ensaios preliminares são apresentados na íntegra de maneira sucinta e discutidos na seção que finda este capítulo.

Saliente-se que, nos casos em que a linha foi lançada mais verticalmente, os resultados foram sensivelmente prejudicados, dado que a linha apresentava um menor número de ciclos até sua estabilização na posição estática.

Além dos amortecimentos estruturais, foi possível a determinação, a partir desse conjunto de experimentos, das frequências naturais de vibração da linha, em suas diferentes condições de lançamento e preenchimento interno.

A fim de ilustrar o conjunto dos ensaios de decaimentos realizado, foram confecci- 

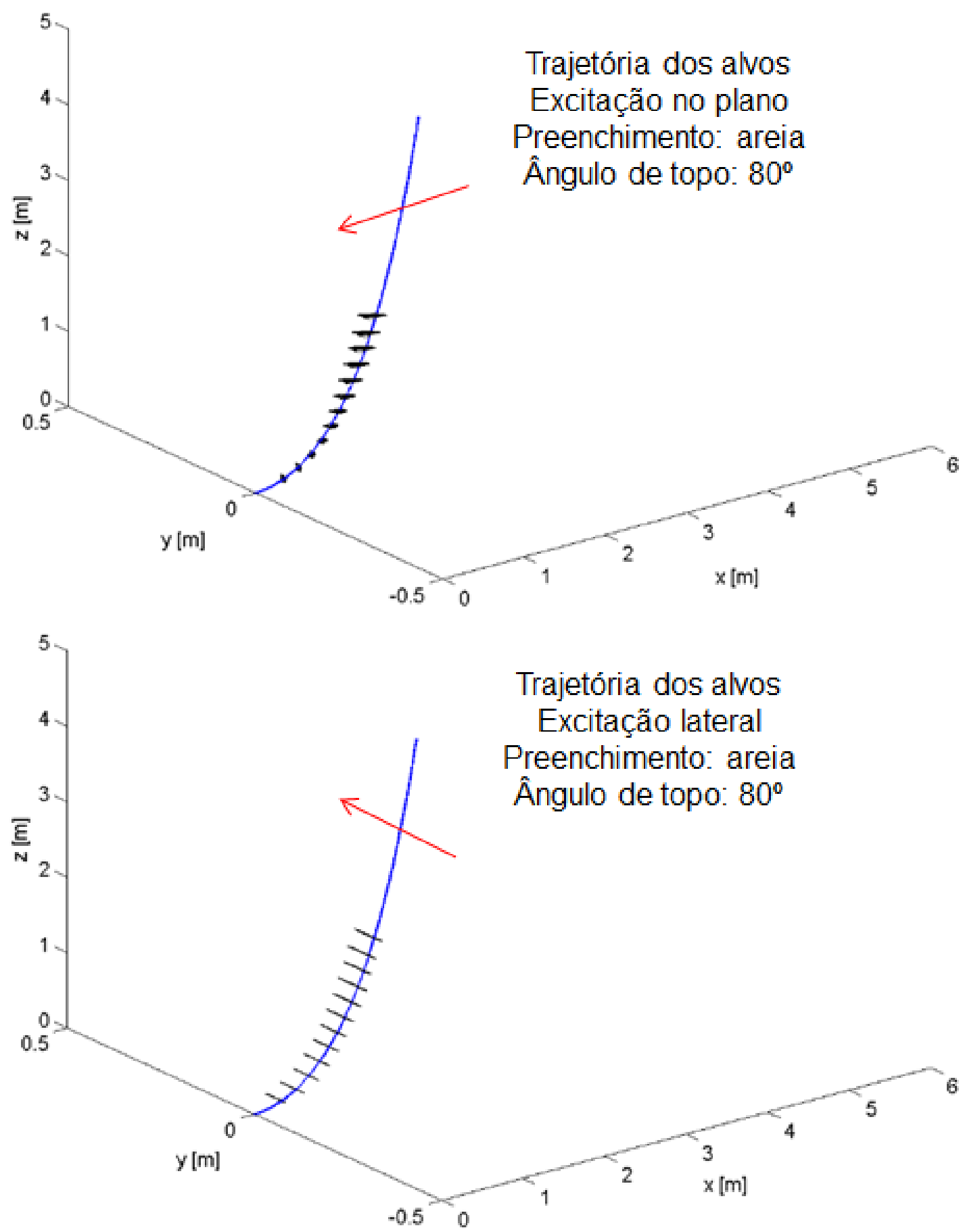

Figura C.32: Exemplo das trajetórias assumidas pelos alvos nos ensaios de decaimento. A seta vermelha indica a direção aproximada da excitação pontual promovida.

onadas as Figuras C.35 a C.38, referentes às mesmas condições dos dois gráficos apresentados anteriormente, com os resultados de todos os alvos reconhecidos pelo sistema de rastreamento óptico (cada cor representa um alvo distinto).

Os gráficos ilustrados mostram as frequências excitadas como resultados dos pulsos pontuais impostos ao modelo, para ambas as direções.

Note-se, a partir das Figuras C.35 a C.38, que é possível identificar um baixo número de frequências de vibração para cada situação referente aos experimentos realizados. 

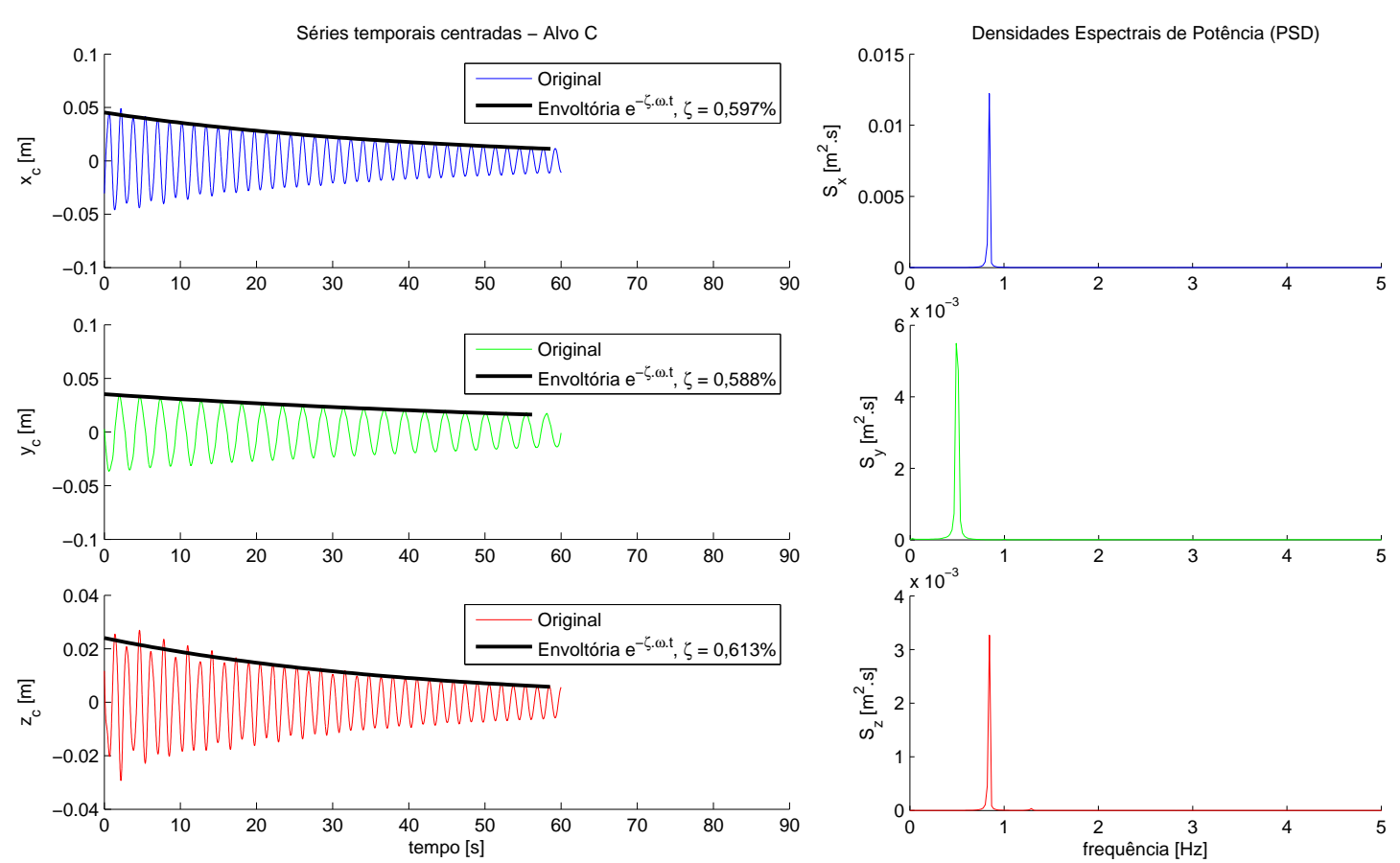

Figura C.33: Determinação do amortecimento estrutural (tubo com areia, $\theta_{t}=66,2^{\circ}$ ).

À esquerda, as séries temporais centradas dos deslocamentos, com a curva de aproximação exponencial (decaimento), para todas as direções. À direita, os respectivos gráficos de densidade espectral de potência (PSD).
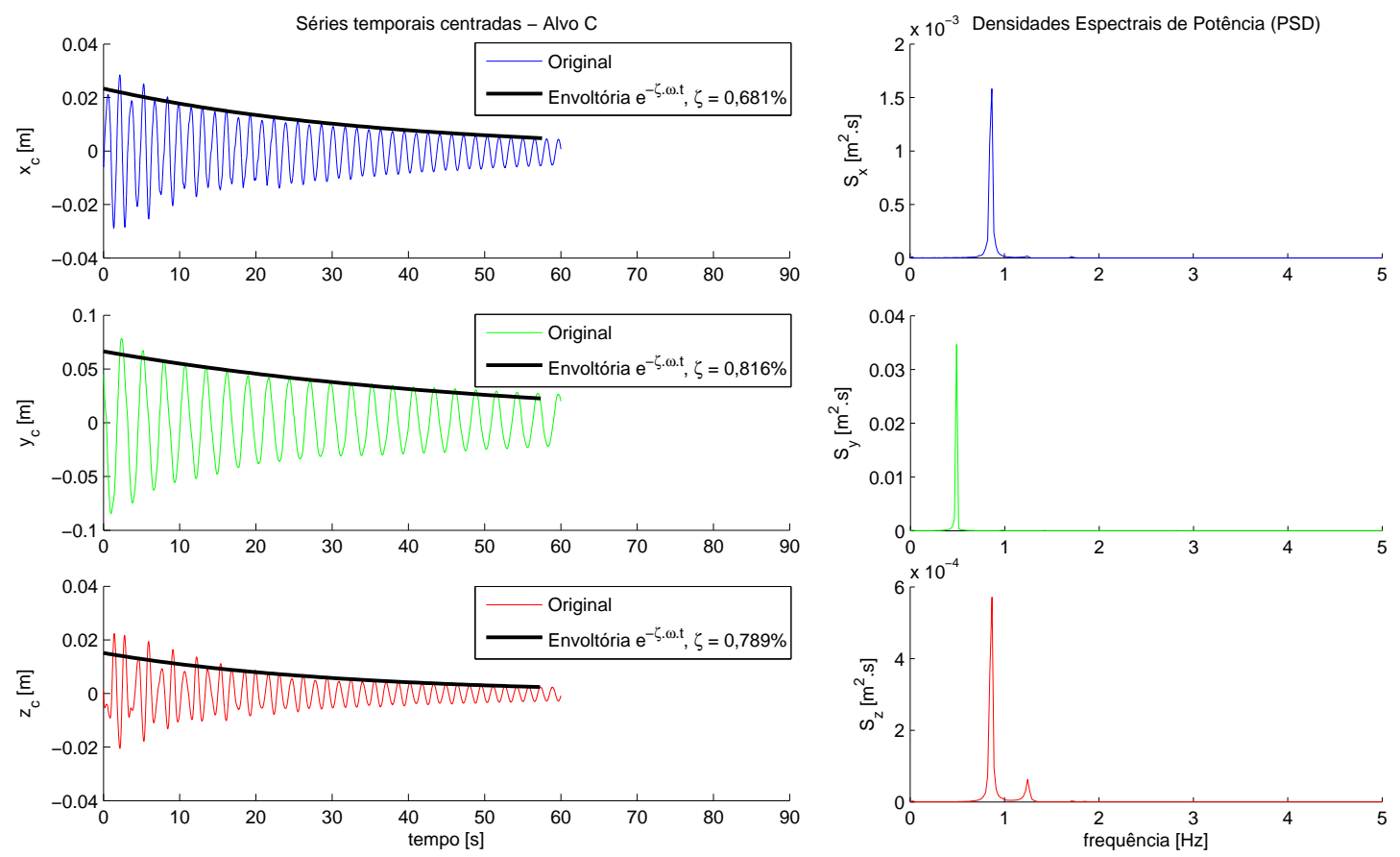

Figura C.34: Determinação do amortecimento estrutural (tubo com água, $\theta_{t}=63,5^{\circ}$ ).

À esquerda, as séries temporais centradas dos deslocamentos, com a curva de aproximação exponencial (decaimento), para todas as direções. À direita, os respectivos gráficos de densidade espectral de potência (PSD).

Alguns dos picos verificados possuem uma quantidade muito baixa de energia e não é possível afirmar que essas frequências sejam relevantes para os ensaios finais. 

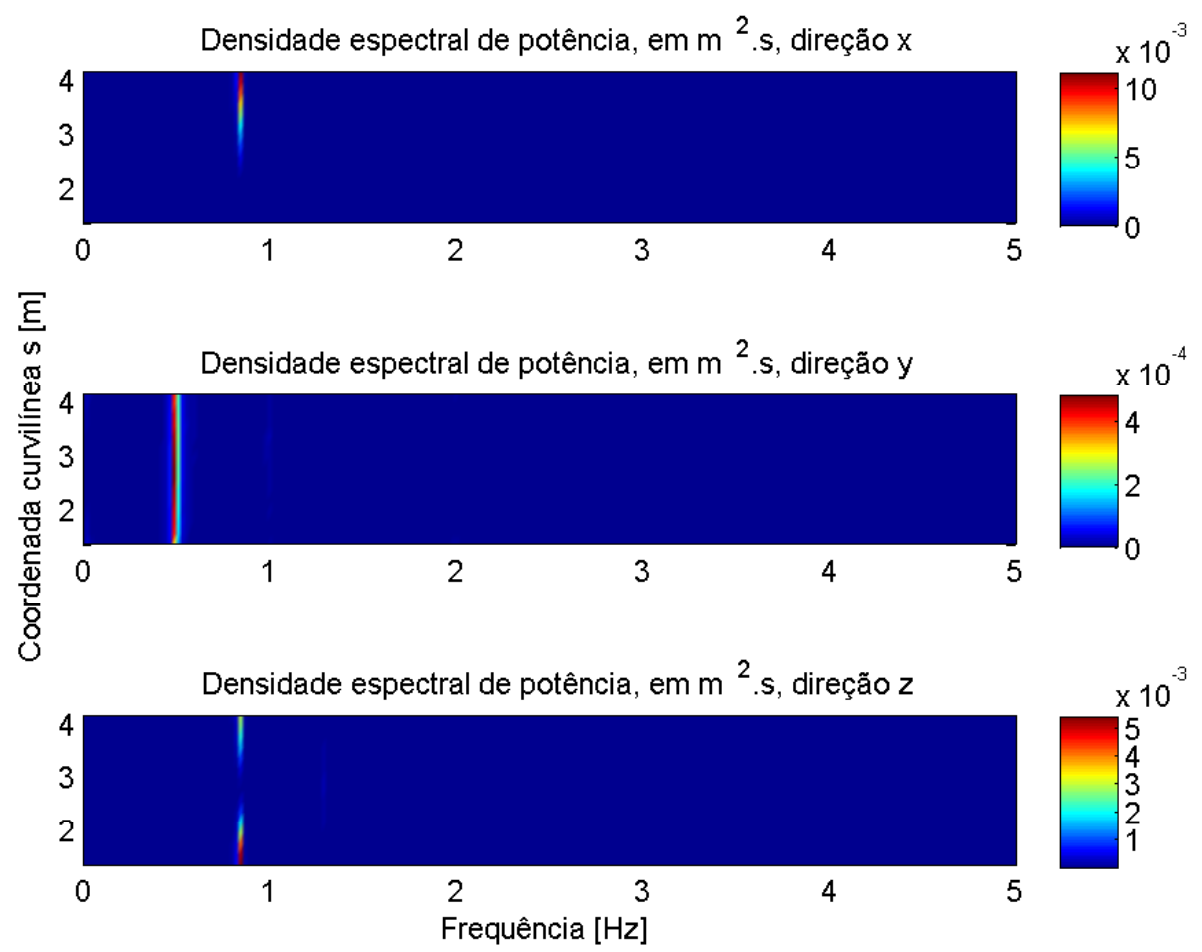

Figura C.35: PSD de deslocamentos de todos os alvos, tubo com areia, excitação longitudinal em 0xyz.
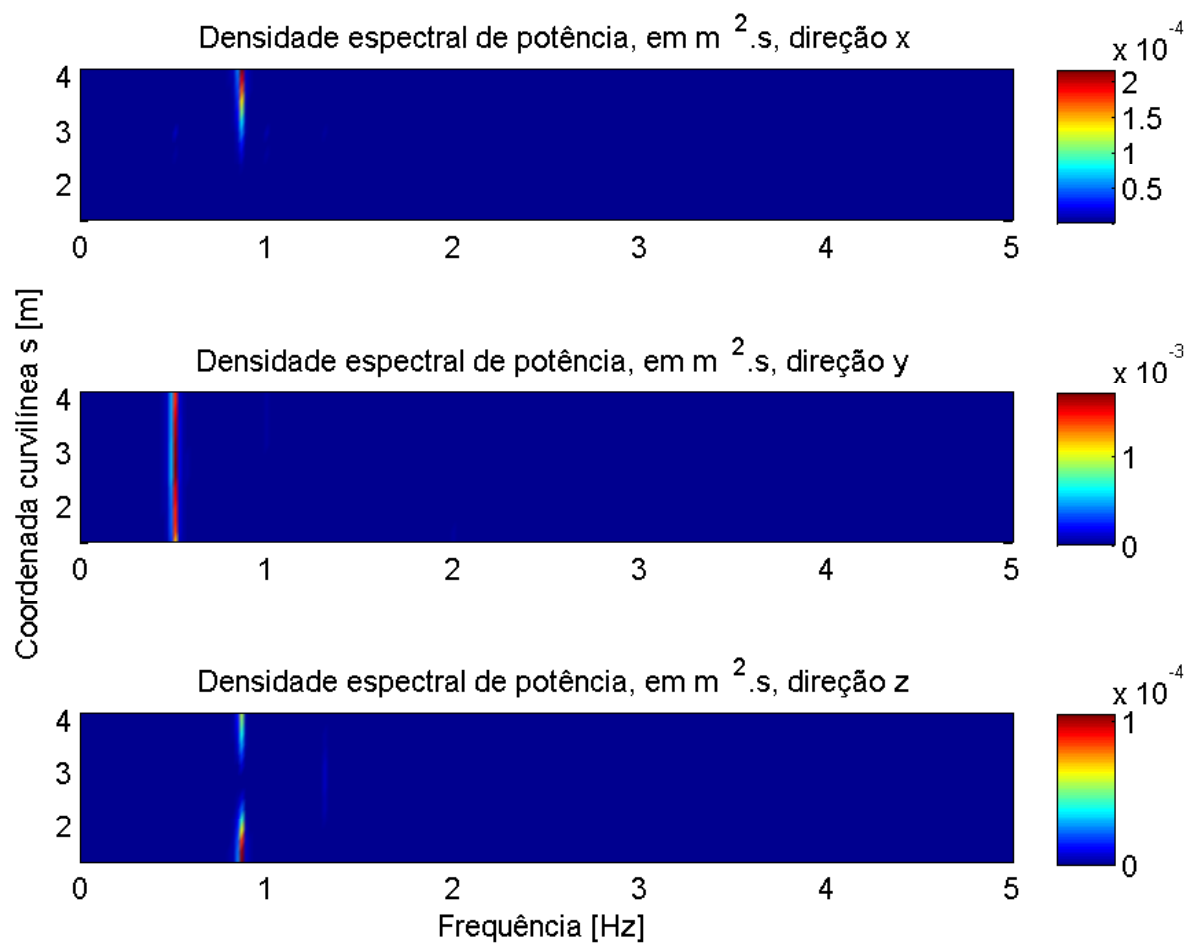

Figura C.36: PSD de deslocamentos de todos os alvos, tubo com areia, excitação transversal em 0xyz. 

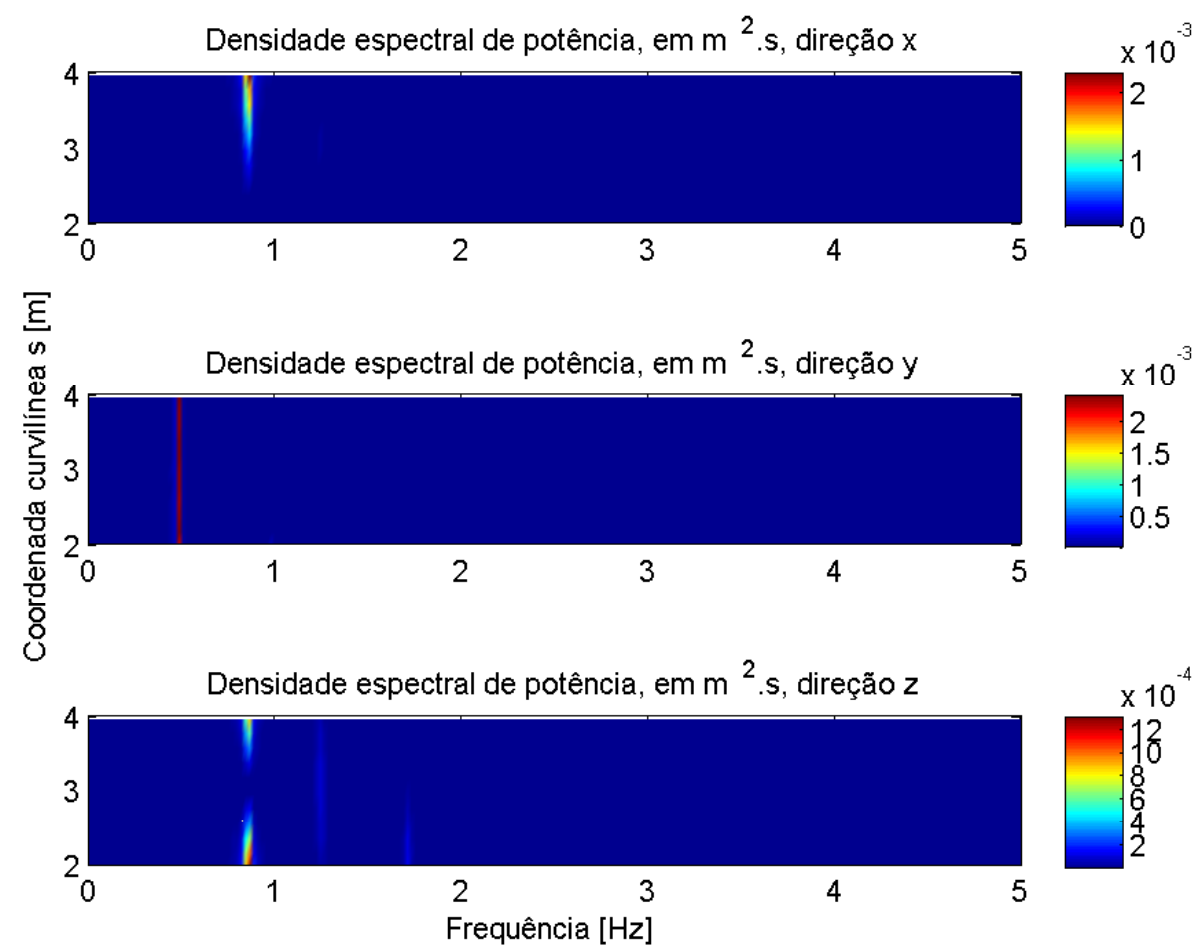

Figura C.37: PSD de deslocamentos de todos os alvos, tubo com água, excitação longitudinal em 0xyz.
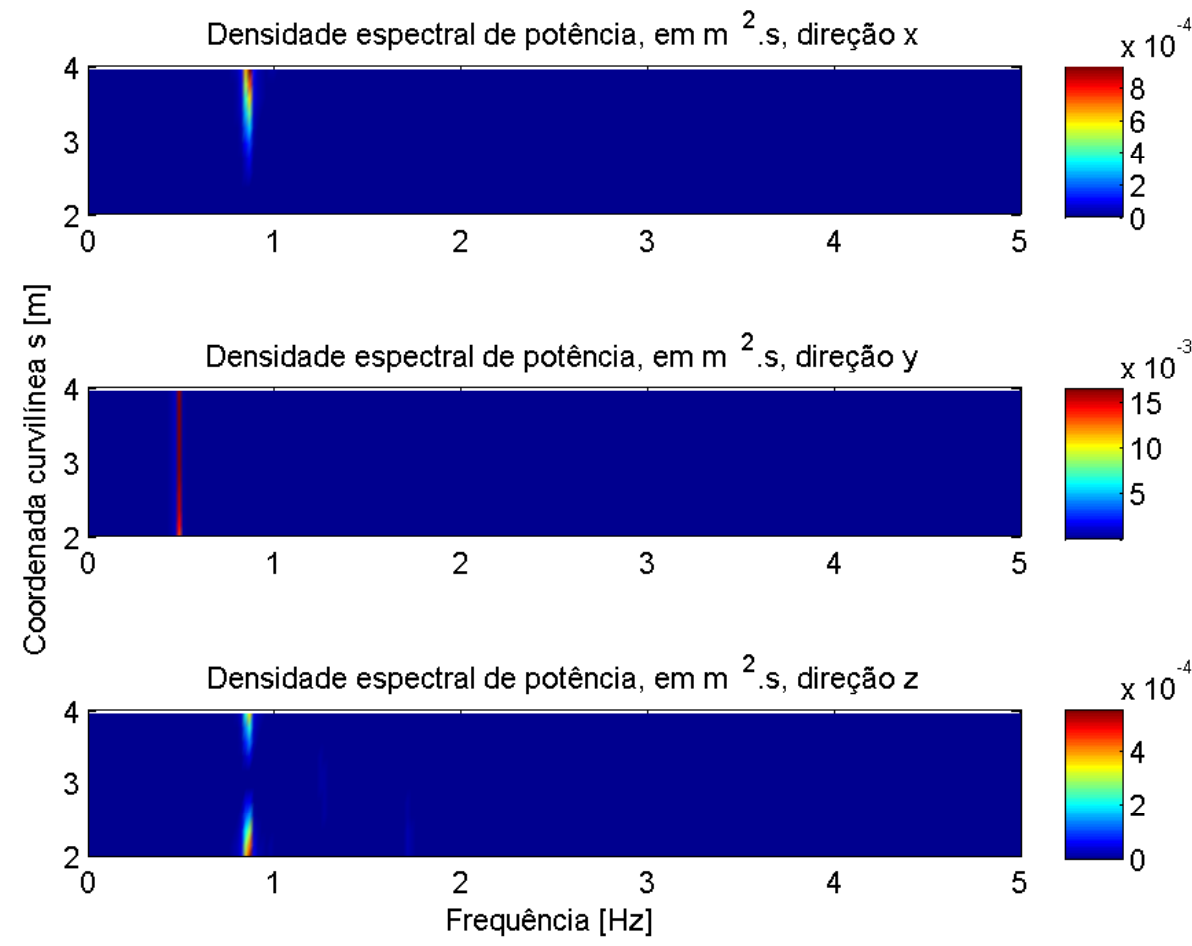

Figura C.38: PSD de deslocamentos de todos os alvos, tubo com água, excitação transversal em 0xyz. 
A seguir, são apresentadas três tabelas com os valores dos amortecimentos estruturais médios, determinados nos ensaios de decaimento. As Tabelas C.9 a C.11 apresentam os resultados, respectivamente, para as direções $x$, y e $z$ definidas. Cada uma dessas tabelas contém os valores desses amortecimentos, separados por preenchimento utilizado e ângulo de topo nominal inicial do modelo.

Tabela C.9: Amortecimentos estruturais do modelo no ar - direção x

\begin{tabular}{|c|c|c|}
\hline \multicolumn{1}{|c|}{ Experimento } & Água & Areia \\
\hline Ângulo de topo: $65^{\circ}$ / Alvo A & $0,912 \%$ & $0,577 \%$ \\
Ângulo de topo: $65^{\circ}$ / Alvo B & $0,756 \%$ & $0,631 \%$ \\
Ângulo de topo: $65^{\circ}$ / Alvo C & $0,681 \%$ & $0,597 \%$ \\
\hline Ângulo de topo: $75^{\circ}$ / Alvo A & $0,569 \%$ & $0,454 \%$ \\
Ângulo de topo: $75^{\circ}$ / Alvo B & $0,507 \%$ & $0,461 \%$ \\
Ângulo de topo: $75^{\circ}$ / Alvo C & $0,510 \%$ & $0,464 \%$ \\
\hline Ângulo de topo: $85^{\circ}$ / Alvo A & $0,641 \%$ & $1,014 \%$ \\
Ângulo de topo: $85^{\circ}$ / Alvo B & $0,659 \%$ & $1,069 \%$ \\
Ângulo de topo: $85^{\circ}$ / Alvo C & $0,609 \%$ & $0,907 \%$ \\
\hline \hline
\end{tabular}

Tabela C.10: Amortecimentos estruturais no ar - direção y

\begin{tabular}{|l|c|c|}
\hline \multicolumn{1}{|c|}{ Experimento } & Água & Areia \\
\hline Ângulo de topo: $65^{\circ}$ / Alvo A & $0,883 \%$ & $0,656 \%$ \\
Ângulo de topo: $65^{\circ}$ / Alvo B & $0,836 \%$ & $0,592 \%$ \\
Ângulo de topo: $65^{\circ}$ / Alvo C & $0,816 \%$ & $0,588 \%$ \\
\hline Ângulo de topo: $75^{\circ}$ / Alvo A & $0,490 \%$ & $0,389 \%$ \\
Ângulo de topo: $75^{\circ}$ / Alvo B & $0,522 \%$ & $0,330 \%$ \\
Ângulo de topo: $75^{\circ}$ / Alvo C & $0,394 \%$ & $0,258 \%$ \\
\hline Ângulo de topo: $85^{\circ}$ / Alvo A & $1,565 \%$ & $1,865 \%$ \\
Ângulo de topo: $85^{\circ}$ / Alvo B & $1,405 \%$ & $1,821 \%$ \\
Ângulo de topo: $85^{\circ}$ / Alvo C & $1,527 \%$ & $1,808 \%$ \\
\hline \hline
\end{tabular}

Tabela C.11: Amortecimentos estruturais no ar - direção z

\begin{tabular}{|c|c|c|}
\hline \multicolumn{1}{|c|}{ Experimento } & Água & Areia \\
\hline Ângulo de topo: $65^{\circ}$ / Alvo A & $0,778 \%$ & $0,593 \%$ \\
Ângulo de topo: $65^{\circ}$ / Alvo B & $0,898 \%$ & $0,965 \%$ \\
Ângulo de topo: $65^{\circ}$ / Alvo C & $0,789 \%$ & $0,613 \%$ \\
\hline Ângulo de topo: $75^{\circ}$ / Alvo A & $0,516 \%$ & $0,438 \%$ \\
Ângulo de topo: $75^{\circ}$ / Alvo B & $0,573 \%$ & $0,535 \%$ \\
Ângulo de topo: $75^{\circ}$ / Alvo C & $0,508 \%$ & $0,473 \%$ \\
\hline Ângulo de topo: $85^{\circ}$ / Alvo A & $0,624 \%$ & $0,724 \%$ \\
Ângulo de topo: $85^{\circ}$ / Alvo B & $0,627 \%$ & $0,729 \%$ \\
Ângulo de topo: $85^{\circ}$ / Alvo C & $0,623 \%$ & $0,773 \%$ \\
\hline \hline
\end{tabular}

Como esperado, os valores mais baixos para os amortecimentos são encontrados na compilação dos resultados para a direção $x$, embora seja importante perceber que os valores variam bastante e, principalmente, deve-se ter o cuidado de notar a influência dos vínculos nas extremidades do modelo (rótula no topo e âncora na região do TDZ, 
caracterizada pelos alvos "C" e "A", respectivamente), nos valores apresentados.

Alguns pontos são dignos de observação. Para um mesmo caso, o modelo com água apresentou, em geral, maiores amortecimentos estruturais que aquele preenchido com areia. Além disso, os menores valores auferidos ocorreram para o lançamento da linha sob um ângulo de topo nominal de $75^{\circ}$. Os maiores valores observados, no entanto, referem-se à configuração quase vertical, exatamente para a direção $y$, dado que, nessas situações, a linha apresentava-se mais retesada e, portanto, com menor liberdade de movimentação, para ambos os preenchimentos.

Com respeito aos amortecimentos estruturais determinados, cabe salientar que em todos os casos os valores obtidos foram menores que $2 \%$, caracterizando o chamado amortecimento subcrítico, típico de materiais viscoelásticos. Visualmente, esse comportamento é passível de confirmação pelas oscilações com amplitudes decrescentes das Figuras C.33 e C.34.

Com o objetivo de explicitar os valores das frequências ilustrados graficamente em várias das figuras apresentadas anteriormente, foram construídas as Tabelas C.12 e C.13, nas quais são compiladas, numericamente, as frequências excitadas que foram passíveis de identificação, pelos métodos e equipamentos utilizados.

Os resultados são apresentados em termos dos ângulos de topo nominais em que os modelos foram lançados. Em cada figura, são explicitadas as frequências percebidas pelo sistema de monitoramento óptico e pela célula de carga.

A Tabela C.12 apresenta os resultados auferidos para o modelo preenchido com areia, enquanto que a Tabela C.13 compila as frequências para o modelo com água.

Tabela C.12: Frequências observadas, sistema de rastreamento x célula de carga (modelo com areia).

\begin{tabular}{|c|c|c|c|c|c|}
\hline \multicolumn{6}{|c|}{ Ensaios de decaimento - Picos no PSD } \\
\hline \multicolumn{3}{|c|}{ Sistema óptico - frequência em $\mathrm{Hz}$} & \multicolumn{3}{|c|}{ Célula de carga - frequência em $\mathrm{Hz}$} \\
\hline 65 & 75 & 85 & 65 & 75 & 85 \\
\hline 0,8667 & 0,2220 & 0,5111 & 0,8333 & 0,4833 & 0,5000 \\
\hline 1,3110 & 0,7110 & 1,0000 & 1,2830 & 0,7000 & 1,0170 \\
\hline 1,5110 & 1,2000 & 1,4890 & 1,6670 & 1,2000 & 1,4500 \\
\hline 2,0000 & 1,7110 & 1,9780 & 1,9330 & 1,7000 & 1,8500 \\
\hline 2,5110 & 2,1560 & 2,2670 & 2,5000 & 2,1000 & 2,2330 \\
\hline 2,9560 & 2,1560 & 2,4890 & 2,8670 & 2,1500 & 2,4000 \\
\hline 3,1110 & 2,6440 & 2,6890 & 3,3170 & 2,6830 & 2,6670 \\
\hline 3,4670 & 3,0670 & 2,9780 & 3,8330 & 2,8830 & 3,2000 \\
\hline 3,8220 & 3,5780 & 3,6890 & 4,4000 & 3,4000 & 3,6000 \\
\hline 4,5110 & 3,9560 & 3,9780 & & 4,1170 & 4,0170 \\
\hline
\end{tabular}

Por essas tabelas, é possível notar que, a despeito dos valores diferenciados de amortecimento estrutural dos dois modelos ensaiados, as frequências percebidas são, por vezes, muito próximas entre si.

Essas, a priori, podem ser consideradas como as frequências naturais de vibrar, enquanto que as demais tendem a ser tratadas como espúrias. 
Tabela C.13: Frequências observadas, sistema de rastreamento x célula de carga (modelo com água).

\begin{tabular}{|c|c|c|c|c|c|}
\hline \multicolumn{6}{|c|}{ Ensaios de decaimento - Picos no PSD } \\
\hline \multicolumn{2}{|c|}{ Sistema óptico - frequência em $\mathrm{Hz}$} & \multicolumn{3}{c|}{ Célula de carga - frequência em Hz } \\
\hline 65 & 75 & 85 & 65 & 75 & 85 \\
\hline 0,8667 & 0,2220 & 0,2667 & 0,8500 & 0,3833 & 0,2667 \\
\hline 1,2440 & 0,7778 & 0,6889 & 1,2330 & 0,7667 & 0,6167 \\
\hline 1,7110 & 1,2440 & 1,1110 & 1,7170 & 1,2170 & 1,0830 \\
\hline 1,8220 & 1,8890 & 1,6220 & 1,8670 & 1,7330 & 1,6000 \\
\hline 2,4000 & 2,1330 & 2,0670 & 2,4500 & 2,0830 & 2,0500 \\
\hline 2,8220 & 2,3780 & 2,4900 & 3,1000 & 2,3000 & 2,3000 \\
\hline & 2,8220 & 2,4890 & 3,3170 & 2,6883 & 2,4830 \\
\hline & 3,0670 & 3,5330 & 3,4500 & 3,0500 & 2,7670 \\
\hline & 3,7330 & 3,7330 & 3,9330 & 3,6170 & 3,3000 \\
\hline & & & 4,4170 & 4,0830 & 3,7000 \\
\hline
\end{tabular}

\section{C.2.6 Compilação dos resultados de caracterização do modelo}

Esta seção tem como finalidade a apresentação resumida dos resultados obtidos com os ensaios de caracterização do modelo de linha flexível a ser utilizado nos ensaios finais, a fim de cumprir com os objetivos da presente tese.

A Tabela C.14 encerra a compilação dos resultados dos ensaios de caracterização das propriedades físico-mecânicas da magueira de silicone utilizada como modelo, tanto com relação à ausência, quanto ao uso de preenchimento.

Tabela C.14: Características do modelo em silicone, dados de ensaios

\begin{tabular}{|c|c|c|}
\hline Característica & Símbolo (Unidade) & Magnitude \\
\hline Diâmetro externo & $D_{\text {ext }}(\mathrm{mm})$ & 14,06 \\
Diâmetro interno & $D_{i n t}(\mathrm{~mm})$ & 6,86 \\
\hline Módulo de elasticidade & $E\left(\mathrm{MN} / \mathrm{m}^{2}\right)$ & 3,103 \\
Densidade do silicone & $\rho\left(\mathrm{kg} / \mathrm{m}^{3}\right)$ & $1.281,7$ \\
\hline Peso linear no ar (vazio) & $m g(\mathrm{~N} / \mathrm{m})$ & 1,491 \\
Peso linear imerso (vazio) & $q(\mathrm{~N} / \mathrm{m})$ & $-0,029$ \\
Rigidez axial média (vazio) & $E A(\mathrm{~N})$ & 367,08 \\
Rigidez flexional (vazio) & $\left.E I(\mathrm{Nm})^{2}\right)$ & $5,616 \cdot 10^{-3}$ \\
\hline Peso linear no ar (com areia) & $m g(\mathrm{~N} / \mathrm{m})$ & 1,993 \\
Peso linear imerso (com areia) & $q(\mathrm{~N} / \mathrm{m})$ & 0,475 \\
Rigidez axial (com areia) & $E A(\mathrm{~N})$ & $385,54-422,57$ \\
Rigidez flexional (com areia) & $\left.E I(\mathrm{Nm})^{2}\right)$ & vide Tabela C.7 \\
\hline Peso linear no ar (com água) & $m g(\mathrm{~N} / \mathrm{m})$ & 1,852 \\
Peso linear imerso (com água) & $q\left(\mathrm{~N} / \mathrm{m}^{2}\right)$ & 0,334 \\
Rigidez axial (com água) & $E A(\mathrm{~N})$ & $351,47-421,74$ \\
Rigidez flexional (com água) & $E I\left(\mathrm{Nm}{ }^{2}\right)$ & vide Tabela C.8 \\
\hline \hline
\end{tabular}

\section{C.2.7 Conclusões acerca dos resultados de caracterização}

A presente seção teve, como objetivo principal, apresentar a caracterização das propriedades físico-mecânicas dos modelos com preenchimentos em areia e água, a fim 
de compará-los entre si e corroborar (ou refutar) os resultados preliminares, que apontavam para resultados suficientemente distintos, que poderiam sugerir a realização de ensaios com ambos os modelos, a fim de se obter um conjuntos mais amplo de informações a respeito do fenômeno em estudo.

Após a apresentação de todos os resultados, é possível comparar as simulações iniciais (Tabelas C.3 e C.4 relativas, respectivamente, ao TDP e ao topo), com as realizadas com dados provenientes da caracterização dos modelos (Tabela C.15).

Tabela C.15: Compilação dos dados referentes às simulações pós-caracterização.

\begin{tabular}{|c|c|c|c|c|c|c|c|c|c|}
\hline \multirow{2}{*}{\multicolumn{2}{|c|}{ AREIA (TDP) }} & \multicolumn{8}{|c|}{ Período [ S ] } \\
\hline & & 0,7 & 0,8 & 0,9 & 1,0 & 1,1 & 1,2 & 1,3 & 1,4 \\
\hline \multirow{5}{*}{ 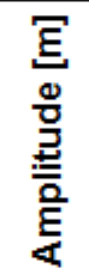 } & 0,050 & 5 & 5 & 7 & 8 & 9 & 9 & 9 & 9 \\
\hline & 0,100 & 18 & 18 & 19 & 18 & 19 & 19 & 18 & 19 \\
\hline & 0,150 & 22 & 22 & 22 & 22 & 22 & 21 & 20 & 19 \\
\hline & 0,200 & 23 & 23 & 23 & 22 & 21 & 19 & 16 & 7 \\
\hline & 0,250 & 23 & 23 & 21 & 20 & 15 & 7 & 0 & 11 \\
\hline
\end{tabular}

\begin{tabular}{|c|c|c|c|c|c|c|c|c|c|}
\hline \multirow{2}{*}{\multicolumn{2}{|c|}{ AREIA (TOP) }} & \multicolumn{8}{|c|}{ Período [ S ] } \\
\hline & & \multirow{2}{*}{$\frac{\mathbf{0 , 7}}{0}$} & \multirow{2}{*}{$\frac{\mathbf{0 , 8}}{0}$} & \multirow{2}{*}{$\frac{0,9}{0}$} & \multirow{2}{*}{$\begin{array}{c}1,0 \\
0\end{array}$} & \multirow{2}{*}{$\begin{array}{c}1,1 \\
3\end{array}$} & \multirow{2}{*}{$\frac{1,2}{6}$} & \multirow{2}{*}{$\frac{1,3}{6}$} & \multirow{2}{*}{$\frac{1,4}{6}$} \\
\hline 呈 & 0,050 & & & & & & & & \\
\hline \multirow{4}{*}{ 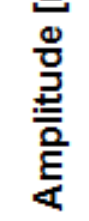 } & 0,100 & 9 & 11 & 11 & 10 & 10 & 9 & 12 & 25 \\
\hline & 0,150 & 14 & 13 & 12 & 11 & 11 & 10 & 19 & 25 \\
\hline & 0,200 & 15 & 14 & 13 & 12 & 10 & 9 & 8 & 6 \\
\hline & 0,250 & 15 & 14 & 12 & 11 & 9 & 4 & 0 & 7 \\
\hline
\end{tabular}

\begin{tabular}{|c|c|c|c|c|c|c|c|c|c|}
\hline \multirow{2}{*}{\multicolumn{2}{|c|}{ ÁGUA (TDP) }} & \multicolumn{8}{|c|}{ Período [ S ] } \\
\hline & & \multirow{2}{*}{$\frac{\mathbf{0 , 7}}{0}$} & \multirow{2}{*}{$\frac{\mathbf{0 , 8}}{0}$} & \multirow{2}{*}{$\frac{0,9}{0}$} & \multirow{2}{*}{$\begin{array}{c}1,0 \\
0\end{array}$} & \multirow{2}{*}{$\frac{1,1}{0}$} & \multirow{2}{*}{$\frac{1,2}{0}$} & \multirow{2}{*}{$\frac{1,3}{1}$} & \multirow{2}{*}{$\frac{1,4}{2}$} \\
\hline 呈 & 0,050 & & & & & & & & \\
\hline$\Phi$ & 0,100 & 12 & 13 & 12 & 13 & 13 & 12 & 12 & 12 \\
\hline ב & 0,150 & 18 & 18 & 17 & 17 & 16 & 15 & 14 & 12 \\
\hline 을 & 0,200 & 20 & 20 & 19 & 17 & 16 & 14 & 9 & 0 \\
\hline$\overline{4}$ & 0,250 & 20 & 18 & 17 & 14 & 8 & 0 & 0 & 4 \\
\hline
\end{tabular}

\begin{tabular}{|c|c|c|c|c|c|c|c|c|c|}
\hline \multirow{2}{*}{\multicolumn{2}{|c|}{ ÁGUA (TOP) }} & \multicolumn{8}{|c|}{ Período [ S ] } \\
\hline & & \multirow{2}{*}{$\frac{\mathbf{0 , 7}}{0}$} & \multirow{2}{*}{$\frac{\mathbf{0 , 8}}{0}$} & \multirow{2}{*}{$\frac{0,9}{5}$} & \multirow{2}{*}{$\begin{array}{l}1,0 \\
10\end{array}$} & \multirow{2}{*}{$\frac{1,1}{9}$} & \multirow{2}{*}{$\frac{1,2}{9}$} & \multirow{2}{*}{$\frac{1,3}{8}$} & \multirow{2}{*}{$\begin{array}{l}\mathbf{1 , 4} \\
13 \\
\end{array}$} \\
\hline 呈 & 0,050 & & & & & & & & \\
\hline 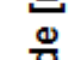 & 0,100 & 16 & 15 & 14 & 13 & 12 & 11 & 21 & 25 \\
\hline 总 & 0,150 & 18 & 16 & 15 & 14 & 13 & 12 & 25 & 25 \\
\hline 흘 & 0,200 & 18 & 17 & 16 & 14 & 12 & 11 & 14 & 7 \\
\hline 4 & 0,250 & 18 & 17 & 15 & 13 & 11 & 8 & 0 & 18 \\
\hline
\end{tabular}

A fim de esmiuçar o conjunto desses resultados, foram construídas as Figuras C.39 a C.40, que ilustram graficamente os resultados tabulados. 


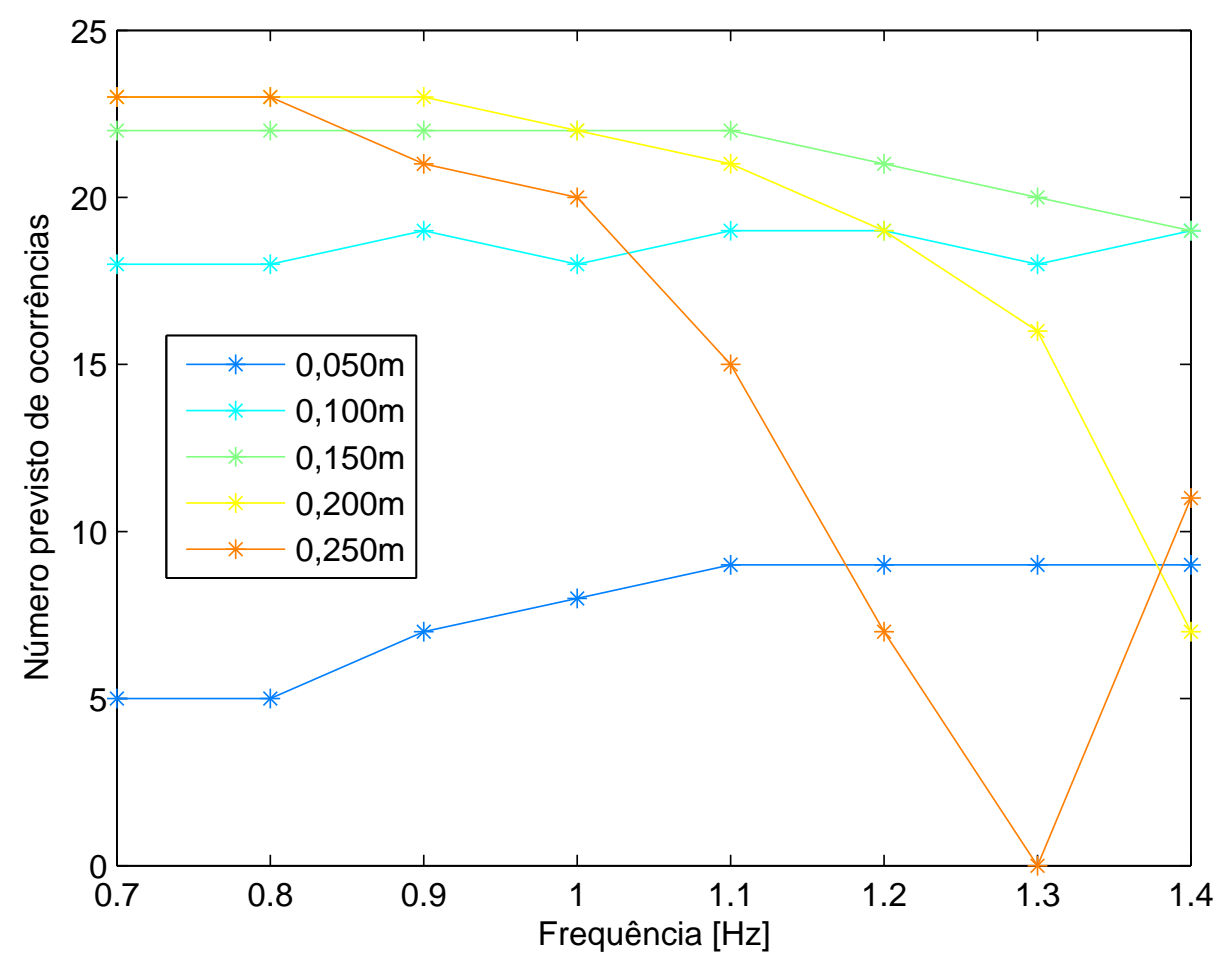

Figura C.39: Número de casos de compressão previstos para o TDP, areia, pós-caracterização.

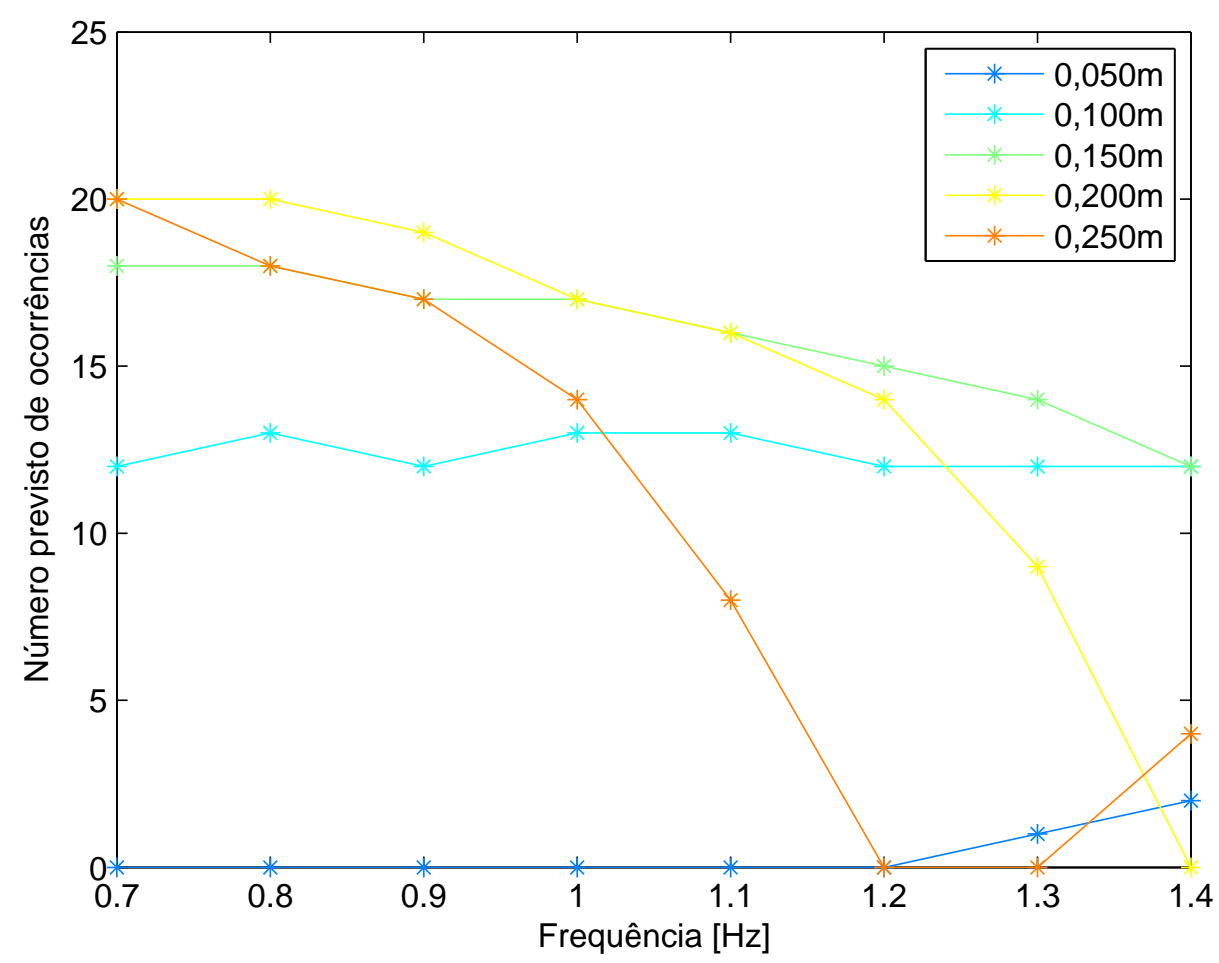

Figura C.40: Número de casos de compressão previstos para o TDP, água, pós-caracterização. 
Com relação ao número previsto de compressões dinâmicas tem-se, resumidamente:

- Modelo com areia: 290; com água: 397; no TDP, pré-caracterização;

- Modelo com areia: 653; com água: 425; no TDP, pós-caracterização;

- Modelo com areia: 512; com água: 786; no topo, pré-caracterização;

- Modelo com areia: 392; com água: 528; no topo, pós-caracterização;

Os citados valores, relacionados com a quantidade de ocorrências de compressão dinâmica previstas, podem ser apresentados graficamente, devidamente agrupados, para melhor compreensão por parte do leitor (ver Figura C.41).

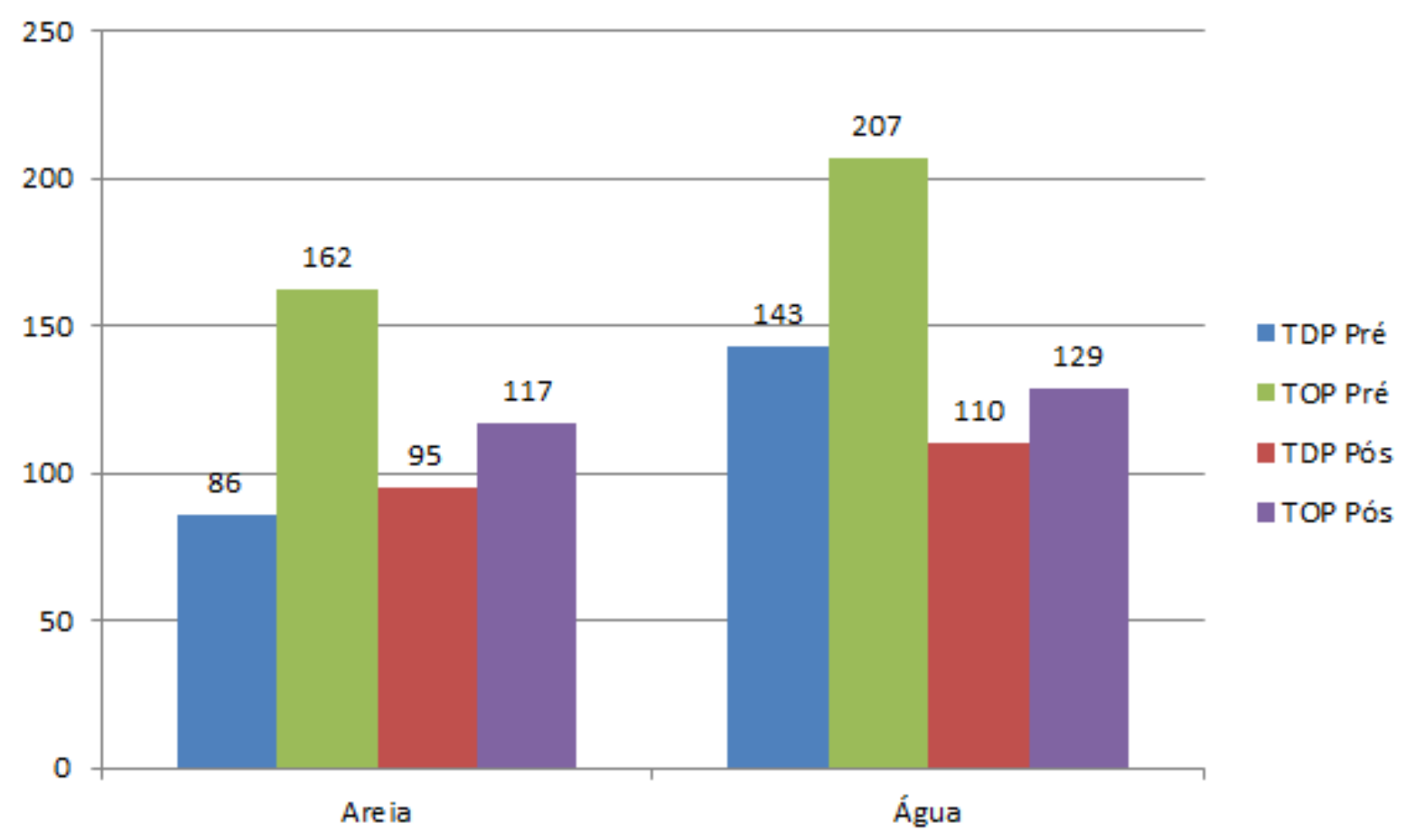

Figura C.41: Comparação gráfica dos resultados, separados por preenchimento do tubo.

Após a caracterização do modelo por meio de medições e experimentos específicos, é possível verificar algumas conclusões a respeito do número esperado de compressões dinâmicas para os casos avaliados.

No que tange ao TDP, a previsão de ocorrência do fenômeno em estudo aumentou de probabilidade, enquanto que para o topo esse valor decaiu, para ambos os modelos. Por outro lado, o número previsto de compressões dinâmicas no topo diminuiu para os modelos considerados.

Além disso, é imediata a verificação de que o número de ocorrências previsto é maior para o modelo com areia no TDP e para o outro modelo no topo. Dadas essas considerações, embasadas pelos resultados do presente capítulo e do que o antecede, optou-se pela utilização de um único modelo, preenchido com areia. 
Essa escolha é resultado de três fatores principais: do maior peso linear próprio, relativamente ao tubo com água; das previsões de ocorrência de compressão dinâmica (especialmente no TDP); e dos níveis de tração avaliados (que permitem, a princípio, uma identificação mais precisa do fenômeno em questão).

Entretanto, o número de condições avaliadas (1.000) foi demasiado grande para ser reproduzido experimentalmente, embora tenha servido aos propósitos de verificar diversas condições de lançamento e de excitação. Cabe, então, a diminuição racional do número de situações a serem confrontadas pelos ensaios a serem realizados.

Nesse ponto, cabe uma consideração importante. De acordo com Merino et al. (2010), em um estudo numérico-experimental sobre risers flexíveis sob torção, é importante a avaliação das respostas da linha com vistas nos efeitos devidos à imposição de movimentos nos sentidos horário e anti-horário, dadas as diferenças verificadas.

Essa consideração também foi estudada, por exemplo, em (Campos \& Martins, 2001) e (Larsen et al., 2012).

A imposição de movimentos de topo em dois sentidos dobra a quantidade de ensaios a serem realizados, independentemente das demais variáveis (ângulo de topo e o par amplitude/frequência de excitação).

Recuperando informações do capítulo anterior, foi determinado que não seriam avaliados, por meio de ensaios, lançamentos com ângulos de topo menores que $60^{\circ}$. Adicionalmente, ficou evidente, pelos resultados do Item C.1, que a faixa situada entre $65^{\circ}$ e $85^{\circ}$ parecia conter informações valiosas a respeito do fenômeno em estudo. Para tanto, é imperativa a utilização de ancoragem no fundo.

Defina-se, pelo conjunto desses argumentos, que os ângulos a serem ensaiados são: $65^{\circ}, 70^{\circ}, 80^{\circ}$ e $85^{\circ}$.

Com respeito às amplitudes, cabe a percepção de que o extremo superior avaliado não encerra variações de comportamento que justifique sua incorporação na matriz de ensaios. O mesmo não ocorre para o limite inferior das simulações. Postas essas considerações, decidiu-se pela realização dos experimentos a partir de três amplitudes de excitação (movimento circular uniforme): 0,050m; 0,100m e 0,200m.

Por fim, em termos dos períodos dos movimentos de topo a serem prescritos ao modelo, foi mencionado no último tópico do Capítulo 4, uma região de interesse situada entre 1,10 s e 1,30s. Além disso, o comportamento dinâmico frequências relativamente altas, dentro da faixa considerada, encerra uma variação bastante interessante na previsão de ocorrência de compressão dinâmica. Dessa forma, optou-se pela imposição de movimentos com períodos de 0,80 s; $1,00 \mathrm{~s}$; e $1,25 \mathrm{~s}$, a fim de avaliar a importância relativa dessa variável no fenômeno em estudo.

Definida dessa maneira, a matriz de ensaios encerrará um total de 72 experimentos.

Com relação à previsão de compressões dinâmicas no modelo sob as 72 condições a serem ensaiadas, foi confeccionada a Figura C.42, na qual é possível verificar 0 
número de casos previstos ${ }^{16}$, bem como comparar o comportamento esperado para ambos os modelos, mesmo que apenas um deles tenha sido escolhido e será utilizado nos ensaios (tubo de silicone, com preenchimento em areia).
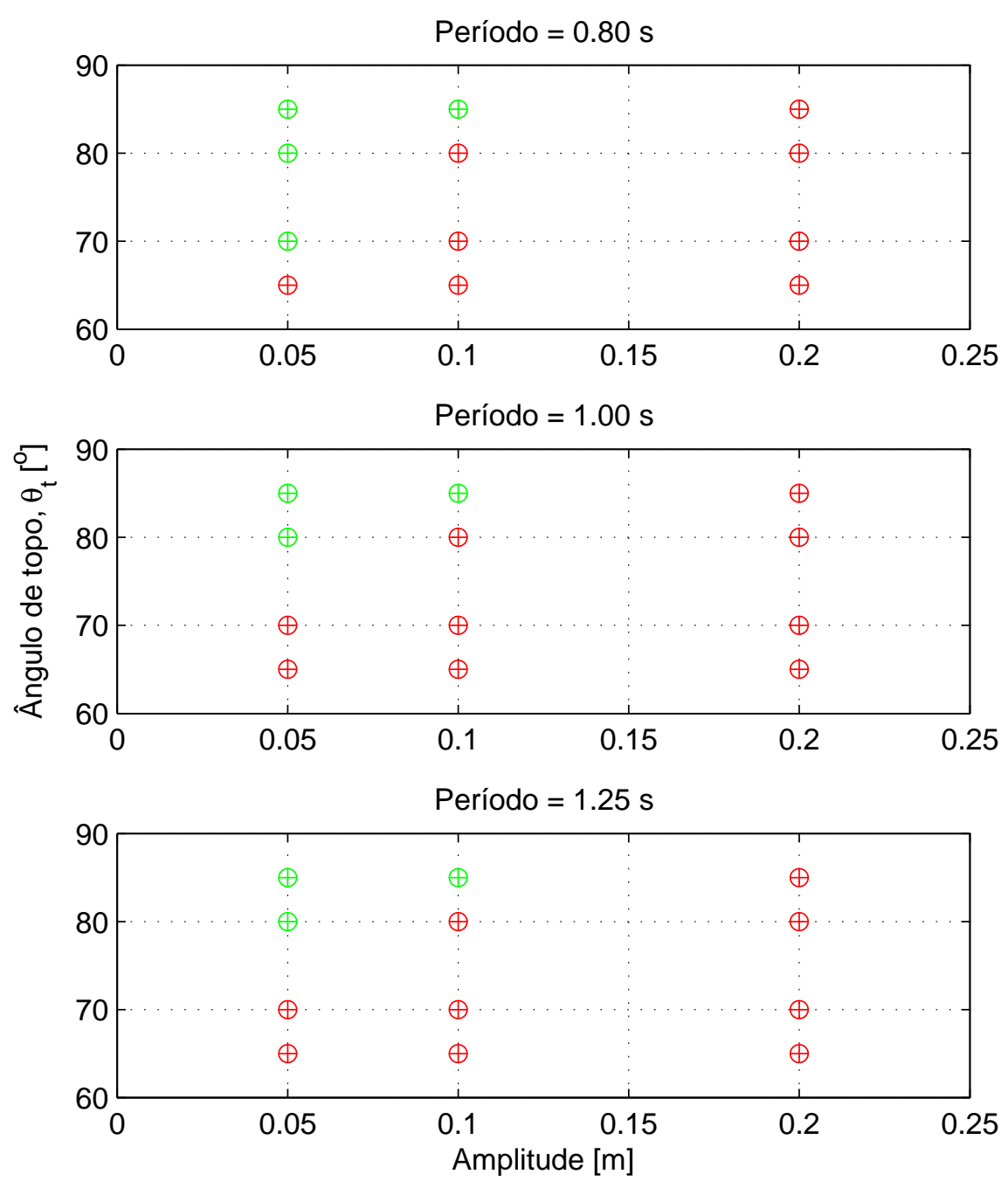

Figura C.42: Previsão de ocorrência de compressão dinâmica no TDP para os ensaios.

Na Figura C.42, "+' representa o modelo com areia, "o" o modelo com água. Em vermelho, os casos de ocorrência de compressão; em verde, os de ausência.

Essa figura corrobora a escolha do material de preenchimento do tubo de silicone, com base em um argumento distinto dos apresentados anteriormente: as diferenças entre os comportamentos, dadas a matriz de ensaios e as reais características dos modelos, são diminutas, na prática.

Das 72 condições de ensaio, os modelos com areia e água apresentariam, potencialmente, o mesmo comportamento com relação à ocorrência do fenômeno do TDP, que é o ponto de interesse, diferindo em apenas 4 situações nos casos relativos ao topo.

\footnotetext{
${ }^{16}$ São previstos 62 (59) casos de compressão dentre as 72 condições, para o TDP (topo). Cabe lembrar que todas as avaliações feitas para o topo, salvas raras exceções, foram retiradas do corpo principal do texto, por não fazerem parte do cerne desta tese.
} 
Em última instância, a validação experimental das características do modelo flexível construído permitiu a reavaliação analítica dos comprimentos de ondas de flexão esperados durante os ensaios. As Tabelas C.16 e C.17 encerram esses valores, respectivamente, para os modelos preenchidos com areia e água. Os valores determinados para os comprimentos de onda são passíveis de comparação direta com os obtidos preliminarmente à caracterização do modelo (vide Tabelas C.5 e C.6).

Tabela C.16: Previsões analíticas dos comprimentos das ondas de flexão durante os ensaios (modelo com areia, pós-caracterização)

\begin{tabular}{|c|c|c|c|c|}
\hline Caso & $\lambda_{\text {máx }}^{B I}[\mathrm{~m}]$ & $\lambda_{\text {máx }}^{E P}[\mathrm{~m}]$ & $\lambda_{\text {mín }}^{B I}[\mathrm{~m}]$ & $\lambda_{\text {mín }}^{E P}[\mathrm{~m}]$ \\
\hline Amplitude 0,050m e período 1,20s & 0,8937 & 0,7009 & 0,3203 & 0,3926 \\
\hline Amplitude 0,100m e período 1,00s & 0,8319 & 0,6602 & 0,2924 & 0,3584 \\
\hline Amplitude 0,200m e período 0,80s & 0,7565 & 0,6098 & 0,2615 & 0,3205 \\
\hline \hline
\end{tabular}

Para o modelo com preenchimento em areia, a caracterização do modelo flexível levou a previsões de comprimentos de ondas de flexão diferenciados com relação aos valores máximos, de sorte que os mínimos permaneceram praticamente inalterados com as avaliações anteriores.

Tabela C.17: Previsões analíticas dos comprimentos das ondas de flexão durante os ensaios (modelo com água, pós-caracterização)

\begin{tabular}{|c|c|c|c|c|}
\hline Caso & $\lambda_{\text {máx }}^{\text {II }}[\mathrm{m}]$ & $\lambda_{\text {máx }}^{E P}[\mathrm{~m}]$ & $\lambda_{\min }^{B I}[\mathrm{~m}]$ & $\lambda_{\min }^{E P}[\mathrm{~m}]$ \\
\hline Amplitude 0,050m e período 1,20s & 0,8796 & 0,6854 & 0,3204 & 0,3927 \\
\hline Amplitude 0,100m e período 1,00s & 0,8225 & 0,6477 & 0,2925 & 0,3585 \\
\hline Amplitude 0,200m e período 0,80s & 0,7509 & 0,6003 & 0,2616 & 0,3207 \\
\hline \hline
\end{tabular}

O modelo com preenchimento em água apresentou o mesmo comportamento. Além disso, cabe notar que as diferenças entre os valores constantes nas Tabelas C.16 e C.17, para um mesmo caso, passaram a ser diminutas. Como o principal objetivo experimental desta tese é mensurar essa grandeza durante os ensaios finais, essas tabelas corroboram o fato de que a realização dos mesmos com ambos os materiais de preenchimento não traria resultados significantemente distintos.

A definição da matriz de ensaios é resultado direto dos ensaios de caracterização, posto que apenas após esse experimentos preliminares foi possível ter um nível de certeza maior com relação às propriedades do modelo ensaiado e, consequentemente, avaliar mais precisamente a quantidade de compressões dinâmicas esperadas nos ensaios finais.

Postas essas considerações, optou-se pelo uso do modelo com preenchimento em areia. O início do próximo capítulo explicitará estuturadamente a matriz de ensaios, bem como algumas poucas, mas importantes, considerações a respeito dos ensaios e simulações numéricas. Saliente-se que, essa escolha, tem por finalidade a apresentação de particularidades não descritas anteriormente. 